\title{
Sustentabilidade e
}

Responsabilidade Social em Foco 
Editora Poisson

\section{Sustentabilidade e Responsabilidade Social em Foco Volume 14}

1a Edição 
Editor Chefe: Dr. Darly Fernando Andrade

\section{Conselho Editorial}

Dr. Antônio Artur de Souza - Universidade Federal de Minas Gerais

Msc. Davilson Eduardo Andrade

Msc. Fabiane dos Santos Toledo

Dr. José Eduardo Ferreira Lopes - Universidade Federal de Uberlândia

Dr. Otaviano Francisco Neves - Pontifícia Universidade Católica de Minas Gerais

Dr. Luiz Cláudio de Lima - Universidade FUMEC

Dr. Nelson Ferreira Filho - Faculdades Kennedy

Ms. Valdiney Alves de Oliveira - Universidade Federal de Uberlândia

Dados Internacionais de Catalogação na Publicação (CIP)

S587s
Sustentabilidade e Respponsabilidade Social
em Foco: Volume 14/ Organização Editora
Poisson - Belo Horizonte - MG: Poisson,
2019
Formato: PDF
ISBN: $978-85-7042-069-5$
DOI: $10.5935 / 978-85-7042-069-5$
Modo de acesso: World Wide Web
Inclui bibliografia
1. Gestão 2. Produção. 3. Engenharia
I. Título

O conteúdo dos artigos e seus dados em sua forma, correção e confiabilidade são de responsabilidade exclusiva dos seus respectivos autores.

www.poisson.com.br

contato@poisson.com.br 


\section{SUMÁRIO}

Capítulo 1: 0 futuro dos estudos de sistemas de energias renováveis na perspectiva da inovação 7

Laura Visintainer Lerman, Natália Eloísa Sander, Raquel de Abreu Pereira Uhr

Capítulo 2: Aproveitamento de resíduos sólidos orgânicos para geração de energia elétrica: Uma ideia sustentável. 21 Thays Lorranny da Silva Januário, Jefferson Luiz Alves Marinho, Janeide Ferreira Alencar de Oliveira

Capítulo 3: Estudo de caso em uma associação de coleta de resíduos sólidos 29

Adna Amorim dos Santos , Lucas Marcos Silva Queiroz, Lo-Ruana Karen Amorim Freire Sanjulião, Thales Volpe Rodrigues, Carlos Henrique Fernandes, Maria José Reis

Capítulo 4: A política nacional de resíduos sólidos (Lei o‥ 12.305, de 2 de agosto de 2010), a logística reversa e a logística militar.

Adriana Salete Dantas de Farias

Capítulo 5: Processo de logística reversa de pós-consumo e reciclagem: Estudo de caso de uma grande empresa de baterias de Goiás. 50

Renata Cristina Almeida de Mendonça Veloso, José Ribamar Tomaz da Silva Filho, Rosângela Sarmento Silva, Tony Stevão Alves da Silva, Caroline Alves Resende

Capítulo 6: Análise da remoção da demanda bioquímica de oxigênio e demanda química de oxigênio na estação de tratamento de esgoto gertrudes localizada na cidade de Ponta Grossa - PR. 62

Tatiana Gulminie Josué, Lariana Negrão Beraldo de Almeida, Mariana dos Santos do Nascimento, André Spanhol

Capítulo 7: Composição dos ativos intangíveis das empresas listadas no índice de carbono eficiente da b3

Francisca Francivânia Rodrigues Ribeiro Macêdo, Maria Maciléya Azevedo Freire, Antônio Rodrigues Albuquerque Filho

Capítulo 8: Economia Circular: Repensando as cápsulas de café expresso .. 85 


\section{SUMÁRIO}

Capítulo 9: Impactos da (in)formalização dos serviços de construção civil 94

Jefferson Pereira da Silva Castro, Samuel Carvalho De Benedicto, Mônica de Oliveira Rocha, Cibele Roberta Sugahara

Capítulo 10: Implantação de um resort e seu impacto socioambiental - Maricá-RJ ... 106

Eduardo Cantarelli Vanconcelos Ferreira Cantarelli, Fabio Medeiros dos Santos, Gabriele Cristine Bernardo de Carvalho, Luan de Carvalho Dantes

Capítulo 11: 0 avanço das ações antrópicas, nos anos de 1984, 1991, 2001 e 2008, no entorno da área de captação das barragens de Água fria I e II 112

Camila da Silva Sotero, Paulo Sérgio Monteiro Mascarenhas, Odair Lacerda Lemos

Capítulo 12: Relatos da situação econômica e ambiental dos agricultores do Assentamento Caracol, Município de Bela Vista, MS após 20 Anos de sua Criação ...... 133

Ionara dos Santos Biscola, Viviane Mallmann, Lucas Wagner Ribeiro Aragão, Shaline Séfara Lopes Fernandes, Tauane Catilza Lopes Fernandes

Capítulo 13: A economia social e solidária produzida por camponeses migrantes.... 139 Maria Antonia Veiga Adrião

Capítulo 14: A compreensão dos valores ecológicos e culturais do Parque Zoobotânico Arruda Câmara através da educação ambiental. 148

Antônia Arisdélia Fonseca Matias Aguiar Feitosa, Maria Neide Moura Martins de Andrade, Dayana Priscyla da Silva França

Capítulo 15: As dimensões do comportamento ambiental dos consumidores no Distrito Federal. 157

Elivaldo Ribeiro de Santana

Capítulo 16: Inovação em rede socio técnica: um novo projeto social para agricultura familiar ecológica?. 164

Lucimar Santiago de Abreu, Stéphane Bellon, Tercia Zavaglia Torres

Capítulo 17: Participação e mobilização dos atores sociais no território central da cidadania de Rondônia - TCCRO, Brasil.

Tânia Olinda Lima, Clodoaldo de Oliveira Freitas, Eliane Silva Leite, Bruna Érica de Oliveira 


\section{SUMÁRIO}

Capítulo 18: Responsabilidade Socioambiental no Turismo: 0 caso da empresa Ambiental Viagens e Turismo.

Denise Rugani Töpke, Mariana Pires Vidal López

Capítulo 19: A percepção ambiental dos turistas que visitam a APA dos Recifes de Corais no Rio Grande do Norte.

Maria Célia Fernandes, Ana Neri da Paz Justino, Jurema Márcia Dantas da Silva

Capítulo 20: Transporte Público: Eficiente promotor da Qualidade de Vida.

Jurandir Moura Dutra, Marcelo José de Lima Dutra, Samara Barbosa de Menezes, Josildo Severino de Oliveira

Autores: 


\section{Capítulo 1}

\section{O FUTURO DOS ESTUDOS DE SISTEMAS DE ENERGIAS RENOVÁVEIS NA PERSPECTIVA DA INOVAÇÃO}

\section{Laura Visintainer Lerman}

Natália Eloísa Sander

Raquel de Abreu Pereira Uhr

Resumo: A pesquisa teve como o objetivo a identificação de lacunas na pesquisa de sistemas de energias renováveis e inovação, visto que sistema de energia renovável (SER) pode ser economicamente mais benéfico em comparação ao sistema energético atual. Além disso, ocorreu a ascensão de artigos em relação a aspectos da inovação e de novos centros de pesquisa focados em inovação. Consequentemente, utilizou-se a análise de redes sociais (ARS) com objetivo de realizar a pesquisa bibliométrica e sociométrica. Para isso, analisou-se cinquenta artigos do Web of Science. Os principais elementos analisados foram os autores e as palavras-chave das pesquisas. Identificou-se que há temas já bastante explorados como Renewable Energy, Energy Transition, Energy, Innovation, Engineering, Renewable Energy Systems, Sustainability, Business model e computational intelligence. Além disso, existe uma lacuna de pesquisa relacionada à Micro Renewable Energy Systems. Outrossim, as redes analisadas que possuem machine learning, software integration e artificial intelligence, organic rankine cycle e $\mathrm{CO} 2$ emissions como palavras-chave podem ser exploradas nas próximas pesquisas.

Palavras-chave: sistemas de energias renováveis, inovação, análise de redes sociais. 


\section{INTRODUÇÃO}

Schumpeter (1912) destaca que o conceito de inovação abrange os seguintes casos: (i) a introdução de um novo bem ou de uma nova qualidade de um bem; (ii) a introdução de um novo método de produção; (iii) a abertura de um novo mercado; (iv) a conquista de uma nova fonte de suprimento de matérias-primas ou produtos semimanufaturados; e (v) a realização da nova organização de uma indústria, como a criação de uma posição de monopólio ou o desmembramento de uma posição de monopólio. Entretanto, com o passar dos anos, observaram-se diferentes entendimentos de como ocorre o processo de inovação. Além disso, ocorreu a ascensão de artigos em relação a aspectos da inovação (FAGERBERG, 2005; FAGERBERG; VERSPAGEN, 2009) e de novos centros de pesquisa focados em inovação. Por exemplo, é enfatizado que empresas inovadoras têm competências específicas com intuito de explorar novas possibilidades e exploit seus resultados (PAVITT, 1991). Portanto, cada empresa, para inovar, possui capacidades (LALL, 1992; COHEN; LEVINTHAL, 1990) No entanto, essa análise é realizada a nível de firma, cada empresa gera seu processo de inovação diferente da outra, o que é realizado de forma diferente dependendo do porte da empresa (PAVITT, 2005; SCOZZI et al., 2005).

Embora a empresa pense muito em inovação para se manter competitiva no mercado, é importante a participação do governo, por exemplo, a partir de políticas públicas de incentivo à inovação (LUNDVALL; BORRÁS, 2005) e políticas de inovação relacionadas a sistemas de energias renováveis (FRANK et al., 2018). Para tanto, é fundamental que exista não só a participação do governo e da empresa, e, sim, uma interação da universidade-empresa-governo (ETZKOWITZ, 2011; BRUNEEL et al., 2010 e PERKMANN et al., 2013).

Além disso, globalmente, ocorreu um aumento da demanda de energia, o que é um fator essencial para o desenvolvimento de outras fontes de energia nos países tanto desenvolvidos quanto em desenvolvimento. Consequentemente, segundo IRENA (2018), a energia renovável precisa ser ampliada pelo menos seis vezes mais rápido para o mundo começar a atingir as metas estabelecido no Acordo de Paris.

Brini et al. (2017) ressaltam que as fontes de energia renovável adquiriram uma grande relevância, porque são fontes mais limpas e que geram um menor impacto ambiental. Ademais, países que utilizam fontes limpas serão, em menor grau, relacionados a combustíveis fósseis e serão menos impactos pela crise econômica (BRINI et al., 2017). Fu et al. (2017) acrescentam que os países, à medida que se tornam industrializados e aderem à economia global, participarão de uma cadeia de valor sustentável e suportarão uma economia renovável.

Portanto, conforme Peidong et al. (2009), a energia renovável é uma opção inevitável para o desenvolvimento econômico sustentável e para a coexistência harmoniosa do ser humano. Consequentemente, todas as regiões do mundo podem se beneficiar da transformação de energia, embora a distribuição dos benefícios varie de acordo com o contexto socioeconômico (IRENA, 2018).

Outrossim, sistema de energia renovável (SER) pode ser economicamente mais benéfico em comparação ao sistema energético atual (MATHIESEN et al., 2011). E, quando se pensar em um plano para se transformar um sistema energético em 100\% renovável, é essencial pensar em novas tecnologias, redução da demanda e melhorias na infraestrutura (MATHIESEN et al., 2011), por exemplo. Mathiesen et al. (2011) destacam que é só realizar a transformação de um sistema de energia convencional para um SER já garante grandes vantagens socioeconômicas.

Para isso, a inovação é fundamental, visto que é necessário o desenvolvimento de novas tecnologias para energias renováveis; as empresas necessitam focalizar em quais capacidades de inovação são essenciais para se manterem competitivas em sistemas de energias; quais processos de inovação são essenciais para que a empresa possa competir nesse mercado; entender quais políticas de inovação que o governo deve utilizar para criar um ambiente propício para o desenvolvimento de um SER (FRANK et al., 2018); quais interações entre governo-indústria-universidade são mais benéficas para o SER.

Portanto, é necessário entender como está ocorrendo a relação das pesquisas que envolvem a inovação e o SER, quais as linhas de pesquisas que estão consolidadas relacionados ao SER e a inovação; quais pesquisas estão em expansão e quais lacunas de pesquisa existem. Consequentemente, será realizado um estudo bibliométrico (envolvendo os autores e coautores de artigos e os conteúdos das pesquisas, analisados por meio das palavras-chave) com a utilização da análise de redes sociais para responder à seguinte questão: Qual a direção das pesquisas de SER em relação à inovação?

Para isso, de acordo com Brass (2011), a rede social ao invés de se centrar nos atores em si, tem como foco as relações entre eles. Entende-se, dessa forma, que o indivíduo se encontra inserido na rede junto com 
suas interconexões, o que representa o esforço das relações sociais dentro dos grupos (BRASS, 2011; WISE, 2012).

É possível entender a rede social como um conjunto ou grupo de pessoas que possuem algum tipo de interações entre elas (WASSERMAN; FAUST, 1994; SCOTT, 2012). Existem diversos tipos de rede, além das redes sociais. Um deles é a rede de informações, o exemplo clássico é o de citação de artigos acadêmicos: os nós são os artigos, e as conexões são as citações, as quais indicam que o Artigo A referenciou o Artigo B (NEWMAN, 2001). Entretanto, além de se identificar as citações, é possível verificar quais autores estão cooperando com quais para a publicação de artigos e se as palavras-chave que eles utilizam estão alinhadas.

Complementarmente, existem artigos bibliométricos utilizando a análise de redes sociais (ARS) para identificar o desenvolvimento de tecnologias de energia solar através da inovação aberta (DE PAULO; PORTO, 2017) e já outros tinham como objetivo avaliar os artigos relacionados à inovação em energias limpas e combustíveis fósseis (BORGES; PORTO, 2017). Portanto, existe uma lacuna de pesquisa em relação à inovação e os sistemas de energias renováveis. 0 objetivo do artigo é identificar as lacunas de pesquisa da relação ao SER e à inovação. Além disso, é possível detectar também os temas já consolidados, as ramificações já foram exploradas e as ramificações que podem ser exploradas.

\section{METODOLOGIA}

Com a análise dos modelos de redes, é possível usar a estrutura da rede como um indicador de compreensão de como a informação é distribuída em um grupo de pessoas (BURT et al., 2013). Quando os indivíduos interagem são produzidos dados, informações e conhecimento. Desse modo, as relações formadas concomitantemente e ciclicamente entre as pessoas são consideradas fontes de conhecimento.

Assumindo que SER e inovação são temas fundamentais para o desenvolvimento de energias mais limpas e renováveis, foram coletados artigos acadêmicos que continham "renewable energy systems" e innovation nos seus títulos, resumos, palavras-chave e no texto. Os artigos foram coletados no Web of Science, que é uma interface usada para banco de dados de citações do Institute of Scientific Information (ISI). Dessa forma, cinquenta artigos foram selecionados com intuito de se realizar uma análise de conteúdo. Depois, foi feita a consolidação dos dados. Os mesmos foram passados para o Unicet Software, em formato de matriz quadrada, programa computacional utilizado para analisar redes sociais. Por fim, utilizou-se o software Netdraw para o desenho da rede, um software que é utilizado para a visualização das redes sociais (BORGATTI et al., 2002).

\section{RESULTADOS}

Na Figura 1, há a representação do sociograma dos autores de artigos relacionados a SER e à inovação, o qual é composto por um conjunto de pontos vermelhos, que representam os nós/atores, os quais estão conectados por linhas, que são as interações entre as pessoas, ou melhor, com quem os pesquisadores publicaram artigos. Além disso, há pontos azuis, em que são representados blocos e pontos de corte (se o autor não estivesse ali, os autores não teriam aquela conexão). No momento em que há um autor em azul, há um ponto de corte.

No estudo, os nós representam os autores dos artigos, e as linhas com quem eles se comunicam para o desenvolvimento de pesquisas nas respectivas áreas de atuação, ou seja, com coautores. No caso dos autores, percebe-se há um grupo de autores que publicaram sozinhos (no caso 9 pesquisadores) e não estão vinculados a outros pesquisadores nas respectivas publicações. Ademais, trinta e sete grupos com diversos autores pesquisando e publicando em conjunto. Logo, há uma oportunidade de desenvolver relações entre os pesquisadores, uma vez que são apresentados vários atores sozinhos e trinta e sete grupos distintos. 
Figura 1 - Sociograma da rede de relacionamento entre os autores

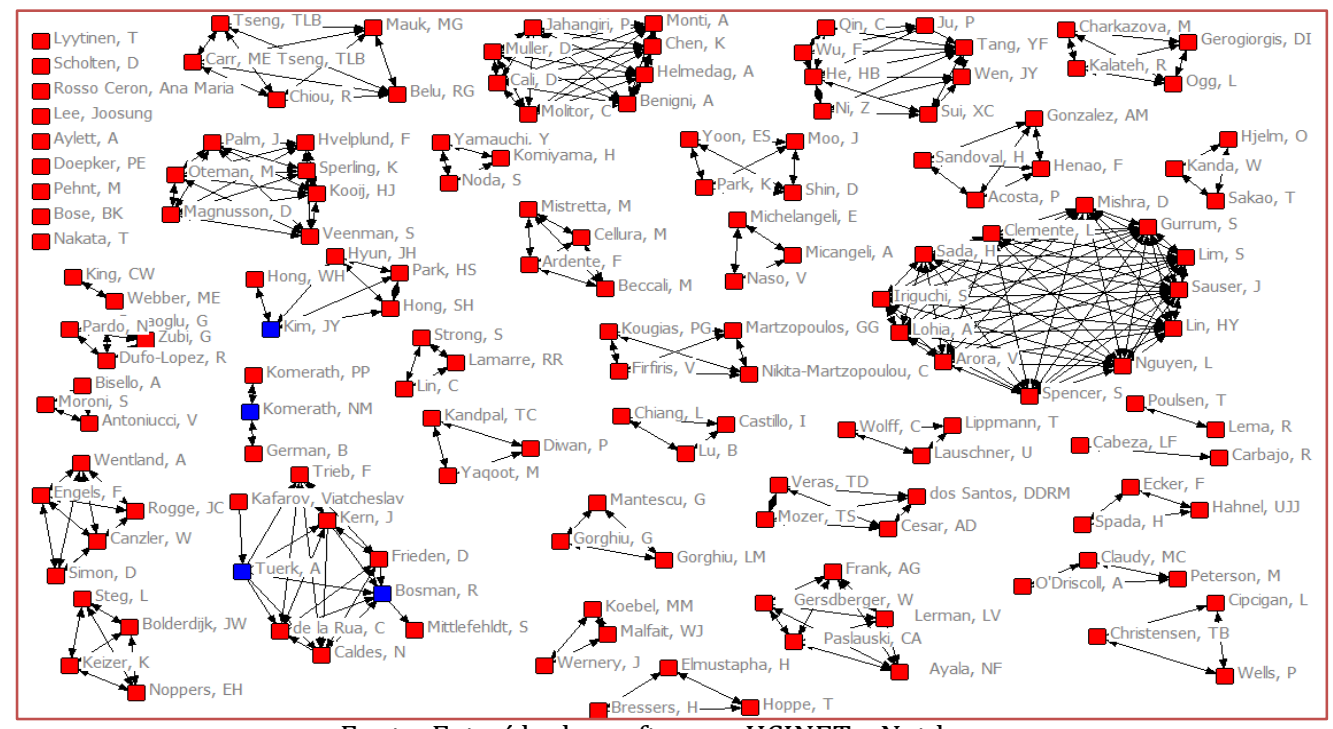

Fonte: Extraído dos softwares UCINET e Netdraw.

Na Figura 2, há a mesma representação para as palavras-chave. No entanto, as cores estão invertidas, em azul, estão as palavras-chave que são essenciais para relacionar os grupos de palavras, que não estariam interligadas se não estivessem ali. A fim de se utilizar outra abordagem para encontrar pontos que a rede está conectada por apenas um ator, deve-se perguntar: se um nó for removido, a estrutura se dividiria? Se existem esses nós, eles são denominados pontos de corte. Dessa forma, é possível imaginar como se esses pontos de cortes sejam atores importantes, os quais podem atuar como intermediários entre os grupos, os quais estariam desconectados sem eles. Essas divisões dos pontos de rede são denominadas de blocos (HANNEMAN; RIDDLE, 2005). Os itens em azul na Figura 1 são esses blocos, já, na Figura 2, os itens em vermelho são os blocos. Na rede autores, eles são: Kim, JY; Komerath, NM. Já, na rede de palavras, são Renewable Energy, Energy Transition, Energy, Biomass/wood energy, Innovation, Engineering, Renewable Energy Systems, Sustainability, Business model e computational intelligence. No Quadro 1, estão destacados os pesquisadores, o título dos artigos publicados e as palavras-chave.

Na figura 2, percebe-se que há quatorze grupos que não estão relacionados à grande rede. Além disso, há dez palavras-chave que se fossem retiradas a grande rede não estaria tão interligada. Ademais, um dos indicadores de redes sociais (RS) é a densidade, a qual indica o potencial de conectividade e de ligações da rede. Para a calcular, é necessário saber quantas ligações são efetuadas na rede dividido pelo o total de ligações possíveis, que é quando a rede é totalmente conectada. Sendo assim, quanto maior o valor da densidade, mais os atores utilizam suas redes de parcerias. Conforme as rotinas do software UCINET, pode-se calcular a densidade, e o resultado encontrado foi de $2,28 \%$ na rede de autores e $2,56 \%$ na rede de palavras-chave. Isto é, há muitas relações a serem exploradas tanto na rede de autores quanto na rede de palavras: $97,72 \%$ e $97,44 \%$, respectivamente. 
Figura 2 - Sociograma da rede de relacionamento entre palavras-chave

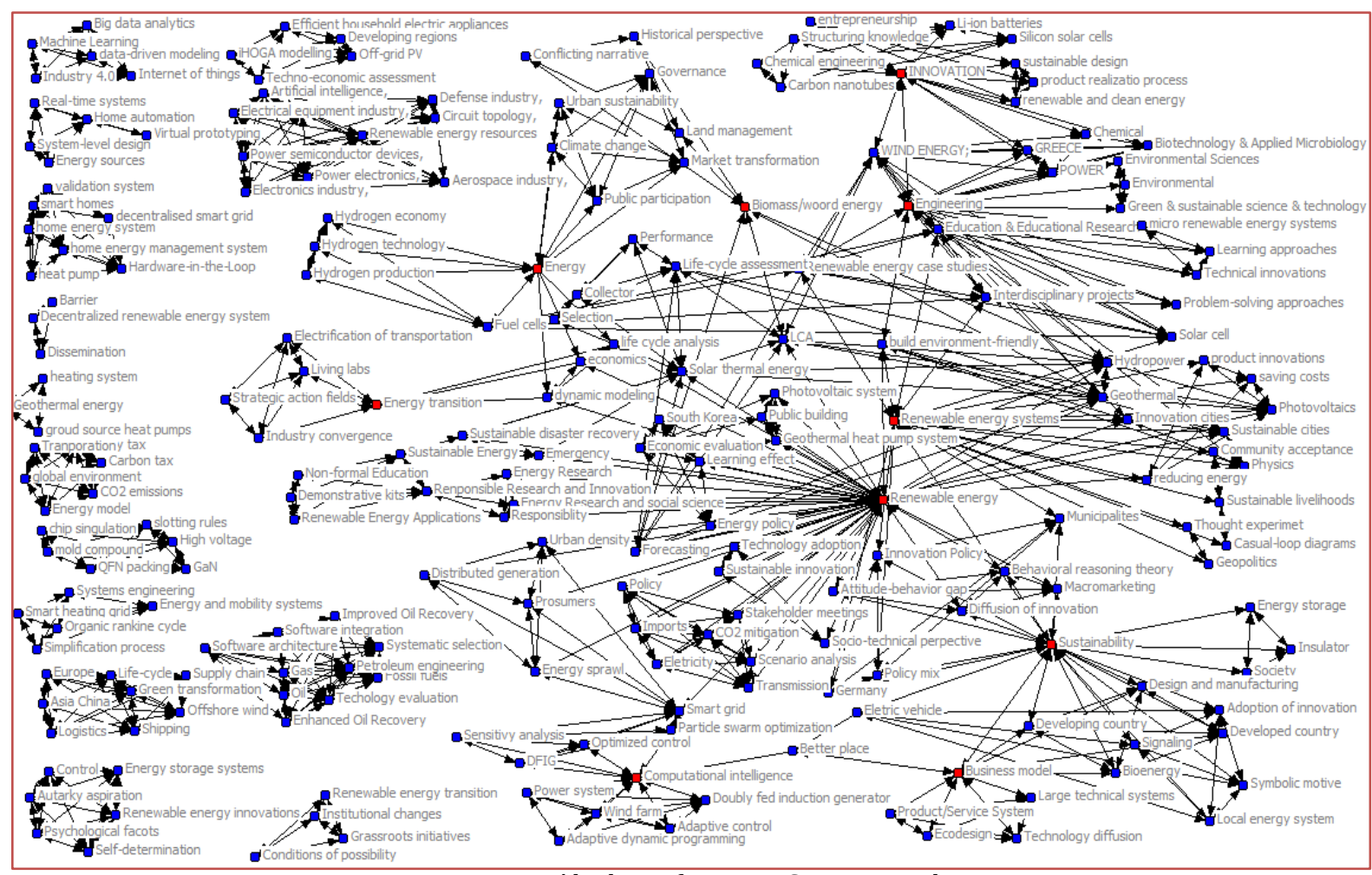

Fonte: Extraído dos softwares UCINET e Netdraw

Outro indicador de RS é o grau de centralidade, que demonstra o índice de exposição ao fluxo de conhecimento que permeia a rede. No caso, refere-se ao fato de se ter a oportunidade de influenciar e de ser influenciado diretamente (HALGIN, 2008). Em relação à centralidade de Bonacich, um dos tipos de centralidade, os atores podem procurar alinhar e coordenar as suas próprias conexões, além das conexões de outros atores que estão ligados a eles. Se um ator tiver um maior número de conexões, e os atores ligados a ele tiverem um nível de conexão igualmente alto, o nível de poder individual é maior.

Dessa maneira, ser mais poderoso fornece fontes alternativas de informação, de transferência de conhecimento e dá a capacidade de disseminar as informações, de forma estratégica (BONACICH, 1987). 0 valor de $\beta$ reflete o raio de poder. Se $\beta>0$, a centralidade maior está relacionado com pessoas mais centrais. Se $\beta<0$, a centralidade maior está relacionada com pessoas não centrais (BONACICH, 1987). No estudo, o valor de Beta encontrado foi de 0,09 para os autores. Já, para as palavras-chave, foi de 0,10 . Logo, há uma forte relação com atores e conteúdos mais centrais nas duas redes. Portanto, ambas as centralidades estão relacionadas a nós mais centrais para pesquisadores e palavras-chave.

A fim de se analisar uma rede, em relação à intermediação ainda, é necessário identificar a distância geodésica, a qual mede a distância que um ator está de outro ator. A média da distância geodésica é 1,1, e o desvio padrão, de 0,4 , isto é, um pesquisador necessita entrar em contato com outros 2 atores da rede a fim de conseguir realizar a coautoria. Ademais, a média da distância geodésica, para as palavras-chave é de 3,8, e o desvio-padrão, de 1,6, com intuito de outra palavra chave é necessário passar por 4 palavras-chave para chegar em outra. 
Quadro 1 - Pesquisadores dos pontos de corte, título dos artigos e palavras-chave

\begin{tabular}{|c|c|c|}
\hline Pesquisador & Título dos Artigos & Palavras-chave \\
\hline \multirow{2}{*}{ KIM, JY } & $\begin{array}{l}\text { An Analysis of the Plans to Reduce } \\
\text { Demand for Energy and Introduce } \\
\text { Renewable Energy Systems in } \\
\text { Innovation Cities }\end{array}$ & $\begin{array}{c}\text { Engineering; Physics; Innovation cities; build } \\
\text { environment-friendly; sustainable cities; renewable } \\
\text { energy systems; renewable energy }\end{array}$ \\
\hline & $\begin{array}{l}\text { The economic evaluation of } \\
\text { installing renewable energy } \\
\text { system into public buildings in } \\
\text { Sinseo Innovation City, Daegu }\end{array}$ & $\begin{array}{l}\text { Economic evaluation; Renewable energy; Public } \\
\text { building; Photovoltaic system; Geothermal heat pump } \\
\text { system }\end{array}$ \\
\hline \multirow{3}{*}{ KOMERATH, NM } & $\begin{array}{l}\text { Extrovert: Experience With Cross- } \\
\text { Disciplinary Learning }\end{array}$ & $\begin{array}{c}\text { Education \& Educational Research; Engineering; } \\
\text { Interdisciplinary projects; problem-solving } \\
\text { approaches }\end{array}$ \\
\hline & $\begin{array}{l}\text { Testbeds Connecting Space } \\
\text { Technology To Terrestrial } \\
\text { Renewable Energy }\end{array}$ & $\begin{array}{l}\text { Education \& Educational Research; Engineering; } \\
\text { micro renewable energy systems; Technical } \\
\text { innovations ; Learning approaches }\end{array}$ \\
\hline & $\begin{array}{c}\text { Terrestrial Micro Renewable } \\
\text { Energy Applications of Space } \\
\text { Technology }\end{array}$ & Micro Renewable Energy Systems \\
\hline
\end{tabular}

Fonte: autora.

No Quadro 2, estão as palavras-chave que são pontos de corte, títulos dos artigos, autores envolvidos e todas as palavras-chave. Dessa forma, é possível verificar que esses pesquisadores possuem interesses em comum e podem, no futuro, vir a desenvolver algum projeto em parceria, caso tenham a oportunidade.

Quadro 2 - Palavras-chave do ponto de corte, título dos artigos, pesquisadores dos artigos e demais palavras-chave

\begin{tabular}{|c|c|c|c|}
\hline $\begin{array}{l}\text { Palavras-chave } \\
\text { do ponto de } \\
\text { corte }\end{array}$ & Título dos Artigos & Pesquisadores dos artigos & Palavras-Chave \\
\hline \multirow{5}{*}{$\begin{array}{l}\text { Renewable } \\
\text { energy }\end{array}$} & $\begin{array}{l}\text { Renewable energy research } \\
\text { and technologies through } \\
\text { responsible research and } \\
\text { innovation looking glass: } \\
\text { Reflexions, theoretical } \\
\text { approaches and } \\
\text { contemporary discourses }\end{array}$ & Carbajo, R., \& Cabeza, L. F. & 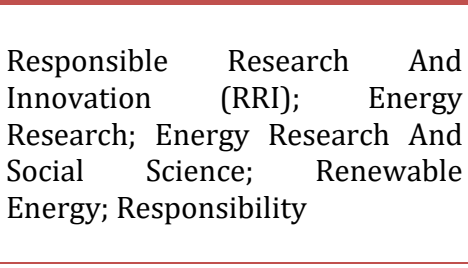 \\
\hline & $\begin{array}{l}\text { Rescuing the concept of } \\
\text { solar electricity transfer } \\
\text { from North Africa to } \\
\text { Europe }\end{array}$ & $\begin{array}{l}\text { Trieb, F., Kern, J., Caldés, N., de } \\
\text { la Rua, C., Frieden, D., \& Tuerk, } \\
\text { A. }\end{array}$ & $\begin{array}{lrr}\text { Policy; } & \text { Stakeholder } & \text { Meetings; } \\
\text { Imports; } & \text { Scenario } & \text { Analysis; } \\
\text { Renewable } & \text { Energies; } & \text { Electricity; } \\
\text { CO2 Mitigation; Transmission }\end{array}$ \\
\hline & $\begin{array}{lr}\text { Advancing } & \text { societal } \\
\text { readiness } & \text { toward } \\
\text { renewable energy } & \text { system } \\
\text { adoption with a socio- } \\
\text { technical perspective }\end{array}$ & Yun, S., \& Lee, J. & $\begin{array}{lr}\text { Renewable } & \text { Energy; } \\
\text { Adoption; } & \text { Tochnology } \\
\text { Perspective; } & \text { Sustainable } \\
\text { Innovation } & \\
\end{array}$ \\
\hline & $\begin{array}{l}\text { Energy sprawl, land taking } \\
\text { and distributed generation: } \\
\text { towards a multi-layered } \\
\text { density }\end{array}$ & $\begin{array}{l}\text { Moroni, S., Antoniucci, V., \& } \\
\text { Bisello, A. }\end{array}$ & 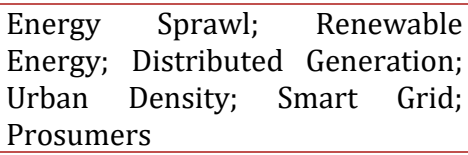 \\
\hline & $\begin{array}{l}\text { Understanding the } \\
\text { Attitude-Behavior Gap for } \\
\text { Renewable Energy Systems } \\
\text { Using Behavioral } \\
\text { Reasoning Theory }\end{array}$ & $\begin{array}{l}\text { Claudy, M. C., Peterson, M., \& } \\
\text { O’Driscoll, A. }\end{array}$ & $\begin{array}{l}\text { Renewable } \text { Energy; Diffusion Of } \\
\text { Innovation; Attitude-Behavior } \\
\text { Gap; Behavioral Reasoning } \\
\text { Theory; } \quad \text { Sustainability; } \\
\text { Macromarketing }\end{array}$ \\
\hline
\end{tabular}


Quadro 2 - Palavras-chave do ponto de corte, título dos artigos, pesquisadores dos artigos e demais palavras-chave (continuação...)

\begin{tabular}{|c|c|c|c|}
\hline $\begin{array}{l}\text { Palavras-chave } \\
\text { do ponto de } \\
\text { corte }\end{array}$ & Título dos Artigos & Pesquisadores dos artigos & Palavras-Chave \\
\hline \multirow{6}{*}{$\begin{array}{l}\text { Renewable } \\
\text { energy }\end{array}$} & $\begin{array}{l}\text { Sustainability after the } \\
\text { Thermal Energy Supply in } \\
\text { Emergency Situations: The } \\
\text { Case Study of Abruzzi } \\
\text { Earthquake (Italy) }\end{array}$ & \multirow[t]{2}{*}{$\begin{array}{l}\text { Micangeli, A., Michelangeli, E., } \\
\text { \& Naso, V. }\end{array}$} & $\begin{array}{llr}\text { Solar } & \text { Thermal } & \text { Energy; } \\
\text { Emergency; Sustainable } & \text { Disaster } \\
\text { Recovery; Renewable } & \text { Energy; } \\
\text { Sustainable Energy } & \\
\end{array}$ \\
\hline & $\begin{array}{l}\text { Economic evaluation of } \\
\text { renewable energy systems } \\
\text { under varying scenarios } \\
\text { and its implications to } \\
\text { Korea's renewable energy } \\
\text { plan }\end{array}$ & & $\begin{array}{llr}\text { Economic } & \text { Evaluation; } & \text { Energy } \\
\text { Policy; } & \text { Learning } & \text { Effect; } \\
\text { Renewable } & \text { Energy; South Korea }\end{array}$ \\
\hline & $\begin{array}{l}\text { An Analysis of the Plans to } \\
\text { Reduce Demand for Energy } \\
\text { and Introduce Renewable } \\
\text { Energy Systems in } \\
\text { Innovation Cities }\end{array}$ & $\begin{array}{l}\text { Park, H. S., Hong, S. H., Kim, J. } \\
\text { Y., \& Hyun, J. H. }\end{array}$ & $\begin{array}{l}\text { Engineering; Physics; Innovation } \\
\text { Cities; Build Environment- } \\
\text { Friendly; Sustainabe Cities; } \\
\text { Renewable Energy Systems; } \\
\text { Renewable Energy }\end{array}$ \\
\hline & $\begin{array}{l}\text { The economic evaluation of } \\
\text { installing renewable energy } \\
\text { system into public } \\
\text { buildings in Sinseo } \\
\text { Innovation City, Daegu }\end{array}$ & Kim, JY \& Hong, WH & $\begin{array}{l}\text { Economic Evaluation; Renewable } \\
\text { Energy; Public Building; } \\
\text { Photovoltaic System; Geothermal } \\
\text { Heat Pump System }\end{array}$ \\
\hline & $\begin{array}{l}\text { Methodology for } \\
\text { calculating the ability of } \\
\text { renewable energy systems } \\
\text { to manufacture themselves }\end{array}$ & King, C. W., \& Webber, M. E. & $\begin{array}{l}\text { Renewable Energy; Life Cycle } \\
\text { Analysis; Economics; Energy } \\
\text { Transition; Dynamic Modeling }\end{array}$ \\
\hline & $\begin{array}{lrr}\text { Dynamic } & \text { life } & \text { cycle } \\
\text { assessment } & (\mathrm{LCA}) & \text { of } \\
\text { renewable } & & \text { energy } \\
\text { Technologies } & & \end{array}$ & Pehnt, M. & $\begin{array}{l}\text { LCA; Life Cycle Assessment, } \\
\text { Forecasting, Renewable Energy, } \\
\text { Photovoltaics, } \\
\begin{array}{l}\text { Hydropower Beothermal, } \\
\text { Solar Thermal }\end{array}\end{array}$ \\
\hline \multirow{2}{*}{$\begin{array}{l}\text { Energy } \\
\text { transition }\end{array}$} & $\begin{array}{l}\text { From "living lab" to } \\
\text { strategic action field: } \\
\text { Bringing together energy, } \\
\text { mobility, and Information } \\
\text { Technology in Germany }\end{array}$ & $\begin{array}{l}\text { Canzler, W., Engels, F., Rogge, J. } \\
\text { C., Simon, D., \& Wentland, A. }\end{array}$ & $\begin{array}{l}\text { Energy Transition, Electrification } \\
\text { Of Transportation, Industry } \\
\text { Convergence, Strategic Action } \\
\text { Fields, Living Labs }\end{array}$ \\
\hline & $\begin{array}{l}\text { Methodology for } \\
\text { calculating the ability of } \\
\text { renewable energy systems } \\
\text { to manufacture themselves }\end{array}$ & King, C. W., \& Webber, M. E. & $\begin{array}{l}\text { Renewable Energy; Life Cycle } \\
\text { Analysis; Economics; Energy } \\
\text { Transition; Dynamic Modeling }\end{array}$ \\
\hline \multirow[b]{2}{*}{ Energy } & 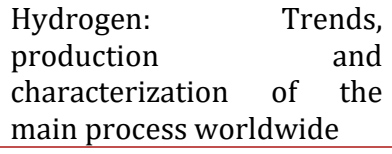 & $\begin{array}{l}\text { da Silva Veras, T., Mozer, T. S., } \\
\text { \& da Silva César, A. }\end{array}$ & $\begin{array}{l}\text { Energy; Hydrogen Economy; } \\
\text { Hydrogen Technology; Hydrogen } \\
\text { Production; Fuel Cells }\end{array}$ \\
\hline & $\begin{array}{l}\text { Networked urban climate } \\
\text { governance: neighborhood- } \\
\text { scale residential solar } \\
\text { energy systems and the } \\
\text { example of Solarize } \\
\text { Portland }\end{array}$ & Aylett, A. (2013). & $\begin{array}{l}\text { Urban Sustainability; } \text { Climate } \\
\text { Change; Energy; Governance; } \\
\text { Public Participation; Market } \\
\text { Transformation }\end{array}$ \\
\hline \multirow{2}{*}{$\begin{array}{l}\text { Biomass/wood } \\
\text { energy }\end{array}$} & $\begin{array}{l}\text { Seeing forests as fuel: How } \\
\text { conflicting narratives have } \\
\text { shaped woody biomass } \\
\text { energy development in the } \\
\text { United States since the } \\
\text { 1970s }\end{array}$ & Mittlefehldt, S. & $\begin{array}{l}\text { Historical Perspective; } \\
\text { Biomass/Wood } \\
\text { Conflicting Narratives; Land } \\
\text { Management }\end{array}$ \\
\hline & $\begin{array}{lrr}\text { Dynamic } & \text { life } & \text { cycle } \\
\text { assessment } & \text { (LCA) } \text { of } \\
\text { renewable } & \text { energy } \\
\text { technologies } & & \end{array}$ & Pehnt, M. & $\begin{array}{l}\text { LCA; Life Cycle Assessment, } \\
\text { Forecasting, Renewable Energy, } \\
\text { Photovoltaics, } \\
\text { Hydropower Beothermal, Biomass, Wind, } \\
\text { Solar Thermal }\end{array}$ \\
\hline
\end{tabular}


Quadro 2 - Palavras-chave do ponto de corte, título dos artigos, pesquisadores dos artigos e demais palavras-chave(continuação...)

\begin{tabular}{|c|c|c|c|}
\hline $\begin{array}{l}\text { Palavras-chave } \\
\text { do ponto de } \\
\text { corte }\end{array}$ & Título dos Artigos & Pesquisadores dos artigos & Palavras-Chave \\
\hline \multirow{3}{*}{ Innovation } & $\begin{array}{l}\text { Barriers to social acceptance of } \\
\text { renewable energy systems in } \\
\text { Colombia }\end{array}$ & Rosso-Cerón, A. M., \& Kafarov, V. & $\begin{array}{l}\text { Wind Energy; Power; Innovation; } \\
\text { Greece }\end{array}$ \\
\hline & $\begin{array}{l}\text { Sustaining Sustainable } \\
\text { Engineering Design Projects }\end{array}$ & Doepker, PE & $\begin{array}{llr}\text { Sustainable } & \text { Design; } & \text { Product } \\
\text { Realization } & \text { Process; Renewable And } \\
\text { Clean } & \text { Energy; } \quad \text { Innovation; } \\
\text { Entrepreneurship } & \end{array}$ \\
\hline & $\begin{array}{l}\text { Chemical Engineering for } \\
\text { Technology Innovation }\end{array}$ & $\begin{array}{l}\text { Yamauchi, Y., Noda, S., \& } \\
\text { Komiyama, H. }\end{array}$ & $\begin{array}{lrr}\text { Carbon Nanotubes; } & \text { Chemical } \\
\text { Engineering; Innovation; } & \text { Li-Ion } \\
\text { Batteries; Silicon Solar } & \text { Cells; } \\
\text { Structuring Knowledge } & \end{array}$ \\
\hline \multirow{5}{*}{ Engineering } & $\begin{array}{l}\text { Consumer renewable energy } \\
\text { technology adoption decision- } \\
\text { making; comparing models on } \\
\text { perceived attributes and } \\
\text { attitudinal constructs in the } \\
\text { case of solar water heaters in } \\
\text { Lebanon }\end{array}$ & $\begin{array}{l}\text { Elmustapha, H., Hoppe, T., \& } \\
\text { Bressers, H. }\end{array}$ & $\begin{array}{l}\text { Green \& Sustainable } \begin{array}{c}\text { Science \& } \\
\text { Technology; } \\
\text { Environmental; }\end{array} \text { Envineering, } \\
\text { Sciences }\end{array}$ \\
\hline & $\begin{array}{l}\text { Student Learning Experience } \\
\text { from Renewable Energy Case } \\
\text { Studies }\end{array}$ & Chiou, R. & $\begin{array}{l}\text { Education \& Educational Research; } \\
\text { Engineering; Renewable Energy } \\
\text { Systems; Renewable Energy Case } \\
\text { Studies; Wind Energy; Fuel Cell; Solar } \\
\text { Cell; Interdisciplinary Projects }\end{array}$ \\
\hline & $\begin{array}{l}\text { Extrovert: experience with } \\
\text { cross-disciplinary learning }\end{array}$ & Komerath, NM \& German, B. & $\begin{array}{lr}\text { Education \& Educational Research; } \\
\text { Engineering; } \\
\text { Projects; Problem-Solving Approaches }\end{array}$ \\
\hline & $\begin{array}{l}\text { Testbeds Connecting Space } \\
\text { Technology To Terrestrial } \\
\text { Renewable Energy }\end{array}$ & Komerath, NM & $\begin{array}{l}\text { Education \& Educational Research; } \\
\text { Engineering; Micro Renewable Energy } \\
\text { Systems; Technical Innovations ; } \\
\text { Learning Approaches }\end{array}$ \\
\hline & $\begin{array}{l}\text { An Analysis of the Plans to } \\
\text { Reduce Demand for Energy } \\
\text { and Introduce Renewable } \\
\text { Energy Systems in Innovation } \\
\text { Cities }\end{array}$ & $\begin{array}{l}\text { Park, H. S., Hong, S. H., Kim, J. Y., \& } \\
\text { Hyun, J. H. }\end{array}$ & $\begin{array}{l}\text { Engineering; Physics; Innovation } \\
\text { Cities; Build Environment-Friendly; } \\
\text { Sustainable Cities; Renewable Energy } \\
\text { Systems; Renewable Energy }\end{array}$ \\
\hline \multirow{6}{*}{$\begin{array}{l}\text { Renewable } \\
\text { energy systems }\end{array}$} & $\begin{array}{l}\text { The contribution of innovation } \\
\text { policy criteria to the } \\
\text { development of } \\
\text { renewable energy systems } \\
\text { local renewable energy } \\
\text { systems }\end{array}$ & $\begin{array}{l}\text { Frank, A. G., Gerstlberger, W., } \\
\text { Paslauski, C. A., Lerman, L. V., \& } \\
\text { Ayala, N. F. }\end{array}$ & $\begin{array}{l}\text { Sustainability; Innovation Policy; } \\
\text { Policy Mix; Renewable Energy } \\
\text { Systems; Germany; Municipalities }\end{array}$ \\
\hline & $\begin{array}{l}\text { An Analysis of the Plans to } \\
\text { Reduce Demand for Energy } \\
\text { and Introduce Renewable } \\
\text { Energy Systems in Innovation } \\
\text { Cities }\end{array}$ & $\begin{array}{l}\text { Park, H. S., Hong, S. H., Kim, J. Y., \& } \\
\text { Hyun, J. H. }\end{array}$ & $\begin{array}{l}\text { Engineering; Physics; Innovation } \\
\text { Cities; Build Environment-Friendly; } \\
\text { Sustainable Cities; Renewable Energy } \\
\text { Systems; Renewable Energy }\end{array}$ \\
\hline & $\begin{array}{l}\text { Photovoltaics: theory to reality } \\
\text { at the bowdoin-geneva } \\
\text { community center in } \\
\text { dorchester, massachusetts }\end{array}$ & Lamarre, R. R., Lin, C., \& Strong, S. & $\begin{array}{l}\text { Photovoltaics; Reducing Energy; } \\
\text { Renewable Energy System; Product } \\
\text { Innovations; Saving Costs }\end{array}$ \\
\hline & $\begin{array}{l}\text { On the Acceptance and } \\
\text { Sustainability of Renewable } \\
\text { Energy Projects-A Systems } \\
\text { Thinking Perspective }\end{array}$ & $\begin{array}{l}\text { González, A. M., Sandoval, H., } \\
\text { Acosta, P., \& Henao, F. }\end{array}$ & $\begin{array}{l}\text { Renewable } \quad \text { Energy } \quad \begin{array}{c}\text { Systems; } \\
\text { Sustainable }\end{array} \text { Livelihoods; Community } \\
\text { Acceptance; Causal-Loop Diagrams }\end{array}$ \\
\hline & $\begin{array}{l}\text { The geopolitics of renewables; } \\
\text { exploring the political } \\
\text { implications of renewable } \\
\text { energy systems }\end{array}$ & Scholten, D., \& Bosman, R. & $\begin{array}{l}\text { Geopolitics; Renewable Energy } \\
\text { Systems; Thought Experiment }\end{array}$ \\
\hline & $\begin{array}{l}\text { Student Learning Experience } \\
\text { from Renewable Energy Case } \\
\text { Studies }\end{array}$ & Chiou, R. & $\begin{array}{l}\text { Education \& Educational Research; } \\
\text { Engineering; Renewable Energy } \\
\text { Systems; Renewable Energy Case } \\
\text { Studies; Wind Energy; Fuel Cell; Solar } \\
\text { Cell; Interdisciplinary Projects }\end{array}$ \\
\hline
\end{tabular}


Quadro 2 - Palavras-chave do ponto de corte, título dos artigos, pesquisadores dos artigos e demais palavras-chave (continuação...)

\begin{tabular}{|c|c|c|c|}
\hline $\begin{array}{l}\text { Palavras-chave } \\
\text { do ponto de } \\
\text { corte }\end{array}$ & Título dos Artigos & Pesquisadores dos artigos & Palavras-Chave \\
\hline \multirow{5}{*}{ Sustainability } & $\begin{array}{l}\text { The contribution of innovation } \\
\text { policy criteria to the } \\
\text { development of } \\
\text { renewable energy systems } \\
\begin{array}{l}\text { local renewable } \\
\text { systems }\end{array}\end{array}$ & $\begin{array}{l}\text { Frank, A. G., Gerstlberger, W., } \\
\text { Paslauski, C. A., Lerman, L. V., \& } \\
\text { Ayala, N. F. }\end{array}$ & $\begin{array}{l}\text { Sustainability; Innovation } \\
\text { Policy Mix; } \quad \text { Renewable Energy } \\
\text { Systems; Germany; Municipalities }\end{array}$ \\
\hline & $\begin{array}{l}\text { Energy in buildings-Policy, } \\
\text { materials and solutions }\end{array}$ & $\begin{array}{l}\text { Koebel, M. M., Wernery, J., \& } \\
\text { Malfait, W. J. }\end{array}$ & $\begin{array}{l}\text { Society; Energy Storage; Insulator; } \\
\text { Sustainability }\end{array}$ \\
\hline & $\begin{array}{l}\text { Sustainable Business Models of } \\
\text { Small-Scale Renewable Energy } \\
\text { Systems: Two Resource-Scarce } \\
\text { Approaches for Design and } \\
\text { Manufacturing }\end{array}$ & Lyytinen, T. & $\begin{array}{ll}\text { Sustainability; Business Model; Design } \\
\text { And Manufacturing; } & \text { Bioenergy; } \\
\text { Developing Country; } & \text { Developed } \\
\text { Country } & \end{array}$ \\
\hline & $\begin{array}{l}\text { The adoption of sustainable } \\
\text { innovations: Driven by } \\
\text { symbolic and environmental } \\
\text { motives }\end{array}$ & $\begin{array}{l}\text { Noppers, E. H., Keizer, K., } \\
\text { Bolderdijk, J. W., \& Steg, L. }\end{array}$ & 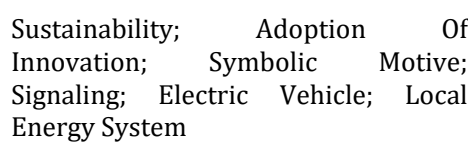 \\
\hline & $\begin{array}{l}\text { Understanding the Attitude- } \\
\text { Behavior Gap for Renewable } \\
\text { Energy Systems Using } \\
\text { Behavioral Reasoning Theory }\end{array}$ & $\begin{array}{l}\text { Claudy, M. C., Peterson, M., \& } \\
\text { O’Driscoll, A. }\end{array}$ & $\begin{array}{l}\text { Understanding The Attitude-Behavior } \\
\text { Gap For Renewable Energy Systems } \\
\text { Using Behavioral Reasoning Theory }\end{array}$ \\
\hline \multirow{3}{*}{ Business model } & $\begin{array}{l}\text { Sustainable Business Models of } \\
\text { Small-Scale Renewable Energy } \\
\text { Systems: Two Resource-Scarce } \\
\text { Approaches for Design and } \\
\text { Manufacturing }\end{array}$ & Lyytinen, $\mathrm{T}$. & $\begin{array}{ll}\text { Sustainability; Business Model; Design } \\
\text { And Manufacturing; } & \text { Bioenergy; } \\
\text { Developing Country; } & \text { Developed } \\
\text { Country } & \end{array}$ \\
\hline & $\begin{array}{l}\text { Components of business } \\
\text { concepts for the diffusion of } \\
\text { large scaled environmental } \\
\text { technology systems }\end{array}$ & Kanda, W., Sakao, T., \& Hjelm, O. ( & $\begin{array}{l}\text { Large Technical Systems; Business } \\
\text { Model; Technology Diffusion; } \\
\text { Product/Service System; Ecodesign }\end{array}$ \\
\hline & $\begin{array}{l}\text { Can innovative business } \\
\text { models overcome resistance to } \\
\text { electric vehicles? Better Place } \\
\text { and battery electric cars in } \\
\text { Denmark }\end{array}$ & $\begin{array}{l}\text { Christensen, T. B., Wells, P., \& } \\
\text { Cipcigan, L. }\end{array}$ & $\begin{array}{l}\text { Business Models; Electric Cars; Better } \\
\text { Place }\end{array}$ \\
\hline \multirow{2}{*}{$\begin{array}{l}\text { Computational } \\
\text { intelligence }\end{array}$} & $\begin{array}{l}\text { Reactive power control of grid- } \\
\text { connected wind farm based on } \\
\text { adaptive dynamic } \\
\text { programming }\end{array}$ & $\begin{array}{l}\text { Tang, Y., He, H., Ni, Z., Wen, J., \& } \\
\text { Sui, X. }\end{array}$ & $\begin{array}{l}\text { Computational Intelligence; Adaptive } \\
\text { Dynamic Programming; Doubly Fed } \\
\text { Induction Generator; Wind Farm; } \\
\text { Power System; Adaptive Control }\end{array}$ \\
\hline & $\begin{array}{l}\text { Optimized Control of DFIG- } \\
\text { Based Wind Generation Using } \\
\text { Sensitivity Analysis and } \\
\text { Particle Swarm Optimization }\end{array}$ & $\begin{array}{l}\text { Tang, Y., Ju, P., He, H., Qin, C., \& Wu, } \\
\text { F. }\end{array}$ & $\begin{array}{l}\text { Computational Intelligence; DFIG; } \\
\text { Optimized Control; Particle Swarm } \\
\text { Optimization; Sensitivity Analysis; } \\
\text { Smart Grid }\end{array}$ \\
\hline
\end{tabular}

Fonte: autora.

No Quadro 2, foi possível observar que o artigo Methodology for calculating the ability of renewable energy systems to manufacture themselves está relacionado a duas palavras de corte: renewable energy e energy transition. Além disso, o artigo Dynamic life cycle assessment (LCA) of renewable energy technologies está presente em renewable energy e biomass. 0 artigo entitulado An Analysis of the Plans to Reduce Demand for Energy and Introduce Renewable Energy Systems in Innovation Cities relaciona-se com renewable energy, engineering, renewable energy system. Ademais, o artigo Student Learning 
Experience from Renewable Energy Case Studies está relacionado a engineering e a renewable energy systems. The contribution of innovation policy criteria to the development of local renewable energy systems relaciona-se com o renewable energy systems e sustaintability. E o artigo Sustainable Business Models of Small-Scale Renewable Energy Systems: Two Resource-Scarce Approaches for Design and Manufacturing está relacionado a palavras-chave: sustaintability e business model.

Além disso, mais uma análise utilizada em redes sociais sobre centralidade é Betweenness, o grau de intermediação, que pode expressar os controles de comunicação. Além disso, para Alejandro e Norman (2005, p.20) "interpreta-se como a possibilidade que um nó tem para intermediar as comunicações entre pares de nós”. Nesse caso, na Figura 3, pode-se observar que há três autores que fazem essa intermediação: He, Hb; Tang, YF e Kim, JY. Outrossim, construiu-se o Quadro 3 com os autores, títulos dos artigos e as palavras-chave.

Figura 3 - Rede de centralidade Betweenness entre os pesquisadores de sistemas de energias renováveis e inovação

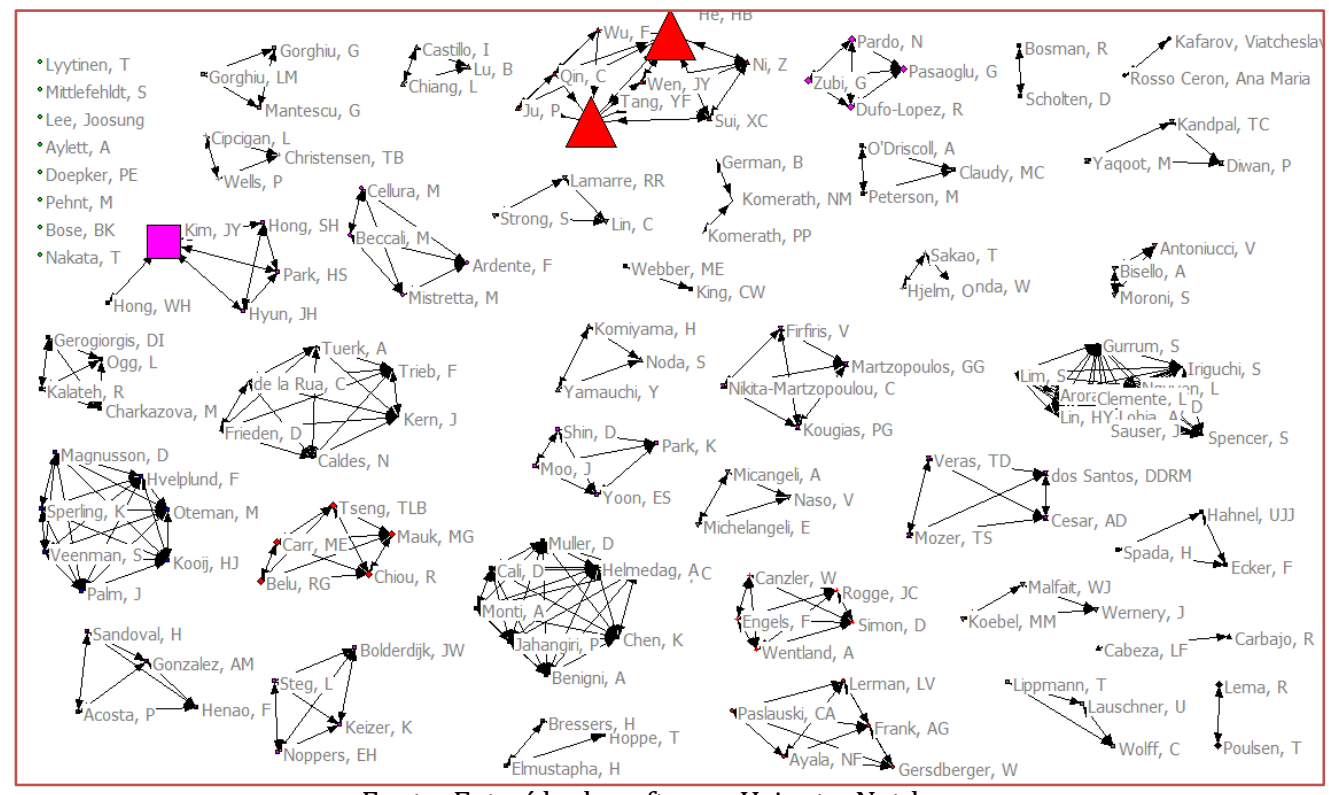

Fonte: Extraído do software Ucinet e Netdraw.

Quadro 3 - Autores da centralidade Betweenness, títulos dos artigos e as palavras-chave

\begin{tabular}{|c|c|c|}
\hline Autores & Título & Palavras-chave \\
\hline \multirow[b]{2}{*}{$\mathrm{He}, \mathrm{HB}$} & $\begin{array}{l}\text { Reactive power control of grid- } \\
\text { connected wind farm based on } \\
\text { adaptive dynamic programming }\end{array}$ & $\begin{array}{l}\text { Computational intelligence; Adaptive dynamic } \\
\text { programming; Doubly fed induction generator; Wind } \\
\text { farm; Power system; Adaptive control }\end{array}$ \\
\hline & $\begin{array}{l}\text { Optimized Control of DFIG-Based } \\
\text { Wind Generation Using Sensitivity } \\
\text { Analysis and Particle Swarm } \\
\text { Optimization }\end{array}$ & $\begin{array}{l}\text { Computational intelligence; DFIG; optimized control; } \\
\text { particle swarm optimization; sensitivity analysis; } \\
\text { smart grid }\end{array}$ \\
\hline \multirow[t]{2}{*}{ Tang, YF } & $\begin{array}{l}\text { Optimized Control of DFIG-Based } \\
\text { Wind Generation Using Sensitivity } \\
\text { Analysis and Particle Swarm } \\
\text { Optimization }\end{array}$ & $\begin{array}{l}\text { Computational intelligence; DFIG; optimized control; } \\
\text { particle swarm optimization; sensitivity analysis; } \\
\text { smart grid }\end{array}$ \\
\hline & $\begin{array}{l}\text { Reactive power control of grid- } \\
\text { connected wind farm based on } \\
\text { adaptive dynamic programming }\end{array}$ & $\begin{array}{l}\text { Computational intelligence; Adaptive dynamic } \\
\text { programming; Doubly fed induction generator; Wind } \\
\text { farm; Power system; Adaptive control }\end{array}$ \\
\hline
\end{tabular}


Quadro 3 - Autores da centralidade Betweenness, títulos dos artigos e as palavras-chave (continuação...)

\begin{tabular}{|c|c|c|}
\hline Autores & Título & Palavras-chave \\
\hline \multirow{2}{*}{ Kim, JY } & $\begin{array}{l}\text { An Analysis of the Plans to Reduce } \\
\text { Demand for Energy and Introduce } \\
\text { Renewable Energy Systems in } \\
\text { Innovation Cities }\end{array}$ & $\begin{array}{c}\text { Engineering; Physics; Innovation cities; build } \\
\text { environment-friendly; sustainable cities; renewable } \\
\text { energy systems; renewable energy }\end{array}$ \\
\hline & $\begin{array}{l}\text { The economic evaluation of } \\
\text { installing renewable energy } \\
\text { system into public buildings in } \\
\text { Sinseo Innovation City, Daegu }\end{array}$ & $\begin{array}{c}\text { Economic evaluation; Renewable energy; Public } \\
\text { building; Photovoltaic system; Geothermal heat pump } \\
\text { system }\end{array}$ \\
\hline
\end{tabular}

Fonte: autora.

Há apenas um artigo do Quadro 1 que não está no Quadro 3: Terrestrial Micro Renewable Energy Applications of Space Technology. Logo, é uma das lacunas de pesquisa a ser explorada. Ashok (2007) destaca o micro-hydro-wind systems são uma combinação ótima para eletrificação em áreas rurais. $\mathrm{Na}$ análise de Betweenness gráfica das palavras-chave, há algumas palavras que se destacam: Energy, energy transition, innovation, engineering, renewable energy systems, renewable energy, sustainability, computational intelligence, business model e biomass/wood energy. Além disso, são as mesmas palavraschave do Quadro 2. Na figura 4, em vermelho, as palavras estão em destaque. Consequentemente, esses temas já foram explorados com mais frequência em relação as palavras-chave das pesquisas.

Figura 4 - Rede de centralidade Betweenness entre as palavras-chave de sistemas de energias renováveis e inovação

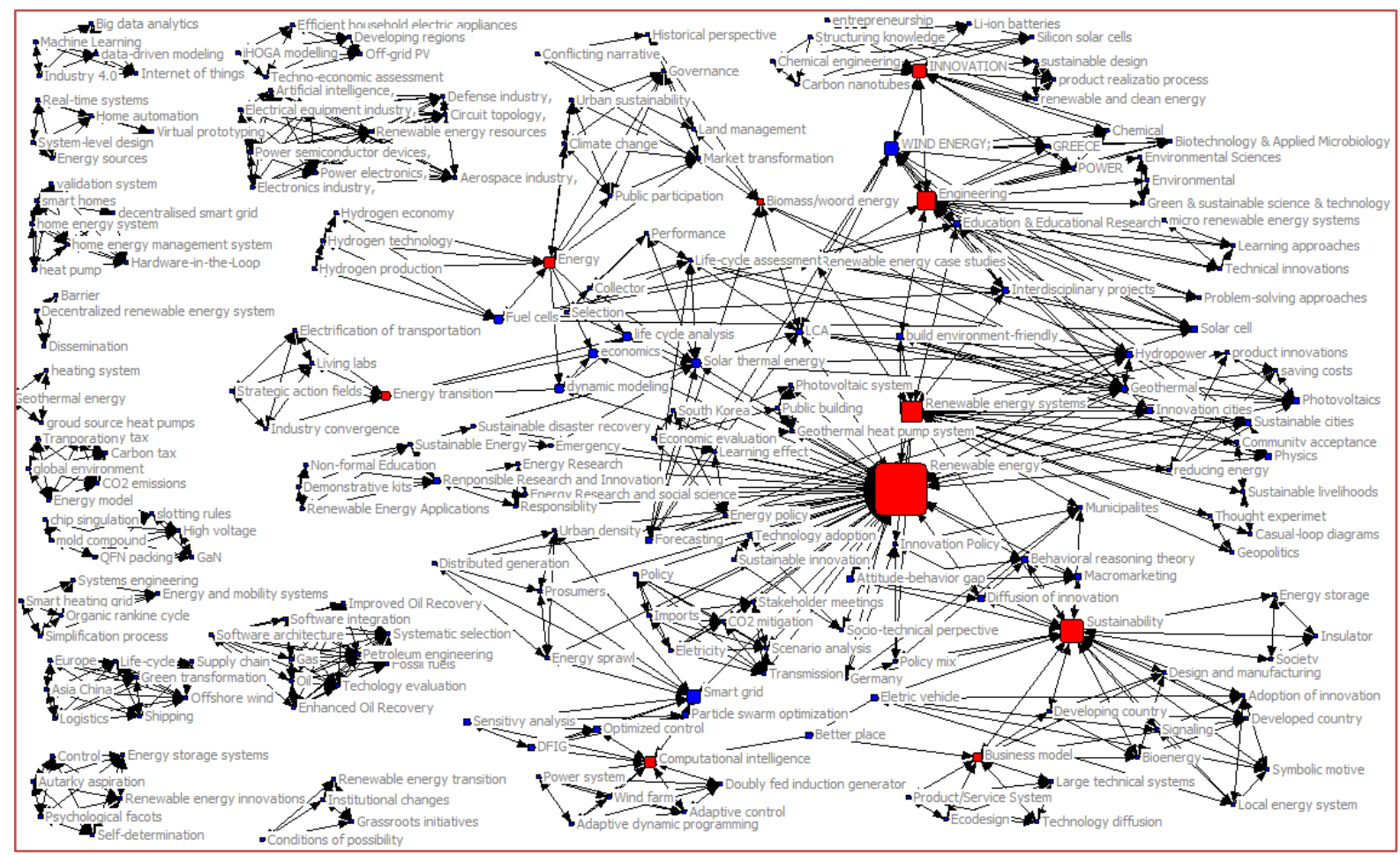

Fonte: autora.

Além disso, é importante avaliar o quais são as palavras-chave que estão na fronteira em relação a essas palavras mais exploradas. Por conseguinte, essas palavras em fronteira são zonas que podem ser exploradas, em que a rede está em expansão, elas estão no Quadro 4. 
Quadro 4 - Palavras-chave destacas pela ARS e as palavras-chave relacionados a elas que são temas de fronteira (estão nos extremos da rede)

\begin{tabular}{|c|c|}
\hline $\begin{array}{l}\text { Palavras-chave da } \\
\text { ARS }\end{array}$ & Palavras-chave que estão na fronteira \\
\hline Energy & $\begin{array}{l}\text { Hydrogen economy, Hydrogen technology; Hydrogen production; climate change; market } \\
\text { transformation; public participation; urban sustainability; governance }\end{array}$ \\
\hline Energy transition & Electrification of transport; living labs, strategic action fields, industry convergence; \\
\hline Innovation & $\begin{array}{c}\text { Entrepreneurship, lio-on batteries, structuring knowledge, chemical engineering, carbon } \\
\text { nanotubes, silicon solar cells, sustainable design, product realization process, renewable and } \\
\text { clean energy; }\end{array}$ \\
\hline Sustainability & Energy storage; insulator, Society \\
\hline Business model & Large technical systems, product/service system; ecodesign; technology diffusion \\
\hline $\begin{array}{l}\text { Computational } \\
\text { intelligence }\end{array}$ & $\begin{array}{l}\text { Doubly fed induction generator; power system; wind farm; adaptive control; adaptive } \\
\text { dynamic programming }\end{array}$ \\
\hline $\begin{array}{l}\text { Renewable Energy } \\
\text { System }\end{array}$ & $\begin{array}{l}\text { Thought experiment; Geopolitics; Municipalities; Policy mix; Product innovations, saving } \\
\text { costs, reducing energy, sustainable livelihood; casual-loop diagrams }\end{array}$ \\
\hline Renewable energy & $\begin{array}{l}\text { Diffusion of innovation; socio-technical perspective; macromarketing; behavioral reasoning } \\
\text { theory; sustainable innovation; attitude- behavior gap; co2 mitigation }\end{array}$ \\
\hline Engineering & $\begin{array}{c}\text { Technical innovations; learning approaches, problem-solving approaches; green \& } \\
\text { sustainable science \& technology }\end{array}$ \\
\hline
\end{tabular}

Fonte: autora.

Outrossim, há quatorze redes de palavras que estão separadas do grupo que está mais interligado. Há alguns estudos desses grupos separados, os quais poderiam se conectar com a grande rede interligada. Por exemplo, os grupos que possuem as palavras-chave machine learning, software integration e artificial intelligence poderiam, de alguma forma, relacionar-se com computational intelligence (que está no grande grupo) (KALOGIROU, 2011). 0 grupo que possui organic rankine cycle pode se relacionar com chemical engineering (que está no grande grupo) (HETTIARACHCHI, HD et al., 2007). 0 grupo que possui CO2 emissions poderia relacionar com CO2 mitigation (que está no grande grupo) (SIMS et al., 2003). Dessa forma, há oportunidade de se desenvolver diversas pesquisas na zona de fronteira a fim de expandir o conhecimento em sistemas de energias renováveis e inovação.

\section{CONSIDERAÇÕES FINAIS}

Há muitas oportunidades de expansão das conexões entre os pesquisadores, visto que a densidade da rede é de, aproximadamente, $2 \%$. Além disso, alguns pesquisadores são chaves para o desenvolvimento de pesquisas em forma de parceria. Se Kim, JY e KOMERATH, NM não estivessem na rede, haveria um ponto de corte na rede. Dessa forma, eles são fundamentais para a coesão e o desenvolvimento de pesquisas. Os pesquisadores $\mathrm{He}, \mathrm{Hb}$; Tang, YF e Kim, JY são fundamentais para intermediar comunicação entre os demais atores a fim de se publicarem artigos relacionados à SER e à inovação. Sendo assim, é importante aprimorar essa predisposição deles demonstrada pela análise de redes sociais.

Além disso, há diversas oportunidades em relação aos conteúdos, visto que a densidade da rede é de, aproximadamente, $2 \%$. Igualmente, há temas um pouco mais consolidados que outros, visto que são capazes de intermediar conexões, tais como Energy, energy transition, innovation, engineering, renewable energy systems, biomass, renewable energy, sustainability, computational intelligence e business model. Dessa forma, esses temas são fundamentais para o desenvolvimento da pesquisa de outros artigos, como eles são utilizados como base em diversas pesquisas, já estão mais consolidados em relação a sistemas de energias renováveis e inovação. Além disso, há uma lacuna de pesquisa em relação à Micro Renewable energy Systems. 
Há diversos conteúdos em expansão, que envolvem os mais variados temas desde a difusão da inovação a geopolítica, uma vez que o tema de inovação é bastante amplo envolve diversas áreas: capacidades de inovação, sistemas de inovação, universidade empreendedora, integração indústria-universidade-governo, por exemplo. Nos temas em expansão, é possível perceber que ainda existem conexões novas para se abordar em relação a sistemas de energias renováveis e inovação. Além disso, é possível conectar à rede grande com as menores, a partir de algumas palavras-chave, por exemplo: machine learning, software integration e artificial intelligence relacionam-se com computational intelligence; organic rankine cycle relacionado com chemical engineering; $\mathrm{CO} 2$ emissions relacionado com $\mathrm{CO} 2$ mitigation.

Como limites dessa pesquisa, é que só foi utilizada a base de artigos Web of Science. Além disso, não se realizou uma limitação temporal, logo os artigos podem estar em um escopo de tempo bastante amplo. Os artigos foram publicados nas mais variadas revistas e journals, ou melhor, não houve especificação de journals. Para pesquisas futuras, é importante avaliar se, em outra base de dados, em outros journals, há alguma forma de correlação entre os grupos separados e a rede mais densa e consolidada. Outro ponto importante é entender como ocorrerá o comportamento da pesquisa sobre os temas em expansão, se há essa tendência mesmo, através de uma comprovação empírica.

\section{REFERÊNCIAS}

[1] ALEJANDRO, V.; NORMAN, A; Manual Introdutório à Análise de Redes Sociais: Medidas de Centralidade. 2005

[2] ASHOK, S. Optimised model for community-based hybrid energy system. Renewable energy, v. 32, n. 7, p. 1155-1164, 2007.

[3] BONACICH, Ph. Power and Centrality: A Family of Measures.The American Journal of Sociology, 92: 11701182,1987

[4] BORGATTI, S. P.; EVERETT, M. G.; FREEMAN, L. C. Unicet IV: Network Analysis Software. Research Gate, 2002.

[5] BORGES, JÚLIO CÉSAR; PORTO, GECIANE. Inovação em combustíveis fósseis e energias limpas: um estudo bibliométrico comparativo das disciplinas, origens e tendências. 2017.

[6] BRASS, Daniel J. A social network perspective on industrial/organizational psychology. Handbook of industrial and organizational psychology, v. 1, p. 107-117, 2011.

[7] BRINI, Riadh; AMARA, Mohamed; JEMMALI, Hatem. Renewable energy consumption, International trade, oil price and economic growth inter-linkages: The case of Tunisia. Renewable and Sustainable Energy Reviews, v. 76, p. 620-627, 2017.

[8] BRUNEEL, Johan; D’ESTE, Pablo; SALTER, Ammon. Investigating the factors that diminish the barriers to university-industry collaboration. Research policy, v. 39, n. 7, p. 858-868, 2010.

[9] BURT, R. S.; KILDUFF, M.; TASSELLI, S. Social network analysis: Foundations and frontiers on advantage. Annual review of psychology, v. 64, p. 527-547, 2013.

[10] COHEN, Wesley M.; LEVINTHAL, Daniel A. Absorptive capacity: A new perspective on learning and innovation. In: Strategic Learning in a Knowledge economy. 2000. p. 39-67.

[11] DE PAULO, Alex Fabianne; PORTO, Geciane Silveira. Solar energy technologies and open innovation: A study based on bibliometric and social network analysis. Energy Policy, v. 108, p. 228-238, 2017.

[12] Etzkowitz, Henry. The Triple Helix of University -Industry -Government Implications for Policy and Evaluation. Science Policy Institute. 2011

[13] FAGERBERG, Jan; MOWERY, David C.; NELSON, Richard R. (Ed.). The Oxford handbook of innovation. Oxford university press, 2005.

[14] FAGERBERG, Jan; VERSPAGEN, Bart. Innovation studies-The emerging structure of a new scientific field. Research policy, v. 38, n. 2, p. 218-233, 2009.

[15] FRANK, Alejandro Germán et al. The contribution of innovation policy criteria to the development of local renewable energy systems. Energy Policy, v. 115, p. 353-365, 2018.

[16] FU, Xin et al. Spatial structure, inequality and trading community of renewable energy networks: A comparative study of solar and hydro energy product trades. Energy Policy, v. 106, p. 22-31, 2017.

[17] HALGIN, D. An Introduction to UCINET and NetDraw. Boston College. 2008.

[18] HANNEMAN, R.; RIDDLE, M. Introduction to social network methods. 2005.

[19] HETTIARACHCHI, HD Madhawa et al. Optimum design criteria for an organic Rankine cycle using lowtemperature geothermal heat sources. Energy, v. 32, n. 9, p. 1698-1706, 2007. 
[20] IRENA. Global Energy Transformation: A roadmap to 2050, International Renewable Energy Agency, Abu Dhabi. 2018.

[21] KALOGIROU, Soteris A. Artificial neural networks in renewable energy systems applications: a review. Renewable and sustainable energy reviews, v. 5, n. 4, p. 373-401, 2001.

[22] LALL, Sanjaya. Technological capabilities and industrialization. World development, v. 20, n. 2, p. 165-186, 1992.

[23] LUNDVALL, Bengt-Åke; BORRÁS, Susana. Science, technology, and innovation policy. In: Oxford handbook of innovation. Oxford University Press, 2005. p. 599-631.

[24] Martinot E, McDoom O. Promoting energy efficiency and renewable energy: GEF climate change projects and impacts 1999.

[25] MATHIESEN, Brian Vad; LUND, Henrik; KARLSSON, Kenneth. 100\% Renewable energy systems, climate mitigation and economic growth. Applied energy, v. 88, n. 2, p. 488-501, 2011.

[26] NEWMAN, M. E.J. The structure of scientific collaboration networks. Proceedings of the National Academy of Sciences, v. 98, n. 2, p. 404-409, 2001.

[27] PAVITT, Keith. Innovation processes. In: The Oxford handbook of innovation. 2005.

[28] PAVITT, Keith. Key characteristics of the large innovating firm. British Journal of Management, v. 2, n. 1, p. 41-50, 1991.

[29] PEIDONG, Zhang et al. Opportunities and challenges for renewable energy policy in China. Renewable and Sustainable Energy Reviews, v. 13, n. 2, p. 439-449, 2009.

[30] PERKMANN, Markus et al. Academic engagement and commercialisation: A review of the literature on university-industry relations. Research policy, v. 42, n. 2, p. 423-442, 2013.

[31] SCHUMPETER, JA. The theory of economic development, 1912

[32] SCOTT, J. Social network analysis. Sage, 2012.

[33] SCOZZI, Barbara; GARAVELLI, Claudio; CROWSTON, Kevin. Methods for modeling and supporting innovation processes in SMEs. European Journal of Innovation Management, v. 8, n. 1, p. 120-137, 2005.

[34] SIMS, Ralph EH; ROGNER, Hans-Holger; GREGORY, Ken. Carbon emission and mitigation cost comparisons between fossil fuel, nuclear and renewable energy resources for electricity generation. Energy policy, v. 31, n. 13, p. 1315-1326, 2003.

[35] WASSERMAN, S.; FAUST, K.. Social network analysis: Methods and applications. Cambridge university press, 1994.

[36] WISE, Sean Evan. The impact of intragroup social network topology on group performance: understanding intra-organizational knowledge transfer through a social capital framework. 2013. Tese de Doutorado. University of Glasgow. 


\section{Capítulo 2}

\section{APROVEITAMENTO DE RESIDDUOS SÓLIDOS ORGÂNICOS PARA GERAÇÃO DE ENERGIA ELÉTRICA: UMA IDEIA SUSTENTÁVEL}

\section{Thays Lorranny da Silva Januário \\ Jefferson Luiz Alves Marinho \\ Janeide Ferreira Alencar de Oliveira}

Resumo: Mais de 50\% do volume de resíduo sólido urbano coletado no Brasil é composto por matéria orgânica, sendo grande parte deste resíduo remetido inadequadamente para aterros e lixões, onde misturados com outros resíduos sólidos promove a emissão do biogás. Esse gás é composto principalmente por metano, um dos gases causadores do efeito estufa, entretanto se coletado, deixa de gerar um impacto ao meio ambiente e pode ser aproveitado para a produção de energia elétrica. Com base nisso, objetivou-se neste trabalho apresentar a ampla capacidade brasileira de gerar energia elétrica de maneira integralmente sustentável através da biodigestão de resíduos sólidos orgânicos alimentares. Para elaboração deste trabalho foi realizada uma Revisão Sistemática da Literatura (RSL). A base de dados utilizada foi artigos científicos de periódicos e congressos, nacionais e internacionais; livros; dissertações e fontes relevantes e confiáveis da Internet o mais atual possível. Estudos de vários autores mostraram ser possível o uso de gás hidrogênio produzido do metano gerado em degradação de resíduos orgânicos, como os encontrados em aterros sanitários, para a produção de energia elétrica. Outros estudos sobre a digestão anaeróbia de resíduos sólidos orgânicos em países em desenvolvimento mostraram que esses resíduos podem gerar biogás para produção de energia. A produção de energias renováveis é uma das formas de aproveitamento de resíduos orgânicos no Brasil, contribuindo ao mesmo tempo para o aumento da matriz energética mundial, redução de lançamentos inadequados no meio ambiente, geração de oportunidades de negócios, renda e trazendo maior desenvolvimento sustentável.

Palavras-chave: Potencial energético, Resíduos sólidos orgânicos, Biogás, Biomassa, Sustentabilidade. 


\section{INTRODUÇÃO}

A crescente preocupação ambiental das últimas décadas resultou numa série de questionamentos sobre a exploração dos recursos naturais renováveis e principalmente não renováveis. A preocupação não se limita a exploração final do recurso, mas também aos seus impactos sobre o meio (PINTO, 2014).

Na atualidade, em consequência do desenvolvimento industrial, crescimento da população e sua adoção crescente de novos padrões de consumo, juntamente com a falta de conhecimento, interesse e sensibilidade da sociedade frente ao meio ambiente, causou uma desenfreada produção de resíduos sólidos urbanos. Como consequência, os resíduos sólidos gerados pelo homem provocam diversos riscos à saúde pública, resultando em devastação e enorme degradação ambiental, modificando e criando novas tendências econômicas, sociais e administrativas envolvidas nesta questão. Acredita-se que uma das metas mais difíceis esteja na colaboração e efetiva participação da população quanto à maneira correta de dispor o resíduo no local apropriado para tal fim, sendo que uma das premissas da Política Nacional de resíduos sólido (PNRS) está na minimização da geração de resíduos (SCHOTT FILHO et al., 2017; VALLE; BRAZ; SANTOS, 2013).

Os riscos que o descarte inadequado de resíduos como os lixões representam à saúde pública e ao meio ambiente, começaram a ser foco de maior atenção desde a década de 1970. Com o aumento da consciência em relação a temas como aquecimento global e desenvolvimento sustentável, os gestores de serviços de tratamento e disposição de resíduos têm sido pressionados a melhorar o controle das operações relacionadas e a minimizar os impactos ambientais (TOZETTO, 2008).

A NBR 10.004 (2004, p. 1) que trata dos resíduos sólidos, inclusive sua classificação, considerando a crescente preocupação da sociedade com relação às 63 questões ambientais e ao desenvolvimento sustentável define resíduos sólidos como sendo:

Resíduos nos estados sólidos e semissólidos, resultantes de atividades de origem industrial, doméstica, hospitalar, comercial, agrícola, de serviço e de varrição. Ficam incluídos nesta definição os lodos provenientes do sistema de tratamento de água, aqueles gerados em equipamentos e instalações de controle de poluição, bem como determinados líquidos, cujas particularidades tornem inviável o seu lançamento na rede pública de esgotos ou corpos de água, ou exijam para isso solução técnica e economicamente inviável em face à melhor tecnologia disponível.

Segundo dados da ABRELPE (2012) mais de 50\% do volume de resíduo sólido urbano coletado no Brasil é composto por matéria orgânica. Esse resíduo é em grande parte remetido desacertadamente para aterros e lixões, onde misturados com outros resíduos sólidos promove a emissão de biogás. Esse gás é composto principalmente por metano, um dos gases causadores do efeito estufa, entretanto se coletado, deixa de gerar um impacto ao meio ambiente e pode ser utilizado para a produção de energia elétrica. Além disso, a matéria orgânica em decomposição no aterro ou lixão produz o chorume, uma substância líquida decorrente da putrefação orgânica que pode contaminar o solo, o lençol freático, rios e córregos. Em função da grande quantidade de matéria orgânica, também atrai insetos vetores de doenças aos seres humanos.

O Brasil é um grande gerador de resíduos orgânicos, tendo em vista sua população, larga produção de alimentos, combustíveis, criação de animais e diversos processos produtivos que eliminam subprodutos passíveis de aproveitamentos na produção de energia renovável (OLIVEIRA; FERREIRA; OLIVEIRA, 2016).

Com base nisto, objetivou-se neste trabalho apresentar a ampla capacidade brasileira de gerar energia elétrica de maneira integralmente sustentável através da biodigestão de resíduos sólidos orgânicos alimentares.

\section{REFERENCIAL TEÓRICO}

O conceito de desenvolvimento sustentável foi reconhecido internacionalmente em 1972, na Conferência das Nações Unidas sobre o Meio Ambiente Humano, realizada em Estocolmo, Suécia, apresentando a definição do desenvolvimento que procura satisfazer as necessidades da geração atual, sem comprometer a capacidade das gerações futuras de satisfazerem as suas próprias necessidades. As populações humanas que vivem no mundo, e que fazem parte de todas as gerações teriam de absorver o conhecimento sobre a sustentabilidade, repassá-lo e agir sensatamente. Por isso, a questão do desenvolvimento sustentável assumiu importância em termos mundiais, oferecendo conhecimento sobre o aproveitamento dos recursos e na descoberta de novas práticas e alternativas de desenvolvimento. Tudo isso representa a chance de que as populações presentes e futuras cheguem a um nível satisfatório de desenvolvimento 
social e econômico e de realização humana e cultural, fazendo ao mesmo tempo, uso razoável dos recursos da terra e preservando as espécies e os habitats naturais como forma de diminuição dos impactos ambientais e sociais. Diante desse cenário, o maior desafio da humanidade é a busca da exploração sustentável dos recursos naturais, campo aonde pesquisas sobre energias renováveis vêm se intensificando, possibilitando a geração de informações que possibilitem o aproveitamento dos resíduos (PEREIRA et al., 2015).

Quando se trata de energias renováveis e desenvolvimento tecnológico é importante o aproveitamento do potencial de algumas fontes de energia disponíveis no país como a energia solar, eólica, fotovoltaica e de biomassa (PEREIRA et al., 2015). A utilização do biogás, oriundo da biodigestão anaeróbia, tem sido afirmada como uma opção de grande eficiência no tratamento de biomassa. É importante lembrar que este tipo de resíduo deve receber devida atenção, caso mal manejado, pode ser extremamente danoso ao meio ambiente, produzindo gás metano, impactando negativamente na qualidade do ar atmosférico, assim como infiltrar-se no solo, causando sérios problemas ao alcançar o lençol freático (DEUBLEIN; STEINHAUSER, 2008).

Biomassa é matéria orgânica, morta ou viva, existente nos organismos (animais ou vegetais) de uma determinada comunidade. Podem ser recuperadas através dos resíduos florestais, agrícolas, pecuários e até mesmo urbanos, podendo ser-lhe dadas algumas utilizações úteis, entre as quais produção de energia. Assim, a biomassa vegetal e animal apresenta características semelhantes quando o tema é aproveitamento energético (PEREIRA et al., 2015).

No Brasil e no mundo, o uso da biomassa como fonte energética está sendo incrementado a cada ano, procurando-se fomentar a valorização dos aspectos ambientais, sociais e econômicos. Sendo assim, resíduos ou subprodutos orgânicos de processamentos diversos podem ser recuperados em forma de energia renovável. Um fator importante dessas fontes de energia é que muitas delas podem ser usadas no mesmo local onde foram geradas, descentralizando a produção de energia, minimizando a logística e criando possibilidades de autossuficiência energética para vários produtores (OLIVEIRA; FERREIRA; OLIVEIRA, 2016).

Corroborando com esses argumentos, o Programa das Nações Unidas para o Desenvolvimento (PNUD) lançou em dezembro de 2015 a Agenda 2030 para o Desenvolvimento Sustentável, com os 17 Objetivos de Desenvolvimento Sustentável (ODS) (PNUD, 2015). De acordo com esse documento, deve ser buscado “Um mundo onde o meio ambiente humano seja seguro, resiliente e sustentável, e onde exista acesso universal à energia de custo razoável, confiável e sustentável" (PNUD, 2015, p. 3) e deve-se "[...] desenvolver sociedades do conhecimento, tal como a inovação científica e tecnológica em áreas tão diversas como medicina e energia" (PNUD, 2015, p. 5).

0 objetivo 7 do PNUD é diretamente relacionado à energia: "Assegurar a todos o acesso confiável, sustentável, moderno e a preço acessível à energia" (PNUD, 2015, p. 15), enfatizando as energias renováveis, a eficiência energética, a cooperação internacional em pesquisa e tecnologias de energia limpa, a infraestrutura para energia limpa e os serviços de energia modernos e sustentáveis para todos nos países em desenvolvimento.

No Brasil, a partir do lançamento da Política Nacional de Resíduos Sólidos (PNRS) - Lei 12.305 de 2010 (BRASIL, 2010a) e do Decreto № 7.404, de 23 de dezembro de 2010, que regulamenta a Lei oㅡ 12.305 (BRASIL, 2010b), entende-se por destinação final ambientalmente adequada a "[...] destinação de resíduos que inclui a reutilização, a reciclagem, a compostagem, a recuperação e o aproveitamento energético [...]" [grifo nosso], desde que sejam observadas todas as normas e restrições legais. No artigo 7o a PNRS também cita o aproveitamento energético como prática a ser incentivada nas empresas.

A biodigestão anaeróbia é um processo conhecido há muito tempo e seu emprego para a produção de biogás para a conversão em energia de cozimento, iluminação e como biofertilizante é muito comum nos países asiáticos, a exemplo da China e Índia. 0 interesse pelo biogás, no Brasil, intensificou-se nas décadas de 1970 e 1980, especialmente entre os suinocultores. Programas oficiais estimularam a implantação de muitos biodigestores com foco, principalmente, na geração de energia e na produção biofertilizante e diminuição do impacto ambiental (KUNZ; OLIVEIRA, 2006).

0 mecanismo de decomposição anaeróbica se desenvolve pela ação de um consórcio de microrganismos (fermentativos, acetogênicos e metanogênicos) altamente vorazes que em condições ideais de umidade e temperatura, passam a predominar no meio, provocando a degradação de forma acelerada dos resíduos. Este processo ocorre de forma simples e natural com quase todos os compostos orgânicos, formando assim o biogás, produto da degradação anaeróbica, sendo composto principalmente por metano (50 a 
70\%), que é um gás de efeito estufa que contribui com o aquecimento global e CO2 (30 a 45\%), além de resquícios de outros gases, como Nitrogênio (0 a 10\%), Hidrogênio ( 0 a $5 \%$ ), Oxigênio ( 0 a 1\%), gás sulfídrico (0 a 1\%) e vapor d'água (0,3\%). Esse gás pode ser coletado dos sistemas de degradação anaeróbica e usado como combustível (geração de calor ou energia) (POLPRASERT, 2007; KUNZ; OLIVEIRA, 2006). O biogás é um gás inflamável, inodoro, incolor e insípido, com possível mau cheiro atribuído ao gás sulfídrico que é o componente de menor porcentagem (DEUBLEIN; STEINHAUSER, 2008). Após a fermentação é necessário passar por processos de limpeza chamados de desumidificação. Para se obter o biogás é imprescindível o processo que se dá através da decomposição anaeróbica, que se desenvolve ao longo de três fases distintas: liquefação, acidulação e gaseificação (OLIVEIRA, 2004).

0 uso dos biodigestores para o tratamento de biomassa é bastante disseminado em todo o mundo, tanto em países desenvolvidos quanto em países em desenvolvimento. Os biodigestores são sistemas fechados onde são depositados materiais orgânicos que são diluídos em água, para que ocorra a fermentação anaeróbica, na qual resultará em biogás. Esses gases produzidos são coletados e armazenados em compartimentos chamados gasômetros para posterior utilização (DEUBLEIN; STEINHAUSER, 2008). Vários modelos de biodigestores têm sido desenvolvidos e adaptados para se buscar um aumento da eficiência desses sistemas aliado a uma redução de custos dos equipamentos (REUNIÃO TÉCNICA SOBRE BIODIGESTORES PARA TRATAMENTO DE DEJETOS DE SUÍNOS E USO DE BIOGÁS, 2006). Um cuidado que deve ser tomado com a utilização de biodigestores diz respeito ao efluente líquido que sai do sistema, não podendo ser descartado nos corpos receptores, por ainda apresentar um alto potencial poluidor, especialmente quando considerado nitrogênio e fósforo (KUNZ; OLIVEIRA, 2006).

Em relação à gestão de resíduos, a Agenda 2030 propõe "até 2030, reduzir o impacto ambiental negativo per capita das cidades, inclusive prestando especial atenção à qualidade do ar, gestão de resíduos municipais e outros" (PNUD, 2015, p. 26).

Somando-se à necessidade de uma melhor gestão dos resíduos e de se assegurar o acesso à energia, o aproveitamento de resíduos orgânicos para a geração de energia torna-se uma alternativa significativa e promissora.

\section{METODOLOGIA}

Para elaboração deste trabalho foi realizada uma Revisão Sistemática da Literatura (RSL). De acordo com Sampaio e Mancini (2007), revisão sistemática é uma forma de pesquisa que utiliza como fonte de dados a literatura sobre determinado tema. Os mesmos autores ainda destacam que esse tipo de investigação disponibiliza um resumo das evidências relacionados a determinado fenômeno ou área de estudo, mediante a aplicação de métodos explícitos e sistematizados de busca, apreciação crítica e síntese da informação selecionada.

A base de dados utilizada foi artigos científicos de periódicos e congressos, internacionais e nacionais; teses; dissertações; livros; e fontes relevantes e confiáveis da Internet sobre o assunto, o mais atual possível.

\section{RESULTADOS}

Segundo Pinto (2014), a utilização de resíduo orgânico para a geração de energia em larga escala traz como benefícios, a segurança energética com a geração descentralizada e pode promover a captação de recursos internacionais decorrentes da possível venda de Certificados de Emissão de Carbono para países, conforme prevê o Protocolo de Quioto se as propostas seguiram os Mecanismos de Desenvolvimento Limpo (MDL).

O Brasil se destaca no cenário internacional como um importante ator ligado ao Mecanismo de Desenvolvimento Limpo (MDL), um dos instrumentos do Protocolo de Quioto criados para ajudar os países desenvolvidos a alcançar suas metas de redução de emissões de carbono e incentivar financeiramente os países em desenvolvimento. Em termos do potencial de reduções de emissões associado aos projetos de MDL, o Brasil ocupa a terceira posição, sendo responsável pela redução de 375.889.172 tCO2e, o que corresponde a $6 \%$ do total mundial para o primeiro período de obtenção de créditos, que podem ser de no máximo 10 anos para projetos de período fixo ou de 7 anos para projetos de período renovável (os projetos são renováveis por no máximo três períodos de 7 anos dando um total de 21 anos) (MMA, 2010). 
Dados oficiais mostram que em 2016, as fontes de energias renováveis utilizadas no Brasil atingiram 43,5\%, enquanto registrou-se apenas 14,11\% de uso dessas fontes no panorama mundial. Em 2017, a participação de renováveis na Matriz Energética Brasileira manteve-se entre as mais elevadas do mundo representando 43,1\%. 0 avanço do gás natural foi compensado principalmente pela eólica e biomassas da cana, lixívia e biodiesel (EPE, 2018).

Segundo dados do IPEA (2012), mais de 54\% dos brasileiros ascenderam socialmente entre 2003 e 2011 , incorporando 40 milhões de pessoas que passaram a consumir mais na última década, consequentemente gerando mais resíduos. A geração diária brasileira de Resíduos Sólidos Urbanos (RSU) em 2012 foi de 201.058 toneladas de resíduos.

Atualmente os resíduos orgânicos representam mais da metade dos RSU descartados nas cidades brasileiras, o país apresenta altos volumes de desperdício de alimentos, tanto nas cadeias produtivas e de distribuição, quanto no varejo, armazenamento e comercialização (PINTO, 2014). Um estudo realizado pela Empresa Brasileira de Pesquisa Agropecuária (EMBRAPA, 2013), revelou que se perdem anualmente 37 quilos de hortaliças e 35 quilos de frutas por habitante.

O resíduo orgânico biodegradável é classificado pela ABNT (Associação Brasileira de Normas Técnicas) como não inerte. Muitas vezes esse material é tratado com indiferença, contudo oferece riscos ao meio ambiente, apresentando risco ambiental devido à produção do chorume e metano. A matéria orgânica presente no lixo também é um agente que propicia a proliferação dos microrganismos e atrai vetores que encontram no lixo condições favoráveis de desenvolvimento (PINTO, 2014).

Segundo Oliveira (2004), a geração de energia elétrica com o uso de biogás como combustível pode ser dividida nas seguintes tecnologias disponíveis no momento:

1- Conjunto Gerador de Eletricidade - Consiste em um motor de combustão interna Ciclo Otto (álcool, gasolina ou diesel) adaptado para o uso do biogás como combustível, acoplado a um gerador de eletricidade, independente da rede de energia elétrica da concessionária local.

2- Conjunto Gerador Economizador de Eletricidade - Consiste em um motor de combustão interna Ciclo Otto (álcool, gasolina ou diesel) adaptado para o uso do biogás como combustível, acoplado a um motor assíncrono, de dois ou quatro polos, que passa a gerar energia ao ser conectado à rede de energia elétrica da concessionária local.

No primeiro caso, o conjunto é independente da rede de energia elétrica local, gerando energia dentro de propriedade com o sistema de distribuição interno isolado. No segundo caso, o equipamento gera energia somente se estiver conectado à rede de distribuição da concessionária de energia elétrica, deixando de funcionar se a mesma sofrer interrupção, o que elimina possibilidades de acidentes quando técnicos estiverem na manutenção nas redes elétricas externas. Neste caso, a energia gerada é distribuída na propriedade e na rede externa até o transformador mais próximo (OLIVEIRA, 2004).

Outro método é a queima direta do biogás em caldeiras para cogeração (COELHO et al., 2006).

Os estudos de Duerr et al. (2007) mostraram ser possível o uso de gás hidrogênio produzido do metano gerado em degradação de resíduos orgânicos, como os encontrados em aterros sanitários, para a produção de energia elétrica.

Khalid et al. (2011) realizaram estudos com a digestão anaeróbia de resíduos sólidos orgânicos, salientando que a taxa de produção é de cerca de 770 g/hab.dia em países em desenvolvimento, com crescimento crescente a cada ano. Segundo os autores, à época do estudo, a geração mundial de resíduos sólidos municipais era de cerca de dois bilhões de toneladas por ano, com previsão de chegar a três bilhões em 2025. Desse montante, há uma parcela significativa de resíduos orgânicos passíveis de decomposição biológica, como a digestão anaeróbia, que pode gerar biogás para produção de energia.

\section{CONCLUSÃO}

A produção de energias renováveis é uma das formas de aproveitamento de resíduos orgânicos no Brasil, contribuindo ao mesmo tempo para o aumento da matriz energética mundial, redução de lançamentos inadequados no meio ambiente, geração de oportunidades de negócios, renda e trazendo maior desenvolvimento sustentável, ou seja, garantindo um sistema ambientalmente correto, socialmente justo, economicamente viável, culturalmente aceito e espacialmente equilibrado. 
As tecnologias à base de fontes renováveis influenciarão na participação da matriz energética nacional na medida em que o desenvolvimento e progresso de conversão e uso se tornarem disponíveis e forem comparativamente preferidas pelos provedores de serviços de energia e consumidores.

A conversão energética do biogás pode ser apresentada como uma solução para o grande volume de resíduos produzidos, visto que reduz o potencial tóxico das emissões de metano ao mesmo tempo em que produz energia elétrica, agregando, desta forma, ganho ambiental e redução de custos. Outras vantagens também estão agregadas com a utilização do biogás, como: redução dos resíduos orgânicos descartados; redução das emissões de CO2; uso descentralizado de energia, gerando mais confiabilidade no setor energético; redução de odores pela decomposição dos restos orgânicos; uso veicular como combustível; geração de fertilizantes biológicos (diminuindo assim a utilização de fertilizantes químicos no solo); redução da poluição do solo e corpos d'água, já que evita o contato com o chorume; e produção de energia térmica a partir de armazenamento de energia solar de acordo com as necessidades, independentemente da época do ano.

Os principais desafios para a solução dos problemas relacionados aos resíduos sólidos orgânicos no Brasil estão ligados à disposição irregular, coleta informal e a insuficiência do sistema de coleta pública, uma vez que nem todo resíduo gerado é coletado e tratado. É importante ressaltar que atualmente, com o limite da capacidade dos aterros quase esgotados e a preocupação com desenvolvimento sustentável, explorar o ciclo de vida dos produtos até o final de sua vida útil e garantir sua destinação apropriada, além de ajudar na redução do lixo gerado, passa a ser uma obrigação com a nova LEI 12.305/2010, que institui a Política Nacional de Resíduos Sólidos, Capítulo II, Art.3ํ - XV. Desde de 2014, os aterros sanitários não podem receber resíduos, apenas rejeitos, ou seja, os resíduos sólidos que, depois de esgotadas todas as possibilidades de tratamento e recuperação por processos tecnológicos disponíveis e economicamente viáveis, não apresentem outra possibilidade que não a disposição final ambientalmente adequada, a fim de evitar a contaminação de lençóis freáticos, através de sistemas de captação de chorume e aproveitamento dos gases gerados na biodigestão e decomposição da matéria orgânica.

\section{REFERÊNCIAS}

ASSOCIAÇÃO BRASILEIRA DE NORMAS TÉCNICAS (ABNT). NBR 10004: Resíduos Sólidos - Classificação. Rio de Janeiro, 2004.

ABRELPE. Caderno Informativo sobre Recuperação Energética de Resíduos Sólidos. 2012. Disponível em:

<http://www.abrelpe.org.br/_download/informativo_recuperacao_energetica.pdf>. Acesso em: 05 mar. 2018.

BRASIL. Presidência da República. Lei nº 12.305 - Política Nacional de Resíduos Sólidos. 2010a. Disponível em: <http://www.planalto.gov.br/ccivil_03/_ato2007-2010/2010/lei/l12305.htm>. Acesso em: 05 mar. 2018.

BRASIL. Presidência da República. Decreto no. 7.404 - Regulamenta a Lei no. 12.305. 2010b. Disponível em:

<http://www.planalto.gov.br/ccivil_03/_ato2007-2010/2010/decreto/d7404.htm>. Acesso em: 05 mar. 2018.

COELHO, S. T.; VELÁZQUEZ, S. M. S. G.; MARTINS, O. S.; ABREU, F. C. A conversão da fonte renovável biogás em energia. In: CONGRESSO BRASILEIRO DE PLANEJAMENTO ENERGÉTICO (CBPE), 5, 2006, Brasília. Anais... Brasília: V CBPE, 2006.

COSTA, D. F. Biomassa como fonte de energia, conversão e utilização. (Monografia). Programa Interunidades de Pós-Graduação em Energia (PIPGE) do Instituto de Eletrotécnica e Energia (IEE) da Universidade de São Paulo, São Paulo, 2002.

DEUBLEIN, D.; STEINHAUSER, A. Biogas from waste and renewable resources. Weinheim: WILEYVCH Verlag GmbH \& Co. KGaA, 2008.

DUERR, M.; GAIR, S.; CRUDEN, A.; MCDONALD, J. Hydrogen and electrical energy from organic waste treatment. International Journal of Hydrogen Energy, v. 32, 705-709, 2007.

EMBRAPA. EMPRESA BRASILEIRA DE PESQUISA AGROPECUÁRIA. Desperdício de alimentos é desperdício de recursos naturais e financeiros. $2013 . \quad$ Disponível em: <http://www.embrapa.br/imprensa/noticias/2013/junho/1a-semana/desperdicio-de-alimentos-e- 
desperdicio-de-recursos-naturais-e-financeiros/?searchterm=desperdicio alimentos $>$. Acesso em: 24 set. 2018.

EPE. EMPRESA DE PESQUISA ENERGÉTICA. Matriz energética e elétrica. 2018. Disponível em: < http://epe.gov.br/sites-pt/publicacoes-dados-abertos/publicacoes/PublicacoesArquivos/publicacao303/topico-397/Relat\%C3\%B3rio\%20S\%C3\%ADntese\%202018-ab\%202017vff.pdf>. Acesso em: 20 set. 2018.

IPEA. INSTITUTO DE PESQUISA ECONÔMICA APLICADA. Diagnóstico dos Resíduos Sólidos Urbanos.

2012. Disponível em :<

http://www.ipea.gov.br/agencia/images/stories/PDFs/relatoriopesquisa/121009_relatorio_residuos_sol idos_urbanos.pdf >. Acesso em: 24 set. 2018.

KHALID, A.; ARSHAD, M.; ANJUM, M.; MAHMOOD, T.; DAWSON, L. The anaerobic digestion of solid organic waste. Waste Management, v.31, p. 1737-1744, 2011.

KUNZ, A.; OLIVEIRA, P. A. V. Aproveitamento de dejetos de animais para geração de biogás. Revista de Política Agrícola. Ano XV, n. 3, jul./ago./set. 2006. Disponível em:< https://ainfo.cnptia.embrapa.br/digital/bitstream/item/63324/1/Paginas-de-pol-agr-03-20064-p.-2835.pdf $>$. Acesso em: 05 set. 2018.

MMA. Ministério do Meio Ambiente. Estudo sobre o Potencial de Geração de Energia a partir de Resíduos de Saneamento (lixo, esgoto), visando incrementar o uso de biogás como fonte alternativa de energia renovável. Programa das Nações Unidas para o Desenvolvimento - PNUD. 2010. Disponível em: <http://www.mma.gov.br/estruturas/164/_publicacao/164_publicacao10012011033201.pdf>. Acesso em: 05 set. 2018.

OLIVEIRA, P. A. V. Produção e aproveitamento do biogás. In: OLIVEIRA, P. A. V. de. Tecnologias para o manejo de resíduos na produção de suínos: manual de boas práticas. Concórdia: Embrapa Suínos e Aves, 2004. Cap. 4, p.43-55.

OLIVEIRA, S. V. W. B.; FERREIRA, A. H.; OLIVEIRA, M. M. B. Aproveitamento de resíduos para geração de energia: ecoeficiência e sustentabilidade. ENGEMA: Encontro Internacional sobre Gestão Empresarial e Meio Ambiente. 2016. Disponível em: http://engemausp.submissao.com.br/18/anais/arquivos/197.pdf>. Acesso em: 30 set. 2018.

PEREIRA, M. S.; GODOY, T. P.; GODOY, L. P.; BUENO, W. P.; WEGNER, R. S. Energias renováveis: biogás e energia elétrica provenientes de resíduos de suinocultura e bovinocultura na UFSM. Revista Eletrônica em Gestão, Educação e Tecnologia Ambiental. Santa Maria, v. 19, n. 3, set-dez. 2015. Disponível em: <https://periodicos.ufsm.br/reget/article/view/18064/pdf>. Acesso em: 05 mar. 2018.

PINTO, P. A. Projeto de aproveitamento de resíduo sólido orgânico com geração de energia. Estudo de caso: Empresa Bayer S.A. 2014. 76 p. Monografia (Especialização em Gestão Ambiental e Negócios no Setor Energético) - Instituto de Energia e Ambiente, Universidade de São Paulo, São Paulo, 2014.

PNUD. PROGRAMA DAS NAÇÕES UNIDAS PARA O DESENVOLVIMENTO. Transformando Nosso Mundo: a Agenda 2030 para o Desenvolvimento Sustentável. 2015. Disponível em: <http://www.pnud.org.br/Docs/Agenda2030completo_PtBR.pdf>. Acesso em: 05 mar. 2018.

POLPRASERT, C. Organic Waste Recycling: Tecnology and Management. 3. ed. London: IWA Publishing, 2007.

REUNIÃO TÉCNICA SOBRE BIODIGESTORES PARA TRATAMENTO DE DEJETOS DE SUÍNOS E USO DE BIOGÁS, 2006, Concórdia. Anais... Concórdia: Embrapa Suínos e Aves, 2006. 53 p. (Embrapa Suínos e Aves. Documentos, 106). Coordenação de: Airton Kunz e Paulo A. V. de Oliveira.

SAMPAIO, R. F.; MANCINI, M. C. Estudos de revisão sistemática: um guia para síntese criteriosa da evidência científica. Rev. bras. fisioterapia, São Carlos, v. 11, n. 1, p. 83-89, jan/fev, 2007.

SCHOTT FILHO, O.; AGUIAR, A. C. M.; SILVA, E. C. R.; PEREIRA, T. C.; FERREIRA, J. A.; BORGES, A. C. Projeto Estiva: uma iniciativa de gestão de resíduos sólidos urbanos em comunidades de baixa renda. Revista ELO - Diálogos em Extensão 23 Volume 06, número 03 - dezembro de 2017. Disponível em:< https://www.elo.ufv.br/index.php/elo/article/view/273/178>. Acesso em: 30 set. 2018.

TOZETTO, C. M. Modelagem matemática de aterros sanitários com a simulação hidrológica da geração de lixiviado: estudo de caso do aterro sanitário de Curitiba. 2008. 154 f. Dissertação (Mestrado em 
Engenharia de Recursos Hídricos e Ambiental) - Setor de Tecnologia, Universidade Federal do Paraná, Curitiba, 2008. Disponível em: $<$ https://docs.ufpr.br/ bleninger/dissertacoes/149Carolina_Morsoletto_Tozetto.pdf $>$. Acesso em: 30 set. 2018.

VALLE, J.; BRAZ, E. M. Q.; SANTOS, C. L. Resíduos sólidos urbanos. Revista Ceciliana Dez 5(2): 1-4,2013. Disponível em:< http://sites.unisanta.br/revistaceciliana/edicao_10b/1.pdf>. Acesso em: 30 set. 2018. 


\section{Capítulo 3}

\section{ESTUDO DE CASO EM UMA ASSOCIAÇÃO DE COLETA DE RESÍDUOS SÓLIDOS}

Adna Amorim dos Santos

Lucas Marcos Silva Queiroz.

Lo-Ruana Karen Amorim Freire Sanjulião

Thales Volpe Rodrigues

Carlos Henrique Fernandes

Maria José Reis

Resumo: Este artigo descreve características de associações de catadores em especifico de Minas Gerais ressaltando problemas de produtividade, e através de um estudo específico mostra as dificuldades que impedem a melhoria na produtividade no setor de coleta de resíduos sólidos. É composto por uma revisão bibliográfica e logo após um estudo realizado em uma associação de Itaú de Minas - MG, identificando os principais problemas que afetam a melhoria, o grupo teve acompanhamento de uma assessoria onde foram desenvolvidos trabalhos para fortalecimento do grupo, incentivo à importância de tomarem decisões juntos. Uma das necessidades identificadas é um local apropriado para destinar os materiais que muitas vezes se encontram armazenados nas residências dos catadores para o benefício da saúde, higiene, aumento da qualidade de vida além de possibilitar a execução de outros projetos futuramente o que contribuiria com o crescimento da renda gerada pela atividade. Palavras-chave: Coleta Seletiva; Associação; Catadores de reciclados. 


\section{INTRODUÇÃO}

A geração de resíduos sólidos gerados através de diversas atividades humanas é um grande desafio aos poderes públicos, e consequentemente à administração municipal. Na metade do século XX, com novos padrões industriais a alta produção de resíduos vem crescendo em ritmo acelerado e a capacidade de absorção dos mesmos pela natureza não tem sido proporcional. Podemos ver mediante a alta produção (velocidade que é gerado) e concepção de produtos (na descartabilidade) e além de tudo isso a diversidade de materiais de difícil degradação e maior toxidade. De acordo com Silva, Donel e Cuellar (2003) resíduo é a matéria criada pelo próprio homem resultados das atividades diárias humanas e consumismo, que após ser utilizada não é absorvida pelo meio ambiente, gerando inevitavelmente o aumento dos resíduos e materiais estranhos ao meio natural.

A falta de planejamento e praticidade em técnicas de descarte, tem ocasionado inadequação, como passivos do meio ambiente capazes de comprometer a qualidade de vida e os recursos naturais. De acordo com pesquisa realizada pela Revista da Lata, seis anos após a aprovação da Política Nacional de Resíduos Sólidos no Brasil, apenas 18\% dos municípios possuem coleta seletiva de resíduos (REVISTA DA LATA, 2017).

Com o advento das cooperativas de catadores, foi elevado o número de postos de trabalho e para os que conseguem organizar-se nestas cooperativas ou empresas, há um crescimento em sua remuneração e sua situação de semiclandestinidade tende a ser superada com o crescimento do mercado e da consciência social (CALDERONI, 1998). A implantação de uma associação, executaria a coleta seletiva, a conscientização da sociedade e a diminuição de materiais desapropriados para os aterros, e ajudando na eliminação do lixão.

0 aumento de informações de acordo com Robles (2015), a rotina exaustiva, com as novas tendências, cenários de transformação constante, torna impossível um resultado de sucesso para a associação se não atuarem de forma colaborativa, a solução e superação dos desafios estão na rede de conhecimento e não mais em uma ou duas pessoas esforçadas e talentosas. É preciso preocupar-se com a gestão de pessoas, pois é fundamental para a força e continuidade do projeto, propondo que precisam atuar juntos e dividirem as responsabilidades, e os desafios. É um processo de autoconhecimento do grupo, precisa-se de orientações e lideranças, que pratiquem o que falem, possuindo inteligência emocional e empatia sincera, criando um ambiente harmonioso e de confianças onde as experiências e novas ideias, sejam encorajadas e reconhecidas pela equipe.

O objetivo deste artigo é por meio do estudo da logística reversa da coleta resíduos sólidos em conjunto com as características de uma associação em Itaú de Minas, identificar os problemas que dificultam a melhoria da produtividade neste setor e promover o fortalecimento no trabalho com o grupo de catadores de Itaú de Minas visando um trabalho em equipe, uma forma de estarem prontos e capacitados, com uma visão unanime em sentido aos seus direitos e deveres de levar uma associação ou cooperativa à diante. Propor medidas para melhor qualidade de vida e bem-estar dos catadores, além disso, identificar as principais necessidades para aumento de capacidade da coleta em grupo e geração de renda em trabalhos sociais no município.

Esse trabalho é justificado pela falta de execução de gerenciamento dos resíduos no município, onde os catadores executam um trabalho independente, autônomos, e sem amparo. Sua qualidade de vida é totalmente atingida devido ao acumulo de recicláveis em suas casas até a venda para empresas do ramo, com perigo de doenças, proliferação de animais peçonhentos e transmissores de doenças, e pela incansável rotina diária de coleta.

Portanto deve-se estudar melhor o processo de execução da logística de reversa dos resíduos sólidos no município. Pois a falta de trabalho com a sociedade traz grande dificuldade para os mesmos na incansável rotina diária de coleta, e não é obtido ganho favorável e seus direitos de amparo ao catador não são executados.

\section{REVISÃO BIBLIOGRÁFICA}

\subsection{LOGÍSTICA REVERSA}

O conceito de logística reversa está presente a tempos, mas é de grande dificuldade datar o surgimento deste termo com exatidão, em dias atuais as definições da logísticas reversa revelam conceitos ainda em construção à novos negócios e pesquisas revelando-se em processo de fusão apresentando um vasto campo (BRITO e DEKKER, 2002). 
Logística reversa, segundo Gonçalves e Martins 2006, inclui-se a preocupação dos governos e a necessidade de sua realização também decorre de crescentes números de leis que incentivam a reciclagem de recipientes e materiais de embalagens e que proíbem o descarte indevido. A logística reversa condiz com a área da logística empresarial, que planeja, controla e opera as informações logísticas, dos bens de pós-venda e pós consumo, por meios de canais de distribuição reversos, não só agregando valores financeiros, mas ecológicos, legal entre outros (LEITE, 2003). A Figura 1 apresenta-o processo simples da logística reversa do material reciclável como um todo.

FIGURA 1 - Fluxo da logística reversa de resíduos sólidos.

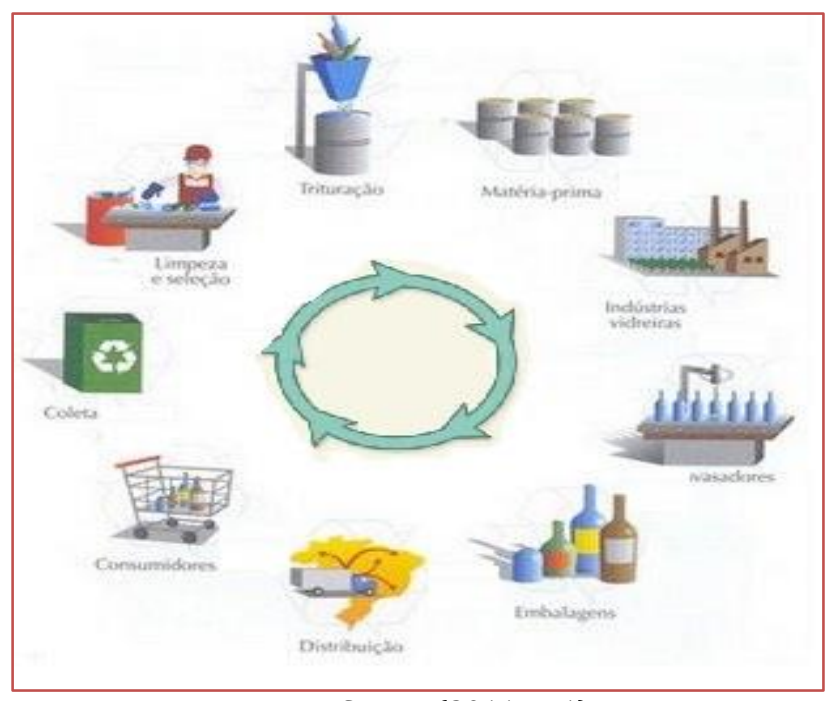

Fonte: Santos (2011, p. 1).

\subsection{O PROCESSO DE COLETA DE RESÍDUOS SÓLIDOS E A LOGÍSTICA REVERSA}

De acordo com as informações do IPEA (2010), com o passar dos anos e com o propósito de reverter a exclusão social os catadores de materiais recicláveis vêm buscando coletivamente a superação que impedem de apropriarem um maior valor por seu trabalho, com as estimativas divulgadas pelo IPEA, apenas $2.4 \%$ da coleta de resíduos sólidos no Brasil, são de forma seletiva o restante são coletas regulares às quais se misturam com outros materiais, a quais sofrem contaminação, dificultando ou até mesmo impossibilitando a reciclagem dos materiais.

Com incentivo ao consumismo, a quantidade e a variabilidade de materiais descartáveis avolumam inesperadamente. Diante disto, o poder público tem como dever buscar e executar alternativas que minimizam os impactos sobre o meio ambiente, causado por estes resíduos sólidos e entre as alternativas uma das mais favoráveis é a coleta seletiva e a qual possibilita posteriormente a realização da reciclagem dos materiais (SILVA et al.,2013).

Esta coleta de materiais recicláveis com a destinação dos resíduos sólidos corretamente tem o sentido de logística reversa, pois há o envolvimento das operações no transporte, no planejamento, e no monitoramento de rotas. 0 planejamento de uma logística reversa proporciona resultados e benefícios à sociedade, sendo ele bem estruturado como em melhor rota, frota, e localização e também com a finalidade de minimizar o tempo e custo.

Os aspectos legais que conduzem a implantação e a gestão de resíduos sólidos nos municípios tem como fundamento a legislação brasileira, sendo ela federal, estadual e municipal, a Tabela 1 apresenta a jurisdição que rege mediante aos resíduos sólidos. 
TABELA 1- Aspectos Legais

\begin{tabular}{|c|c|}
\hline \multicolumn{2}{|c|}{ Legislação Federativa } \\
\hline ABNT 8.419/1894 & Gerenciamento de Resíduos Sólidos. \\
\hline Lei no 9.605/1998 & $\begin{array}{l}\text { Dispõe sobre as sanções penais e administrativas derivadas } \\
\text { de condutas e atividades lesivas ao meio ambiente, e dá } \\
\text { outras providências. }\end{array}$ \\
\hline Resolução CONAMA nº 275/2001 & $\begin{array}{l}\text { Estabelece o código de cores para os diferentes tipos de } \\
\text { resíduos, a ser adotado na identificação de coletores e } \\
\text { transportadores bem como nas campanhas informativas } \\
\text { para a coleta seletiva. }\end{array}$ \\
\hline NBR $10.004 / 2004$ & Classificação dos resíduos sólidos. \\
\hline Lei no $11.107 / 2005$ & $\begin{array}{l}\text { Dispõe sobre normas gerais de contratação de consórcios } \\
\text { públicos e dá outras providencias. }\end{array}$ \\
\hline Decreto Federal №5.940/2006 & $\begin{array}{l}\text { Institui a separação dos resíduos recicláveis descartados } \\
\text { pelos órgãos e entidades da administração pública federal } \\
\text { direta e indireta, na fonte geradora, e a sua destinação as } \\
\text { associações e cooperativas dos catadores de materiais } \\
\text { recicláveis. }\end{array}$ \\
\hline Lei n $11.445 / 2007$ & Lei Nacional de Saneamento Básico. \\
\hline Lei no $12.305 / 2010$ & Política Nacional de Resíduos sólidos. \\
\hline CBO - Classificação Brasileira de Ocupações & $\begin{array}{l}\text { Catador de material reciclável é profissão reconhecia pelo } \\
\text { ministério do trabalho e emprego. }\end{array}$ \\
\hline \multicolumn{2}{|c|}{ Legislação Estadual } \\
\hline Lei no $11.720 / 1994$ & Política Estadual de Saneamento Básico. \\
\hline Lei no $13.766 / 2000$ & $\begin{array}{l}\text { Política Estadual de apoio e incentivo a coleta seletiva de } \\
\text { lixo. }\end{array}$ \\
\hline Lei no $18.031 / 2009$ & Política Estadual de Resíduos sólidos. \\
\hline Decreto no $45.181 / 2009$ & $\begin{array}{l}\text { Regulamenta a lei no } 18.031 \text {, de } 12 \text { de janeiro de } 2009 \text {, e dá } \\
\text { outras providencias. }\end{array}$ \\
\hline DN Copam no 172 de 2011 & Institui o Plano estadual de coleta Seletiva de Minas Gerais \\
\hline \multicolumn{2}{|c|}{ Legislação Municipal } \\
\hline Lei $\mathrm{n}^{\circ} 1.709 / 2004$ & $\begin{array}{l}\text { Dispõe sobre o sistema de limpeza urbana no município de } \\
\text { Itaú de Minas. }\end{array}$ \\
\hline Lei no $31 / 2010$ & $\begin{array}{l}\text { Considerando as disposições dos art.182 da Constituição } \\
\text { Federal, do Capítulo III da Lei Federal no } 10.257 \text {, de } 10 \text { de } \\
\text { julho de } 2001 \text { - Estatutos das Cidade e dos artigos } 227 \text { a } \\
234 \text { do título III, Capitulo VIII, Capitulo BII - da Política } \\
\text { Urbana da Lei Orgânica do Município de Itaú de Minas. }\end{array}$ \\
\hline Lei no 791/2010 & $\begin{array}{l}\text { Dispõe sobre o uso de papel reciclado e implantação de } \\
\text { coleta seletiva por parte dos órgãos e entidades da } \\
\text { Administração Pública Municipal Direta e indireta e poder } \\
\text { legislativo. }\end{array}$ \\
\hline Lei no 817/2011 & $\begin{array}{l}\text { Dispões sobre o uso de sacolas plásticas biodegradáveis } \\
\text { para acondicionamento de produtos e mercadorias a serem } \\
\text { utilizados nos estabelecimentos comerciais em todo o } \\
\text { município de Itaú de Minas. }\end{array}$ \\
\hline
\end{tabular}




\subsection{CASOS DE ASSOCIAÇÕES DE COLETA SELETIVA EM MINAS GERAIS}

A associação como todos os outros empreendimentos tem suas características e tributos, mas para que efetivamente possa realizar o trabalho de melhorias em organizações é imprescindível tomar conhecimento dos fatores que participam da cultura de trabalho, os ambientes que o envolvem e suas implicações como um todo (OLIVEIRA, LIMA, LIMA, 2009).

Lima e Oliveira (2008) fizeram estudos das atividades de coleta seletiva em outros municípios, e muitos deles enfrentam a escassez de recursos. Com o estudo verificaram que os maiores obstáculos para as associações de catadores, são:

Relações institucionais extra organização: logística de coleta, relações com a administração municipal, qualidade do material proveniente da coleta seletiva e de doadores, relação com grandes doadores;

Organização do trabalho e gestão interna à organização: organização do trabalho (divisão de tarefas, jornada de trabalho, rotatividade, qualificação) e disciplina (ritmo de trabalho, absenteísmo), conflitos internos, regras de distribuição dos ganhos (por produção, coletiva...);

Organização física do processo de produção: postos de triagem, fluxo de produção; dimensões dos galpões; economia de movimentos na separação: deslocamentos das pessoas, movimentação de material, fases e movimentos de triagem.

Os autores identificaram que as dificuldades para ganhos da produtividade, em se tratando de dificuldades técnicas enfrentadas pelas associações são resultados não somente de características da organização e pessoais, mas ao processo de catação e ao setor de reciclagem como um todo. A implantação de infraestrutura para a triagem é um impasse para melhorias e reivindicações na pesquisa de Dias (2002), os problemas são decorrentes de uma série de fatores de ausência de estudos, fluxo de tarefas, localização e participação da população.

Em Associações de Catadores presentes nos municípios mineiros de Barroso, Campo Belo e São João DelRei, Oliveira e Abreu (2008) realizaram uma pesquisa e detectaram que apesar do avanço já conquistado pelos catadores ainda há a presença de obstáculos prejudiciais a eficiência deste canal reverso. Em Campo Belo, por exemplo, existe a coleta e o obstáculo principal é a baixa adesão da população na separação dos resíduos que podem ser reciclados. Nos outros dois municípios a coleta seletiva existe, porém somente em alguns bairros por conta dos catadores. 0 Quadro 1 mostra comparativos a respeito da pesquisa sobre as associações de coleta seletiva nas cidades de mencionadas. No município de Barroso, verifica-se que a associação não possui os equipamentos essenciais para a realização das atividades operacionais, impossibilitando o planejamento logístico e a eficiência da produção.

QUADR0 1 - Informações e comparativos entre associações. Fonte: Oliveira e Abreu (2008) apud Oliveira, Lima, Lima (2009).

\begin{tabular}{|c|c|c|c|}
\hline & BARROSO & CAMPO BELO & SÃO JOÃO DEL-REI \\
\hline $\begin{array}{l}\text { MOTIVO DE CRIAÇÃO } \\
\text { DAS ASSOCIAÇÕES }\end{array}$ & $\begin{array}{l}\text { Deliberação Normativa } \\
\text { COMPAM 52/2001; } \\
\text { Assinatura de Termos de } \\
\text { Ajustamento de Conduta } \\
\text { (TAC) }\end{array}$ & $\begin{array}{l}\text { Deliberação Normativa } \\
\text { COMPAM 52/2001; } \\
\text { Adequação pra } \\
\text { recebimento de fundos do } \\
\text { ISMS ecológico }\end{array}$ & $\begin{array}{l}\text { Impulsionado por } \\
\text { projeto da UFSJ }\end{array}$ \\
\hline $\begin{array}{l}\text { PARTICIPAÇÃO EM } \\
\text { INCUBAÇÃO }\end{array}$ & ITCP/UFSJ & Não participa & ITCP/UFSJ \\
\hline $\begin{array}{l}\text { ATUAÇÃO DA } \\
\text { PREFEITURA NA } \\
\text { ASSOCIAÇÃO }\end{array}$ & $\begin{array}{l}\text { Campanhas de educação } \\
\text { ambiental; } \\
\text { Fomece o galpão e } \\
\text { pagamento das despesas }\end{array}$ & $\begin{array}{l}\text { Serviço terceirizado para } \\
\text { a prefeitura; } \\
\text { Fornece local, transporte, } \\
\text { equipamentos, } \\
\text { alimentação; } \\
\text { Campanhas de educação } \\
\text { ambiental }\end{array}$ & $\begin{array}{l}\text { Fornece o depósito e } \\
\text { pagamento das } \\
\text { despesas; } \\
\text { Campanhas de educação } \\
\text { ambiental }\end{array}$ \\
\hline $\begin{array}{l}\text { ACONDICIONAMENTO } \\
\text { DOS RESÍDUOS }\end{array}$ & Aterro Controlado & Aterro Sanitário & Aterro controlado \\
\hline $\begin{array}{c}\text { RESTRIÇÕES PARA A } \\
\text { ASSOCIAÇÃO }\end{array}$ & $\begin{array}{l}\text { Falta de equipamentos para } \\
\text { a operacionalização do } \\
\text { trabalho; } \\
\text { Implantação efetiva da } \\
\text { coleta seletiva na cidade }\end{array}$ & $\begin{array}{l}\text { Baixa adesão da } \\
\text { população na coleta } \\
\text { seletiva }\end{array}$ & $\begin{array}{l}\text { Implantação efetiva da } \\
\text { coleta seletiva na cidade }\end{array}$ \\
\hline $\begin{array}{l}\text { ABRANGÊNCIA DA } \\
\text { COLETA SELETIVA }\end{array}$ & Restrita à alguns bairros & Em todos os bairros & Restrita à alguns bairros \\
\hline
\end{tabular}


Em um estudo desenvolvido por Ribeiro e Lima (2000), os autores mencionam um problema enfrentado por catadores em Uberlândia, onde a coleta seletiva dos resíduos sólidos não produziu efeitos, pois a qualidade do material era baixa, devido à presença de resíduos orgânicos observados na separação da esteira da usina de triagem.

A participação dos catadores, segundo Cruz (2002), como agente ambiental que fazem o recolhimento de materiais recicláveis tem papel fundamental e muito importante para o mercado de recicláveis.

Calderoni (1998), define o catador como “...o agente da reciclagem que retira os materiais recicláveis diretamente dos lixões ou aterros ou materiais descartados pelas calçadas, destinando-os a sucateiros.” É de grande benefício todo esse trabalho para a limpeza urbanística, mas muitas das vezes passam despercebidos e até sofrem um prejulgamento negativo, estes materiais são encaminhados para empresas do ramo e poupam recursos da natureza, exercendo um papel muito importante, bem como uma alternativa de renda (ABREU, 2001).

\section{MÉTODO DE PESQUISA}

Miguel et al. (2010) destacam diversos métodos de pesquisa, tais como a pesquisa bibliográfica, o estudo de caso, o levantamento (survey), o experimento, a modelagem e simulação e a pesquisa-ação. Uma vez que esta pesquisa conta com a participação ativa nas pesquisas literárias, e também presente no acompanhamento, desenvolvimento do projeto e análise minuciosa do grupo dos catadores, o método que mais se compatibiliza é o estudo de campo. Também chamada de pesquisa-ação, é uma forma qualitativa na qual o participante trabalha explicitamente com, para e por pessoas em vez de estudar sobre elas. Com foco maior na geração de soluções para problemas do cotidiano (POPE, MAYS, 2009).

De acordo com Lopes (2006) esse tipo de pesquisa faz com que o autor entre em contato direto com o ambiente onde o problema ocorre. Muito empregado em levantamentos sobre as partes mais baixas da comunidade. A Figura 2 representa o ciclo da pesquisa-ação, sendo que o mesmo se repete até que se alcancem os objetivos propostos ou seja determinado o fim do projeto.

FIGURA 2 - Estrutura padrão para condução da pesquisa-ação. Fonte: Adaptado de Miguel et al. (2010) e Thiollent (2011)

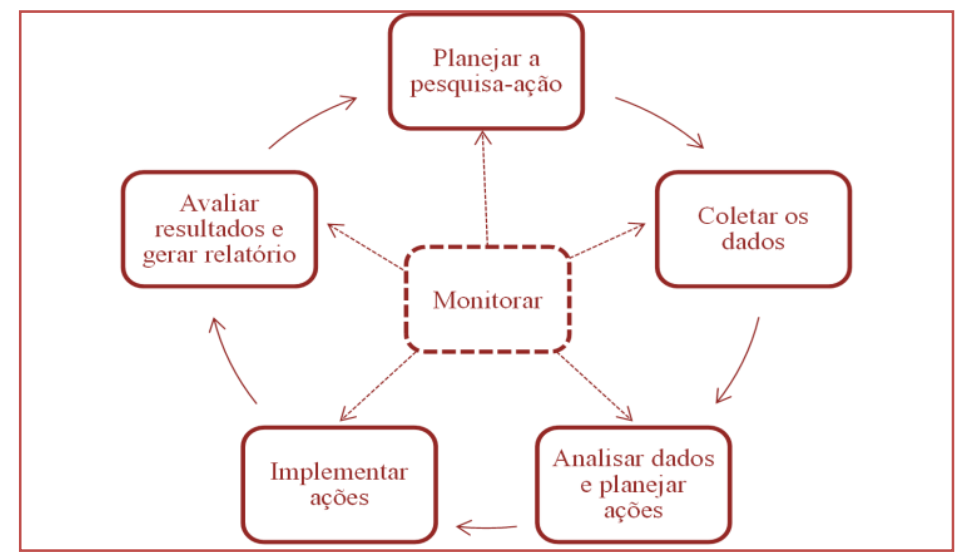

Foram realizadas pesquisas bibliográficas para enfatizar as teorias e embasamento do estudo, e feito um período de realização de pesquisas e acompanhamento junto ao grupo, um período de 24 meses. Dentre os instrumentos e técnicas usados para a coleta dos dados foram coletados dados documentais, em relatórios fornecidos pela associação, e por meio de observação in loco, com participação nas reuniões e promoção de discussão direcionada realizadas mensalmente com o grupo onde era possível identificar seu modo de pensar e forma com as decisões eram tomadas, além de participação nos eventos sociais elaborados pelos mesmos. Após a análise qualitativa dos dados a fim de atingir o objetivo da pesquisa foram traçadas as ações, a intervenção ocorreu por meio de uma assessoria realizada pela pesquisadora, que trazia orientações, treinamentos para promoção de aprendizados no propósito de reaproxima-los focando o 
trabalho em equipe, sempre ressaltando a importância e os benefícios de se trabalhar associados, e destacando os interesses mútuos do grupo.

\section{DESENVOLVIMENTO}

\subsection{ASSOCIAÇÃO DOS CATADORES DE ITAÚ DE MINAS}

0 estudo foi desenvolvido na cidade de Itaú de Minas o município conta com 16.082 habitantes de acordo com o IBGE (2017). Por meio dos dados coletados diferente da maioria das cidades brasileiras, a associação de catadores foi criada mediante ao projeto NRDC - Núcleo Rotary Desenvolvimento Comunitário - Itaú Recicla que é a base de apoio para o crescimento da associação que tem sido desenvolvida em Itaú de Minas fundada em julho de 2013, contendo hoje 16 associados ao projeto. A mesma, tem como objetivo a inclusão social, união dos catadores para melhor geração de renda, demonstração de sua importância na sociedade, conservação e execução de seus direitos mediante as leis federais, estaduais e municipais, e o plano diretor do município.

Analisando o Gráfico 1, é possível notar que houve uma diminuição no número de associados, desde a fundação até o presente momento.

GRÁFICO 1- Número de Associados.

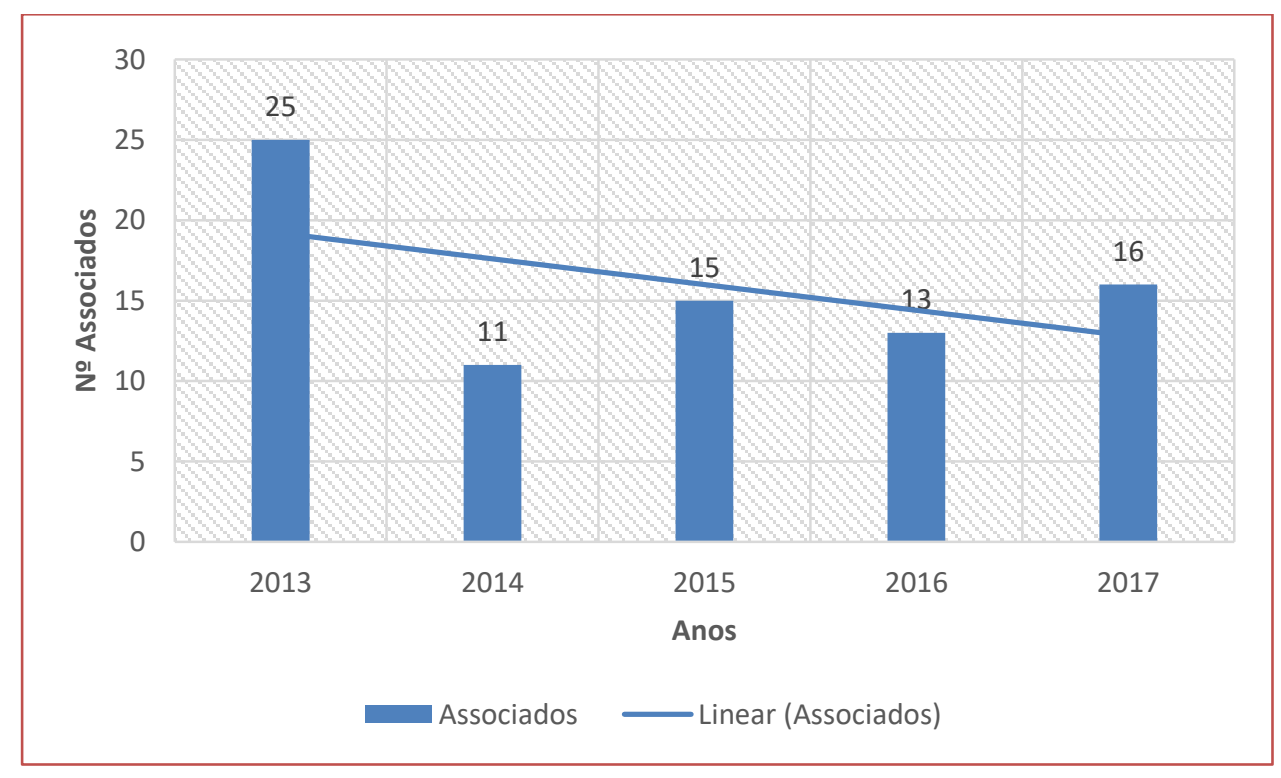

Fonte: Da Autora.

Durante a realização da pesquisa foi observado que a associação de Catadores do município enfrenta alguns obstáculos que prejudicam a produtividade e eficiência deste canal reverso. Por exemplo, a coleta seletiva dos resíduos sólidos vem sendo trabalhada com a sociedade, porém, um dos principais problemas que é enfrentado é a baixa adesão da população na separação dos resíduos que podem ser reciclados visto que somente em alguns bairros acontece estas separações de materiais recicláveis e orgânicos, e a coleta seletiva é realizada através dos catadores, o que ocasiona perdas de material, de qualidade e de tempo. Pois na maioria das vezes a coleta seletiva não é realizada de forma efetiva e os materiais não podem ser reciclados, pois apresentam contaminação de outros resíduos orgânicos, problema vivenciado por outras associações em outros municípios como em Uberlândia citado por Oliveira, Lima, Lima (2009).

A associação não possui os materiais ou equipamentos de coleta para a realização das atividades operacionais, impossibilitando o planejamento logístico e a eficiência da produção. Mas esta situação é visualmente identificada em vários outros municípios do estado de Minas Gerais de acordo com Lima e Oliveira (2008).

Segundo informações de Borderô (2017) os somatórios de resíduos sólidos de lixo/ano recolhidos na cidade de Itaú de Minas são de 44.892,4 Kg, subdivido em 996.2kg de alumínio, 30.982,2 Kg de papelão, 8.411,1 Kg de plástico, 4.499,2 Kg de Ferro e 3,8 Kg de cobre, o Gráfico 2 apresenta os valores computados do ano de 2017. 
GRÁFICO 2- Quantidade de material computada no ano 2017.

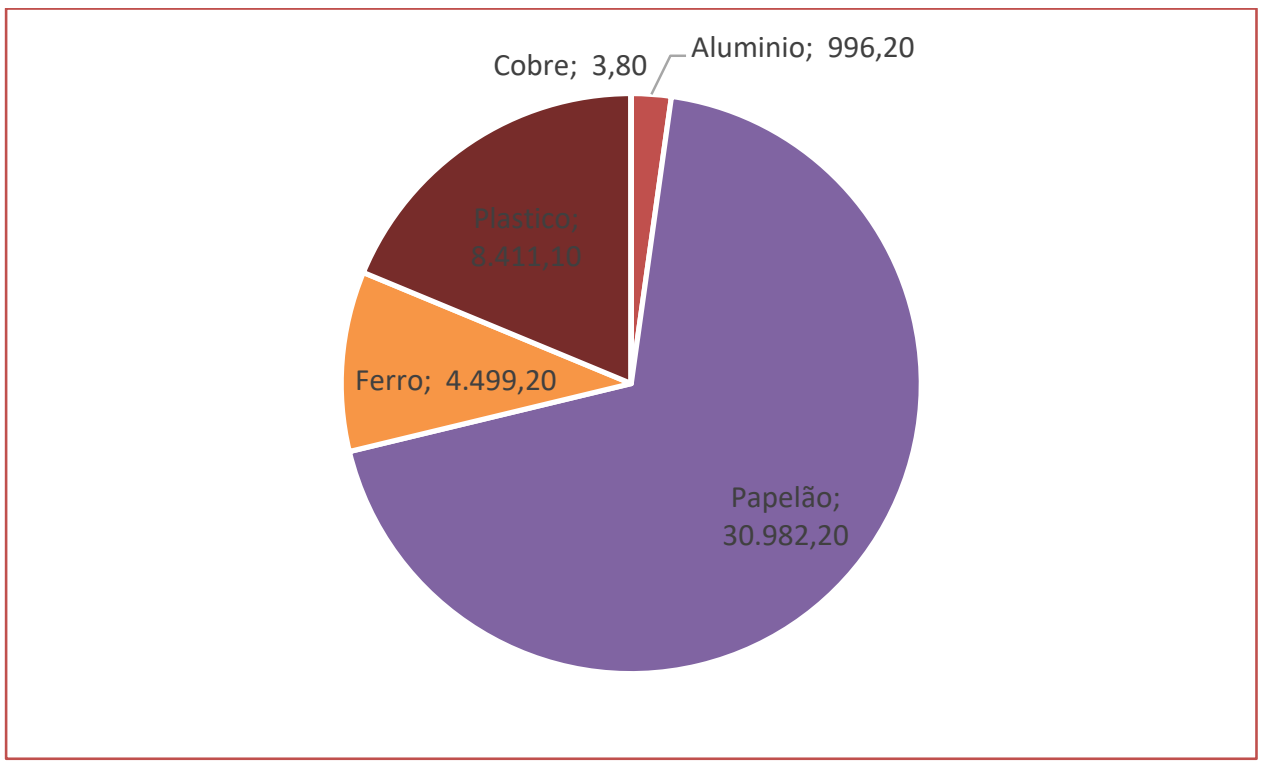

Fonte: Da autora

Com relação às condições de trabalho os catadores de reciclados vivem em condições precárias, com exposição à contaminação presente em lixos. Desde o início de 2016, este grupo vem sendo assessorado por uma consultoria externa, e recebendo apoio da Prefeitura Municipal de Itaú de Minas. 0 grupo aprovou seu Estatuto social, elegendo o seu corpo diretor responsável por condução do mesmo. As empresas colaboram com a coleta diária e com as atividades desenvolvidas pelos catadores, separando os materiais para que posteriormente possa ser coletado. No município há dois bairros que incentivam todo o trabalho fazendo a junção dos materiais reciclados, nos quais o catador faz a coleta uma vez por semana. Em suas atividades diárias no final de seu expediente os catadores seguem com seus carrinhos para a venda nos sucatões. 0 percurso de coleta não é bem definido, cada um faz sua própria rota, logo após recolherem o material até o limite que suportam, e cada catador segue para a venda.

Na fundação da associação os catadores eram completamente dispersos, com seus trabalhos individuais, nas reuniões realizadas mensalmente foram detectadas muitas faltas dos associados, mas atualmente o grupo se fortalece mediante à trabalhos sociais, e através das reuniões com aplicação de dinâmicas direcionadas (Figura 3) o grupo tem apresentado grande interesse nesta nova jornada, executando trabalhos colaborativos que resultou no destaque dentro da comunidade onde despertou a atenção de empresários que fizeram a doação de novos carrinhos, EPI's e uniformes. Anteriormente a relação entre eles eram de competitividade, posteriormente à criação da associação passou-se a desenvolverem um trabalho colaborativo tornando o ambiente onde passam um tempo juntos melhor.

FIGURA 3 - Ações do grupo de catadores.
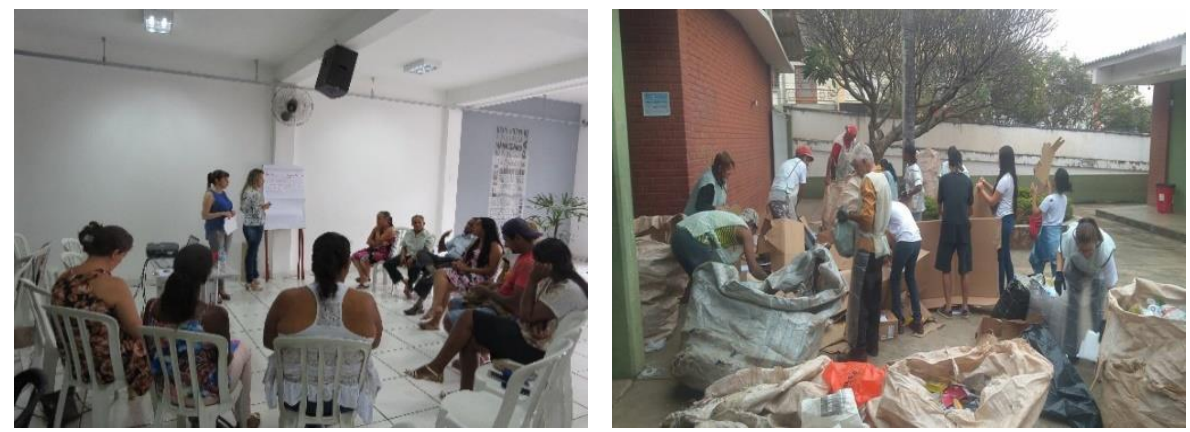


\subsection{PRINCIPAIS PROBLEMAS ENFRENTADOS PELA ASSOCIAÇÃO}

Com base nas observações realizadas, foi possível observar e apontar os principais problemas e questões que dificultam o crescimento da associação em produtividade, gestão humana, entre outros.

Durante a coleta de dados foi identificada a necessidade de maior envolvimento por parte da comunidade itauense para colaboração com os serviços dos catadores. Também é perceptível que a participação da sociedade só será possível a medida que a associação tenha equipamentos e espaço suficiente para trabalhar com outros bairros, o que ainda não acontece. Além disso a associação é carente de equipamentos e um local amplo que poderia melhorar as condições de trabalho dos catadores, como por exemplo, esteiras e baias para separação do material e organização do material coletado, na Tabela 2 são mencionados alguns fatores que dificultam o progresso da mesma.

TABELA 2 - Problemas identificados, que impedem melhoria da associação.

\begin{tabular}{|c|c|}
\hline \multirow{4}{*}{$\begin{array}{l}\text { CONDIÇÕES DE } \\
\text { TRABALHO }\end{array}$} & Problemas ergonômicos; \\
\hline & Dores, devidos ao carregamento de peso e postura incorreta; \\
\hline & Longas jornadas de caminhada, para realização da coleta; \\
\hline & Exposição diretamente a lixos. \\
\hline \multirow{3}{*}{$\begin{array}{l}\text { QUALIDADE DO } \\
\text { MATERIAL }\end{array}$} & O material reciclável, na maioria das vezes, está misturado ao lixo úmido; \\
\hline & A falta de qualidade do material, devido estar sujo; \\
\hline & A perca de tempo na separação do material na hora da coleta. \\
\hline \multirow{3}{*}{$\begin{array}{l}\text { INFRAESTRUTURA E } \\
\text { EQUIPAMENTOS }\end{array}$} & O trabalho não atinge todos os bairros; \\
\hline & Falta de um local de armazenamento, regularizado; \\
\hline & Falta de maquinários e equipamentos. \\
\hline \multirow{3}{*}{ VENDAS } & Venda a sucatões a preços muito baixos; \\
\hline & Falta de comprador fixo; \\
\hline & Baixo lucro devido aos atravessadores. \\
\hline
\end{tabular}

Fonte: Da autora

Apesar de palestras repassadas para a população poucas pessoas separam o lixo reciclável o que dificulta o trabalho dos catadores. Campanhas eficientes de conscientização na população do município poderiam trazer bons resultados e deveriam ser realizadas mais frequentemente, até que a comunidade tenha como hábitos benéficos a separação dos resíduos que necessita da participação e apoio poder público.

\section{CONSIDERAÇõES FINAIS}

A coleta de resíduos sólidos tem um grande papel como um todo, se forem destinados adequadamente pode resultar em empregos e geração de renda, além de contribuir para um desenvolvimento sustentável, mas para isso faz-se necessário um planejamento para que este projeto de associação siga por muitos anos.

Por meio do estudo foi identificado um problema logístico da coleta seletiva de materiais recicláveis, e foram listados os problemas que dificultam a melhoria da produtividade no setor de coleta dos mesmos.

O Brasil carece de modelos para implantação de programas de coleta seletiva que sejam autossustentáveis, pois as existentes são muito dependentes de recursos do poder público, impossibilitando um crescimento maior. Através dos estudos abordados referente a revisão bibliográfica juntamente com o estudo em questão, nota-se que os mesmos problemas se repetem em várias cidades, e são assuntos de muita importância tanto para comunidade quanto ao poder público, e também a qualidade de vida dos catadores.

O estudo identificou um dos gargalos para o crescimento da associação, que é a falta do local apropriado para triagem e armazenamento do material, para melhoria e andamento do processo de coleta dos 
resíduos sólidos da mesma, este local, poderá abrir oportunidades para estudos futuros, como a gestão logística de rotas e frotas da associação. Tal fato é bastante dependente do poder público municipal para o qual futuramente será de grande benefício, por reduzirem os gastos públicos com a coleta, transporte e destinação dos resíduos sólidos urbanos, aumentando a vida útil de seus aterros sanitários, pela diminuição dos resíduos descartados pelo processo comum.

É importante ressaltar a necessidade do apoio da sociedade, os atores fundamentais para o sucesso da coleta, precisando esta ser sensibilizada para que possam compreender a importância desta separação dos materiais recicláveis, que ocorre através da educação ambiental que conduz a transformação de suas ações.

Dessa forma, o trabalho realizado no presente estudo, atingiu seu objetivo em realizar um estudo sobre a associação de catadores do município, e promover o fortalecimento da mesma, além de identificar os obstáculos existentes e oportunidades de melhoria. Uma das sugestões para trabalho futuro seria conseguir um local apropriado para o armazenamento que resultara na continuidade dos trabalhos melhorando a qualidade de vida dos catadores e grande aumento da geração de renda. Foi uma experiência extremamente importante para os associados, e para a pesquisadora, ter a oportunidade de discutir os problemas relacionados ao funcionamento desta organização, e trazer contribuições tanto para gestão dos resíduos recicláveis e ressaltar a responsabilidade do poder público municipal, quanto a qualidade de vida dos membros da associação.

\section{REFERÊNCIAS}

[1] ABREU, M. F. Do lixo à Cidadania: Estratégias para a Ação. Brasília: Caixa, 2001.

[2] CALDERONI, S. Os bilhões perdidos no Lixo. 2ª Edição. São Paulo: 1998.

[3] CRUZ,A.L.M; A reciclagem dos resíduos sólidos urbanos: um estudo de caso. Florianópolis. 2002. Disponível em: <https://repositorio.ufsc.br/bitstream/handle/123456789/82430/227599.pdf?sequence=1>. Acesso em: $29 / 12 / 2017$.

[4] BRITO, M. P. \& DEKKER, R. Reverse logísticos: a framework. Econometric Institute. Report EI 2002-38, Erasmus University Rotterdam, The Netherlands, 2002.

[5] DIAS, S. M. Construindo a cidadania: avanços e limites do projeto de coleta seletiva em parceria com a ASMARE. Dissertação. Instituto de Geociências da UFMG. Belo Horizonte, 2002.

[6] GONÇALVES, M. E. \& MARINS, F. A. S. Logística Reversa numa empresa de laminação de vidros: um estudo de caso. Revista Gestão \& Produção, Vol.13, n.3, p.397-410, 2006.

[7] IPEA - INSTITUTO DE PESQUISA ECONÔMICA APLICADA. Pesquisa sobre pagamento por serviços ambientais urbanos para gestão de resíduos sólidos. Brasília: Ipea, 2010. Disponível em: <http:// goo.gl/tTVr>.

[8] LEITE, P. R. Logística Reversa: meio ambiente e competitividade. São Paulo: Pearson Prentice Hall, 2003

[9] LIMA, F.P.A. \& OLIVEIRA, F. G. Produtividade técnica e social das associações de catadores: por um modelo de reciclagem solidáira. In: KEMP, V. H. \& CRIVELLARI, H. M. T. (orgs.). Catadores na cena urbana: construção de políticas socioambientais, p. 225-248. Belo Horizonte: Autêntica Editora, 2008

[10] LOPES, J.E.G.; RIBEIRO F.J.F.; PEDERNEIRAS, M. M. M.; RIBEIRO, I. B.; Pesquisa-Ação: Uma Abordagem para a Produção. RCO - Revista de Contabilidade e Organizações - FEA-RP/USP, v. 3, n. 7, p. 125-126, set-dez 2009.

[11] MIGUEL, P.; FLEURY, A.; MELLO, C.; NAKANO, D.; TURRIONI, J.; LEE HO, L.; MORABITO, R.; MARTINS, R.; PUREZA, V. Metodologia de pesquisa em engenharia de produção e gestão de operações. 2 ed. Rio de Janeiro: Elsevier, 2010.

[12] OLIVEIRA, R. L. \& ABREU, J. C. de. Políticas de apoio à gestão ao empreendimento coletivo dos catadores de materiais recicláveis em três municípios. VII Congresso de produção científica UFSJ - São João Del-Rei, MG, Brasil, 11 a 14 de novembro, 2008.

[13] OLIVEIRA, R. LIMA, J. LIMA, R. LOGÍSTICA REVERSA: O CASO DE UMA ASSOCIAÇÃO DE OLETA SELETIVA DE MATERIAIS RECICLÁVEIS EM ITAJUBÁ - MG, 2009.

[14] POPE, C. Mays, N. Pesquisa qualitativa na atenção à saúde. 3ª ed. Porto Alegre: Artmed; 2009

[15] Revista online da lata. A reciclagem do Brasil em Numeros. Publicado em 09/2017, disponivel em http://www.abralatas.org.br/a-reciclagem-do-brasil-em-numeros/ acessado em 20/01/2018.

[16] RIBEIRO, T.F.\& LIMA, S.C. Coleta Seletiva de Lixo Domiciliar - Estudo de Casos. Caminhos de Geografia Revista on Line Programa de Pós-Graduação em Geografia UFU. 2000. 
[17] ROBLES, R. Da competitividade a colaboração - o caminho para o engajamento para as empresas. Inovando na gestão de pessoas.2015. Disponível em: https://pt.linkedin.com/pulse/da-competitividade-\%C3\%A0colabora\%C3\%A7\%C3\%A3o-o-caminho-do-para-empresas-robles acessado em 19/01/2018.

[18] SANTOS, T. Politica nacional de resíduos sólidos, 2011. Disponível em: https://maesso.wordpress.com/2011/06/21/politica-nacional-de-residuos-solidos/ acessado em: 22/03/2018.

[19] SILVA, E. M. T.; DONEL, F.; WOLlMANN, A. R., CUELlAR, J. O planejamento como instrumento de implementação da coleta seletiva de resíduos sólidos urbanos. XXIII Encontro Nacional de Engenharia de Produção ENEGEP - Ouro Preto, MG, Brasil, 21 a 24 de outubro, 2003. 


\section{Capítulo 4}

\section{A POLÍTICA NACIONAL DE RESÍDUOS SÓLIDOS (LEI No. 12.305, DE 2 DE AGOSTO DE 2010), A LOGÍSTICA REVERSA E A LOGÍSTICA MILITAR}

\section{Adriana Salete Dantas de Farias}

Resumo: 0 presente ensaio teve com objetivo identificar oportunidades de desenvolvimento de atividades de Logística Reversa na Logística Militar, como forma de contribuir para o alcance dos objetivos da Política Nacional dos Resíduos Sólidos e proporcionar maior efetividade para a Logística Nacional. Para tanto, foi realizada uma revisão bibliográfica, em torno dos principais conteúdos abordados, notadamente, Politica Nacional de Resíduos Sólidos, Logística Reversa e Logística Militar. Posteriormente, foram estabelecidas relações teóricas entre esses conteúdos, buscandose evidenciar oportunidades de implementação da Logística Reversa na Logística Militar. Como principais resultados verificou-se que existem várias atividades de Logística Reversa sendo implementadas, porém, sem uma doutrina militar específica. A principal conclusão apresentada é que há a necessidade de incorporar os princípios da PNRS nas atividades militares de forma sistêmica e regulamentada, para que a prática de atividades de Logística Reversa possa gerar benefícios ambientais, sociais e econômicos, contribuindo assim para o fortalecimento da Logística Nacional. 


\section{INTRODUÇÃO}

O tratamento e descarte de resíduos sólidos há muito tempo tornou-se uma questão discutida em nível mundial. Por isso, cada vez mais importância é dada ao desenvolvimento de alternativas para gerenciar a destinação de resíduos sólidos, desde sua geração até o descarte final, com o fim de minimizar o impacto ambiental decorrente.

À medida que os recursos naturais são extraídos da natureza, em quantidades excessivas, as fontes naturais diminuem e podem, gradativamente, impedir sua recomposição porque muitas vezes a extração para fins mercadológicos não respeita as condições necessárias para manter a capacidade de resiliência dos meios naturais. Outro problema refere-se ao descarte inadequado dos resíduos sólidos ao meio ambiente, o que pode gerar consequências graves, em função do aumento da poluição, e, reduzir a qualidade de vida das pessoas e das demais espécies dos ecossistemas.

O Brasil passou por um intenso ritmo de industrialização a partir de 1960, que levou ao aumento da concentração da população em áreas urbanas, provocando significativos impactos ao meio ambiente. 0 governo brasileiro instituiu, a partir da década de 70, os primeiros órgãos públicos voltados a questões ambientais, a exemplo da Secretaria do Meio Ambiente (SEMA), a Companhia de Tecnologia de Saneamento Ambiental (CETESB) e o Conselho Estadual de Proteção Ambiental (CEPRAM) (DIAS, 2011).

Em 31 de Agosto de 1981 foi instituída a Política Nacional do Meio Ambiente, regulamentada pela Lei noo. 6938/81 (BRASIL, 1981). A partir de então, muitos setores começaram a ser regulamentado para minimizar os impactos ambientais decorrentes de suas atividades econômicas. Posteriormente, legislações foram esenvolvidas visando atribuir responsabilidade às fontes geradoras e ao poder público, quanto ao descarte de seus resíduos sólidos.

A Lei 12.305, de 02 de Agosto de 2010 (BRASIL, 2010), estabelece a Política Nacional de Resíduos Sólidos PNRS sendo o instrumento legal nacional mais recente que normatizam a gestão dos Resíduos Sólidos Urbanos - RSU.

A PNRS tem como prioridade diminuir a geração de resíduos sólidos e, consequentemente, diminuir a poluição do meio ambiente. Para tanto, estimula a implementação de várias atividades, dentre as quais destacam-se as atividades da Logística Reversa. Na lei 12305/2010, Título I, Capítulo II, Art. 3ơ, XII, encontra-se a seguinte definição de Logística Reversa:

"logística reversa: instrumento de desenvolvimento econômico e social caracterizado por um conjunto de ações, procedimentos e meios destinados a viabilizar a coleta e a restituição dos resíduos sólidos ao setor empresarial, para reaproveitamento, em seu ciclo ou em outros ciclos produtivos, ou outra destinação final ambientalmente adequada;"

De forma complementar, Leite (2009) propõe a seguinte definição de Logística Reversa:

"A Logística Reversa é responsável por gerenciar as atividades de planejamento, implementação e controle de materiais e informações obtidos após sua venda ou consumo, que podem retornar ao ciclo de negócios onde foram gerados, ou que podem ser encaminhados a outros ciclos produtivos, para revalorização e reintegração ao mercado, de diferentes formas ou utilidades, através dos canais reversos de distribuição (LEITE, 2009, p. 12)".

A análise dessas definições permite reconhecer a Logística Reversa como instrumento de gestão ambiental, capaz de orientar a implementação de diversas formas de coleta de resíduos sólidos, em diferentes origens, desde unidades domiciliares até instituições públicas e privadas, com o objetivo de encaminhar os resíduos coletados ao setor empresarial para que possam ser revalorizados, e assim, reaproveitados em outras atividades produtivas ou comerciais, evitando o descarte desses itens. Também é possível verificar a preocupação com o descarte adequado dos resíduos sólidos coletados, quando na impossibilidade de uma revalorização, para mitigar o impacto ambiental resultante.

As Organizações Militares também utilizam recursos materiais na execução de suas competências e, por isso, têm a responsabilidade de gerenciar os resíduos sólidos gerados. Nesse contexto, apresenta-se a questão proposta para orientar as análises a serem desenvolvidas nesse ensaio teórico: Como o desenvolvimento de atividades de Logística Reversa na Logística Militar pode contribuir para o alcance dos objetivos da Política Nacional dos Resíduos Sólidos, e robustecer a Logística Nacional? 
Em função desse questionamento, tem-se como objetivo desse ensaio: Identificar oportunidades de desenvolvimento de atividades de Logística Reversa na Logística Militar, que podem contribuir para o alcance dos objetivos da Política Nacional dos Resíduos Sólidos e proporcionar maior efetividade para a Logística Nacional.

Dessa forma, serão analisadas as funções da Logística Militar em relação às atividades da Logística Reversa, visando identificar oportunidades de sua implementação para contribuir com o atingimento dos objetivos da PNRS nas Forças Singulares.

\section{DESENVOLVIMENTO}

\subsection{A POLITICA NACIONAL DE RESÍDUOS SÓLIDOS}

Dentre os objetivos da PNRS, listados no Título II, Capítulo 2, Art. 7ํㅜ, tem-se como quatro primeiros objetivos os seguinte (BRASIL, 2010):

I - proteção da saúde pública e da qualidade ambiental;

II - não geração, redução, reutilização, reciclagem e tratamento dos resíduos sólidos, bem como disposição final ambientalmente adequada dos rejeitos;

III - estímulo à adoção de padrões sustentáveis de produção e consumo de bens e serviços;

IV - adoção, desenvolvimento e aprimoramento de tecnologias limpas como forma de minimizar impactos ambientais;

Esses objetivos, associados aos demais estabelecidos na PNRS, demonstram a preocupação contida nessa legislação em criar condições para a efetiva gestão ambiental nacional, estando relacionada ao atendimento de alguns dos Objetivos Fundamentais de Estado, principalmente relacionados à manutenção da qualidade de vida da população e à preservação das riquezas naturais do País.

O gerenciamento de resíduos sólidos deve seguir uma hierarquia para implementação de ações estratégicas de gestão ambiental que devem ser empregadas nas diversas instituições/processos onde os resíduos são gerados. Segundo Gasi e Ferreira (2006) há uma hierarquia de prioridade de atividades capazes de evitar a geração de resíduos sólidos. Essa hierarquia corresponde ao atendimento das seguintes prioridades:

- Prioridade 1: não gerar - identificar alternativas com a finalidade de eliminar o poluente diretamente na sua fonte, buscando alcançar o nível de poluição zero.

- Prioridade 2: minimizar geração - não conseguindo eliminar o poluente, deve-se buscar alternativas que visem a minimização do mesmo em seu processo gerador.

- $\quad$ Prioridade 3: reciclar dentro do processo - uma vez gerado o resíduo, averiguar as possibilidades de reaproveita-los dentro do processo em que foi gerado.

- $\quad$ Prioridade 4: reciclar fora do processo - esgotadas todas as possibilidades de reciclagem dentro do processo, os resíduos devem ser encaminhados para reciclagem fora do processo.

- Prioridade 5: tratar e dispor - não sendo possível reciclar os poluentes internamente e externamente ao processo, esses devem ser, em último caso, tratados e dispostos de forma ambientalmente adequada.

Relacionando as prioridades listadas e os objetivos da PNRS destacados verifica-se que muitos deles podem ser atendidos através da implementação de atividades de Logística Reversa.

\subsection{A LOGÍSTICA REVERSA E SUAS PRINCIPAIS ATIVIDADES DE REVALORIZAÇÃo DE RESÍDUOS SóLIDOS}

Leite (2009) identifica as atividades de logística reversa como canais de distribuição reversos, denominando-as da seguinte forma: reciclagem, remanufatura, desmanche, reuso e destinação final segura. Essas atividades serão brevemente apresentadas a seguir: 
Reciclagem - é o canal reverso de reintegração, uma vez que os materiais constituintes dos produtos descartados são extraídos industrialmente e transformados em matérias-primas secundárias ou recicladas que serão reincorporadas à fabricação de novos produtos. Para que essas matérias-primas secundárias retornem a um novo ciclo produtivo é necessária a realização de etapas como: coleta, seleção e preparação, reciclagem industrial e reintegração ao ciclo produtivo.

No Brasil, os materiais mais comuns submetidos à revalorização pela reciclagem são os metais (incluindo o alumínio), o papel e o plástico. Esses materiais têm tecnologias de processamento para reciclagem já estabelecidas. A demanda de mercado desses materiais é relativamente estável, tendo diversos usos na indústria. Além disso, a reciclagem desses materiais permite obter um elevado percentual de manutenção de características originais e, também, um alto volume de recuperação. Por exemplo, a recuperação na reciclagem dos metais é de mais de $80 \%$ em relação à quantidade de entrada no processo de reciclagem e o custo do material reciclado é bem inferior ao o material extraído da natureza.

Remanufatura - Processo que trata um produto ou seus componentes através de alterações na forma física para reestabelecimento de sua função original. A remanufatura corresponde a qualquer atividade de manutenção/substituição de componentes de um bem, que permite a recuperação de sua utilidade e/ou implique na extensão de sua vida útil. A exceção dos itens descartáveis, os demais itens (semi-duráveis ou duráveis) podem ser submetidos a processos industriais de remanufatura para revalorização e retorno ao mercado (primário ou secundário).

Desmanche - Canal reverso que realiza um processo industrial de desmontagem no qual os componentes de um bem durável, em fim de vida útil, ainda preservam sua utilidade, ou apresentam condições de remanufatura ou de reuso, são separados de partes ou materiais sem condições de revalorização. Os componentes ainda úteis são enviados, diretamente ou após remanufatura, para o mercado de peças usadas. O Desmanche é muito utilizado em equipamentos eletro-eletrônicos em fim de vida útil, ou em veículos com perda total ou parcial onde a recuperação se torna inviável economicamente, ou ainda em equipamentos e veículos que foram retirados de linha de produção, cujas peças sobressalentes são difíceis de serem encontradas no mercado. 0 Desmanche e fornecedor natural de atividades reversas de reuso (comercio de segunda mão) ou de remanufatura (consertos em geral). No caso dos itens inservíveis, esses devem ser encaminhados para a Destinação Final Segura.

Reuso - Canal reverso que viabiliza a extensão do uso de um produto de pós-consumo ou de seu componente, com a mesma função para a qual foi originalmente desenvolvida (sem nenhum tipo de remanufatura, ainda que possa alimentar um atividade de remanufatura depois que ocorre a mudança de posse entre usuários). 0 reuso corresponde a continuidade do uso de um item por outro usuário, depois do primeiro. Em geral, identifica-se o canal reverso de reuso no comércio de segunda mão, onde bens em condições de uso são vendidos em negócios formais ou informais, mantendo um valor de mercado, ainda que inferior ao de um produto novo semelhante. 0 reuso pode acontecer em atividades produtivas ou comerciais, quando a vida útil do bem é consumida por mais de um usuário, à medida que esses itens são substituídos/trocados por novos itens ou perdem o valor para seu primeiro usuário.

Destinação Final Segura - é o último local de destino para o qual são enviados produtos, materiais e resíduos em geral sem condição de revalorização. A disposição final ambientalmente adequada é definida como a distribuição ordenada de rejeitos em locais adequados, conforme as normas operacionais específicas, de modo a evitar danos ou riscos à saúde pública e à segurança e a minimizar os impactos ambientais. A forma mais comum desse canal reverso são os aterros sanitários, ou seja, os locais adequados para disposição de resíduos sólidos urbanos, uma vez que segue critérios de engenharia e normas operacionais específicas, previstas no processo de licenciamento ambiental para sua instalação. Para itens perigosos/contaminantes, a Destinação Final Segura é feita de modo separado e utilizando diferentes tecnologias, uma delas é a incineração, muito comum para embalagens de produtos químicos e resíduos hospitalares.

Os canais reversos apresentados correspondem a diferentes formas de revalorização de uma parte dos itens que fluem no sentido inverso, do usuário consumidor ao fornecedor, entre empresas ou instituições, motivadas por problemas relacionados à qualidade em geral ou a acordos comerciais estabelecidos em ciclos de negócios. 
A logística militar é parte da Logística Nacional e corresponde ao processo de planejamento e execução do apoio ao movimento e sustentação de forças em uma operação militar. A logística visa a integrar os esforços de sustentação estratégica, operacional e tática às operações (BRASIL, 2016).

Nas Organizações Militares - OM's, as atividades Logística são agrupadas em funções logísticas que são responsáveis por prever e prover os meios necessários a realização daquela função nas atividades militares. As funções logísticas militares são descritas a seguir, conforme o MD 42-M-02 (BRASIl, 2016):

- Função Logística Recursos Humanos - é o conjunto de ações relacionadas com a aplicação do potencial humano, objetivando o cumprimento das missões das Forças Armadas;

- Função Logística Saúde - é o conjunto das ações relacionadas com a conservação do potencial humano, nas melhores condições de aptidão física e psíquica, objetivando o cumprimento da missão das Forças Armadas, através de medidas sanitárias de prevenção e recuperação;

- Função Logística Suprimento - é o conjunto de ações realizadas no sentido de prever e prover às diferentes organizações e elementos todos os itens de material necessários ao seu equipamento, vida, treinamento e emprego. Abrange a parte das operações de salvados, que implica o retornado material recuperado aos canais de suprimento, bem como a determinação de qualidade e a evacuação do material;

- Função Logística Manutenção - compreende as ações executadas para conservar, em condições de uso, o material existente ou restaurá-lo a essa condição;

- Função Logística Engenharia - compreende as ações de planejamento e execução de obras e de instalações necessárias às atividades militares;

- Função Logística Transporte - compreende o deslocamento de meios materiais e de recursos humanos visando ao atendimento das necessidades das Forças Armadas; e,

- Função Logística Salvamento - é o conjunto de ações relacionadas com o combate a incêndios, controle de avarias, reboque, desencalhe e reflutuação, recuperação de cargas ou itens específicos, em meios navais e embarcações, e desobstrução de portos e rios.

Como também é observado no Manual de Logística Militar, destaca-se que para cada uma das funções logísticas, devem ser consideradas as três fases da logística: determinação das necessidades, obtenção e distribuição (BRASIl, 2016):

- Determinação das Necessidades - decorre do exame pormenorizado dos planos propostos e, em particular, das ações e operações previstas, definindo quais são as necessidades, quando, em que quantidade, com que qualidades e em que local deverão estar disponíveis. A importância desta fase é ressaltada pela complexidade a ela inerente e por constituir- se na base em que se assentarão as fases subsequentes.

- Obtenção - é a fase em que são identificadas as fontes e tomadas às medidas para adquirir ou obter os recursos necessários.

- Distribuição - consiste em fazer chegar, oportuna e eficazmente, aos usuários, todos os recursos fixados pela determinação das necessidades.

Apesar da Logística Militar está bem definida nas funções logísticas apresentadas, apenas na função salvamento há explicitação da ocorrência de atividades de Logística Reversa, notadamente tratando-se da coleta de itens e/ou equipamentos que exigem, por motivos diversos, operações de busca e salvamento. Porém, não há doutrina para orientar para qual tipo de revalorização os materiais salvados devam encaminhados. Há apenas orientação legal para o desfazimento de bens inservíveis ou para descarte de materiais perigosos.

\subsubsection{LOGÍSTICA MILITAR E LOGÍSTICA REVERSA}

No Manual de Campanha EB20-MC-10.204, do Exercito Brasileiro (BRASIL, 2014) há uma abordagem sobre a logística reversa, onde essa atividade nas operações terrestres realizadas pelo EB é definida como um conjunto de ações, técnicas e procedimentos para o planejamento e a execução do fluxo inverso de recursos logísticos, sem estágios intermediários, do usuário consumidor até a fonte de obtenção e/ou ponto de coleta à retaguarda. 
Nesse Manual, é observado que a Logística Reversa deve receber especial atenção pela possibilidade de gerar restrições à liberdade de ação, relacionadas às questões ambientais, considerando a legislação ambiental nacional que se aplica às Forças Armadas.

Como a atuação do Exercito é prioritariamente terrestre, a previsão de ocorrência do fluxo reverso de itens materiais é de que o sentido do retorno se inicie no usuário consumidor, por isso, considera-se que os mesmos órgãos que executam a distribuição física realizam a logística reversa. Desse modo, o final do fluxo direto, onde aconteceu a entrega dos itens aos usuários consumidores, é considerado o ponto de início do fluxo reverso.

A partir da coleta, os itens que motivaram o retorno devem seguir para os responsáveis na cadeia de suprimentos, indo ate o ponto onde deve acontecer algum tipo de tratamento/revalorização para recuperação de sua utilidade ou, na impossibilidade da recuperação, o ponto onde se inicia as operações para descarte seguro dos itens retornados.

No Manual (BRASIL, 2014) é destacado que a Organização Militar deve prever e planejar o retorno de itens materiais desde a fase inicial da operação, para evitar desperdício de recursos, mitigar impactos ambientais e maximizar as capacidades de transporte. Além disso, os mecanismos de reversão de materiais devem fazer parte dos contratos de obtenção, comprometendo os fornecedores no destino final de envases, rejeitos e materiais recicláveis, destacando a responsabilidade dos fabricantes pelos itens fornecidos durante o ciclo de vida.

Finalmente, o Manual (idem) estabelece a forma de execução da logística reversa na Força Terrestre, recomendando que sejam considerados os seguintes aspectos:

a) responsabilidade patrimonial;

b) disponibilidade e confiabilidade de dados (exemplos: identificação, tipo, localização, condições de uso e outros) dos sistemas de informações logísticas disponíveis;

c) necessidades de meios de transporte, pessoal e infraestrutura; e,

d) definição da destinação final (exemplo: retorno à cadeia de suprimento ou desfazimento).

Dessa forma, a realização de atividades de Logística Reversa é contemplada nas atividades das operações terrestres executadas pelo Exercito Brasileiro, e a reversão dos meios (retorno do pessoal, dos equipamentos e dos materiais adquiridos, adjudicados ou mobilizados aos seus locais de origem) por ocasião do encerramento das operações, é considerada como capacidade básica da Logística Militar. Após a recuperação dos meios, esses devem ser avaliados e processados visando a sua destinação final. Assim, a Logística Reversa nas atividades terrestres contribui para a otimização do ciclo de vida dos materiais e o recompletamento de recursos humanos, reduzindo os impactos ambientais das operações.

A doutrina de Logística Militar do Ministério da Defesa ainda não contempla, de forma ampla, a orientação para implementação de atividades de Logística Reversa nas Forças Armadas, sendo o conteúdo do Manual de Campanha EB20-MC-10.204, do Exercito Brasileiro (BRASIL, 2014) um avanço em relação à abordagem que é dada à Logística Reversa no MD 42-M-02 (BRASIl, 2016), ainda que esse segundo documento tenha sido publicado em período mais recente.

\subsection{IDENTIFICAÇÃO DE PRÁTICAS DE LOGÍSTICA REVERSA EM ORGANIZAÇõES MILITARES}

Em todas as funções da Logística Militar há possibilidade de algum tipo de retorno de itens, o que representa oportunidades de realizar atividades de Logística Reversa. Assim, na Logística de Recursos humanos, na Logística de Saúde, na Logística de Suprimento, na Logística de Manutenção, na Logística de Engenharia e na Logística de transporte, além da Logística de salvamento, pode acontecer algum fluxo reverso de materiais, por motivos técnicos, comerciais, legais etc.

Como as funções logísticas são realizadas para suportar atividades militares, é comum que o fluxo reverso ou as oportunidades de desenvolver atividades de Logística Reversa aconteça nas Organizações Militares OM. Por exemplo, no CENTRO DE CONTROLE DE INVENTÁRIO DA MARINHA - CCIM, onde ocorrem várias atividades logísticas, a gestão dos almoxarifados, que implicam no recebimento, registro e separação de materiais para atender solicitações das OM podem também implicar em realizar Logística Reversa quando ocorrem avarias em partes ou no próprio equipamento armazenado.

Quando pequenos reparos são feitos, as operações de recuperação da utilidade original correspondem à atividade de remanufatura. Quando o pequeno reparo não é suficiente para recuperar a utilidade do item 
ou, quando um item se torna obsoleto, então a operação que deve ser realizada é a "gestão de excessos" que é o início do descarte/ desfazimento de materiais ou itens inservíveis total ou parcialmente ou que se tornaram obsoleto/ desnecessários. A gestão de excesso no CCIM corresponde ao envio de materiais para leilão, ou seja, é o início do caminho reverso dos itens inservíveis para revalorização em atividades de negócios secundários, produtivos ou comerciais, que podem ser a primeira etapa de uma cadeia de suprimentos reversa. O descarte de materiais armazenados, ainda que sem uso ou pouco uso pode ser a fonte de canais reversos de desmache, reciclagem, remanufatura e/ou reuso.

Outro exemplo de remanufatura nas instalações do CCIM é a manutenção de caixas e de palets de madeira que são utilizados para acondicionamento dos grandes itens estocados. A recuperação desses itens de apoio à armazenagem amplia sua vida útil e representa uma economia pela aquisição tardia de itens semelhantes para substituição desses.

Outros exemplos também podem ser citados. Um deles ocorre no Centro Tecnológico do Corpo de Fuzileiro Naval - CTecCFN, localizado na Parada Lucas/RJ; e, notadamente, na Oficina de fundição de metal da Marinha, onde são reciclados materiais metálicos descartados que se transformam em matéria prima secundária, para a fabricação de panóplias e brindes fornecidos como brindes aos visitantes da Marinha. Nesse exemplo, há a fundição o ferro descartado após uso de munição (estojos dos projéteis) e demais itens inservíveis feitos em metal.

No Parque de Material da Aeronáutica do Rio de Janeiro e no Parque de material bélico do Rio de Janeiro, ambos instalados no Galeão, embalagens descartadas em operações de manutenção, inspeção, consumo podem ser reaproveitados para acondicionamento de vários itens, como ferramentas, por exemplo. Nesse caso, ocorre um reuso de embalagens que são resistentes e oferecem condições de preservação de vários itens. Assim, embalagens de metal, de madeira e de polímeros podem ser reutilizadas para acondicionar outros itens nessas OM.

Toda oficina de manutenção exerce a função de remanufatura, por realizar alguma alteração física na forma de um item, ampliando sua vida útil. Quando não é possível a recuperação da utilidade de um item, pode ocorrer a identificação de separação de partes inservíveis de outras que tem condições de uso. Essas pequenas operações, além de representarem uma economia de novas aquisições, permitem a continuidade das operações de determinado equipamento avariado, que teria que esperar o cumprimento de prazos e etapas de um processo de licitação, qualquer que seja o tipo, e o tempo de reposição do fornecedor para voltar a sua normalidade de funcionamento.

Ações de Logística Reversa podem também ser observadas nos Parque de manutenção de aeronaves que atendem a frota da FAB. Tomando como exemplo as atividades do Parque de Material Aeronáutico de Lagoa Santa (PAMA-LS) que está localizado na Região Metropolitana de Belo Horizonte, que é uma organização militar que presta serviços de fabricação de peças, inspeção, manutenção e reparação de grande parte da frota de aeronaves da Força Aérea Brasileira.

No PAMA-LS são gerados vários tipos de resíduos em função da realização de atividades de desmontagens e as demais atividades de manutenção de aeronaves (são gerados resíduos de peças, embalagens, pintura, materiais inservíveis, resíduos químicos etc.). Esses resíduos se descartados/ manipulados de forma incorreta podem gerar vários problemas, alguns, pela possibilidade de contaminação (no caso de resíduos químicos) ou ainda, causar perdas na qualidade do ar, do solo e da agua, além de ocasionarem poluição e outros problemas relacionados. Por outro lado, é possível recuperar e reaproveitar alguns itens, de acordo com seu material constituinte e/ou, em função do estágio no ciclo de vida.

No caso dos resíduos de metais, o que considerado inservível é cortado e amassado, para ser alienado como sucata. 0 que é considerado servível (tecnicamente em vida útil), como material aeronáutico, mas não tem mais utilidade nas atividades do PAMA pode ser destinado a leilão, de acordo com regulamentação vigente. A alienação tem previsão de acontecer uma vez por ano, fazendo parte das atividades administrativas do Parque.

Outra ação de logística reversa é a coleta seletiva, observada é a existência de contentores para coleta de resíduos recicláveis (papel, papelão, plástico), gerados em qualquer fase do processo, ou de atividades de apoio, que são posteriormente doados a uma cooperativa e retirados pela mesma e encaminhados para reciclagem e/ou reuso. Enquanto embalagens de substâncias químicas são encaminhadas para incineração por uma empresa contratada e habilitada para isso.

Toda a instalação do PAMA-LS foi sujeita ao licenciamento ambiental e atende às exigências ambientais estabelecidas. Por isso, mantém uma reserva ambiental de sua área total e realiza o tratamento de efluentes antes do descarte no meio ambiente. A mistura química liquida utilizada para banho de peças, 
após o uso, é reservada em tambores e coletada também por uma empresa especializada para descarte adequado.

Em relação à recuperação do valor econômico, algumas atividades de remanufatura de pequenas recuperações de peças e a pintura das aeronaves representam uma extensão da vida útil desses itens e, um ganho indireto de patrimônio do Parque. Como resultado de atividades de remanufatura, também foi feita uma modificação em uma aeronave T-25, onde foi colocado outro motor de maior potencia e feita adição de mais uma pá na hélice. Essa aeronave modificada, tem condições de voo e conseguiu maior potencia em relação a versão original. Todavia, é mantida em um hangar do PAMA-LS e utilizada eventualmente para demonstração. Não houve repetição dessa modificação porque a potência conseguida com as alterações, economicamente, não compensa o aumento no consumo de combustível para manter a aeronave em utilização.

Outra forma de atribuir utilidade a um item que se tornou obsoleto é pela doação para outra finalidade de uso. Pode-se doar aeronaves ou outros meios inservíveis para alocação em ambientes públicos, a exemplo de doações de uma aeronave Mirage F103 III, de helicópteros UH-1H e de Xavante AT-26 pela Força aérea, para serem expostos em praças públicas e assim, cumprirem uma função social.

0 descarte de material inservível, avariados sem possibilidade de recuperação, vencidos ou decorrentes do descarte após o consumo nas forças armadas é previsto e pode ser realizado através de um plano de alienação. Os metais descaracterizados e desmilitarizados geralmente são adquiridos por empresas siderúrgicas e são insumos de processos de reciclagem.

\subsection{OPORTUNIDADES PARA A INSTITUCIONALIZAÇÃO DE LOGÍSTICA REVERSA EM ORGANIZAÇÕES MILITARES}

Umas das primeiras ações que podem ser instituídas nas Forças Armadas é a implementação da coleta seletiva nas $\mathrm{OM}$, de forma a recuperar os materiais recicláveis para beneficiamento dentro ou fora das $\mathrm{OM}$. A coleta seletiva pode ir além dos materiais clássicos coletados (metal, plástico e papel), que já tem demanda estáveis no mercado.

Dependendo da atividade realizada na OM, podem ser coletados os resíduos orgânicos, resíduos de madeira etc. Os resíduos orgânicos podem ser utilizados para preparação de adubo (compostagem) que pode ser utilizado em hortas ou em jardins na própria OM ou em instituições adotadas por uma OM para receberem a compostagem como doação. Os resíduos de madeira podem ser reaproveitados para produção de bancos, estantes, mesas pequenas, que podem ornamentar ambientes de visitação e/ou descanso das pessoas que frequentam uma OM. Além disso, resíduos de madeiras podem ser utilizados como material para fazer alguns reparos em outros itens de madeira, como pallets ou caixotes, utilizados nas atividades de armazenagem.

O desmanche de equipamentos eletro-eletrônicos inservíveis ou com custo de recuperação de utilidade economicamente inviável, pode ser normatizado para retirada e reaproveitamento de itens e componentes com utilidades preservadas, para que possam servir como sobressalentes e itens de manutenção de outros equipamentos, antes de serem encaminhados para desfazimento, cumprindo a tarefa de desqualificação e/ou desmilitarização. Além da economia de custos de aquisição de novas peças sobressalentes, o desmanche permite manter a continuidade das operações que, no caso da falta de itens para reposição/ manutenção, tria que ficar impedidos de uso ate a chegada dos novos itens comprados. Então o desmanche alimenta as operações de remanufatura e reduzem custos e tempos de espera nas operações de manutenção/ recuperação de equipamentos.

Uma opção que pode ter valor ambiental significativo é a coleta e tratamento de agua proveniente de banho ou de limpezas de ambientes para tratamento e reuso na irrigação de jardins e para limpeza de ambientes externos, como calçadas e terraços, até para a lavagem externa de veículos e algumas peças de oficinas/ funilarias. Esse tipo de atividade reversa caracteriza o reuso do material para uma função secundaria para a qual apresente utilidade.

Para todas essas oportunidades existem tecnologias e procedimentos padronizados que podem ser adquiridos ou desenvolvidos nas OM sem maior complexidade de implementação e podem representar significativa economia de custos (com agua ou energia) além de reduzirem o consumo dos recursos naturais envolvidos.

Essas são algumas poucas oportunidades identificadas a partir da aplicação de alguns conceitos de LR nas atividades militares. Porém, a observação da rotina das OM e a abertura para sugestões de 
reaproveitamento de materiais de consumo/expediente podem indicar muitas novas possibilidades de aplicação dos conceitos de Logística Reversa nas atividades militares.

Importante também é dimensionar os volumes coletados e avaliar o potencial de ganho com o beneficiamento desses. Isso estimula a continuidade das atividades reversas e demonstra os diferentes tipos de ganhos (econômicos, ambientais, sociais, legais etc.) que podem advir da implementação das atividades de Logística Reversa.

Sobre os ganhos sociais, é importante ressaltar que eles são mais difíceis de mensurar e podem ocorrer de forma direta ou indireta. Por exemplo, se uma OM "adota" uma instituição de ensino, para executar algumas atividades de manutenção de suas instalações, pode utilizar sobras de material de construção ou fazer pequenas doações de materiais que viabilizarão a execução dos serviços de manutenção e melhor ambientação da instituição adotada. Esse beneficio social não tem como ser medido mas é evidente que serão mútuos, porque a instituição beneficiada disporá de melhores condições para realizar suas atividades e a OM melhora sua imagem na comunidade onde está inserida, o que, além de permitir aos envolvidos desenvolver um olhar sobre a responsabilidade social individual e coletiva, reforça a importância das Forças Armadas.

\section{CONSIDERAÇÕES FINAIS}

Através do gerenciamento da logística reversa, as empresas podem maximizar o seu desempenho produtivo, com o uso racional dos seus recursos; podem atender a exigências legais relativas ao tratamento e descarte dos resíduos gerados; e podem satisfazer demandas sociais para a redução do impacto ambiental de suas atividades produtivas. Além disso, o estabelecimento de canais reversos pode representar oportunidades estratégicas de melhoria do serviço da empresa e/ou oportunidades de novos negócios para atendimento de nichos de mercados.

As atividades de Logística Reversa fazem parte da PNRS e estão presentes na Logística Militar, formalmente, na função Logística Salvamento; e, também, no que tange ao descarte de resíduos sólidos contaminantes ou perigosos. Todavia, a PNRS busca desenvolver princípios muito além do descarte adequado de resíduos sólidos.

No caso da gestão da logística em atividades militares, o desenvolvimento de atividades de Logística Reversa pode e deve ser ampliado para que os benefícios esperados sejam auferidos, principalmente os benefícios ambientais. Ainda que as exigências legais, no que tange ao descarte correto e ao desfazimento de materiais inservíveis estejam sendo atendidas, a prioridade de eliminação ou a redução da geração dos resíduos sólidos, por exemplo, ainda são se verifica na rotina de uma OM.

Destaca-se uma melhor ênfase dada a Logística Reversa na doutrina de Logística Militar do EB, contida no Manual de Campanha EB20-MC-10.204 (BRASIL, 2014) que contempla a realização de atividades de logística reversa em quase todas as operações logísticas terrestres. Podendo esse Manual ser o ponto de partida para a formalização da pratica Logística Reversa nas atividades militares das Forças Singulares.

As práticas de Logística Reversa, além dos benefícios ambientais diretamente relacionados, podem reduzir custos de operações e/ou necessidade de aquisição/produção de novos produtos, em função da possibilidade da ampliação de sua utilidade, ainda que em um uso secundário.

Além de identificar oportunidades de implementação e práticas de logística reversa na Logística Militar, buscou-se, nesse trabalho, chamar atenção para a viabilidade e a grande contribuição que a incorporação, de forma sistêmica, de atividades de Logística Reversa na doutrina da Logística Militar, pode gerar benefícios econômicos, ambientais e sociais, que, por sua vez, atendem aos objetivos da Política Nacional dos Resíduos Sólidos e reforçam a importância da Logística Reversa para a efetividade da Logística Nacional. 


\section{REFERÊNCIAS}

[1] BRASIL. Lei no 6.938, de 31 de agosto de 1981. Política Nacional do Meio Ambiente. Disponível em: <http://www.planalto.gov.br/ccivil_03/leis/16938.htm>. Acesso em maio de 2017.

[2] _. Decreto no 5.940, de 25 de Outubro de 2006. Disponível em: http://www.planalto.gov.br/ccivil_03/_ato2004-006/2006/decreto/d5940.htm. Acesso em: Abril de 2017.

[3] ___ Lei no 12.305, de 2 de agosto de 2010. Institui a Política Nacional de Resíduos Sólidos; altera a Lei no 9.605, de 12 de fevereiro de 1998; e dá outras providências. Ministério do Meio Ambiente, Brasília, DF, 2010. Disponível em: <http://www.planalto.gov.br/ccivil_03/_ato2007-2010/2010/lei/lei12305.htm>. Acesso em: Abril de 2017.

[4] _ Ministério da Defesa. O Manual de Campanha EB20-MC-10.204. Logística. 3ạ Edição, Brasil: 2014.

[5] ___ Escola Superior de Guerra. NCE 60-2015: Logística Nacional. Departamento de Estudos - DALMob. Rio de Janeiro: 2015.

[6] BRASIL. Ministério da Defesa. MD 42-M-02: Doutrina de Logística Militar. $3^{\underline{a}}$ ed. Brasil: 2016.

[7] DIAS, R. Gestão Ambiental: responsabilidade social e sustentabilidade. 2ª ed. - São Paulo: Atlas, 2011.

[8] GASI, T. M. T; FERREIRA, E. Produção Mais Limpa. In: VILELA JÚNIOR, A; DEMAJORVIC, J (Org.). Modelos e Ferramentas de Gestão Ambiental: desafios e perspectivas para as organizações. São Paulo: Editora SENAC, 2006.

[9] LEITE, P. R. Logística Reversa: meio ambiente e competitividade. 2a ed. São Paulo: Pearson Prentice Hall, 2009 


\title{
Capítulo 5
}

PROCESSO DE LOGÍSTICA REVERSA DE PÓS-CONSUMO E RECICLAGEM: ESTUDO DE CASO DE UMA GRANDE EMPRESA DE BATERIAS DE GOIÁS

\author{
Renata Cristina Almeida de Mendonça Veloso \\ José Ribamar Tomaz da Silva Filho \\ Rosângela Sarmento Silva \\ Tony Stevão Alves da Silva \\ Caroline Alves Resende
}

Resumo: Este artigo teve como objetivo descrever os processos de logística reversa de pós-consumo e a reciclagem de baterias praticada por uma grande empresa do Grupo Moura que se divide em RBM (Redes de Baterias Moura) distribuídas em todo o país. A metodologia utilizada nesta pesquisa baseou-se na análise de conteúdo e análise qualitativa. Como instrumento básico de coleta de dados, utilizou-se de entrevistas e um questionário semi-estruturado aplicado na empresa diretamente com as pessoas responsáveis pela logística reversa e pela reciclagem das baterias. Como resultado foi possível identificar que a empresa se preocupa em conscientizar seus revendedores nas boas práticas de gestão da reciclagem, seja ela por meio de descontos ou por obrigações legais. A pesquisa também revelou que a empresa não recicla não só seus produtos mais também os das marcas dos concorrentes, caracterizando-se em uma empresa sustentável, independentemente da marca dos produtos que deverão ser reutilizados. A RBM são abastecidas com $100 \%$ das baterias novas e recicláveis. E por meio desta ação, a empresa consegue reduzir custos materiais e operacionais, com cerca de $90 \%$ de economia de matéria-prima. Uma vez que a reutilização de materiais descartados, também podem proporcionar economia com matérias-primas e a preservação do meio ambiente.

Palavras-Chaves: baterias, logística reversa e reciclagem. 


\section{INTRODUÇÃO}

Atualmente as organizações empresariais vêm desempenhando um comportamento ambiental mais ativo, transformando uma postura antes passiva em oportunidades de negócios. A preservação do meio ambiente deixa de ser uma obrigação legal e passa a ser uma fonte adicional aos negócios. No cenário econômico atual, muitas organizações procuram se tornar competitivas, minimizando o impacto ambiental e agindo com responsabilidade. Estas também descobriram que ao controlar a geração e destinação de seus resíduos economizariam e conquistariam o reconhecimento da sociedade. Sendo assim, algumas organizações passaram a trabalhar com a logística reversa e a reciclagem integrada em seus processos de produção (SUBRAMANIAN et al., 2014).

Por conta deste desequilíbrio, nasce à preocupação ecológica dos consumidores, aparecem novas leis ambientais e mudamos novos padrões de competitividade nas empresas surgindo então às preocupações com a imagem corporativa das mesmas incentivando assim, a criação dos canais reversos que vieram para solucionar o problema da quantidade de produtos descartados no meio ambiente (DYCKHOFF, 2004).

Atualmente as organizações empresariais vêm desempenhando um comportamento ambiental mais ativo, transformando uma postura antes passiva em oportunidades de negócios. A preservação do meio ambiente deixa de ser uma obrigação legal e passa a ser uma fonte adicional aos negócios. No cenário econômico atual, muitas organizações procuram se tornar competitivas, minimizando o impacto ambiental e agindo com maior responsabilidade (FULLER et al, 1995).

Estas empresas também descobriram que ao controlar a geração e destinação de seus resíduos, economizariam e conquistariam o reconhecimento da sociedade. Sendo assim, algumas organizações passaram a trabalhar com a logística reversa e a reciclagem integrada em seus processos de produção.

Ribeiro e Gomes (2004) definem que logística, é o gerenciamento estratégico da aquisição, movimentação e armazenamento de materiais, peças e produtos acabados. Sua distribuição ocorre pelos sistemas e canais de modo a maximizar os lucros por meio do atendimento de pedidos a custos razoáveis.

0 verdadeiro papel da logística reversa, neste contexto é o de facilitar o retorno do produto ao ciclo produtivo, que é viabilizado por meio da devolução dos mesmos pelo consumidor ao seu fornecedor direto, para que assim ele o remeta ao seu fabricante. 0 fabricante, por sua vez, se encarregara pela reciclagem do produto como insumo. Dada à destinação adequada, este será reintegrado ao ciclo dos negócios.

Como pode ser visto a Logística está estrategicamente posicionada entre as áreas importantíssimas de uma empresa sendo elas: o fluxo de todas as atividades de estocagem, manuseio, transporte de produtos e informações desde o ponto de consumo até o ponto de origem, com a simples finalidade de atender as exigências dos consumidores.

São devidas a essas questões que o grupo Baterias Moura localizada em Pernambuco decidiu então aderir às práticas de logística reversa de pós-consumo e reciclagem das baterias em seu processo de produção. Diante deste fato, levantou-se a seguinte problemática: Como é realizado o processo de logística reversa de pós-consumo e a reciclagem de baterias do Grupo Moura?

Em relação à problemática acima definida, este artigo tem como objetivo descrever os processos de logística reversa de pós-consumo praticada pela RBM (Redes de Baterias Moura) situada em Goiânia e a reciclagem de baterias praticada pela Moura com sede na cidade de Pernambuco.

O presente artigo está organizado da seguinte maneira: após essa introdução, é apresentada uma revisão da literatura com ênfase nos conceitos e definições de logística reversa e reciclagem. Logo em seguida é incluída a metodologia de pesquisa que descreve o tipo, instrumento de pesquisa e o perfil dos entrevistados. Os resultados contemplam a caracterização do Grupo Moura e discute as implicações obtidas por meio da transcrição de texto. E por fim, são apresentadas as conclusões do presente artigo.

\section{REFERENCIAL TEÓRICO}

O referencial teórico a seguir tem como propósito fornecer embasamento conceitual acerca desta temática, com vistas a responder à problemática deste estudo e ao seu objetivo proposto. Inicialmente parte-se para a reflexão sobre as definições de logística, logística reversa e por último a gestão ambiental e a reciclagem. 


\subsection{LOGÍSTICA}

A logística surgiu a partir de uma necessidade organizacional que visa atender seus clientes de forma eficiente, levando em conta a qualidade, a redução dos prazos e dos custos (FLEISCHMANN, 2001).

Segundo Martins et al (2004), a logística teve sua origem em atividades militares e foi desenvolvida com o intuito de alocar os recursos certos no local certo, na hora certa, com um só objetivo: vencer batalhas. Hoje, a logística é responsável por planejar, operar e controlar todo o fluxo de mercadorias, desde o fornecedor até o consumidor.

Segundo Ballou (2006), adaptando a definição de logística do Council of Logistics Management (CLM), tem-se:

Processo de planejar, implantar e controlar fluxos eficientes e eficazes de mercadorias, serviços e informações desde seu ponto de origem até o ponto de consumo, com a finalidade de atender às exigências dos clientes (BALLOU, 2006).

Seguindo por estas definições, Ballou (2006) apresenta ainda os componentes do sistema logístico, sendo eles:

- Serviços ao cliente;

- Previsão de demanda;

- Comunicações de distribuição;

- Controle de estoque;

- Manuseio de materiais;

- Processamento de pedidos;

- Peças de reposição e serviços de suporte;

- Escolha de locais para fábrica e armazenagem;

- Embalagem;

- Manuseio de produtos devolvidos;

- Reciclagem de sucata;

- Tráfego e transporte;

- Armazenagem e estocagem.

Esses componentes servem como pontes de ligações entre os locais de produção e os mercados consumidores e são de grande importância para o sucesso das empresas, pois o controle das mesmas é quem vai dizer se a empresa será competitiva ou não no setor em que ela atua. E vale ressaltar que, é necessário definir um planejamento estratégico em todas essas atividades, haja vista que ela garantirá a permanência da empresa no setor por muito tempo (SANTOS, 2012).

Logística, de acordo com Campos (2009), é definido como, operação integrada que cuida dos suprimentos e distribuição dos produtos de forma racionalizada, que planeja, coordena e executa todo o processo, a fim de reduzir os custos e aumentar a competitividade de uma empresa.

Ribeiro e Gomes (2004) também descrevem que a logística, é o gerenciamento estratégico da aquisição, movimentação e armazenamento de materiais, peças e produtos acabados. Sua distribuição ocorre pelos sistemas e canais de modo a maximizar os lucros por meio do atendimento de pedidos a custos razoáveis.

Nas afirmações de Fleury, Wanke e Figueiredo (2007), a logística destaca-se em três funções fundamentais: estoque, armazenamento e transporte. Estas características têm sua origem no fim da economia extrativista e início nas atividades produtivas organizadas, que deixa em evidência o quanto à logística é antiga. Para os autores, a logística é um instrumento de marketing e uma ferramenta gerencial que tem a capacidade de agregar valor por meio dos serviços prestados.

Para Ricarte (2009), a logística possui outras atividades que são subdivididas em primárias e de apoio. Nas atividades primárias encontramos: o transporte (trata-se da movimentação dos materiais interna e externamente), a manutenção de estoques (disponibilidade maior de mercadorias) e o processamento de pedidos (atividade que permite que os produtos sejam levados aos consumidores o mais rápido possível). 
Como pode ser visto a Logística está estrategicamente posicionada entre as áreas importantíssimas de uma empresa sendo elas: o fluxo de todas as atividades de estocagem, manuseio, transporte de produtos e informações desde o ponto de consumo até o ponto de origem, com a finalidade de atender os consumidores que se encontram cada vez mas exigentes.

Portanto, as informações mencionadas anteriormente têm por objetivo conceituar a logística e as atividades que a mesma realiza, e em sequência, será apresentado o conceito sobre a Logística Reversa.

\subsection{LOGÍSTICA REVERSA}

O crescimento muito acelerado da população mundial gerou a necessidade de maior velocidade da produção. $\mathrm{O}$ avanço tecnológico veio para sanar esta necessidade, e no entanto,

com toda essa aceleração, surgiram os resíduos que poluem o meio ambiente, por causa de sua

disposição final inadequada, o que acarreta no desequilíbrio ambiental do planeta (SUBRAMANIAN et al., 2014).

Por conta deste desequilíbrio, nasce à preocupação ecológica dos consumidores, aparecem novas leis ambientais, e mudamos novos padrões de competitividade nas empresas surgindo então às preocupações com a imagem corporativa das mesmas incentivando assim, a criação dos canais reversos que vieram para solucionar o problema da quantidade de produtos descartados no meio ambiente (MOORI, 2010).

Kaynak et al. (2011), afirmam que a logística reversa está relacionada á atividades envolvidas com o gerenciamento de redução, movimentação e disposição dos produtos e é um importante instrumento contra a degradação ambiental.

Segundo Guarnieri (2005), uma das vantagens para a empresa que adota o processo de logística reversa é a diferenciação do serviço, uma vez que atualmente, os varejistas acreditam que os clientes valorizam as empresas que possuem políticas de retorno de produtos. Isto envolve, é claro, uma estrutura para recebimento, classificação e expedição de produtos retornados. Esta tendência se reforça pela existência de legislação de defesa dos consumidores, garantindo-lhes o direito de devolução ou troca.

Já Garcia (2006), defende a teoria de que a logística reversa complementa à logística tradicional, pois enquanto a última tem o papel de levar produtos de sua origem até os clientes, a logística reversa completa o ciclo, trazendo de volta os produtos já utilizados dos diferentes pontos de consumo a sua origem. No processo da logística reversa, os produtos passam por uma etapa de reciclagem e voltam novamente à cadeia.

Conforme Pires (2007), a Logística Reversa está ligada a questões legais e ambientais, mas ao mesmo tempo também a questões econômicas, o que a coloca em ênfase e a faz como importante estudo no contexto atual das organizações.

\subsection{LOGÍSTICA REVERSA E SUA ÁREA DE PÓS-VENDA E PÓS-CONSUMO}

Mukhopadhyay e Setaputra (2006), defendem que a Logística Reversa é uma área que planeja, opera e controla fluxos e informações do retorno de bens de pós-venda e pós-consumo ao ciclo dos negócios. Esse processo se desenvolve pelos canais de distribuição reversos e agregam valor de diversas naturezas sendo elas de caráter: econômico, ecológico, legal, logístico, de imagem corporativa entre outros. Os canais de distribuição reversos de pós-venda são formados por diferentes possibilidades de retorno de produtos, com pouco ou nenhum uso, devolvidos pelo consumidor ao varejista ou ao fabricante e do varejista ao fabricante, por motivos diversos como: problemas de qualidade, danos, erros de expedição, validade, estoque excedido, consignação ou defeito.

Quanto aos canais de distribuição reversos de pós-consumo, estes são entendidos como o ciclo de vida útil dos produtos e seu descarte pela sociedade. Após este descarte, os produtos obsoletos são coletados e reintegrados ao processo produtivo como matéria-prima secundária que será reutilizada para fabricação de novos produtos (LEITE, 2009).

Motta (2009) descreve que existem três categorias de bens de pós-consumo, sendo elas: os bens descartáveis, semiduráveis e os duráveis. Os bens descartáveis são aqueles cuja duração é de algumas semanas e são constituídos tipicamente de produtos de embalagem. Os bens duráveis apresentam duração 
de anos a décadas. Já os bens semiduráveis apresentam duração de alguns meses e são considerados como uma categoria intermediária aos bens descartáveis e duráveis.

Diante do exposto, observa-se que o fluxo reverso de pós-consumo é representado por materiais descartados de produtos, depois de esgotada sua vida útil e retornam ao ciclo produtivo depois de coletados. Mas para que ocorra esta reintegração no mercado é necessário que estes bens sejam desmanchados ou reciclados.

Em busca de entender melhor estes processos, Carter et al. (2007) definem desmanche como um sistema de revalorização de um produto que após ser coletado sofre o processo de desmontagem nos quais seus componentes serão separados por partes e seguiram para reciclagem industrial.

Conforme Motta (2009), Reciclagem significa canais reversos de revalorização nos quais os materiais dos produtos descartados são extraídos industrialmente e transformados em matéria-prima secundárias ou recicladas que serão reincorporadas na fabricação de novos produtos.

Conforme apresentado, observa-se também que a logística reversa está relacionada com o meio ambiente devido às constantes movimentações de resíduos, provenientes de fabricação e devolução de produtos, que podem causar impactos negativos ao meio ambiente. Por este motivo foram criados sistemas de gestão ambiental para fornecer ferramentas e procedimentos que poderão facilitar a prática da logística reversa.

\subsubsection{GESTÃO AMBIENTAL E RECICLAGEM}

Para Barbieri (2006), a Gestão Ambiental, é definida como atividades administrativas operacionais, que planejam, direcionam, controlam e alocam recursos com o intuito de obter efeitos positivos sobre o meio ambiente, reduzindo ou eliminando os danos ou problemas causados pelas ações humanas, evitando assim a poluição e degradação do meio ambiente.

Os programas de gestão ambiental entraram para os grupos de projetos prioritários das empresas, haja vista que, há multas estabelecidas para as organizações que danifiquem e prejudiquem o meio ambiente, previstas por leis federais (VIEIRA, 2009).

No entendimento de Dias (2008), As leis ambientais, juntamente com as instituições ambientais e as atividades de controle de contaminação realizadas por estas, limitam a liberdade da empresa para contaminar. 0 Estado utiliza esses instrumentos legais com o intuito de proteger a saúde da sociedade e o bem comum.

Seguindo o assunto Dias (2008), também descreve:

A gestão ambiental tem ganhado cada vez mais destaque, em termos de competitividade, devido aos benefícios que traz ao processo produtivo como um todo e a alguns fatores em particular que são potencializados [...] melhorando assim a imagem da organização (DIAS, 2008).

Nas afirmações de Schenini (2005), a melhor maneira para identificar os produtos que respeitam o meio ambiente, é verificar se os mesmos possuem um "selo verde", que é representado por um logotipo identificador dessa característica e é vinculado a um sistema de certificação aceito como é o caso da ISO 14000 (ABNT, 2009).

A obtenção da certificação ISO 14000 por uma empresa pode ajudá-la a transmitir confiança nos produtos e serviços vendidos e prestados, pois esta identificação mostra que a mesma é comprometida em atender às disposições de sua política, que é dar maior ênfase à prevenção do que às ações corretivas, além de demonstrar que está atenta aos requisitos legais e a incorporação do processo de melhoria contínua (MOTTA, 2009).

As leis ambientais caminham no sentido de tornar as empresas cada vez mais responsáveis por todo o ciclo de vida de seus produtos, o que significa que o fabricante é responsável pela destinação correta de seus produtos após a entrega aos clientes e pelo impacto ambiental provocado pelos seus resíduos gerados em todo o processo produtivo, e, também após seu consumo (CAMARGO; SOUZA, 2005).

A reciclagem, neste caso, também vem se tornando cada vez mais umas das ferramentas principais da gestão ambiental, pois é nela que observamos o processo de transformação de um material sem vida útil, que após ser recolhido, separado e selecionado, vira uma nova matéria-prima ou um produto novo. A reciclagem gera economia de matérias-primas, água e energia, é menos poluente e alivia os aterros 
sanitários, cuja vida útil é aumentada, poupando espaços preciosos da cidade que poderiam ser usados para outros fins como parques, hospitais, casas e etc (Movimento Nacional de Catadores de Material Reciclável, 2010).

Diante de todas essas indagações expostas nos capítulos anteriores podemos refletir que o objetivo principal da logística reversa é reduzir a poluição do meio ambiente e o desperdício de seus insumos por meio da reutilização e da reciclagem.

\section{METODOLOGIA}

A metodologia de uma pesquisa acerca de um determinado assunto é muito importante e se faz extremamente necessária para determinação dos métodos de coleta de dados que deverão ser utilizados para a sua construção (GIL, 2008).

Como metodologia adotada neste estudo, utilizou-se de duas abordagens, a primeira correspondeu a análise de conteúdo e a segunda análise qualitativa, pois não poderiam ser traduzidos e nem interpretados através de números (GIL, 2008). Sua natureza é descritiva, por se tratar de um estudo que descreverá o processo da logística reversa e da reciclagem de baterias da empresa Baterias Moura localizada no Estado de Pernambuco, com filial no Estado de Goiás.

Como método de estudo, adotou-se também o estudo de caso, por se tratar de um estudo que levantará como questão o senso comum, no qual investigará a prática da logística reversa em uma empresa do ramo de baterias, de modo que este apresente a pesquisa de forma ampla, detalhada e preserve suas características (YIN, 2005).

O instrumento utilizado para a coleta de dados ocorreu por meio de entrevistas e também por um questionário semiestruturado, com perguntas contidas em um roteiro, com a finalidade de se obter mais informações da empresa, sobre a prática da logística reversa e a sua relação com a reciclagem. Estas informações serão transcritas nas análises dos resultados. 0 questionário foi composto por 18 questões que se dividem em duas fases. A primeira caracteriza os respondentes (questões de 1 a 5), com as seguintes abordagens: 1) Cargo na empresa; 2)Tempo de exercício no cargo; 3) Grau de instrução; 4) Gênero e 5) Idade. A segunda fase (questões de 6 a 18) corresponde às perguntas relacionadas à: Coleta, transporte, prática da logística reversa e processo de reciclagem das baterias na empresa.

Após a elaboração do questionário, utilizou-se de um arquivo de texto para obtenção dos dados necessários para a análise da logística reversa e a reciclagem da empresa. 0 questionário depois de validado foi aplicado com cinco participantes por meio de entrevista a fim de enfatizar todo o preenchimento e esclarecer dúvidas que fossem encontradas acerca do assunto.

Portanto, o questionário foi aplicado, respondido e depois organizado. Para tabulação desses dados, utilizou-se do aplicativo software Excel. Com as respostas organizadas foi possível verificar que as mesmas interagem com o referencial teórico deste presente estudo bem como se relacionam e dão suporte ao tema explorado.

Os respondentes deste estudo são de 2 empresas localizadas no município de Goiânia, Estado de Goiás, de um universo de mais de 70 que compõem a rede do Grupo Moura. Os mesmos foram escolhidos por se tratarem de funcionários com mais de 5 anos de casa e por exercerem funções estratégicas diretamente e indiretamente ligadas ao processo de logística reversa e reciclagem das baterias, no entanto, ambos detêm de muitas informações sobre os propósitos desta pesquisa.

No Quadro 3 é possível visualizar essas questões, as quais foram aplicadas na empresa de forma semiestruturada. 
Quadro 3: Perguntas contidas no questionário de pesquisa.

\begin{tabular}{|c|c|}
\hline \multicolumn{2}{|r|}{ CARACTERIZAÇÃO DOS RESPONDENTES } \\
\hline P1 & Cargo na empresa \\
\hline P2 & Tempo de exercício no cargo \\
\hline P3 & Grau de instrução \\
\hline $\mathrm{P} 4$ & Gênero \\
\hline P5 & Idade \\
\hline \multicolumn{2}{|r|}{ LOGÍSTICA REVERSA E RECICLAGEM DA EMRESA } \\
\hline P6 & Em sua opinião o que é a logística reversa de pós-consumo? \\
\hline P7 & Em sua opinião o que é a reciclagem? \\
\hline P8 & Por que a empresa resolveu adotar a logística reversa de pós-consumo? \\
\hline P9 & $\begin{array}{l}\text { Existe um departamento específico na empresa responsável por coletar, transportar e } \\
\text { reciclar as sucatas de baterias? }\end{array}$ \\
\hline P10 & $\begin{array}{l}\text { Como é feita a conscientização por parte da empresa aos revendedores de baterias, para que } \\
\text { os mesmos façam à devolução das baterias usadas? }\end{array}$ \\
\hline P11 & A empresa recicla somente produtos oriundos de sua produção? \\
\hline P12 & Como é feita a coleta das baterias usadas nos revendedores? \\
\hline P13 & $\begin{array}{l}\text { Como é realizado o transporte das baterias usadas dos revendedores até a sua destinação } \\
\text { final? }\end{array}$ \\
\hline P14 & Descreva o processo de reciclagem das baterias usadas? \\
\hline P15 & Quais as vantagens da empresa ao praticar a logística reversa de pós-consumo? \\
\hline P16 & Quais as desvantagens da empresa ao praticar a logística reversa de pós-consumo? \\
\hline P17 & $\begin{array}{l}\text { Qual é o percentual de reaproveitamento das sucatas de baterias na produção de baterias } \\
\text { novas? }\end{array}$ \\
\hline P18 & $\begin{array}{l}\text { Como é realizada a conscientização por meio da empresa aos seus colaboradores, para que os } \\
\text { mesmos colaborem com a gestão ambiental da empresa? }\end{array}$ \\
\hline
\end{tabular}

Fonte: Dados da pesquisa 2014

Legenda: Pergunta - P

A pesquisa ocorreu entre os meses de março e abril de 2014. 0 presente artigo analisou a importância da logística reversa de pós-consumo além de explanar acerca de suas vantagens e desvantagens e ainda verificou a questão da conscientização por parte dos revendedores de baterias e dos colaboradores da empresa em questão, no intuito de analisar se a responsabilidade socioambiental está inserida nas estratégias e nas ações da empresa.

\section{ANÁLISE E DISCUSSÃO DOS RESULTADOS}

\subsection{DADOS COLETADOS POR MEIO DO INSTRUMENTO DE PESQUISA}

De acordo com o levantamento realizado nesta pesquisa, foi possível observar que todos os entrevistados são do sexo masculino e estão ligados direta ou indiretamente com a logística reversa de pós-consumo e com a reciclagem das sucatas de baterias. Este fato foi identificado por meio dos cargos que os mesmos exercem.

Os entrevistados aqui apresentados serão denominados por uma numeração para preservação de sua identidade, e por isso, não serão divulgados seus nomes. 0 entrevistado de número 1 (E1) exerce o cargo de sócio administrador de uma das redes de baterias Moura (RBM); o entrevistado de número 2 (E2) é 
supervisor de logística também de uma das redes de baterias Moura (RBM); o entrevistado de número 3 (E3) é diretor de metais e sustentabilidade da Moura; o entrevistado de número 4 (E4) é chefe de produção da Moura, e por último o entrevistado de número 5 (E5) é analista ambiental da Moura. Portanto, norteando-se pelo objetivo deste artigo, esta seção utilizar-se-á de transcrições dos depoimentos dos entrevistados, como forma de melhor apresentar os dados coletados, correlacionando com as informações obtidas, também por meio do instrumento de pesquisa.

Com relação às perguntas feitas por meio do questionário aplicado, foi possível verificar a importância da prática da logística reversa e do processo de reciclagem utilizado pela empresa.

Nas questões P6 e P7 a pesquisa revelou como os entrevistados definem com suas próprias palavras o que é logística reversa de pós-consumo e reciclagem: "Logística reversa de pós-consumo é o tratamento ambiental adequado dos resíduos sólidos ou líquidos de produtos comercializados no mercado. E a reciclagem é a recuperação industrial ou artesanal dos produtos descartados na natureza" (E1). "Em suma a logística reversa de pós-consumo visa captar, armazenar e transportar produtos que após seu esgotamento ou inutilização são reenviados a sua origem para serem reciclados. Já a reciclagem é o reaproveitamento dos materiais que serão utilizados como matéria-prima de novos produtos" (E2). "A logística reversa de pós-consumo é o processo de captação de produtos após a sua vida útil e a reciclagem é a transformação destes produtos em novas matérias-primas, com a finalidade de utilizá-los para a produção de novos produtos" (E3).

"A logística reversa de pós-consumo é o processo pelo qual os produtos após sua vida útil retornam a sua origem para fins de reciclagem". A reciclagem por sua vez tem como finalidade cíclica a recuperação de materiais e componentes que em forma de matéria-prima secundária ajudarão na produção de novos produtos, além de evitar a contaminação do meio ambiente" (E4).

"Logística reversa de pós-consumo nada mais é que o retorno dos produtos inutilizados ou com vida útil esgotada ao seu produtor de origem. E a reciclagem é o processo pelo qual este produto é reaproveitado e transformado em nova matéria-prima chamada de secundária por não se tratar de uma matéria-prima virgem" (E5). Analisando esses dados pode-se perceber que todos os entrevistados sabem definir o que é a logística reversa de pós-consumo e o papel da reciclagem.

Quando questionados o motivo pelo qual a empresa resolveu adotar a prática da logística reversa de pósconsumo, questão P8, os mesmos responderam: "O Brasil tem carência de matéria-prima natural do seu principal insumo o "chumbo", o que naturalmente gera a necessidade de realização da reciclagem" (E1). "O Mundo é movido por automóveis, e todos eles precisam da energia das baterias, que após sua vida útil são rejeitadas. Para que isso não aconteça de forma inadequada no meio ambiente a empresa optou por captar suas sucatas e reciclá-las" (E2). "A empresa visa o aproveitamento sustentável das sucatas de baterias, reutilizando seus resíduos sólidos e líquidos para a constituição de novas baterias" (E3). "Devido à carência de matéria-prima o "chumbo", a empresa percebeu que ao recolher seu produto em forma de sucata e reciclá-lo economizaria cerca de $60 \%$ na compra de chumbo virgem" (E4). "Evitar que anualmente toneladas de chumbo e ácido sulfúrico sejam lançadas na natureza de forma inadequada, causando com isso a poluição do solo, do ar e dos lençóis freáticos" (E5).

Analisando esses resultados observa-se que os entrevistados não partilham da mesma opinião em relação o motivo pelo qual a empresa resolveu adotar a logística reversa em seu processo de produção, as respostas indicam que alguns têm como idéia, a economia com matérias-primas e outros a preservação do meio ambiente.

Na P9, os respondentes informam se há ou não um departamento específico na empresa responsável por coletar, transportar e reciclar a sucata de baterias. Todos os entrevistados responderam que "Sim há, e o nome do departamento é Diretoria de Sustentabilidade, localizada em PE, o qual controla todas as operações e processos referentes à logística reversa de pós-consumo e reciclagem das baterias usadas". Analisando esse dado pode-se observar que todos os entrevistados estão cientes que a empresa possui um departamento específico que trata todo o processo de logística reversa e reciclagem de baterias.

Em relação à P10, que infere a conscientização dos revendedores de baterias a devolverem as baterias usadas a Moura, todos comentaram a seguinte afirmação.

"Na nossa política comercial nós estimulamos a devolução de baterias usadas, com descontos no preço de baterias novas, além de instruir aos nossos revendedores por meio de cartazes a obrigatoriedade da regulamentação do CONAMA n ${ }^{\circ} 401$, de 4 de novembro de 2008, "que estabelece os limites máximos de chumbo, cádmio e mercúrio e os critérios e padrões para o gerenciamento ambientalmente adequado das pilhas e baterias portáteis, das baterias chumbo-ácido, automotivas e industriais e das pilhas e baterias 
dos sistemas eletroquímicos níquel-cádmio e óxido de mercúrio, comercializadas no território nacional". Analisando esse dado pode-se analisar que a empresa se preocupa em conscientizar seus revendedores nas boas práticas de gestão da reciclagem, seja ele por meio de descontos ou por obrigações legais.

Quando questionado sobre a P11, se a empresa recicla apenas seus produtos, os entrevistados foram unânimes e afirmaram que:

"Independente de sua marca, as baterias são rejeitas após sua vida útil, então a empresa a fim de evitar danos ambientais adota a política de reciclagem também de produtos não oriundos de sua produção".

Ao analisar esse dado pode-se avaliar que todos os respondentes têm a consciência de que a empresa recicla não só seus produtos, mas também as das marcas concorrentes.

$\mathrm{Na}$ P12 e P13, os respondentes nos explicam como é realizada a coleta e o transporte das baterias usadas até sua disposição final:

\begin{abstract}
"Através de veículos equipados com equipamentos de proteção ambiental do veículo e individual do motorista e eventualmente do ajudante quando houver a necessidade, a operação é realizada no ato da entrega dos produtos novos, obedecendo às semelhanças de características". (E1)

“O processo de logística reversa é longo; Começa pelas RBM’S espalhadas pelo país, que tem como função coletar as baterias velhas em seus revendedores e enviarem a Moura em Belo Jardim". (E2)
\end{abstract}

Ao analisar esses dados pode-se perceber que os entrevistados responderam a essas questões embasadas em seus cargos, pois em algumas respostas a obrigação de captar as sucatas é dos mesmos e em outras essa obrigação é de terceiros.

Na P14, também é possível observar opiniões convergentes, de como os entrevistados descrevem o processo de reciclagem das baterias usadas.

\begin{abstract}
"As baterias usadas têm como constituintes básicos a caixa, as grades de chumbo e o óxido de chumbo, que depois de separados seguem para um moinho onde serão quebrados por impacto". "O plástico é encaminhado para a repla onde será usado para a fabricação de novas caixas de baterias". "O metal segue para forno e refino". "O óxido de chumbo vai para fusão controlada, onde se originará novas ligas de chumbo que por sua vez serão reutilizados na fabricação de baterias novas". (E3)
\end{abstract}

A partir desses dados verifica-se que todos os entrevistados têm opiniões semelhantes e que conhecem o processo de reciclagem das baterias usadas e sabe de maneira simples conceituar este processo.

Nas P15 e P16, os respondentes comentam sobre as vantagens e desvantagens de se praticar a logística reversa de pós-consumo e a reciclagem na empresa.

"Em se tratando de vantagens a empresa cumpre com as normas do CONAMA e em relação às desvantagens a empresa tem um custo muito alto com todo o processo". (E1)

"A empresa tem como vantagem a redução de seus custos com matériaprima, e como desvantagem tem altos custos com o processo". (E4)

Pode-se observar com esses resultados que em relação às vantagens os respondentes abordam temáticas divergentes hora a empresa tem como vantagem a economia, e outro o cumprimento das leis ambientais. Já em relação as desvantagens as respostas são convergentes pois ambos percebem como desvantagem os altos custos com a manutenção dos processos de logística reversa e reciclagem.

Quando questionado sobre qual é o percentual de reaproveitamento das sucatas de baterias na produção de baterias novas, os respondentes comentam.

"A empresa tem cerca de $90 \%$ de economia de matéria-prima. As RBM'S são abastecidas com $100 \%$ das baterias novas recicláveis. Já para o mercado internacional por razões de climas frios é recomendável a exportação de baterias com matéria-prima virgem". (E1) 
"Por não conseguir reaproveitar cerca de $10 \%$ das sucatas, a empresa chega a ter uma economia de $90 \%$ com a compra de novas matériasprimas". (E3)

De acordo com esses dados o reaproveitamento das matérias-primas é bem alto, o que leva a reciclagem ser fator importantíssimo na economia de novos materiais virgens.

E por último na questão P18 os respondentes informam como é realizada a conscientização por meio da empresa aos seus colaboradores, para que os mesmos colaborem com a gestão ambiental da empresa. Foi possível verificar pelas informações dos respondentes, que a empresa oferece para os seus colaboradores, MESMO para aqueles que ocupam funções administrativas e operacionais, treinamentos nos normas do CONAMA, e ainda disponibiliza em sua extranet vídeos, treinamentos e manuais das práticas da logística reversa e da reciclagem da empresa.

Os resultados apresentados indicam que o Grupo Moura assume seu papel enquanto empresa sustentável além de desempenhar sua função de responsabilidade socioambiental.

\section{CONSIDERAÇÕES FINAIS}

Em relação ao objetivo deste artigo, para o desenvolvimento desta pesquisa, pode ser verificado que o mesmo foi alcançado quando se descreve as relações existentes entre a logística reversa e o papel da reciclagem, praticados pela empresa.

Conforme pode ser observado, foi possível verificar que a empresa se preocupa em conscientizar seus revendedores nas boas práticas de gestão da reciclagem, seja ele por meio de descontos ou por obrigações legais.

A pesquisa também revelou que a empresa recicla não só seus produtos mais também os das marcas concorrentes, caracterizando-se em uma empresa sustentável, independentemente da marca dos produtos que deverão ser reutilizados.

Quanto aos gerenciamentos eficientes da logística reversa e da reciclagem por parte da empresa, tornamse importantes ferramentas que podem oferecer vantagens competitivas no mercado, onde o retorno destes produtos de pós-consumo, caracterizados por serem descartados porque chegaram ao final de sua vida útil, podem ser reaproveitados e assim retomados ao ciclo produtivo.

Além disso, constatou-se também que por meio desta ação a empresa consegue reduzir custos materiais e operacionais, com cerca de $90 \%$ de economia de matéria-prima. Uma vez que a não utilização desses recursos e sim a reutilização de materiais descartados, também podem proporcionar economia com matérias-primas e a preservação do meio ambiente.

A pesquisa identificou ainda, que as RBM são abastecidas com 100\% das baterias novas recicláveis. Já para o mercado internacional por razões de climas frios é recomendável a exportação de baterias com matériaprima virgem.

Cabe ressaltar ainda, que esta empresa trabalha na legalidade de seus processos e se encontra sempre preocupada com o meio ambiente, o que pode ser percebido por meio dos procedimentos utilizados para o transporte, armazenamento e reciclagem, onde é levada em consideração a eficiência no transporte da sucata para que não ocorram acidentes e consequentemente agressões ao meio ambiente.

A realização de uma armazenagem segura preparada para a estocagem das baterias descartadas, além da reciclagem que mantém sistemas organizados para que o processo não ocasione danos ao ambiente, proporciona a organização ganhos econômicos com a transformação da sucata em produto para a comercialização. 


\section{REFERENNCIAS}

[1] ABTN, 2009. Selo de certificação ambiental. Disponível em: <http://www.abnt.org.br/m5.asp?Cod_noticia=296\&cod_pagina=965>. Acesso em: 26 Fevereiro 2014.

[2] BALLOU, R. H. Gerenciamento da Cadeia de Suprimentos/Logística - 5 a. Edição. Porto Alegre: Bookman Editora, 2006. $616 \mathrm{p}$.

[3] BARBIERI, José Carlos. Gestão Ambiental empresarial: conceitos, Modelos e instrumentos. 2. Ed. São Paulo: Saraiva 2007.

[4] BATERIAS MOURA. < https://www.moura.com.br/ > Acesso em: 06 Abril. 2014.

[5] Brasil Projeto de lei no 1991; 2007 art 7o inciso XII, p.3. Disponível em: <http://www.camara.gov.br/sileg/integras/501911.pdf.> Acesso em: 22 Fevereiro 2014.

[6] CAMARGO, I.; SOUZA, A. E. Gestão dos resíduos sob a ótica da logística reversa. In: ENCONTRO NACIONAL DE GESTÃO EMPRESARIAL E MEIO AMBIENTE, 8., 2005, Rio de Janeiro, Anais... Rio de Janeiro: ENGEMA, 2005.

[7] CAMPOS, Tatiane. Logística Reversa: Aplicação ao problema das embalagens do CEAGESP. Disponível em: <file:AgnesPaula/Downloads/TatianaDeCampos.pdf.> Acesso em: 15 Novembro 2013.

[8] CARTER, C. R.; ELLRAM, L. M. Reverse Logistics: a review of the literature and FLEURY, P.F.; WANKE, P.; FIGUEIREDO, K.F.; Logística Empresarial: a perspectiva brasileira. 1 ed., 9.reimpr. São Paulo: Atlas, 2007.

[9] DYCKHOFF, Harald, LACKES, Richard, REESE, Joachim(editors). Supply Chain Management and Reverse Logistics. Berlin, Springer, 2004.

[10] FLEISCHMANN, Moritz. Quantitative Models for Reverse Logistics. Berlin, Springer, 2001.

[11] FULLER, Donald. ALLEN, Jeff. Reverse channel systems. In POLONKY, Michael J. et al.

[12] Environmental marketing: strategies practice, theory and research. N.York, Hawtorth Press, 1995.

GARCIA, Manuel Garcia. Logística Reversa: uma alternativa para reduzir custos e criar valor. XII SIMPEP, Bauru - SP, 2006.

[13] GIL, Antônio Carlos. Como elaborar projetos de pesquisa. 4. Ed. São Paulo: Atlas, 2008.

[14] GUANIERI, Patrícia et al. A logística reversa de pós-venda e pós-consumo agregando valor econômico, legal e ecológico às empresas - Congresso de Administração e Congresso Sul Brasileiro de Comércio Exterior, Paraná, 2005. <http://engema.org.br/upload/pdf/edicoesanteriores/XI/ENGEMA2009_312.pdf> Acesso: 26 fevereiro 2014.

[15] KAYNAK, R.; RIOPEL, D.; ABDUL-KADER, W. A reverse logistic decisions conceptual framework. Computers \& Industrial Engineering, v.61, p. 561-581, 2011.

[16] Leite, P. R. (2003) Logística Reversa: meio ambiente e competitividade. São Paulo: Pearson Prentice Hall. (2009) Logística Reversa: meio ambiente e competitividade. 2. Ed. São Paulo: Pearson Prentice Hall.

[18] LOGÍSTICA REVERSA - UM ESTUDO OPERACIONAL DAS BATERIAS AUTOMOTIVAS EM CAMPO GRANDE, MS, V.1. N.3, 2012. Disponível em: <http://www.bateriasmoura.com.br/index/article/viewFile/81/9>. Acesso em: 26 Fevereiro 2014.

[19] MARTINS, P. G. \& Alt, P. R. C. (2004) Administração de Materiais e Recursos Patrimoniais. São Paulo: Saraiva. 2. Ed. São Paulo: Saraiva 2007.

MOTTA, Gisele. Logística reversa em baterias automotivas: um estudo na Pioneiro Ecomentais LTDA. Florianópolis SC 2009.Disponível em: <http://tcc.bu.ufsc.br/Adm283936.pdf?>. Acesso: 22 fevereiro 2014.

[20] Movimento Nacional de Catadores de Material Reciclável. Coleta Seletiva, 2010. Disponível em: <http://www.mncr.org.br/>. Acesso em: 26 Fevereiro 2014.

[21] MUKHOPADHYAY, S. K.; SETAPUTRA, R. The role of 4PL as the reverse logistics integrator; optimal pricing and return policies. International Journal of Physical 17 Distribuition \& Logistics Management. Bradford, v. 36, n. 9, p. 716-729, 2006.

PIRES, Nara. Modelo para a logística reversa dos bens de pós-consumo em um ambiente de cadeia de suprimentos. Florianópolis 2007. Disponível em: <https://repositorio.ufsc.br/bitstream/handle/123456789/89963/246350.pdf/sequence=1>. Acesso $\quad$ em: 22 Fevereiro 2014.

[22] RESOLUÇÃO CONAMA no 257. De 30 de junho de 1999. D.O.U. №139. 1999.

[23] 는 401. De 4 de novembro de 2008. D.O.U. N²15. 2008.

[24] RICARTE, Marcos. Introdução a Logística Empresarial. Disponível em: <http://br.geocities.com/marcosricarte/Logistica.html>. Acesso em: 26 Fevereiro 2014. 
[25] SANTOS, Antônio. Contribuição da logística reversa para empresa de reciclagem de plástico: Um estudo de caso na empresa LEOSPLAST localizada em Picos-PI 2012. Disponível em: <http://www.ufpi.br/subsiteFiles/admpicos/arquivos/files/projeto/20/Izaac/20corre/C3A7C/3A3/20/final/20gust avo2/02.pdf>. Acesso em: 13 Março 2014.

[26] SCHENINI, Pedro Carlos. Logística reversa: estudo de caso. In: Gestão Ambiental Sócio Empresarial. Florianópolis: Ed. Papa Livros, 2005.

[27] SUBRAMANIAN, N; ABDULRAHMAN, M; GUNASEKARAN, A. Critical barriers in implementing reverse logistic in the Chinese manufacturing sectors. International Jornal of production Economics, v. 147, p. 460-471, 2014.

[28] VIEIRA, Karina; SOARES, Thereza; SOARES, Laila. A Logística Reversa do Lixo Tecnológico: um estudo sobre o projeto de coleta de lâmpadas, pilhas e baterias da BRASKEM. Salvador, v. 3, n.3, 2009. Disponível em:< http://www.revistargsa.org/rgsa/article/viewFile/180/>. Acesso em: 26 Fevereiro 2014.

[29] YIN, R.K. Estudo de caso: Planejamento e métodos. 3. Ed. Porto Alegre: Bookman, 2005. 


\section{Capítulo 6}

ANÁLISE DA REMOÇÃO DA DEMANDA BIOQUÍMICA DE OXIGÊNIO E DEMANDA QUÍMICA DE OXIGÊNIO NA ESTAÇÃO DE TRATAMENTO DE ESGOTO GERTRUDES LOCALIZADA NA CIDADE DE PONTA GROSSA - PR

\section{Tatiana Gulminie Josué \\ Lariana Negrão Beraldo de Almeida \\ Mariana dos Santos do Nascimento \\ André Spanhol}

Resumo: Devido ao intenso crescimento populacional viu-se a necessidade do tratamento dos efluentes gerado pela população. Para isso foram criadas as estações de tratamento de esgoto (ETE). Na cidade de Ponta Grossa, uma das ETE's chama-se Gertrudes e atende aproximadamente 7\% da população da cidade de Ponta Grossa, com uma vazão nominal de 30L/s. Essa unidade utiliza tratamento primário anaeróbio, e esse se dá através de um Reator Anaeróbio de Fluxo Ascendente (RALF) e tratamento secundário que se dá via filtro biológico aeróbio ou filtro percolador. 0 objetivo do estudo realizado foi analisar a eficiência de remoção da Demanda Química de Oxigênio (DQO) e Demanda Bioquímica de Oxigênio (DBO) do esgoto tratado. Os resultados encontrados foram comparados com as legislações vigentes, sendo essas o Conselho Nacional de Meio Ambiente (CONAMA 430) e a Secretaria de Meio Ambiente (SEMA021) e, também, com outros realizados em estações de tratamento de esgoto que possuem o mesmo sistema da ETE Gertrudes. As coletas foram realizadas na entrada de esgoto bruto e na saída de esgoto tratado e foram realizadas analises físico-químicas das amostras para saber a eficiência de remoção e se a ETE cumpre com os padrões exigidos pela legislação.

Palavras Chave: DBO, DQO, RALF, Filtro Percolador. 


\section{INTRODUÇÃO}

Todas as cidades produzem águas residuais que podem ser denominadas como esgoto urbano. Essas águas têm características similares com alto poder de poluição. Devido a esse alto poder de poluição vem à necessidade do tratamento para que possam retornar aos corpos hídricos sem produzir danos à natureza.

Para que esses esgotos sejam tratados foram construídas as estações de tratamento de esgoto que tem como principal objetivo tratar o esgoto gerado pela população de modo a propiciar melhor qualidade de vida e proteção do meio ambiente. Para que o efluente retorne aos corpos hídricos com a qualidade exigida, as estações de tratamento de esgoto (ETE) devem fornecer um tratamento que cumpra as normas estabelecidas por conselhos nacionais, estaduais e municipais.

No Paraná, o órgão responsável pelo tratamento de águas e efluentes é a Companhia de Saneamento do Paraná (SANEPAR). É considerada uma das melhores empresas no tratamento de esgoto do Brasil e a que possui uma das melhores tecnologias para esse fim.

Um tratamento de esgoto pode se dar de duas maneiras: tratamento aeróbio e tratamento anaeróbio. Ambos utilizam bactérias para degradação da matéria orgânica presente no efluente. As ETE's da Sanepar são compostas por reatores do tipo UASB (Upflow Anaerobic Sludge Blanket) ou RALF (Reatores Anaeróbios de Fluxo Ascendente) operando anaerobiamente. É importante salientar que, para que o efluente possa entrar no RALF e receber o tratamento anaeróbio, é necessário que ele receba um tratamento preliminar ou gradeamento que visa a retirada de sólidos grosseiros desse efluente. Esse processo pode ocorrer por peneiramento, por exemplo.

Outro ponto importante de citar é que, mesmo o tratamento primário ou tratamento via RAFL se tratar de um tratamento eficaz, ele ainda não consegue retirar toda a matéria orgânica presente no esgoto necessitando de um tratamento secundário. Na SANEPAR, esse tratamento secundário geralmente se dá através de filtros biológicos aeróbios.

Na cidade de Ponta Grossa destacam-se os seguintes tratamentos: Reator RALF associado a filtro anaeróbio, RALF associado a filtro biológico percolador, RALF associado a lagoa de estabilização (SANEPAR, 2015).

0 tratamento de efluentes pode ser dado através de tratamento anaeróbio e tratamento aeróbio. Ambos os tratamentos utilizam bactérias para degradar a matéria orgânica presente no meio. A diferença entre eles é a utilização do oxigênio para sobrevivência das bactérias, onde as bactérias aeróbias não sobrevivem em meios sem oxigênio. Os tratamentos de esgoto aeróbio podem acontecer de diversas maneiras: lodos ativados, filtros biológicos aeróbios, lagoas de estabilização, lagoas facultativas, lagoas aeradas facultativas, lagoas aeradas com mistura completa, lagoas de polimento. Isso também ocorre com o tratamento anaeróbio, que pode acontecer das seguintes maneiras: reator anaeróbio tipo RALF, fossa séptica, tanque imhoff, lagoas anaeróbias, filtros anaeróbios, entre outros.

0 tratamento anaeróbio é um processo biológico, onde os tipos de microorganismos presentes no efluente transformam compostos orgânicos complexos. Trata-se de um processo biológico pelo fato de que a degradação ocorre através de bactérias presentes no meio. Esse processo também ocorre na ausência de oxigênio. (CHERNICHARO et all, 2011, apud FAGUNDES, 2010, p.18).

0 reator RALF é um exemplo de processo anaeróbio, pois funciona através de processos biológicos onde utiliza a matéria orgânica presente no meio para degradar e digerir compostos orgânicos sem a utilização do oxigênio. Porém, o reator RALF apresenta a desvantagem em relação a sua eficiência, necessitando de um tratamento complementar que pode ser feito através de filtros biológicos aeróbios.

A Figura 1 representa o esquema de um reator RALF localizado em uma das Estações de Tratamento de Esgoto da cidade de Ponta Grossa - PR. 
Figura 1 - Esquema do reator RALF

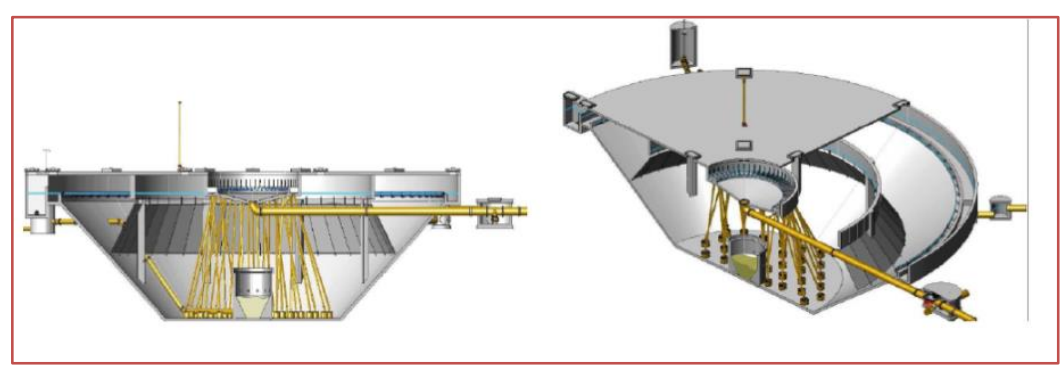

O princípio de funcionamento do reator RALF é relativamente simples. Consiste em introduzir o lodo e distribuir o mesmo em toda base do reator. 0 esgoto é então forçado a percolar por todo o manto de biomassa que é mantido no interior do reator. Nesse processo de percolação, todas as partículas finas que estão suspensas são filtradas e os componentes solúveis são absorvidos pela biomassa presente, que irá converter esses componentes solúveis em gás carbônico e metano, além de formar uma nova biomassa (BÁREA, 2015).

Todo gás gerado pela degradação pela biomassa é direcionado para os coletores de biogás que estão presentes na parte de cima do reator. Os sólidos e o liquido que ficou no reator são direcionados para os compartimentos de decantação. Ocorre então a recirculação desses sólidos, pois os mesmos retornam para o compartimento em que o manto de biomassa se encontra. Nos decantadores encontram-se os vertedores que realizam a retirada do efluente tratado no reator (BÁREA, 2015).

As vantagens do reator RALF perto de outros processos anaeróbios convencionais são: baixa produção de lodo, baixa demanda de área, baixo custo de implementação e operação, baixo consumo de energia, produção de biogás metano (combustível), boa desidratabilidade do lodo, reinicio de operações relativamente rápido, elevada concentração do lodo excedente (BARBOZA; AMORIM, 2015).

Os tratamentos anaeróbios, apesar de serem relativamente eficientes, ainda necessitam de tratamentos auxiliares ou secundários devido não conseguirem degradar toda matéria orgânica presente no esgoto. é desejável que o processo auxiliar seja com baixo ou zero consumo de energia visando a economia e rentabilidade. Devido a isso é muito comum encontrar processo primário via RALF e processo secundário via Filtros Biológicos Aeróbios em muitas estações, pois essa combinação vem se mostrando eficiente no tratamento de esgotos.

Os filtros biológicos aeróbios podem também ser chamados de leito percoladores. Esse nome se dá devido o seu sistema possuir um material filtrante que funciona como um "recheio" podendo ser pedra brita, por exemplo. São nessas pedras que os microorganismos se fixam para fazer a degradação da matéria orgânica através da percolação em fluxo descendente (AISSE, et all, 2000, P. 1). Devido o sistema ser aeróbio, os microorganismos presentes no meio necessitam de oxigênio para sua sobrevivência, obrigando o sistema possuir um sistema de aeração.

A Figura 2 representa o filtro biológico que é utilizado em uma das estações de tratamento de esgoto da cidade de Ponta Grossa.

Figura 2 - Ilustração do filtro biológico instalado na ETE - Cará Cará

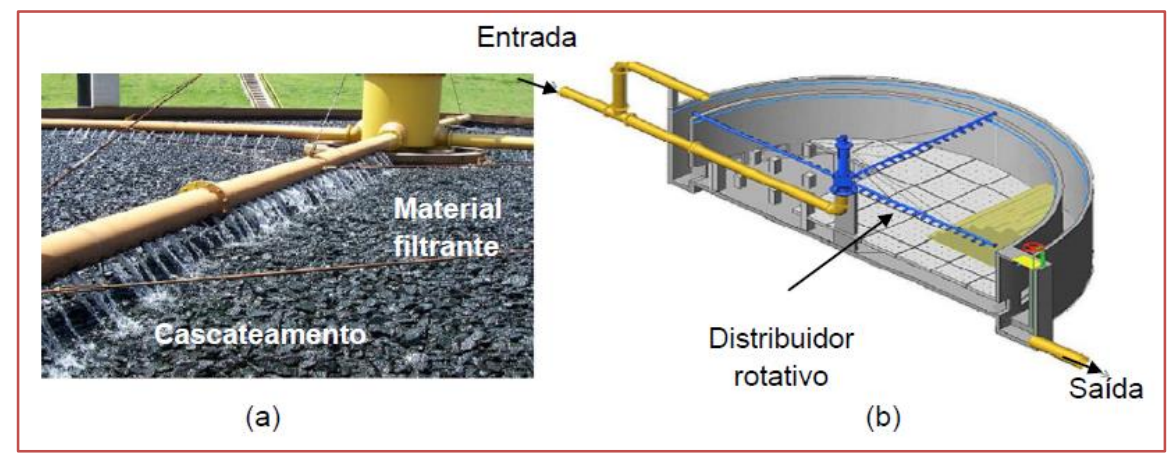


O funcionamento desses filtros é baseado na entrada do esgoto pela tubulação, sendo está ligada a distribuidores rotativos que distribuem todo o esgoto de maneira uniforme no recheio. 0 recheio utilizado pela SANEPAR é a pedra brita numero 4, e é nesse recheio que as bactérias se fixam para degradar a matéria orgânica restante no esgoto. Todo lodo gerado por esse sistema é decantado.

Esses filtros também possuem um sistema de drenagem que faz tanto a coleta do liquido já percolados, como também permite a circulação do ar através do leito. Os líquidos coletados são encaminhados a um decantador que tem como função separar os sólidos do efluente final (AISSE, et all, 2000, P. 1). A circulação de ar dentro do sistema é de extrema importância pois as bactérias degradadoras desse sistema são aeróbias e necessitam de oxigênio para sua sobrevivência.

Diversos são os parâmetros que devem ser analisados quando se trata de tratamento de esgoto. São eles: demanda bioquímica de oxigênio, demanda química de oxigênio, sólidos sedimentáveis, sólidos solúveis totais, $\mathrm{pH}$, nitrogênio, fósforo, carbono orgânico total (COT) e surfactantes. Todos esses indicadores possuem parâmetros de lançamento após receberem o tratamento, e esses parâmetros são regidos por alguns órgãos. Os órgãos responsáveis que determinam os padrões de lançamento é o Conselho Nacional do Meio Ambiente (CONAMA) a nível federal e a Secretaria de Meio Ambiente 021 (SEMA 021). A tabela 1 representa os padrões exigidos pela legislação:

Tabela 1 - Padrões de lançamento de efluentes aos corpos hídricos

\begin{tabular}{|c|c|c|}
\hline PARÂMETROS & CONAMA 430 & SEMA 021 \\
\hline DBO & $\begin{array}{c}\text { Redução mínima } \\
\text { de } 60 \%\end{array}$ & $90 \mathrm{mg} \cdot \mathrm{L}^{-1}$ \\
DQO & - & $225 \mathrm{mg} \cdot \mathrm{L}^{-1}$ \\
Óleos vegetais e & - & $50 \mathrm{mg} \cdot \mathrm{L}^{-1^{*}}$ \\
gorduras animais \\
Óleos minerais
\end{tabular}

Fonte: Resolução CONAMA 430 (2011) e Resolução SEMA 021 (2009)

Dentre todos os parâmetros que devem seguir a legislação, apenas a DBO e a DQO foram estudadas mais profundamente neste trabalho.

A DBO é a retirada do oxigênio da água através de bactérias aeróbias que tiram suas fontes de vida e energia do oxigênio. Trata-se de um parâmetro que mede a capacidade de um determinado efluente ser decomposto através das bactérias aeróbias presentes no meio. A consequência desse processo é o consumo de energia (BARBOSA, 2003). Esse indicador mede a quantidade de oxigênio consumida para degradar a matéria orgânica, sendo ele o mais empregado para medição da poluição do meio.

A DQO é usada para indicar o conteúdo orgânico das águas residuais e superficiais. Esse indicador avalia o quanto de oxigênio dissolvido (OD) consumido em meio ácido que leva a degradação da matéria orgânica (SOUZA, 2015).

O principal objetivo do trabalho foi analisar a eficiência do tratamento de esgoto na ETE, comparando os resultados obtidos com a legislação vigente. Os resultados também foram comparados com outros trabalhos realizados em outras ETE's da cidade que possuem tratamento de esgoto diferenciado (composto de RALF e lagoa de estabilização) e também com trabalhos realizados em ETE's que possuem o 
mesmo sistema de tratamento da ETE Gertrudes. Os parâmetros analisados foram a Demanda Bioquímica de Oxigênio (DBO) e Demanda Química de Oxigênio (DQO).

\section{METODOLOGIA}

0 estudo foi realizado em uma estação de tratamento de esgoto da SANEPAR chamada Gertrudes que se localiza no bairro Schangrilá no município de Ponta Grossa. A pesquisa teve inicio na metade do ano de 2015, sendo finalizada na metade do ano de 2016. 0 corpo hídrico receptor desta estação é o Arroio Gertrudes, afluente do Rio Taquari, sendo esse pertencente ao Rio Tibagi. 0 valor médio de lançamento da ETE Gertrudes é $21 \mathrm{~L} / \mathrm{s}$.

A ETE Gertrudes iniciou sua operação em 2003 e possui uma vazão nominal de $30 \mathrm{~L} / \mathrm{s}$, atendendo aproximadamente 7\% da cidade de Ponta Grossa (aproximadamente 7 mil imóveis). É constituída de estação elevatória de esgoto bruto, tratamento preliminar e biológico, reator do tipo RALF e filtro biológico aeróbio. No ano que a pesquisa se sucedeu, esta estação estava passando por reformas e ampliações a fim de dobrar a sua capacidade de vazão nominal.

Para a pesquisa foram realizadas coletas mensais entre os meses de novembro de 2015 a abril de 2016, totalizando seis coletas. A amostragem foi realizada no pós gradeamento, antes da entrada do reator RALF e na saída do filtro biológico aeróbio, ambas realizadas no mesmo dia.

As amostras foram coletadas em baldes específicos e transferidas para frascos de polietileno. Os frascos com as amostras foram ensacados e colocados em caixa de isopor com gelo. As amostras foram mantidas resfriadas durante todo trabalho de campo para minimizar a atividade biológica.

As análises realizadas neste trabalho fazem parte dos parâmetros físico-químicos para avaliação da qualidade do tratamento de esgoto. Para comparação dos resultados utilizaram-se valores registrados em literatura técnica e padrões determinados por legislação vigentes de lançamento de efluentes sanitários.

Para determinação dos parâmetros DQO e DBO utilizou o equipamento Pastel UV - Secomam sendo todas as análises realizadas em triplicada. Esse equipamento é de origem francesa e atua como um espectrofotômetro analisador de qualidade de águas e efluentes. As informações obtidas pelo aparelho são de origem quantitativa onde é feito uma estimativa da concentração de parâmetros monitorados em tempo real de acordo com o dispositivo de calibração e de origem qualitativa onde o espectro da amostra é comparado com o modelo digital interno.

0 equipamento também faz comparação do perfil da amostra com o tipo de agua selecionado, podendo ser água ou efluente, completando assim os dados quantitativos. Isso permite com que os dados quantitativos se tornem válidos e detecta a presença de poluentes químicos. 0 equipamento trabalha com faixa espectral de 200 a $320 \mathrm{~nm}$ e possui dois caminhos óticos de 5 e $10 \mathrm{~mm}$.

\section{RESULTADOS E DISCUSSÃO}

Diversos são os fatores que podem ter influenciado nos resultados das análises. Dias muito chuvosos tornam o esgoto mais dissolvido, assim como dias muito secos fazem com que o esgoto fique mais concentrado, influencias como horário da coleta, redes de esgoto industriais ligadas clandestinamente ao sistema coletor, entre outros.

A partir dos resultados encontrados é possível fazer uma comparação com a legislação e com outros trabalhos já realizados e poder concluir a eficiência de tratamento da estação Gertrudes. Os valores apresentados são referentes ao Esgoto Bruto (EB) e ao Esgoto Tratado (ET).

\subsection{DEMANDA BIOQUÍMICA DE OXIGÊNIO}

A Tabela 2 a seguir apresenta os valores encontrados através de analises para demanda bioquímica de oxigênio tanto para EB quanto para ET: 
Tabela 2 - Valores de DBO para esgoto bruto e tratado

\begin{tabular}{|c|c|c|c|c|}
\hline \multirow{2}{*}{ Coleta } & Data & EB (mg/L) & ET (mg/L) & Eficiência de Tratamento (\%) \\
\hline 1 & $20 / 11 / 2015$ & 62,2 & 52,6 & 15,43 \\
\hline 2 & $23 / 12 / 2015$ & 176,6 & 75,75 & 57,1 \\
\hline 3 & $29 / 01 / 2016$ & 200,6 & 68,2 & 66,0 \\
\hline 4 & $19 / 02 / 2016$ & 162 & 85 & 47,53 \\
\hline 5 & $23 / 03 / 2016$ & 169,3 & 72,25 & 57,32 \\
\hline 6 & $19 / 04 / 2016$ & 498,3 & 79 & 84,14 \\
\hline & Média & 211,5 & 72,13 & 54,58 \\
\hline
\end{tabular}

Von Sperling (2005) determina faixas médias de eficiências das estações de tratamento de esgoto considerando tratamento através de RALF com pós-tratamento composto de filtro biológico aeróbio de aproximadamente 80 a 93\% para DBO. Sendo assim, e de acordo com os resultados encontrados a ETE Gertrudes não possui tratamento eficiente para DBO visto que, de acordo com os resultados encontrados, a eficiência media é de $54,58 \%$.

Porém, se for comparar com a legislação vigente SEMA 021 que determina os padrões de lançamento para esgoto tratado e que diz que a quantidade de DBO na amostra final deve ser menor que $90 \mathrm{mg} / \mathrm{L}$. Portanto, como a media do esgoto tratado foi de $72,13 \mathrm{mg} / \mathrm{L}$ e todos os resultados encontrados em cada analise foram menores que $90 \mathrm{mg} / \mathrm{L}$ é possível afirmar que a ETE atende a legislação.

A ETE Cara-Cará que possui o mesmo sistema de tratamento da ETE Gertrudes também mostrou eficiência de tratamento na remoção de DBO, visto que a media final do esgoto tratado foi $57,8 \mathrm{mg} / \mathrm{L}$, resultando em uma eficiência média de 90\%.

Schoenhals et al.. (2007) em um estudo realizado utilizando RALF para tratamento de efluentes monitorou o Tempo de Detenção Hídrica (TDH) e mostrou que nesse período de monitoramento o TDH estava abaixo do valor de projeto do sistema. Isso não é recomendado, pois acarreta uma sobrecarga no sistema causando a queda da eficiência do tratamento.

Um baixo TDH faz com que os microorganismos não tenham tempo de ação adequado para digestão da matéria orgânica presente no efluente e, portanto, a não adequação aos parâmetros do processo, afetando diretamente a eficiência de parâmetros físico-químicos de remoção, nesse caso a DBO.

Parâmetros como DQO e DBO são indispensáveis em estudos de caracterização de esgoto sanitários e tornam-se muito uteis quando utilizadas conjuntamente, onde é possível observar a biodegradabilidade dos esgotos, sendo os valores de DQO superiores aos de DBO (CETESB, 2016).

\subsection{DEMANDA QUÍMICA DE OXIGÊNIO}

A Tabela 3 a seguir apresenta os valores encontrados através de analises para demanda química de oxigênio tanto para EB quanto para ET: 
Tabela 3 - Valores de DQO para esgoto bruto e tratado

\begin{tabular}{|c|c|c|c|c|}
\hline \multirow{2}{*}{ Coleta } & Data & Esgoto Bruto $(\mathrm{mg} / \mathrm{L})$ & Esgoto Tratado (mg/L) & Eficiência de Tratamento (\%) \\
\hline 1 & $20 / 11 / 2015$ & 154,7 & 126,3 & 18,35 \\
\hline 2 & $23 / 12 / 2015$ & 738,3 & 191,5 & 74,06 \\
\hline 3 & $29 / 01 / 2016$ & 673,3 & 162,6 & 75,85 \\
\hline 4 & $19 / 02 / 2016$ & 631,7 & 168,7 & 73,29 \\
\hline 5 & $23 / 03 / 2016$ & 695 & 149,5 & 78,48 \\
\hline 6 & $19 / 04 / 2016$ & 1166,7 & 165,3 & 65,83 \\
\hline & Média & 676,61 & 160,65 & $67,64 \%$ \\
\hline
\end{tabular}

Para a DQO, a legislação SEM 021/09 delimita o valor de $225 \mathrm{mg} / \mathrm{L}$. Analisando a média final dos resultados, e também os resultados encontradas em todas as analises de esgoto tratado pode-se dizer que para remoção de DQO o sistema mostrou eficiência de 67,64\% atendendo a legislação aplicada.

Segundo Haandel e Lettinga (1194), a maior parte da remoção de DQO se dá no reator RALF, sendo este capaz de atingir uma remoção de $65 \%$ a $80 \%$ da taxa de DQO presente no esgoto. com isso, apenas 1/3 da DQO presente no esgoto bruto seguiria para filtro biológico aeróbio.

Em um trabalho realizado por Machado Filho (2015) na ETE Cara-Cará que possui o mesmo sistema de tratamento da ETE Gertrudes, os resultados dos valores médios de DQO no esgoto foram de 113,6 mg/L, obtendo uma eficiência de remoção de $92 \%$. Ele atribui a eficiência de remoção ao tratamento secundário, ou seja, o filtro biológico aeróbio citando a importância de um tratamento secundário em uma ETE.

Devido à elevada média de remoção de DQO de esgoto tratado tanto na estação em estudo quanto na estação em comparação, ambas possuindo o mesmo sistema de tratamento, é possível considerar eficiente um sistema de tratamento preliminar, seguido por reator RALF e filtro biológico aeróbio na remoção de DQO do esgoto.

Segundo Metcalf \& Eddy (2003) a relação DBO/DQO atua como um indicativo desta biodegradabilidade do efluente. Altos valores desta razão indicam que a fração biodegradável é elevada. Para efluentes domésticos essa razão está na faixa de 0,3 a 0,8, onde valores acima de 0,5 indicam que o esgoto é facilmente tratável biologicamente. Já valores $\leq 0,3$ indicam que o esgoto pode estar contaminado com elementos tóxicos ou componentes que possuem baixa biodegradabilidade necessitando de tratamentos físico-químicos adicionais.

A Tabela 4 mostra essa razão entre DBO/DQO das coletas analisadas:

Tabela 4 - Relação DBO/DQO

\begin{tabular}{|c|c|c|}
\hline COLETA & DIA & DBO/DQO \\
\hline 1 & $20 / 11 / 2015$ & 0,4020 \\
\hline 2 & $23 / 12 / 2015$ & 0,2391 \\
\hline 3 & $29 / 01 / 2016$ & 0,2979 \\
\hline 4 & $19 / 02 / 2016$ & 0,2564 \\
\hline 5 & $23 / 03 / 2016$ & 0,2435 \\
\hline 6 & $19 / 04 / 2016$ & 0,4271 \\
\hline MÉDIA & & 0,311 \\
\hline
\end{tabular}

Fonte: Autoria própria 
A média dos resultados foi maior que 0,3 o que caracteriza o esgoto como facilmente biodegradável. Porém, se analisar os valores individualmente, a maioria apresenta valores menores que 0,3 caracterizando um efluente com baixo grau de biodegradabilidade, necessitando assim de tratamentos adicionais devido ao fato desse efluente possuir chances de estar contaminado.

\section{CONCLUSÃO}

A partir dos resultados analisados é possível concluir que a estação de tratamento de Esgoto Gertrudes é eficiente na remoção de DQO e DBO no esgoto tratado, visto que ambos os parâmetros estão dentro dos padrões exigidos pelas legislações vigentes. Também é possível concluir que o conjunto reator RALF e filtro biológico aeróbio formam um sistema eficiente de remoção desses parâmetros.

Outro ponto a se concluir é que o RALF necessita de um tratamento complementar, pois esse sistema não consegue ser eficaz individualmente.

Os resultados encontrados foram satisfatórios no cumprimento da legislação.

\section{REFERÊNCIAS}

[1] AISSE, Miguel Mansur et al. I-108 - Avaliação do sistema reator UASB e filtro biológico para o tratamento de esgoto sanitário. In: XXVII Congresso Interamericano de Engenharia Sanitária d Ambiental, 27., 2000, Porto Alegre. I108 - Avaliação do sistema reator UASB e filtro biológico para o tratamento de esgoto sanitário. Porto Alegre: Qualitymark, 2000.p. 1 - 9.

[2] BARBOSA, João Marcelo do Nascimento. "Estudo do comportamento da DBO em suporte aeróbio de oxigênio puro". Coeficientes cinéticos e Fatores de correlação". 2003. 170 f. Dissertação (Mestrado) - Curso de Saúde Pública, Fundação Oswaldo Cruz, Rio de Janeiro, 2003.

[3] BARBOZA, Marcio Gomes; AMORIM, Eduardo L. C. de. Tratamento anaeróbio de esgotos através de reatores do tipo uasb. Disponível em: <http://www.ctec.ufal.br/professor/elca/Reatores UASB v2.pdf>. Acesso em: 17 maio 2015.

[4] BARÉA, Luis César. RALF, Reator Anaeróbio de Manto de Lodo e Fluxo Ascendente reduzindo custos e economizando energia no Tratamento de Esgotos. Disponível em: <http://www.sanepar.com.br/sanepar/calandrakbx/filesmng.nsf/1B9DF09C9EAE4D2B832573760042EB40/\$Fil e/APRESENTAÇÃO_RALF_SANEPAR -.pdf?OpenElement>. Acesso em: 17 maio 2015.

[5] CETESB - COMPANHIA DE TECNOLOGIA DE SANEAMENTO AMBIENTAL. Disponível em <http://www.cetesb.sp.gov.br/userfiles/file/agua/aguassuperficiais/aguasinteriores/variaveis/aguas/variaveis_qui micas/carbono_organico_di ssolvido_e_carbono_organico_total.pdf>. Acesso em 10 mar. 2016

[6] CHERniCHARO, C. A. L. et al. Influência da alteração e da distribuição do tamanho de partículas no desempenho de reator UASB no tratando esgoto doméstico. Eng. Sanit. Ambient., Rio de Janeiro, v. 14, n. 2, p. 159-166, abr./jun. 2009.

[7] HAANDEL A. V.; LETTINGA, G. Tratamento anaeróbio de esgotos - um manual para regiões de clima quente. Campina Grande; Guerreiro e Catunda, 1994.

[8] JURGENSEN, Décio et al. Tratamento Biológico Anaeróbio. Curitiba: Sanepar, 2005.

[9] MACHADO FILHO, José Geraldo. Tratamento biológico de esgoto sanitário composto por reator anaeróbio de leito fluidizado e filtro percolador com inserção de uma etapa intermediária de aeração. 2015. 59 f. Tese (Doutorado) Curso de Engenharia Sanitária e Ambiental, Universidade Estadual de Ponta Grossa, Ponta Grossa, 2015.

[10] METCALF \& EDDY. Wastewater engineering: treatment, disposal, reuse. 3 ed.New York, McGraw - Hill Book, 1991. $1334 \mathrm{p}$.

[11] SANEPAR (Companhia de Saneamento do Paraná), 2005. Disponível em: <http://site.sanepar.com.br/sanepar/tratamento>. Acesso em 08 jun. 2015

[12] SChoenhals, M.; FRARE, L. M.; SARMEnTO, L. A. V. Análise do Desempenho de Reatores Anaeróbios de Fluxo Ascendente e Manta de Lodo no Tratamento de Efluentes da Suinocultura. Engenharia Ambiental - Espirito Santo do Pinhal, v. 4, p. 005-023, jan/jun 2007.

[13] SOUZA, Líria Alves de. Demanda Química de Oxigênio. Disponível em: <http://www.mundoeducacao.com/quimica/demanda-quimica-oxigenio.htm>. Acesso em: 17 maio 2015.

[14] VON SPERLING, M. Princípios de tratamento biológico de águas residuárias: introdução à qualidade das águas e ao tratamento de esgotos. 3. ed. Belo Horizonte: DESA/UFMG, 2005. 425p 


\section{Capítulo 7}

\section{COMPOSIÇÃO DOS ATIVOS INTANGÍVEIS DAS EMPRESAS LISTADAS NO ÍNDICE DE CARBONO EFICIENTE DA B3}

\section{Francisca Francivânia Rodrigues Ribeiro Macêdo \\ Maria Maciléya Azevedo Freire \\ Antônio Rodrigues Albuquerque Filho}

Resumo: Este estudo teve por objetivo analisar a composição dos ativos intangíveis das empresas listadas no índice de carbono eficiente (ICO2) da B3. Para tal, realizou-se pesquisa descritiva, conduzida por meio de análise documental e abordagem quantitativa dos dados, em uma amostra que compreendeu 28 companhias. Foram utilizadas informações constantes no sítio da B3, especificamente, no balanço patrimonial e nas notas explicativas, analisadas uma a uma, ao longo dos anos de 2010 a 2015. Os resultados demonstraram que as empresas do mercado tradicional apresentaram valores mais representativos quanto aos montantes de ativos intangíveis, enquanto as do novo mercado registraram maior representatividade dos ativos intangíveis no ativo total e fixo. Observou-se ainda que, os intangíveis mais evidenciados nos relatórios contábeis foram softwares, ágio, marcas e patentes, contratos de concessão e outros intangíveis. Constatou-se, dentro do período em análise, que houve um registro ascendente na divulgação de ativos intangíveis na categoria marcas e patentes, ágio sobre investimento e carteira de clientes. Ao final, concluiu-se que tais empresas vêm aumentando gradativamente o registro dos ativos intangíveis em seus balanços, refletindo positivamente na qualidade da informação contábil.

Palavras-chave: Composição. Ativos intangíveis. Empresas do ICO2. 


\section{INTRODUÇÃO}

A necessidade premente de maior qualidade e confiança nas informações contábeis, aliado a exigência contínua na busca por novas formas de geração de valor, vem induzindo as empresas a empreender em seu ambiente e em seus processos, características que ofereçam vantagens competitivas (PEREZ; FAMÁ, 2006).

Os ativos intangíveis, de acordo com Kayo et al. (2006), vem crescendo em importância na formação de valor da empresa. Os autores mencionam que a justificativa para a relevância em evidenciar-se tais ativos, dá-se justamente porque os potenciais investidores, valorizam sobremaneira, a inserção, no balanço patrimonial, de ativos intangíveis como marca, inovação, ativos humanos, dentre outros.

Perez e Famá (2006), Machado e Famá (2011), Decker et al. (2013), Leite e Santos (2013), Marin, Liszbinski e Kronbauer (2015) consideram os ativos intangíveis como ativos invisíveis, intelectuais, tratados como sendo diretamente ligados a geração de valores, ao direito de benefícios futuros, mas, que não possuem corpo físico ou financeiro.

No Brasil, desde o processo de harmonização da contabilidade local às normas e padrões internacionais (concretizado por meio da Lei no 11.638/2007), o processo de registro dos ativos intangíveis no balanço patrimonial das empresas brasileiras, tornou-se elemento obrigatório, devendo figurar dentro do ativo não circulante.

Diante do exposto, percebe-se que as empresas agem em prol de maximizar seus benefícios e terem suas práticas legitimadas pela sociedade em geral e pelos investidores. Outra atitude que corrobora tal assertiva é o fato de algumas organizações fazerem parte de carteiras de índices da Bolsa de Valores, Mercadorias e Futuros de São Paulo (B3). Tais índices auxiliam os investidores a decidirem em qual entidade irão fazer seu aporte de recursos, tendo em vista que, são indicadores de desempenho de um conjunto de ações, portanto, os ajuda a entender melhor algumas práticas adotadas pelas empresas que os compõem.

Dentre os índices da B3, tem-se o Índice Carbono Eficiente (ICO2), o qual é formado por "empresas que se comprometeram a participar da iniciativa da adoção de ações transparentes relacionadas às emissões de gases de efeito estufa (GEE), medindo a eficiência das mesmas quanto a emissão de carbono" (B3, 2015).

Lima et al. (2014), mencionam que as empresas do ICO2 levam em consideração o volume de emissão e o faturamento bruto, possibilitando às empresas participantes pleitear um benefício econômico e, consequentemente, propicia a valorização de suas ações.

Os autores ainda esclarecem que o fato das empresas participarem da carteira do ICO2, reflete em uma captação de recursos a um custo menor, atuando assim como uma vantagem competitiva, além de incitar uma maior confiabilidade de suas informações, gerando com isso, um interesse maior por parte dos acionistas, principalmente no tocante a seus ativos intangíveis.

Destarte, dada a deferência da temática, eis que surgiu o questionamento da pesquisa: Qual a composição dos ativos intangíveis das empresas listadas no índice de carbono eficiente (ICO2) da B3? Para responder à pergunta da pesquisa, traçou-se como objetivo analisar a composição dos ativos intangíveis das empresas listadas no índice de carbono eficiente (ICO2) da B3.

A importância desta pesquisa pode ser observada ao ler-se a afirmação de autores como Barbosa et al. (2013), Cassimiro Lima et al. (2014) e Souza et al. (2014). Tais autores constataram em seus estudos que o índice de carbono eficiente (ICO2), tem contribuído para a criação de investimentos levando em consideração as práticas de sustentabilidade e rentabilidade, as quais são fatores determinantes na geração de valor.

A justificativa para realização deste estudo decorre, dentre outros, do fato dos ativos intangíveis serem um diferencial competitivo que atribuem valor ao negócio (PEREZ; FAMÁ, 2006; KAYO et al., 2006; MARIN; LISZBINSKI; KRONBAUER, 2015) e que, portanto, precisam ser registrados criteriosamente pelas empresas. Ademais, por serem um importante fator de diferenciação das empresas, os ativos intangíveis vêm despertando interesse de diversos pesquisadores, a exemplo de estudos como o desenvolvido por Machado e Famá (2011), Decker et al. (2013), Viviani et al. (2014), Marin, Liszbinski e Kronbauer (2015), dentre outros.

Aliado a isso, uma vez que, a preocupação com o meio ambiente e com o aquecimento global é o grande desafio enfrentado pela humanidade neste século, tratar sobre o Índice Carbono Eficiente, cujo principal 
objetivo é "incentivar as empresas emissoras das ações mais negociadas a aferir, divulgar e monitorar s emissões de GEE" (B3, 2015), mostra-se como um assunto relevante.

\section{REFERENCIAL TEÓRICO}

Esta seção traz os posicionamentos teóricos e empíricos que serviram de base para o desenvolvimento da linha de raciocínio da pesquisa. Inicialmente, apresentam-se ponderações sobre os ativos intangíveis. Na sequência, trazem-se informações sobre os critérios de reconhecimento dos ativos intangíveis. Por último, evidenciam-se estudos anteriores que abordaram a temática em análise.

\subsection{ATIVOS INTANGÍVEIS}

O interesse no estudo dos ativos intangíveis vem aumentando consideravelmente ao longo dos anos e, essa ascendência deve-se ao acréscimo de valor que tais ativos proporcionam na geração de riquezas das empresas (KAYO; TEH; BASSO, 2005).

Contudo, apesar de ser assunto em pauta nas entidades do Brasil e do mundo, bem como, em diversas pesquisas científicas (como por exemplo, MARIN; LISZBINSKI; KRONBAUER, 2015), a conceituação e caracterização dos ativos intangíveis não tem uma uniformidade padrão, o que faz com que os pesquisadores tenham dificuldade em defini-los (Moura, 2011; MOURA; THEISS; CUNHA, 2014). Para autores como Perez e Famá (2006) e Moura, Theis e Cunha (2014), ativo intangível é sinônimo de ativo intelectual e invisível, capital intelectual, recursos intangíveis e goodwill.

Machado e Famá (2011) entendem que ativos intangíveis não são simplesmente aqueles que não possuem existência física ou são intocáveis. Nascimento et al. (2012), entendem que os ativos intangíveis proporcionam direitos, benefícios futuros, além de representarem grande diferencial competitivo.

Já para o Comitê de Pronunciamentos Contábeis (CPC 04), ativos intangíveis são conhecimentos, sistemas, licenças, propriedade intelectual, reputação, imagem e marcas registradas, sendo identificáveis, controlados e geradores de benefícios econômicos futuros.

Segundo Barbosa e Gomes (2002, p. 2), os intangíveis são classificados em quatro tipos: "(1) conhecimento acadêmico e tácito de seus funcionários; (2) processos facilitadores de transferência e aquisição de conhecimento; (3) relacionamento com clientes, fornecedores e mercado de trabalho; e (4) capacitação em pesquisa e desenvolvimento." Para Sveiby (1998), os ativos intangíveis são divididos em três grupos, a saber: competência dos funcionários, estrutura interna e estrutura externa

Quanto à mensuração dos ativos intangíveis, o Comitê de Pronunciamentos Contábeis (CPC 04) estabelece que a entidade deve observar os gastos incorridos. Este pronunciamento esclarece ainda que o ativo intangível deve ser separável e resultar de direitos contratuais e legais, onde o referido ativo deve gerar benefícios econômicos em favor da entidade e seu custo deve ser mensurado com segurança, podendo a empresa optar pelo método de custo ou pela reavaliação da política contábil desde que, neste segundo, seja permitido legalmente.

No caso da mensuração da vida útil do ativo intangível, caso o mesmo possua vida útil definida, utiliza-se a abordagem de amortização, porém, quando não possui ou se não for possível obter com confiabilidade a sua determinação, utiliza-se a abordagem dos testes de delimitação (CPC 04).

Deste modo, após as definições e esclarecimentos do que são ativos intangíveis, qual a sua classificação e mensuração, faz-se necessário compreender quais são os critérios de reconhecimento destes ativos.

\subsection{CRITÉRIOS DE RECONHECIMENTO DOS ATIVOS INTANGÍVEIS}

Os ativos tem um importante papel na contabilidade. Fernandes (1998) e Goulart (2002), comentam que os ativos representam o conjunto de bens e direitos que compõem benefícios futuros para a entidade, caracterizados principalmente por seu potencial de resultado econômico, podendo ser divididos em tangíveis (corpóreos) e intangíveis (incorpóreos).

No tocante aos ativos intangíveis, Kreuzberg, Rigo e Klann (2013) mencionam que os ativos intangíveis são bens e direitos incorpóreos, diretamente ligados a capacidade de geração de riquezas. Perez e Famá (2006) e Kayo et al. (2006) destacam que os AIs possuem como principal característica a singularidade, o 
que os torna únicos e de exclusiva propriedade, enquanto os ativos tangíveis podem ser adquiridos com maior facilidade.

Kayo et al. (2006) comentam que o reconhecimento dos ativos intangíveis em referência a sua área de estratégia é entendido como recursos, dos quais incluem todos os ativos, informações, conhecimento dentre outros fatores que podem levar a empresa a obter lucros anormais e atuar como vantagem competitiva.

Perez e Famá (2006) alertam que o fato de um ativo existir não é o bastante para reconhece-lo contabilmente. Hendriksen e Van Breda (1999), Crisóstomo (2009), Marin, Liszbinski e Krounbauer (2015) relatam que para ser feito o reconhecimento de qualquer ativo, faz-se imperativo que este se encaixe em todos os seus parâmetros específicos, quais sejam: definição apropriada, mensurabilidade, relevância e precisão.

No Brasil, o CPC 04 define algumas medidas específicas para a evidenciação de ativos intangíveis, algumas destas obrigatórias e outras voluntárias, devendo ser separadas por classe e por informações de valor de custo. Segundo Macêdo et al. (2014, p. 330) "a cada dia as empresas passam a evidenciar mais informações para atender aos órgãos reguladores (evidenciação compulsória), ou para demonstrar maior transparência na sua administração (evidenciação voluntária)."

Em suma, infere-se que a evidenciação dos ativos intangíveis é uma maneira do ente dar maior segurança e propiciar melhor simetria nas informações repassadas para o cliente, fornecedores, governo e stakeholders (MOURA, 2011). Notou-se, sobretudo, que é necessário que sejam seguidos sérios critérios de reconhecimento dos ativos intangíveis, para que o registro seja a representação fiel e correta destes ativos e, deste modo, atuem como um diferencial e vantagem competitiva da organização.

\subsection{ESTUDOS ANTERIORES SOBRE ATIVOS INTANGÍVEIS}

A articulação do presente artigo decorre da leitura de trabalhos com abordagens semelhantes, publicados em periódicos, sendo os estudos que contribuíram para o delineamento desta pesquisa, descritos a seguir de forma breve. Iniciando com a pesquisa de Perez e Famá (2006) que analisaram o impacto da presença de ativos intangíveis não contabilizados no desempenho das empresas. Os resultados indicaram o quanto a contabilidade das empresas objeto da análise (norte-americanas) necessitavam que fossem registrados os ativos intangíveis em seus balanços, pois, mostraram-se componentes estratégicos que impactavam no desempenho da entidade.

Decker et al. (2013), verificaram se existia relação entre os ativos intangíveis na rentabilidade das empresas listadas no Îndice Bovespa. Foram analisadas as empresas listadas no Índice Bovespa da B3 no período de 2006 a 2011, utilizando demonstrativos contidos no sítio da B3 e métodos estatísticos test tStudent e correlação de Pearson. A pesquisa demonstrou que o grau de intangibilidade das empresas intangíveis-intensivas foi superior aos das empresas tangíveis-intensivas, porém, esta segunda apresentou um retorno patrimonial superior ao da primeira.

Macêdo et al. (2014) analisaram quais informações ambientais voluntárias eram mais evidenciadas pelas companhias abertas listadas no Îndice Carbono Eficiente (ICO2) da B3. A amostra compreendeu 34 companhias. A identificação das práticas de evidenciação ambiental voluntária ocorreu de acordo com o estudo de Murcia et al. (2008). Os resultados evidenciaram que entre as oito dimensões do índice, as informações sobre créditos de carbono se destacaram com maior nível de evidenciação. Aliado a isso, constatou-se que uma maior evidenciação ambiental voluntária contribuía para que as companhias fossem vistas como organizações mais transparentes e úteis perante a sociedade.

Moura, Theiss e Cunha (2014) analisaram a relação existente entre a proporção dos ativos intangíveis no ativo total e o gerenciamento de resultados em empresas brasileiras listadas em diferentes níveis de governança corporativa da B3. A amostra compreendeu 203 companhias abertas, listadas em diferentes níveis de Governança Corporativa da B3, onde foi analisado o percentual dos ativos intangíveis em relação ao ativo total e o gerenciamento de resultados por meio de informações colhidas nas notas explicativas, relatórios da administração e banco de dados Economática relativos ao período de 2009 a 2010. Os resultados evidenciaram que havia uma boa representatividade de intangíveis e índices consideráveis de gerenciamento de resultados. Demonstram também que houveram correlações estatisticamente significativas entre intangibilidade e gerenciamento de resultados somente entre as empresas listadas no Novo Mercado. 
Viviani et al. (2014) analisaram a relação existente entre a evidenciação ambiental voluntária e os indicadores de desempenho empresarial de companhias abertas participantes do índice carbono eficiente (ICO2). A amostra compreendeu 26 empresas de diferentes níveis de governança corporativa e setores econômicos da B3 que se encontravam listadas no ICO2. Os resultados revelaram que a variável índice de evidenciação ambiental voluntária não apresentou correlação estatisticamente significante com os indicadores de desempenho empresarial.

Percebe-se que a maioria das pesquisas apresentadas evidencia principalmente o quanto os ativos intangíveis atuam como um diferencial na empresa, seja na geração de valor, desempenho empresarial, rentabilidade, gerenciamento de resultados. Pode-se perceber que a evidenciação dessas informações m companhia de forma voluntária ou involuntária é de suma importância para transmitir segurança e reflı de forma positiva na imagem da empresa.

\section{PROCEDIMENTOS METODOLÓGICOS}

Para atender ao objetivo proposto de analisar a composição dos ativos intangíveis das empresas listadas no índice de carbono eficiente (ICO2) da B3, o referido estudo utilizou-se de pesquisa descritiva, documental e abordagem quantitativa dos dados.

No que concerne aos objetivos, esta pesquisa classifica-se como descritiva. Segundo Gil (2008, p. 28) "a pesquisa descritiva objetiva principalmente descrever características de determinada população ou fenômeno ou o estabelecimento de relação entre as variáveis, significativamente utilizando técnicas padronizadas de coleta de dados". Esta pesquisa buscou descrever a composição dos ativos intangíveis das empresas listadas no índice de carbono eficiente da B3, baseando-se no reagrupamento de acordo com a classificação proposta por Sveiby (1998), em que os ativos intangíveis são divididos em três grupos, quais sejam: competência dos funcionários, estrutura interna e estrutura externa.

Quanto aos procedimentos, classifica-se como documental. Segundo Silva e Grigolo (2002) esse tipo de pesquisa busca introduzir valor as informações coletadas, selecionando-as com cuidado, para análise ainda de forma bruta.

Neste estudo, foram utilizadas informações constantes no sítio da B3. Do balanço patrimonial foram retirados os valores do ativo total e do ativo intangível. Ao passo que, as informações pertinentes ao tipo de ativo intangível evidenciado pelas empresas do ICO2 foram retiras das notas explicativas, analisadas uma a uma, ao longo dos anos de 2010 a 2015.

O período selecionado para a análise (2010 a 2015), justifica-se pelo fato de que antes do ano de 2010 a maioria das empresas do ICO2 não divulgavam os dados sobre o intangível nas notas explicativas, ponto principal do trabalho.

Quanto à abordagem, este estudo enquadra-se como quantitativo. Richardson (2012) afirma que este tipo de pesquisa se caracteriza por empregar quantificação na coleta e tratamento das informações, utilizando técnicas estatísticas. Este estudo, utilizou análise estatísticas descritivas (média, mínimo, máximo e desvio padrão) para interpretar os dados.

Além de descrever a composição dos ativos intangíveis das empresas listadas no ICO2, comparando-os com o ativo total das respectivas empresas, as quais foram divididas de acordo com os níveis de governança corporativa da B3, a saber: mercado tradicional, nível 1, nível 2 e novo mercado. No Quadro 1 podem-se observar as empresas que compõem o índice de carbono eficiente da B3 (ICO2). 
Quadro 1 - Listagem das empresas do ICO2

\begin{tabular}{|l|l|l|}
\hline \multicolumn{2}{|c|}{ AMBEV S.A. } & \multicolumn{1}{c|}{ CIA ENERGETICA DE MINAS GERAIS } \\
BCO BRADESCO S.A. & CIELO S.A. & OI S.A. \\
\hline AMBEV S.A. & $\begin{array}{l}\text { CIA ENERGETICA DE MINAS GERAIS } \\
\text { - CEMIG }\end{array}$ & NATURA COSMETICOS S.A. \\
\hline BCO BRADESCO S.A. & CIELO S.A. & OI S.A. \\
\hline BCO BRASIL S.A. & FIBRIA CELULOSE S.A. & $\begin{array}{l}\text { RUMO LOGISTICA OPERADORA } \\
\text { MULTIMODAL S.A. }\end{array}$ \\
\hline $\begin{array}{l}\text { BMFBOVESPA S.A. BOLSA VALORES } \\
\text { MERC FUT }\end{array}$ & ITAU UNIBANCO HOLDING S.A. & SUZANO PAPEL E CELULOSE S.A. \\
\hline BR MALLS PARTICIPACOES S.A. & ITAUSA INVESTIMENTOS ITAU S.A. & TELEFÔNICA BRASIL S.A. \\
\hline BRADESPAR S.A. & JBS S.A. & TIM PARTICIPACOES S.A. \\
\hline BRASKEM S.A. & KLABIN S.A. & ULTRAPAR PARTICIPACOES S.A. \\
\hline BRF S.A. & LOJAS AMERICANAS S.A. & VALE S.A. \\
\hline CCR S.A. & LOJAS RENNER S.A. & \\
\hline CIA BRASILEIRA DE DISTRIBUIÇÃO & $\begin{array}{l}\text { MRV ENGENHARIA E } \\
\text { PARTICIPACOES S.A. }\end{array}$ & \\
\hline
\end{tabular}

Fonte: Dados da pesquisa.

Observa-se no Quadro 1, que o índice de carbono eficiente é composto por 28 empresas (população do estudo). Contudo, algumas empresas apresentaram informações insuficientes para a realização da análise dos dados sobre os tipos de ativos intangíveis evidenciados, quais sejam: Ambev S.A., Bradespar S.A., Klabin S.A., Rumo Logística Operadora Multimodal S.A.

Diversos tipos de empresas participam do ICO2, indústrias, grandes bancos brasileiros, distribuidoras, empresas de telecomunicação, mineradoras, entre outras. Segundo informações constantes na B3, o ICO2 é um indicador de extrema importância, posto que, por meio de uma evidenciação ambiental voluntária, vem adotando práticas eficientes quanto a emissão de gases do efeito estufa (GEE), assim, atuando em uma economia chamada de "baixo carbono".

A importância de se estudarem as empresas do ICO2 e o tema ativos intangíveis é amparada em pesquisas empíricas que foram realizadas, bem como, nas afirmações feitas por alguns pesquisadores. Por exemplo, autores como Barbosa, Silva e Almeida (2013), ressaltaram a importância das empresas listadas no ICO2 em um cenário econômico e ambientalmente correto; Macêdo et al. (2014) enfatizaram a evidenciação ambiental voluntária em companhias listadas no ICO2; Souza et al. (2014) analisaram as ações empresariais adotadas nas empresas participantes do ICO2.

No que concerne aos ativos intangíveis, percebe-se que estes vem assumindo um papel de destaque no cenário empresarial, conforme atestado em pesquisas como quanto a governança corporativa (MACHADO; FAMÁ, 2011), o ciclo de vida e criação de valores (KAYO et al., 2006), características estratégicas e o desempenho econômico empresarial (PERES; FAMÁ, 2006), (MACHADO; FAMÁ, 2011), gerenciamento de resultado (MOURA; THEISS; CUNHA, 2014), evidenciando a relevância dos mesmos.

\section{DESCRIÇÃO E ANÁLISE DOS RESULTADOS}

Esta seção contém a descrição e análise dos dados coletados. Primeiramente apresenta-se valor dos ativos intangíveis das empresas do ICO2 de acordo com os níveis de governança corporativa. Na sequência, trazse o percentual dos intangíveis em relação ao ativo total e fixo. Por último, evidenciam-se quais são os tipos de ativos intangíveis de cada uma das empresas objeto da amostra.

Na Tabela 1 podem-se observar os valores dos ativos intangíveis das empresas do ICO2, no período de 2010 a 2015, divididas de acordo com os níveis de governança corporativa. 
Tabela 1 - Valores dos ativos intangíveis das empresas do período de 2010 a 2015 de acordo com os níveis de governança corporativa da B3

\begin{tabular}{|c|c|c|c|c|c|}
\hline $\begin{array}{l}\text { Setor econômico da } \\
\text { B3 }\end{array}$ & № empresas & Mínimo & Máximo & Média & Desvio Padrão \\
\hline \multicolumn{6}{|c|}{2015} \\
\hline Mercado Tradicional & 5 & - & 13.236.391,14 & $3.786 .991,37$ & $5.459 .570,31$ \\
\hline Nível 1 & 9,00 & - & $5.263 .248,71$ & $1.913 .604,59$ & $2.023 .927,57$ \\
\hline Nível 2 & 1,00 & $8.479,43$ & $8.479,43$ & $8.479,43$ & \\
\hline Novo Mercado & 13,00 & - & $5.614 .822,57$ & $1.536 .765,63$ & $2.205 .603,99$ \\
\hline Totais & 28,00 & - & $24.122 .941,85$ & $2.382 .511,93$ & $9.689 .101,87$ \\
\hline \multicolumn{6}{|c|}{2014} \\
\hline Mercado Tradicional & 5 & - & $15.436 .512,00$ & $3.896 .688,40$ & $6.643 .592,38$ \\
\hline Nível 1 & 9 & - & $6.495 .000,00$ & $1.936 .666,89$ & $2.306 .839,60$ \\
\hline Nível 2 & 1 & $11.337,00$ & $11.337,00$ & $11.337,00$ & - \\
\hline Novo Mercado & 13 & - & $9.707 .106,00$ & $2.291 .196,38$ & $3.319 .278,64$ \\
\hline Totais & 28 & - & $15.436 .512,00$ & $2.382 .511,93$ & $3.703 .432,85$ \\
\hline \multicolumn{6}{|c|}{2013} \\
\hline Mercado Tradicional & 5 & - & $14.975 .663,00$ & $3.682 .760,80$ & $6.458 .215,65$ \\
\hline Nível 1 & 9 & - & $5.700 .657,00$ & $1.730 .752,00$ & $2.076 .095,10$ \\
\hline Nível 2 & 1 & $9.300,00$ & $9.300,00$ & $9.300,00$ & - \\
\hline Novo Mercado & 13 & - & $4.908 .962,00$ & $1.327 .689,08$ & $2.042 .118,82$ \\
\hline Totais & 28 & - & $14.975 .663,00$ & $1.830 .708,21$ & $3.192 .618,02$ \\
\hline \multicolumn{6}{|c|}{2012} \\
\hline Mercado Tradicional & 5 & - & $11.708 .212,00$ & $2.971 .269,40$ & $5.039 .886,57$ \\
\hline Nível 1 & 9 & - & $4.975 .556,00$ & $2.203 .017,22$ & $2.177 .480,31$ \\
\hline Nível 2 & 1 & $8.654,00$ & $8.654,00$ & $8.654,00$ & - \\
\hline Novo Mercado & 13 & - & $4.751 .661,00$ & $1.274 .555,15$ & $1.993 .341,33$ \\
\hline Totais & 28 & - & $11.708 .212,00$ & $1.830 .763,32$ & $2.737 .306,69$ \\
\hline \multicolumn{6}{|c|}{2011} \\
\hline Mercado Tradicional & 5 & - & $19.828 .404,00$ & $6.864 .522,60$ & $8.913 .073,33$ \\
\hline Nível 1 & 9 & - & $5.261 .181,00$ & $1.933 .440,33$ & $2.197 .976,61$ \\
\hline Nível 2 & 1 & $7.100,00$ & $7.100,00$ & $7.100,00$ & - \\
\hline Novo Mercado & 13 & - & $7.454 .336,00$ & $1.650 .474,62$ & $2.575 .556,47$ \\
\hline Totais & 28 & - & $19.828 .404,00$ & $2.613 .815,93$ & $4.510 .852,16$ \\
\hline \multicolumn{6}{|c|}{2010} \\
\hline Mercado Tradicional & 5 & - & $12.667 .244,00$ & $3.031 .232,80$ & $5.437 .934,77$ \\
\hline Nível 1 & 9 & - & $4.881 .765,00$ & $1.863 .785,22$ & $2.064 .730,26$ \\
\hline Nível 2 & 1 & $7.655,00$ & $7.655,00$ & $7.655,00$ & - \\
\hline Novo Mercado & 13 & - & $7.380 .772,00$ & $1.404 .481,38$ & $2.455 .020,66$ \\
\hline Totais & 28 & - & $12.667 .244,00$ & $1.792 .719,43$ & $2.966 .328,97$ \\
\hline
\end{tabular}

Fonte: dados da pesquisa. 
Conforme pode ser observado na Tabela 1, as empresas do mercado tradicional foram as que apresentaram as maiores médias dos valores de ativos intangíveis no período de 2010 a 2015, resultado este que destoa do encontrado por Moura, Theiss e Cunha (2014), vez que, no período analisado pelos autores (2009 e 2010) os maiores valores de intangíveis foram registrados pelas empresas do novo mercado.

Destaca-se que a empresa "JBS", do setor de consumo não cíclico, foi aquela que teve a maior média do período dentre as empresas do mercado tradicional. Nota-se que o valor mínimo neste nível foi zero, denotando que existem empresas que não possuíam registro de ativos intangíveis, quais sejam: Lojas Americanas, do setor de consumo cíclico e Suzano Papel, do setor de materiais básicos.

Ao passo que o valor máximo foi de $R \$ 12.667 .244,00$ em 2010 , elevando-se para $R \$ 15.436 .512,00$ em 2014, registrado pela empresa JBS do mercado tradicional, seguida da empresa CCR SA do novo mercado, setor de construção e transporte.

Outro ponto interessante a se mencionar é que a CCR SA não teve registro de intangíveis em seu balanço nos anos de 2012 e 2013. O desvio padrão por sua vez, evidenciou baixa homogeneidade entre as empresas do mercado tradicional.

Também é possível verificar, ainda na Tabela 1, que a média entre as empresas do novo mercado foi inferior à média das empresas do nível 1 no período de 2010 a 2013, porém, no ano de 2014 as empresas do novo mercado apresentaram média superior ( $\mathrm{R} \$ 2.291 .196,38)$.

De modo geral, percebe-se que o valor médio dos ativos intangíveis, que no ano de 2010 era equivalente a $\mathrm{R} \$ 1.792 .719,43$, elevou-se para $\mathrm{R} \$ 2.613 .815,93$ em 2011, reduziu para $\mathrm{R} \$ 1.830 .763,32$ em 2012, apresentou um pequeno aumento em 2013 (R\$ 1.830.763,32) e elevou-se para R\$2.382.511,93 em 2014. Portanto, apresentando uma variação positiva de aproximadamente 33\% de 2010 para 2014.

Julgou-se ainda interessante analisar a representatividade dos intangíveis em relação ao ativo total dentro de cada nível de governança corporativa da B3, conforme descrito na Tabela 2.

Tabela 2 - Representatividade dos intangíveis no ativo total das empresas no período de 2010 a 2015 de acordo com os níveis de governança corporativa da B3

\begin{tabular}{|c|c|c|c|c|c|}
\hline Setor econômico da B3 & $\begin{array}{c}\text { № } \\
\text { empresas }\end{array}$ & Mínimo & Máximo & Média & Desvio Padrão \\
\hline \multicolumn{6}{|c|}{2015} \\
\hline Mercado Tradicional & 5 & 0,00 & 47,55 & 15,6748 & 19,52910 \\
\hline Nível 1 & 9 & 0,00 & 41,84 & 13,7413 & 15,17996 \\
\hline Nível 2 & 1 & 0,15 & 0,15 & 0,1525 & - \\
\hline Novo Mercado & 13 & 0,00 & 58,98 & 20,4569 & 20,16745 \\
\hline Totais & 28 & - & 148,52 & 50,03 & 54,88 \\
\hline \multicolumn{6}{|c|}{2014} \\
\hline Mercado Tradicional & 5 & - & 38,76 & 11,94 & 17,04 \\
\hline Nível 1 & 9 & - & 39,08 & 9,21 & 13,24 \\
\hline Nível 2 & 1 & 0,13 & 0,13 & 0,13 & - \\
\hline Novo Mercado & 13 & - & 87,08 & 23,78 & 29,53 \\
\hline Totais & 28 & - & 87,08 & 16,14 & 23,23 \\
\hline \multicolumn{6}{|c|}{2013} \\
\hline Mercado Tradicional & 5 & - & 41,38 & 12,29 & 18,09 \\
\hline Nível 1 & 9 & - & 37,84 & 8,77 & 12,46 \\
\hline Nível 2 & 1 & 0,15 & 0,15 & 0,15 & - \\
\hline Novo Mercado & 13 & - & 78,75 & 16,53 & 23,25 \\
\hline Totais & 28 & - & 78,75 & 12,69 & 18,78 \\
\hline
\end{tabular}


Tabela 2 - Representatividade dos intangíveis no ativo total das empresas no período de 2010 a 2015 de acordo com os níveis de governança corporativa da B3

(continuação...)

\begin{tabular}{|c|c|c|c|c|c|}
\hline Setor econômico da B3 & $\begin{array}{c}\text { № } \\
\text { empresas }\end{array}$ & Mínimo & Máximo & Média & Desvio Padrão \\
\hline \multicolumn{6}{|c|}{2012} \\
\hline Mercado Tradicional & 5 & - & 41,56 & 12,67 & 18,32 \\
\hline Nível 1 & 9 & - & 36,99 & 14,43 & 15,86 \\
\hline Nível 2 & 1 & 0,15 & 0,15 & 0,15 & - \\
\hline Novo Mercado & 13 & - & 79,54 & 16,52 & 23,26 \\
\hline Totais & 28 & - & 79,54 & 14,58 & 19,36 \\
\hline \multicolumn{6}{|c|}{2011} \\
\hline Mercado Tradicional & 5 & - & 53,56 & 23,18 & 24,77 \\
\hline Nível 1 & 9 & - & 39,77 & 15,43 & 17,15 \\
\hline Nível 2 & 1 & 0,13 & 0,13 & 0,13 & - \\
\hline Novo Mercado & 13 & - & 94,53 & 19,96 & 26,49 \\
\hline Totais & 28 & - & 94,53 & 18,37 & 22,60 \\
\hline \multicolumn{6}{|c|}{2010} \\
\hline Mercado Tradicional & 5 & - & 45,42 & 14,41 & 19,26 \\
\hline Nível 1 & 9 & - & 41,31 & 15,96 & 17,23 \\
\hline Nível 2 & 1 & 0,15 & 0,15 & 0,15 & - \\
\hline Novo Mercado & 13 & - & 94,94 & 18,13 & 26,58 \\
\hline Totais & 28 & - & 94,94 & 16,13 & 21,65 \\
\hline
\end{tabular}

Nota-se na Tabela 2, que o novo mercado destacou-se com o maior índice médio de intangibilidade, ou seja, dentre o ativo total, as empresas desse nível de governança possuíam, em média, nos anos de 2010 e 2015 , o equivalente a $10 \%$ e $8 \%$ de ativos intangíveis. Todavia, destaca-se que tais empresas obtiveram médias iguais as do mercado tradicional nos anos de 2012 e 2013, enquanto o mercado tradicional obteve maior média no ano de 2011.

Verificou-se que as empresas com maiores percentuais de representatividade do novo mercado foram empresas do setor de construção e transporte, telecomunicações e materiais básicos (Rumo Log, CCR SA, Fibria). Percebe-se que esse cenário mudou desde a pesquisa realizada por Moura, Theiss e Cunha (2014) nos de 2009 e 2010, visto que, os autores verificaram que o setor do novo mercado de maior representatividade de intangível no ativo total foram os setores de construção e transporte, utilidade pública e consumo não cíclico.

Observa-se que a empresa representante do Nível 2 (Klabin SA) não registrou percentual de ativos intangíveis em relação ativo total. Algumas outras empresas dos demais níveis de governança corporativa também não tiveram representatividade dos intangíveis no ativo total, como a BR Malls Par e o Bradesco, por exemplo. 0 maior percentual de ativos intangíveis no ativo total que foi evidenciado, refere-se ao registrado pela empresa Rumo Log (setor de construção e transporte - novo mercado), nos anos de 2010 e 2011 (58\%).

No geral, o desvio padrão observado nas empresas deste nível, mostrou que os dados estão espalhados por uma gama de valores. Em outras palavras, não há uma homogeneidade nos percentuais de intangíveis no ativo total registrados pelas empresas do novo mercado, mostrando-se que os valores estão mais dispersos em relação à média. Ao passo que houve maior homogeneidade nos percentuais nas empresas do nível 1.

De forma geral, ao analisar máximas, médias e desvio padrão, nota-se que nos anos de 2010 e 2011 houve um registro percentual maior de ativos intangíveis em relação ao ativo total, comparativamente aos demais anos da amostra.

Infere-se que tais registros em quantidades maiores, nos respectivos anos, é reflexo da adoção das novas normas e, na época, da recente obrigatoriedade do registro destes elementos, vez que, passou a ser 
obrigatório o registro de intangíveis no balanço patrimonial após a edição da Lei no 11.638/2007, que tornou compulsória a introdução do Intangível no Ativo Não Circulante.

Em seguida, o Pronunciamento Técnico CPC 04 (2008), com base no International Accounting Standard (IAS) 38, estabeleceu critérios de contabilização relativos ao reconhecimento e mensuração dos ativos intangíveis, exigindo a divulgação de informações específicas sobre eles em notas explicativas aos relatórios institucionais das empresas.

Observa-se ainda na Tabela 2, que as empresas de nível 1 apesar de terem menor percentual comparadas as que tiveram maior representatividade, foram as que mantiveram resultados mais estáveis, enquanto o mercado tradicional e o novo mercado registraram maiores oscilações de aumento e queda no percentual de intangíveis no ativo total, até o ano de 2014.

Após observar o percentual de ativo intangível no ativo total, entende-se que seria proveitoso analisar-se a representatividade dos ativos intangíveis no ativo fixo das empresas no período de 2010 a 2015 , novamente dentro de cada nível de governança corporativa da B3.

Tabela 3 - Representatividade dos intangíveis no ativo fixo das empresas no período de 2010 a 2015 de acordo com os níveis de governança corporativa da B3

\begin{tabular}{|c|c|c|c|c|c|}
\hline Setor econômico da B3 & $\begin{array}{c}\text { № } \\
\text { empresas }\end{array}$ & Mínimo & Máximo & Média & Desvio Padrão \\
\hline \multicolumn{6}{|c|}{2015} \\
\hline Mercado Tradicional & 5 & 0,00 & ,33 & ,0869 & , 13548 \\
\hline Nível 1 & 9 & 0 & 0,2 & 0,0537 & 0,07173 \\
\hline Nível 2 & 1 & ,00 & ,00 & ,0007 & - \\
\hline Novo Mercado & 13 & 0,00 & ,53 & 0933 & , 15177 \\
\hline Totais & 28 & - & 1,06 & 0,23 & 0,36 \\
\hline \multicolumn{6}{|c|}{2014} \\
\hline Mercado Tradicional & 5 & - & 0,19 & 0,05 & 0,08 \\
\hline Nível 1 & 9 & - & 0,14 & 0,04 & 0,05 \\
\hline Nível 2 & 1 & 0,00 & 0,00 & 0,00 & - \\
\hline Novo Mercado & 13 & - & 0,56 & 0,10 & 0,16 \\
\hline Totais & 28 & - & 0,56 & 0,07 & 0,12 \\
\hline \multicolumn{6}{|c|}{2013} \\
\hline Mercado Tradicional & 5 & - & 0,22 & 0,06 & 0,09 \\
\hline Nível 1 & 9 & - & 0,15 & 0,04 & 0,05 \\
\hline Nível 2 & 1 & 0,00 & 0,00 & 0,00 & - \\
\hline Novo Mercado & 13 & - & 0,17 & 0,06 & 0,08 \\
\hline Totais & 28 & - & 0,22 & 0,05 & 0,07 \\
\hline \multicolumn{6}{|c|}{2012} \\
\hline Mercado Tradicional & 5 & - & 0,24 & 0,06 & 0,10 \\
\hline Nível 1 & 9 & - & 0,14 & 0,04 & 0,05 \\
\hline Nível 2 & 1 & 0,00 & 0,00 & 0,00 & - \\
\hline Novo Mercado & 13 & - & 0,19 & 0,06 & 0,08 \\
\hline Totais & 28 & - & 0,24 & 0,05 & 0,07 \\
\hline
\end{tabular}


Tabela 3 - Representatividade dos intangíveis no ativo fixo das empresas no período de 2010 a 2015 de acordo com os níveis de governança corporativa da B3

(continuação...)

\begin{tabular}{|c|c|c|c|c|c|}
\hline \multicolumn{6}{|c|}{2011} \\
\hline Mercado Tradicional & 5 & - & 0,30 & 0,12 & 0,15 \\
\hline Nível 1 & 9 & - & 0,15 & 0,05 & 0,06 \\
\hline Nível 2 & 1 & 0,00 & 0,00 & 0,00 & - \\
\hline Novo Mercado & 13 & - & 0,58 & 0,09 & 0,16 \\
\hline Totais & 28 & - & 0,58 & 0,08 & 0,13 \\
\hline \multicolumn{6}{|c|}{2010} \\
\hline Mercado Tradicional & 5 & - & 0,28 & 0,07 & 0,12 \\
\hline Nível 1 & 9 & - & 0,16 & 0,05 & 0,06 \\
\hline Nível 2 & 1 & 0,00 & 0,00 & 0,00 & - \\
\hline Novo Mercado & 13 & - & 0,58 & 0,08 & 0,16 \\
\hline Totais & 28 & - & 0,58 & 0,07 & 0,13 \\
\hline
\end{tabular}

Fonte: dados da pesquisa.

Verifica-se na Tabela 3 que dentro dos anos analisados, as empresas do novo mercado sobressaíram-se com maiores as médias de representatividade dos ativos intangíveis no ativo fixo em praticamente todos os anos da análise, a exceção do ano de 2011 onde o mercado tradicional obteve maior média. Percebe-se que existem empresas que não possuem ativos intangíveis, desta forma o valor mínimo encontrado foi zero.

O maior percentual de ativo intangível no ativo total foi evidenciado pela empresa Vale (setor de materiais básicos - nível 1), no ano de 2010. Porém, de modo geral foram as empresas do novo mercado que registraram os maiores percentuais $(94,94 \%)$.

Nota-se ainda que, o desvio padrão das empresas do novo mercado apresentou valores altos e oscilação ao longo dos anos, indicando que os dados destas empresas estão espalhados por uma gama de valores, portanto, estão mais dispersos em relação à média.

Observa-se que a empresa de nível 2 Klabin SA, comparada as demais, obteve as menores médias, na sequência vem as de nível 1 onde dentro do período de análise sofreu quedas e oscilações fechando 2014 com média de 9,21\%.

A segunda menor média trata-se das empresas do mercado tradicional, que em 2010 registraram um percentual de 14,41\%, aumentando em 2011 e depois veio sofrendo declínio nos anos seguintes, terminando 2014 com 11,94\%. A propósito, a empresa do mercado tradicional que teve a menor média percentual de intangíveis em relação ao ativo total, foi a Americanas.

Percebe-se que de forma geral, ao longo dos anos em estudo, houveram oscilações de queda e aumento nos diversos níveis de governança corporativa no tocante aos percentuais de ativos intangíveis no ativo fixo, porém, não foram de grande magnitude.

Por fim, buscaram-se os intangíveis evidenciados nos relatórios contábeis que compõem o subgrupo ativo intangível no balanço patrimonial das empresas e, posteriormente, realizou-se o reagrupamento de acordo com a classificação proposta por Sveiby (1998), em que os ativos intangíveis são divididos em três grupos, a saber: competência dos funcionários, estrutura interna e estrutura externa, conforme exposto na Tabela 4. 
Tabela 4 - Ativos intangíveis evidenciados pelas empresas da amostra no período de 2010 a 2015

\begin{tabular}{|c|c|c|c|c|c|c|c|c|c|c|c|c|c|}
\hline \multirow{2}{*}{$\begin{array}{l}\text { Intangíveis evidenciados na amostra } \\
\text { pesquisada }\end{array}$} & \multirow{2}{*}{$\begin{array}{l}\text { Total } \\
\text { Empr. }\end{array}$} & \multicolumn{2}{|c|}{2010} & \multicolumn{2}{|c|}{2011} & \multicolumn{2}{|c|}{2012} & \multicolumn{2}{|c|}{2013} & \multicolumn{2}{|c|}{2014} & \multicolumn{2}{|c|}{2015} \\
\hline & & № & $\%$ & № & $\%$ & № & $\%$ & № & $\%$ & № & $\%$ & № & $\%$ \\
\hline \multicolumn{14}{|c|}{ Capital Interno } \\
\hline Softwares/Sistemas informatizados & 28 & 19 & 68 & 20 & 71 & 20 & 71 & 20 & 71 & 19 & 68 & 19 & 68 \\
\hline Softwares em andamento/desenvol. & 28 & 2 & 7 & 4 & 14 & 5 & 18 & 5 & 18 & 5 & 18 & 5 & 18 \\
\hline Direitos de uso de infraestrutura & 28 & 2 & 7 & 3 & 11 & 3 & 11 & 4 & 14 & 3 & 11 & 3 & 11 \\
\hline Intangíveis em desenvolvimento & 28 & 3 & 11 & 3 & 11 & 3 & 11 & 3 & 11 & 3 & 11 & 3 & 11 \\
\hline Tecnologia & 28 & 1 & 4 & 1 & 4 & 1 & 4 & 1 & 4 & 1 & 4 & 1 & 4 \\
\hline Desenvolvimento de projetos & 28 & 2 & 7 & 1 & 4 & 1 & 4 & 1 & 4 & 1 & 4 & 1 & 4 \\
\hline Direitos por aquisição de folha pagto & 28 & 2 & 7 & 2 & 7 & 2 & 7 & 2 & 7 & 2 & 7 & 2 & 7 \\
\hline \multicolumn{14}{|c|}{ Capital Externo } \\
\hline Marcas e patentes & 28 & 8 & 29 & 8 & 29 & 9 & 32 & 9 & 32 & 11 & 39 & 11 & 39 \\
\hline Contratos de Concessão & 28 & 10 & 36 & 7 & 25 & 8 & 29 & 9 & 32 & 6 & 21 & 6 & 21 \\
\hline Contratos de exclusividade & 28 & 0 & 0 & 0 & 0 & 1 & 4 & 1 & 4 & 0 & 0 & 0 & 0 \\
\hline Licenças regulatórias & 28 & 1 & 4 & 2 & 7 & 2 & 7 & 2 & 7 & 2 & 7 & 2 & 7 \\
\hline Ágio sobre investimentos & 28 & 16 & 57 & 15 & 54 & 16 & 57 & 18 & 64 & 18 & 64 & 18 & 64 \\
\hline Relacionamento com clientes & 28 & 1 & 4 & 2 & 7 & 3 & 11 & 4 & 14 & 4 & 14 & 4 & 14 \\
\hline Carteira de clientes & 28 & 3 & 11 & 3 & 11 & 4 & 14 & 4 & 14 & 5 & 18 & 5 & 18 \\
\hline Relacionamento com fornecedor & 28 & 1 & 4 & 1 & 4 & 1 & 4 & 1 & 4 & 1 & 4 & 1 & 4 \\
\hline Contratos com clientes e fornecedores & 28 & 2 & 7 & 2 & 7 & 2 & 7 & 2 & 7 & 2 & 7 & 2 & 7 \\
\hline Acordos de não competição & 28 & 1 & 4 & 1 & 4 & 2 & 7 & 2 & 7 & 2 & 7 & 2 & 7 \\
\hline Uso de lavras & 28 & & 0 & & 0 & 1 & 4 & 1 & 4 & 1 & 4 & 1 & 4 \\
\hline Fidelização de integrados & 28 & 1 & 4 & 1 & 4 & 1 & 4 & 1 & 4 & 1 & 4 & 1 & 4 \\
\hline Fundo de comércio & 28 & 3 & 11 & 3 & 11 & 3 & 11 & 3 & 11 & 3 & 11 & 3 & 11 \\
\hline Direitos de exploração & 28 & 3 & 11 & 3 & 11 & 3 & 11 & 2 & 7 & 2 & 7 & 2 & 7 \\
\hline \multicolumn{14}{|c|}{ Competências dos funcionários } \\
\hline Know-how & 28 & & 0 & & 0 & & 0 & & 0 & 0 & 0 & 1 & 4 \\
\hline \multicolumn{14}{|c|}{ Outros intangíveis (não detalhados) } \\
\hline Outros intangíveis & 28 & 25 & 89 & 24 & 86 & 25 & 89 & 25 & 89 & 22 & 79 & 23 & 82 \\
\hline
\end{tabular}

Fonte: Dados da pesquisa.

A Tabela 4 apresenta os tipos de ativo intangível que compõem o grupo ativo intangível do balanço patrimonial e que foram citados de forma narrativa e mensurados individualmente nos relatórios anuais de administração e nas notas explicativas das empresas analisadas referentes ao período de 2010 a 2015. Contudo, algumas empresas apresentaram informações insuficientes para a realização da análise dos dados sobre tipos de ativos intangíveis evidenciados, quais sejam: Ambev S.A., Bradespar S.A., Klabin S.A., Rumo Logística Operadora Multimodal S.A.

Seguindo a classificação de Sveiby (1998), os resultados indicaram que as empresas sob análise possuíam uma estrutura intangível interna composta por softwares/sistemas informatizados, softwares em andamento/desenvolvimento, direitos de uso de infraestrutura, intangíveis em desenvolvimento, tecnologia, desenvolvimento de projetos e direitos por aquisição de folha de pagamento.

Uma estrutura externa composta por marcas e patentes, contratos de concessão, contratos de exclusividade, licenças regulatórias, ágio sobre investimentos, relacionamento com clientes, carteira de 
clientes, relacionamento com fornecedor, contratos com clientes e fornecedores, acordos de não competição, uso de lavras, fidelização de integrados, fundo de comércio e direitos de exploração.

Em relação à competência dos funcionários, não foram identificados intangíveis nessa classificação. Ressalta-se que, muitas empresas deixaram de detalhar alguns de seus AIs, desta forma, identificando-os como outros intangíveis.

Dentre os intangíveis evidenciados destacaram-se no período, os softwares (registrados como intangíveis por aproximadamente $70 \%$ das empresas da amostra); ágio sobre investimento (cerca de $59 \%$ ); marcas e patentes (32,2\%); contratos de concessão $(28,6)$ e outros intangíveis (torno de $86 \%$ ). Percebe-se que de 2010 a 2014 houve um acréscimo principalmente em marcas e patentes, ágio sobre investimentos e carteira de clientes.

Outros estudos já realizados identificaram, em linhas gerais, classificações de tipos de intangíveis similares aos verificados por esta pesquisa. Por exemplo, Antunes et al. (2009) identificaram como intangíveis mais utilizados os softwares (79\%), ágio (63\%) e marcas e patentes (31\%); Cunha et al. (2010) o destaque foi para os softwares (72\%), ágio (37,5\%) e marcas e patentes (30\%); Rita et al. (2010) identificou ágio $(73,4 \%)$, softwares $(15 \%)$ e direitos contratuais $(8,66 \%)$ como os de maior relevância; Moura (2011) constatou uma maior evidenciação de softwares (85\%), ágio sobre investimento (49\%), contratos e concessão (36\%) e marcas e patentes (31\%).

Desta forma, percebe-se que assim como nestas pesquisas mencionadas foram identificados como intangíveis mais destacados pelas empresas brasileiras, os softwares, ágio, marcas e patentes e contratos de concessão.

\section{CONSIDERAÇõES FINAIS}

O objetivo do trabalho foi analisar a composição dos ativos intangíveis das empresas listadas no índice de carbono eficiente (ICO2) da B3, verificando o valor dos ativos intangíveis, o percentual dos intangíveis em relação ao ativo total e fixo, os tipos de ativos intangíveis evidenciados nas empresas objeto da amostra de acordo com os níveis de governança corporativa ao qual submetem-se.

Para isso, realizou-se pesquisa descritiva, conduzida por meio de análise documental e abordagem quantitativa dos dados, em uma amostra que compreendeu 28 companhias listadas no ICO2, onde foram utilizadas informações constantes no sítio da Bolsa de Valores, Mercadorias e Futuros de São Paulo (B3), especificamente do balanço patrimonial e notas explicativas das respectivas empresas, dividindo-as nos níveis de governança corporativa ao qual pertencem.

Os resultados demonstraram que as empresas do mercado tradicional apresentam maior relevância dos valores de ativos intangíveis, enquanto as do novo mercado obtiveram maior representatividade dos ativos intangíveis no ativo total e fixo.

De forma geral, percebeu-se que os ativos intangíveis vêm manifestando variação ascendente ao longo dos anos. Apesar das oscilações de aumento e queda registradas no período de 2010 a 2015 houveram avanços no registro destes elementos pelas empresas, além de maior variabilidade de intangíveis demonstrados nas notas explicativas.

O dados mostraram que os intangíveis mais evidenciados nos relatórios contábeis foram softwares, evidenciados por aproximadamente $70 \%$ das empresas, seguido por ágio sobre investimento com cerca de $59 \%$, marcas e patentes com $32,2 \%$, contratos de concessão que representam 28,6 e outros intangíveis em torno de $86 \%$.

Constatou-se que dentro do período de análise prevaleceu uma evidenciação maior de intangíveis ao longo dos anos, onde esse acréscimo é encontrado principalmente em marca e patentes, ágio sobre investimento e carteira de clientes.

Concluiu-se que as empresas brasileiras vêm aumentando gradativamente o registro dos ativos intangíveis em seus balanços, desde a sua obrigatoriedade que se deu após o advento da Lei $\mathrm{n}^{0}$ $11.638 / 2007$ e posterior regulamentação dos critérios de contabilização relativos ao reconhecimento e mensuração dos ativos intangíveis feitos por meio do Pronunciamento Técnico CPC 04 de 2008.

Pelos estudos que realizados até o momento, amparado nos próprios resultados desta pesquisa, percebeuse que a proporção de investimentos em ativos intangíveis passou a ser expressiva ao longo dos anos, em contraste com o desinteresse de outrora. 
Infere-se, portanto, que a ascendência de registros e relevância dos intangíveis haverá de perdurar, visto que, como já comprovado por alguns estudos, dentre outras coisas, a qualidade da informação contábil aumenta consideravelmente com a inserção deste ativo.

A limitação desta pesquisa repousou no fato de que algumas empresas ainda não divulgaram os intangíveis em seus balanços, dificultando uma análise mais apurada e completa. Ademais, os anos da análise mostraram-se como outra limitação do estudo, vez que, no período anterior a 2010 poucas empresas faziam o registro do intangível em seu balanço patrimonial.

Como recomendação para pesquisas futuras, sugere-se estudar a referida amostra em anos posteriores; a realização da análise de companhias que compõem outros índices da B3; a combinação dos intangíveis das empresas desta amostra com o gerenciamento de resultados ou mesmo com o desempenho.

\section{REFERÊNCIAS}

[1] ANTUNES, M. T. P.; S, Luciana C.P.; SAIKI, T.G. 2009. Evidenciação dos Ativos Intangíveis (Capital Intelectual) por empresas brasileiras à luz da Lei no 11.638/07. In: Congresso Brasileiro de Custos, 16, Fortaleza, 2009. Anais... Fortaleza, ABC, p. 1-15.

[2] BARBOSA, José Geraldo P.; GOMES, Josir Simeone. Um estudo exploratório do controle gerencial de ativos e recursos intangíveis em empresas brasileiras. Revista administração contemporânea, v. 6, n. 2, Curitiba, maio/agosto, 2002.

[3] BARBOSA, Josilene da S.; ALTOÉ, Stella M. Lima; SILVA, Wesley V.; ALMEIDA, Lauro B. de. Índice carbono eficiente (ICO2) e retorno das ações: um estudo de eventos em empresas não financeiras de capital aberto. Revista de Contabilidade e Organizações, v. 19, Universidade Federal do Paraná, outubro, 2013.

[4] B3. Segmento de Listagem. Disponível $\quad$ em:
http://www.bmfbovespa.com.br/indices/ResumoCarteiraTeorica.aspx?Indice=ICO2\&idioma=pt-br. Acesso em: novembro de 2015.

[5] BRASIL. Lei no 11.638, de dezembro de 2007. Altera e revoga dispositivos da Lei no 6.404, de 15 de dezembro de 1976, e da Lei no 6.385, de 7 de dezembro de 1976, e estende às sociedades de grande porte disposições relativas à elaboração e divulgação de demonstrações financeiras. Disponível em: < http://www.planalto.gov.br/ccivil_03/_ato2007-2010/2007/lei/l11638.htm>. Acesso em: dezembro de 2015.

[6] CASSIMIRO LIMA, Áurea Isis; SOUZA, André Luis; FARIA, Joliano Almeida; RODRIGUES, Lívia. Previsão das séries temporais do Índice de Carbono Eficiente (ICO2) da B3: uma análise por meio de modelos de alisamento exponencial. Revista Exacta, v. 12, n. 3, Universidade Nove de Julho São Paulo, Brasil, 2014.

[7] CRISÓSTOMO, Vicente Lima. Ativos Intangíveis: estudo comparativo dos critérios de reconhecimento, mensuração e evidenciação adotados no Brasil e em outros países. Contabilidade, Gestão e Governança, v. 12, n. 1, p. 50-68, Brasília, jan/abr, 2009.

[8] CUNHA, Alessandra Garcia da; SOUZA, Andréia Alves de; SANTANA, Luiz Felipe de; MAGALHÃES, Vanessa Gonçalves de; PELEGRINI, Verônica Siqueira; MALAQUIAS, Rodrigo F. Evidenciação de Ativos Intangíveis: um Estudo com Empresas Brasileiras. In: Simpósio de Excelência em Gestão e Tecnologia, 7, Resende, 2010. Anais... Rio de Janeiro, AEDB.

[9] DECKER, Fabiana; ENSSLIN, Sandra Rolim; REINA, Diane Rossi Maximiano; REINA, Donizete. A relação entre os ativos intangíveis e a rentabilidade das empresas listadas no índice Bovespa. Reuna, v.18, n. 4, p. 75-98, Belo Horizonte - MG, Brasil, out/dez. 2013.

[10] FERNANDES, Tania Maria da Conceição Benther Machado. Ativo e sua mensuração. Caderno de estudos, n.18, São Paulo, Maio/Agosto, 1998.

[11] GIL, A. C. Métodos e técnicas de pesquisa social. 6. ed. São Paulo: Atlas, 2008.

[12] GOULART, André Moura Cintra. O conceito de ativos na contabilidade: um fundamento a ser explorado. Revista contabilidade e finanças, v.13, n. 28, São Paulo, jan./abr, 2002.

[13] HENDRIKSEN, Eldon S.; VAN BREDA, Michael F. Teoria da contabilidade. São Paulo: Atlas, 1999.

[14] KAYO, Eduardo Kazuo. A estrutura de capital e o risco das empresas tangível e intangível intensivas: uma contribuição ao estudo da valoração de empresas. Tese (Doutorado em Administração) - Faculdade de Economia e Administração, São Paulo, 2002.

[15] ____ KIMURA, Herbert; MARTIN, Diógenes Manoel Leiva; NAKAMURA, Wilson Toshiro. Ativos intangíveis, ciclo de vida e criação de valor. Revista administração Contemporânea, v. 10, n. 3, Curitiba, jul./set., 2006. 
[16] KREUZBERG, Fernanda; RIGO, Vitor Paulo; KLANN, Roberto Carlos. Relação entre os indicadores de desempenho financeiro e a intangibilidade dos ativos: um estudo das empresas listadas na B3. In: XVII SIMPÓSIO DE ADMINISTRAÇÃO DA PRODUÇÃO, LOGÍSTICA E OPERAÇõES INTERNACIONAIS, 2013,São Paulo. Anais... São Paulo: FGV, p. 1-15.

[17] LEITE, Thaís Silva; SANTOS, David Ferreira Lopes. A relação dos ativos intangíveis e o valor de mercado na indústria de materiais básicos do brasil. Revista Brasileira de Administração Científica, v. 4, n. 1, Aquidabã, Jan, Fev, Mar, Abr, Mai, Jun, 2013.

[18] MACÊDO, Francisca Francivânia Rodrigues Ribeiro; MOURA, Geovanne Dias de; GOLLO, Vanderlei; KLANN, Roberto Carlos. Evidenciação ambiental voluntária de companhias listadas no índice carbono eficiente da B3. RACE, Unoesc, v. 13, n. 1, p. 329-352, jan./abr., 2014.

[19] MACHADO, Julio Henrique; FAMÁ, Rubens. Ativos intangíveis e governança corporativa no mercado de capitais brasileiro. Revista Contemporânea de Contabilidade, v. 8, n. 16, p. 89-110, Florianópolis, Brasil, jul./dez., 2011.

[20] MARIN, Julia Karsburg; LISZBINSKI, Bianca Bigolin; KRONBAUER, Clóvis Antônio. Análise do reconhecimento contábil de ativos intangíveis em empresas brasileiras do setor financeiro. ReCont: Registro Contábil, v. 6, n. 2, Ufal, Maceió/AL, mai./ago., 2015.

[21] MOURA, Geovanne Dias de; THEISS, Viviane; CUNHA, Paulo Roberto. Ativos intangíveis e gerenciamento de resultados: uma análise em empresas brasileiras listadas na B3. Revista Base (Administração e Contabilidade) da UNISINOS, v. 11, n. 2, Universidade do Vale do Rio dos Sinos São Leopoldo, Brasil, abril/junho, 2014.

[22] ___. Conformidade do disclosure obrigatório dos ativos intangíveis e práticas de governança corporativa: Uma análise de empresas listadas na Bovespa. Blumenau, SC. Dissertação de Mestrado. Universidade Regional de Blumenau, 102 p., 2011.

[23] NASCIMENTO, Eduardo Mendes; MARQUES, Vagner Antônio; OLIVEIRA, Marleide Cerqueira de; CUNHA, Jacqueline Veneroso Alves da. Ativos intangíveis: análise do impacto do grau de intangibilidade nos indicadores de desempenho empresarial. Ref. Cont., v. 31, n. 1, p.37-35, UEM Paraná, Janeiro/abril, 2012.

[24] PEREZ, Marcelo Monteiro; FAMÁ, Rubens. Características estratégicas dos Ativos Intangíveis e o desempenho econômico da empresa. eGesta - Revista Eletrônica de Gestão de Negócios, v. 2, n. 2, abr./jun., 2006.

[25] _. Ativos Intangíveis e o desempenho empresarial. Revista contabilidade e finanças, v. 17, n. 40, São Paulo, jan./abr., 2006.

[26] COMITÊ DE PRONUNCIAMENTOS CONTÁBEIS. Pronunciamento Técnico CPC 04 - Ativo intangível. Disponível em: <static.cpc.mediagroup.com.br/.../187_CPC_04_R1_rev\%2006.pdf>. Acesso em: novembro de 2015.

[27] RICHARDSON, Roberto Jarry. Pesquisa Social: métodos e técnicas. 3. ed., 14 reimpr. - São Paulo: Atlas, 2012.

[28] RITTA, C.O.; ENSSLIN, S.R.; RONCHI, S.H. A evidenciação dos ativos intangíveis nas empresas brasileiras: Empresas que apresentaram informações financeiras à Bolsa de Valores de São Paulo e Nova York em 2006 e 2007. Revista Eletrônica de Ciência Administrativa, Campo Largo, 9 (1):62-75, 2010.

[29] SILVA, Marise Borba de; GRIGOLO, Tênis Maris. Metodologia para iniciação científica a prática da pesquisa e da extensão II. Caderno pedagógico. Florianópolis: Udesc, 2002.

[30] SVEIBY, K.E. A Nova Riqueza das Organizações: Gerenciando e Avaliando Patrimônios de conhecimento. Rio de Janeiro, Campus, 260 p., 1998. 


\section{Capítulo 8}

\section{ECONOMIA CIRCULAR: REPENSANDO AS CÁPSULAS DE CAFÉ EXPRESSO}

\section{Fabiana Rodrigues Barboza de Andrade \\ Lilian Bechara Elabras Veiga}

Resumo: 0 café é a segunda bebida mais consumida no Brasil, perdendo apenas para a água. A introdução das cápsulas de café expresso no mercado brasileiro, contribuiu para o aumento deste consumo. Sob a ótica ambiental, o fim da vida útil das cápsulas de café expresso constitui um sério problema relativo a geração e disposição dos resíduos. Os problemas resultantes do descarte, grande parte das vezes, inadequado das cápsulas exigem alternativas sustentáveis e economicamente viáveis. Nesse sentido, a Economia Circular, vem sendo apontada globalmente como uma alternativa para minimizar os efeitos negativos resultantes do aumento dos padrões ilimitados de produção e consumo, assim como reduzir o crescente desperdício de "valiosos" recursos naturais, muitos dos quais finitos e escassos. Ao eliminar o conceito de "fim do ciclo de vida", a Economia Circular, busca manter os recursos em uso, circulando na economia o máximo possível, extraindo ao máximo o seu valor. Neste sentido, os produtos e materiais são reutilizados e recuperados de forma a aumentar a sua permanência, sua circularidade na economia. Diante do conceito de economia Circular, esse estudo apresenta o crescente mercado das cápsulas de café expresso no Brasil, o consequente aumento nos resíduos gerados pelas embalagens monodoses, sugerindo a Economia Circular como uma possível alternativa sustentável e viável. A título de exemplificação apresenta-se o caso da Nespresso, empresa pioneira na venda de café em cápsulas no mundo. Contudo, apesar dos avanços conseguidos pela Nespresso, a empresa não conseguiu atingir a circularidade. O sucesso da Economia Circular pressupõe uma maior cooperação e parceria entre os agentes público e privado. Para tanto, uma visão mais abrangente e integradora é necessária, na qual os interesses destes atores possam convergir para um mesmo objetivo: um desenvolvimento sustentável em pró de um bem-estar comum.

Palavras-chave: Economia circular, Sustentabilidade, Capsulas de Café Expresso, Resíduos 


\section{INTRODUÇÃO}

O café é a segunda bebida mais consumida no Brasil, perdendo apenas para a água. Com a introdução das cápsulas de café expresso no mercado, estima-se que o consumo continue a crescer. Pesquisa realizada pela Associação Brasileira da Indústria de Café (EMBRAPA, 2015) aponta que apesar do cenário de estabilidade, até 2019, o crescimento do consumo das cápsulas irá dobrar de volume. Esse crescimento pode ser atribuído também a perda da patente da Nespresso, em 2013, que contribuiu para o aumento da concorrência no setor. De acordo com a revista eletrônica Negócio do Varejo (2016), "agora, as máquinas da Nespresso são compatíveis com cápsulas de mais de 200 concorrentes no mundo".

Do ponto de vista ambiental, o fim da vida útil das cápsulas de café constitui um sério problema no que diz respeito à geração e disposição desses resíduos. Os problemas enfrentados pelo descarte inadequado das cápsulas exigem alternativas sustentáveis e economicamente viáveis. Nesse sentido, podemos destacar a Economia Circular (EC), um modelo econômico que busca substituir o modelo de produção tradicional linear (extrair, transformar e descartar) pelo modelo de produção circular: "Baseada na eficiência produtiva, a EC é apresentada hoje como uma alternativa viável e atrativa, pois traz o máximo de valor e utilidade para os produtos, componentes e materiais" (MUSEU DO AMANHÃ, 2016). A EC busca manter os recursos em uso, circulando na economia, extraindo ao máximo o seu valor. Neste sentido, os produtos e materiais são reutilizados e recuperados de forma a aumentar a sua permanência na economia, reduzindo, consequentemente o consumo de recursos naturais e a geração de resíduos.

Diante desse modelo de circularidade da economia, tendo em vista o aumento considerável da produção das embalagens individuais para café, e seu descarte inadequado, este artigo tem por objetivo apresentar o crescente mercado das cápsulas de café expresso no Brasil e o consequente aumento dos resíduos gerados pelas embalagens monodoses, apresentando a EC como uma possível alternativa sustentável e viável para minimizar esse problema. Neste sentido, apresenta-se a título de exemplificação o caso da Nespresso, empresa pioneira na venda de café em cápsulas no mundo.

\section{ECONOMIA CIRCULAR}

Na última década, o conceito de EC vem despertando a atenção mundial. 0 conceito está sendo apontado por países desenvolvidos e desenvolvimento, como uma possível forma de minimizar os efeitos negativos resultantes do aumento dos padrões ilimitados de produção e consumo, assim como para reduzir o crescente desperdício de "valiosos" recursos naturais, muitos dos quais finitos e escassos (GHISELLINI el al., 2016). A EC promove o modelo cíclico de produção e consumo, em contraste ao modelo linear "extrair-transformar-descartar", onde, após a extração da matéria-prima, a manufatura e uso dos produtos; estes são descartados na natureza como resíduos. Assim, ao eliminar o conceito de "fim do ciclo de vida", a EC, busca manter os recursos em uso, circulando na economia o máximo possível, extraindo ao máximo o seu valor. Neste sentido, os produtos e materiais são reutilizados e recuperados de forma a aumentar a sua permanência na economia. Como Wrinkler (2011) explica, muitos impactos ambientais negativos resultantes do processo produtivo poderiam ser evitados se as empresas, de forma análoga aos sistemas naturais, estabelecessem sistemas de produção com ciclo fechado, em busca de uma maior eficiência no uso dos recursos.

A transição global para o modelo de EC vem sendo disseminada globalmente, através de instituições como Ellen MacArthur Foundation, Cradle to Cradle Products Innovation Institute, entre outras.

A Ellen Macarthur Foundation $(2013,2014)$ caracteriza a EC como um sistema que é "restaurativo e regenerativo por princípio. Seu objetivo é manter produtos, componentes e materiais em seu mais alto nível de utilidade e valor, o tempo todo, distinguindo entre ciclos técnicos e biológicos. Esse novo modelo econômico busca, em última instância, dissociar o desenvolvimento econômico global do consumo de recursos finitos". Para a instituição, a EC tem por objetivo aumentar a eficiência da utilização dos recursos, a fim de alcançar um melhor equilíbrio e harmonia entre economia, meio ambiente e sociedade. Neste sentido, a EC busca estabelecer um novo modelo de desenvolvimento econômico, de produção, distribuição e recuperação de produtos.

\section{CAFÉ NO BRASIL}

O Brasil é o maior exportador de café no mercado mundial e ocupa a segunda posição, entre os países consumidores da bebida. Devido à diversidade das regiões ocupadas pela cultura do café, o país produz tipos variados do produto, fato que possibilita atender às diferentes demandas mundiais (ABIC, 2018). 
Conforme dados do Ministério da Agricultura, Pecuária e Abastecimento (MAPA), a cafeicultura brasileira é uma das mais exigentes do mundo, em relação às questões sociais e ambientais, havendo uma preocupação em garantir a produção de um café sustentável.

\subsection{EVOLUÇÃO E MERCADO}

O café chegou ao norte do Brasil em 1727 trazido da Guiana Francesa. Devido às condições climáticas do país, o cultivo de café se espalhou rapidamente, e sua cultura se estabeleceu primeiramente no Vale do Rio Paraíba, iniciando em 1825 um novo ciclo econômico no país. Em sua trajetória pelo Brasil o café passou pelo Maranhão, Bahia, Rio de Janeiro, São Paulo, Paraná e Minas Gerais. Em um curto espaço de tempo, o café passou de uma posição relativamente secundária, para ser o produto de base da economia brasileira (REVISTA CAFEICULTURA, 2011).

Por quase um século, o café foi a grande riqueza brasileira, e as divisas geradas pela economia cafeeira aceleraram o desenvolvimento do Brasil e o inseriram nas relações internacionais de comércio (REVISTA CAFEICULTURA, 2011 a). A quebra na bolsa de Nova York em 1929 desestabilizou a economia cafeeira. Milhões de sacas de café foram queimadas na tentativa de estancar a queda de preços provocada pelos excedentes de produção. Com a recuperação da economia mundial a região Sudeste assume a liderança como centro produtor brasileiro (Revista Cafeicultura, 2009). No período de novembro de 2013 a outubro de 2014, o café havia se tornado a segunda bebida mais consumida no País, perdendo apenas para a água (EMBRAPA, 2015 a).

Em 2016, o Brasil era o maior produtor e exportador de café e segundo maior consumidor do produto no mundo. Em dezembro de 2016, o produto representou 9,8\% das exportações brasileiras, movimentando cerca de US\$ 600,74 milhões (MAPA, 2017).

O café em pó (torrado e moído) é o mais consumido, porém, vem ocorrendo uma migração. Um dos segmentos que mais vem crescendo é o do café em cápsulas, que demandam grãos de melhor qualidade. Segundo a ABIC (2015), o volume de vendas de cápsulas no país cresceu 52,4\% entre os anos de 2013 e 2014. 0 número de empresas que passaram a atuar neste segmento foi de oito em 2014, para 70 em 2015.

O estudo intitulado "Tendências do Mercado de Cafés" (Euromonitor International, 2016) apresentou como o mercado de café está estruturado no Brasil e as tendências predominantes no setor. Os resultados apontam que em 2014, das 980 mil toneladas de café consumido, o mercado de café em cápsulas correspondia a $0,6 \%$ do volume total consumido no Brasil. Para 2019, o estudo estimou que as cápsulas corresponderão a 1,1\% do consumo, ou seja, um crescimento médio anual de 15,3\% para o período de 2014 a 2019, e que o mercado de cápsulas deverá crescer até 2019 em 120\%. Esse crescimento é atribuído a maior disponibilidade de cápsulas, a partir da queda da patente da Nespresso, tornando mais acessível o consumo. Importante mencionar, que quando foi criada, a máquina da Nespresso era protegida por 1.700 patentes, que vem sendo gradualmente derrubadas na justiça.

A figura 1 apresenta a estimativa de evolução do mercado de café em cápsula no Brasil, conforme a pesquisa da ABIC (ABIC, 2015).

Figura 1 - Estimativa de Evolução do Mercado de Café em Cápsula no Brasil

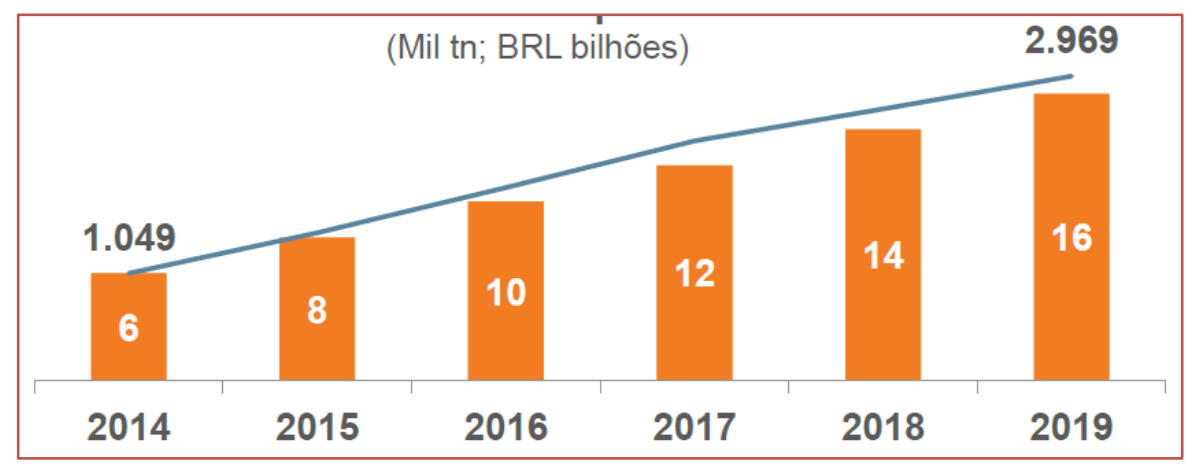




\subsection{MERCADO DAS CÁPSULAS DE CAFÉ}

As cápsulas de café chegaram ao Brasil em 2006, com a Nespresso, empresa do Grupo Nestlé. Desde então o crescimento em vendas desse setor vem sendo considerável, visto que saltou de $\mathrm{R} \$ 19$ milhões para R\$1,4 bilhão nos últimos dez anos (BICC, 2016). Atualmente existem vários tipos de cápsulas para café, dentre as quais se destacam as cápsulas em papel, plástico e metal, conforme demonstrada na figura 2.

Figura 2 - Cápsulas de papel, plástico e alumínio

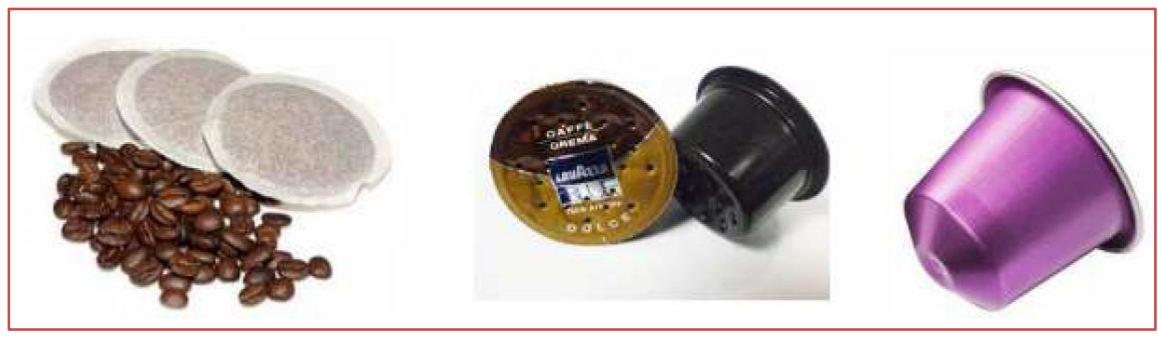

Fonte: Reis et al (2012)

A cápsula de papel, embora não proteja completamente o café da exposição à radiação solar e do contato com o ar, é muito leve, reciclável, barata e fácil de fabricar.

Para a fabricação da cápsula de plástico, utiliza-se o polipropileno, que é resistente à umidade e ao calor, reciclável e de baixo custo. Apesar de garantir as propriedades do café (aroma e sabor) por até 12 meses, este polímero é sensível aos raios ultravioleta e aos agentes de oxidação, degradando-se facilmente (REIS et al., 2012 a).

A cápsula em alumínio é o modelo mais popular no Brasil, pois assegura a manutenção, de forma eficaz, por um longo período, das propriedades do café, protegendo-o do contato direto com o oxigênio e a luz solar. 0 alumínio, por ser inerte, não influencia no aroma e no sabor do café. Sob a ótica ambiental o alumínio é um metal infinitamente reciclável, e ao ser reciclado sua pegada ecológica é menor do que quando é produzido (ABAL, 2017).

Por serem recentes, muitos países não dispõem de uma legislação específica sobre as cápsulas de alumínio. Embora funcionais, as novas cafeteiras monodoses, representam uma preocupação em relação ao meio ambiente, pois cada vez que uma cápsula é consumida, um novo resíduo é gerado.

\subsection{PRODUÇÃO DE ALUMÍNIO E IMPACTOS ASSOCIADOS}

A matéria-prima principal do alumínio metálico é a alumina (óxido de alumínio), extraída de um mineral, a bauxita. 0 processo de produção do alumínio envolve três etapas, tendo início com a mineração - extração da bauxita. Após o tratamento e o processamento do minério, obtém-se a alumina, que, em um terceiro momento, através de processo eletrolítico, é transformada em alumínio metálico (alumínio primário) (ANDRADE et al., 2001). O metal obtido, alumínio primário, é resistente, anticorrosivo, reciclável, permitindo que seja utilizado de forma extensiva para a produção de diversos itens, tais como ligas metálicas, laminados e extrudados (CARDOSO et al.,2011). Para a produção de uma tonelada de alumínio primário, são necessárias 4,5 toneladas de bauxita (PEREIRA, 2015).

Por ser um metal estável, a produção de alumínio demanda grande quantidade de energia. 0 custo da energia no processo da obtenção do alumínio é um fator determinante, responsável por cerca de 35\% do custo de produção do metal (CARDOSO et al.,2011 a).

Os impactos são gerados ao longo de toda a cadeia produtiva, desde a extração da bauxita (mineração) até a transformação da alumina em alumínio (refino). Na mineração é gerado um grande volume de resíduo de rocha. Nesta etapa o solo perde a capacidade de reter água, tornando-se inadequado para cultivos anuais. No refino, é gerada uma lama vermelha, que normalmente é descartada em áreas já mineradas. Essa prática leva à contaminação do lençol freático e dos córregos próximos, além de elevar o teor de sódio dos poços artesianos vizinhos.

O processamento do alumínio primário, resulta na emissão de gases altamente poluentes (PEREIRA, 2015 a). A produção mundial de alumínio responde por cerca de $2 \%$ dos gases de efeito estufa (GEE). Ao 
contrário de outros materiais, o alumínio ao ser reciclado não perde suas propriedades, podendo ser reutilizado, indo, assim, de encontro as premissas da EC.

\section{CAPSULAS DE CAFÉ:}

\subsection{CÁPSULAS NESPRESSO}

A Nespresso é uma empresa autônoma de gestão global do Grupo Nestlé S.A., fundada em 1986, com sede em Lausanne, Suíça. A empresa está presente em mais de 60 países (NESPRESSO, 2017 a). Quando fundada, em 1986, a empresa possuía 5 empregados, em 2000, este número chegou a 331, e hoje conta com 12.000 empregados distribuídos nas 450 boutiques e 3 fábricas, Avenches, Orbe e Romont, todas na Suíça.

A empresa, pioneira no segmento global de cafés em cápsulas, preocupada com a sustentabilidade de seu negócio, investe em toda a sua cadeia de valor, desde a capacitação/ treinamento dos fazendeiros quanto a melhores práticas agrícolas, iniciativas para redução de custos, cultivo sustentável, à coleta e reciclagem das capsulas de café.

O programa de reciclagem da Nespresso teve início em 1991, na Suíça. A participação dos consumidores é fundamental. Para isso a empresa investiu no aumento do número de pontos de coleta de cápsulas, em quinze países recolhe as cápsulas diretamente na casa dos consumidores ao realizar uma entrega (Nespresso Recycling@Home Initiative) ou mesmo, as cápsulas podem ser enviadas pelo correio sem custo para o consumidor. Em vinte países através do aplicativo Nespresso é possível identificar o ponto de coleta mais próximo. Em 2013, a empresa possuía 14.000 pontos de coleta no mundo. No Brasil, existem 25 pontos de coleta localizados nas boutiques da marca e, também, em lojas parceiras (NESPRESSO, 2017 b). Ao final de 2015 , a Nespresso coletava $86 \%$ das cápsulas em 39 países. A meta estabelecida é $100 \%$ até 2020. Percebe-se que as opções de coleta variam de país para país, se adequando aos sistemas de reciclagem locais.

A empresa recicla $75 \%$ das cápsulas vendidas no mundo, tendo reduzido a pegada de carbono por cápsula em $20 \%$. 0 alumínio é a principal matéria prima utilizada na produção das cápsulas de café da Nespresso. A quantidade de alumínio utilizado é de um grama. Uma lata de refrigerante utiliza 13 a 14 gramas de alumínio (NESPRESSO, 2017 c). Além do alumínio, a borra do café presente nas cápsulas também apresenta oportunidades de revalorização. Alguns países como a Suíça, Reino Unido, Austrália e Emirados Árabes Unidos, separam as borras de café do alumínio e utilizam como fertilizantes adubados e briquetes de aquecimento. Outros países utilizam a borra de café para gerar energia, através do processo de pirolise ou na produção de biogás, como na Áustria e a Suíça.

Com base nos princípios da EC, as cápsulas descartadas nos pontos de coleta da Nespresso são enviadas a um centro, onde é feita a separação da borra do café do alumínio, para que cada resíduo tenha a destinação adequada. A borra do café é enviada a uma empresa que a transforma em compostos orgânicos, e o alumínio se transforma em insumo para cadeias produtivas como as de tintas e vigas metálicas, para uso na construção civil. Percebe-se assim que o alumínio reciclado não é utilizado para a fabricação de novas cápsulas, sendo reinserido em outra cadeia produtiva (INCAE, 2015).

Visando identificar os impactos ambientais da sua cadeia de valor, principalmente quanto ao consumo de energia e emissão de gases de efeito estufa, a Nespresso realizou a Avaliação do Ciclo de Vida (ACV) de seu processo produtivo (INCAE, 2015 a). Os principais resultados apontaram que:

- As maiores emissões de GEE provem do cultivo do café e do uso da máquina Nespresso.

- A dose de café contida em uma cápsula consume precisamente a quantidade certa de energia, água e café, evitando assim o desperdício.

- Ao comparar a cápsula da Nespresso com as de três outros fabricantes existentes no mercado, a ACV concluiu que a da Nespresso, feita de alumínio, e depois reciclada, produz o menor impacto ambiental.

A partir do resultado da ACV, a empresa investiu na melhoria de seu desempenho ambiental em diversas áreas: cultivo do café, inovação das máquinas, operações de negócios e reciclagem das cápsulas usadas.

A Nespresso tornou-se um dos primeiros membros da Iniciativa Economia Circular 100 (CE 100), liderada pela Fundação Ellen MacArthur. A CE 100 é uma plataforma global que reúne empresas líderes e inovadoras visando impulsionar a transição para uma EC. 
Cabe mencionar, que no Brasil, a Nestlé é signatária, no âmbito da Política Nacional de Resíduos Sólidos (PNRS, Lei 12.305 de 2010) do Acordo Setorial para a Reciclagem de Embalagens, assinado em novembro de 2015, sob coordenação do Compromisso Empresarial para a Reciclagem - Cempre.

\subsection{CÁPSULAS DE CAFÉ COMPOSTÁVEIS PURPOD100}

Após a queda da patente da Nespresso, o número de empresas produzindo café em cápsulas aumentaram, e o consumo se popularizou elevando assim os problemas ocasionados pela destinação incorreta das embalagens.

Diante desse novo cenário surgiu uma preocupação com os impactos causados pelo descarte indevido das cápsulas no meio ambiente. Para resolver essa questão, a empresa canadense Club Coffee desenvolveu uma alternativa sustentável, as cápsulas compostáveis PurPod100.

A PurPod100 se decompõe no meio ambiente em até 84 dias e pode ser utilizada em compostagem após o consumo, uma vez que contém nutrientes benéficos às plantas, a própria borra de café é utilizada como fertilizante natural (Revista Cafeicultura, 2016). As cápsulas são certificadas pelo Biodegradable Products Institute, BPI (BICC, 2016). O BPI é uma associação Norte Americana, que promove o uso e reciclagem de materiais poliméricos biodegradáveis, via compostagem. As cápsulas PurPod100, são produzidas com o próprio resíduo gerado durante o processamento do café. As cascas retiradas no processo de torra formam um bioplástico, que é a base para a cápsula, diminuindo assim a extração da matéria prima (Revista Cafeicultura, 2016 a). A cápsula é dividida em três partes (figura 3): selo, feito de papel e outros materiais compostáveis, impresso com tinta orgânica; anel, feito de resinas de fontes renováveis e resíduos de café (bioplástico); e a malha, que armazena o pó, produzida também com resíduos de café e outras substâncias compostáveis (PURPOD100, 2017).

Figura 3 - Estrutura da Cápsula Compostável

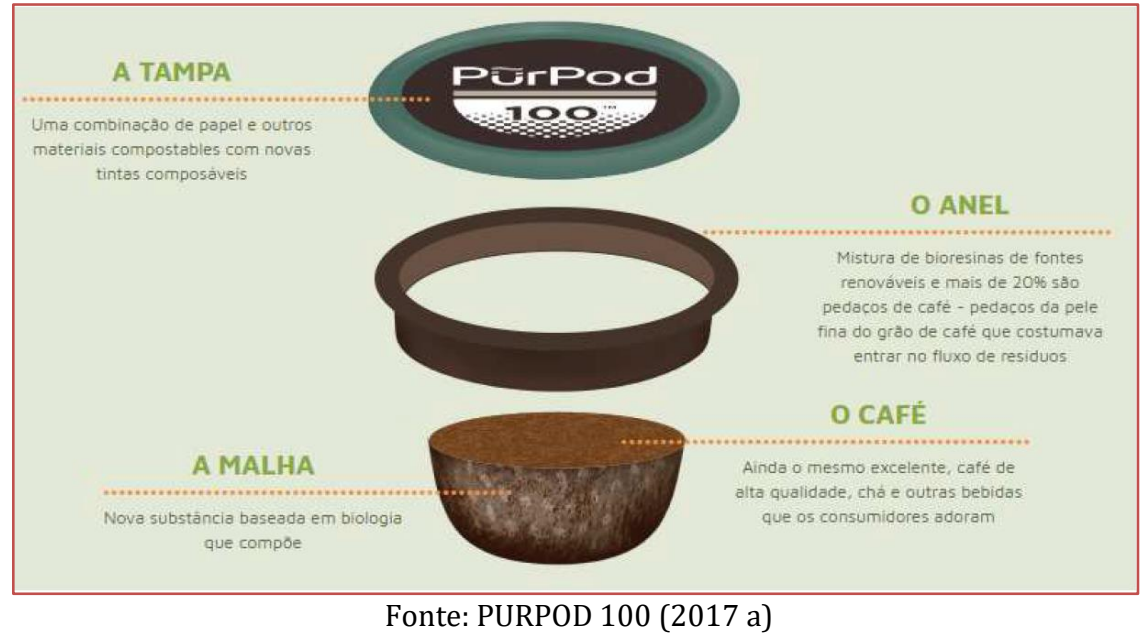

Entre as alternativas compostáveis, a barreira reside no fato de que as cápsulas, tal como as de plástico ou alumínio, precisam ser destinadas corretamente após o uso. Neste caso, para usinas de compostagem. (BICC, 2016 a).

O governo brasileiro, através da promoção de políticas públicas que envolvem a sustentabilidade, relacionadas ao tratamento de resíduos sólidos e as indústrias de materiais de embalagens compostáveis, tem buscado promover e apoiar o desenvolvimento da indústria da compostagem. Tal fato visa impulsionar o mercado de bioplásticos no país. (MMA, 2017).

\subsection{CÁPSULAS REUTILIZÁVEIS TOSTIO}

Visando uma alternativa ao sistema convencional de cápsulas descartáveis, e minimizar os problemas com o volume de resíduo gerado, a Tostio criou as cápsulas reutilizáveis de inox e alumínio. 
As cápsulas Tostio são compatíveis com diversas máquinas, dentre elas a Nespresso. A substituição do sistema convencional de cápsulas descartáveis pelo sistema reutilizável (Figura 4), resulta na redução da extração de recursos naturais e dos impactos ambientais, e à médio prazo, em uma economia para o consumidor (TOSTIO, 2016).

Figura 4 - Cápsulas Ecologicamente Corretas

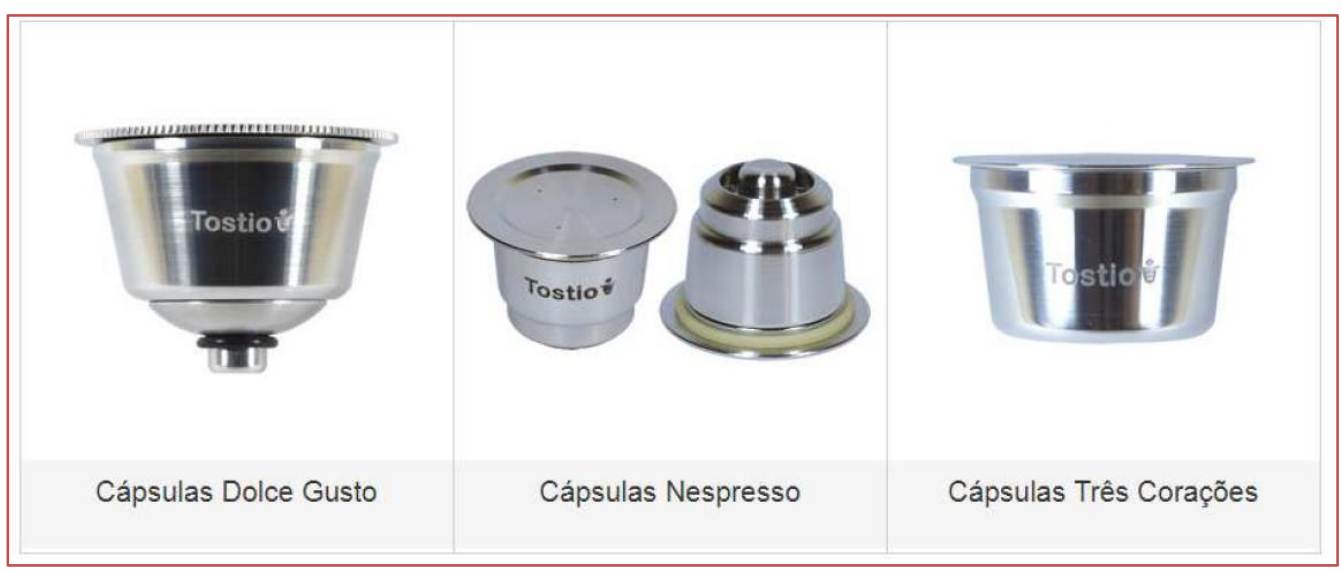

Fonte: TOSTIO (2016 a)

De acordo com a empresa Tostio, com base em um consumo diário de 2 cafés por dia, ao utilizar a cápsula reutilizável, o consumidor tem uma economia significativa, conforme demonstrado na figura 5.

Figura 5- Economia com a Cápsula Tostio

\begin{tabular}{|c|c|}
\hline $\begin{array}{l}365 \text { dias } X 2 \text { expressos }=730 \text { expressos por ano } \\
\text { Cápsulas Nespresso com custo de R\$ } 1,75 \text { a unidade } \\
730 \text { expressos } X \text { R\$ } 1,75 \text { por cápsula descartável = }\end{array}$ & $\begin{array}{l}365 \text { dias } \times 2 \text { expressos }=730 \text { expressos por ano } \\
\text { Café orgânico de alta qualidade }=\mathrm{R} \$ 40,00 / \mathrm{Kg}=\mathrm{R} \$ 0,25 \text { por dose } \\
730 \text { expressos } X \mathrm{R} \$ 0,25 \text { por dose }+\mathrm{R} \$ 139,00 \text { Cápsula Tostio }=\end{array}$ \\
\hline$R \$ 1.277,50$ & $R \$ 321,50$ \\
\hline
\end{tabular}

Fonte: TOSTIO (2016 a)

\section{CONSIDERAÇÕES FINAIS}

Conforme apresentado neste trabalho, o consumo de café expresso em cápsula tende a aumentar, e com isso as empresas necessitam repensar a forma como seus produtos são desenvolvidos, bem como o descarte correto de suas embalagens.

O atual padrão linear de produção e consumo representa um grande problema para o meio ambiente, resultando no aumento na demanda por recursos naturais, impactos ambientais e sociais adversos e, principalmente, na depleção de recursos naturais renováveis ou não renováveis. Deste modo, o desenvolvimento sustentável, através da EC pode ser uma alternativa aos anseios da sociedade.

A EC é um conceito de disseminação recente, que repensa o tradicional sistema industrial, rompendo com a sua linearidade, apresentando assim possibilidades para reduzir a quantidade de resíduos gerados, e consequentemente a extração de recursos naturais, proporcionando assim ganhos ambientais e econômicos, a partir da reinserção dos materiais, resultando em ciclos contínuos na economia.

Conforme evidenciado neste trabalho, a Nespresso, com a colaboração de seus consumidores, vem investido, a partir dos princípios da EC, em toda a sua cadeia de valor, buscando fechar o seu ciclo produtivo. As iniciativas da empresa se iniciam com práticas de cultivo sustentável, coleta e reciclagem das capsulas de café. Apesar de possuir um sistema próprio de reciclagem das cápsulas, estas ainda não são reinseridas na sua cadeia de produção. Outros modelos de cápsulas como a PurPod100 e a Tostio vem apresentando alternativas ao sistema convencional de cápsulas descartáveis. 
Entretanto, apesar dos avanços conseguidos pela Nespresso, a empresa não se conseguiu atingir a circularidade, ou seja, encontrar meios de produção, distribuição e consumo dos recursos existentes de forma mais coesiva, economicamente eficaz e ecologicamente viável e socialmente justa.

O sucesso da EC pressupõe uma maior cooperação e parceria entre os agentes público e privado. Para tanto, uma visão mais abrangente e integradora é necessária, na qual os interesses destes atores possam convergir para um mesmo objetivo: um desenvolvimento sustentável em pró de um bem-estar comum.

\section{AGRADECIMENTOS}

Agradecemos ao Instituto Federal de Educação, Ciência e Tecnologia do Rio de Janeiro pelo desenvolvimento deste estudo.

\section{REFERÊNCIAS:}

[1] ABAL - Associação Brasileira do Alumínio, 2017. Disponível em: http://www.abal.org.br/aluminio/caracteristicas-quimicas-e-fisicas/. Acesso março 2017.

[2] ABIC - Associação Brasileira da Indústria de Café. Relatório customizado preparado pelo Euromonitor International para Associação Brasileira da Indústria de Café (ABIC). Consórcio Pesquisa Café, 2015. 38p. Disponível em: http://consorciopesquisacafe.com.br/arquivos/consorcio/consumo/Tendencia_do_Mercado_de_Cafe__2015_1.pdf. Acesso junho 2016.

[3] ABIC - Associação Brasileira da Indústria de Café. O Café Brasileiro na Atualidade. 2018. Disponível em: http://abic.com.br/o-cafe/historia/o-cafe-brasileiro-na-atualidade/ Acesso abril 2018.

[4] ANDRADE, MLA, CUNHA, LMS, GANDRA, GT. A Indústria do Alumínio: desempenho e impactos da crise energética. 2001. Banco Nacional do Desenvolvimento Econômico e Social (BNDES).

[5] BRASIL. Política Nacional de Resíduos Sólidos, Lei no 12.305, de 2 de agosto de 2010. Disponível em:< http://www.planalto.gov.br/ccivil_03/_ato2007-2010/2010/lei/112305.htm>. Acesso outubro 2016.

[6] BICC, Bureau de Inteligência Competitiva do Café. Relatório Internacional de Tendências do Café. v.5, n.11. 12 p. 2016. Disponível em: < http://www.icafebr.com.br/publicacao2/v.5\%20n.11.pdf>. Acesso maio 2017.

[7] CARDOSO, JGR, et al. A indústria do alumínio: estrutura e tendências. Banco Nacional de Desenvolvimento Econômico e Social. 2011.

[8] ELLEN MACARTHUR FOUNDATION. Towards the Circular Econom: towards the economic and business rationale for an accelerated transition. 2013. Disponível em: https://www.ellenmacarthurfoundation.org/. Acesso maio 2017.

[9] ELLEN MACARTHUR FOUNDATION. Towards the Circular Economy: accelerating the scale-up across global supply chains. 2014. Disponível em: https://www.ellenmacarthurfoundation.org/. Acesso maio 2017.

[10] EMBRAPA - Empresa Brasileira de Pesquisa Agropecuária. Café é a segunda bebida mais consumida no Brasil. 2015. Disponível em: <https://www.embrapa.br/web/portal/busca-de-noticias/-/noticia/2574254/cafe-e-asegunda-bebida-mais-consumida-no-brasil>. Acesso junho 2016.

[11] REVISTA CAFEICULTURA. Crise de 1929 atingiu economia e mudou a ordem política no Brasil. 2009. Disponível em: < http://revistacafeicultura.com.br/?mat=27265>. Acesso abril 2017.

[12] REVISTA CAFEICULTURA. História do Café no Brasil. 2011. Disponível em: < http://revistacafeicultura.com.br/?mat=40384>. Acesso abril 2017.

[13] REVISTA CAFEICULTURA. Empresa canadense cria cápsula biodegradável de café. 2016. Disponível em: < http://revistacafeicultura.com.br/index.php?tipo=ler\&mat=62997>. Acesso abril 2017.

[14] EUROMONITOR INTERNATIONAL. Tendências do Mercado de Cafés. 36p. 2016. Disponível em: <http://consorciopesquisacafe.com.br/arquivos/consorcio/consumo/Tendencias_do_Mercado_Cafe_2016.pdf>. Acesso junho 2016.

[15] GHISELLINI, P., CIALANI, C., ULGIATI, S. A review on circular economy: the expected transition to a balanced interplay of environmental and economic systems. Journal of Cleaner Production 114:11-32. 2016.

[16] INCAE Business School. How should Nespresso Capitalize on the Opportunities of the Circular Economy to build a Premium Proposition for Aspirational Consumers? 2015. Disponível em: http://www.incae.edu/en/search/site/. Acesso junho 2016. 
[17] MAPA. Ministério da Agricultura, Pecuária e Abastecimento. 2017. Disponível em: <http://www.agricultura.gov.br/assuntos/politica-agricola/cafe/cafeicultura-rasileira\#section-3>. Acesso junho 2017.

MMA. Ministério do Meio Ambiente. Compostagem. 2017. Disponível em: <http://www.mma.gov.br/estruturas/secex_consumo/_arquivos/compostagem.pdf>. Acesso julho 2017.

[18] MUSEU DO AMANHÃ. Seminário Economia Circular e Sustentabilidade na Gestão de Resíduos Sólidos Urbanos. 2017. Disponível em: <https://museudoamanha.org.br/pt-br/seminarioeconomia-circular>. Acesso julho 2017.

[19] NESPRESSO. From pioneer to reference in premium portioned coffee. 2017a. Disponível em: <http://www.nestle-nespresso.com/about-us/our-company>. Acesso maio 2017.

[20] NESPRESSO. Pontos de Coleta Nespresso. 2017b. Disponível em: <https://www.nespresso.com/br/pt/localizador-lojas\#RECYCLING>. Acesso maio 2017.

[21] NESPRESSO. Aluminium Stewardship Initiative unveils new global standard for aluminium sustainability. 2017c. Disponível em: <https://www.nestle-nespresso.com/newsandfeatures/aluminiumstewardship-initiativeunveils-new-global-standard-for-aluminium-sustainability->. Acesso maio 2017.

[22] PEREIRA, S. V. Notas de aula da disciplina de Produção Industrial. Instituto Federal de Educação, Ciência e Tecnologia do Rio de Janeiro, 2015.

[23] PURPOD100. 2017. Disponível em: <http://purpod100.com/\#>. Acesso maio 2017.

[24] REIS, M. A. A. et alComo se fazem cápsulas para café. Portugal: Faculdade de Engenharia da Universidade do Porto - FEUP. 2012. Disponível em: <http://paginas.fe.up.pt/ projfeup/bestof/12_13/files/REL_1M6_04.PDF>. Acesso junho 2016.

TOSTIO. 2016. Disponível em: <http://www.tostio.com.br/produto/10185/capsula-reutilizaveltostio-inoxcompativel-com-sistema-nespresso>. Acesso outubro 2016.

[25] TOSTIO. 2016a. Disponível em: <http://www.tostio.com.br/conteudo/39/capsula-ecologica>. Acesso outubro 2016

[26] WINKLER, H. Closed-loop production systems-A sustainable supply chain approach. 4(3):243-246. 2011. 


\section{Capítulo 9}

\section{IMPACTOS DA (IN)FORMALIZAÇÃO DOS SERVIÇOS DE CONSTRUÇÃO CIVIL}

\section{Jefferson Pereira da Silva Castro \\ Samuel Carvalho De Benedicto \\ Mônica de Oliveira Rocha \\ Cibele Roberta Sugahara}

Resumo: Este trabalho tem como objetivo discutir os efeitos da (in)formalização dos serviços empregados em canteiros de obras, a partir de considerações técnicas, sociais, econômicas e ambientais. 0 estudo foi desenvolvido a partir da revisão de bibliografia relacionada às boas práticas sustentáveis em canteiros de obras e análise documental de uma importante pesquisa realizada pelo Instituto Datafolha em 2015 para averiguar a qualidade dos serviços de construção civil no País. 0 estudo revela que o setor de construção civil é um dos maiores causadores de impactos ambientais e sociais. 0 mesmo consome ao redor de 75\% dos recursos extraídos da natureza; é responsável por cerca de 50\% do $\mathrm{CO} 2$ lançado na atmosfera e por quase metade da quantidade dos resíduos sólidos gerados no mundo e apresenta um alto índice de informalidade tanto com relação aos funcionários construtores quanto a participação de profissionais responsáveis pelas construções. Portanto, esse setor deve adotar medidas para reduzir esses impactos. Entre outras ações, é cada vez mais necessária a criação de leis que visem processos sustentáveis, profissionais de engenharia com novas competências que incluem planejamento, controle e uma visão mais ampla do segmento. Contudo, isso surtirá efeito quando a sociedade passar a demandar mais o apoio desses profissionais em serviços relacionados à construção civil, já que atualmente grande parte das obras não possui engenheiros ou arquitetos envolvidos na criação de projetos ou na condução delas, como mostra o resultado da pesquisa utilizada como base deste artigo.

Palavras-chave: Resíduos de construção civil. Projetos sustentáveis. Profissionais de engenharia e arquitetura. Informalidade. 


\section{INTRODUÇÃO}

A construção civil tem uma participação de aproximadamente $40 \%$ de toda a economia mundial (HANSEN, 2008). Isto mostra o tamanho desta indústria e o quanto ela influencia não só na economia, mas também no meio ambiente e na sociedade como um todo. 0 mercado da construção civil é bastante produtivo e complexo, o qual abrange diversos setores industriais, entre estes: mineração, metalurgia do alumínio e do cobre, siderurgia do aço, indústria da cerâmica, madeira, plásticos, vidro, equipamentos elétricos e mecânicos, fios, cabos, prestadores de serviços, escritórios de projetos, serviços de engenharia, construção de ferrovias, rodovias, hidrelétricas, refinarias, portos, aeroportos, estaleiros, etc. (ANJOS; LEITE, 2016).

Entretanto, este segmento econômico é caracterizado por ser um dos maiores geradores de resíduos e desperdício de matéria prima; agressão ao meio ambiente; trabalho informal e em condições precárias; baixa higiene; baixos salários, precárias condições dos equipamentos de proteção individual; baixa ocorrência de treinamento dos trabalhadores; o Brasil lidera as estatísticas do número de acidentes fatais e não fatais (ANJOS; LEITE, 2016).

Como destacam Baptista Jr. e Romanel (2013), parte dos resíduos originados na construção civil é proveniente de demolições. Entretanto, grande parte é originada de desperdício de materiais em construções novas, resultante de projetos imprecisos, contendo especificações de materiais e detalhes incorretos, além de falta de planejamento na execução das obras. Isso é uma das consequências da falta de emprego de mão de obra de profissionais com formação técnica, como engenheiros e arquitetos. Os resíduos produzidos durante a fase de construção resultam das perdas do processo construtivo em suas etapas diversas, como planejamento, projeto, materiais, etc. A escolha adequada de tecnologias é fundamental no processo, porquanto influenciará na geração maior ou menor de perdas (BLUMENSCHEIN, 2007).

No Brasil, como mostra o IPEA (2012), a construção civil é a principal responsável por geração de resíduos sólidos urbanos. Deste modo, os resíduos da construção civil (RCC) representam um grave problema em muitas cidades brasileiras. Por um lado, a disposição irregular destes resíduos pode gerar problemas de ordem estética, ambiental e de saúde pública. Por outro lado, eles representam um problema que sobrecarrega os sistemas de limpeza pública municipais, visto que, no Brasil, os RCC podem representar de $50 \%$ a $70 \%$ da massa dos resíduos sólidos urbanos - RSUs.

Neste sentido, o Guia de Vigilância Epidemiológica da Fundação Nacional de Saúde (FUNASA, 2007) alerta de que o lançamento indevido de resíduos sólidos da construção civil, seja em vias públicas, calçadas, quintais e terrenos baldios - e sua permanência por longos períodos - contribuem de forma significativa para o agravamento de riscos à saúde humana, uma vez que permitem a proliferação de vetores de doenças infecciosas e zoonoses. Segundo Silva Júnior (2017), diversas doenças tradicionais como a cólera, leishmaniose visceral e leptospitose e outras emergentes como dengue, chikungunya e zika estão indiscutivelmente associadas às deficiências de manejo dos resíduos sólidos da construção civil.

Entretanto, além de causador de altos impactos ambientais, o setor de construção civil também é extremamente informal (ARANHA et al., 2016). Dados do Instituto de Pesquisa Econômica Aplicada (IPEA, 2010) revelam que a informalidade gera muito desperdício, aumenta desnecessariamente o consumo de energia e é responsável por grande parte da agressão à natureza. Por isso, é importante reduzir o alto grau de informalidade da economia brasileira, já que é totalmente incompatível com a industrialização e a sustentabilidade.

Segundo estudo realizado pelo Reporter Brasil, com o apoio da ONG Deutsche Gewerkschaftsbund (DGB), atualmente, mais de $8 \%$ dos trabalhadores brasileiros atuam na construção civil. Entretanto, suas condições de trabalho no setor são ruins, com alta informalidade e rotatividade, e índice preocupante de acidentes. Nos últimos anos, o setor ganhou notoriedade ao ser envolvido com o trabalho análogo ao escravo. Dezenas de casos vieram à luz em todo o país, quando o Ministério do Trabalho e Previdência Social (MTPS) apertou o cerco contra violações aos direitos dos operários. Em 2013, pela primeira vez na história, o número de trabalhadores reduzidos à condição de escravos nos centros urbanos foi superior ao das áreas rurais. Em 2015, do total de trabalhadores encontrados pelos fiscais nestas condições, 17\% trabalhavam na construção civil. (ARANHA et al., 2016).

Diante das considerações expostas, pergunta-se: Quais as consequências técnicas, econômicas e ambientais são manifestadas nos canteiros de obras da construção civil, diante da ausência dos serviços de engenheiros e arquitetos e da informalidade relativa aos trabalhadores que executam as obras? A partir deste questionamento, coloca-se como objetivo deste estudo: discutir os efeitos da (in)formalização dos serviços empregados em canteiros de obras, a partir de considerações técnicas, econômicas e ambientais. 
O estudo foi desenvolvido a partir da revisão de bibliografia relacionada às boas práticas sustentáveis em canteiros de obras e análise de uma pesquisa que foi realizada para averiguar a qualidade dos serviços de construção civil no País. Este estudo visa contribuir com a discussão acerca da problemática dos serviços de construção civil praticados sem planejamento ou emprego de processos sustentáveis.

\section{REFERENCIAL TEÓRICO}

O setor de construção globalmente consome cerca de $40 \%$ do total de pedra bruta, cascalho e areia produzidos; em torno de $20 \%$ da madeira virgem; e por volta de $40 \%$ da energia elétrica. 0 elevado consumo de materiais torna a construção civil no principal responsável por geração de resíduos sólidos urbanos, o que demanda um eficiente sistema de coleta e destino dos RCC (SODAGAR, 2013).

No cenário nacional, a coleta de RCC tem ocorrido, de modo que, os provenientes de áreas públicas perfazem o montante de 7.192.372,71 t/ano e os que são de origem privada, o montante de 7.365.566,51 t/ano, totalizando 14.557.939,22 t/ano. Dos 5.564 municípios brasileiros, 4.031 apresentam serviços de manejo de RCC, ainda que precariamente. Deste total, 392 municípios $(9,7 \%)$ possuem alguma forma de processamento dos resíduos (IBGE, 2010).

Conforme a Lei Federal n. 12.305 (BRASIL, 2010), todo entulho originado nas obras é de responsabilidade dos seus geradores e deve ser reintegrado ao processo produtivo, podendo descartar em locais apropriados apenas para uma guarda temporária. Entretanto, segundo o SNIS (2012), 4.513.272 toneladas chegam às áreas de transbordo de RCC, aterro de RCC e áreas de reciclagem, representando apenas 31\% dos resíduos coletados nos 373 municípios pesquisados.

No contexto da construção civil, uma das formas de reduzir a extração de bens naturais é através do reuso de materiais de obras. Já a redução de carbono, é possível com o aumento da produção de energia renovável. Para tanto, é fundamental a criação de programas que incentivem estas práticas e profissionais que se preocupam com os impactos das obras que projetam (MMA, 2017).

Depois da água, o concreto é o material mais utilizado no planeta. Estima-se que a cada ano é consumido um metro cúbico de concreto para cada um dos sete bilhões de habitantes. A indústria da construção deve estar consciente de que o cimento é uma fonte de gases de efeito estufa que tem estado em constante crescimento, já sendo o terceiro maior gerador de dióxido de carbono (GILMORE, 2010).

A indústria de cimento gera altas emissões de gases de efeito estufa (óxido de enxofre, óxido de nitrogênio, monóxido de carbono e compostos de chumbo) por meio da energia térmica utilizada comumente para cozinhar a matéria-prima, e através da liberação de dióxido de carbono resultante das reações químicas que ocorrem durante o processo de cozimento. Além de consumir $2 \%$ de toda a energia global, as cimenteiras também são responsáveis por 5\% da emissão de dióxido de carbono (CO2) de todo o mundo (MAURY; BLUMENSCHEIN, 2012).

Como argumenta Gilmore (2010), dentro de um contexto de sustentabilidade é essencial novos tipos de cimentos que requerem temperatura de queima mais baixa, e que liberem menos gases de efeito estufa. Várias investigações levaram a cimentos que poderiam ser descritos como ecológico ou verde, pois não geram quantidades significativas de dióxido de carbono durante o cozimento. Outra proposta que tem sido incorporada à indústria de cimento é a reciclagem de materiais durante a fabricação do concreto. Nestes termos, vários pesquisadores veem na indústria de concreto um potencial consumidor de materiais de desperdício. Como exemplo disso é a utilização de pneus, pois apenas nos Estados Unidos a cada ano mais de 250 milhões de pneus são descartados.

Os edifícios construídos no futuro devem estar sob o olhar de horizontes muito mais longos do que os atuais. Dentro de tal contexto, as condições estabelecidas para o desenvolvimento sustentável vão muito além da expectativa de vida atual das estruturas de concreto armado, que é de 50 anos, o que significa eliminar a necessidade de monitoramento periódico da sua quebra, e medidas para minimizar a manutenção. Paradoxalmente, enquanto várias estruturas de concreto armado construídas pelos romanos continuam em boas condições, tendo resistido à passagem do tempo em excelente estado, várias estruturas importantes construídas durante o século XX se deterioraram com uma velocidade sem precedentes. De acordo com vários especialistas, o fator que tem contribuído para a quebra precoce das estruturas de concreto armado moderno, tem sido o uso indiscriminado de sistemas que visam atingir uma alta percentagem de resistência e que possuem alto teor de sulfato. Além disso, é importante que os engenheiros estruturais considerem a importância da durabilidade da obra no momento do desenvolvimento do projeto, levando em conta, por exemplo, que a deterioração do concreto e corrosão do 
aço estão intimamente ligadas à porosidade e as rachaduras do concreto, não é conveniente ignorar a interação química entre o concreto e o ambiente (GILMORE, 2010).

Portanto, se faz necessário a combinação entre resistência e durabilidade dos materiais e estruturas das obras, já que é uma forma de evitar o surgimento de patologias construtivas, ampliar a vida útil da construção e postergar a necessidade de reformas (SANTUCCI, 2015).

Outro fator que contribui para o alto volume de emissão de dióxido de carbono é a energia elétrica consumida para manter os ambientes agradáveis. A quota nacional de consumo de energia dos edifícios pode oscilar dependendo do país, entre 25 - 50\%. Na Europa o consumo é de aproximadamente 50\%, o que gerou emissão, apenas no Reino Unido, de cerca de 41,7 toneladas de carbono em 2014, representando 27\% do total das emissões no País (SODAGAR, 2013).

Conforme John et. al. (2005), a sociedade passa em média 90\% do tempo em ambientes construídos, de modo que para manter: luz, ar, som, poeira, temperatura, etc., em níveis agradáveis, se consome em torno de $40 \%$ de toda energia produzida no planeta, sendo que, por volta de $50 \%$ do dióxido de carbono liberado no meio ambiente é proveniente da energia elétrica. Assim sendo, podemos concluir que para manter os ambientes internos confortáveis, geramos grande impacto à natureza. Um caminho promissor para resolver isso está nos projetos que tentam maximizar a qualidade interna dos ambientes, planejandoos com arejamento, isolamento térmico, acústico e iluminação natural de boa qualidade, criando um interior agradável e com custos operacionais que podem ser mínimos, e refletirão em reduções substanciais no uso de combustíveis fósseis.

Outro ponto importante é a flexibilidade dos projetos, pois esta influenciará de fato o aproveitamento futuro da edificação e de suas partes, já que, frequentemente, o usuário quer ampliar, melhorar ou até mesmo personalizar a sua edificação, visando alcançar maior nível de satisfação. Desta forma, é preferível a utilização de um sistema construtivo que possibilite ampliações e outras modificações, em vez de soluções limitadas, sem possibilidade de futuras intervenções ou, quando a única alternativa para a intervenção é a demolição (BLUMENSCHEIN, 2007).

Edificações antigas, que não foram projetadas para minimização dos impactos causados à natureza ou economia de recursos, podem ser modernizadas, com o emprego de técnicas que as tornam mais sustentáveis, através de tecnologias que possibilitam a produção de sua própria energia, uso adequado da água e emissão de baixos níveis de gases do efeito estufa (SENA NETO; ALCÂNTARA, 2015).

A reformulação de uma construção é uma operação que ocorre quando uma série de atividades da edificação necessita ser realizada em conjunto, muitas vezes devido a uma combinação de obsolescência e deterioração. Mas estas não devem ser as únicas razões para reformulação de um prédio, o motivo também pode ser para torná-lo mais sustentável (SENA NETO; ALCÂNTARA, 2015).

Conforme Cibse (2004), edifícios remodelados apresentam uma oportunidade para agregar valor e reduzir o custo de carbono dos edifícios através de uma melhor concepção eficiente de energia. Em geral, a remodelação oferece excelentes oportunidades para melhorar a eficiência energética, embora às vezes ela possa aumentar o consumo de energia quando os serviços forem aprimorados, por exemplo, pela introdução do ar condicionado.

Segundo Baptista e Romanel (2013), no Brasil diversas empresas e segmentos da indústria da construção vêm incorporando alternativas saudáveis em seus projetos, como prédios inteligentes com monitoramento do consumo de recursos, emprego de sistemas naturais para o conforto ambiental nas edificações, novas tecnologias para o reuso e reciclagem de resíduos sólidos e líquidos, dentre outras. 0 incentivo acontece em parte por um mercado crescente e cada vez mais competitivo de produtos sustentáveis, abrindo espaço para organizações criarem um sistema de certificação baseado em selos de qualidade para padronizar e quantificar os níveis de sustentabilidade de uma edificação. Muitas empresas certificadoras patrocinam esses selos, derivados do pioneiro método de avaliação da qualidade da construção civil - Programa Nacional de Eficiência Energética em Edificações — PROCEL Edifica (PROCEL, 2003), no Brasil.

Um importante aspecto da sustentabilidade nos canteiros de obras, diz respeito as condições de trabalho dos executores. Para o IPEA (2010), deve-se considerar que a construção sustentável gera o chamado "emprego verde", que se caracteriza pelo emprego formal e digno. São diversos os estudos que apontam para as várias oportunidades que se abrirão no futuro a partir da implementação de novas práticas da construção. 0 que se espera do setor de construção civil é que cada vez mais se especialize na resolução de problemas, como o aumento da eficiência energética, uso racional de água, melhora das condições de 
trabalho - eliminando a mão de obra que atua em condições precárias -, e minimização dos efeitos causados ao meio ambiente.

Muitas vezes, no canteiro de obras, diversas empresas atuam em conjunto. As empreiteiras realizam a subcontratação de pequenas empresas ou mão de obra direta, à margem da legislação trabalhista. A construtora responsável assina o projeto e torna-se uma mera gerenciadora do empreendimento. A rotatividade de mão de obra é proposital: no final de cada etapa da construção, há uma dispensa coletiva de trabalhadores que voltam a ser contratados em etapas posteriores. Deste modo, com o objetivo de reduzir o custo do trabalho e maximizar a eficácia produtiva, implantam medidas de descentralização de um número crescente de tarefas, em condições precárias e menos protegidas, criando em cascata um segundo mercado de trabalho sem direitos trabalhistas e previdenciários, em que os riscos de acidentes de trabalho e doenças profissionais tornam-se ainda maiores para os terceirizados e para os trabalhadores informais (TAKAHASHI et al., 2012).

Ao tratar desse contexto, Aranha et al. (2016) salienta que existem algumas ações positivas ocorrendo no setor em relação à organização do trabalho, como é o caso do Compromisso Nacional para Aperfeiçoamento das Condições de Trabalho na Indústria da Construção, assinado em março de 2012. Este pode ser considerado um avanço por organizações vinculadas aos direitos dos trabalhadores brasileiros, porquanto abriu espaço para negociação, resultando num acordo nacional que estabelece regras e padrões nacionais para as condições e relações de trabalho nas obras. Entretanto, as condições degradantes de trabalho nesse setor são ainda preocupantes.

Outro aspecto que também merece ser considerado neste estudo diz respeito a ausência dos serviços de engenheiros e arquitetos em muitos canteiros de obras. Tais construções podem apresentar sérios problemas estruturais e arquitetônicos e outras patologias inerentes ao processo (SILVEIRA, 2002). Para Grilo et al. (2003) toda obra deve ser adequadamente projetada e o aspecto "qualidade" deve ser uma obcessão do início ao fim. Silva (2015) afirma que existem diversos fatores associados à gestão de um projeto de construção civil. Quando se trata de um projeto, o controle dos processos favorece a tomada de decisões pontuais, racionalização dos custos, aumento da produtividade e melhoria da qualidade, com base no conhecimento amplo das tarefas, recursos e prazos. A falta de domínio e controle do projeto dentro das áreas de planejamento, recursos humanos, suprimentos, execução, entre outros, aumenta a variabilidade em torno do planejamento do projeto. Identificar as falhas antecipadamente minimiza os impactos com relação ao custo, prazo, qualidade e meio ambiente. No entanto, quando isso não ocorre, a sucessão de falhas altera todo o escopo deste projeto. A presença de um engenheiro e arquiteto para desenvolver um projeto e acompanhar a sua execução poderá evitar ou amenizar as falhas e conseqüências descritas anteriormente.

De acordo com Martins et al. (2014), a função do engenheiro tem estado em constante evolução, de modo que para atender esta necessidade evolutiva, deve-se ter uma visão sistêmica, pensar na obra como um todo, desde aspectos operacionais e econômicos até ambientais. E, para que tais mudanças sejam possíveis, é necessário um profissional com perfil diferente do "tocador de obras". Essa nova conjuntura exige características mais aperfeiçoadas de tais profissionais, tornando indispensável o domínio sobre inovação, foco no cliente, planejamento, conhecimento de sistemas de gestão da qualidade, sustentabilidade e uma visão humanista.

Como salienta Blumenschein (2007), arquitetos e engenheiros projetistas têm uma grande responsabilidade ao conceber e desenvolver projetos. As tipologias de edificações caracterizadas por formas mais compactas, a flexibilidade do projeto, a utilização de pré-fabricados de fácil montagem e desmontagem, com dimensões padronizadas - que permitam a sua reutilização no futuro -, e o uso de materiais e componentes certificados e/ou produzidos a partir de resíduos reciclados podem ser apontadas como boas alternativas. No momento do planejamento para a escolha da tecnologia a ser utilizada, deverá se buscar a menor geração de resíduos, por meio da aplicação de critérios que orientam: racionalização, padronização e otimização. Além de se considerar informações sobre o ciclo de vida dos materiais que serão empregados nas diversas tecnologias, desde a extração da matéria-prima até o seu potencial de reciclagem.

Neste contexto, o IPEA (2010) afirma que inovação tecnológica implica em pesquisa e conhecimento. Entretanto, é muito pequena a transferência de conhecimento acumulado na rede de pesquisa e desenvolvimento tecnológico das universidades e dos institutos de pesquisas relacionados à construção civil para o meio de produção. Há uma distância muito grande entre as empresas construtoras, representando o mercado consumidor e a rede de pesquisas, como produtoras de soluções tecnológicas. 
Tem-se que aproximar estes importantes atores, de modo a tornar mais eficiente e produtivo o resultado dos trabalhos elaborados pelos cientistas e pesquisadores.

\section{METODOLOGIA}

A abordagem metodológica da pesquisa é de caráter qualitativo, transversal, descritivo e documental, conforme orientações de Marconi e Lakatos (2007). A fase teórica da pesquisa foi construída pautando-se em diversos trabalhos já publicados sobre informalidade e a formalidade dos serviços empregados em canteiros de obras, a partir de considerações técnicas, econômicas e ambientais. Na literatura pesquisada, buscou-se um suporte teórico para responder a principal questão de pesquisa, quer seja: Quais as consequências técnicas, econômicas e ambientais manifestadas nos canteiros de obras da construção civil, diante da ausência dos serviços de engenheiros e arquitetos e da informalidade relativa aos trabalhadores que executam as obras?

Em sua fase empírica, foram coletadas informações em Relatório de Pesquisa publicado pelo Instituto Datafolha, o qual resulta de uma Pesquisa Survey (com dados quantitativos) e uma Pesquisa Focus Groups (com dados qualitativos), ambas realizadas a pedido do Conselho de Arquitetura e Urbanismo do Brasil (CAU/BR, 2015). Participaram da pesquisa Datafolha 2.419 indivíduos representando a população economicamente ativa, entre 18 e 75 anos, em 177 munícipios brasileiros, em junho de 2015 . A pesquisa possui margem de erro de dois pontos percentuais. Na Pesquisa Focus Groups utilizou-se a abordagem qualitativa onde foram realizados 12 grupos de discussão em seis capitais, com oito pessoas em cada grupo. Os participantes foram escolhidos por meio de amostra não probabilística, baseada no perfil dos entrevistados obtido na etapa quantitativa. As entrevistas foram realizadas em Agosto de 2015.

A pesquisa Datafolha (Survey e Focus Grups) teve o propósito de: (i) obter uma avaliação dos serviços executados por profissionais da área de construção civil; (ii) conhecer a opinião da população acerca da reserva técnica, atribuições de engenheiros, arquitetos e urbanistas e sua imagem, e; (iii) levantar atributos, benefícios e valores relevantes em relação à atuação desses profissionais.

A coleta e registro dos dados documentais ocorreram segundo Souza et al. (2013). Segundo Barros e Lehfeld (2000), esse tipo de pesquisa visa a verificação e a transcrição das características de determinado cenário, grupo ou o estabelecimento de relações entre variáveis sem a interferência do autor.

Finalmente, procedeu-se a análise dos dados documentais de modo descritivo buscando compreender as consequências técnicas, econômicas e ambientais manifestadas nos canteiros de obras da construção civil, diante da ausência dos serviços de engenheiros e arquitetos e da informalidade relativa aos trabalhadores desse segmento. Os dados da pesquisa foram analisados de acordo com as orientações de Kua e Lee (2002), que tratam das técnicas de análise de dados com foco na sustentabilidade no ambiente organizacional.

\section{RESULTADOS E DISCUSSÃO}

Os dados da pesquisa Datafolha (Survey e Focus Grups) foram sintetizados e seus principais resultados se encontram aqui sintetizados.

Apesquisa revela que, dos entrevistados, 54\% já fizeram reformas ou construções. Destes, menos de 15\% utilizaram os serviços de um arquiteto ou engenheiro na obra. A pesquisa qualitativa, feita nos grupos de discussão, constatou que o fator preponderante na escolha de mestres de obras e pedreiros, em detrimento à profissionais especializados, é de ordem financeira. Adicionalmente há facilidade de acesso a esses profissionais, fortalecendo ainda mais o mercado informal de construção civil.

Estes achados da pesquisa encontram respaldo na pesquisa realizada por Silva (2015), a qual mostra os resultados, muitas vezes desastrosos, da execução de obras sem a presença de profissionais especializados. Há no Brasil, muitas construções, mormente as residenciais, que são desenvolvidas sem um projeto formal elaborado por engenheiro e arquiteto. Existem diversas conseqüências relativas a ausência de um projeto bem estruturado por engenheiro de obra e arquiteto. As principais conseqüências são: (i) perdas de materiais; (ii) uso de matérias primas de baixa qualidade; (iii) execução da obra por pessoas não qualificadas; (iv) ausência de uso de equipamentos de proteção individual; (v) aumento do uso de mão de obra informal; (vi) acentuação da precarização do ambiente e das condições de trabalho; (vii) aumento do número de acidentes de trabalho; (viii) uso de materiais em proporções inadequadas 
(cimento, areia, brita ferragens, etc.); (ix) falhas estruturais e estéticas; (x) aumento do retrabalho; (xi) agressões ao meio ambiente, tais como aumento do consumo de água e energia, descarte inadequado de rejeitos.

A pesquisa Datafolha revela que a informalidade, muitas vezes, traz vantagem para o contratante devido ao baixo valor da mão de obra disponível, ausência de pagamento de impostos e baixo custo para manutenção das atividades desses profissionais. Também não requerem estrutura física, escritório para atendimento de clientes, galpões para armazenagem de ferramentas, investimento em ferramentas, equipamentos de segurança e aperfeiçoamento profissional. Por outro lado, na pesquisa qualitativa, a maioria dos entrevistados, que já realizou reforma ou construção, avaliou a experiência como ruim, basicamente por três aspectos: planejamento, mão de obra e material.

Os resultados aqui descritos corroboram com Aranha et al. (2016) que tratam das consequências da informalidade no setor da construção. Apesar dos investimentos bilionários e da massiva geração de emprego, o crescimento da construção civil não foi capaz de resolver um problema crônico: as más condições de trabalho. Alojamentos precários, riscos à integridade física e jornadas acima do limite permitido estão entre as irregularidades mais comuns. Violações à legislação trabalhista não são exclusividade de pequenas obras e de empregadores descapitalizados. Acidentes graves e até mesmo exploração de trabalho escravo também são recorrentes em empreendimentos de grande porte, tocados por empreiteiras que figuram entre as maiores companhias do país. E o histórico recente de graves acidentes de trabalho na construção civil revela que as medidas que têm sido tomadas por entidades envolvidas não foram suficientes para alterar o quadro. Os canteiros somam mais de $8 \%$ dos acidentes registrados no país.

O trabalho de Souza (2015) também aponta que a força de trabalho da construção civil convive em condições de trabalho precárias, razão da intensa rotatividade de mão de obra. Conforme dados do Dieese (2014), constantemente, as construtoras buscam mecanismos para: reduzir o salário dos trabalhadores; aumentar a intensidade do trabalho, com a incorporação de metas de produção e uso abusivo de horas extras. Estes fatores ganham contornos significativos, mesmo quando se trata de relações formais de trabalho.

Quanto ao planejamento, as principais dificuldades apontadas pelos entrevistados da pesquisa Datafolha foram: orçamento, tamanho da obra e cronograma. Em função da ausência de conhecimento e má assessoria, a maioria deles demonstra dificuldade em calcular o orçamento da obra impactando a previsão correta dos gastos. Outra dificuldade refere-se ao planejamento que, frequentemente, é modificado por surgirem novas necessidades que não foram previamente identificadas, gerando retrabalho, atraso e custos adicionais. Por fim, outro ponto identificado foi a dificuldade de montar um cronograma em função de constantes atrasos, gerando transtorno e prejuízo financeiro.

A dificuldade em calcular o orçamento da obra foi objeto de estudo realizado por Santos (2015). Tais dificuldades são enfrentadas por pessoas não qualificadas que executam uma obra, por falta de conhecimento na área de Engenharia de Custos. A ausência de orçamentos, que normalmente, ocorre em obras informais, a deixa vulnerável sob os aspectos financeiro e técnico. Por outro lado, empresas que elaboram orçamentos de obras sem utilizar as regras de adequadas de orçamentação, acabam tendo prejuízos em suas operações e até mesmo podem chegar a falir dependendo da gravidade do erro de orçamento apresentado e das multas rescisórias dos contratos assinados. A necessidade de controle de custos, intrínseca a qualquer setor do mercado, vem se mostrando cada vez mais essencial num contexto de economia em que frequentemente divulga-se falência de empresas, em que há uma luta constante pela sobrevivência comercial, e onde a disputa com a concorrência é cada vez mais acirrada e, em algumas vezes, desonesta. A construção civil, que implica na gestão de ações simultâneas, envolvendo amplo número de recursos materiais e humanos, necessita de orçamento paramétrico para estimativas iniciais de custo, verificando a viabilidade inicial do empreendimento e posteriormente, o orçamento analítico ajuda com um melhor gerenciamento dos custos durante a execução do empreendimento.

Quanto à mão de obra, a maior dificuldade detectada pelos respondentes da pesquisa Datafolha foi a baixa qualificação técnica e comportamental, destacada pela ausência de comprometimento. A mão de obra geralmente é formada por pedreiros multitarefas, que fazem de tudo um pouco, sem grande conhecimento das atividades. A falta de conhecimento associada à ausência de comprometimento com o cronograma gera retrabalho, atrasos e impactam o custo e tempo de execução. Os profissionais que atuam no mercado informal não costumam se preocupar com cursos de qualificação e, comumente, possuem tanto dificuldades técnicas para realização dos serviços, quanto de gestão de contratos e atendimento aos clientes, afetando prazo de entrega e qualidade. Com a informalidade dos serviços, a especialização 
profissional não é disseminada, ou seja, alguns profissionais se propõem a executar uma multiplicidade de serviços, desde encanamento, hidráulica, elétrica, pintura ou qualquer outro necessário para viabilizar o andamento da obra. No entanto a ausência de conhecimento impacta a qualidade, prazo e custo da obra, trazendo prejuízos já mencionados na pesquisa. Diante deste cenário, pela informalidade, requisitantes do serviço não têm, geralmente, um canal de reclamação para buscar ressarcimento de danos, já que não há formalização do contrato, vinculação com um profissional licenciado ou uma empresa jurídica com papel de responsabilidade.

Estes achados da pesquisa são também confirmados por um estudo realizado pela Abramat (2017), o qual aponta que, no Brasil, há um contingente significativo de pessoas ocupadas no setor da construção. Associadas a essa cifra bastante positiva, há duas outras estatísticas desalentadoras: o alto número de pessoas na informalidade e a baixa produtividade dessa mão de obra. Quase $50 \%$ dos trabalhadores ocupados na cadeia atuam no segmento informal do setor da construção e, não por acaso, a sua produtividade representa $44 \%$ da média do país. Esses números, em grande medida, estão relacionados à outra grande dificuldade do setor: a falta de qualificação da mão de obra. A conjugação de informalidade, baixa qualificação e baixos níveis de produtividade são grandes desafios que justificam a necessidade de estabelecer um conjunto de diretrizes para superar essas dificuldades.

Ainda em complemento, outra pesquisa realizada pelo Conselho Brasileiro de Construções Sustentáveis (CBCS, 2014) aponta que o aumento da formalidade dos serviços de construção permite a economia de recursos naturais, redução do efeito das emissões de gases nocivos, equilíbrio ambiental, redução do consumo de energia, racionalização do uso da água e contribui com o aumento dos níveis de renda da população.

Quanto ao material, os respondentes da pesquisa Datafolha afirmam que há dificuldade em identificar qual é a quantidade certa para comprar. A orientação é realizada pelo pedreiro, que muitas vezes não acerta a quantidade necessária, ora exigindo do cliente retrabalho de compra, ora desperdiçando material com sobras. Este fator também impacta o cronograma e custo da obra, já que o material comprado em menor quantidade diminui o poder de negociação do proprietário da construção. 0 descarte dos resíduos gerados, muitas vezes, não recebe o destino desejado pelas autoridades locais.

Os desperdícios aqui apentados encontram eco no trabalho de Dodagar (2013), segundo o qual o setor de construção consome aproximadamente $40 \%$ do total de pedra bruta, cascalho e areia produzidos; cerca de $20 \%$ da madeira virgem; e por volta de $40 \%$ da energia elétrica. Parte desse consumo é resultado do desperdício e mal uso feito por pessoas não qualificadas. Neste aspecto, os resultados da pesquisa Datafolha também encontram respaldo no estudo realizado por Kawa (2015) o qual enfatiza que o aumento descontrolado e sem critérios técnicos de resíduos da construção e demolição gera grandes impactos ambientais, sobretudo na formação de áreas irregulares de descarte em locais de preservação ambiental, afetando o equilíbrio ecológico, a drenagem superficial, com obstrução de córregos, erosão de solos, etc. Nas cidades, a disposição de resíduos em vias públicas e terrenos baldios interferem nas condições de tráfego de pedestres e veículos, ao mesmo tempo em que incentiva o descarte de outros materiais de origem industrial e doméstica, nem sempre inertes, com a consequente degradação de espaços urbanos.

A pesquisa Datafolha questionou os entrevistados sobre sobre a experiência ou intenção de contratação de profissionais especializados da construção civil para reformas e/ou construção. 0 resultado aponta que cerca de 7\% dos entrevistados já contrataram tais profissionais. Os motivos apontados para a contratação foram: $50 \%$ devido a expertise técnica, e; $78 \%$ porque ficaram satisfetos com a qualidade dos serviços profissionais prestados. Embora não tenham utilizado, $70 \%$ dos respondentes afirmaram que contratariam os serviços. Outro ponto identificado refere-se ao processo de escolha do profissional. Dentre os entrevistados (7\%) que já utilizaram os serviços de engenheiros e arquitetos, $78 \%$ afirmam que o meio utilizado para escolher os profissionais foi a networking. Ou seja, a escolha foi realizada mediante busca de indicações e informações, via rede de contatos familiares e/ou de amigos. Outras referências, como a busca de informações nas prefeituras, internet e lojas especializadas, também foram utilizadas, embora com menor destaque.

Para o Conselho de Arquitetura e Urbanismo do Brasil (CAU/BR, 2015), esta realidade poderia ser diferente no país, uma vez que os engenheiros, arquitetos e urbanistas ajudam a fazer escolhas explorando todos os cenários possíveis e apresentando a solução que melhor se adapta às necessidades e ao seu bolso do proprietário da obra. Estes profissionais podem ajudar a tomar decisões baseadas no melhor custobeneficio, proporcionando economia nos materiais e na obra como um todo. Entretanto, a informalidade, das pequenas obras de reforma, ampliação e até de construções nas mais diversas cidades do país, 
principalmente nas áreas mais periféricas, não aparece nas estatísticas conjunturais por conta da imensa diversidade existente. Entretanto, a construção de obras sem assistência de um profissional apresentam, quase todas, o mesmo vício: são mais caras do que se tivessem sido construídas com a assistência de um profissional; há mais desperdícios; o conforto térmico, tão necessário numa construção habitacional não é tratado tecnicamente; a clandestinidade gera ilegalidade, podendo levar a multa, embargo e até demolição, como determina os códigos de obras das cidades brasileiras.

Na pesquisa Datafolha, quando se analisa a intenção de contratação de serviços de engenheiro, arquiteto e urbanista, observa-se que os atributos de escolha passam a ser mais amplos que os atuais. A escolha se baseia na experiência no tipo de construção, preço, indicação de amigos e parentes e a relação custo X benefício. A pesquisa mostra que a principal razão para não contratação dos serviços de engenheiro, arquiteto e urbanista é de natureza financeira (falta de dinheiro, valor alto). Adicionalmente se observa que existe uma confusão e certo desconhecimento sobre o conceito de projeto estrutural e arquitetônico e as respectivas atribuições dos profissionais da engenharia e arquitetura, que também podem impactar neste fator.

A pesquisa Datafolha indica que os cidadãos pesquisados ainda desconhecem a Lei oㅡ. 11.888, em vigor desde 24 de junho de 2009 (BRASIL, 2009), que garante o direito à assistência técnica gratuita. De acordo com essa Lei, todo cidadão de renda até três salários-mínimos tem direitos, gratuitamente, aos serviços de profissionais da arquitetura e da engenharia, os quais devem ser remunerados pelo Estado. A referida Lei contribui para formalizar o processo de edificação, reforma ou ampliação da habitação perante o poder público municipal e outros órgãos públicos.

Para o cumprimento da Lei no ${ }^{1}$ 11.888, que ainda é pouco conhecida no país, o Conselho de Arquitetura e Urbanismo do Brasil (CAU/BR, 2015) defende que:

Cabe ao cidadão conhecer e exigir dos governantes e participar na implantação do sistema de atendimento de assistência técnica e o cumprimento da Lei. Participar da elaboração e acompanhar o cumprimento dos Planos Municipais de Habitação. Exigir a inclusão dos Programas de Assistência Técnicas no orçamento da cidade. Exigir responsável técnico nos projetos e no acompanhamento de construção, ampliação ou reforma da moradia e de espaços públicos, na recuperação de áreas degradadas e de risco, no planejamento e na regularização fundiária. Divulgar os programas de assistência técnicas e sensibilizar parentes, amigos e vizinhos quanto à importância de construir com responsabilidade com assistência de profissionais. Exigir qualidade nos projetos, nas obras e na urbanização.

Cabe às Prefeituras implantar e fiscalizar. Implantar e executar serviços permanentes e gratuitos de assistência técnica nas áreas de arquitetura, urbanismo e engenharia de composição paritária com a sociedade civil. Selecionar as famílias que terão direito ao serviço e garantir atendimento direto, facilitando o diálogo por meio de sistemas integrados. Garantir recurso anual no orçamento para os programas. Contratar e qualificar arquitetos e engenheiros para trabalhar nos programas, buscando a parceria de entidades profissionais através de convênio ou parceria na seleção e contratação de equipes. Firmar convênios e parcerias para a capacitação profissional nas áreas de arquitetura, urbanismo ou engenharia. Elaborar seus planos Municipais de Habitação em consonância com os Planos Diretores e os Planos de Proteção Ambiental.

Cabe aos profissionais saber e aplicar. Qualificar-se para trabalhar com programas de Habitação de Interesse Social, de regularização fundiária e de erradicação de assentimentos precários. Incentivar a observação da lei e a regularização dos imóveis. Identificar e prevenir a população sobre ocupação de área inadequada e o uso de construção insegura. Conhecer e propor soluções respeitando o meio ambiente, a cultura e os modos de vida locais, eliminando riscos, racionalizando custo, proporcionando qualidade e segurança às moradias.

Quanto a contratação de serviços para planejamento urbano, observa-se maior uniformidade de resultados, ou seja, 94\% dos respondentes consideram a presença do profissional de arquitetura importante e 93\% avaliam que o governo só deveria iniciar uma obra pública após apresentação de um projeto completo e bem detalhado. Esta mesma uniformidade não é percebida quando se analisa a ética e reserva técnica. Segundo a pesquisa, $64 \%$ dos brasileiros economicamente ativos concordam que os engenheiros, arquitetos e urbanistas devem indicar lojas ou prestadores de serviço a seus clientes. Porém, 54\% entendem que não deveriam ganhar uma comissão em dinheiro por esse serviço.

Os resultados da pesquisa evidenciam que a falta de (in)formação torna o conhecimento de processos sustentáveis, por parte de profissionais informais, quase que inviável, contribuindo para que sejam contínuos os problemas discutidos na revisão de bibliografia deste estudo, como a falta de um olhar mais 
amplo que tenta projetar obras que maximizam o espaço, aproveitam da luminosidade natural, pensam numa boa acústica com intuito de reduzir os ruídos do ambiente ao redor e aproveitam o clima externo e instalam materiais com o fim de proporcionar uma temperatura agradável, diminuindo assim a necessidade de uso de ar condicionado ou aquecedores.

Torna-se fundamental investir na qualificação dos profissionais, reduzir a informalidade do setor, implementar tecnologias e construções inteligentes que maximizem o espaço, aproveitem a luz natural, aproveitem o clima ambiente. Somente com uma visão sistêmica de sustentabilidade o setor da construção civil poderá sair da lista dos maiores responsáveis pelos impactos ambientais e sociais do Brasil. Cada vez mais a preocupação global com os impactos ambientais se torna presente na sociedade e cria uma pressão em todos os setores. 0 impacto causado pela ação do homem é crucial para o desenvolvimento futuro e a vida na Terra necessita dos recursos naturais para se manter em equilíbrio.

Projetos concebidos a partir da ideia de que em algum momento poderá ter os seus materiais reaproveitados, permitem a maximização do reuso. Com a finalidade de minimizar a geração de resíduo e elaboração de um plano para medidas corretivas de problemas identificados nas obras, é importante se montar um diagnóstico das perdas ocorridas, visando estabelecer indicadores que, ao longo do seu processo de produção, poderão facilitar a tomada de decisões relacionadas à escolha da melhor tecnologia que devem ser implantadas, visando à melhoria do processo e à minimização das perdas.

\section{CONCLUSÃO}

O setor de construção civil, no Brasil, ainda é extremamente informal, devido, sobretudo, a grande quantidade de profissionais sem formação técnica disponíveis no mercado, que ofertam mão de obra barata em comparação a oferecida por engenheiros civis e arquitetos.

Como mostra a pesquisa, devido à falta de recursos financeiros para projetar e construir uma obra, a alternativa geralmente é a contratação de mestre de obras, que, devido à falta de conhecimento técnico, calculam erroneamente o cronograma e a quantidade de material necessário para cada etapa da obra. 0 que pode gerar atraso na conclusão do serviço, sobra de material ou falta dele. A pesquisa corrobora com a afirmação de Laghari et al (2016), de que a indústria da construção contribui amplamente com a grande quantidade de desperdício, o que, comumente, afeta a margem de lucro dos empreiteiros. Ou, dependendo do tipo de contrato de serviço - sendo que em alguns casos não existe nem contrato -, o prejuízo pode ser do proprietário da obra. Muitas vezes, materiais de construção são utilizados em grandes quantidades durante as diferentes fases da obra, atingindo cerca de $50 \%$ a $60 \%$ do custo total do projeto.

Devido à grande representatividade dos materiais no custo total da obra, caso não sejam criteriosamente planejados, podem causar grandes prejuízos. 0 desperdício na construção acaba por ser um problema abrangente enfrentado pelos profissionais da construção no Brasil.

A pesquisa evidencia que, ao longo da construção, a qualidade da execução dos serviços garante a minimização de perdas e a durabilidade da edificação; perdas que serão incorporadas ao edifício (por exemplo, espessuras muito grandes de argamassa de revestimento), ou então serão visíveis na forma de resíduos, ou entulhos.

A ausência total ou parcial dos serviços de engenheiros e arquitetos em canteiros de obras é comum no Brasil. Muitas construções - especialmente as residenciais -, são implementadas sem um projeto formal e o acompanhamento de engenheiro e arquiteto. Tais situações levam a uma gama de conseqüências: uso de matérias primas de baixa qualidade; perdas de materiais; uso de materiais em proporções inadequadas, comprometendo a qualidade das construções; presença de pessoas não qualificadas na execução das obras; falta de uso de equipamentos de proteção individual; alto índice de mão de obra informal; condições degradantes do ambiente de trabalho; número elevado doenças laborais e de acidentes de trabalho; falhas estruturais e estéticas nas obras; índice alto de retrabalho; agressões ao meio ambiente, tais como aumento do consumo de água e energia, descarte inadequado de rejeitos; dentre outros. Tais construções podem apresentar sérios problemas estruturais e arquitetônicos e outras patologias inerentes ao processo.

A informalidade no segmento da construção civil deve ser reduzida. A redução da informalidade dos serviços de construção pode gerar economia de recursos naturais, redução do efeito das emissões de gases nocivos, equilíbrio ambiental, redução do consumo de energia, racionalização do uso da água e contribui com o aumento dos níveis de renda da população. Para tanto, deve-se aumentar o investimento em educação, para diminuir profissionais com baixo conhecimento técnico e salários degradantes. Outro fator 
importante que deve ser levado em consideração é a mudança de conteúdo programático dos cursos de formação dos profissionais que atuam na construção civil, incluindo uma visão mais ampla que engloba: planejamento, controle e conscientização acerca de impactos sociais e ambientais.

\section{REFERÊNCIAS}

[1] ABRAMAT - ASSOCIAÇÃO BRASILEIRA DE MATERIAIS DE CONSTRUÇÃO. A cadeia produtiva da construção e o mercado de materiais. 2017. Disponível em: <http://www.abramat.org.br/datafiles/publicacoes/estudocadeiaprodutiva.pdf $>$. Acesso em: 26 jan. 2017.

[2] ANJOS, B. R.; LEITE, C. V. A. O meio ambiente do trabalho na construção civil. Disponível em: <http://www9.unaerp.br/revistas/index.php/cbpcc/article/download/288/426>. Acesso em: 15 jan. 2017.

[3] ARANHA, A. et al. Monitor \#4: Os direitos dos peões na construção civil. São Paulo: Repórter Brasil, 2016.

[4] BARROS, A. J. S.; LEHFELD, N. A. S. Fundamentos de metodologia científica. São Paulo: Pearson, 2000.

[5] BAPTISTA JR, J. V.; ROMANEL, C. Sustentabilidade na indústria da construção: uma logística para reciclagem dos resíduos de pequenas obras. Revista Brasileira de Gestão Urbana, v. 5, n. 2, p. 27-37, jul./dez. 2013.

[6] BLUMENSCHEIN, R. N. Gestão de resíduos sólidos em canteiros de obras. Brasília, DF: CADT/UnB, 2007. Dossiê Técnico.

[7] BRASIL. Lei no. 11.888, de 24/12/2008. Assegura às famílias de baixa renda assistência técnica pública e gratuita para o projeto e a construção de habitação de interesse social. Diário Oficial da República Federativa do Brasil. 2008. Disponível em: <http://www.planalto.gov.br/ccivil_03/_ato2007-2010/2008/lei/l11888.htm>. Acesso em: 28 fev. 2017.

[8] BRASIL. Lei 12.305, de 2/08/2010. Institui a Política Nacional de Resíduos Sólidos. Diário Oficial da República Federativa do Brasil. 2010. Disponível em: <http://www.planalto.gov.br/ ccivil_03/_ato20072010/2010/lei/l12305.htm>. Acesso em: 25 jan. 2017.

[9] CBCS - CONSELHO BRASILEIRO DE CONSTRUÇÃO SUSTENTÁVEL. Aspectos da construção sustentável no Brasil e promoção de políticas públicas. 2014. Disponível em: <http://www.cbcs.org.br/website/aspectos-construcaosustentavel>. Acesso em: 27 fev. 2017.

[10] CIBSE - CHARTERED INSTITUTION OF BUILDING SERVICES ENGINEERS. Guide F. Energy Efficiency in Buildings. London, UK: CIBSE, 2004.

[11] CAU/BR - CONSELHO DE ARQUITETURA E URBANISMO DO BRASIL. Pesquisa CAU/BR Datafolha. 2015a. Disponível em: <https://www.caubr.gov.br/pesquisa2015/ index.php/contratacao-de-arquitetos-e-urbanistas/>. Acesso em: 21 jan. 2017.

[12] CAU/BR - CONSELHO DE ARQUITETURA E URBANISMO DO BRASIL. Manual do arquiteto e urbanista. 1ํㅡㄹ ed. Brasília: CAU/BR, 2015b.

[13] DIEESE. Rotatividade setorial: dados e diretrizes para a ação sindical. 2014. Disponível em: <http://library.fes.de/pdf-files/bueros/brasilien/10943.pdf>. Acesso em: 26 fev. 2017.

[14] GILMORE, A. T. El futuro del diseño sismorresistente de las edificaciones de concreto reforzado: uma visión basada em la sustentabilidad. Concreto y Cemento: Investigación y Desarrollo, v. 2, n. 1. Dec. 2010.

[15] GRILO, L. M. et al. Implementação da gestão da qualidade em empresas de projeto. Ambiente Construído, Porto Alegre, v. 3, n. 1, p55-67, jan/mar. 2003.

[16] FUNASA - FUNDAÇÃO NACIONAL DA SAÚDE. Guia de Vigilância Epidemiológica. 6ª ed., 2ª reimpressão Brasília: Ministério da Saúde, 2007.

[17] HANSEN, S. Gestão socioambiental: meio ambiente na construção civil. Florianópolis, SC: SENAI/SC, 2008.

[18] IBGE - INSTITUTO BRASILEIRO DE GEOGRAFIA E ESTATÍSTICA. Pesquisa Nacional de Saneamento Básico 2008. Rio de Janeiro: IBGE, 2010.

[19] IPEA - INSTITUTO DE PESQUISA ECONÔMICA APLICADA. Sustentabilidade Ambiental no Brasil: biodiversidade, economia e bem-estar humano (Livro 7). Brasília: IPEA, 2010.

[20] IPEA - INSTITUTO DE PESQUISA ECONÔMICA APLICADA. Diagnóstico dos Resíduos Sólidos da Construção Civil. Brasília: IPEA, 2012.

[21] JOHN, G. et al. Sustainable building solutions: a review of lessons from the natural world. Building and Environment, v. 40, n. 3, p. 319-328, 2005. 
[22] KAWA, L. A reciclagem dos resíduos de pequenas obras. 2015 . Disponível em: <http://professoralucianekawa.blogspot.com.br/2015/11/a-reciclagem-dos-residuos-de-pequenas.html>. Acesso em: 12 jan. 2017.

[23] KUA, H. W.; LEE, S. E. Demonstration intelligent building - a methodology for the promotion of total sustainability. Building and Environment, v. 37, n. 3, p. 231-240, 2002.

[24] MARCONI, M. A.; LAKATOS, E. M. Metodologia do trabalho científico. 7aㅡ ed. São Paulo: Atlas, 2007.

[25] MARTINS, V. W. B. et al. Análise do desenvolvimento de competências gerenciais na construção civil através do modelo da Aprendizagem Baseada em Problemas. Ambiente Construído, Porto Alegre, v. 14, n. 1, p. 155-175, jan./mar. 2014.

[26] MAURY, M. B.; BLUMENSCHEIN, R. N. Produção de cimento: Impactos à saúde e ao meio ambiente. Sustentabilidade em Debate, Brasília, v. 3, n. 1, p. 75-96, jan/jun 2012.

[27] MMA - MINISTÉRIO DO MEIO AMBIENTE. Construções sustentáveis. $2017 . \quad$ Disponível em:<http://www.mma.gov.br/cidades-sustentaveis/urbanismo-sustentavel/ $\quad$ constru\%C3\%A7\%C3\%A3osustent\%C3\%A1vel>. Acesso em: jan. 2017.

[28] PROCEL - PROGRAMA NACIONAL DE CONSERVAÇÃO DE ENERGIA ELÉTRICA. Programa Nacional de Eficiência Energética em Edificações - PROCEL Edifica. 2003. Disponível em: <www.procelinfo.com.br>. Acesso em: 21 jan. 2017.

[29] SANTOS, N. M. Orçamentação na construção civil. Revista Especialize On-line IPOG, Goiânia, V. 10, N. 1, p. 115, dez. 2015

[30] SANTUCCI, J. Patologia e desempenho das construções. Crea-RS - Conselho em Revista, Porto Alegre, n. 107, p. 26-31, abr. 2015.

[31] SENA NETO, P. G.; ALCÂNTARA, R. L. Ferramentas de Sustentabilidade em Edificações. Gestão, Educação e Tecnologia Ambiental, Santa Maria, v. 19, n. 3, p. 505-528, set-dez. 2015.

[32] SILVA, F. C. Análise de falhas em projetos de construção civil. 2015. Disponível em: <http://www.ietec.com.br/clipping/2015/boletim/agosto/gp-agosto-analise-falhas-projetos-construcao-civil.pdf> Acesso em: 27 fev. 2017.

[33] SILVA JUNIOR, J. M. Disposição irregular de resíduos sólidos e impactos à saúde. Revista Jus Navigandi, Teresina, v. 16, n. 2961, 10 ago. 2011. Disponível em: <https://jus.com.br/ artigos/19735>. Acesso em: 27 fev. 2017.

[34] SILVEIRA, J. C. et al. Problemas encontrados em obras devido às falhas no processo de projeto. 2002. Disponível em: <http://www.dcc.ufpr.br/mediawiki/images/2/27/problemas_encontrados_ em_obras_devido_\%c3\%80s_falhas.pdf>. Acesso em: 27 fev. 2017.

[35] SODAGAR, B. Sustainability potentials of housing refurbishment. Buildings, v. 3, p. 278-299, 2013.

[36] SOUZA, R. S. Relações de trabalho e o processo de precariedade na construção civil brasileira. Estudos do Trabalho, v. 9, n. 17, p. 1-22, 2015.

[37] SOUZA, G. S. et al. Metodologia da pesquisa científica. Porto Alegre, RS: Animal, 2013.

[38] TAKAHASHI, M. A. B. C. et al. Precarização do Trabalho e Risco de Acidentes na construção civil: um estudo com base na Análise Coletiva do Trabalho (ACT). Saúde Social, São Paulo, v.21, n.4, p.976-988, 2012.

[39] logia da pesquisa científica: a construção do conhecimento e do pensamento científico no processo de aprendizado. Porto Alegre, RS: Anim 


\section{Capítulo 10}

\section{IMPLANTAÇÃO DE UM RESORT E SEU IMPACTO SOCIOAMBIENTAL - MARICÁ-RJ}

\section{Eduardo Cantarelli Vanconcelos Ferreira Cantarelli}

\section{Fabio Medeiros dos Santos}

Gabriele Cristine Bernardo de Carvalho

\section{Luan de Carvalho Dantes}

Resumo: 0 estudo em questão analisa o impacto socioambiental causado pela implantação de um Resort no Município de Maricá/ Rio de Janeiro, denominado Complexo Turístico- Residencial Fazenda de São Bento da Lagoa em uma Área de Proteção Ambiental (APA). Este é uma área de extrema relevância, pois ali são realizadas uma série de pesquisas, coordenadas por biólogos de instituições federais do estado e por também se possuir a Comunidade de Zacarias, tradicional na pesca artesanal. Avaliando a situação dos envolvidos, levou-se em consideração a RIMA (Relatório de Impacto Ambiental), feita pela empresa cujo interesse é implantar o Resort e a realidade dos pescadores e de toda população da região, e a posição do governo do Estado do Rio de Janeiro nas audiências públicas ocorridas para a aprovação do resort.

Palavras-Chave: Impacto Socioambiental, Área de Proteção Ambiental (APA), Resort, Zacarias. 


\section{INTRODUÇÃO}

Através do artigo 182 da Constituição Federal (1988) e da Lei Federal n. 10.257/01, o plano diretor é definido como "instrumento básico da política de desenvolvimento e expansão urbana" (BRASIL, 2001, p. 12). Tal apresentação é dada em forma de Lei Municipal, que deve ser elaborada através da metodologia participativa e aprovada pela Câmara de Vereadores. 0 plano diretor deve ser, portanto, um compromisso assumido entre a comunidade local e o Poder Público.

De acordo com Loureiro (2010), as questões sócio- ambientais que tratam de Unidades de Conservação (UCs) vem sendo travado com frequência na última década no Brasil. Não são poucos, nem recentes, os conflitos que envolvem UCs, comunidades tradicionais, agentes econômicos e governo. Especialmente no Rio de Janeiro, diversos noticiários mostraram a entrada de investimentos com fins urbanos de grupos estrangeiros nos setores turístico e imobiliário em UCs situadas na área costeira.

Até meados de 2006, a legislação urbanística do município de Maricá era composta por dois instrumentos reguladores: o Plano de Desenvolvimento Urbano (Lei n. 463, de 17 de dezembro de 1984) e o Código Municipal de Obras (Lei n. 77, de 14 de dezembro de 1978). Atualmente, encontra-se vigente o novo Plano Diretor do Município de Maricá (Lei Complementar n. 145/06).

As áreas mais polêmicas são as Áreas de Proteção Ambiental - APAs de Maricá, no município do mesmo nome, e do Pau Brasil nas localidades do Peró, em Cabo Frio e Tucuns, em Búzios. Tal inquietação se deve aos anúncios de instalação de resorts nas UCs e em trechos do ecossistema de restinga, com total aprovação das prefeituras e do órgão ambiental do estado, a Fundação Estadual de Engenharia Ambiental - FEEMA (atualmente incorporada ao Instituto Estadual do Ambiente - INEA).

Na APA de Maricá vale ressaltar a presença da comunidade pesqueira de Zacarias, que se encontra na localidade desde o século XVIII. Assim, observa-se que o projeto de implantação de um resort, poderá descaracterizar grande parte da APA, a única com uma grande área de vegetação de restinga preservada do município, e comprometer a comunidade de pescadores. Este ecossistema abriga flora e fauna significativa (inclusive aves migratórias e espécies endêmicas e ameaçadas de extinção), além de possuir sítios arqueológicos a serem estudados, consistindo num patrimônio ambiental, cultural, arqueológico e científico. (LOUREIRO, 2010)

Desde a década de 1980, o território de Maricá modificou- se consideravelmente. As principais mudanças deram-se no aumento populacional e, por consequência, no incremento das atividades imobiliárias. Em 2002, as obras de duplicação da Rodovia Amaral Peixoto (RJ-106) incentivaram veranistas a fixarem residência no município,

atraíram novos investidores e estimularam, mais uma vez, a especulação imobiliária. Esta alteração de cenário de certa forma inviabilizou a aplicação do Plano de Desenvolvimento Urbano em diversos de seus artigos. Porém, ao mesmo tempo, fomentou a elaboração de nova legislação urbanística para o município, condizente com a atual realidade local. Após outubro de 2006, essa nova legislação estrutura-se, fundamentalmente, no Plano Diretor de Maricá. (MONTEIRO, 2008)

A instalação do Complexo Petroquímico de Rio de Janeiro

- COMPERJ no município de Itaboraí, ao norte de Maricá promoveu certo dinamismo econômico na região. Este empreendimento da Petrobrás trará grandes transformações na economia, no setor industrial e no fluxo populacional previsto para os próximos vinte anos. A localização da nova inserção é de característica estratégica, já que se localiza entre o grande empreendimento e o litoral, tornando o projeto do resort um novo quadro econômico regional.

Loureiro (2010) identifica os seguintes agentes da disputa territorial:

- MEMBROS DO EXECUTIVO E LEGISLATIVO ESTADUAL E MUNICIPAL - representado pelos governantes daquela área e que estão a favor da construção de um resort na APA;

- PROPRIETÁRIOS/EMPRESÁRIOSLUSO- ESPANHÓIS - buscam se apropriar daquela área para a construção de um empreendimento bilionário;

- COMUNIDADE DE PESCADORES - querem permanecer na área ocupada de onde provém o seu sustento; 


\section{A HISTÓRIA DE DE ZACARIAS}

A comunidade de Zacarias situa-se há mais de dois séculos na região, localizada dentro da Área de Proteção Ambiental (APA), na margem da Lagoa de Maricá, ocupando uma faixa com cerca de 100 metros de largura. "Escandido entre a Ponta da Pedra e a Ponta do Capim, o casario do povoado amoldava-se à vegetação baixa da restinga". (Mello e Vogel, 2004, p. 29). Segundo os relatos dos pescadores, hoje habitam a comunidade de Zacarias entorno de 60 famílias que vivem da pesca*, sendo a população em si constituída de mais de 300 pessoas. Esta comunidade é descendente de três principais famílias (o clã dos Marins, Costa e os Marques) e os não nativos estão na comunidade por relações de casamento e muitas vezes são descendentes das mesmas famílias, mas moravam em Niterói ou em Saquarema. (LOUREIRO, 2010)

A visão da paisagem é uma constante descoberta, pois depende do quê, do como, do quando e do quanto se vê, variando por causa de deslocamentos físicos, frequência e luminosidade durante os diferentes períodos do dia. Entretanto, para o observador, a paisagem, formada por elementos abióticos e bióticos, apresenta-se de forma fracionada - parte de uma dimensão maior -, e a sua totalidade não é visualizada com um simples olhar. Por conseguinte, o homem apreende partes isoladas da paisagem, pois tende a desconsiderar o todo (EMÍDIO, 2006, p. 57).

A população apresenta dominância de homens, e sua maior parte tem como atividade econômica à pesca, porém alguns pescadores têm outro emprego complementar em sua renda mensal, muitas vezes ligado ao setor terciário (construção civil). Em relação à pesca artesanal, o município de Maricá até o início da década de 50 tinha sua economia baseada na própria pesca, no entanto a partir da abertura do canal de Ponta Negra, ligando a Lagoa de Guarapina ao mar houve uma redução nos estoques pesqueiros da região, principalmente $o^{*}$ Dados não oficiais, obtidos através de entrevistas com os moradores zacarieiros, filiados a Associação Comunitária de Cultura e Lazer dos Pescadores da Comunidade de Zacarias. Entrevistas concedidas no dia 04/02/2009. 8 camarão, devido à inversão da salinidade e nos dias de hoje a produção está reduzida para um atendimento precário à demanda local. (LOUREIRO, 2010)

À medida que as organizações ambientais se comunicam com os pescadores no sentido de criar uma cooperação sobre o uso da APA-Maricá, os pescadores se dão conta que é preciso um maior cuidado com o uso da natureza e isso se inclui como importante pauta de debate na Associação de Pescadores de Zacarias (ACCLAPEZ). A pesca artesanal ao redor desse território se inclui na lagoa e algumas vezes no mar. Todo o trabalho com pesca desses dois ambientes e da restinga para ser separado o peixe, limpo e vendido na aldeia. A utilização em conjunto desses ambientes é motivo suficiente para que se considere a preservação como fator fundamental.

Todavia essa relação entre os grupos nem sempre é harmoniosa e os conflitos e a luta pela permanência na área da APA-Marica já são antigos. Ao conversar com os pescadores, os mesmos relatam que há um relativo isolamento da comunidade de pescadores das demandas públicas, o governo desde sempre dificultou a inclusão de serviços básicos na vila dos pescadores. Esse isolamento fazia parte da estratégia de controle dos governos que sucederam o poder municipal, como uma forma de estimular a evasão dos pescadores de seus terrenos. Suas casas, até pouco tempo atrás, não tinham luz, não tinham canalização de esgoto e diversas vezes os pescadores foram ameaçados de serem expulsos por não terem título de propriedade. Grande parte da área em que moram pertencia à antiga Fazenda São Bento da Lagoa que atualmente foi vendida aos proprietários do resort.

São evidentes os estragos causados pelo esgoto não tratado, pela crescente expansão de casas em torno da lagoa e, principalmente, ao redor dos rios que desaguam neste ambiente, quando aparecem enormes quantidades de espuma por causa do excesso de matéria orgânica de origem doméstica. Também não existe pesca em grande parte da lagoa por causa redução atual na entrada de peixes em pontos de despejo de esgoto. Com isso reduz-se o número de famílias que vivem somente da pesca, como também o número de pescadores amparados pelo auxílio defeso já que estes procuram somar as suas rendas outras formas de trabalho formais.

Em 1984, após a ameaça de desapropriação da Comunidade de Zacarias, o governo estadual criou a Área de Preservação Ambiental de Maricá, abrangendo a Restinga, a Ponta do Fundão e a Ilha Cardosa, contemplada com a proibição total de parcelamento de terras para fins urbanos. 
Um Plano de Manejo requer a existência de um Grupo Gestor - SNUC (Sistema Nacional de Unidades de

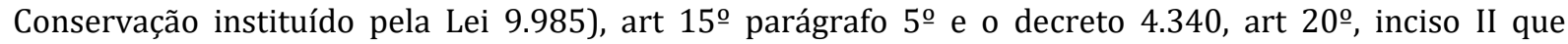
determina ser da competência deste Conselho acompanhar a elaboração, implementação e revisão do plano, que só foi formado em 2008.

Em julho de 2007 a CECA (Comissão Estadual de Controle Ambiental) em sua Deliberação № 4.854, de 19 de julho de 2007, torna a área mais permissiva de parcelamento e para tentar legitimar esse Plano de Manejo convoca a população para uma reunião pública onde apresentaria o plano. Mesmo com a pouquíssima divulgação do encontro, o Movimento Pró-Restinga conseguiu lotar a plenária exigindo que o Plano fosse debatido e mostrando os diversos pontos que feriam leis federais e estaduais e desrespeitavam os interesses da comunidade de Zacarias. A CECA não conseguiu naquele momento a aprovação do Plano de Manejo e ficou de voltar à cidade, para outra reunião, com um novo texto.

No dia 4 de dezembro de 2007 o governador Sergio Cabral assina o Decreto 41.048 instituindo o Plano de Manejo para a APA de Maricá tornando seu parcelamento ainda mais permissivo que o da CECA.

O Plano decretado não considera a Lei do Bioma Mata Atlântica - Lei no 11428 de 22 de dezembro de 2006, assim como o Código Florestal — Lei no 4.771 de 15 de setembro de 1965 -, artigos 1ํㅡ, 2o e 3ํㅜ e o Plano Nacional de Gerenciamento Costeiro - Decreto no 5.300 de 7 de dezembro de 2004 -, artigos $2^{\circ}$ o

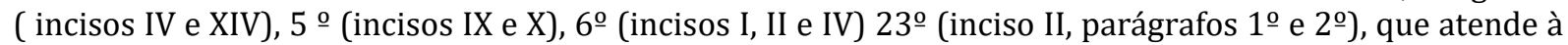
convenção das Nações Unidas para o Direito do Mar da qual o Brasil é signatário.

O Plano de Manejo contém equívocos graves, como o de considerar a vegetação rasteira (típica do ecossistema em questão) como área degradada, sujeita à ocupação urbana. 0 mesmo acontece em áreas desprovidas de vegetação, como em alguns campos de dunas, também consideradas como áreas degradadas quando na verdade são características do mesmo ecossistema. Inclui-se ainda que estas duas porções correspondem ao segundo cordão arenoso, que é o mais antigo, logo, um elemento estrutural da feição geomorfológica, além de ser um fundamental aporte de areia para a defesa e equilíbrio da costa do estado do Rio de Janeiro e da Região Sudeste.

\section{PROJETO DO RESORT - VISÃO DO EMPREENDIMENTO}

O projeto de construção que no caso de liberação será executado pelo Instituto de Desenvolvimento Brasileiro (IDB), braço no Brasil do grupo de empresários portugueses e espanhóis, que são os atuais proprietários da área, e prevê um investimento segundo o projeto estimado na ordem de U\$ 4 bilhões, sendo $\mathrm{R} \$ 320$ milhões investidos em água e esgoto. 0 empreendimento imobiliário e turístico é do tipo resort. (DOMINGUES, 2010)

Um dos argumentos do projeto de construção do resort denominado Fazenda São Bento da Lagoa, seria a junção de comodidade com a natureza. Outro fator seria a tranquilidade, a segurança e o conforto de uma área isolada, permitindo que as pessoas desfrutem dos mais elevados padrões de qualidade de vida. Segundo o grupo Madri- Lisboa, o futuro complexo turístico e residencial que se instalará na restinga de Maricá, entre a lagoa de Maricá e o Oceano Atlântico, possui $8 \mathrm{~km}$ de praia com areia branca e mar cristalino, aproximadamente 840 hectares. 0 resort possuirá uma área de projeto exclusivo, englobando moradias de luxo (condomínio de casais e prédios), marina privada para mil embarcações (a partir da abertura de um novo canal) grandes zonas desportivas (campo de golfe), SPA, teatro, parque empresarial, piscinas, hotéis que permitirá aos frequentadores em seu tempo livre, desfrutar de toda essa magnífica estrutura. Faz parte ainda do projeto, a criação de um complexo de turismo ecológico e a recuperação das áreas de brejo.

De acordo com Loureiro (2010), o projeto baseia-se nos problemas que segundo o grupo são de grande importância, como a desordem urbanística, a deterioração da natureza e a necessidade de maior qualidade de vida para a população maricaense. 0 slogan do projeto do resort é: "Fazenda de São Bento da Lagoa, um lugar onde se despertam os sentidos".

\subsection{A INSTALAÇÃO DO RESORT - VANTAGENS E DESVANTAGENS}

Segundo o ex-prefeito de Maricá, Ricardo Queiróz, a instalação do empreendimento será de ganho ambiental, uma vez que de acordo com o projeto o grupo irá investir $\mathrm{R} \$ 320$ milhões em água potável e esgoto sanitário tratado, o que vai contemplar todo o município, além de revitalizar as lagoas, tornando-as navegáveis e atrativas. Outro argumento do ex-prefeito é a possibilidade de cerca de quarenta mil 
empregos (utilizando e qualificando profissionalmente a mão de obra local) em torno da implantação do resort e da emancipação econômica que o investimento garantirá a Maricá. Em uma reunião pública no dia 10/10/2007 pela Feema - Fundação Estadual de Engenharia do Meio Ambiente - no município, o exprefeito Ricardo Queiróz, alertou para o risco da aceleração da degradação da área devido à aproximação da instalação do complexo petrolífero (COMPERJ) em Itaboraí, o que irá refletir em um aumento populacional de Maricá. Ressaltou a importância de instalação de empreendimentos turísticas na área, o que pode ser fundamental para a sua conservação, bem como ser fator decisivo no desenvolvimento sustentável da cidade, através do segmento turístico. (LOUREIRO, 2010)

Outro ponto citado pelo ex-prefeito foi à manutenção da comunidade de pescadores de Zacarias com melhorias habitacionais, construção e implantação de um Instituto de Pesquisa da Restinga, com o objetivo de conservar e proteger a vegetação nativa, além de acompanhar a qualidade das águas e do ar e por último a instalação da Casa do Pescador com o intuito de desenvolver atividades econômicas e educacionais para os pescadores e os familiares. (LOUREIRO, 2010)

Ao analisar os ganhos que a instalação do resort poderá provar, o ex-prefeito afirmou: "Temos que pensar com muita responsabilidade, o ganho não vai ser só econômico, vamos ganhar muito em meio ambiente e por consequência, também vamos crescer socialmente. Maricá só tem a ganhar com este projeto", lembrando ainda da perenidade da indústria turística ao contrário do crescimento promovido pela atividade petrolífera, que tem tempo para acabar. Em virtude de várias reivindicações da comunidade, universidades que desenvolvem pesquisas no local e apelo popular o projeto passou por várias alterações afim de se adequar e reduzir significativamente os impactos gerados. (LOUREIRO, 2010)

o prazo para o iniciar o projeto depende da Feema e da Serla, já que é necessário a aprovação de ambos, já que realizam o estudo técnico, e de audiência pública. Muitas coisas são questionadas na construção do resort, como a questão política, segundo matéria do jornal 0 Globo, vereadores de Maricá viajaram para a Espanha, com tudo pago pelos empresários do grupo o qual está investindo na construção. Isso gera dúvida na legitimidade da aprovação desse projeto, devido aos "interesses" desses vereadores. Também pode-se notar que a imprensa local está fazendo campanha a favor da construção. Consequentemente forma nos leitores uma imagem positiva desse possível resort. 0 próprio jornal "A voz de Marica" estampou em sua capa a seguinte manchete: "Marica quer o resort: A imprensa maricaense faz campanha para a construção do resort na restinga".

\section{CONCLUSÃO}

De acordo com Loureiro (2010), no que tange a futura utilização da área de proteção ambiental, na reserva seria incentivado o uso da restinga para realização de pesquisas cientificas (a ser implantado por instituições de pesquisa) bem como visitas guiadas (cobrando um valor simbólico), excursões de programas de educação ambiental ou cursos avulsos (sobre ecologia, sistema de lacunas, etc). Vale ressaltar que a mão-de-obra utilizada neste projeto seria a local que no caso da restinga de Maricá são os próprios pescadores da comunidade de Zacarias e seus familiares, após passarem por um curso de formação de guias que poderá ser elaborado, por exemplo, pela prefeitura. Sendo assim, os pescadores manteriam sua principal atividade econômica tradicional, a pesca e teriam uma renda extra, oriunda com o trabalho de guia do 13 parque. Além de garantir a pesca artesanal, estariam assegurados a ecossistema, a área costeira, o sistema lagunar, os sítios arqueológicos e a pesquisa científica.

Portanto, a partir da situação retratada, vimos como necessidade informar para as pessoas no sentido de fazer emergir para o foco discursivo vigente toda a questão que envolve a implementação do resort na restinga, não como oposição direta a esse tipo de construção no município de Maricá, mas sim a instalação deste tipo de infraestrutura de tamanha magnitude dentro de uma Área de Preservação Ambiental. É necessário deixar bem claro que na concepção do grupo de pesquisa, a implantação do resort que possui um projeto bem "elaborado" e grandioso seria de bom proveito para a economia do município, porém somente se for construído em local apropriado, fora da área de proteção ambiental. Caso o resort seja realmente construído na APA, todo ecossistema local será atingido e poderá ter consequências irreversíveis. Em relação à comunidade de pescadores de Zacarias provocará o fim de suas atividades que duram centenas de anos. Considerando que o ambiente da restinga é formado por uma especificidade de recursos naturais (biótico e abiótico) acreditamos ser a melhor forma de utilização da área, como citamos anteriormente, a instalação de um parque ecológico que viabilizaria a preservação de seus atributos naturais, ao mesmo tempo movimentaria a economia do município de forma a prover um desenvolvimento econômico que assegure aos pescadores sua fonte de renda e conscientizaria todos 
moradores da região de Maricá sobre a importância da preservação ambiental enquanto uma questão social. (LOUREIRO, 2010)

Quanto à dragagem das lagoas; este é com certeza o impacto mais sério do projeto, e neste caso não se trata de suposição, pois se a Marina projetada for implantada todo o sistema lacunar terá que ser dragado. Como a profundidade média deste sistema hoje, segundo dados de cartas batimétricas não deve passar de algo entorno dos $60 \mathrm{~cm}$, os impactos são previsíveis: salinização, desestabilização de margens, diminuição significativa do espelho d’água e, inclusive, a possibilidade da desestabilização da faixa arenosa da restinga. (HOLZER, 2010)

Além do impacto social e econômico no mercado imobiliário, o alto valor do empreendimento poderá ocasionar uma série de impactos ambientais irreversíveis. Um acompanhamento crítico se faz necessário para fins de analisar os efeitos deste impacto, além de estimular formas mais conscientes de uso e gestão do espaço urbano que não desintegrem o "modo de vida" dos grupos tradicionais.

\section{REFERÊNCIAS}

[1] VIEIRA, Isabela. Moradores de Maricá querem parque em área ameaçada pela especulação imobiliária. Agência Brasil, 11 jul. 2009. Disponível em: http://memoria.ebc.com.br/agenciabrasil/noticia/2009-07- 11/moradores-de-marica-querem-parque-em-areaameacada-pela-especulacao-imobiliaria. Acesso em: 17 jun. 2016.

[2] MAPA DE CONFLITOS ENVOLVENDO INJUSTIÇA AMBIENTAL E SAÚDE NO BRASIL. Disponível em : http://www.conflitoambiental.icict.fiocruz.br/index.php?p ag=ficha\&cod=116 . Acesso em: 02 jun. 2016

[3] IDB BRASIL LTDA. RELATÓRIO DE IMPACTO AMBIENTAL - RIMA. Disponível em: http://www.idbbrasil.com.br/rima-idb.pdf. Acesso em: 04 mai. 2016.

[4] PREFEITURA DE MARICÁ. Disponível em: http://www.marica.rj.gov.br/?s=noticia\&n=2999 . Acesso em: 09 mai. 2016 


\section{Capítulo 11}

O AVANÇO DAS AÇÕES ANTRÓPICAS, NOS ANOS DE 1984, 1991, 2001 E 2008, NO ENTORNO DA ÁREA DE CAPTAÇÃO DAS BARRAGENS DE ÁGUA FRIA I E II

\section{Camila da Silva Sotero}

Paulo Sérgio Monteiro Mascarenhas

Odair Lacerda Lemos

Resumo: A exploração dos recursos naturais, em favor do desenvolvimento humano, tem se tornada agressiva ao longo dos anos. 0 homem modifica o meio ambiente a sua volta, buscando meios para satisfazer as suas necessidades, sem se preocupar com o equilíbrio deste. As cidades abastecidas pelas Barragens de Água Fria I e II, localizadas no sudoeste baiano, têm enfrentado grandes períodos de racionamento de água nos últimos anos. Diante desta situação, o presente estudo teve como objetivo analisar o avanço das atividades agropecuárias no entorno da bacia de captação das Barragens de Água Fria I e II, em especial, dentro das áreas destinadas à mata ciliar e mata de topo de morro conforme o Código Florestal Brasileiro de 1965. Foram utilizadas imagens de satélite da região pesquisada nos períodos de 1984, 1991, 2001 e 2008, estratificando as análises em áreas totais, áreas de mata ciliar e áreas de topo de morro com o intuito de traçar um comportamento individual do uso e ocupação do solo para cada situação. Desde o período de 1984, as florestas da região ocupavam apenas $37,83 \%$ do solo da sub-bacia estudada, em 2008 este percentual cai para apenas 20,29\%. Sendo assim, através deste trabalho, percebe-se a real influência da retirada abusiva da camada vegetal original, principalmente, nas áreas determinadas como áreas de preservação permanente, para o equilíbrio e funcionamento da sub-bacia de captação das barragens de Água Fria I e II, contribuindo assim para os extensos períodos de seca vivenciados pelos moradores da região e pelas populações abastecidas por estas barragens.

Palavras-Chave: Mata Ciliar, Mata de Topo de Morro, Barra do Choça, Barragens de Água Fria I e II. 


\section{INTRODUÇÃO}

A evolução do homem e o desenvolvimento de sua habilidade de explorar o meio a sua volta em prol de benefício próprio é marcado pelo equilíbrio entre o ecossistema de um lugar qualquer e o ser humano. Através deste, o homem tem pautado as suas ações ao longo do tempo, no entanto, com a consolidação do capitalismo e o fortalecimento do imediatismo, as ações que outrora pautadas em equilíbrio, se tornaram predatórias, deixando de respeitar os limites impostos pelo meio ambiente.

A bacia hidrográfica, assim como todo o meio ambiente, também vem sofrendo essas constantes modificações humanas haja vista que essa (em conjunto com todos os seres pertencentes a ela) é um local viável para a ocupação humana.

A bacia hidrográfica é um exemplo disso: a dinâmica dos fatores bióticos e abióticos combina-se com a atividade antrópica promovendo fluxos de matéria e energia onde o estado de estabilidade é atingido a partir do equacionamento entre as entradas e saídas, alterando as características do solo, da água e do canal fluvial. (OLIVEIRA, 2006, p.1)

De acordo com Oliveira (2006), a bacia hidrográfica é caracterizada como o conjunto de fluxos de matéria em estabilidade que garantem o funcionamento do círculo vicioso. Ou seja, a mesma só existe e desempenha o seu papel quando encontrada em equilíbrio em todos os seus setores.

Sendo assim, surgiu a necessidade de um trabalho que visasse a análise do avanço da agricultura e da pecuária nas proximidades dos rios que abastecem as barragens de Água Fria I e II, bem como das matas ciliares e de topo de morro, nos anos de 1984, 1991, 2001 e 2008, a fim de verificar se este avanço da agropecuária tem sido de maneira agressiva ou tem respeitado as diretrizes impostas pelo Código Florestal Brasileiro de 1965 e as suas determinações em relação às Áreas de Preservação Permanente (APP).

Diante da importância das bacias hidrográficas e dos seus papéis na manutenção do equilíbrio terrestre, percebe-se tamanha importância do seu estudo e de sua análise com o intuito de verificar como tem sido o avanço humano nas mesmas e amenizar ou erradicar a ação predatória que pode vir prejudicar uma determinada bacia hidrográfica.

Uma bacia hidrográfica que tem deficiências quanto a sua mata ciliar no entorno dos rios sofre com as intempéries humanas e naturais numa escala maior, causando assim problemas ambientais que interferem em todo o ciclo hidrológico, bem como na sociedade que está alojada nela. Portanto, estudar sobre o avanço humano em uma bacia está muito mais além do que conhecer o uso e a ocupação do solo, a análise serve também de ferramenta para indicar como tem sido o comportamento desta bacia, os problemas que ela tem enfrentado por conta das transformações antrópicas e as consequências destas ações tanto para o meio ambiente quanto para a sociedade ali presente.

A área de estudo deste trabalho se dá na Zona Rural do município de Barra do Choça, Bahia, que abriga em seu território as bacias de captação das barragens de Água Fria I e II, responsáveis pelo abastecimento hídrico de Vitória da Conquista e Barra do Choça e das localidades de Barra Nova, São Sebastião, José Gonçalves, Bate Pé, Pradoso e Iguá. Essas não tem atendido a demanda do abastecimento urbano destas localidades e, com isso, vem sofrendo, ao longo do tempo, com as secas que atingem a região em um determinado período do ano.

Tal deficiência das barragens podem ser ocasionadas por uma soma de motivos, como o aumento populacional das comunidades abastecidas, secas que se estendem por períodos longos e práticas agropecuárias encontradas no entorno das bacias de captação. Com isso, este trabalho é de suma importância para a população atendida pelas barragens, bem como pela prefeitura do município de Barra do Choça, que através das análises poderá pensar em atividades que venham extinguir práticas predatórias na região das bacias de captação. Ademais, o trabalho contribuíra para o estudo de pesquisadores que queiram entender a real importância e influência das bacias estudadas no abastecimento hídrico de Vitória da Conquista, Barra do Choça e região.

\subsection{BACIA HIDROGRÁFICA}

A água disponível ao consumo humano é proveniente das bacias hidrográficas encontradas no planeta. Estas são um conjunto de fenômenos naturais que ocorrem de maneira que mantêm o equilíbrio destas águas em seus limites. 
De acordo com Cruciani (1976), uma microbacia hidrográfica é área de formação natural, drenada por um curso d'água e seus afluentes, a montante de uma seção considerada, de modo que toda a água venha a convergir para uma única área, denominada exutório.

Em outras palavras, uma bacia hidrográfica é uma área delimitada por limites topográficos, que possui um ciclo hidrológico capaz de fornecer e manter o equilíbrio de água na região estudada.

Este ciclo hidrológico se caracteriza pelos fenômenos ocorrentes dentro de uma bacia que são responsáveis pelo funcionamento equilibrado da área. Este é composto pela precipitação, infiltração, escoamento superficial e evapotranspiração, como mostra a figura 01.

\section{Figura 1: Ciclo Hidrológico}

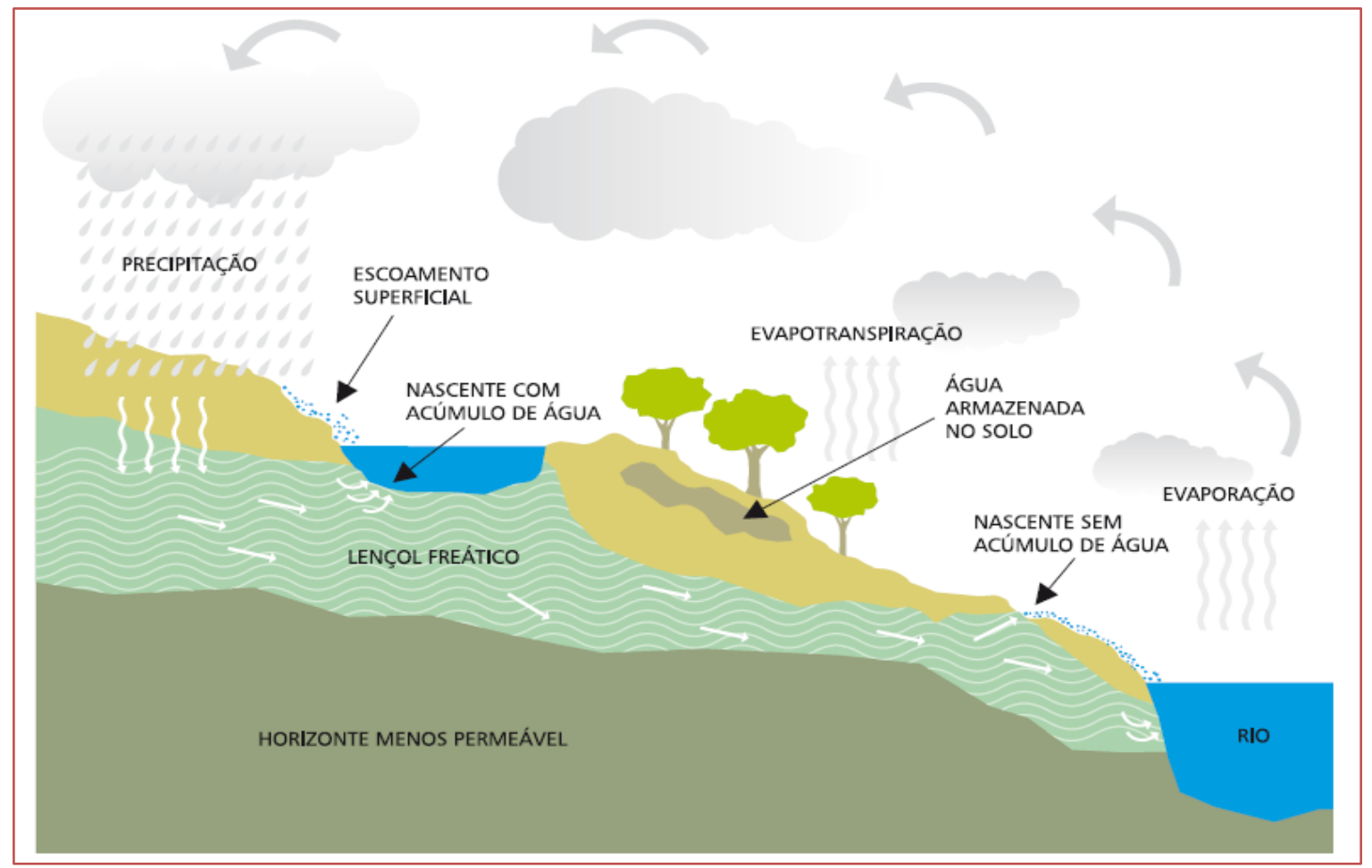

Fonte: Cad. Mata Ciliar, 2009

A constância deste ciclo, bem como o seu correto funcionamento, é responsável pela disponibilização de água em rios e afluentes, gerando assim, água para o consumo humano.

Este ciclo, apesar de ter suas fases delimitadas pelo processo da água no decorrer da bacia hidrográfica, para que esteja em condições adequadas, necessita de um conjunto de ações dentro da área de sua bacia. Ou seja, ele depende não somente da chuva e sua intensidade, mas também do uso e ocupação do solo, do tipo do solo, da cobertura vegetal, da temperatura e da declividade desta bacia.

Todos estes fatores desempenham papel fundamental para a manutenção do equilíbrio da bacia hidrográfica e, caso um seja modificado, o mesmo trará danos não somente a si, mas a todo o ciclo hidrológico e, consequentemente, a bacia hidrográfica e disponibilidade de água local.

\subsection{MATA CILIAR E AS LEIS REGULAMENTADORAS}

Matas Ciliares, ou Matas de Galeria, são as florestas que se encontram nas margens de todos os cursos d'água e das nascentes, independente de serem perenes ou intermitentes. Tais matas apresentam variação em sua composição biológica e comportamento de acordo com o solo em que está situada e a região em que pertence. (OLIVEIRA-FILHO et al 1990; PERMAC 2011; REZENDE 1998; RODRIGUES 2001). 
De acordo com Oliveira-Filho et al (1990), apesar das matas ciliares não apresentarem extensas áreas de uso e ocupação do solo, essas são de extrema importância para a proteção dos rios, lagos, olhos d'água e nascentes. Além disso, as matas ciliares também contribuem para a manutenção do equilíbrio do curso normal das águas e de toda a bacia hidrográfica a que pertencem.

Diante de tamanha relevância das matas ciliares e de seus constantes usos abusivos, buscou-se criar diretrizes que viessem respaldar toda esta flora, que por ser encontrada em pequena área, quando comparada a outras matas, sofriam constantes desmatamentos, acarretando em diversos prejuízos ao local descoberto.

O Brasil, hoje, possui uma gama de regulamentações promulgadas em leis que visam à preservação destas áreas. Tais leis são consideradas mundialmente eficazes quanto à questão da sustentabilidade e da preservação ambiental. No entanto, ao longo dos anos, ocorreram mudanças nas diretrizes a fim de beneficiar uma parcela da população brasileira em detrimento de uma eficaz proteção ambiental pelos poderes federais, estaduais e municipais.

\subsubsection{CÓDIGO FLORESTAL DE 1965}

O antigo Código Florestal Brasileiro, Lei 4771/65, foi promulgado em 15 de Setembro de 1965 e teve como principal finalidade regulamentar em Lei quais seriam os objetos a serem conservados e as punições referentes ao não cumprimento do mesmo.

Na Lei 4771/65 fica conceituado o significado de todos os termos utilizados na área, bem como suas especificidades. De acordo com esta, as matas ciliares (responsáveis pela proteção e manutenção do curso normal dos rios e cursos d'água) são consideradas APP's (Áreas de Preservação Permanente), visto que são imprescindíveis para a qualidade do meio ambiente e a sua conservação é de interesse social, mas mantida e controlada pelos governos municipais, estaduais e federal.

Área de preservação permanente: área protegida nos termos dos arts. $2^{\circ}$ e $3^{0}$ desta Lei, coberta ou não por vegetação nativa, com a função ambiental de preservar os recursos hídricos, a paisagem, a estabilidade geológica, a biodiversidade, o fluxo gênico de fauna e flora, proteger o solo e assegurar o bem-estar das populações humanas. (BRASIL, 1965)

De acordo com o Art. $1 \S 2^{\circ}$ do Código Florestal de 1965, é considerada Área de Preservação Permanente toda área coberta ou não por vegetação nativa que tenha a função de preservar o meio ambiente e que são protegidas pelos poderes governantes; e ainda determina que seja de interesse social todas as ações necessárias para a proteção da integridade das vegetações nativas encontradas dentro das APP's.

Ainda de acordo com o antigo Código Florestal Brasileiro em seu Art. 2º́ é considerada preservação permanente todas as vegetações que atendam as características apontadas em lei.

Consideram-se de preservação permanente, pelo só efeito desta Lei, as florestas e demais formas de vegetação natural situadas:

a) ao longo dos rios ou de outro qualquer curso d'água, em faixa marginal;

b) ao redor das lagoas, lagos ou reservatórios d'água naturais ou artificiais;

c) nas nascentes, mesmo nos chamados "olhos d'água", seja qual for a sua situação topográfica;

d) no topo de morros, montes, montanhas e serras;

e) nas encostas ou partes destas, com declividade superior a $45^{\circ}$, equivalente a $100 \%$ na linha de maior declive;

f) nas restingas, como fixadoras de dunas ou estabilizadoras de mangues;

g) nas bordas dos taboleiros ou chapadas;

h) em altitude superior a 1.800 (mil e oitocentos) metros, nos campos naturais ou artificiais, as florestas nativas e as vegetações campestres. (BRASIL, 1965) 
Sendo assim, as matas ciliares por serem classificadas como APP's também foram caracterizadas detalhadamente para que não pudesse surgir ambiguidade e confusões quando a lei fosse executada, como mostra a Tabela 01.

Tabela 1: Faixa Marginal das matas ciliares de acordo com a disposição dos rios e cursos d'água

\begin{tabular}{|l|c|}
\hline \multicolumn{1}{|c|}{ Disposição dos rios ou qualquer curso d'água } & $\begin{array}{c}\text { Faixa Marginal das Matas } \\
\text { Ciliares (APP) }\end{array}$ \\
\hline Cursos d'água de menos de $10(\mathrm{dez})$ metros de largura & $30 \mathrm{~m}$ \\
\hline Cursos d'água que tenham de $10(\mathrm{dez})$ a 50 (cinquenta) metros de largura & $50 \mathrm{~m}$ \\
\hline Cursos d'água que tenham de 50 (cinquenta) a 200 (duzentos) metros de largura & $100 \mathrm{~m}$ \\
\hline Cursos d'água que tenham de 200 (duzentos) a 600 (seiscentos) metros de largura & $200 \mathrm{~m}$ \\
\hline Cursos d'água que tenham largura superior a 600 (seiscentos) metros & $500 \mathrm{~m}$ \\
\hline
\end{tabular}

Fonte: BRASIL, 1965.

Ou seja, além de conceituar os termos referentes ao meio ambiente e sua proteção, o Código especifica também como deve ser a configuração desses no campo, quantificando áreas e comprimentos mínimos a serem estabelecidos e cumpridos não somente pelos poderes municipais, estaduais e federal, mas também pela comunidade residente nas regiões mencionadas em Lei. Deixando claro que durante a vigência do estudado Código era permanentemente proibido alterações nestas florestas consideradas permanentes.

A supressão de vegetação em área de preservação permanente somente poderá ser autorizada em caso de utilidade pública ou de interesse social, devidamente caracterizados e motivados em procedimento administrativo próprio, quando inexistir alternativa técnica e locacional ao empreendimento proposto. (BRASIL, 1965)

Tais alterações ou supressões, por serem proibidas, caso fossem infligidas, fariam com que a pessoa jurídica ou física responsável pelo ato estivesse suscetível a penas previstas em Lei, como prisão de três meses a um ano e/ou multa de uma a cem vezes o salário mínimo mensal.

É notório que desde 1965, o Brasil possui respaldo legal para proteger e manter toda a sua cobertura vegetal e matas nativas em prol de uma qualidade ambiental, no entanto é sabido que a nação por ser um país agrário apresentou resistências quanto ao Código, visto que, na visão de muitos, tal Lei prejudicaria aqueles que trabalhavam com o solo, fazendo com que esta não fosse respeitada em prática e, futuramente, fosse repensado em um novo Código Florestal Brasileiro.

\subsubsection{CÓDIGO FLORESTAL BRASILEIRO DE 2012}

Com os constantes impasses entre os proprietários de terras e o governo representado pela Lei 4771/65, sentiu-se a necessidade da elaboração de um novo Código Florestal Brasileiro, haja vista que o antigo, além de causar discórdia entre a população e o poder federal, já não estava mais sendo cumprido. Logo, em 25 de Maio de 2012, a atual presidente, Dilma Vana Rousseff, promulga a Lei 12651/12 como o novo Código Florestal Brasileiro.

O Código Florestal de 2012 foi criado na finalidade de somar ao antigo na expectativa de melhorar o quadro em que se encontravam as florestas brasileiras, ou seja, este procurou não se distanciar tanto do Código Florestal de 1965, mas buscou atender aos pedidos dos proprietários de terra, principalmente, aqueles que possuíam extensas áreas de cultivo.

De acordo com a Lei 12651/12, as matas ciliares ainda são consideradas APP's, por serem constituídas de florestas que se estendem ao longo das margens dos rios e cursos d'água, protegendo-os contra diversos riscos, como o assoreamento.

No entanto, no novo Código Florestal Brasileiro, há a inserção de um novo conceito de área de preservação permanente: 
III - as áreas no entorno dos reservatórios d'água artificiais, decorrentes de barramento ou represamento de cursos d'água naturais, na faixa definida na licença ambiental do empreendimento; (BRASIL, 2012)

Sendo assim, a partir de 2012, não somente áreas das faixas marginais de rios seriam consideradas APP's, mas também áreas dos reservatórios de água artificiais decorrente de barramento ou represamento de cursos d'água naturais. Assegurando assim, cobertura vegetal capaz de proteger e manter a reserva hídrica em volume normal de funcionamento.

Assim como a nova Lei inseriu conceitos, a mesma também modificou outros de maneira que viesse a beneficiar terceiros. No antigo Código Florestal (4771/65), não importava se os olhos d'água eram perenes ou intermitentes, ambos teriam a proteção por Lei de sua faixa marginal caracterizada como APP. Contudo, o novo Código Florestal (12651/12) deixa claro que somente os olhos d'água perenes estariam assegurados pela Lei, ficando assim, os intermitentes a mercê dos desejos e anseios dos poderes estaduais e municipais ou dos proprietários de terras em última instância.

IV - as áreas no entorno das nascentes e dos olhos d'água perenes, qualquer que seja sua situação topográfica, no raio mínimo de 50 (cinquenta) metros; (BRASIL, 2012)

Assim como houve essa diferenciação de cuidados entre as nascentes e os olhos d'água, ocorreu da mesma maneira com as acumulações naturais e artificiais de águas. De acordo com a Lei 12651/12, art 4오 § 4o:

$\S 4^{0}$ Nas acumulações naturais ou artificiais de água com superfície inferior a 1 (um) hectare, fica dispensada a reserva da faixa de proteção prevista nos incisos II e III do caput, vedada nova supressão de áreas de vegetação nativa, salvo autorização do órgão ambiental competente do Sistema Nacional do Meio Ambiente - Sisnama.

Com estas novas ressalvas levantadas pelo atual Código Florestal Brasileiro, o quadro que se tem acerca de matas ciliares pode ser visto na tabela 02 .

Tabela 2: Faixa Marginal das matas ciliares de acordo com a disposição dos rios e cursos d'água

\begin{tabular}{|l|c|}
\multicolumn{1}{|c|}{ Disposição dos rios ou qualquer curso d'água } & $\begin{array}{c}\text { Faixa Marginal das Matas } \\
\text { Ciliares (APP) }\end{array}$ \\
\hline Cursos d'água de menos de 10 (dez) metros de largura & $30 \mathrm{~m}$ \\
\hline Cursos d'água que tenham de 10 (dez) a 50 (cinquenta) metros de largura & $100 \mathrm{~m}$ \\
\hline Cursos d'água que tenham de 50 (cinquenta) a 200 (duzentos) metros de largura & Faixa Marginal das Matas \\
\hline Ciliares (APP)
\end{tabular}

Fonte: BRASIL, 2012.

Apesar da inclusão das faixas marginais dos reservatórios d'água artificiais, é sabido que a Lei 12651/12, fora feita para atender muito mais aos proprietários de terra (que queriam um respaldo maior do governo para explorar suas terras) do que em prol do meio ambiente.

No novo Código Florestal de 2012 há muito mais exceções para que possam criar lacunas nas leis do que ideias e ações a mais para fortalecer o uso sustentável, bem como a consciência ambiental brasileira.

É evidente que há a proteção das matas ciliares no entorno dos rios e cursos d'água, porém seria imprescindível que houvesse uma preocupação maior com os rios e nascentes, sejam eles perenes ou não, a fim de revitalizá-los e fortalecê-los. 


\subsubsection{LEI ESTADUAL 10431/06 E DECRETO ESTADUAL 11235/08}

No estado da Bahia, além da atual Lei 12651/12, está em vigor uma Lei Estadual de 2006 regulamentada e acrescentada por um Decreto Estadual de 2008.

É sabido que uma Lei Estadual não tem poder suficiente para ir de contramão a uma Lei Federal, sendo assim o processo legislativo do nosso país funciona de maneira hierárquica. Com isso, tanto a Lei 10431/06 quanto o Decreto 11235/08 caracterizam-se por especificar e delegar funções e poderes a órgãos e municípios, bem como somar conceitos que por ventura não foram mencionados no Código Florestal Brasileiro.

É válido ressaltar que tanto a Lei Estadual 10431/06, quanto o Decreto 11235/08 foram pensados e promulgados antes da reestruturação do antigo Código Florestal Brasileiro de 1965, logo alguns pontos da legislação estadual entram em contradição ao Código Florestal de 2012. Como exemplo desta situação, tem-se a questão das matas ciliares em nascentes e olhos d'água que no Código de 2012 são protegidas somente as do entorno dos rios perenes, já a Decreto 11235/08 em seu art. 277, defende que:

XIV - as nascentes, ainda que intermitentes e os chamados "olhos d'água", qualquer que seja a sua situação topográfica, num raio mínimo de 50 (cinqüenta) metros ao seu redor, de tal forma que proteja, em cada caso, a bacia de drenagem contribuinte;

O que corrobora para o antigo Código Florestal Brasileiro (Lei 4771/65) que se incumbe de preservar as matas das faixas marginais de quaisquer nascentes e olhos d'água sejam eles perenes ou não.

Por serem leis estaduais, tais diretrizes apresentam uma característica mais específica e mais detalhada, explicitando em todos os detalhes as funções responsáveis por cada setor e poder, bem como as penalidades referentes às infrações tanto do Código Florestal Brasileiro, quando da Lei 10431/06 somada ao Decreto 11235/08.

Art. 372 - Sem prejuízo das sanções penais e civis, aos infratores serão aplicadas as seguintes penalidades, independentemente de sua ordem de enumeração:

I - advertência;

II - multa de $\mathrm{R} \$ 500,00$ (quinhentos reais) a $\mathrm{R} \$ 50.000 .000,00$ (cinqüenta milhões de reais);

III - interdição temporária ou definitiva;

IV - embargo temporário ou definitivo;

$\mathrm{V}$ - demolição;

VI - apreensão dos animais, produtos e subprodutos da fauna e flora, instrumentos, apetrechos, equipamentos ou veículos de qualquer natureza utilizados na infração;

VII - suspensão parcial ou total de atividades;

VIII - suspensão de venda e fabricação do produto;

IX - destruição ou inutilização de produto;

$X$ - perda ou restrição de direitos consistentes em:

a) suspensão de registro, licença ou autorização;

b) cancelamento de registro, licença e autorização;

c) perda ou restrição de benefícios e incentivos fiscais;

d) perda ou suspensão da participação em linhas financiamento em estabelecimentos públicos de crédito;

e) proibição de licitar e contratar com a Administração Pública pelo período de até 03 (três) anos. (BAHIA, 2008)

Como as diretrizes, tanto federais quanto estaduais, conceituam matas ciliares como APP's (Área de Preservação Permanente), é proibida a supressão destas em quaisquer condições. Caso tais práticas ainda 
sejam realizadas, a pessoa, física ou jurídica, responsável por tais sofrerá punições como: advertência e multas (estipuladas por ambas as Leis - Federal e Estadual) e prisões (determinadas de acordo com as punições previstas no Código Florestal de 1965).

\subsection{MATA DE TOPO DE MORRO E AS LEIS REGULAMENTADORAS}

As matas de topo de morro não são tão difundidas e conhecidas quanto às matas ciliares, no entanto essas são respaldadas pelos antigo e atual Código Florestal Brasileiro de 1965 e 2012 respectivamente, bem como por uma Resolução da CONAMA (Conselho Nacional do Meio Ambiente) no 303/02.

Apesar da mata de topo de morro ser caracterizada como Área de Preservação Permanente (APP) desde 1965 pelo Código Florestal Brasileiro, esta não apresentava descrições quanto as suas características e os seus limites. Somente em 2002, através da Resolução CONAMA 303/02, houve a definição dos morros, montanhas e conjunto de morros, bem como a metodologia a ser empregada para se identificar as áreas destinadas a APP's (Área de Preservação Permanente).

De acordo com CONAMA 303/02:

IV - morro: elevação do terreno com cota do topo em relação a base entre cinqüenta e trezentos metros e encostas com declividade superior a trinta por cento (aproximadamente dezessete graus) na linha de maior declividade;

V - montanha: elevação do terreno com cota em relação a base superior a trezentos metros;

Segundo a Resolução, uma mesma área pode conter tanto morros, quanto montanhas; o que difere uma forma de relevo da outra é a sua elevação, ou diferença de cotas.

A Resolução não só define morro e montanhas, mas também regulamenta quais áreas destas formas de relevo devem ser destinadas às áreas de preservação permanente, que posteriormente seriam acrescidas e regulamentadas também pela Lei 12651/2012.

Art. 3o Constitui Área de Preservação Permanente a área situada:

V - no topo de morros e montanhas, em áreas delimitadas a partir da curva de nível correspondente a dois terços da altura mínima da elevação em relação a base; (BRASIL, 2002; Resolução CONAMA no 303/2002, Art. 3의

IX - no topo de morros, montes, montanhas e serras, com altura mínima de 100 (cem) metros e inclinação média maior que $25^{\circ}$, as áreas delimitadas a partir da curva de nível correspondente a $2 / 3$ (dois terços) da altura mínima da elevação sempre em relação à base, sendo esta definida pelo plano horizontal determinado por planície ou espelho d'água adjacente ou, nos relevos ondulados, pela cota do ponto de sela mais próximo da elevação; (BRASIL, 2012; Lei 12651, Cap. II, Art. 4º̣)

Sendo assim, é considerada APP, em topos de morros e montanhas, toda área delimitada a partir da curva de nível correspondente a dois terços da menor altura da elevação em relação a base do morro ou montanha.

As áreas de topo de morro/montanha são de suma importância para a manutenção do equilíbrio de uma região e, principalmente, de uma bacia hidrográfica. Os morros ou montanhas podem coincidir com os divisores de água e delimitadores topográficos de uma bacia, sendo estes responsáveis por delimitar as bacias circunvizinhas, bem como por separar o curso das águas provenientes das chuvas.

Como as áreas de topo de morro e montanhas são definidas como áreas de preservação permanente pelos Códigos Florestais Brasileiros, o desrespeito quanto a sua proteção e a sua preservação também está sujeito a penalidades citadas no Decreto Estadual no 11235 de 2008 como infrações. 


\subsection{BARRA DO CHOÇA E AS PRÁTICAS AGRÍCOLAS EM SEU TERRITÓRIO}

O município de Barra do Choça, pertencente ao estado da Bahia que se encontra a $14^{\circ} 51^{\prime} 51^{\prime \prime} \mathrm{Sul}, 40^{\circ} 33^{\prime}$ $33^{\prime \prime}$ Oeste, é destaque no cenário baiano e nacional como produtor de café, haja vista que, durante muito tempo, a prática era a principal fonte de renda do município tanto para os moradores locais quanto para aqueles que vinham à cidade durante as épocas de colheitas. Portanto, para que se faça a análise do avanço das práticas agrícolas no município, é necessário que se entenda como ocorreu este avanço, sendo assim, há a importância do estudo da implementação da cultura cafeeira na cidade de Barra do Choça.

No setor primário, a partir da década de setenta, o café passou a ser a principal atividade do município, tanto na geração de renda como de emprego. A partir de então, Barra do Choça tem experimentado um verdadeiro crescimento em sua economia, com as maiores áreas de plantio de café do Estado, cerca de 18.000 mil hectares e com 30 milhões de covas 54 plantadas. (DUTRA NETO, 2001 apud DI LAURO, 2011)

Segundo Dutra Neto apud Di Lauro (2011), somente na década de setenta que o café é implantado na cidade de Barra do Choça, mesmo sendo tão próxima ao município de Vitória da Conquista. No entanto, esta demora da implantação não alterou o que a cultura propiciaria para o município em termos de economia. Em pouco tempo, (ainda na mesma década, ou seja, menos de dez anos) a prática agrícola se fortaleceu na cidade devido à configuração do seu solo que, por apresentar um clima Tropical Subúmido, favoreceu a nova cultura praticada.

Tais condições físicas favoráveis aliadas a um grande número de mão-de-obra disponível para o trabalho na lavoura sustentaram esta prática agrícola como fonte principal de renda por mais de 20 anos.

Entre 1970 a 1997, o município de Barra do Choça, teve um notável crescimento econômico promovido pela implantação da cultura cafeeira na região, pois, pode-se observar que em início da década de 70 , ocorreram maciços investimentos do Governo Federal em estradas, construções civis, além dos investimentos na cafeicultura. (DI LAURO, 2011)

A implementação da cultura cafeeira no município não se deu de forma planejada, com isso não houve estudos prévios acerca de como seria feita esta injeção da nova prática agrícola, nem onde seria aplicada. A mão-de-obra, por sua vez, não era especializada e não detinha conhecimento sobre as melhores condições para a nova cultura e para o solo que receberia esta nova espécie.

Até então, o solo que, antes na cidade, era usado apenas para a sobrevivência dos poucos moradores que ali moravam, passou a ser uma fonte de renda, expondo-o a ações predatórias e intensas que trariam sérios problemas ambientais a região.

0 pacote tecnológico aplicado na região e que estimulava a mecanização e uma cafeicultura a pleno sol, incidiu em impactos ambientais, tais como o aumento do desmatamento, contaminação de nascentes com o excesso de agrotóxicos, compactação do solo, entre outros. (SANTOS, 2001)

Os problemas ambientais decorrentes das práticas abusivas em conjunto com a seca que se implantou no final da década de noventa e início de 2000, atrelada as condições subumanas enfrentadas pelos lavradores que moravam na região impulsionaram uma crise na cultura cafeeira, como salienta Oliveira (2005):

A crise era assustadora: primeiro porque o pequeno produtor havia passado por um período de estiagem que o levou a perdas substanciais; segundo porque se endividou quando pensava ter condições de saldar os compromissos assumidos. Vale lembrar que as perdas a que nos referimos não devem ser atribuídas unicamente à problemas climáticos, mas às precárias condições materiais desse sujeito [...]. Assim, os problemas sociais do campo não só permaneceram como aumentaram, provocando um aprofundamento das desigualdades sociais e aumento da pobreza.

Esta crise da cultura cafeeira intensificada pela exclusão e desigualdade social na cidade fez com que a partir do ano 2000, o café, em Barra do Choça, sofresse uma estagnação quanto ao crescimento de sua área (aproximadamente $12.000 \mathrm{ha}$ ), dando chance para novas fontes de renda. 
Como a população barrachocense não tinha acesso à educação, não havia muitas opções de renda para a grande massa vinda das lavouras. Sendo assim, só restava para essa parte dos moradores a atividade agrária, visto que esta não requer mão-de-obra especializada. (OLIVEIRA, 2005)

A pecuária se fortaleceu nesse período de crise, aumentando a sua área de uso e ocupação do solo. Tal prática não estava tão dependente das chuvas, assim como o café, e dava a oportunidade de um trabalho braçal menos árduo o que chamou a atenção da população barrachocense. (OLIVEIRA, 2005)

Entretanto, ao contrário do que se especulou na época, o café não perdeu espaço no município, apenas teve o seu crescimento diminuído graças à implantação de uma nova fonte de renda. Ou seja, a partir dos anos 2000, há um avanço equiparado de ambas as fontes principais de renda somadas as práticas agrícolas destinadas a consumo próprio no município que fortaleceu a degradação ambiental de Barra do Choça.

\subsection{BARRAGENS DE ÁGUA FRIA I E ÁGUA FRIA II}

As barragens de Água Fria I e Água Fria II estão localizadas no município de Barra do Choça, Bahia, e são alimentadas pelas sub-bacias do Rio Água Fria e Rio dos Monos que são afluentes da sub-bacia do rio Catolé, principal rio da cidade.

As barragens apesar de serem uma ligada a outra, não foram construídas na mesma época. A princípio, construiu-se a barragem de Água Fria I para abastecer as comunidades vizinhas próximas a Barra do Choça, que sofria com as constantes secas comuns da região. Ao longo dos anos, a demanda hídrica das cidades abastecidas pela barragem aumentou de tamanha forma que fora preciso a construção de uma nova barragem que viesse fomentar a capacidade da barragem já existente.

Isto é, ambas as barragens foram construídas pela EMBASA (Empresa Baiana de Águas e Saneamento) subordinada a Secretária de Infraestrutura do Governo do Estado da Bahia, com a primeira sendo em 1970 e a segunda que tinha por finalidade ampliar a reserva de água bruta de $300.000 \mathrm{~m}^{3}$ para $6.500 .000 \mathrm{~m}^{3} \mathrm{em}$ $1982 / 1984$.

As bacias de captação das barragens apresentam um clima Tropical Subúmido e são beneficiadas por fazerem parte do Piemonte Oriental do Planalto de Vitória da Conquista porque este funciona como uma barreira orográfica na região. Enfim, as nuvens carregadas que chegam do litoral ao entrar nessa região se deparam com uma barreira e para que possam continuar a se movimentar, precisam perder peso, descarregando assim chuvas que são responsáveis pela importância destas bacias e suas barragens. Devido a isso, Barra do Choça hoje é considerada um dos principais municípios referentes a disposição hidrográfica, haja vista que está localizado em uma região que sofre de secas intensas, por isso a cidade tem abarcado em seu território nos dias atuais três barragens em funcionamento: Água Fria I e Água Fria II (área de estudo) e Serra Preta (construída recentemente para atender mais municípios vizinhos a cidade).

Além da diversificada rede hidrográfica encontrada no município de Barra do Choça, o tipo de solo presente, especificadamente, na região do entorno das barragens de Água Fria I e Água Fria II são favoráveis para a constante vazão dos rios durante todo o ano. 0 solo silto-argiloso por ser profundo e poroso permite que mesmo nas épocas de estiagem haja o escoamento de água nesses rios, alimentando as bacias estudadas.

Quanto ao uso e ocupação do solo destas sub-bacias de captação, é sabido que a área de estudo era originalmente coberta pela Floresta Estacional Semidecidual e pela Floresta Estacional Decidual.

Estudos anteriores referentes ao uso e ocupação do solo nesta área de estudo, já mostravam que a cobertura vegetal original desta região já teria sido extinta pela ação predatória das práticas agropecuárias, deixando apenas restos de matas que remetem a configuração original de outrora.

As barragens estudadas passaram por uma situação complicada nos últimos anos decorrente de um longo período de seca que se alastrou na região. Tal problemática enfrentada resultou no racionamento de águas no município de Vitória da Conquista, Bahia (maior favorecido pelo abastecimento hídrico das barragens), que incitou a construção de uma adutora do rio Catolé até as barragens, atitude esta considerada imediata da EMBASA.

A partir de toda a importância levantada pelas barragens de Água Fria I e II e da constante exploração que vem sofrendo, fez se necessário este estudo que verificasse a real situação em que se encontra a Sub-bacia 
Hidrográfica de Captação das Barragens de Águas Frias e auxiliasse na tomada de decisões para uma melhoria do quadro.

\section{MATERIAL E MÉTODOS}

A pesquisa teve como objetivo principal analisar como tem sido a evolução do uso e ocupação do solo e do panorama das áreas de topo de morro e matas ciliares da Sub-bacia que abastece as Barragens de Água Fria I e Água Fria II no período de 1984, 1991, 2001 e 2008; e consistiu numa pesquisa fundamentada no geoprocessamento de imagens de satélite.

As imagens utilizadas no trabalho foram disponibilizadas pelo INPE (Instituto Nacional de Pesquisas Espaciais) de forma gratuita. Estas foram obtidas pelo satélite LANDSAT 5, órbita-ponto 216/070, referente aos anos buscados pelo trabalho: 1984, 1991, 2001 e 2008.

Para o geoprocessamento das imagens e a sua correção geométrica, utilizou-se a imagem georreferenciada do satélite GLS órbita-ponto 216/070 e o programa ERDAS IMAGINE 9.1, versão teste.

Após o tratamento das imagens, a pesquisa tomou o campo de delimitação da área de estudo - área de contribuição das bacias Água Fria I e II e áreas destinadas à mata ciliar e topo de morro da região. Esta delimitação foi realizada pela ferramenta ArcGis 10.1, versão teste, aliada a carta topográfica da região e seu Modelo Digital de Elevação (MDE).

A carta topográfica que abrange a região da Sub-bacia das Barragens de Água Fria I e II é SD-24-Y-A, cedida pela SUDENE (Superintendência do Desenvolvimento do Nordeste) referente ao município de Vitória da Conquista - BA. O MDE (Modelo Digital de Elevação) em que a Sub-bacia das Barragens de Água Fria I e II está inserida é o no 14 S42, disponibilizado pelo INPE (Instituto Nacional de Pesquisas Espaciais) através de seu Banco de Dados Geomorfométricos do Brasil organizados em seu projeto TOPODATA que possui Modelos Digitais de Elevação (MDE) elaborados a partir de dados SRTM.

Para se ter a classificação das imagens de satélite ao longo dos anos 1984, 1991, 2001 e 2008, seguiu-se a ordem cronológica dos processos necessários na ferramenta ArcGis 10.1: delimitação da área de drenagem, delimitação da área de mata ciliar e delimitação da mata de topo de morro.

Para a delimitação da área de drenagem foram utilizados os dados SRTM, disponibilizados pelo TOPODATA, e da coordenada do ponto que corresponde ao exutório da Sub-bacia das barragens de Água Fria I e II.

Para a delimitação das matas ciliares, utilizou-se a carta topográfica da região, cedida pela SUDENE (Superintendência do Desenvolvimento do Nordeste) fomentada nos dados cedidos pelo Código Florestal Brasileiro.

E, por fim, para a delimitação das áreas de topo de morro, fez-se o uso dos dados SRTM, para a elaboração do TIN (Triangulated Irregular Network - Grade Triangular do Terreno) de forma que pudesse visualizar as cotas do terreno em visão 3D e assim delimitar as áreas de mata de topo de morro, de acordo com as especificações da CONAMA 303/02.

Após o processo de delimitação das áreas, unificou-se os dados obtidos e fez-se o recorte das imagens de satélite para que, posteriormente, estas fossem classificadas. A classificação das imagens foi supervisionada e se deu através da ferramenta ERDAS IMAGINE $9.1 \mathrm{com}$ as seguintes classes: Floresta, Campos, Agricultura e Água.

A classe Floresta abrangeu as camadas vegetais nativas da Sub-bacia estudada; a de Agricultura é composta pelas fazendas destinadas a, principalmente, lavoura cafeeira e eucalipto; os Campos são os pastos usados para a pecuária; e a Água é a própria água da região.

Com as imagens classificadas, as áreas foram quantificadas através do programa ArcGis 10.1 e no mesmo, foram organizados os mapas temáticos de cada imagem de satélite separada pelas suas especificações.

\section{RESULTADOS E DISCUSSÃO}

De posse dos dados de análise temporal de imagens de satélite, identificados e analisados, verificou-se a real situação das matas ciliares e matas de topo de morro da região da bacia de captação das barragens de Água Fria I e II ao longo dos anos de 1984, 1991, 2001 e 2008. 


\section{1 ÁREA DE VEGETAÇÃO TOTAL}

Conforme as Figura 2, 3, 4 e 5 e a Tabela 3, a área total da Sub-bacia evoluiu da seguinte maneira ao longo dos anos.

Figura 2: Área Total da Sub-bacia das Barragens de Água Fria I e II no ano de 1984

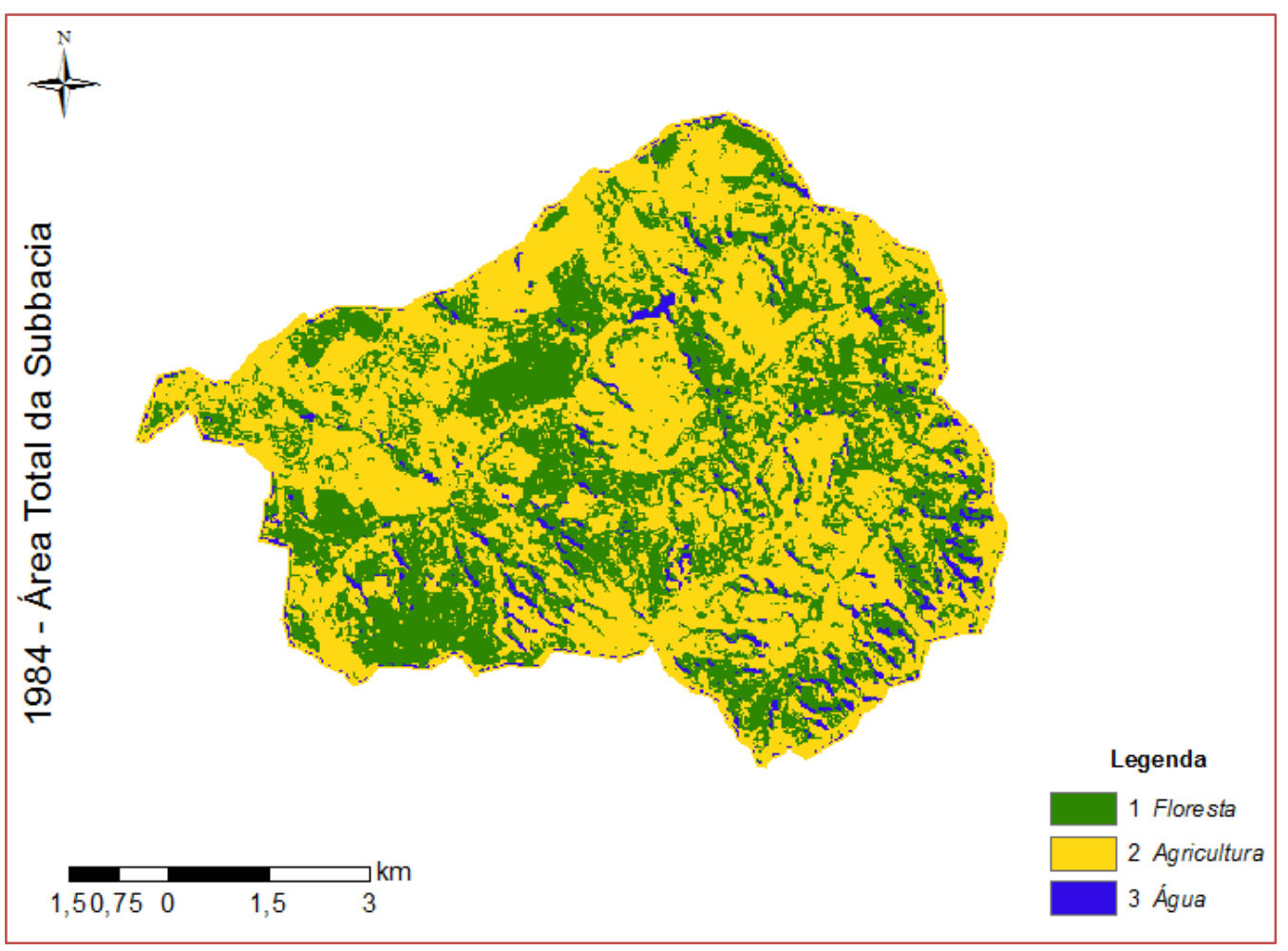

Fonte: Da pesquisa, 2015

Figura 3: Área Total da Sub-bacia das Barragens de Água Fria I e II no ano de 1991

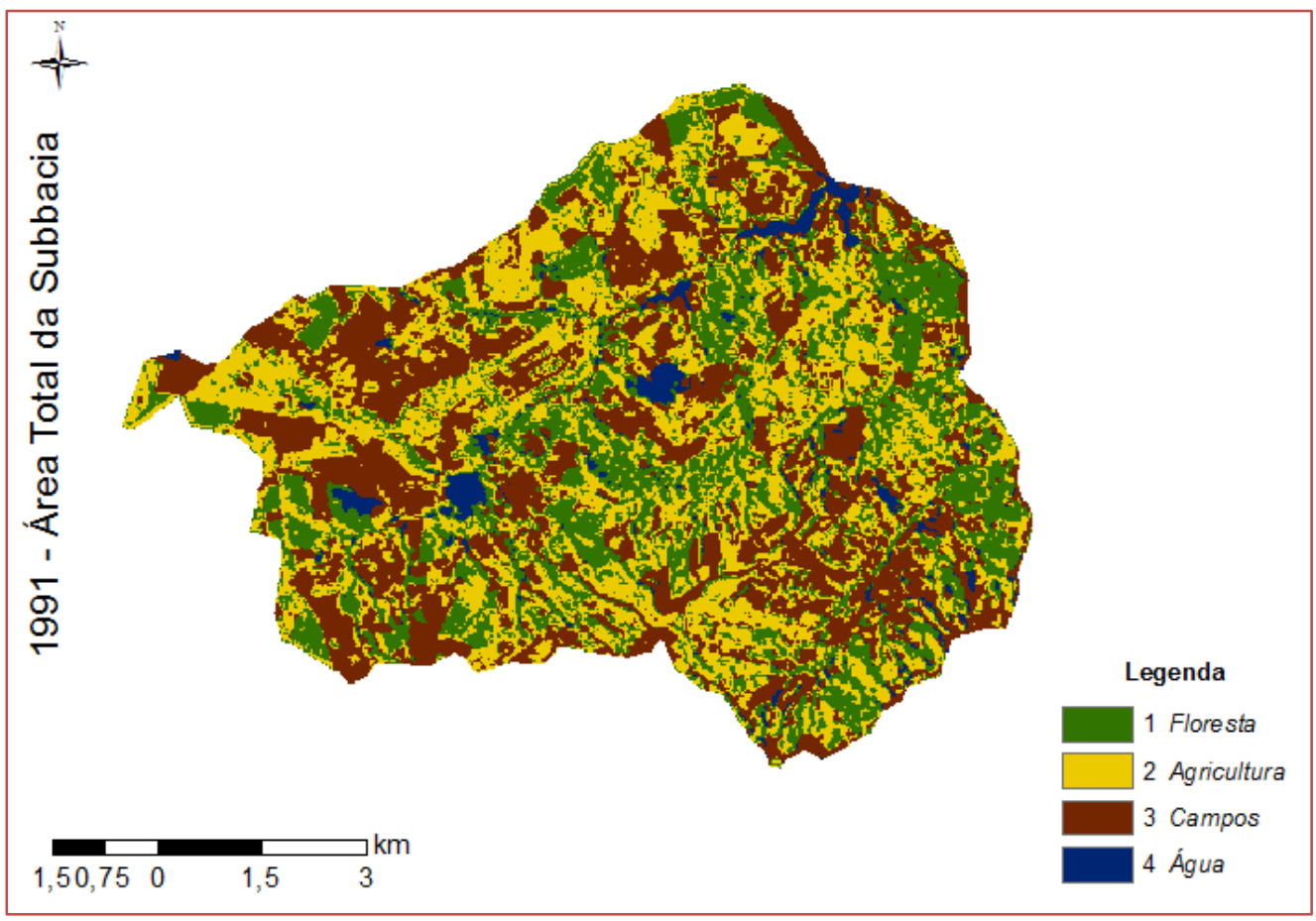

Fonte: Da pesquisa, 2015 
Figura 4: Área Total da Sub-bacia das Barragens de Água Fria I e II no ano de 2001

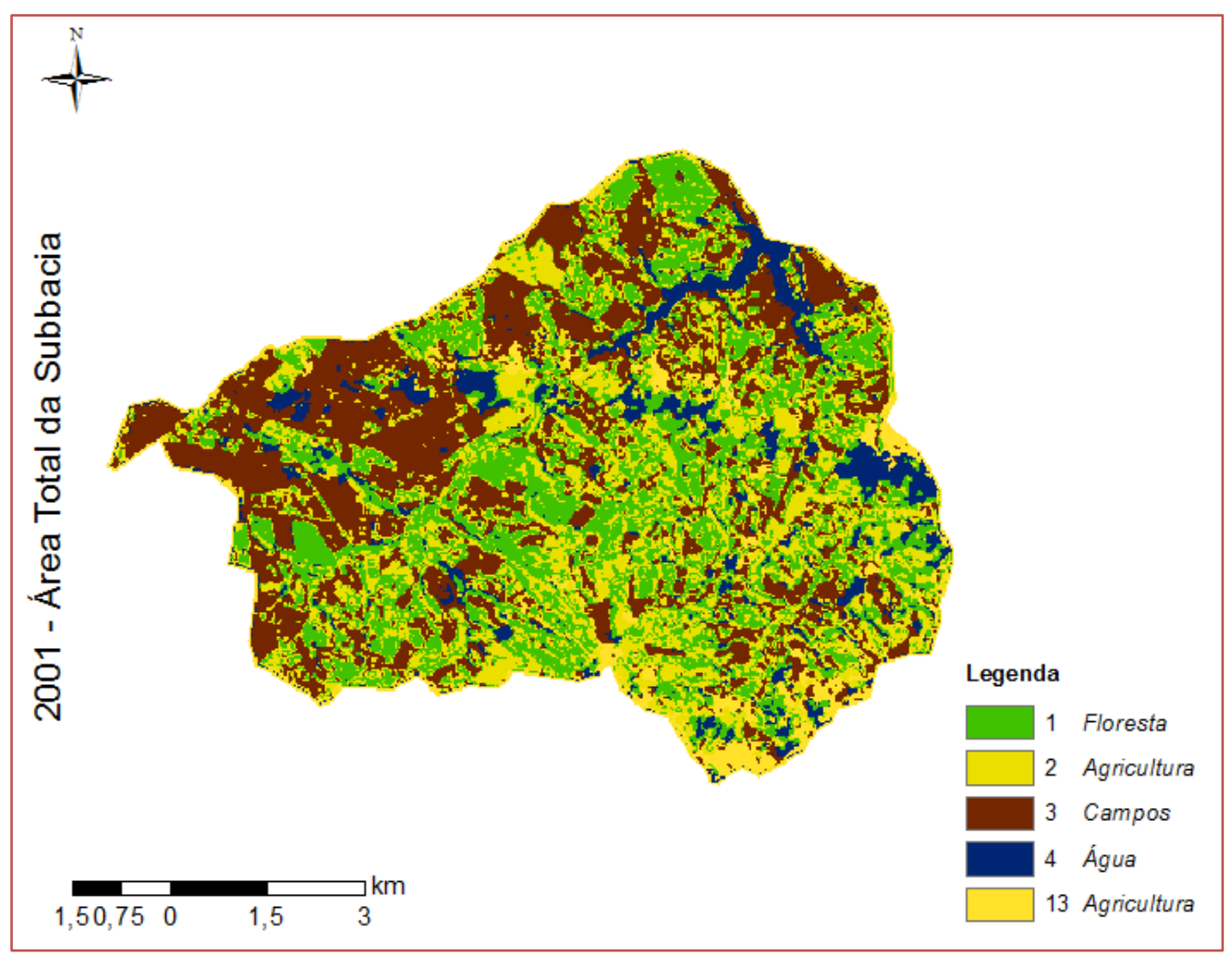

Fonte: Da pesquisa, 2015

Figura 5: Área Total da Sub-bacia das Barragens de Água Fria I e II no ano de 2008

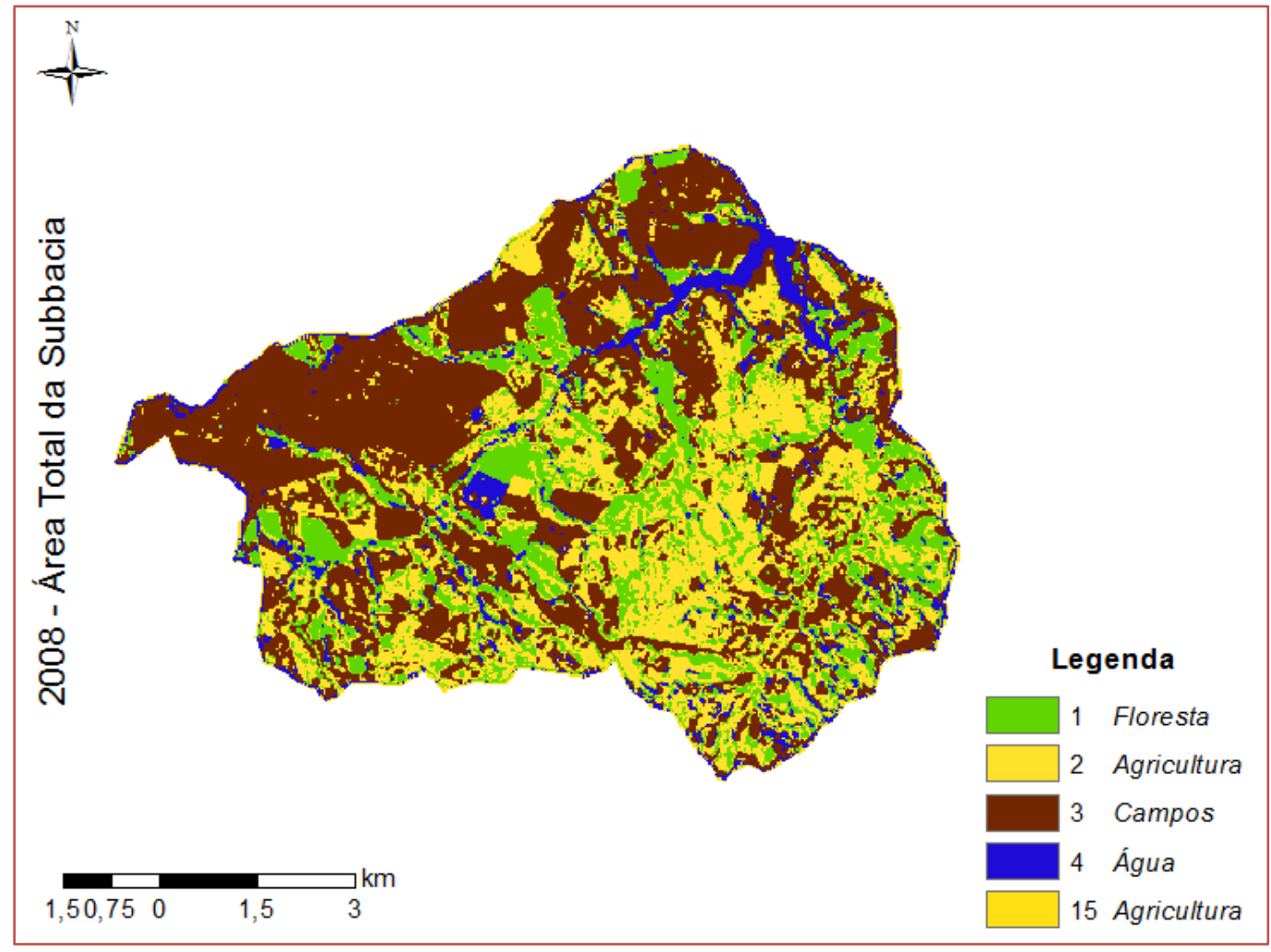

Fonte: Da pesquisa, 2015 
Através do tratamento das imagens de satélite aliadas com as cartas da região, obteve-se a estratificação e a quantificação dos diferentes usos de solo (Floresta, Agricultura, Água e Campos), estes dados para uma melhor compreensão foram reorganizados na tabela a seguir (Tabela 3):

Tabela 3: Uso do solo na Área Total da Sub-bacia das Barragens de Água Fria I e II

\begin{tabular}{|c|c|c|c|c|}
\hline & 1984 & 1991 & 2001 & 2008 \\
\hline 1 - Floresta & $37,83 \%$ & $27,82 \%$ & $27,36 \%$ & $20,29 \%$ \\
\hline 2- Agropecuária & $58,49 \%$ & $68,85 \%$ & $64,31 \%$ & $72,09 \%$ \\
\hline 3 - Água & $3,69 \%$ & $3,32 \%$ & $8,33 \%$ & $7,61 \%$ \\
\hline
\end{tabular}

Os dados obtidos com a pesquisa corroboram para as afirmações já levantadas por Oliveira (2006), onde o município de Barra do Choça, caracterizado pela sua produção cafeeira, abrange na região da Sub-bacia de captação das barragens de Água Fria I e II, extensas áreas de lavoura cafeeira que no decorrer dos anos, sofreu um retrocesso impulsionado, principalmente, pela pecuária.

No entanto, esta mudança de cenário não extinguiu com as extensas áreas de lavoura cafeeira. 0 avanço da pecuária na região consolidou-se ao longo dos anos junto ao cultivo do café (Agropecuária na Tabela 3), estes representam mais da metade da ocupação do solo, o que comprova que as florestas têm perdido seu espaço na Sub-bacia, não totalizando nem 40\% da ocupação do solo na região.

Os dados contidos na Tabela 3 aliados as imagens de satélite tratadas, destacam uma ocupação do solo significativa em relação à água. No intervalo de 1991-2001 (Figuras 3 e 4), há um acréscimo de cerca de $151 \%$ na taxa de ocupação do solo. Este acréscimo não coincide com a construção das barragens, haja vista que a barragem de Água Fria I foi construída em 1970 e a barragem de Água Fria II no período de 1982-1984.

De acordo com a EMBASA (2013), este aumento se dá à prática de construção de lagos artificiais ou pequenas barragens pelos fazendeiros da região, a fim de estocar a água para usá-la em irrigação e consumos afins. Isso se deve a disponibilidade de água durante todo o ano e a falta de conscientização dos fazendeiros quanto à proteção e manutenção da Sub-bacia.

\section{2 ÁREA DE VEGETAÇÃO DE MATA CILIAR}

Nas figura 6, 7, 8 e 9, observa-se a evolução do uso e ocupação do solo das matas ciliares da Sub-bacia das Barragens de Água Fria I e II.

Figura 6: Área Destinada a Mata Ciliar na Sub-bacia das Barragens de Água Fria I e II no ano de 1984

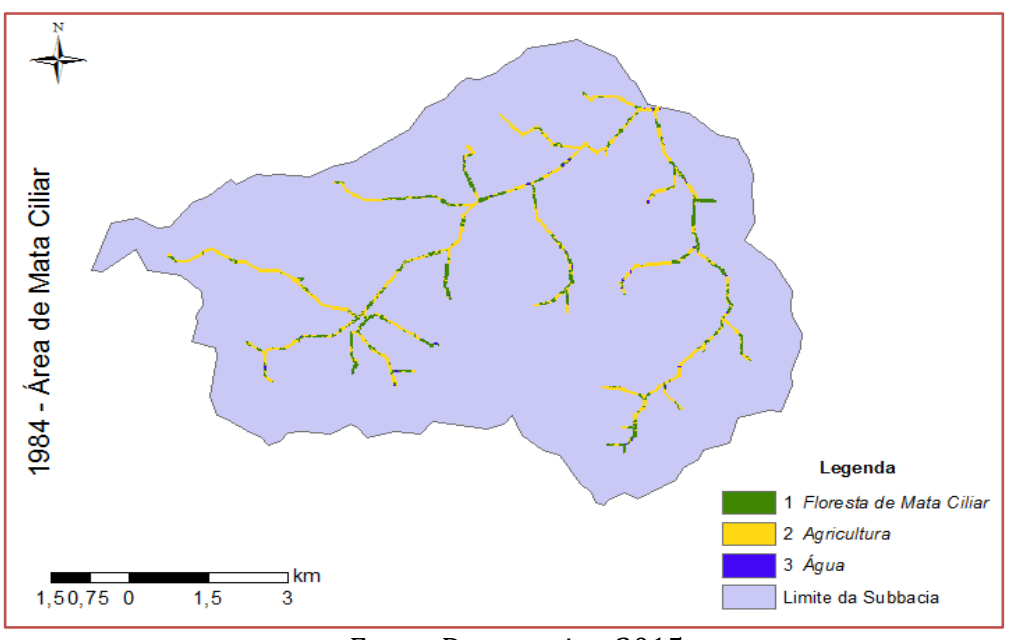

Fonte: Da pesquisa, 2015 
Figura 7: Área Destinada a Mata Ciliar na Sub-bacia das Barragens de Água Fria I e II no ano de 1991

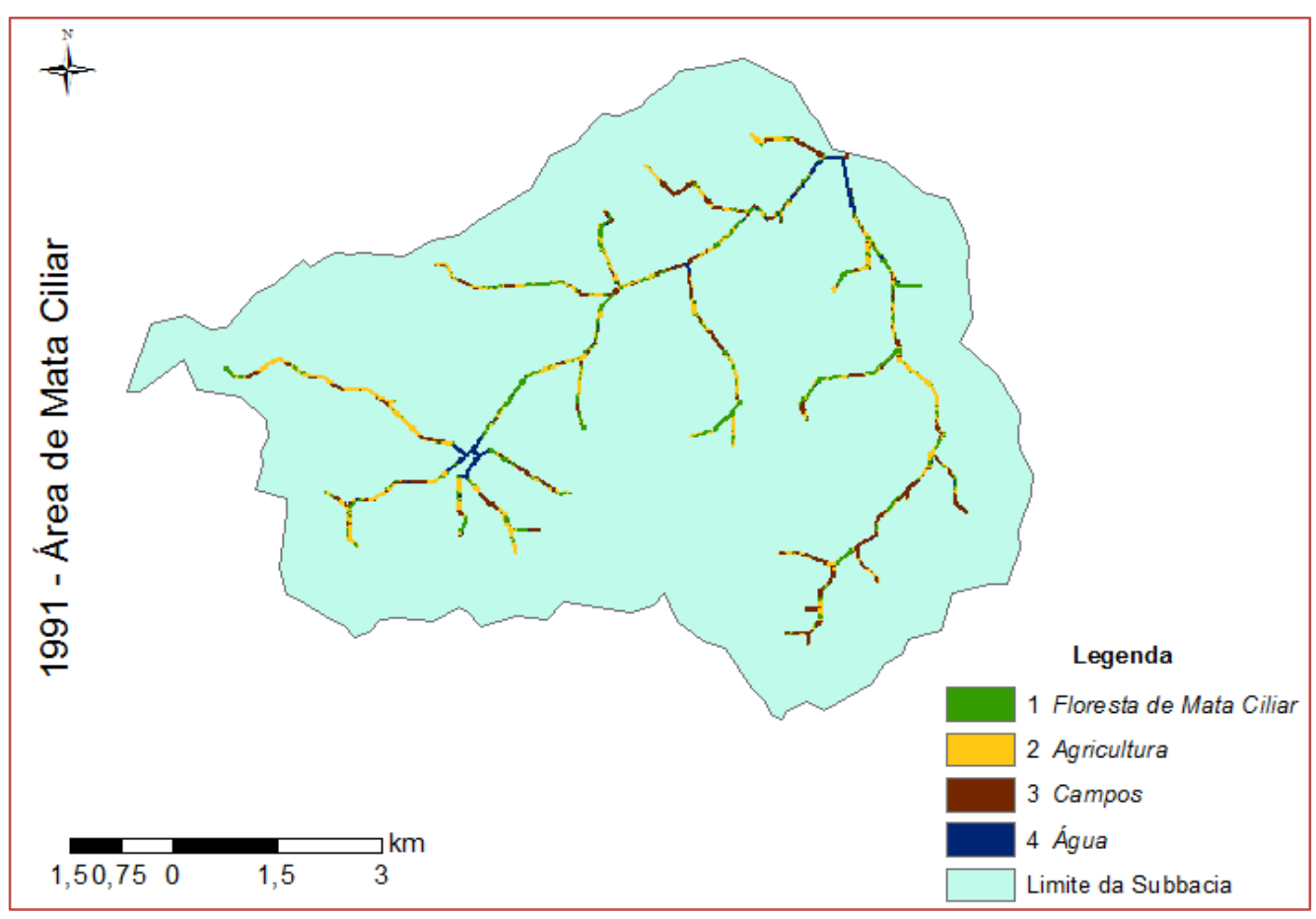

Fonte: Da pesquisa, 2015

Figura 8: Área Destinada a Mata Ciliar na Sub-bacia das Barragens de Água Fria I e II no ano de 2001

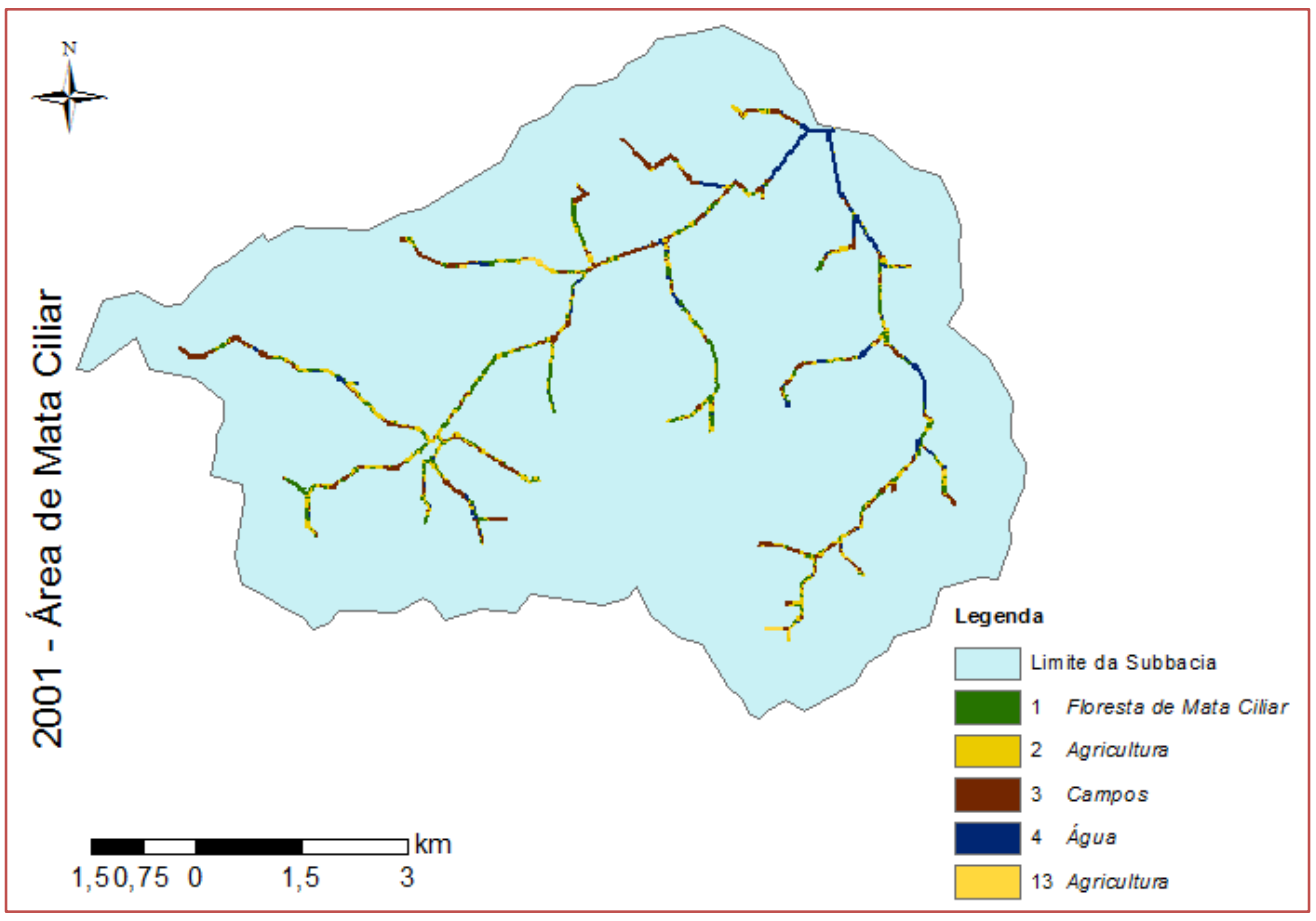

Fonte: Da pesquisa, 2015 
Figura 9: Área Destinada a Mata Ciliar na Sub-bacia das Barragens de Água Fria I e II no ano de 2008

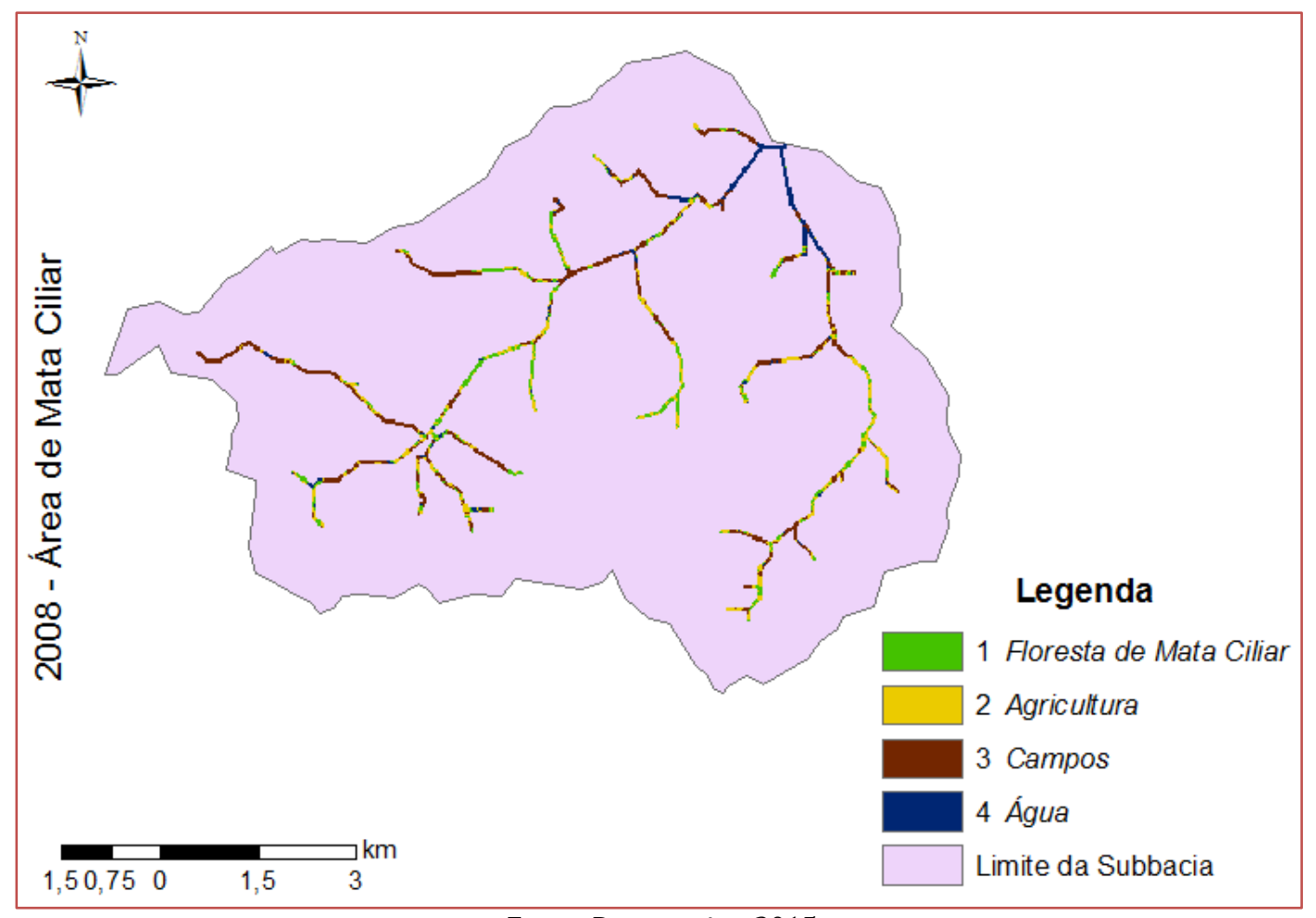

Fonte: Da pesquisa, 2015

As imagens respectivas a cada ano foram estratificadas da mesma maneira que as imagens referentes à área total da Sub-bacia e, para uma melhor compreensão dos dados, os tipos de ocupação do solo foram reorganizados na Tabela 4.

Tabela 4: Uso e ocupação do solo da região destinada a mata ciliar da Sub-bacia das Barragens de Água Fria I e II

\begin{tabular}{|l|l|l|l|l|}
\hline \multicolumn{2}{|c|}{1984} & 1991 & 2001 & 2008 \\
\hline 1 - Floresta de Mata Ciliar & $36,24 \%$ & $27,20 \%$ & $25,02 \%$ & $20,81 \%$ \\
\hline 2- Agropecuária & $61,65 \%$ & $63,95 \%$ & $59,83 \%$ & $67,02 \%$ \\
\hline 3 - Água & $2,11 \%$ & $8,85 \%$ & $15,15 \%$ & $12,18 \%$ \\
\hline
\end{tabular}

De acordo com as porcentagens mostradas pela Tabela 4, percebe-se que a cobertura vegetal nativa (Floresta de Mata Ciliar) na região vem perdendo espaço ao longo dos anos. No intervalo de 1984-2008, a região destinada à mata ciliar da Sub-bacia, perdeu cerca de um pouco mais de $42 \%$ de sua floresta de mata ciliar, área esta que seria destinada a APP (Área de Preservação Permanente) conforme os Códigos Florestais Brasileiros. Além disso, as florestas não ocupam nem $40 \%$ do solo destinado às mesmas por Lei.

As áreas destinadas à agricultura, principalmente, a lavoura cafeeira e a pecuária correspondem a mais de $50 \%$ de uso e ocupação do solo da região em todos os períodos. Ainda que entre os anos de 1991 e 2001 houve um decréscimo em sua ocupação no solo, tais práticas ainda se destacam por ocuparem mais da metade da área destinada à mata ciliar.

Estes números corroboram com os dados relacionados à ocupação do solo pela classificação da água e as afirmações levantadas pela EMBASA (2013) em que os proprietários rurais que possuem terras próximas a região dos rios e das barragens, com destaque para os irrigantes, lançam mão de artifícios para o uso da água encontrada na região, seja por meio de lagos artificiais e/ou pequenas barragens, bem como por bombas nas próprias barragens. Esta situação, além de ser perceptível nas imagens de satélite utilizadas 
na pesquisa, foi detectada também pela EMBASA (2013), no período de uma extensa seca na região, enfrentada pelas populações abastecidas pelas barragens de Água Fria I e II.

\section{3 ÁREA DE VEGETAÇÃO DE TOPO DE MORRO}

A análise das áreas destinadas à mata de topo de morro caracteriza-se pelo seu grau de complexidade, visto que os dados encontrados durante o processo de tratamento das imagens de satélite dependem de fatores externos como nuvens e, principalmente, pico e comportamento dos morros da região.

Nas figuras 10,11, 12 e 13, há o resultado do tratamento aplicado as imagens de satélite.

Figura 10: Área Destinada a Mata de Topo de Morro da Sub-bacia das Barragens de Água Fria I e II em 1984

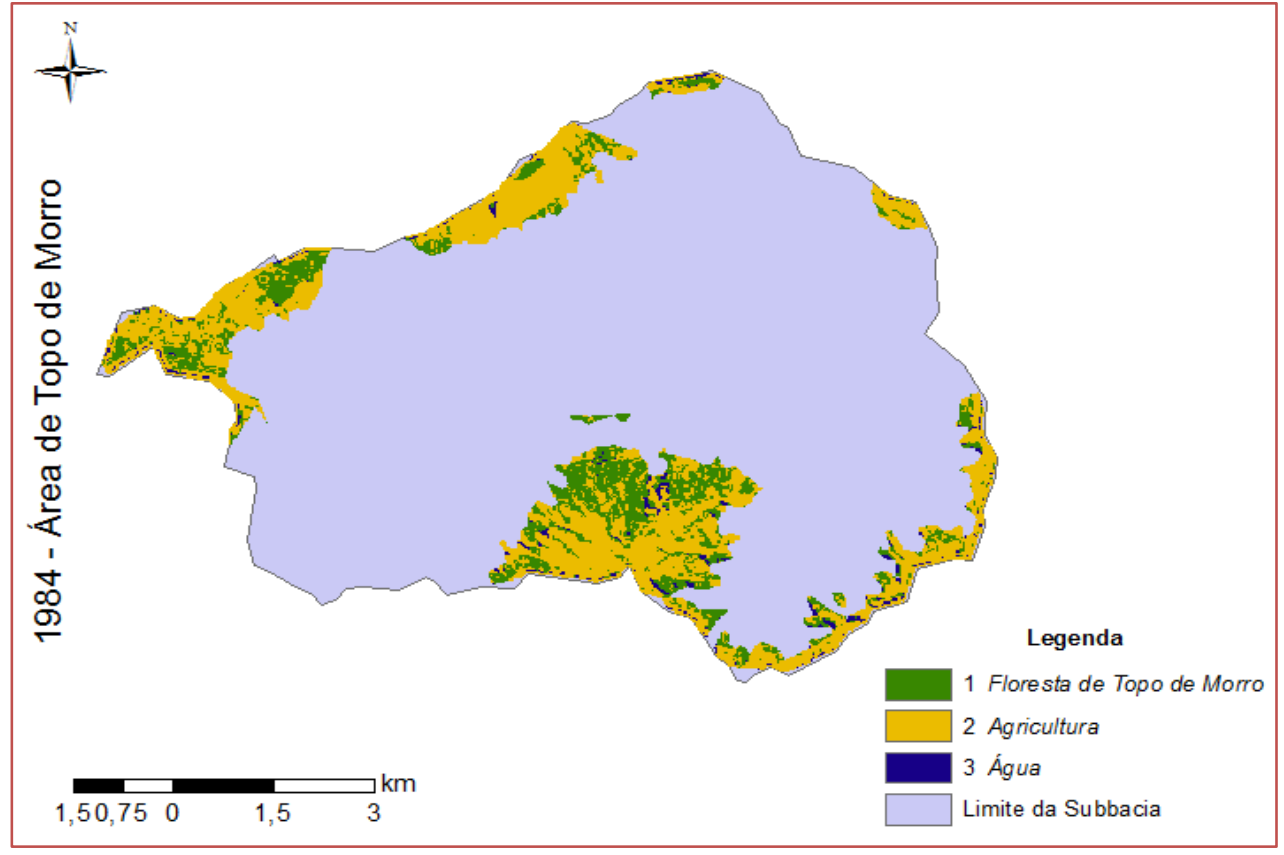

Fonte: Da pesquisa, 2015

Figura 11: Área Destinada a Mata de Topo de Morro da Sub-bacia das Barragens de Água Fria I e II em 1991

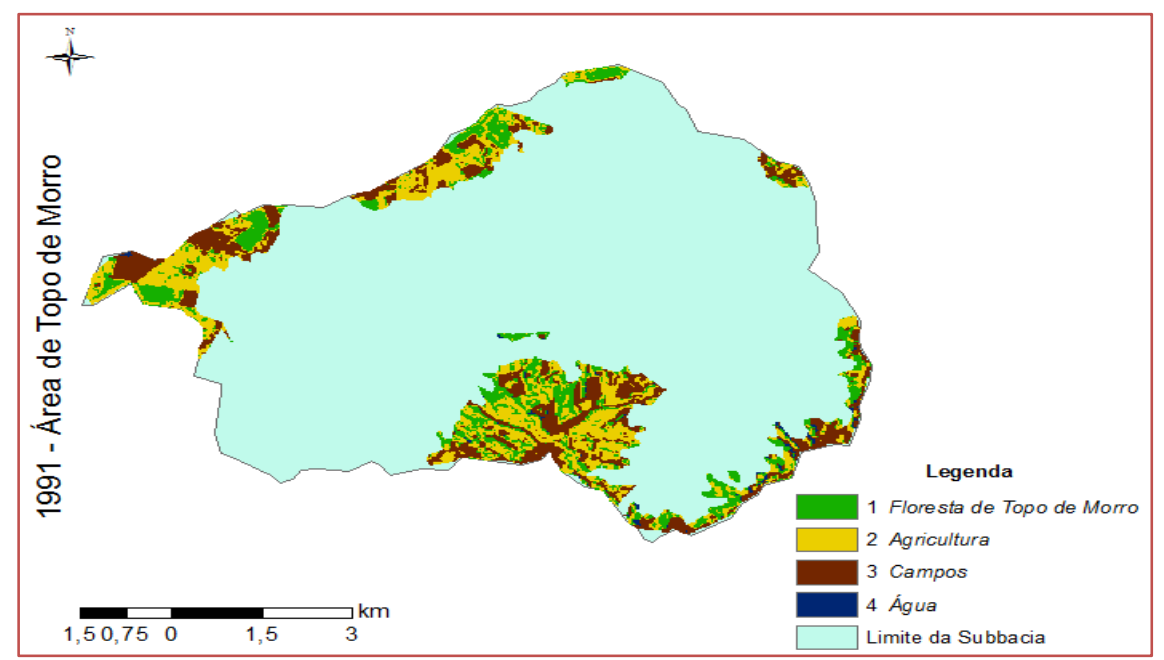

Fonte: Da pesquisa, 2015 
Figura 12: Área Destinada a Mata de Topo de Morro da Sub-bacia das Barragens de Água Fria I e II em 2001

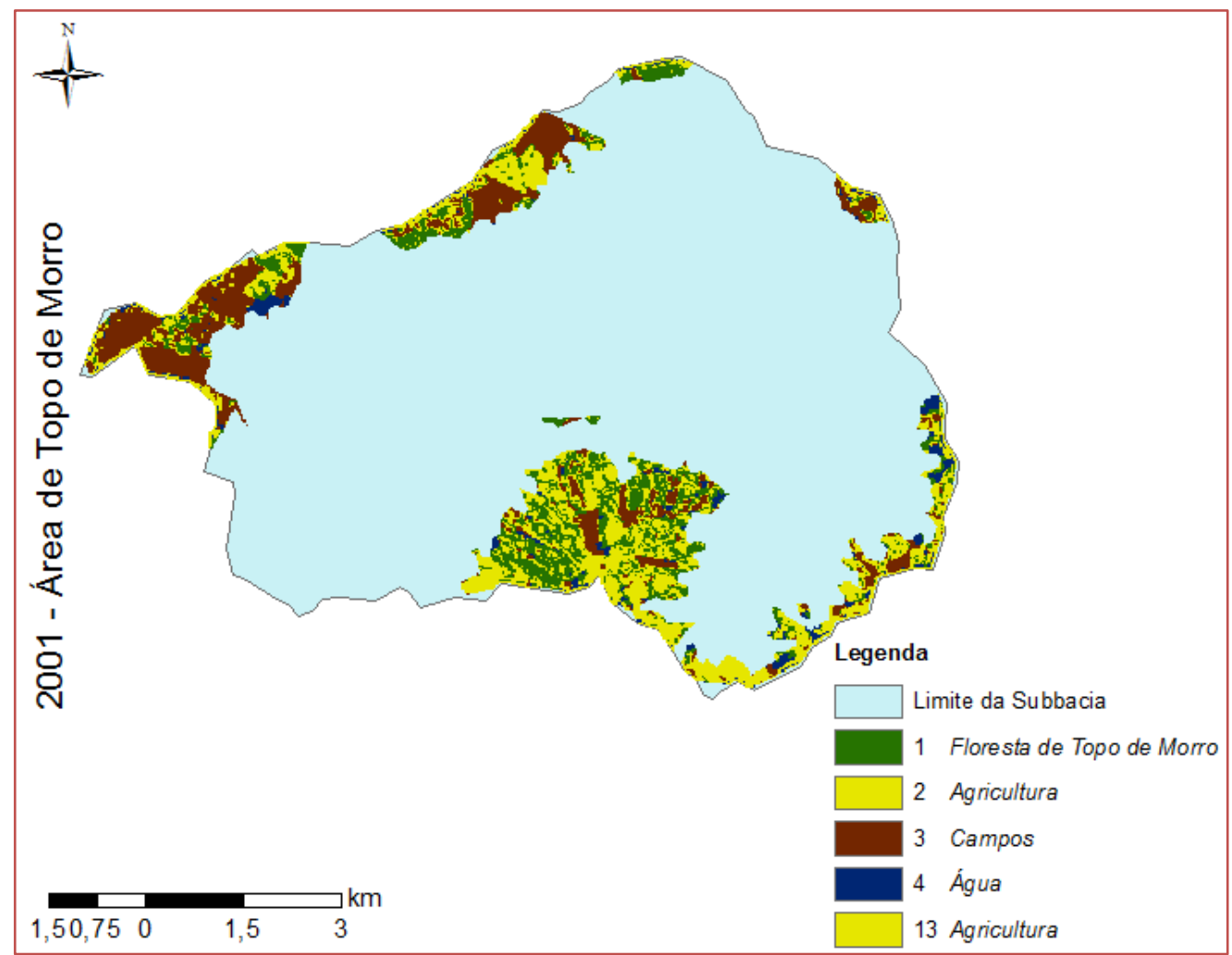

Fonte: Da pesquisa, 2015

Figura 13: Área Destinada a Mata de Topo de Morro da Sub-bacia das Barragens de Água Fria I e II em 2008

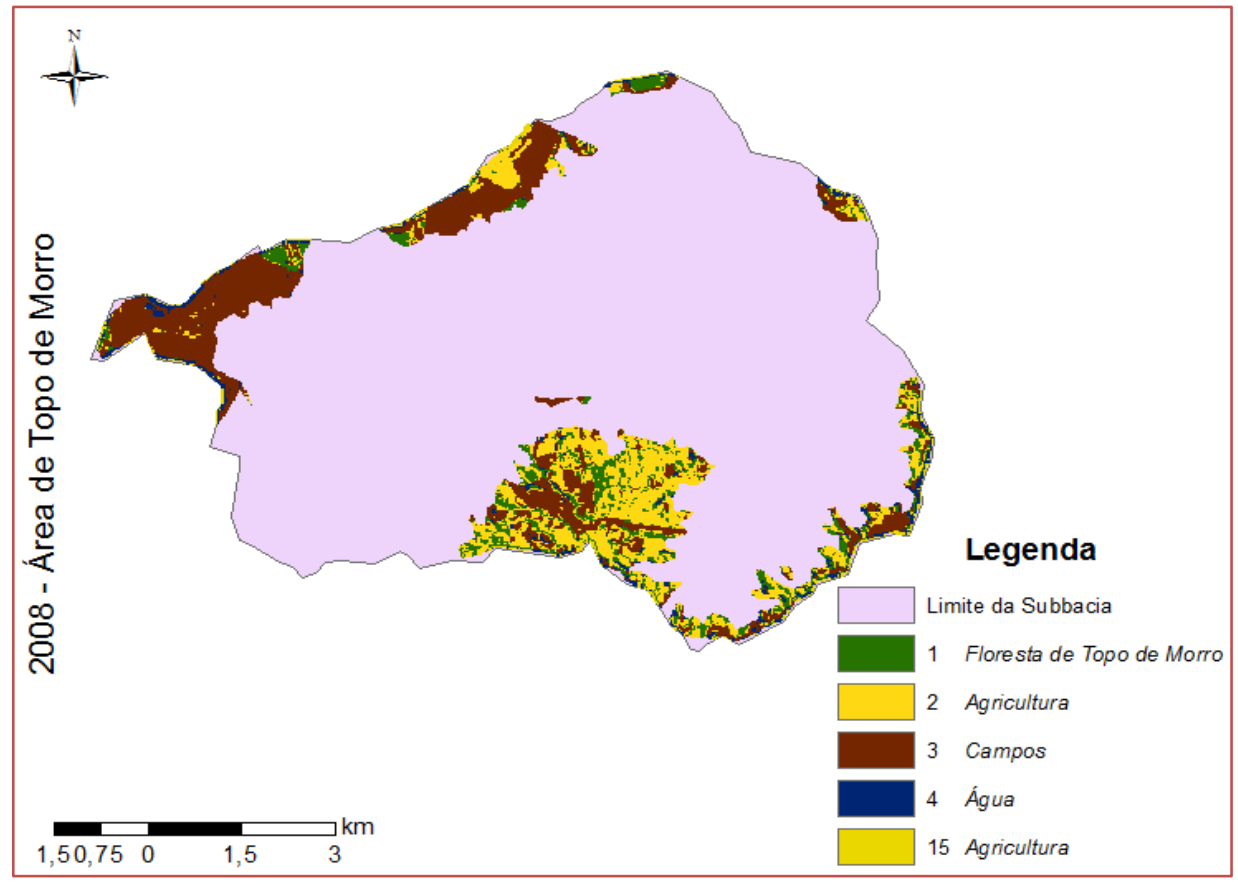

Fonte: Da pesquisa, 2015 
Os tipos de uso e ocupação do solo foram reorganizados para que haja uma melhor leitura e análise da área destinada a mata de topo de morro. (Tabela 5)

Tabela 5: Uso e ocupação do solo da região destinada a mata de topo de morro da Sub-bacia das Barragens de Água Fria I e II

\begin{tabular}{|c|c|c|c|c|}
\hline & 1984 & 1991 & 2001 & 2008 \\
\hline 1 - Floresta de Topo de Morro & $29,58 \%$ & $26,53 \%$ & $23,90 \%$ & $15,37 \%$ \\
\hline 2 - Agropecuária & $66,90 \%$ & $72,13 \%$ & $70,75 \%$ & $77,95 \%$ \\
\hline 3 - Água & $3,52 \%$ & $1,34 \%$ & $5,35 \%$ & $6,67 \%$ \\
\hline
\end{tabular}

De acordo com a pesquisa, o cenário precário da camada vegetal original (Florestas de Topo de Morro) não muda quando analisamos a área de topo de morro.

As florestas de Topo de Morro apresentam uma perda contínua em sua área de ocupação do solo da região. Entre os anos de 1984 a 2008, há um decréscimo de cerca de 48\% das florestas nas áreas destinadas, pelos Códigos Florestais Brasileiros, a mata de topo de morro.

E, em termos totais, a problemática das florestas nesta área encontra-se mais grave em relação a área total da Sub-bacia e a área destinada a mata ciliar, uma vez que as coberturas vegetais nativas não atingem nem 30\% da ocupação do solo estudado.

Em contrapartida ao decréscimo das áreas ocupadas pelas florestas, a agropecuária apresenta um comportamento dominante durante todos os anos, onde o seu menor índice foi no ano de 1984 com uma ocupação de solo de 66,90\%.

As atividades de agricultura e pecuária sofreram uma baixa em sua área de ocupação no período 19912001 (Figura 11 e 12). Este decréscimo não se deu por uma melhora no quadro das florestas, mas, de acordo com a figura 4 e tabela 5, esta se deu por um aumento na ocupação do solo pela classificação denominada água.

No entanto, é necessário se atentar ao fato de que a área destinada à mata de topo de morro é composta por uma região montanhosa e esta costuma apresentar nuvens.

Figura 14: Sub-bacia que abastece as Barragens de Água Fria I e II no período de 2001

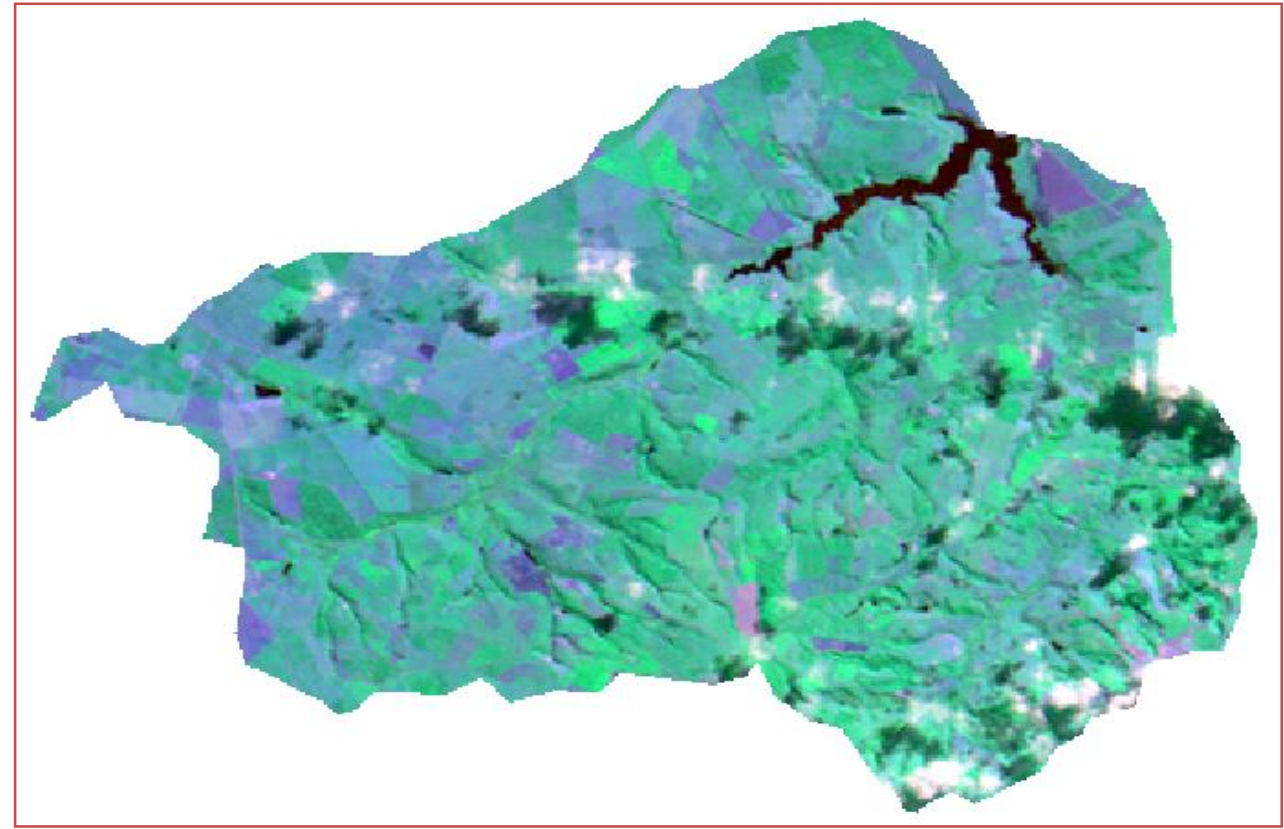

Fonte: Da pesquisa, 2015 
Na imagem do ano de 2001, há uma concentração de nuvens, e quando as mesmas são tratadas, os pixels escuros das nuvens são classificados como água. Portanto, não há como afirmar uma queda na área ocupada pela agropecuária no intervalo 1991-2001 devido à sombra das nuvens.

\section{CONSIDERAÇÕES FINAIS}

De acordo com os dados levantados e analisados através da pesquisa, é perceptível a situação delicada em que as florestas da Sub-bacia que abastece as Barragens de Água Fria I e II vêm enfrentando ao longo dos anos. Desde o período de 1984, onde ainda não se tinha o registro da Barragem Água Fria II, as florestas já não ocupavam 40\% do espaço determinado pelo Código Florestal Brasileiro de 1965 como Áreas de Preservação Permanente.

Esta problemática é prejudicial não somente ao comportamento dos rios ao longo dos anos, bem como a manutenção do equilíbrio hidrológico da Sub-bacia, afetando assim, o abastecimento hídrico da população abastecida pelas barragens, haja vista que ocorre um comprometimento da perenidade dos rios e suas vazões, gerando um menor volume de água armazenado nestes reservatórios, e assim um déficit de água para a população, racionamentos de água e cortes do funcionamento a fim de se manter volume suficiente até o próximo período de cheia da região.

Aliado a essa problemática, há outro fator, também levantado nas análises das imagens de satélite, tão prejudicial quanto à pequena área de florestas na Sub-bacia que abastece as barragens: o extenso uso da agropecuária. A região em que se encontram as barragens e, consequentemente, a Sub-bacia que abastece as mesmas apresenta um clima e solo propício para o cultivo de lavouras, principalmente, café e bovinocultura extensiva. Tais práticas, além de ocupar extensas áreas do uso do solo, previamente determinadas como Áreas de Preservação Permanente por Lei, fazem o uso excessivo das águas dos rios da região de maneira incorreta a fim de manter a sustentabilidade da propriedade.

Sendo assim, a sociedade brasileira têm enfrentado ao longo dos últimos anos situações-problemas referentes à escassez de água, principalmente, em regiões que se costumava ter cursos d'águas suficientes para abastecer as populações locais. Diante de tal problemática, é perceptível a necessidade da mudança de hábitos quanto ao uso hídrico pelo ser humano. Tal mudança atingiria todos os processos do setor de abastecimento humano, desde a proteção das nascentes e corpos d'água aliada as áreas de mata ciliar, bem como a proteção dos barramentos artificiais, assegurando assim mata ciliar no entorno deles, até a conscientização por parte do consumidor, no produto final, racionalizando e economizando o recurso que erroneamente é conhecido como renovável.

\section{REFERÊNCIAS}

[1] BAHIA. Lei no 10431, de 20 de Dezembro de 2006. Dispõe sobre a política de meio ambiente e de proteção à biodiversidade do Estado da Bahia. Diário Oficial do Estado da Bahia. Salvador, 20 dez 2006. Disponível em: governoba.jusbrasil.com.br/legislacao/85743/lei-10431-06. Acesso em: 11 Março 2014.

[2] _. Decreto no 11235, de 10 de Outubro de 2008. Aprova o regulamento da Lei no 10431, de 20 de dezembro de 2006. Diário Oficial do Estado da Bahia. Salvador, 10 out 2008. Disponível em: governoba.jusbrasil.com.br/legislacao/75345/decreto-11235-08. Acesso em: 11 Março 2014.

[3] _. Manual sobre Restauração de Matas Ciliares. Salvador: PERMAC (Programa Estadual de Restauração de Matas Ciliares), 2011.

[4] BRASIL. Lei no 4771, de 15 de Setembro de 1965. Institui o novo Código Florestal. Diário Oficial da República Federativa do Brasil, Poder Executivo. Brasília DF, 15 set 1965. Disponível em: www.planalto.gov.br/ccivil_03/leis/14771.htm. Acesso em: 12 Fevereiro de 2014.

[5] BRASIL. Lei no 4771, de 15 de Setembro de 1965. Dispõe sobre a proteção da vegetação nativa. Diário Oficial da República Federativa do Brasil, Poder Executivo. Brasília DF, 15 Set. 1965. Disponível em: http://www.planalto.gov.br/ccivil_03/leis/14771.htm. Acesso em: 12 Fevereiro de 2014.

[6] _. Lei no 12651, de 25 de Maio de 2012. Dispõe sobre a proteção da vegetação nativa. Diário Oficial da República Federativa do Brasil, Poder Executivo. Brasília DF, 25 mai 2012 . Disponível em: www.planalto.gov.br/ccivil_03/_ato2011-2014/2012/lei/l12651.htm. Acesso em: 12 Fevereiro de 2014. 
[7] CONAMA - Conselho Nacional de Meio Ambiente. Resolução no 303, de 13 de Maio de 202. Dispõe sobre parâmetros, definições e limites de Áreas de Preservação Permanente. Disponível em: http://www.mma.gov.br/port/conama/res/res02/res30302.html. Acesso em: 12 Fevereiro de 2014.

[8] CRUCIANI, D. E. Hidrologia. Piracicaba: ESALQ, 1976.

[9] DI LAURO, Aluztane. Análise do uso e ocupação da terra em Vitória da Conquista, Barra do Choça e Planalto: estudo das transformações socioambientais a partir da implantação da lavoura cafeeira (1970 a 2008). Salvador: Universidade Federal da Bahia, 2011.

[10] DUTRA NETO, Claudionor. Cafeicultura do Planalto de Vitória da Conquista: perspectivas para um desenvolvimento sustentável. Brasília, DF: Universidade de Brasília, 2001.

[11] EMBASA - Empresa Baiana de Águas e Saneamento. Disponível em: www.embasa.ba.gov.br/. Acesso em: 28 de Fevereiro de 2014 Seca na Bahia: Ações de Enfrentamento. Salvador: EMBASA, 2013.

[13] INPE - Instituto Nacional de Pesquisas Espaciais. Disponível em: www.inpe.br/. Acesso em: 05 de Março de 2014.

[14] OLIVEIRA, Jacson Tavares de. Bacia de Captação da barragem Água Fria II em Barra do Choça/BA: evolução do uso da terra e modificações nos solos sob diferentes manejos. Ilhéus (Ba): UESC, 2006.

[15] OLIVEIRA, M. R. Associativismo Rural: O Caso das Associações dos Pequenos Produtores Rurais de Barra do Choça-Ba. Maceió: Universidade Federal de Alagoas, 2005.

[16] OLIVEIRA-FILHO A. T.; RATTER, J. A.; SHEPHERD, G. J. Floristic Composition and Community Structure of a Central Brazilian Gallery Forest. Flora 184 (2), 1990.

[17] RODRIGUES, R. R.; LEITÃO FILHO, H. F. Matas ciliares, conservação e recuperação. São Paulo: Editora da Universidade de São Paulo: FAPESP, 2001.

[18] SANTOS, P. R. P. Associações dos pequenos produtores de café no município de Barra do Choça: perspectivas para o desenvolvimento sustentável. Brasília: Universidade de Brasília, 2001.

[19] SÃo PAULO. Cadernos da Mata Ciliar. São Paulo: SMA (Secretaria de Estado do Meio Ambiente), 2009.

[20] SUDENE - Superintendência do Desenvolvimento do Nordeste. Disponível em: www.sudene.gov.br/. Acesso em: 06 de Fevereiro de 2014. 


\section{Capítulo 12}

RELATOS DA SITUAÇÃO ECONÔMICA E AMBIENTAL DOS AGRICULTORES DO ASSENTAMENTO CARACOL, MUNICÍPIO DE BELA VISTA, MS APÓS 20 ANOS DE SUA CRIAÇÃO

\section{Ionara dos Santos Biscola}

Viviane Mallmann

Lucas Wagner Ribeiro Aragão

Shaline Séfara Lopes Fernandes

Tauane Catilza Lopes Fernandes

Resumo: No MS, mais de 27 mil famílias foram assentadas, e tiveram a oportunidade de realizarem um sonho de conquistar seu pedacinho de terra. No entanto, ao longo de 20 anos, como está a situação econômica e ambiental dessas famílias? Elas se fortaleceram no campo ou não? A agroecologia tem auxiliado na formação de agroecossistemas sustentáveis para geração de renda dessas famílias? Enfim, baseados nesses questionamentos, esse estudo teve por objetivo conhecer as dificuldades e as fortalezas dos produtores através do relato da situação econômica e ambiental ao longo de 20 anos da existência do assentamento Caracol. Com base nos relatos, chegou-se à conclusão que existem dificuldades, como a falta de assistência técnica, a falta de conhecimento para trabalhar no campo diante de problemas (lotes com solos rasos e pedregosos). Também verificou-se que o assentamento e partes da APP encontram-se degradados. Sendo assim, se faz necessário incentivos por meio de políticas públicas que amparem esses assentados para que os mesmos tenham uma qualidade de vida e possam geram renda em seus lotes, mais para que isso ocorra, é fundamental a capacitação e a transferência de tecnologias, ou seja, a informação tem que estar acessível para os assentamentos mais longínquos.

Palavras-chave: agricultura campesina, áreas degradadas, capacitação do home no campo, assistência técnica. 


\section{CONTEXTO}

Agroecologia é um campo do conhecimento de caráter multidisciplinar que apresenta uma série de princípios, que nos permitem estudar, analisar, dirigir e avaliar agroecossistemas (ALTIERE, 1987).

Sendo assim, acredita-se que a agroecologia direciona os envolvidos para um caminho de sistemas produtivos no campo de forma mais sustentável, e esse sistema de manejo tende a recuperar a intimidade do homem com a terra, além de respeitar os limites dos ecossistemas naturais e dos agroecossistemas, assegurando aos agricultores quem vivem no campo o valor de uso e a função social da terra (MARI et al., 2017).

Em 1998 aproximadamente 101.094 famílias foram assentadas no Brasil, (BERGAMASCO, 1997). No Mato Grosso do Sul, referente ao censo de 31 de dezembro de 2017, consta que 27.764 famílias foram assentadas, em 204 assentamentos, em uma área total de 716.212,19 ha (INCRA, 2018).

No entanto, depois de assentados, e de realizarem um sonho tanto almejado de conquistarem um pedaço de terra para cultivar, a agricultura campesina tem se fortalecido? Esse questionamento é importante, visto que são muitas familias assentadas no Mato Grosso do Sul.

Sendo assim, esse estudo teve por objetivo conhecer as dificuldades e as fortalezas dos produtores através do relato da situação econômica e ambiental ao longo de 20 anos da existência do assentamento Caracol.

\section{DESCRIÇÃO DA EXPERIÊNCIA}

O assentamento Caracol pertence ao município de Bela Vista, MS. O acesso é realizado pela MS-472, que divide o assentamento Nery Ramos Volpato e assentamento Caracol pelo rio Piripucu. Está localizado nas

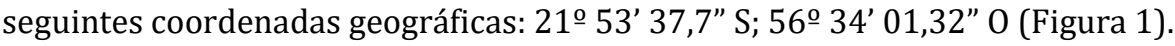

Figura 1. Localização do Assentamento Caracol, Bela Vista, MS, Brasil, 2018.

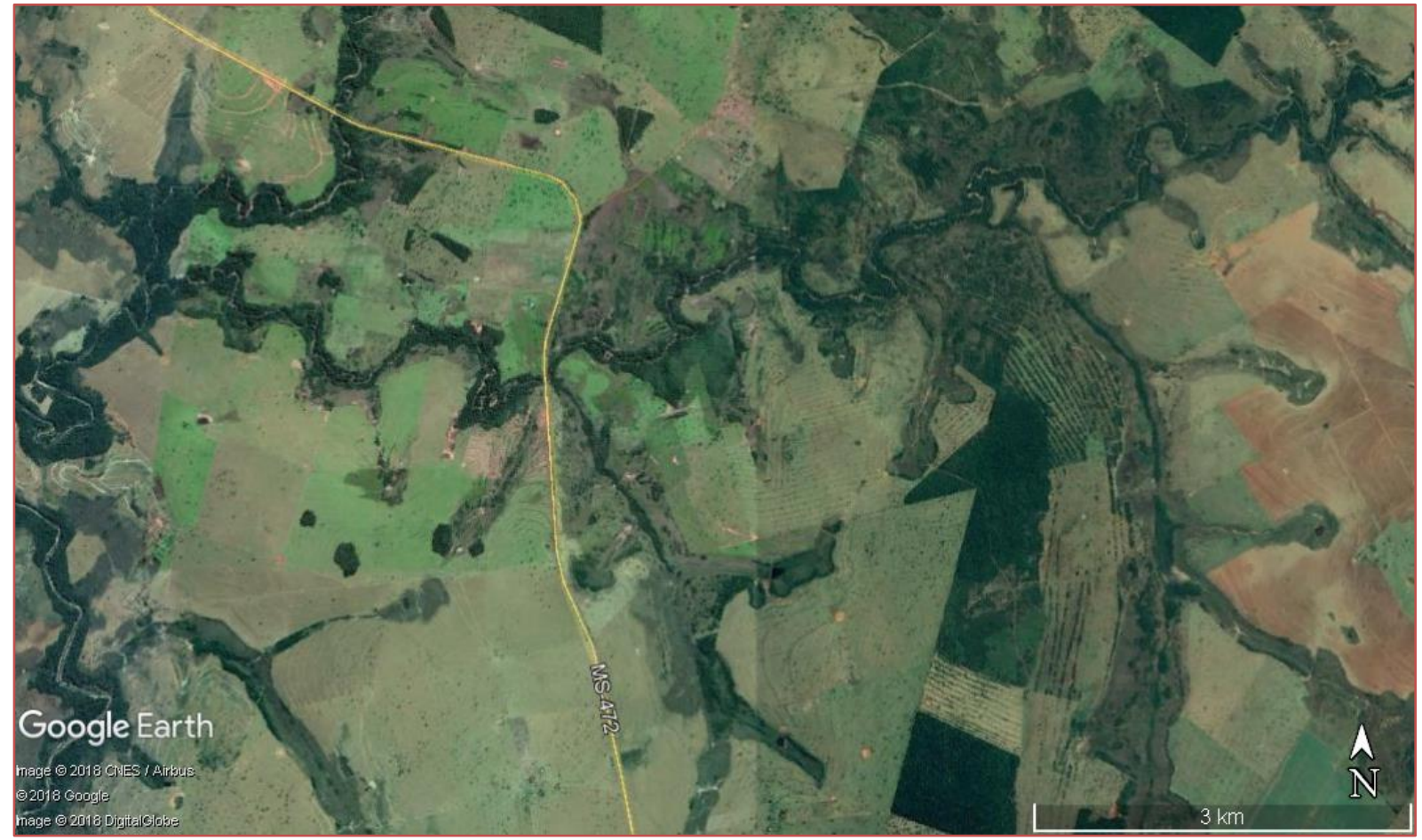

0 assentamento foi criado e reconhecido pelo INCRA em 11 de agosto de 1998, com capacidade para 152 famílias, tendo atualmente 152 famílias assentadas, correspondendo a uma área de 6.326,58 hectares

(INCRA, 2018). 
Por meio de uma entrevista com 5 agricultores do assentamento Caracol foi realizado os seguintes questionamentos: qual a sua atividade para subsistência, e as dificuldades encontradas no manejo do lote; como o senhor (a) caracteriza a vegetação nativa; como era a vegetação nativa logo que foi criado o assentamento; existem problemas ambientais no seu lote e no assentamento.

\section{RESULTADOS}

A fazenda adquirida para a criação dos assentamento tinha como atividade principal a pecuária de corte, pois os solos são rasos com afloração de sedimentos rochosos o que facilita essa atividade.

Os produtores do assentamento, se sustentam pela pesca no rio Piripucu e complementam a renda trabalhando em fazendas vizinhas, e outros vivem do arrendamento. Alguns produtores tem produção de gado, porco e carneiro, no entanto, o solo é muito raso na maioria dos lotes e o capim é o único que nasce contornando as rochas.

Os produtores relatam que gostariam de ter a possibilidade de cultivar lavouras de milho, cana e mandioca, mais a existência de solos rasos dificultam o manejo e no momento não conhecem técnicas quem poderiam facilitar tais cultivos.

Numa distância de $6 \mathrm{~km}$ entre lotes, o perfil do solo já se mostra diferenciado e alguns produtores conseguem plantar milho, mandioca, cana, batata-doce, buchas, bananas, feijão e frutíferas (Figura 2).

Figura 2. Colheita de batata-doce por agricultor no Assentamento Caracol, Bela Vista, MS, Brasil, 2018

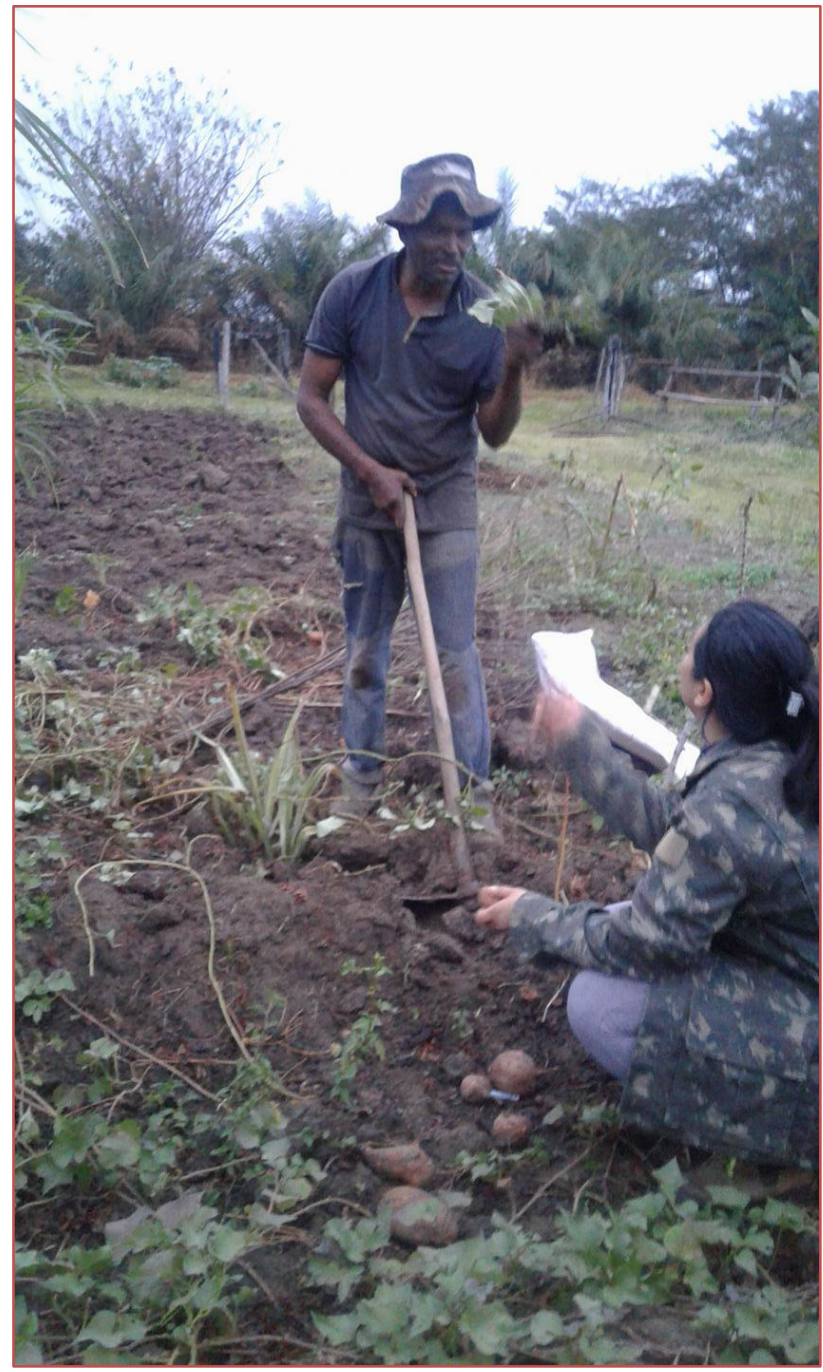


Os assentados identificam a vegetação nativa ao longo dos rios de "matas de espécies altas". Essas matas são características do bioma Mata Atlântica, que atualmente está ameaçado e proibido sua supressão pelo Novo Código Florestal.

Existiam muitas espécies nativas como aroeira (Myracrodruon urundeuva Allemão), angicos (Anadenanthera sp.), ipês (Handroanthus sp. e Tabebuia sp.), maria-barriguda (Ceiba speciosa (A. St.-Hil.) Ravenna), balsamo (Myrocarpus frondosus Allemão), entre outras. Atualmente existem árvores grandes preservadas ainda na APP do assentamento, como a maria-barrigura, também conhecida em outras regiões por paineira com mais de $150 \mathrm{~cm}$ de circunferência altura do peito (CAP) (Figura 3).

Figura 3. Matriz de maria-barriguda com mais de $150 \mathrm{~cm}$ CAP, Assentamento Caracol, Bela Vista, MS, Brasil, 2018.

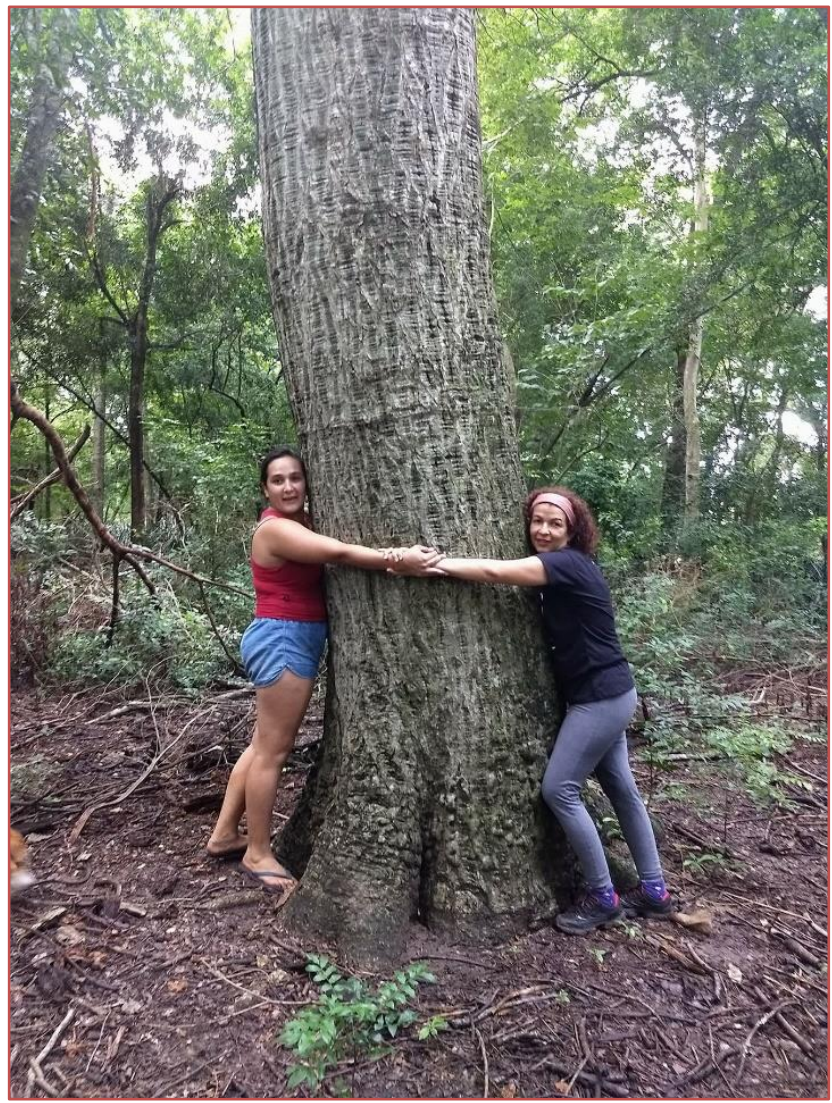

Atualmente no assentamento existem várias áreas degradadas, lotes com a ausência de vegetação nativa. Nas margens do rio Piripucu encontra-se lixos recicláveis, e tal presença é devido a visita de produtores da cidade de Bela Vista ao rio para banhos em finais de semana e também pela visita de pescadores do município e de outros Estados. Na área de preservação permanente (APP) existem caminhos realizados pelos pescadores para facilitar o acesso ao rio, e são os pontos mais desmatados da APP. No rio Piripucu também é realizado pesca ilegal com redes e tarrafas sem autorização do Imasul.

Nove lotes circundam o rio Piripucu possuem reserva cercadas para evitar o pisoteio do gado, no entanto, é notório a presença de braquiária (Urochloa decumbens (Stapf) R.D. Webster) na APP e pontos de assoreamento no rio, que a cada chuva vão aumentando, e geralmente ocorre a queda de muitas árvores na beira do rio pela instabilidade do solo frente a pontos sem vegetação (Figura 4). 
Figura 4. Pontos de assoreamento no rio Piripucu, Assentamento Caracol, Bela Vista, MS, Brasil, 2018.

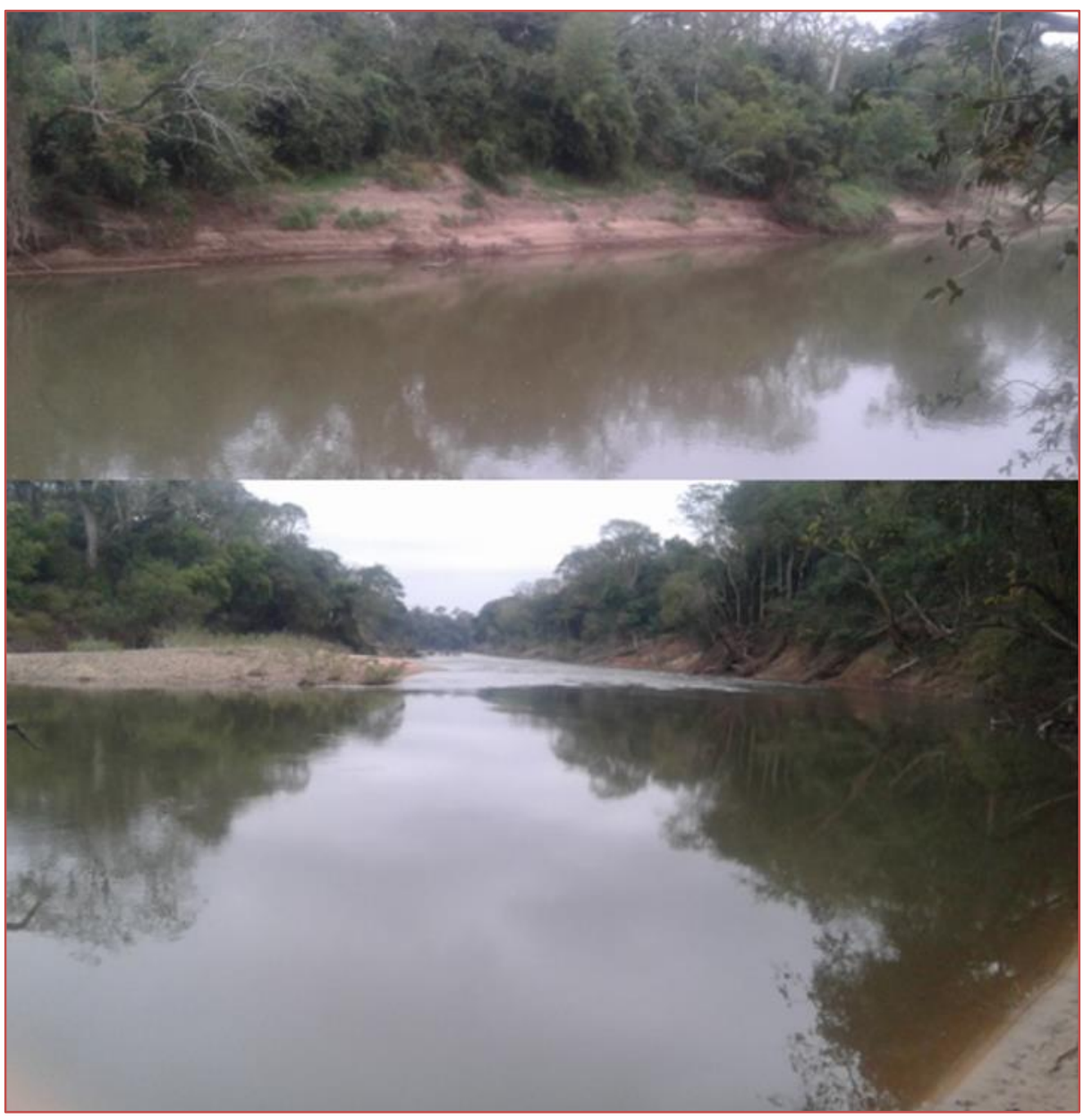

Não existem projetos de recuperação das áreas degradadas no assentamento Caracol. Isso reforça a atenção para implantação de sistemas agroflorestais biodiversos para assegurar a geração de renda para os assentados, além de recuperar as áreas em estágio de degradação avançado e preservar os fragmentos do Bioma Mata Atlântica existentes.

Nas enchentes que sempre ocorrem no período de outubro a novembro o rio carrega muito lixo que é depositado pelas pessoas na APP, e é muito triste ver tamanho descaso com a natureza.

As debilidades encontradas ao longo de 20 anos foram: a falta de assistência técnica para lidar com lotes que tem solo raso com afloramento rochoso; incentivos para as famílias residentes, principalmente na questão ambiental, visto que muitos lotes e áreas da APP estão degradadas; falta de políticas de educação ambiental para conscientização dos assentados, pescadores e moradores do município para evitar poluir e desmatar a vegetação nativa do rio Piripucu.

Acredita-se que para melhorar a situação econômica e ambiental do assentamento Caracol, se faz necessário a existência de políticas públicas voltadas para capacitação dos assentados, identificando das dificuldades e fazendo um acompanhamento das ações dos mesmos, além de gerar mais oportunidades para comercialização dos produtos no mercado, pois muitos agricultores não tem acesso a informação e a tecnologia para descobrir os meios de se inserir no mercado.

No quesito ambiental, políticas voltadas a educação ambiental e o estímulo a formação sistemas agroflorestais biodiversos possibilitarão meios para conservação e recuperação do meio ambiente e fortalecerão a agricultura campesina, gerando renda e proporcionando uma melhor qualidade de vida. 


\section{REFERÊNCIAS}

[1] ALTIERI, M. A. Agroecology: the scientific basis of alternative agriculture. Colorado: Westview Press, Boulder, 1987.

[2] BERGAMASCO, S. M. P. P. A realidade dos assentamentos rurais por detrás dos números. Estud. av., São Paulo, v. 11, n. 31, p. 37-49, 1997.

[3] INCRA. Informações gerais sobre os assentamentos da Reforma Agrária. Disponível em: http://painel.incra.gov.br/sistemas/index.php. Acesso em: 01 out. 2018.

[4] MARI, C. L.; TAVARES, P. D. V. B.; FONSECA, V. M. Alimentos, saberes e educação para o "bem viver": os camponeses um passo adiante. REMEA-Revista Eletrônica do Mestrado em Educação Ambiental, v. 34, n. 3, p. 37-54, 2017. 


\section{Capítulo 13}

\section{A ECONOMIA SOCIAL E SOLIDÁRIA PRODUZIDA POR CAMPONESES MIGRANTES}

\section{Maria Antonia Veiga Adrião}

Resumo: Analisei a economia social e solidária que observei nas experiências urbanas de camponeses migrantes que entrevistei. Designei essas maneiras de lidar com o desemprego no centro urbano de economia social, familiar e solidária para o trabalho, considerando suas características, porque se desenvolvem principalmente no âmbito doméstico e abrangem toda a família, inclusive as crianças. Outra é que estavam em relação com o que já sabiam fazer, estavam ligadas, portanto, à prestação de serviços ou à produção e comercialização de um bem que já sabiam fazer como "café", ou podiam aprender mais facilmente se não soubessem, como cortar, bordar e costurar roupas e chapéus. E estas circunstâncias colocavam as mulheres como protagonistas dessa economia, embora que, por motivos óbvios, eram produtos considerados do domínio feminino. E outra característica estava em relação com o modo de viver organizado, com várias famílias morando em uma mesma residência. E por último, os migrantes procuraram alternativas para seus desempregos por não se sentirem qualificados para os empregos existentes, e como essa economia não prescindia dos filhos, estes também cresceram aprendendo a trabalhar, sobretudo.

Palavras-chave: Migração de Camponeses. Economia familiar. Economia para o trabalho. 
Gostaria de defender neste artigo a noção de "economia plural" refletida por Laville (2017, p. 24) que seria a "[...] economia popular concebida como economia de trabalho que constitui uma das bases essenciais para a gênese da economia solidária." Esta "economia de trabalho" social e solidária pode ser observada nas lembranças de camponeses migrantes moradores das cidades brasileiras pós-abolição, não é exagero nem falta de perspectiva historiográfica cogitar tal unanimidade.

No entanto, refiro-me especificamente àqueles que migraram à cidade de Sobral situada na hoje, região noroeste do estado do Ceará1 entre 1950-1980, os quais entrevistei quando estava realizando a pesquisa que resultou no livro: Os Caminhos do Sol: Atravessar Veredas na Cidade Escurece a Vista (Migração Campo Cidade)2.

Importante esclarecer que, dos vinte sete sobreviventes, vou tratá-los desta forma porque todos relataram suas experiências em convivência com genitores e outros parentes já falecidos que emigraram juntos, ou antes, a essa cidade. Portanto, excedendo dois que vieram empregados, e outros três que contavam com algum rendimento para "negociar", os demais relembraram como foi sobreviver nessa urbe sem emprego e sem reservas monetárias de nenhuma espécie para se manterem, enquanto se "arranjavam" com parentes e amigos.

Dessa maneira, ao chegarem em Sobral, os migrantes3 precisaram inventar (refletindo neste conceito as proposições de Certeau,1996) 4 formas de sobrevivência, e isto abrangia uma organização social e familiar somente explicada pelo costume, pode-se concluir, considerando a prática familiar de as crianças receberem suas primeiras lições sobre trabalho e perseverança nas dificuldades, no roçado, aprendendo a capinar e a seguir em fila plantando o futuro, observando dessa maneira, como agiam seus pais e em alguns casos, avós, tios e irmãos mais velhos.5

Portanto, uma organização familiar costumeira, pode-se concluir, foi conduzida à cidade de Sobral como bagagem e como patrimônio imaterial ou como memória.6

Neste artigo refletirei a respeito dessa economia social, familiar e solidária para o trabalho através de excertos de entrevistas orais realizadas com dois migrantes no decorrer da pesquisa acima mencionada, mas que não chegaram a ser analisados na tese em referência, portanto, são inéditos; e através de referências a migrantes citados no texto aludido, no entanto, que não foram explorados por esse viés conceitual, ou seja, da economia social e solidária.7

Sendo ainda necessário assinalar que, os recortes dos relatos serão citados de forma um tanto ilustrativa, porque precisei fugir das explicações metodológicas sobre o uso da fonte oral sugerida por teóricos da "história oral" como Portelli (2001). Este autor recomenda que as narrativas não devem servir de simples comprovação de situações investigadas por representarem interesses recíprocos, ou seja, são resultado de um diálogo estabelecido entre pesquisador e pesquisados, e porque referem-se a recordações, interpretações e impressões do vivido, e não ao passado propriamente dito. Neste sentido, o contexto onde aconteceram as vivências serve de indício do passado investigado, e completa assim, o relato.

${ }^{1}$ Isto porque essa região do estado até a década de 1970 era denominada de região norte do Ceará. A partir de então esse território foi dividido em duas mesorregiões: as noroeste e norte cearenses compreendendo 83 municípios.

2 Tese defendida em 2017 pelo programa de pós-graduação em História da Universidade Federal do Ceará (UFC), em intercâmbio com a Universidade Estadual De Campinas (UNICAMP) com bolsa CAPES/PROCAD. Publicada pela Editora Novas Edições Acadêmicas em dez. 2018. ISBN 978-613-9-72696-7.

3 Um grupo que abrangia pequenos proprietários, posseiros, moradores das fazendas, moradores das vilas ou "ruas", trabalhadores de aluguel, rendeiros, arrendatários, todos agricultores de poucas ou nenhuma posse que se deslocaram para Sobral entre as décadas de 1950 e 1980.

${ }^{4}$ Com este conceito estou pensando nas possibilidades estudadas por Certeau (1996, p. 92: “É preciso portanto especificar esquema de operações. Como na literatura se podem diferenciar 'estilos' ou maneiras de escrever, também se podem distinguir 'maneiras de fazer' - de caminhar, ler, produzir falar, etc. Esses estilos de ação intervêm num campo que os regula num primeiro nível (por exemplo, o sistema da indústria), mas introduzem aí uma maneira de tirar partido dele, que obedece a outras regras e constitui como que um segundo nível imbricado no primeiro (é o que acontece com a 'sucata'). Assimiláveis a modos de emprego, essas 'maneiras de fazer' criam um jogo mediante a estratificação de funcionários diferentes e interferentes."

5 Conforme um migrante: "Os pequeno, meu pai não deixava ninguém em casa. Com 10 ano botava pra trabalhar. Quando chegava naquele roçado: 'é pra acompanhar os grande, senão acompanhar pega cabo de enxada na cabeça, cuidado pra não arrancar nenhum pé de legume, senão pega peia."

${ }^{6}$ Claro que os conceitos de Thompson (1998) sobre "costumes e cultura popular" fundamentaram essas ideias.

7 Base teórica apoiada também nas reflexões de Singer e Hillenkamp (2017). 
Outra explicação necessária é que, por economia social e solidaria entendo todo um modo de viver na cidade, mas igualmente, todo um modo de viver no "sertão"8 transportado à cidade, por não haver como separar essas experiências, mas igualmente pela condição de expropriação com que se estabeleceram em Sobral. Sem contar que esta cidade estava em elaboração 9 até pelos próprios migrantes que iam chegando como primeiros moradores dos bairros, então, os mais distantes do centro urbano. E desta maneira, proporcionava que permanecessem na fronteira, entre a zona agrícola e a zona urbana.

Isto porque um dos modos de sobrevivência na cidade de Sobral foi fazer o que já sabiam, como realizar roçados e criar animais nos quintais (porcos, aves, jumentos), e obviamente, empregar-se na prestação de serviços domésticos.

E não estou querendo dizer com isto que, essas maneiras de viver eram essências inalienáveis, apenas que, enquanto os migrantes se adaptavam à nova realidade, ou enquanto assimilavam outras práticas de trabalho e de convivência social e até familiar, seu aprendizado geracional servia para assegurar um certo equilíbrio emocional às circunstâncias da sobrevivência nada desprezíveis, como o desemprego, a moradia, as saudades. Temas que são comuns aos estudos migratórios e que também pude observar.

E por que economia familiar? Ora, as formas que assumiam para se manterem empregados representavam um esforço familiar organizado de homens e mulheres adultos que abrangia as crianças. Entre os trabalhos procurados inventariei a confecção sob encomendada de chapéus de palha e de surrões, o corte de chapéus para as manufatureiras de chapéus da cidade que terceirizavam alguns serviços, a confecção de roupas quando a família se dividia entre quem sabia cortar, bordar e costurar. Todos eram trabalhos realizados pelos membros "ociosos"10 das famílias e no âmbito doméstico.

Essa produção se dirigia diretamente ao mercado público de Sobral. Essa categoria pode ser dividida em pelo menos dois tipos de migrantes: os que se deslocaram objetivando negociar nesta praça, e àqueles que uma vez desempregados procuraram assentar uma "venda" por acanhada que fosse como uma "banca de legumes" ou de "café" no mercado ou em outro ponto da cidade.

Sendo que, se não fosse possível arcar com o dispêndio de alocar um espaço no mercado onde pudesse colocar a "banca", esses comércios foram experimentados nas próprias residências, ou em uma "esquina" de uma rua onde o migrante considerasse apropriado, e ainda havia a alternativa de acontecer de forma ambulante: Sr Manuel Matias Santos11, por exemplo, colocou uma "venda de bananas e cachaça" em sua residência, em um dos intervalos de desemprego; dona Neusa Silva (2013)12 pôs uma "banca de café" na esquina de um "armazém do governo" próximo a sua residência, e Raimundo Mendes (2015) 13 não conseguiu ficar no mercado, então passou a vender verduras em um carrinho de mão de porta em porta nos bairros adjuntos à sua residência.

Neste caso, mesmo em se tratando dos descendentes dos "pequenos proprietários", representava uma economia nova e particularmente familiar, pelo modo desconhecido de lidarem com os rendimentos do negócio: com impostos, por exemplo, pois era preciso "pagar o fiscal", com a nova divisão do trabalho familiar. Lembrando que nesta nova divisão familiar do trabalho a mulher assumia uma posição de vanguarda, embora que, apenas em razão de algumas atividades serem atribuídas ao gênero feminino como cortar, costurar, bordar, limpar, mas de todo modo, as migrantes assumiram um importante papel na sustentação das famílias.

E para àqueles que insistiram nos empregos das fábricas, enquanto procuravam ou enquanto passavam por períodos de instabilidade e desempregos, as mulheres asseguraram a condição familiar com o emprego em âmbito doméstico como já sublinhado no corte de chapéus, ou confecção destes ou de roupas,

\footnotetext{
8 Termos que os entrevistados preferirem.

${ }^{9}$ Em geral os entrevistados foram recorrentes no sentido de perceberem a cidade pouco habitada, alguns até bem menos do que as povoações onde moravam, o que não seria difícil no período estudado, pois a população rural até a década de 1970, (tomando este conceito do Instituto Brasileiro de Geografia e Estatística-IBGE) na maior parte das cidades brasileiras era maior que a urbana.

$10 \mathrm{Na}$ falta de um termo melhor, por envolver crianças.

11 SANTOS, Manuel Matias dos. Manuel Matias dos Santos. Trans. manuscrita, Sobral, set. 2013. Entrevista concedida a Maria Antônia Veiga Adrião. Gravação realizada em audiovisual, editada em DVD-R. Citado (ADRIÃO, 2018, p. 250).

12 Id. Ibid. p. 250: SILVA, Neusa Ripardo da. Neusa Ripardo da Silva. Trans. manuscrita, Sobral, set. 2013. Entrevista concedida a Maria Antonia Veiga Adrião. Gravação realizada em audiovisual, editada em DVD-R.

13 Ibid. p. 249. MENDES, Raimundo Bernardino. Raimundo Bernardino Mendes. Trans. manuscrita, Sobral, jan. 2015. Entrevista concedida a Maria Antônia Veiga Adrião. Gravação realizada em audiovisual, editada em DVD-R.
} 
ou com a confecção e venda de roupas mas como negócio próprio, ou de café, ou verduras, ou mesmo na prestação de serviços.

Neste sentido concordo com Hillenkamp (2017, p. 54), quando advertiu que existe também um "caráter feminino" e "uma moral feminista" na "economia popular solidária" que precisa de reconhecimento social e político.

Circunstâncias todas que não faziam parte das experiências dessas famílias antes da migração. Não que as mulheres não trabalhassem antes, ou não assumissem posições de comando, claro que sim, contudo, estas posições não geravam renda que por inaudível que fosse, com o passar do tempo, com o uso de estratégias pensadas para fazer render melhor os ganhos como morar mais de uma família em uma mesma residência, com o passar dos anos, essas maneiras de viver resultaram na ampliação do negócio com a aquisição de máquinas de costurar para quem investiu no ramo de confecção, por exemplo, ou na aquisição da casa própria almejada.

Isto porque uma característica dessa economia é que as famílias se juntavam para administrar melhor as despesas, portanto, iniciavam morando juntas e assim permaneciam. Essa prática pode ser observada nesse passado, na chegada a essa cidade diante das dificuldades iniciais já indicadas, mas tem uma continuidade no presente, com os genitores acolhendo os filhos casados em suas residências. Portanto, a maior parte dos inquiridos à pesquisa ou mora com filhos casados ou mora com estes e outros parentes.

Embora seja preciso cautela nessa constatação e assim, uma investigação dirigida, porque como a cidade cresceu, os novos bairros estão cada vez mais distantes, e desta maneira, os logradouros que antes representavam a fronteira entre o suburbano (conceito que aparece nos relatórios censitários do Instituto Brasileiro de Geografia e Estatística) e o rural, logo, nos confins da cidade, agora são bairros muito próximos do centro comercial, como o Campo dos Velhos onde reside dona Terezinha Fernandes (2014) a qual trouxe na sequência.

Querendo dizer com isto que, as locações de residências permanecem um dos problemas a pesar no orçamento das famílias de trabalhadores, mas a distância e sobretudo, a "violência", os perigos urbanos é que mereceram destaques nas preocupações dos migrantes quanto ao lugar de moradia dos filhos. Questão que merece uma reflexão mais apropriada sem dúvida, porque um problema que ao contrário mereceu discrição por parte dos migrantes, é a situação de emprego e qualificação para o trabalho dos filhos.

Esse extrato da narrativa de dona Terezinha Fernandes esclarece melhor essas vivências:

- Foi aqui mesmo [refere-se ao bairro, Campos dos Velhos], ali, naquela outra rua, ali, depois da esquina, lá nós moramos 5 anos, depois de 5 ano ele [seu esposo] comprou esse terreno aqui, [aponta para o piso], aí a gente começou a casa num ano, fomos terminar no outro. E nessa época, a gente não tinha condições, aí botava um pedaço de compensado aqui nessa porta e botava uma cadeira, pra segurar, que a gente num tinha condições de mandar fazer a porta. 0 portão já tinha, aí foi assim [...].

Ele trabalhava ali no mercado [...] aí o que sobrava da feira, eu, ele, o meu esposo, botava em duas bacias, aí fazia uma rodilha, botava na cabeça dos menino pra eles trazer pra casa, pra ele levar no outro dia [...].

Aí assim a gente [para reflexiva]! Tenho um filho casado que mora, tá morando aqui dentro de casa! Graças a Deus a gente tá vivendo, com ajuda de Deus e nossa senhora. Eu não me esqueço nunca as coisas boas que Deus e nossa senhora têm feito comigo [...]. Eu toda vida fui muito apegada aos meus filho! E tem a casada que mora na casinha lá nos fundo. É também uma pessoa boa, só tem um casal de filho. Aí a gente vive nessa união. Ela num fazia nem almoço lá na casa dela, comia tudo era aqui, depois que ela conseguiu comprar um fogão foi que'la ficou fazendo o almoço dela! 14

Essa senhora nasceu no sítio Taboca em Tianguá-CE., no ano de 1941. Estava com 73 anos quando a entrevistei. Casada, dona de casa aposentada, trabalhava em sua residência como costureira e bordadeira.

\footnotetext{
14 Ibid., 2018, p. 249: FERNANDES, Terezinha Sousa. Terezinha Sousa Fernandes. Transcrição manuscrita, Sobral, fev.
} 2014. Entrevista concedida a Maria Antonia Veiga Adrião. Gravação realizada em audiovisual, editada em DVD-R. 
Porquanto, em meio a uma das sessões da entrevista mostrou-me o interior de sua casa para explicar como se acomodava bem com seus filhos casados e suas famílias. Momento também que ressaltou: "Eu gosto muito daqui, gosto muito daqui! É difícil até eu andar na Serra Grande".15 Isto porque nem sempre foi assim, antes das coisas darem certo, antes de o futuro acontecer, ela temia muito a moradia em Sobral e se pudesse ter escolhido, teria migrado para a cidade de Parnaíba-PI. A justificativa para a migração foi uma discordância familiar, no entanto, seu esposo não quis se distanciar excessivamente dos parentes e amigos.

No que se refere a sua narrativa, como é possível perceber, apresenta indícios dessa economia familiar e solidária à qual analisei até agora, de como a família inteira se envolvia ou era envolvida no trabalho que não era individual, do chefe da família, mas familiar. E na esteira do que ocorria no trabalho familiar camponês, "os meninos" acompanhavam os pais ao mercado para aprenderem a trabalhar, mas também porque era uma característica dessa nova situação, que os filhos ajudassem uma vez que o lucro do negócio pelo que fica dito, dependia disso.

Apesar de ser recorrente nas narrativas até um certo ressentimento pela falta que os "estudos" causaram, e esta foi uma questão comum a todos, porque ser escolarizado como no presente estava relacionado à qualificação para o trabalho, quer os de livre iniciativa como os empregos ligados aos comércios próprios, quer os empregos das fábricas. E essa foi uma ideologia assimilada ainda como moradores do sertão, talvez por terem vivenciado ao longo de suas vidas algumas campanhas governamentais de alfabetização,16 e também, pelas vivências negativas que alguns acumularam nas suas trajetórias de migrantes.

Não obstante, apesar destas experiências negativas e das propagandas, a escola não chegou a ser uma prioridade na educação dos filhos, não ao ponto de absterem-se do trabalho deles.

Lembrando que Sobral não era a única cidade da região com índices migratórios, no entanto, entre os motivos destacados pelos inquiridos para a migração a essa urbe estava a necessidade de estudar, sendo que exclusivamente com este fim apenas um destacou este objetivo, e outra razão assinalada, relacionada com a primeira, estava a necessidade de os filhos estudarem, a despeito de onde moravam não existir escola, situação que três apresentaram.

Então, pode-se concluir que, apesar das narrativas comuns a favor da educação escolar, uma das características dessa economia familiar, social e solidária observada, é a pouca ou nenhuma escolarização dos adultos, e que esta situação reverberou na experiência dos seus descendentes.

Neste sentido, trouxe Sr. João Emílio

- [...] só trabalhava de serviço pesado, só trabalhava de serviço pesado, num tinha estudo né, só trabalhava de serviço pesado [...]. Têm as pessoas, a pessoa sendo um artista, tendo estudo, têm trabalho leve, assim saiba muito né? Quem num estudou? [sorri]! Quem num estudou é? Pelo bem, vamos dizer, a senhora trabalha em que?

- Eu sou professora! Pesquisadora!

- Pois bem, é professora, o serviço num é nada! Nada, praticamente é, só faz ensinar os outro, é verdade! E quem trabalha é pegando peso minha fia? Pegando no pesado! Tem esse negócio não! [...].

- Suas filhas estudaram Seu João Emílio

-Ah! As minha fia, ensinei muito elas a entrar na escola, né? Estudaro, estudaro! Tudo estudaro né, aprendero, sabem ler. Só não são é formada, mas pra trabalhar, pra tudo elas aprendero [...]. Cresceram aqui em Sobral, meus outro menino tudo morrero né, aí elas se criaram graças a

15 A Serra Grande é igualmente conhecida como Serra da Ibiapaba ou chapada da Ibiapaba, sendo uma das microrregiões que compõe a mesorregião noroeste do Ceará.

${ }^{16}$ A respeito das campanhas de escolarização ver o capítulo "Nos Caminhos do Sertão" p. 43-48, e o artigo: A Escola nas Narrativas de Migrantes. Revista de História Oral, Rio de Janeiro, v. 19, n. 1, p. 193-211, jan./jun. 2016b. Disponível em: $\quad<$ http://www.revista.historiaoral.org.br/index.php?journal=rho\&page=article\&op= $\quad$ download\&path $\%$ 5B\%5D=636\&path\%5B\%5D=pdf>. Acesso em 05 maio 2019. 
Deus! Foram criada mais eu, aí foi o tempo que casaram né, o tempo que casaro aí saíram. [...]. 17

Este senhor nasceu na Serra da Meruoca e emigrara para Sobral em razão da "falta de água" provocada pela seca de 1958. Aposentado, casado, pai de dez filhos dos quais apenas duas filhas sobreviveram. Aposentou-se como operário depois de passar por diversas "firmas". Distintamente dos referendados neste artigo, nunca tentou trabalhar em um comercio próprio, todavia, sua esposa que não é migrante, manteve-se com uma "banca de café" no mercado público até adoecer e aposentar-se, situação que muito o envaidece por ela ser "muito trabalhadeira". Nasceu em 1936 estando com 77 anos quando o entrevistei.

0 que mais chamou atenção no relato desse migrante foi sua reclamação por só ter experimentado "trabalho pesado", ou no oposto, por nunca ter se empregado em "trabalho leve", sendo que por diversas vezes em todas as sessões da entrevista, destacou sua posição de analfabeto. Morava com uma de suas filhas e netos.

Trouxe esse trecho da entrevista desse aposentado, pela comparação arguta que fez de sua condição de trabalhador com a minha. Questão que não poderei analisar neste trabalho, mas que ajuda a refletir sobre a noção social em torno do que seja um trabalho leve e um trabalho pesado.

Importante sublinhar que, seu relato apresenta o problema vivenciado por praticamente todos os entrevistados: "ensinei muito elas a entrar na escola, né? Estudaro, estudaro! Tudo estudaro né, aprendero, sabem ler. Só não são é formada, mas pra trabalhar, pra tudo elas aprendero.”. Esta explicação de João Emílio Vasconcelos a respeito de suas filhas que mal frequentaram a escola, apresenta indícios desses estágios dos migrantes, os quais ao mesmo tempo que desejavam ensinar aos filhos o caminho da escola, igualmente precisavam ensiná-los a trabalhar, e ao que fica dito, a educação para o trabalho prevaleceu sobre a educação formal, porque mesmo que seus filhos tenham tido acesso à escola, apenas dois migrantes contavam então com filhos cursando faculdades, e apenas um, com um filho formado.

Assim sendo, entre os entrevistados, três alcançaram concluir um curso superior, e entre estes, um possui os três filhos em processo de formação. Os outros dois mencionados logo acima não são graduados. No entanto, este migrante que conseguiu se formar e está com os filhos seguindo seus passos, não conseguiu o mesmo com os descendentes do primeiro casamento. Sendo viúvo, já estabilizado como "engenheiro", ressalta que somente agora pode dedicar-se à educação dos filhos.

Embora esse problema seja por demais relevante, gostaria de retornar a outra característica também importante dessa economia para o trabalho, para encaminhar à conclusão: que é a necessidade de sair da locação e construir uma casa própria.

As recordações de dona Terezinha Fernandes sinalizam para o esforço que representou deixar de pagar "aluguel". Circunstâncias que propiciaram à construção da sua casa própria que aconteceu aos poucos, deixando vestígios de que a contenção de despesas não se restringiu ao emprego de todos os membros da família. Por outro lado, evidenciando que o negócio prosperou ao ponto de sobrar receita para a aquisição de um terreno e à construção da residência.

João Emílio Vasconcelos também nos relatou suas tentativas de adquirir sua casa própria até finalmente, "sossegar" na casa onde hoje reside. Uma residência que apresenta indícios de como a trajetória urbana deste senhor foi repleta de privações materiais, e assim permaneceu na velhice. Ainda que, uma curiosidade a respeito deste senhor seja que, seu genitor possuía recursos e migrou de Meruoca para Sobral tendo como um dos objetivos a aquisição de uma casa própria em um bairro "banhado pelo Rio Acaraú", e assim o fez, adquiriu uma casa no bairro Pedrinhas, objetivando sobretudo não passar privação de água como vinha acontecendo na Serra da Meruoca.

Outra, é que para o deslocamento a Sobral não foi preciso disponibilizar à venda, a propriedade da família. E por último, no decorrer da vivência em Sobral esta propriedade foi conservada porque segundo esse aposentado, seus genitores não se interessaram para vendê-la "em vida", e depois que faleceram, pelo que entendi do que consegui apurar, como os descendentes vivos em sua maioria não moram no Ceará, e os que residem, ele e uma irmã já idosos e sem condições financeiras nem de saúde para cultivar a terra, esta encontra-se "abandonada". Portanto, sem mais nenhum cultivo, o que dificulta sua venda.

17 Ibid., 2018, p. 250: VASCONCELOS, João Emílio. João Emílio Vasconcelos. Trans. manuscrita, Sobral, ago. 2013. Entrevista concedida a Maria Antônia Veiga Adrião. Gravação realizada em audiovisual editada em DVD-R. 
Importante salientar que, a trajetória de trabalhador desse senhor foi muito difícil como ele deixa transparecer nessa fração de sua entrevista, e sua residência somente foi assegurada com sua aposentadoria. E mais duas senhoras relataram essa transição do aluguel à casa própria já na chegada a Sobral, considerando bens vendidos para tal fim. Os demais levaram mais tempo como dona Terezinha Fernandes supracitada, ou só conseguiram com a aposentadoria como esses senhor. Não obstante, todos destinaram-se a conseguir esse bem maior mais cedo ou mais tarde como se disto dependesse suas permanências nessa cidade.

E por último, pode-se destacar em relação ao tempo presente, os arranjos realizados nas residências para abrigar os filhos casados e suas famílias. No que concerne à residência de dona Terezinha Fernandes, a mesma destacou que nos fundos, no restante do terreno da casa ou no quintal, reside uma filha casada em uma "casinha" construída para esse objetivo. E uma das salas da residência também sofreu uma reforma para abrigar outro filho casado, com esposa e filhos.

A experiência de dona Terezinha Fernandes e de João Emílio Vasconcelos no que pese a morar com filhos casados vai de encontro a grande maioria dos demais migrantes como já assinalado. Com exceção de apenas cinco entrevistados, sendo que destes, uma é solteira e morava com uma irmã casada, e outro que os filhos ainda eram solteiros. Portanto, os demais moravam com filhos e suas famílias em residências adaptadas para este fim.

Milton Santos (2009, p. 43) ao analisar a economia a partir das práticas observadas na produção capitalista com seu "progresso técnico atual", (portanto, de quem tem capital para investir e atualizar-se), e a produção de quem não tem capital para investir e atualizar-se tecnicamente falando, mas inventa formas de se inserir em uma economia urbana, defendeu que: "[...] a economia urbana deve ser estudada como um sistema único, mas composto de dois subsistemas. Nós chamamos esses dois subsistemas de 'circuito superior' e 'circuito inferior'. A cidade não pode mais ser estudada como um todo maciço."

Nessa perspectiva, poderia situar essa economia a qual defendo neste artigo no "circuito inferior"?

Para Milton Santos (2009, p. 43), enquanto:

O Circuito superior emana diretamente da modernização tecnológica, mais bem apresentada atualmente nos monopólios. 0 essencial das relações do circuito superior não é controlado dentro da cidade ou de sua região de influência e sim dentro da estrutura do país ou de países estrangeiros.

Já o "circuito inferior" constrói sua dinâmica de atuação em outro polo, pode-se dizer:

0 circuito inferior é formado de atividades de pequena escala, servindo, principalmente, à população pobre; ao contrário do que ocorre no circuito superior, essas atividades estão profundamente implantadas dentro da cidade, usufruindo de um relacionamento privilegiado com a sua região.

No entanto, não se trata aqui de concordar ou discordar desse autor, mas de perceber como os trabalhadores que chegaram a essa cidade em décadas já distantes, no século XX, desempregados, conseguiram, não sua inclusão no sistema econômico existente, não estou trazendo essa questão, não estou refletindo a respeito daqueles que se colocaram como satisfeitos pelas suas inserções no sistema fabril da cidade e assim se aposentaram. Mas estou trazendo, a partir de alguns exemplos, àqueles que inventaram formas de inserir-se no mercado público da cidade, ou pensaram outros espaços alternativos para fazer negócios, uma vez desempregados.

E dessa maneira, já encaminhando à conclusão, tentando analisar como essa economia alternativa se fazia no quotidiano daqueles que a viveram, destacando algumas das características dessa forma de trabalhar.

Para Santos, essas formas alternativas de admissão dos pobres e dos desempregados na econômica urbana, estão situadas nessa categoria de "circuito inferior" porque "formado de atividades de pequena escala".18 Este é um distintivo que gostaria de destacar porque obviamente ele enumera outros. Concordo que se tratam de atividades difíceis de serem mensuradas a não ser que nos dedicássemos a criar parábolas que envolvessem o custo desses trabalhadores se manterem na cidade, versus o custo de

18 "O circuito inferior é formado essencialmente de diferentes tipos de pequeno comércio, e da produção de bens manufaturados de capital não intensivo, constituída em grande parte de artesanato e também de toda uma gama de serviços não modernos." 
criarem e sustentarem um negócio por inaudível que parecesse, mas que, com a organização já analisada, que abrangia toda a família, fez-se suficiente ao ponto de gerar dividendu. Cálculo complexo de ser realizado passados tantos anos e sem os migrantes possuírem arquivos com os registros de suas despesas e receitas. Porque a verdade é que conseguiram se manter na cidade e ainda prosperaram.

No entanto, importa dizer que, para não permanecerem desempregados, os migrantes colocaram bancas (querendo dizer com isto uma mesa onde expunham o que vendiam), portanto, de café; legumes e frutas; cachaça, carne; carvão, lenha, além disto, empregaram-se vendendo roupas, surrões e chapéus confeccionados no âmbito doméstico com as próprias mãos, ou seja, sem nenhum tipo de maquinário, isto no início, entre outras produções como animais domésticos que supriam a alimentação e, embora isso não tenha sido relatado, talvez até os vendessem também.

Sem dúvida foram atividades pensadas astutamente para se empregarem, e que aconteceram porque conseguiram envolver-se em redes de apoio que asseveraram essas reinvenções. Reinvenção aqui tem o sentido de se tratar de pôr em prática um saber social trazido como memória cultural à cidade, mas que precisaram de novos conhecimentos diante das exigências urbanas.

Não obstante, não tenho o objetivo de fazer uma análise conceitual para explicar quem alimentava essa relação econômica-alternativa no centro urbano, que passava da produção à exposição, da comercialização à compra, numa sequência que perdurou até a aposentadoria, no entanto, com alguns negócios se modernizando.

Pode-se citar o caso da confecção de roupas, esta passou a ser realizada com maquinário apropriado, embora ainda no âmbito doméstico. Igualmente os surrões deixaram de ser confeccionados porque deixaram de ser requisitados, e, embora não tenha me ocorrido indagar ao entrevistado a respeito, conjecturei que esteja em relação com uma produção mais sofisticada de sacolas para depósitos, como as de plástico.

Outro produto que perdeu espaço nas residências das migrantes é o chapéu de palha. Segundo um entrevistado que trabalhou por algum tempo comprando chapéus diretamente nas residências, os "bonés de panos" substituíram os chapéus.

\section{REFERÊNCIAS}

[1] ADRIÃo, M. A. V. Nos Caminhos do Sertão. In: ___. Os caminhos do Sol: Atravessar Veredas na Cidade Escurece a Vista (migração campo cidade). Saarbrücken, AL.: NEA, 2018, p. 36-86.

[2] _. A Escola nas Narrativas de Migrantes. Revista de História Oral, Rio de Janeiro, v. 19, n. 1, p. 193-211, jan./jun. 2016b. Disponível em: <http://www.revista.historiaoral.org.br/index.php?journal=rho\&page=article\&op= download\&path\% 5B\%5D=636\&path\%5B\%5D=pdf>. Acesso em 05 maio 2019

[3] CERTEAU, M. de. Fazer com; Usos e Táticas. In: Ephraim Ferreira Alves. Petrópolis, R.J: Vozes, 1994, p. 91-106. A Invenção do Cotidiano: 1. Artes de fazer. Trad.

[4] FERnANDES, T. S. Terezinha Sousa Fernandes. Transcrição manuscrita, Sobral, fev. 2014. Entrevista concedida a Maria Antonia Veiga Adrião

[5] HILLENKAMP, I. Os Universos da Economia Solidária: economias morais e relações sociais na região sulamericana. In: SOUZA, André Ricardo de; ZANIN, Maria; (org.). Economia Solidária e os Desafios Globais do Trabalho. São Carlos: EDUFSCAR, 2017, p. 47-58.

[6] LAVILLE, J. Economia Solidária e desafios epistemológicos. In: SOUZA, André Ricardo de; ZANIN, Maria; (org.). Economia Solidária e os Desafios Globais do Trabalho. São Carlos: EDUFSCAR, 2017, p. 23-29.

[7] MENDES, R. B. Raimundo Bernardino Mendes. Trans. manuscrita, Sobral, jan. 2015. Entrevista concedida a Maria Antônia Veiga Adrião.

[8] PORTELLI, A. História oral como Gênero. Trad. Maria Therezinha Janine Ribeiro. Projeto História: História e Oralidade. Revista do Programa de Pós-Graduação em História Universidade Católica de São Paulo São Paulo: n. 22, p. 9-36, jun. 2001.

[9] SANTOS, M. M. dos. Manuel Matias dos Santos. Trans. manuscrita, Sobral, set. 2013. Entrevista concedida a Maria Antônia Veiga Adrião.

[10] SANTOS, M. A Pobreza Urbana no Terceiro Mundo: Marginalidade ou Bipolarização? In: Pobreza Urbana. São Paulo, SP: EDUSP, 2009, p. 35-55.

[11] SINGER, P. Propagação Mundial da Economia Solidária. In: Economia Solidária e os Desafios Globais do Trabalho. São Carlos: EDUFSCAR, 2017, p. 15-21. 
[12] SILVA, N. R. da. Neusa Ripardo da Silva. Trans. manuscrita, Sobral, set. 2013. Entrevista concedida a Maria Antônia Veiga Adrião

[13] VASCONCELOS, J. E. João Emílio Vasconcelos. Trans. manuscrita, Sobral, ago. 2013. Entrevista concedida a Maria Antônia Veiga Adrião. 


\title{
Capítulo 14
}

\section{A COMPREENSÃO DOS VALORES ECOLÓGICOS E CULTURAIS DO PARQUE ZOOBOTÂNICO ARRUDA CÂMARA ATRAVÉS DA EDUCAÇÃO AMBIENTAL}

\author{
Antônia Arisdélia Fonseca Matias Aguiar Feitosa \\ Maria Neide Moura Martins de Andrade \\ Dayana Priscyla da Silva França
}

Resumo: Parques Ecológicos em áreas urbanas representam sinais de valoração ambiental - seja pelo sentido social, de lazer, de conhecimento ou de pertencimento emocional - e exercem diversas funções, assumindo importante papel na vida cotidiana dos cidadãos. No século XXI há uma tendência de que estes espaços se tornem centros de estudos e pesquisas, enfatizando a conservação de modo holístico e buscando envolver o público com as questões ambientais mais complexas, partindo-se de abordagens multidisciplinares. 0 presente estudo tem como finalidade indicar a importância ecológica e sociocultural das Áreas Verdes Urbanas para a manutenção dos serviços ecossistêmicos e para os processos educativos - especificamente do Parque Zoobotânico Arruda Câmara (BICA) na cidade de João Pessoa, PB. Buscamos, por meio do estudo de caso demonstrar que as funções do Parque, localizado no centro da cidade de João Pessoa, estão para além do lazer e das visitas à exposição de animais. 0 trabalho está em execução desde junho de 2017 com o intuito de desenvolver junto à equipe do Parque e aos visitantes o sentimento de pertencimento do espaço como parte integrante da nossa natureza (humana e ambiental), através de aulas de campo e explicações do espaço sobre o seu histórico sociocultural e dos serviços ecossistêmicos que o local oferece. A partir da aplicação de 100 questionários, foi possível identificar que os participantes têm sua formação acadêmica entre o ensino médio e pós-graduação, com idade maior do que 15 anos. Foi constatado que $78 \%$ dos que responderam visitam o parque anualmente; $69 \%$ tem algum tipo de conhecimento histórico do Parque; $26 \%$ apontam que os animais chegam ao local através do IBAMA e o mapeamento do local é tido como "bom" para $55 \%$. Espera-se, com estas ações interventivas, edificar uma nova relação da comunidade com o Parque, de modo a valorizá-lo na sua essência e estabelecer novas significâncias à sua convivência com o ambiente.

Palavras-Chaves: Educação Ambiental; Valor Sociocultural; Serviços Ecossistêmicos. 


\section{INTRODUÇÃO}

Os Zoológicos de forma geral eram vistos como locais de exibição de animais e demonstração de poder, ao longo do tempo esses pensamentos foram sendo modificados e hoje existem vários projetos com o intuito de relacionar esses ambientes com pesquisas, estudos e conservação para a preservação dos animais que ali vivem e ser fonte de conhecimento para os visitantes.

Para Wemmer et al.(1991) apud Achutti (2013), zoológico é toda coleção de animais silvestres em cativeiro ou em exibição, não importando que seja pública ou particular, possuindo animais exóticos ou nativos. Os primeiros zoológicos pouco mais eram do que espetáculos de aberração; algumas chegavam a incluir aberrações humanas nas jaulas junto com animais selvagens. Primeiramente os zoológicos tiveram a função de realçar o poder dos líderes e na sequência, proporcionar ao povo o acesso à diversão oferecida pelos animais em exposição. No século XIX, os zoológicos tinham um caráter estritamente taxonômico, com exposições em jaulas visando apenas à manutenção e reprodução. 0 século XX é marcado inicialmente pela tendência ecológica, na compreensão do comportamento animal e dos diferentes habitats. Atualmente temos uma forte tendência conservacionista, marcada pela preocupação em adequar as instalações aos ecossistemas naturais e na conservação in situ (GARCIA, 2006).

As atividades desenvolvidas nos zoológicos, embora com claras propostas educativas, ainda encontram-se presas às funções consideradas clássicas dessas instituições. Desse modo, se considerarmos o potencial educativo dos zoológicos hoje e as discussões advindas do campo da educação não formal e da divulgação científica, torna-se fundamental discutir qual a finalidade educativa desses locais. Em geral nas visitas escolares desenvolvidas em zoológicos os conteúdos trabalhados estão voltados a temas como taxonomia, características morfológicas, etológicas, ecológicas e evolutivas dos vertebrados. Aspectos relativos à instituição, sua missão, função social e educativa nem sempre são abordados nesse tipo de visita. No entanto, essas informações são de fundamental importância para entender o papel não só educativo desses locais hoje, mas também sua função de pesquisa e de conservação. Os zoológicos têm evoluído rapidamente e a tendência é que no século XXI se transformem em Centros de Conservação e de Educação Ambiental (IUDZG, 1993, P. 03) apud Achutti, 2013.

Os Parques Zoológicos, abertos para a visitação pública, são de grande importância nos processos de preservação, conservação e pesquisas referentes à manutenção de espécies ameaçadas de extinção. Muitos têm como objetivos a reprodução e ao aumentar o número de populações possibilita que cresça o conhecimento sobre essas espécies. Isso é básico e permiti que se criem programas de reintrodução de animais na natureza, nascidos em cativeiro.

Além disso, sempre tem como objetivo o bem-estar dos animais, e esse bem-estar pode ser avaliado também, pelos índices de reprodução das espécies mantidas em cativeiro. A reprodução, em qualquer espécie animal, é uma das primeiras funções fisiológicas bloqueadas pelos indivíduos, quando qualquer necessidade básica não estiver sendo atendida. Então, se uma espécie apresentar bons índices de reprodução em cativeiro é sinal que está bem adaptada, com alimentação e cuidados básicos bem atendidos. Outra contribuição importante é através da educação da população, criando uma consciência ecológica de que é preciso poupar nossos recursos naturais, respeitar nossas espécies animais e vegetais, e diminuir a poluição em todos os níveis.

\section{PARQUE ZOOBOTÂNICO ARRUDA CÂMARA, EM JOÃO PESSOA - PB}

O Parque Zoobotânico Arruda Câmara, pode ser caracterizado como sendo um espaço destinado ao lazer, qualidade de vida, pesquisa e conservação. Também é identificada a sua grande capacidade hídrica, pois era uma fonte de abastecimento para a população que fica ao seu redor há décadas atrás, além de apresentar grande diversidade de flora, com presença de espécies nativas e exóticas, e de fauna incluindo animais de origem nacional e exótica com fins de contemplação e conhecimentos de espécies oriundas de vários habitats.

O Parque Zoobotânico Arruda Câmara (PZAC), conhecido também como a BICA, foi inaugurado em 1922, possui uma área de 26,8 hectares e tem grande valor para a sociedade devido às funções ecossistêmicas, socioambiental e cultural que o parque oferece para os visitantes e moradores que ficam no seu entorno e que usufruem de seus serviços cotidianamente.

Permanece sendo o único zoológico do Estado da Paraíba, está presente em uma área protegida de mata nativa do bioma Mata Atlântica, abrigando atualmente cerca de "550 animais nativos e exóticos, 100 espécies, entre aves, répteis e mamíferos [...] o que garante a reprodução de [...] espécies ameaçadas de 
extinção, como o jacaré coroa, jacaré de papo amarelo, jaguatirica, macaco prego galego, onça pintada, entre outros" (PZAC, 2017). Para o público, além dos recursos que o meio ambiente oferece, contam com diversas maneiras de lazer e educação ambiental, que existem no local. No ambiente encontram-se pessoas qualificadas e motivadas a passar conhecimento à população no que se refere à flora e fauna ali encontrada.

A partir de setembro de 2010, deu-se início a entrega do projeto de requalificação do Parque melhorando as condições de acondicionamento dos animais através da construção de novos recintos: Casa dos Répteis, Vila dos Mamíferos, Recinto das Aves e Falconiformes, tornando a Bica uma das melhores opções de lazer e entretenimento da cidade de João Pessoa. E no fim de 2017 foi iniciada uma nova reforma o que irá trazer mais conforto aos animais e seus visitantes.

\subsection{A EDUCAÇ̃̃O AMBIENTAL NO PARQUE ZOOBOTÂNICO ARRUDA CÂMARA}

O Parque Zoobotânico Arruda Câmara funciona como um polo para práticas de educação ambiental em todo município, isso porque a administração e a formatação de EA no PZAC são trabalhadas simultaneamente por dois núcleos voltados à praticas de Educação Ambiental: Um Setor de EA criado em 2007, para atender as demandas de educação ambiental da flora e fauna, e o Centro de Estudos e Práticas Ambientais - CEPAM, criado em 24 de setembro de 2010, e que funciona como um espaço para desenvolver estudos e práticas que envolvam a Educação Ambiental do município, implementando ações para conscientização e preservação do meio ambiente. As ações cotidianas no CEPAM e no setor de EA do parque se voltam ao desenvolvimento de atividades educativas para a preservação dos recursos naturais com a finalidade de sensibilizar a população sobre a importância de garantir o futuro das próximas além de estar comprometido com a promoção de mudanças de comportamento do público visitante e com o seu relacionamento com o ambiente de Parque e de Zoológico, expande seus objetivos para esferas mais amplas como a rua, o bairro, a cidade e a biosfera, na medida em que estimula a criação desses elos coerentes e significativos com o meio ambiente e espera a efetiva prontidão pela defesa do Parque e da Natureza. Tem como objetivo geral trabalhar a temática ambiental de forma holística de modo a sensibilizar e incentivar atitudes de preservação, conservação e manutenção de um Parque gerações. Os dois setores, em conjunto, atendem cerca de 2.000 mil visitantes mensalmente.

Os princípios orientadores do CEPAM pautam-se na Ecopedagogia - uma estratégia que se apresenta como uma pedagogia dos direitos que associa direitos humanos, econômicos, culturais, políticos, ambientais e direitos planetários, impulsionando o resgate da cultura e da sabedoria popular. A ecopedagogia apresenta-se como um novo campo de trabalho para educadores e pesquisadores, evidenciando a educação para uma conscientização ambiental na perspectiva do desenvolvimento sustentável. 0 principal objetivo da Ecopedagogia é inserir a cultura da sustentabilidade em espaços educativos (GUTIÉRREZ e PRADO, 2002).

Mais de 30 mil visitantes foram assistidos pelas ações mobilizadas pela equipe do CEPAM desde sua fundação. São desenvolvidas atividades como: trilhas ecológicas (fauna e flora) seguidas ou não por atividades práticas (desenhos, fichas temáticas, artesanato, etc); vivência em artes (eco-oficinas); dinâmicas, jogos e brincadeiras ecológicas; interação com animais após trilhas ou palestras; projeções de filmes didáticos (curtas e/ou longas); atividades com e na comunidade; capacitações; palestras.

De modo mais específico, o Programa de Educação Ambiental do Parque busca desenvolver práticas de Educação Ambiental, utilizando o potencial da instituição como instrumento para a conscientização e valorização do Parque como patrimônio natural e cultural da sociedade; desenvolver ações educativas que proporcionem o reconhecimento do ZOO como espaço de conservação, pesquisa, educação e lazer; sensibilizar e mobilizar os visitantes e a preservação e conservação ambiental no interior do Parque.

A educação ambiental no parque é tratada de forma ampla e diversificada, sendo desenvolvida junto aos visitantes. 0 PZAC tem infraestrutura básica para o visitante e conta com a presença de trilhas que fornecem uma experiência importante ao mesmo, esse contato pode auxiliar o elo de afinidade entre o ser humano e a natureza (BICA, 2017).

\subsection{CARACTERÍSTICAS PECULIARES E FORMAS DE PERCEBER O PARQUE}

Um fator importante relacionado ao PZAC é o número crescente de visitações anuais, pois este recebe anualmente uma média de 150 mil pessoas. Esses visitantes têm a oportunidade de "[...] interagir com os animais, realizar trilhas, piqueniques e participar de atividades eco-educativas [...]" o que vem a evidenciar 
a importância social do parque para o cotidiano da cidade de João Pessoa/PB, baseando-se no objetivo principal do PZAC que "[...] é estimular o respeito e a preservação do meio ambiente, com foco no conceito de que é preciso: Conhecer para Entender e assim o preservar." (PZAC-Guia do Visitante, 2014)

Além disso, a parte histórica, socioambiental e cultural do parque é muito forte, pois o local serviu como cena para grandes personagens da Paraíba. Um deles é o botânico paraibano Dr. Manoel de Arruda Câmara, cujo nome o Parque leva em sua homenagem, sendo tombado pelo patrimônio, histórico e Artístico da Paraíba (IPHAN) em 1941 e em agosto de 1980 foi tombado pelo Instituto do Patrimônio Histórico e Artístico do Estado da Paraíba. De acordo com o documento oficial do órgão, (Kit Estagiário/E.A. PZAC, SEMAM, 2017).

O outro é o prefeito Walfredo Guedes Pereira que na época fundou o Parque, além de ter transformado a fonte antiga de madeira para pedra calcária. A ampliação do parque ocorreu com a compra da fazenda Paul. Sendo então urbanizado e composto de fauna e flora, culturalmente ainda existe a lenda indígena que deu origem a história da fonte. Algo importante é que a fonte era usada para o abastecimento hídrico do bairro, o Baixo Roger e até hoje continua sendo uma reserva para a localidade por isso é muito importante sua existência e preservação.

Para proteger o meio ambiente que estamos inseridos é necessário perceber e entender o motivo que nos desperta essa preocupação, pois essa é a forma que nos estimula para iniciar e prosseguir com tais cuidados. E para que isso ocorra, devemos nos entender como parte do ambiente, uma ligação real e continua sendo esse pensamento de fundamental importância.

Para colaborar com esse estudo adotaremos o termo topofilia, elaborado pelo geógrafo Yi-Fu Tuan, que segue a linha fenomenológica, seu conceito leva em consideração a percepção que um ser ou grupo social tem do espaço que o rodeia, essa relação está ligada ao sentimento de pertença. Que de acordo com Yi-Fu Tuan (1980). É a ligação de afeto do indivíduo com seu local, com o território onde vive que cria condições de sobrevivência.

Quando o sujeito entende essa relação surge então à transformação do pensamento em ação. Pois é na ação que se conclui essa dinâmica, os levando a sair da inercia. Os resultados dessas ações são revelados de acordo com os pressupostos de FREIRE (2011, pág.108). Não é no silêncio que os homens se fazem, mas na palavra, no trabalho, ação-reflexão.

Também é necessário que a sociedade entenda o meio ambiente de uma forma abrangente, integradora e não segregada. É percebido que muitas vezes a educação ambiental é usada de forma pontual, com denominações e pedagogias diferentes, no intuito de ser difundida e aceita por um máximo de pessoas.

Porém antes de qualquer coisa, devemos identificar e discutir sobre os problemas que estão sendo gerados pela ação do homem na natureza, já que a crítica é necessária para a reflexão do que vem ocorrendo no meio ambiente, sendo importante para que as ações promovidas sejam sentidas e realizadas de forma real, pela e para a população, ao meio ambiente, pois é dessa forma que devem ocorrer melhorias continuas.

Ao contrário da EA conservadora, no que concerne a compreensão da questão ambiental, a EA crítica problematiza, politiza e publiciza o debate, além de promover a inseparabilidade da questão ambiental da questão social. 0 enfoque quanto aos indivíduos na sociedade é de que eles devem superar sempre as perspectivas individualizantes, típicas de uma sociedade capitalista. As ações dos sujeitos realizam-se na sociedade no coletivo pelo coletivo, almejando a autonomia, a criatividade transformadora e liberdades humanas (SILVA, COSTA E ALMEIDA, 2012, pág. 121).

0 termo sustentável ganhou força e amplitude no nosso cotidiano, pois o mesmo refere-se ao uso dos recursos naturais de forma mais qualitativa e não quantitativa, sendo um estimulo para as próximas gerações. Proporcionando uma cooperação entre homem e natureza, na qual é uma inspiração, pois a natureza sabiamente usa de seus matérias sem acarretar prejuízos a ela, focando na qualidade e não na quantidade.

Ao usamos a educação ambiental no espaço, obtemos um apoiador ímpar, que tem a intenção de criar uma conscientização na qual as pessoas tratem da preservação social e ambiental com interesse. Assim, a população participante pode descobrir que dessa forma o ambiente será protegido e que as próximas gerações poderão ter uma consciência ambiental ampla, responsável e transmitir o conhecimento 
adquirido a outros, crescendo a integração com o meio ambiente e dele extrair sua subsistência sem dizimar o ambiente em que vivem e a possibilidade de criar uma sociedade resiliente.

A educação Ambiental é na realidade vivencial e pode abrir oportunidades para novos segmentos criativos e transformadores. Se a vivência for positiva, bem elaborada e conduzida, pode deixar no indivíduo a conviç̧ão, percebida corporalmente, de que a construção de novas relações com o mundo é possível e de que as raízes dessa construção encontram-se nele mesmo, na memória corporal da experiência que teve, adquirindo assim, uma maior autonomia para pensar sobre si mesmo e seu estar no mundo, apoderandose para observar suas limitações e os pressupostos que subsidiam suas ações (MENDONÇA, 2007, pág.120).

Os espaços urbanos com peculiaridades ecológicas e socioculturais devem ser valorizados, não apenas pelo seu valor próprio, mas, pelas atividades desenvolvidas que promovem novas percepções aos envolvidos (guias, visitantes e colaboradores), o que é perceptível após as aulas.

\section{OBJETIVO}

Compreender o valor ecológico do Parque Zoobotânico Arruda Câmara - BICA que se apresenta à cidade de João Pessoa como um espaço verde urbano detentor de funções ecossistêmicas complexas, envolvendo aspectos socioambiental, ecológico, cultural e pessoal.

\section{METODOLOGIA}

Este estudo foi desenvolvido no Parque Zoobotânico Arruda Câmara entre os meses de junho de 2017 e setembro de 2018. Pauta-se na abordagem qualitativa da pesquisa, na perspectiva exploratória e interventiva. 0 estudo de caso foi estratégia adotada, a partir da qual tomamos como pontos fundamentais no estudo aspectos históricos, socioambientais e culturais do Parque, com destaque nas suas primeiras finalidades para a comunidade.

A ideia foi organizar um elenco de informações que clarifiquem aos visitantes os valores que podem ser despertados acerca desta área urbana tão visitada pela população local e pelos turistas. Aspectos que estejam para além de visitas aos recintos e às áreas de lazer. Propomos aprofundar no campo da percepção de valores ecológicos, socioambientais e culturais.

Estudos em fontes oficiais nos permitiram sistematizar uma cronologia histórica do parque para compreendermos suas condições atuais, bem como contribuir com melhorias em ações educativas.

A partir de questionários que foram aplicados junto aos frequentadores do Parque (100 participantes) bem como mediante conversas informais, fomos formatando as primeiras intervenções educativas no sentido de contribuir com a Educação Ambiental já em execução pela equipe técnica deste espaço.

Pensamos na confecção de mapas temáticos e para isto utilizamos a base cartográfica da Prefeitura de João Pessoa e o programa Quantum GIS 1.7.1. Por fim, com as informações adquiridas (Histórico, cultural, serviços ecossistêmicos e mapas), ficarão expostas em banners, em locais estratégicos e visíveis a todos que circulam o ambiente.

\section{RESULTADOS E DISCUSSÕES}

Eixos Orientadores Definidos para as Informações aos Visitantes:

A presença dos animais no Parque Zoobotânico é determinada por alguns fatores, entre eles o tráfico de animais que são retirados da natureza para serem comercializados. Nesse percurso tornam-se vítimas de maus tratos, morrem ou tem membros dilacerados, porém ao chegarem ao parque passam por tratamentos médicos e ficam aos seus cuidados, até que possam voltar à natureza, caso não seja possível sua volta ao meio ambiente, ou ocorra o nascimento de filhotes em cativeiro devem ficar no local para serem cuidados, pesquisados e observados pela comunidade. Para a orientação das trilhas sempre é enfatizado os valores ecossistêmicos que ali se encontram os fatores históricos ocorridos no ambiente, como também dos recintos e das estações que existem, como, A ilha dos mamíferos, Serpentário, Anatídeos, Falconiformes, a Estação da Mata Atlântica, Estação do Solo e Estação da Água.

Ao chegar nelas é descrito o que é mais importante, como que espécies são, sua alimentação, características físicas e comportamentais, sua importância para o meio ambiente, como chegaram, 
doenças adquiridas, se estão em risco de extinção, o tipo de formação florestal, no caso o local tem fragmentos da Mata Atlântica, relação da flora com a fauna, as formações do solo que são identificadas a depender de sua exposição no terreno e a importância da serrapilheira para as interações com a natureza e por fim como é a distribuição hídrica e sua importância para a manutenção dos serviços ambientais. Para que assim todos possam entender de forma completa e clara todo o ambiente e não de forma fragmentada.

As informações expostas em faixas (Banners) serão usadas para direcionar os visitantes ou os interessados em conhecer o ambiente de forma geral, com ou sem a presença dos guias, sendo tais informações exposta de forma resumida com as temáticas já citadas, como o será abordado nas aulas de campo, que animais o parque tem, sua presença e que ambientes são encontrados no local.

Todas as informações têm como finalidade oferecer aos participantes a possibilidade de ampliar sua percepção sobre o local, que percebam a bica como uma fonte de informação, laser, pesquisa e cuidados, tanto com a flora como para a fauna, direcionando sua visão para o local, e assim, o visitante possa ser um agente multiplicador do que ele aprendeu ao participar das visitas

\subsection{A DINÂMICA SUGERIDA ÀS AULAS DE CAMPO}

Nas aulas de campo estão sendo abordados temas como: histórico cultural e socioambiental e os serviços ecossistêmicos que o ambiente oferece. Por meio de questionários aplicados depois das aulas busca-se saber qual o nível de conhecimento sobre o ambiente, motivo de visita e volta ao parque, assim como a sua compreensão sobre as aulas apresentadas. Como também nas aulas, estão sendo explicados os motivos da presença, importância para pesquisas e conservação dos animais. Esses materiais didáticos e informativos ajudaram a revelar aspectos importantes sobre o parque como a:

História sociocultural do parque: resgatando a sua história, como se constituiu, de que modo ocorre a recepção e interação da comunidade com o parque, que fatos ocorreram e foram sendo transformados durante o percurso e quais serviços são oferecidos atualmente no parque.

Serviços ecossistêmicos: Entre os diversos serviços ecológicos oferecidos pelo parque, destacamos: Regulação - climática e recursos hídricos, Culturais - As formas como o parque é usado, lazer, artístico e etc. E de Suporte - Formação do solo, fotossíntese e ciclo de nutrientes. Aproveitando os espaços e os serviços socioeducativos oferecidos pelo parque ao espaço urbano, como as aulas de campo, usando para expor aos usuários todo a lado histórico, ecossistêmico, social e cultural do parque. Através de um questionário que foi aplicado depois das aulas, a um público de 100 visitantes com agendamento prévio, para que se possa entender o pensamento do visitante com relação ao parque após as explicações sobre o mesmo e seus serviços.

Parque como Zoológico - exposição de animais: Enfatizando durante as aulas de campo e recepções os motivos que os fizeram estar lá, como também sua importância para conservação e pesquisas. Desta forma, a comunidade poderá compreender as razoes pelas quais estes animais precisam permanecer no ambiente.

A criação do mapa: A criação dos mapas temáticos servirá de base complementar aos visitantes, que poderão se guiar sozinhos, deixando-os autônomos para escolher aonde ir e quais ambientes são mais atrativos. Para isso usaremos a base cartográfica da Prefeitura de João Pessoa e o programa Quantum GIS 1.7.1 para processar essas informações e gerar como resultados mapas temáticos das trilhas existentes que são mais utilizadas pelos visitantes.

Painéis Temáticos: Após colhermos os dados referentes à origem histórica do parque, os serviços que o local oferece e permanência dos animais, pretende-se organizar um material didático educativo que deve ser utilizado durante as visitações. Bem como expor essas informações em painéis temáticos em locais estratégicos e visíveis a todos que circulam no ambiente. Assim proporcionará que todos conheçam com maior profundidade os aspectos históricos, culturais e ambiental e que a partir disso possam criar ou reavivar um vínculo emocional com o local passando para as gerações futuras.

Com o auxílio de cem (100) questionários aplicados aos visitantes com 13 questões ao fim das aulas de campo, podemos analisar os resultados dos questionários e foi possível constatar alguns pontos que já tínhamos conhecimento, e que foram obtidos através das conversas informais com os visitantes durante as aulas. 0 questionário foi separado por subtemas, definido da seguinte forma: Sobre a Questão Social, no que se trata da formação acadêmica dos entrevistados a maior parte $36 \%$ tem formação superior 
incompleta, 33\% com ensino médio incompleto e 7\% tem especialização, mestrado ou doutorado e a faixa etária está compreendida entre 15 a 61 anos.

Para a valoração do parque: os maiores índices estão para as visitas anuais com 78\% e 9\% mensalmente, as demais tem significância pequena. Os principais motivos de retorno ao local são para adquirir conhecimento com 36\%, proximidade com a natureza $19 \%$, bem-estar $6 \%$, lazer $3 \%$ e os demais $36 \%$ variando entre essas alternativas. No que se diz respeito às informações históricas 31\% dizem não saber nada e $69 \%$ tem algum conhecimento, sendo esse saber divido entre $18 \%$ sobre a fonte, 14\% para a lenda e 12\% para o histórico do parque. Como pode ser visualizado no 1 Gráfico: Frequência de Visita ao Parque, 2 Gráfico: Motivo de Retorno ao Parque e 3 Gráfico: Acesso a Informação Histórica e 4 Gráfico: Qual o Tipo de Informação, respectivamente.

Gráfico 1: Frequência de Visita.

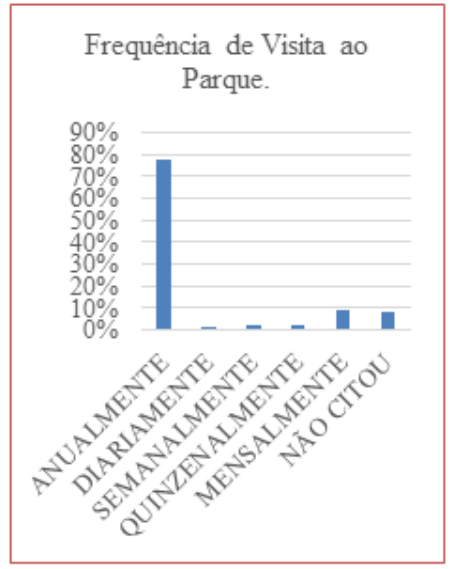

Gráfico 2: Motivo de Retorno.

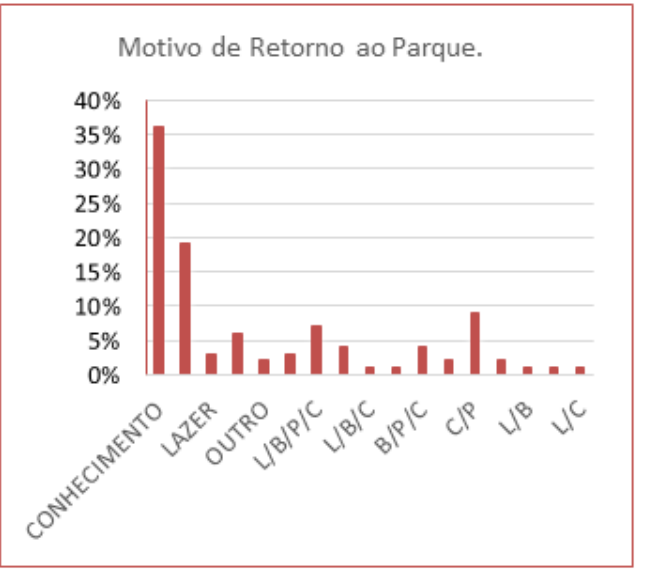

Gráfico 3: Acesso a Informação.

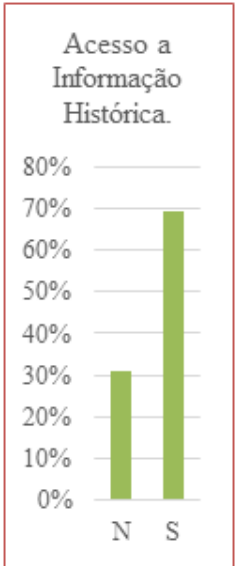

Para o mapeamento do local: podemos identificar que os locais mais citados foram a ilha dos macacos e grandes mamíferos com $43 \%$ e $42 \%$ respectivamente, $39 \%$ o recinto do elefante, $37 \%$ a trilha, $36 \%$ para o serpentário e as aves, e os Falconiformes com 29\%. Também consideram que a sinalização das placas é boa para $55 \%$, regular para $24 \%$ e ótima para $19 \%$. E ainda que $79 \%$ consideram fácil localizar os recintos. Demonstrados nos Gráfico 5: Locais Mais Citados Pelos Visitantes, Gráfico 6: Sinalização das Placas de Orientação, respectivamente. E na questão sobre os animais: $26 \%$ entendeu que os animais são capturados pelo IBAMA e 13\% são doados ou abandonados no espaço e os demais escolheram mais de uma alternativa.

Gráfico 4: Qual o Tipo de Informação.

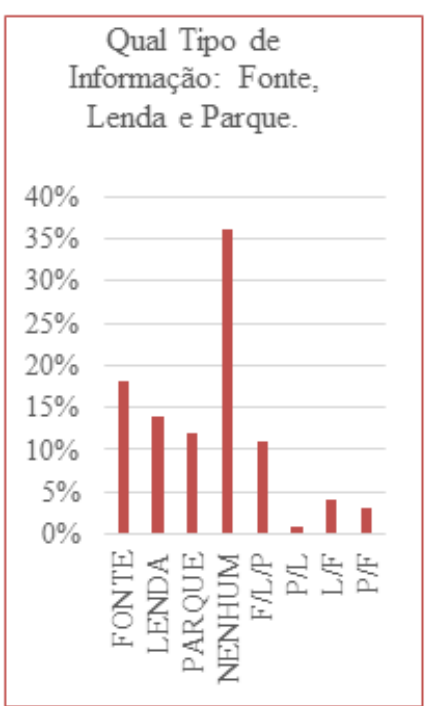

Gráfico 5: Locais Mais Citados Pelos Visitantes.

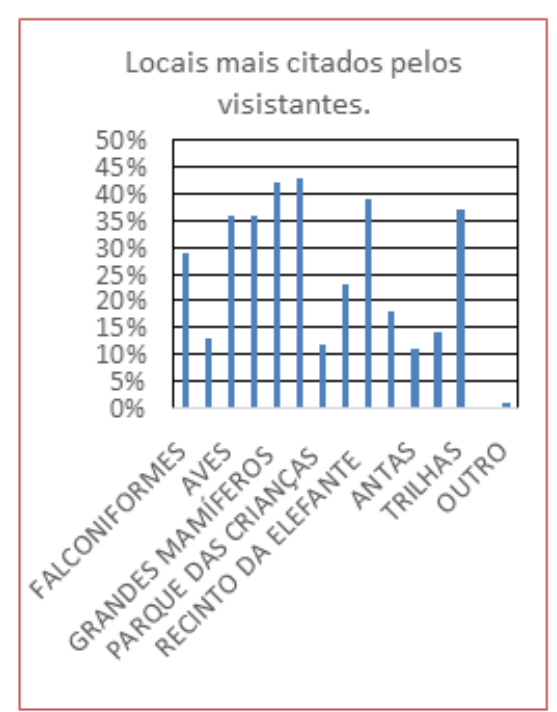

Gráfico 6: Sinalização das Placas de Orientação.

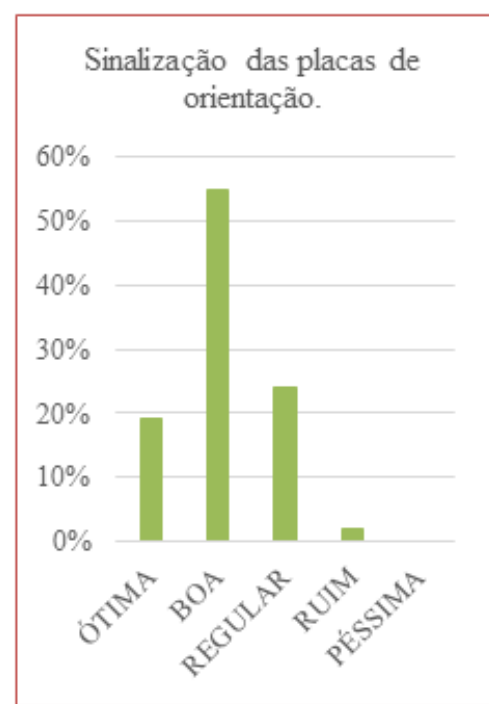


Tais informações nos levam a entender que o público participante tem maior interesse em obter conhecimento e estar próximo à natureza, uma parcela considerável desse público tem conhecimento sobre os fatos históricos, porém é necessário ressaltar e divulgar com maior amplitude os fatos relacionados à lenda indígena que envolve a concepção do Parque e o histórico do local. Pois são indicadores que retratam momentos cronológicos importantes como a ocupação dos indígenas e a forma de identificar suas características, valores e quais os motivos que levaram a construção do parque e os que o mantem, pois hoje é um local de conservação e estudos aplicados, como também outros momentos que ocorreram no espaço.

A questão de os participantes entenderem que os animais são capturados pelo IBAMA (Instituto Brasileiro), nos leva a uma reflexão, que essa captura foi ocasionada pela degradação que os ambientes nos quais estavam os animais sofreu ou vem sofrendo, deixando em evidência os impactos causados pela ação humana. E para o mapeamento do local, apesar da boa indicação das placas e que a localização dos recintos é fácil, deve-se ressaltar que durante as conversas informais e na questão de sugestões ao parque a melhoria no espaço é muito citado e a presença de mais guias é cobrada para que se possa conhecer outros espaços, como também é falado da dificuldade de andar sozinho pelo mesmo, pois a maioria dos locais mais citados está próximo e que muitas vezes não conhecem outros espaços pela má qualidade das placas ou pela falta de um mapa mais acessível. Por fim, as informações adquiridas (Histórico, cultural, serviços ecossistêmicos e mapas), ficarão expostas em banners, em locais estratégicos e visíveis a todos que circulam o ambiente. Espera-se, com estas ações interventivas, estar se edificando uma nova relação da comunidade com o Parque de modo a valorizá-lo na sua essência e, assim, estabelecendo novas significâncias a sua convivência com o ambiente.

\section{CONSIDERAÇÕES}

Os espaços verdes urbanos tendem a se tornar mais valorizados neste século, considerando a necessidade humana de voltar a identificar-se com a natureza e reconhecer seus valores para a qualidade de vida no planeta. Esta concepção mobilizou o estudo e nos levou a entender que com as aulas o público foi possível compreender de forma clara e fácil sobre o histórico dos animais, a explicação de sua presença no parque e outras curiosidades.

As mudanças de visão ocorridas nos órgãos públicos e acadêmicos para com as atividades educativas desenvolvidas nos zoológicos são perceptíveis, pois se verifica que os investimentos nas equipes que trabalham e as pesquisas com essa temática é grande é continuo, a exemplo do local de estudo. Assim, como a estrutura administrativa e física que se adequam as necessidades do público que o frequenta e dos animais que ali estão.

Para o público que procura pelos zoológicos o cuidado deve ser presente e atualizado sempre buscando mais informações para suprir os questionamentos levantados, pois muitos dos visitantes ainda têm em mente ideias destoantes do real motivo que fizeram os animais estar ali, assim como a função do parque. As aulas são de essencial importância para se entender todo o contexto da presença dos animais, o que nota-se que essa interação com os alunos os deixam motivados a proteger os animais, plantas e o próprio local, pois entendem que o lugar é extensão de conhecimento, laser e a proximidade com a sua história e a do município.

Ao fim esperar-se que possam ficar motivados e colaborar como a proteção dos animais e plantas do próprio local, levando esse entendimento para outros espaços e que entendam que o espaço é também local de conhecimento, lazer e um elo de aproximação com sua história e a do município.

\section{REFERÊNCIAS}

[1] ACHUTI, M. R. N. G. O Zoológico como Ambiente Educativo para Vivenciar o Ensino de Ciências. Dissestação de Mestrado. Itajaí (SC) 2003. 68 P.

[2] CARVALHO, I.C.M. Educação Ambiental: a formação do sujeito ecológico. 6ª ed. São Paulo: Cortez, 2012.

[3] Diagnostico Ambiental do Parque Zoobotânico Arruda Câmara. Relatório de Visita Técnica/DIEP 008. Portaria no 028/2005. Estado da Paraíba. Prefeitura Municipal de João Pessoa. Secretaria de Meio Ambiente. Diretoria de Estudos e Projetos Ambientais. Divisão de Pesquisas Ambientais. Diretoria de Controle Ambiental. João Pessoa: Divisão de Botânica, 2006.

[4] FREIRE, P. Pedagogia do oprimido. Rio de Janeiro: Paz e Terra, 2003. 
[5] GARCIA, V. A. R. (2006). O processo de aprendizagem no Zoológico de Sorocaba: análise da atividade educativa visita orientada a partir dos objetos biológicos. Dissertação (Mestrado em Educação) - Faculdade de Educação da Universidade de São Paulo. $224 \mathrm{f}$

[6] GUTIERREZ, Francisco; PRADO, C Ecopedagogia e Cidadania Planetaria-3 ed-São Paulo: Instituto Freire, 2002

[7] MENDONÇA, RITA. Encontros e Caminhos: Formação de Educadoras(es) Ambientais e Coletivos Educadores Volume 2. Luiz Antonio Ferraro Júnior, organizador. - Brasília: MMA, Departamento de Educação Ambiental, 2007. V.2. $120 \mathrm{p}$.

[8] MORIN, EDGAR. Educar na Era Planetária - o pensamento complexo como método de aprendizagem pelo erro e incerteza humana/elaborado para a UNESCO por Edgar Morin, Emílio Roger Ciurana,;Raúl Domingo Motta. 2. ed. Tradução Sandra TrabuccoValenzuela. Revisão técnica da tradução Edgard de Assis Carvalho. São Paulo: Cortez; Brasília, DF: UNESCO, 2007.

[9] PZAC, Parque Zoobotânico Arruda Câmara. Guia do Visitante. Material informativo impresso. Secretária do Meio Ambiente. Prefeitura Municipal de João Pessoa. João Pessoa: SEMAM/PMJP, 2014

[10] Prefeitura Municipal de João Pessoa- Secretaria de Meio Ambiente. Parque zoobotânico arruda Câmara- Kit Estagiário- leitura Obrigatória.

[11] TUAN, YI-FU. Topofilia, um estudo da percepção, atitudes e valores do meio ambiente. Ed. Difel. São Paulo Rio de Janeiro. 1980 


\section{Capítulo 15}

\section{AS DIMENSÕES DO COMPORTAMENTO AMBIENTAL DOS CONSUMIDORES NO DISTRITO FEDERAL}

\section{Elivaldo Ribeiro de Santana}

Resumo: 0 comportamento do consumidor não costuma ser medido diretamente, pois, sua construção é influenciado por vários aspectos, igualmente, sua consciência ecológica também manifestada no comportamento, precisa ser medida em seus aspectos individuais nas práticas socioambientais de responsabilidade para com os impactos provocados por seu consumo. 0 intuito deste trabalho foi analisar o comportamento ambiental dos consumidores no Distrito Federal identificando as dimensões representativas do comportamento, e assim, entender sua contribuição para a sustentabilidade no consumo. Para tanto, realizou-se a aplicação de um questionário obtendo a participação de 131 respondentes que residem no Distrito Federal e fez-se o uso do software SPSS 20.0 para uma análise fatorial. Após a análise dos dados, foi possível identificar quatro dimensões explicativas do comportamento ambiental dos consumidores no Distrito Federal, assim entende-se que o comportamento ambiental para o consumo no Distrito Federal é influenciado pela consciência ecológica relativa à preocupação com o lixo, reação nos hábitos, consumo racional e compra esperta.

Palavras-chave: Consumidor, consciência ecológica, comportamento ambiental. 


\section{INTRODUÇÃO}

Dispertas pela percepção dos desequilíbrios ambientais, crescente ao longo dos anos, as pessoas almejam a qualidade ambiental e aspiram por instrumentos alternativos com enfoque sustentável (SEIFERT, 2011). A crise ambiental vem sendo assimilada gradualmente pela sociedade e seus impactos negativos na vida diária desperta desdobramentos nas ações possíveis de consciência ecológica.

Para Moser (1983), o despertamento de consciência ecológica sempre está associado a fatos, os mais notáveis são a poluição, o crescimento demográfico, ameaças ao progresso, a miséria e a fome no mundo. Os atores envolvidos nesse ambiente de discussão apontam para a perspectiva de superação desses problemas de fundo, manifestando - se favoravelmente tanto com a mudança nos hábitos de consumo quanto nos hábitos pós - consumo.

O desafio imposto pela nova realidade ecológica requer a percepção do consumo como uma das formas de abuso contra a natureza. Para Chauvel e Suarez (2009), a dinâmica acelerada de consumo trouxe impactos para o meio ambiente e a vida dos indivíduos, gerando questões sobre o poder de compra ampliado. 0 modo de consumo atual tem sido influenciado pelo cunho ambiental da sensibilidade ecológica, inquietando o ambiente político e empresarial que observa nesse movimento social o risco de resistência ao consumo ou posicionamentos orientados para a minimização dos impactos do produto e o próprio descarte.

Alphandéry, Bitoun e Dupont (1992) argumentam que existe um consenso ecológico amplo, as correntes de opiniões políticas, científicas, industriais e consumidores estão pensando verde, em proteger a terra, vender produtos limpos e mudar comportamentos respectivamente. Os atores sociais estão pactuando pela sensibilidade ambiental e materializando isso em ações ecologicamente adequadas, nesse sentido, a consciência ecológica avança rumo à consistência ideológica através de atitudes individuais e pontuais, a transformação do comportamento do consumidor pode ser observável em suas percepções ambientais.

Para Giglio (1996, p.34) "Perceber é, portanto, um ato de seleção, de análise e síntese dos estímulos que entramos em contato no fluir de nossa vida. É esta seleção e análise que orienta nossas ações". A capacidade de discernir a crise ambiental e suas tantas possibilidades de enfrentamento, coloca o consumidor em alerta e seu comportamento de consumo pode se tornar igualmente mutável contribuindo para novas opções de ordenamento do comportamento ambiental para o consumo.

Giglio (1996) comenta ainda que na vida temos que escolher entre opções de ordem e superação dos limites, que as alternativas de comportamento inclusive de consumo, dependem da forma como os estímulos do mundo relacionam-se com nossos planos ou expectativas de vida. As transformações que tem motivado o indivíduo cada um a seu modo, revelam a emergência do consumo consciente como opção de ordem expressa no interesse individual pela causa ambiental e os apelos que a chancela da sustentabilidade trouxe aos que buscam a superação dos limites com a mudança de comportamento.

A extensão do diálogo sobre as experiências de consumo faz do consumidor um elemento adequado na definição de dimensões da consciência ecológica. Para entender o comportamento do consumidor como um dos elementos chave do consumo consciente, suas ações precisam ser codificadas para que haja clareza daquilo que traduz a racionalidade de suas ações efetivas frente ao contexto ambiental atual.

\section{OBJETIVO}

O objetivo deste trabalho foi analisar o comportamento ambiental dos consumidores no Distrito Federal identificando as dimensões representativas da consciência ecológica.

\section{METODOLOGIA}

\subsection{MATERIAL}

O instrumento de coleta dos dados foi um questionário utilizado por Almeida et. al. (2012), adaptação similar à escala de comportamento da consciência ecológica proposto por Straughan e Roberts (1999), a reaplicação da escala original já foi feita em vários contextos inclusive o brasileiro para avaliação do nível de consciência ecológica dos consumidores.

0 questionário foi estruturado com 15 questões indicadoras do comportamento ambiental das pessoas como mostra a (figura 1) com suas respectivas médias (M) e desvios padrão (DP). 0 levantamento foi realizado com pessoas residentes na cidade de Brasília-DF no ano de 2014, as questões foram pontuadas 
por uma escala de valor do tipo Likert de cinco pontos variando de "nunca faz" à "sempre faz", sendo o ponto três "as vezes faz" de valor neutro, pois compreende uma indecisão. A amostra foi composta por 131 respondentes selecionados ao acaso ou por conveniência.

Figura 1: Estrutura do questionário que mensurou o comportamento ambiental dos entrevistados.

\begin{tabular}{|l|l|}
\hline $\begin{array}{c}\text { 1) Para cada uma das situações abaixo coloque a NOTA: } \\
\text { 1 se você NUNCA FAZ a situação apresentada }\end{array}$ \\
2 se você DIFICILMENTE FAZ a situação apresentada \\
3 se você AS VEZES FAZ da situação apresentada \\
4 se você FREQUENTEMENTE FAZ da situação apresentada \\
5 se você SEMPRE FAZ da situação apresentada
\end{tabular}

\subsection{MÉTODO}

0 tratamento dos dados foi realizado através do método de análise fatorial exploratória com o uso do software SPSS (Statistical Package for the Social Sciences) versão 20.0. A análise fatorial foi de interesse deste estudo porque facilita o alcance do objetivo proposto, segundo Hair et. al. (2005, p. 388) a análise fatorial "é uma técnica multivariada que pode sintetizar as informações de um grande número de variáveis em um número muito menor de variáveis ou fatores". Segundo Malhotra (2012), a representação do modelo de análise fatorial pode ser descrito como:

$\mathrm{Xi}=\mathrm{Aij} \mathrm{F} 1+\mathrm{Ai} 2 \mathrm{~F} 2+\mathrm{Ai} 3 \mathrm{~F} 3+\ldots+$ Aim Fm + ViUi equação (1)

Onde:

$\mathrm{Xi}=$ iésima variável padronizada

Aij = coeficiente padronizado de regressão múltipla da variável i sobre o fator comum j

$\mathrm{F}=$ fator comum

$\mathrm{Vi}$ = coeficiente padronizado de regressão da variável i sobre o fator único i

Ui = o fator único para a variável i

$\mathrm{m}=$ número de fatores comuns

0 método de análise fatorial sintetiza as relações pouco visíveis das variáveis em estudo, assemelhando as cargas fatoriais e melhorando a compreensão dos dados.

A análise fatorial 
Antes da realização do procedimento de análise fatorial, foi feita uma análise preliminar das questões indicadoras de consciência ecológica, com isso julgou - se conveniente excluir a variável V14 "Para diminuir a poluição, eu uso meu carro o mínimo possível” em conformidade com Field (2009) e Hair et. al. (2009), esses dois autores concordam que a análise irá sempre encontrar uma solução fatorial conjunta para as variáveis, assim as perguntas precisam medir a mesma dimensão conceitual, os autores usam a expressão "se entra lixo, sai lixo".

Realizou-se uma primeira análise fatorial utilizando o método de componentes principais visando obter a totalidade das informações e a rotação ortogonal VARIMAX para maximizar as cargas, suprimiu-se os coeficientes inferiores a 0,50 devido ao tamanho da amostra (HAIR et. al., 2009). Foram identificados quatro dimensões que explicam $57,87 \%$ da variância total dos casos analisados. Porém após examinar a tabela de comunalidades, considerou-se a exclusão de quatro variáveis por apresentarem níveis não aceitáveis de explicação, extração abaixo de 0,50 que significa explicação inferior a $50 \%$ e não desejado para o estudo.

Obteve - se também os seguintes indicadores de adequação da amostra como o índice KMO que atingiu o valor 0,775 indicando que a explicação dos dados através das dimensões encontradas é adequado, o índice é considerado satisfatório conforme Hair et. al. (2009), o teste de esfericidade de Bartlett's apresentou um valor de 463, 226 ( $\mathrm{p}<0,0001)$ Esses valores e o sinal de significância indicam que a análise fatorial exploratória dos dados é adequada e existem relações suficientes entre as variáveis.

As variáveis com comunalidades inferiores a 0,50 foram: V1=0,459 "procuro comprar eletrodomésticos que consumam menos energia", V4=0,490 "tenho tentado reduzir o consumo de energia elétrica na minha casa", V11= 0,373 "procuro comprar alimentos orgânicos em vez de alimentos cultivados com agrotóxicos" e V15= 0,298 "costumo aproveitar o verso das folhas já utilizadas para não desperdiçar papel”, essas variáveis não tem explicação suficiente por isso foram eliminadas (Hair et. al., 2009). A exclusão dessas variáveis possibilitará aumentar o poder de explicação da variância total.

Na segunda análise com as dez variáveis que restaram, o índice KMO apresentou valor de 0,735 inferior ao da primeira análise, o teste de esfericidade de Bartlett's foi 282,096 ( p<0,0001) esses resultados mantém a indicação de adequação do método de análise fatorial, as comunalidades das variáveis estão todas com valores acima 0,60. 0 critério do número de fatores a ser extraído foi o da raiz latente ou autovalor (eigenvalue $=1$ ), assim, entende - se que cada fator encontrado e especialmente o último fator possui um montante de variação que explica suficientemente as dimensões encontradas.

\section{RESULTADOS}

A redução dos dados permitiu extrair quatro dimensões que conseguem explicar 68,35\% da variância total, as comunalidades estão num intervalo de 0,612 a 0,862 todas ao nível de explicação considerada significante como mostrado na tabela 1.

Tabela 1: Matriz rotacionada dos componentes.

\begin{tabular}{|l|l|l|l|l|l|}
\hline Componente (s) dos fatores & $\begin{array}{l}\text { Preocupação } \\
\text { com o lixo }\end{array}$ & $\begin{array}{l}\text { Reação nos } \\
\text { hábitos }\end{array}$ & $\begin{array}{l}\text { Consumo } \\
\text { racional }\end{array}$ & $\begin{array}{l}\text { Compra } \\
\text { esperta }\end{array}$ & Comunalidades \\
\hline $\begin{array}{l}\text { Var2: Procuro comprar } \\
\text { produtos que tenham o } \\
\text { mínimo dembalagem. }\end{array}$ & 0,792 & & & 0,674 \\
\hline $\begin{array}{l}\text { Var8: Procuro comprar } \\
\text { produtos com embalagens } \\
\text { reutilizáveis. }\end{array}$ & 0,787 & & & 0,739 \\
\hline $\begin{array}{l}\text { Var3: Quando posso escolher, } \\
\text { opto pelo produto que } \\
\text { contribui menos para a } \\
\text { poluição ambiental. }\end{array}$ & 0,745 & & & 0,612 \\
\hline $\begin{array}{l}\text { Var6: Eu utilizo um centro de } \\
\text { reciclagem ou, de alguma } \\
\text { forma, separo e reciclo o lixo } \\
\text { da minha casa. }\end{array}$ & & 0,791 & & & \\
\hline
\end{tabular}


Tabela 1: Matriz rotacionada dos componentes.

(continuação...)

\begin{tabular}{|c|c|c|c|c|c|}
\hline & $\begin{array}{l}\text { Preocupação } \\
\text { com o lixo }\end{array}$ & $\begin{array}{l}\text { Reação nos } \\
\text { hábitos }\end{array}$ & $\begin{array}{l}\text { Consumo } \\
\text { racional }\end{array}$ & $\begin{array}{l}\text { Compra } \\
\text { esperta }\end{array}$ & Comunalidades \\
\hline $\begin{array}{l}\text { Var5: Já mudei meus hábitos } \\
\text { de consumo de determinados } \\
\text { produtos por razões } \\
\text { ecológicas. }\end{array}$ & & 0,766 & & & 0,701 \\
\hline $\begin{array}{l}\text { Var7: Já tentei convencer } \\
\text { familiares ou amigos a não } \\
\text { comprarem } \\
\text { prejudiciais } \\
\text { ambiente. }\end{array}$ & & 0,647 & & & 0,655 \\
\hline $\begin{array}{l}\text { Var12: Sempre respeito à } \\
\text { indicação das lixeiras para } \\
\text { reciclagem no descarte do } \\
\text { meu lixo. }\end{array}$ & & 0,517 & & & 0,649 \\
\hline $\begin{array}{l}\text { Var10: Fecho a torneira } \\
\text { enquanto escovo os dentes }\end{array}$ & & & 0,789 & & 0,685 \\
\hline $\begin{array}{l}\text { Var9: Evito deixar a lâmpada } \\
\text { acesa em ambiente } \\
\text { desocupados. }\end{array}$ & & & 0,769 & & 0,615 \\
\hline $\begin{array}{l}\text { Var13: Eu compro o produto } \\
\text { mais barato, não importa o } \\
\text { seu impacto ao meio } \\
\text { ambiente. }\end{array}$ & & & & 0,914 & 0,862 \\
\hline
\end{tabular}

A dimensão 1 "preocupação com o lixo" é a mais importante e explica 31,53\% da variância extraída, seguidos em ordem decrescente de valor pela dimensão 2 "reação nos hábitos" - 14, 41\%, dimensão 3 "consumo racional" - 11,99\% e dimensão 4 "compra esperta"- 10,42\% de explicação da variância respectivamente, mostrando assim a distribuição do poder de explicação das dimensões identificadas conforme a figura 1.

Figura 1: Porcentagem de explicação conceitual das dimensões encontradas.

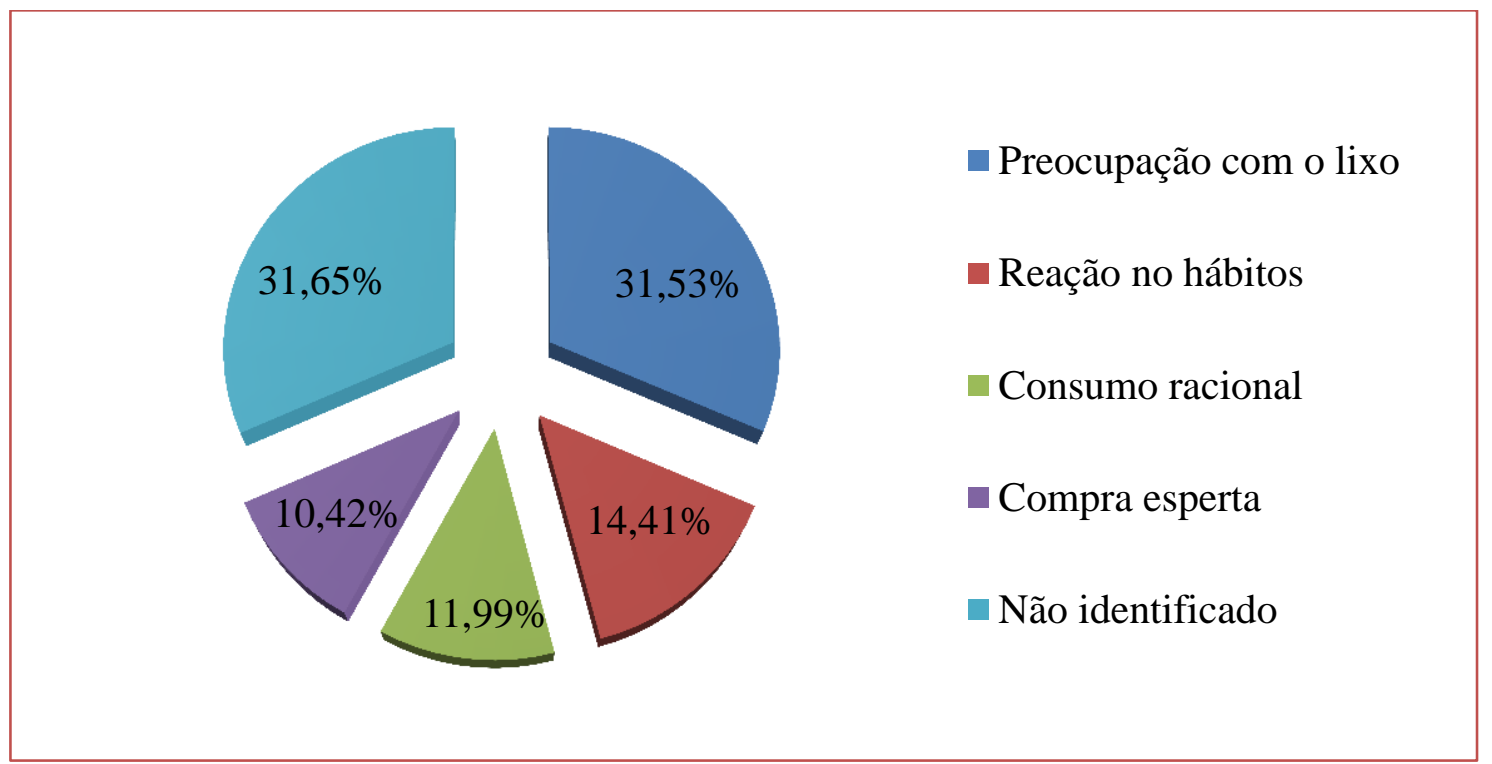




\section{CONCLUSÕES}

A preocupação com o lixo no Distrito Federal faz parte do cotidiano das pessoas como geradoras e coresponsáveis pela disposição adequada do lixo produzido. 0 forte argumento da reciclagem que ganha força nos espaços públicos e na sociedade em geral tem transformado esse tema num assunto de suma importância e consequentemente, isso está inserido no ideário das pessoas. Os escândalos econômicos e a exclusão social dos catadores é outra discussão em torno da gestão do lixo que vem alimentando o assunto e marcando presença na vida e na memória das pessoas determinando alguns comportamentos. Esse fator está conforme a dimensão "reciclagem" de Grohmann, et. al. (2012), a autora argumenta que essa consciência refere-se à preocupação em utilizar apenas produtos que possam ser reciclados ou que de alguma forma possam ser reutilizados.

A reação nos hábitos vem indicando justamente as ações que as pessoas estão adotando em seus hábitos domésticos em relação à separação do lixo e a pretensão de buscar cooperativas de catadores para entrega do material reciclável, no cotidiano social dos consumidores também existe a pretensão de respeito à indicação das cores das lixeiras de reciclagem ou apenas a presença delas nos espaços públicos para o descarte adequado do lixo. A reação nos hábitos pode estar no âmbito do comportamento pessoal e inclusive sendo repassado a outras pessoas com o convencimento de familiares ou amigos. Esse fator está conforme a dimensão "comportamento planejado" de Tódero (2009), a autora argumenta que tal comportamento resulta em benefícios de médio prazo para o consumidor e está associado à reflexão sobre suas praticas de consumo que é diferente dos benefícios diretos.

O consumo racional é motivado por razões econômicas, a economia doméstica alcançada com a redução do consumo de água e energia tem um benefício imediato no aspecto econômico da organização das famílias, além disso, a redução do consumo desses recursos no Distrito Federal é influenciada com subsídios para os consumidores na conta de energia e cálculo diferenciado na conta de água. Esse fator está conforme a dimensão "práticas de economia doméstica" de Tódero (2009), a autora afirma que o não desperdício dos recursos é uma prática que envolve benefícios diretos e imediatos para o individuo.

A compra esperta é parte da preocupação das famílias consumidoras com a renda insuficiente para aquisição de produtos inflacionados que em sua maioria compõe a cesta básica. 0 consumidor da capital brasileira paga até $19 \%$ mais caro pela cesta básica em comparação com a capital que tem o menor preço (ESTADÃO, 2011). Por isso, os consumidores podem optar por não comprar das marcas lideres em vendas e administrar seus salários comprando produtos mais baratos para compensar a lista de itens. Esse comportamento em parte pode oferecer um risco ao crescimento do consumo ecológico, os produtos ecologicamente adequados são diferenciados e geralmente mais caros que os convencionais, a disposição por não pagar mais por um produto ecologicamente correto pode ser uma barreira a ser superada no Distrito Federal.

As dimensões encontradas neste presente trabalho podem indicar espaços de aproximação para os programas de educação ambiental pública e privada junto aos consumidores no Distrito Federal.

\section{REFERÊNCIAS}

[1] ALMEIDA, A. N. de.; ANGElO, H.; SILVA, J. C. G. L. Comportamento das pessoas diante de ações ecologicamente adequadas. In: CONGRESSO BRASILEIRO DE GESTÃO AMBIENTAL, 3, 2012. Goiânia. Disponível em: http://www.ibeas.org.br/congresso/Trabalhos2012/XI-007.pdf. Acesso em 27 nov. 2013.

[2] ALPHANDÉRY, Pierre; BITOUN, Pierre; DUPONT, Yves. O equívoco ecológico: Riscos políticos da inconsequência. Tradução de Lúcia Jahn. São Paulo: Ed. Brasiliense, 1992.

[3] CHAUVEL, Marie Agnes; SUAREZ, Maribel Carvalho. Consumo, Marketing e Sustentabilidade. In: Chauvel, Marie Agnes \& Cohen, Marcos. (orgs.). Ética, sustentabilidade e sociedade: desafios da nossa era. Rio de Janeiro: Mauad $\mathrm{X}, 2009$, p. 161-174.

[4] FIELD, Andy. Descobrindo a estatística usando o SPSS. Tradução de Lorí Viali. 2. ed. Porto Alegre: Artmed, 2009.

[5] GIGLIO, Ernesto. O comportamento do consumidor e a gerência de marketing. São Paulo: Pioneira, 1996.

[6] HAIR, J. F. et. al. Fundamentos de métodos de pesquisa em administração. Tradução de Lene Belon Ribeiro. Porto Alegre: Bookman, 2005.

[7] HAIR, Jr. J. F. et. al. Análise multivariada da dados. Tradução de Adonai Schlup Sant'Anna. 6. ed. Porto Alegre: Bookman, 2009 
[8] MALHOTRA, N. K. Pesquisa de Marketing. Uma orientação aplicada. Tradução de Lene Belon Ribeiro, Monica Stefani. 6. ed. Porto Alegre: Bookman, 2012.

[9] MOSER, Antônio. O problema ecológico e suas implicações éticas. Rio de Janeiro: Vozes, 1983.

[10] PETRY, Rodrigo. "Inflação justifica pesquisa de preços pelo consumidor". O Estado de São Paulo, São Paulo, 29 agos. 2011. Disponível em: . Acesso em 23 mai. 2014.

[11] SEIFFERT, Mari Elizabete Bernardini. Gestão ambiental: instrumentos, esferas de ação e educação ambiental. 2. ed. São Paulo: Atlas, 2011.

[12] STRAUGHAN, R. D.; ROBERTS, J. Environmental segmentation alternatives a look at green consumer behavior in the new millennium. The Journal of Consumer Marketing: Santa Barbara, v. 16, n. 6, p. 558, 1999.

[13] TÓDERO, Mirele. Consumo consciente e percepção do consumidor sobre as ações corporativas vinculadas ao conceito de responsabilidade social: um estudo no setor da saúde. 2009. 172 f. Dissertação (Mestrado em Administração) - Universidade de Caxias do Sul, Caxias do Sul, 2009.

[14] GROHMANN, M. Z., et. al. Comportamento ecologicamente consciente do consumidor: adaptação da escala ECCB para o contexto brasileiro. São Paulo, 2012. Disponível em: . Acesso em 27 ago. 2014. 


\section{Capítulo 16}

\section{INOVAÇÃO EM REDE SOCIO TÉCNICA: UM NOVO PROJETO SOCIAL PARA AGRICULTURA FAMILIAR ECOLÓGICA?19}

\section{Lucimar Santiago de Abreu \\ Stéphane Bellon}

\section{Tercia Zavaglia Torres}

Resumo: 0 tema da agroecologia enquanto projeto social para a agricultura contemporânea visa o respeito ao meio ambiente tende, a contribuir para a discussão das questões agrárias associadas às soluções inovadoras de problemas cruciais ligados ao emprego, a soberania alimentar, a preservação dos agroecosistemas. A agroecologia é fruto de interações e diálogos intensos entre atores sociais que desempenham papel chave para a sua legitimidade social e política, sendo também fruto de experiências práticas de agricultura ecológica. Tais características impulsionaram o seu processo de institucionalização e a construção de políticas públicas. Entretanto, o avanço da agroecologia é marcado por dificuldades que comprometem a disseminação ampla desta importante prática social. Tendo em vista esta realidade o presente artigo tem como objetivo descrever a emergência e o funcionamento da agroecologia em redes sócio técnicas considerada como inovação social. Concluímos que a dinâmica de funcionamento das redes de agroecologia se baseiam na abertura à participação da sociedade civil, a criação de interfaces com um conjunto de instituições da sociedade através de ações coletivas e projetos de desenvolvimento rural, mas o êxito destas ações depende do suporte das políticas públicas.

Palavras-chave: projeto social, desenvolvimento rural, políticas públicas 


\section{INTRODUÇÃO}

Este estudo parte da observação de um cenário de mudanças sociais, políticas e de desenvolvimento da agroecologia no Brasil, mas foi a partir da década de 1980, que o modelo agroindustrial da agricultura denominado ora, convencional passou a ser fortemente questionado e apresentado como um problema crítico para a sustentabilidade e, em especial, para a agricultura familiar. A agroecologia teve sua origem no movimento social em que defendia uma alternativa para a agricultura (ecológica, orgânica, biodinâmica, natural, etc.) evoluiu progressivamente buscando integrar à dimensão social, política e ética para o conceito de agroecologia. A agroecologia no mundo científico tem tido uma multiplicidade de interpretações. Para Altieri (2001), um dos autores pioneiros do campo da agroecologia, ela é a ciência que estuda os agroecossistemas ou as unidades agrícolas de forma abrangente nas quais ocorrem os ciclos minerais, as regulações biológicas, as transformações energéticas e, toma em conta as relações sociais, econômicas e culturais. Segundo o autor, as experiências agroecológicas não são recentes, remontam a 5000 mil anos, uma característica notável desses sistemas era o grau de diversidade das plantas, geralmente na forma de policultivos e ou padrões agroflorestais. A agroecologia é também interpretada como disciplina científica, práticas e movimentos sociais (WEZEL, A. et al. 2009).

No Brasil, Brandenburg (2002), identificou-se três importantes fases: i) a emergência de um movimento contra a industrialização da produção agrícola; ii) o surgimento de novos grupos e de formas de organização social; iii) a institucionalização da agricultura ecológica, acompanhada por uma diluição parcial de seus princípios. Contudo, atualmente, observamos um quarto momento de redefinição e de recomposição de diferentes versões da agricultura alternativa, no qual a agroecologia ocupa um lugar importante e influencia outras agriculturas e o desenvolvimento rural (Ollivier \& Bellon, 2013).

Na atualidade, o modelo convencional convive como o significativo aumento do número de iniciativas e experiências agroecológicas no Brasil, caracterizadas por uma diversidade de estilos de agricultura ecológica (Abreu, et al. 2012). Esse universo social alternativo é protagonizado por produtores e produtoras familiares, técnicos, acadêmicos, organizações sociais, estudantes e agentes da extensão rural que se organizam em redes ou núcleos de agroecologia, constituindo um dispositivo de ação coletiva. Esses "dispositivos" aos poucos se transformam em campo fértil de oportunidades para construir projetos, formalizar e fortalecer redes de parceiros. Portanto, a agroecologia é resultado de uma trajetória social e histórica de um projeto de desenvolvimento alternativo e da tentativa de encontrar respostas aos impactos sociais, econômicos e ecológicos da produção convencional (Abreu \& Bellon, 2013). Por projeto social entende se a construção e aspiração de um novo modelo de desenvolvimento da agricultura, que integra a diversidade de estilos agroecossistemas, onde a ecologia e a justiça social encontram-se no coração do desenvolvimento da economia. Esse modelo integra a diversidade de estilos agroecossistemas.

No Brasil, "dois" modelos de agricultura se confrontam - convencional ou agroindustrial e alternativo inspirado em princípios da agroecologia - neste sentido, a agroecologia pode ser uma oportunidade para construir um projeto de desenvolvimento para a agricultura, mais justo socialmente e equilibrado do ponto de vista ecológico. Os princípios orientadores da agroecologia se diferenciam daqueles da agricultura orgânica, apesar de ocorrer elementos comuns às ambas (Abreu, et al. 2012; Migliorini \& Wezel, 2018). Atualmente o setor dominante da agricultura convencional se posiciona também, à sua maneira, em torno de outras interpretações do conceito de agroecologia (agricultura de baixo carbono controle biológico, plantio direto, etc.). A questão da escala em agroecologia, também coloca questões cruciais: Ao mesmo tempo, em termos de público focal (camponês, agricultor familiar, quilombolas, assentamentos...) portanto, seria a agroecologia aplicada somente para a agricultura familiar? Ou para o conjunto dos produtores do mundo rural? Ou ainda, a agroecologia é um modelo de agricultura concorrente com o convencional ou são modelos coexistentes sem ocorrência de prejuízos para ambos? Esse conjunto de questões, sem dúvidas, devem ser estudadas, empiricamente, tendo em conta a existência de situações distintas em cada localidade; tipos de agricultores e modelos ou estilos de agricultura.

A partir de 2013, a emergência e o fortalecimento das redes de agroecologia foram impulsionados através do lançamento de um conjunto de políticas desenhadas para promover mudanças no modo de produzir alimentos, com vista à proteção dos recursos naturais (Plano Nacional de Agroecologia e Produção Orgânica - PLANAPO). Lançado em 17/11/2013, desdobramento do Decreto da Presidente Dilma R. DECRETO № 7.794, DE 20 DE AGOSTO DE 2012, da Política Nacional de Agroecologia e Produção Orgânica - PNAPO. Esta política tem o objetivo de integrar, articular e adequar políticas, programas e ações indutoras da transição agroecológica e da produção orgânica e de base agroecológica. Entretanto, se o avanço da Agroecologia depender exclusivamente deste suporte, o futuro é ainda incerto. 
Portanto, esse trabalho tem como objetivo geral destacar o atual processo da institucionalização da agroecologia em redes sócio técnicas, o lugar ocupado pelos agricultores, técnicos, pesquisadores e consumidores no processo de transição agroecológica. Compreendemos a institucionalização como a estabilização de redes e, não simplesmente, no sentido formal do termo. Essa preocupação científica se encontra no coração da sociologia que questiona o impacto das políticas públicas agrícolas sobre consumidores ou cidadãos e comunidades rurais.

Para tanto, o artigo visa contribuir para a reflexão em torno da institucionalização da agroecologia em redes sócio técnicas. Primeiramente apresenta-se uma descrição densa da noção de redes sociais visando entender o funcionamento dos coletivos de agroecologia, em seguida, indica os elementos do contexto social e político que contribuíram para a emergência e o desenvolvimento social das redes de agroecologia e, conclui apontando para a sua originalidade em termos de proposta de desenvolvimento rural e, abertura à participação da sociedade civil, a criação de interfaces com um conjunto de instituições da sociedade através de ações coletivas e projetos de desenvolvimento rural e, apresenta novas questões que emergem ainda nesse campo de investigação.

\section{METODOLOGIA}

A problemática da institucionalização de redes sócio técnicas é fruto do desdobramento de pesquisas desenvolvidas no projeto "Agroecologia na França e no Brasil: entre redes científicas, práticas, movimentos sociais e políticas públicas" (acordo CAPES/COFECUB n. 716/2011- 2015). Cuja metodologia envolvia conhecimentos multidisciplinares especialmente no campo da agronomia e da sociologia.

Este trabalho científico especificamente apoiou-se na abordagem teórica e metodológica denominada sociologia compreensiva cuja fonte de inspiração principal é baseada na contribuição de Max Weber, (2004), redefinida e aplicada aos pressupostos teóricos da pesquisa desenvolvida por (Abreu, 2005). A sociologia compreensiva é uma abordagem metodológica de pesquisa que busca compreender a ação social, considerando o indivíduo e suas interações como ponto chave da investigação, para compreender as interações e relações sociais considerar elementos da dimensão econômica, normas morais e valores socioculturais.

Além disto, contou-se neste trabalho com a contribuição da produção e conhecimento disciplinar da agroecologia. Foi conduzida primeiramente, a partir de análise geral da questão e das observações realizadas em eventos, visitas às redes agroecológicas em diversas regiões do país (SP, SC, RJ e DF). Enriquecidas por entrevistas realizadas com alguns dos líderes do movimento agroecológico e pela revisão de documentos e da literatura.

\section{RESULTADOS E DISCUSSÕES}

\subsection{ASPECTOS TEÓRICOS CONCEITUAIS EM TORNO DE REDES SÓCIO TÉCNICAS}

O conceito de rede é utilizado nas ciências sociais há décadas, portanto não é um conceito novo. Autores como Radcliffe-Brown (1952) e Castells (2003) argumentam que a dinâmica da rede com suas características de interconexões e fluxos estariam na base fundante da nova morfologia social. Para os autores a sociedade seria baseada na rede de relações sociais existentes, sustentadas a partir da confluência de interesses ou no manejo dos conflitos resultantes (Saravalle \& Abreu, 2017). Já Marck Granovetter $(1973 ; 1985)$; um dos teóricos do tema das redes sociais enfatiza a dimensão relacional da sociedade em redes e propõe que as redes sejam usadas como categoria analítica. Abramovay (2000), revisitando as concepções de Latour (2005), afirma que as redes sócio técnicas são aquelas que são compostas por um conjunto de especialistas ou técnicos, mas também por elementos não humanos, conferindo seu caráter heterogêneo e altamente imprevisível quanto às articulações que as compõe (Saravalle \& Abreu, 2017).

Nesta morfologia social, os nós podem ser constituídos por atores sociais, grupos de pessoas, instituições, tecnologias, objetos, entre outros, sendo que cada rede possui uma composição específica. Grosso modo ás experiências agroecológicas são articuladas em redes sociais que visam promover o desenvolvimento da agricultura familiar e a preservação dos recursos naturais, através da defesa de valores quase sempre implícitos associados à agroecologia, defende o diálogo entre pesquisa, extensão e ensino em várias regiões e abrangência no território nacional. Essas redes têm como traço característico principal a adoção de métodos que unem em um só processo a produção de conhecimentos e a sua aplicação prática. 
É importante que pesquisadores do campo das ciências sociais e da agronomia também possam acompanhar de perto as complexas redes de atores que atuam na agricultura, alimentação e saúde. Trata se de coletivos ou redes sócio técnicas que colocam novas expectativas em relação ao desenvolvimento da agricultura, a qualidade dos alimentos e a saúde dos animais, das plantas e, portanto da vida humana. Esses coletivos apresentam novos modos de funcionamento e, de relação com mercados e, portanto pressupõem que está em curso a construção de um conjunto de inovações em agricultura.

0 modelo industrial, devido à importância que atribui à produtividade, previsibilidade, homogeneidade e estabilidade das culturas é desenvolvido através de um sistema denominado por Bonneuil et al. (2006) de "agronomia da artificialização" uma vez que as técnicas agrícolas prescritas e os insumos associados (fertilizantes, ciclos, máquinas, variedades geneticamente alteradas) são desenvolvidos em ambiente controlado e depois disseminado geralmente em larga escala. Segundo este modelo de inovação frequentemente descrito como institucionalista fordista, se desenvolveu e continua operando com base na divisão de tarefas entre cientistas encarregados de projetar inovações, extensionistas responsáveis pela sua disseminação e agricultores que as adotam. Mas essa linha de produção de conhecimento baseada em processos de artificialização de ambientes e de padronização é questionada por diferentes agentes do desenvolvimento e por pesquisadores que trabalham com a perspectiva científica da agroecologia. Assim a complexidade, a diversidade e a imprevisibilidade da natureza são tomadas e referenciadas como novos elementos cruciais da inovação e pressuposto para uma nova forma de conceber a inovação que sem dúvidas é emergente, em distintos continentes. Portanto, quais são esses novos formatos de construção de conhecimentos? Segundo os autores imediatamente citados são formas coletivas que emergem e são construídas em torno deste retorno a valorização e a preservação dos recursos naturais e da produção de alimentos tendo como base de suporte a ecologia e relações humanas satisfatórias, acrescentamos baseadas em relações sociais horizontes.

As experiências agroecológicas construídas no contexto de redes sócio técnicas, constituídas por produtores, extensionistas ou técnicos do governo, pesquisadores, consumidores, etc. expressam estilos agrícolas alternativos e, defendem que a inovação técnica e científica não poderá florescer sem a mutação epistemológica que coloca os agricultores e a natureza no centro da produção do conhecimento, contribuindo assim para alimentar a ideia da existência de um acoplamento entre produção de inovações e formas coletivas (Demeulenaere \& Castro 2015).

Mas quais são os acoplamentos definidos entre a produção de inovações e formas coletivas de ação? Isso nos remeteria sem dúvidas às seguintes questões: Qual é a natureza das práticas de pesquisas (construção do conhecimento)? E das práticas alternativas em uso pelos agricultores? Qual é o lugar ocupado pelos agricultores no processo de produção de inovações sócio-eco-técnicas? É possível incluir também inovações no campo da transformação dos produtos e agregação de valores? E no âmbito de processos de certificação (sistemas de garantia da qualidade participativa) e, quanto à diversidade de forma de distribuição dos produtos (circuitos curtos) etc.? .

Esse arranjo de organização denominado rede sócio técnica articula no seu funcionamento um conjunto de atores que buscam através de relações horizontais a troca de conhecimentos e de saberes entre si com o objetivo planejar, gerir e orientar as políticas públicas, articulando e fomentando projetos. À luz de situações concretas observa-se que o coletivo de agroecologia geralmente, é um arranjo social através do qual um grupo sócio técnico se organiza para a construção de projetos e o desenvolvimento de atividades agroecológicas junto à comunidades rurais, com o intuito de apoiar e fortalecer processos em curso de transição da agricultura e, através desses coletivos essas comunidades ou grupos de agricultores passam a ter maior expressão social, política, ambiental e econômica, saindo muitas vezes do anonimato e se fortalecendo na busca por objetivos comuns.

\subsection{DINÂMICA DA CONSTRUÇÃO DE REDE SÓCIO TÉCNICA}

O movimento agroecológico constituído por ONGs e profissionais da agronomia (associações de engenheiros agrônomos), no final da década de 1980, se divide pelo fato de que existiam intensas críticas ao modelo da revolução verde, mas pouca experiência prática de agricultura de base ecológica (Almeida, et, al. 2001). Neste contexto, a construção de projetos junto às comunidades de produtores familiares se tornou uma importante estratégia de ação do movimento e, foram criadas estruturas de organização em diversos países latinos, fato que resultou no aumento considerável de experiências, no Brasil.

Deve se salientar o protagonismo e o papel decisivo da rede de Agricultura Familiar e Agroecologia, associação de "Apoio ao Desenvolvimento de Projetos de Tecnologias Alternativas", criada em 1983, se 
identifica atualmente com agroecologia e agricultura familiar e, com a promoção do desenvolvimento rural sustentável no Brasil (AS-PTA), parte integral da ANA (Associação Nacional de Agroecologia). Esta organização visavam atingir os seguintes objetivos: 1) Controlar o êxodo rural e apoiar os agricultores familiares; 2) Estimular o processo de organização dos agricultores familiares; 3) Promover a adoção de um novo modelo de desenvolvimento. Propunham-se para atingir esses objetivos as estratégias de ação: i) Local: construir novas alternativas para a produção rural; ii) Global: dar visibilidade à produção familiar; iii) Política: Influenciar a formulação de políticas públicas. Na década de 90, evolui e redefine seus métodos e conceitos.

A ANA contribuiu para que a adoção da proposição da agroecologia passasse a ser motivada por um conjunto de organizações políticas comprometidas com a construção de um projeto social, baseada em reivindicações por equidade e justiça social. São às condições de vida dos produtores familiares, associadas aos fatores ecológicos e técnicos que configuram a dinâmica da emergência da agroecologia, fazendo com que agricultores empenhados com a transição em certas situações de uso da terra enveredem por trajetórias diferenciadas. Esses agricultores em diversas localidades são apoiados por essas organizações, as quais estão envolvidas diretamente com os processos de desenvolvimento rural e com a institucionalização da agroecologia, no Brasil. Essa força social é um dos elementos fundamentais das evoluções intensas identificadas nos últimos anos.

\subsection{ARTICULAÇÃO ENTRE REDES E SITUAÇõES CONCRETAS OBSERVADAS}

De modo geral recentemente as redes sócio técnicas também surgem dentro das universidades denominados Grupos de Agroecologia (GA), em sua maioria constituídas por alunos do campo das ciências agrárias e, alguns professores mais diretamente envolvidos com o tema. Em 2010 foi criada a REGA Brasil (Rede Brasileira de Grupos de Agroecologia) durante o II ENGA (Encontro Nacional de Grupos de Agroecologia) em Aldeia Velha-RJ. O Encontro e a Rede inspiram-se em padrões horizontais e auto gestionários de atuação, relação e organização social. No Brasil cinquenta Grupos de Agroecologia estão cadastrados aproximadamente. Somente na região Sudeste estão cadastrados trinta e oito grupos, sendo dezessete no estado de São Paulo (REGA BRASIL, 2016).

Os Grupos de Agroecologia também são Núcleos de Estudos em Agroecologia (NEA). Os núcleos foram criados a partir de 2010, por meio do Edital MDA/SAF/CNPq 058/2010 com o objetivo de qualificar a formação de professores, alunos e técnicos extensionistas, de modo a garantir serviços de assistência técnica e extensão rural (ATER) aos agricultores familiares, considerando os princípios e objetivos da Política Nacional de Assistência Técnica e Extensão Rural (Lei no12.188, de 11 de janeiro de 2010). Desde a sua criação, foram apoiados duzentos e oitenta e um projetos, em cento e duas instituições de ensino superior diferentes. Os núcleos estão distribuídos em todas as regiões políticas do país, com uma predominância na região Nordeste (Saravello, Abreu, 2017). Mas é no estado de Minas Gerais onde se concentra a maior quantidade de municípios por unidade da federação, onde foram criados quarenta grupos em vinte e dois municípios, nos últimos, sete anos.

As organizações constituídas em redes sócio técnicas lutam pelo reconhecimento destas formas ecológicas de articulação e produção de conhecimento e apoio aos agricultores. Tais avanços são consubstanciados no quadro institucional, no âmbito da legislação da qualidade dos sistemas orgânicos e, em políticas que se inspiram no conceito e abordagem da agroecologia e agricultura orgânica, uma vez que reconhecem a importância da integridade cultural das comunidades rurais, da equidade social, da valorização econômica das produções familiares, além do respeito aos recursos naturais.

Em setembro de 2017, a Rede de Grupos de Agroecologia do Brasil celebrou, dialogou, circulou, criou, fez rodas de conversa e de capoeira e demonstrou sua capacidade de resiliência num encontro que convergiu com o VI Congresso Latino Americano de Agroecologia da SOCLA, com o X Congresso Brasileiro de Agroecologia e com o V Seminário de Agroecologia do DF e Entorno, em Brasília, no Centro de Convenções Ulysses Guimarães (https://regabrasil.wordpress.com/author/regabrasil/)

Neste campo das práticas cotidianas políticas, novas identidades vêm sendo construídas e resignificadas, a partir de dinâmicas coletivas da transição agroecológica, favorecendo a criação de ambientes socioculturais propícios à produção e à circulação de informações pertinentes às questões do desenvolvimento local. 0 agricultor experimentador, inovador, técnico e ecologista são algumas das novas formas de auto identificação social que têm permitido precisar contornos de identidades renovadas e promoção de coesão social. Esse processo é fruto da interação e troca de conhecimento em redes sócio técnicas, presentes nas diferentes regiões do país. A relação interativa e dialógica desenvolvida através do 
intercâmbio presencial, permanece como eficiente mecanismo de circulação local dos conhecimentos gerados nos processos de experimentação. É preciso destacar que as redes sociais não anulam às formas tradicionais de sociabilidade presentes no meio rural, mas promove uma ressignificação de valores tradicionais, em novos formatos atualizados pela interação social - encontros de agricultores experimentadores, visitas de intercâmbio, participação em eventos variados, os quais são organizados para valorizar e dar visibilidade ao agricultor(a) inovador(a). Há um esforço sem dúvidas em qualificar as experiências exitosas através da comunicação horizontal entre redes de interação presencial, no entanto, é consenso entre os participantes das redes sociais que é preciso avançar, fortalecendo os mecanismos que permitam a visibilidade das inovações agroecológicas. Isto se traduz em adaptações de ferramentas metodológicas e treinamento dos profissionais. 0 papel dos técnicos e pesquisadores no âmbito das redes sócio técnicas é no sentido de compreender as necessidades dos agricultores e de forma dialógica e interativa encontrar soluções e alternativas para a viabilização dos sistemas agroalimentares, incluindo a distribuição dos alimentos em mercados justos.

Segundo técnico da ANA, as metodologias empregam a escrita e os recursos audiovisuais como suporte para que informações e ensinamentos extraídos das experiências são registrados e transmitidos pelos próprios experimentadores. A inovação agroecológica produzida pelo avanço da agroecologia em rede é um processo cujo produto tem aplicabilidade essencialmente local, mas pode ser divulgada em Redes, uma vez que é fonte de inspirações para a inovação local. Entretanto, esta visão é discutível, pois não ocorreria no seio destas experiências locais, inovações agroecológicas que possam ser aplicadas ou adaptadas a outras situações distintas? Caso contrário, permanece se na perspectiva de agroecosistemas local. E a inovação agroecológica não forçosamente é limitada ao meio local.

Grupos que vivem e produzem em contextos geograficamente distantes consideram a possibilidade de trocas de conhecimentos muito frutífera, uma vez as experiências exitosas desenvolvidas em outros contextos estimulam o processo de inovação, sobretudo quando evoluem em direção aos princípios da agroecologia. As redes locais se inspiram e se fortalecem mutuamente, sempre que colocadas em contato direto.

As redes agroecológicas se constituem em espaços políticos de resistência e disputas pelo território em concorrência com agentes associados ao modelo agroindustrial. A disputa manifesta se de diversas formas: na luta pela terra, mas também na decisão de selecionar esse ou aquele modelo de produção ou na escolha das sementes tradicionais, e na recusa de sementes comercial ou na construção de um canal alternativo de comercialização de alimentos, que possibilita a aproximação entre produtores e consumidores no próprio território, se trata, portanto, da construção de estratégias sociais distintas daquelas que predominam no setor rural da agricultura convencional.

Entretanto, apesar do avanço da agroecologia em redes de inovações, nos parece incerta que o suporte institucional para tal desenvolvimento seja disponível e suficiente, nos anos vindouros, uma vez que acirrou no âmbito da governabilidade do país, a crise política e econômica que certamente comprometerá recursos públicos, haja visto os ajustes preconizados pelo Ministério da Economia, que reduzirá as despesas públicas e pelo elenco de prioridades estabelecidas pelo Ministério da Agricultura, Pecuária e Abastecimento, em diversas áreas do agronegócio e, também no campo da sustentabilidade ambiental, por exemplo o programa agricultura de baixo carbono que está orientado para mitigar os problemas ambientais decorrentes da agricultura intensiva de grande escala. Isso sem dúvidas levará a uma disputa interna no âmbito deste Ministério entre atores deste setor e do Plano Nacional da Produção Orgânica e Agroecologia.

Entretanto para os atores de redes sócio técnicas (conforme é o caso do Núcleo de Agroecologia Apetê Caapuã), as políticas são fundamentais para a profissionalização no campo acadêmico e para atuação na extensão rural junto aos agricultores propiciando o fortalecimento das ações de transição agroecológica. A rede atua desde o apoio à produção agroecológica até a busca por modos de comercialização mais justos e solidários. Como principais pontos negativos são destacados o curto prazo dos projetos, já que o processo de transição agroecológica demandaria uma dedicação de tempo maior, tendo em vista seu caráter participativo, por outro lado são pressionados pela burocracia associada à execução financeira dos projetos, inviabilizando o uso do recurso em tempo hábil, além das dificuldades no custeio das despesas da participação de agricultores nas atividades, como pagamento de diárias e transporte (Saravello \& Abreu, 2017). 
Segundo esses autores, as políticas avaliadas no contexto empírico estudado, formam uma rede de suporte e fomento às atividades do núcleo que são imprescindíveis para a sobrevivência do coletivo e das ações junto às comunidades. Esta é uma experiência singular importante, pois demonstra a importância de projetos de caráter interinstitucional que articulam as diferentes políticas públicas que incidem sobre o mesmo público alvo, potencializando o recurso público. Sendo assim, é fundamental a continuidade dos núcleos ou das redes sócio técnicas como política pública de fomento à agroecologia nos territórios.

Esse cenário é improvável, a incerteza foi colocada explicitamente no fechamento do MDA (Ministério do Desenvolvimento Agrário), não havendo perspectiva futura de manutenção dos NEAs. No final de 2016 foi lançada a Chamada MCTIC/MAPA/MEC/SAF-CASA CIVIL/CNPq № 21/2016 que, com recursos insuficientes, selecionou para manutenção somente 32 núcleos de um conjunto de demanda maior, levou a diminuição do número de projetos selecionados e a redução do montante do orçamento por projeto. Deste modo a maioria das redes sócio técnicas encontra-se em dificuldades para manter as atividades em curso e, para abrir novas frentes. Consequentemente poderão ser interrompidas ações prioritárias de apoio aos processos de transição agroecológica das unidades de produção familiar de diferentes regiões do país.

Um aspecto não menos relevante do resultado desta pesquisa é que ela nos proporcionou uma reflexão crítica da realidade vivenciada e vinculada às atividades desenvolvidas no âmbito da operacionalização dos projetos voltados para a agroecologia, a partir da análise sociológica que corrobora com a sistematização fina da experiência das redes sócio técnicas possibilitou efetuar a reconstrução, o ordenamento histórico e a interpretação crítica de certas experiência em si, do ponto de vista dos atores e parceiros, facilitando a identificação das dificuldades, fragilidades, potencialidades e funcionamento de redes sócio técnicas. Essa dinâmica quando compartilhada com o grupo cria um ambiente de aprendizagem mútua que possibilita redirecionar as ações do projeto, realimentar as ações de pesquisa e subsidiar políticas públicas que contribuam para o desenvolvimento rural sustentável.

\section{CONCLUSÕES}

Concluiu se que a emergência e o avanço da construção social de redes agroecológicas no Brasil contemporâneo, são fruto de políticas públicas agroecológicas e de novas oportunidades de transformação em especial nos sistemas de valores e representação dos atores chaves da agricultura brasileira. Trata se de uma estratégia ainda distinta da que domina o mundo rural contemporâneo, portanto, é no campo das experiências alternativas que se insere a problemática das redes sociais de inovação agroecológica.

Uma das características inovadoras das redes agroecológicas no Brasil, refere se ao estabelecimento de ação baseada no sentido horizontal e dialógica, denominada de redes de inovação, como tem sido designado por lideranças do movimento social. Estas redes sociais reúnem um número crescente de pessoas e organizações sociais, em torno de objetivos comuns, especialmente ligadas ao exercido de cidadania em processos de construção de um novo projeto social para a agricultura familiar.

0 avanço da agroecologia por se constituir num campo de disputa de projeto social, dependerá da força das redes sociais de inovação agroecológica e da visibilidade das inovações produzidas e, do aporte crucial em termos de políticas públicas indutoras do avanço da agroecologia, mas isso é pleno de incertezas no quadro da atual crise a política e econômica do país. Segundo também as configurações específicas dos coletivos de redes sócio técnicas, a relação à agroecologia, é mais ou menos densa e, o contexto de incertezas políticas é importante e define as oportunidades para construção de projetos aplicação de princípios da agroecologia, afetando diretamente os processos de transição da agricultura. Finalmente, as redes de agroecologia poderiam sem dúvidas garantir espaços à participação da sociedade civil, a criação de interfaces com um conjunto de instituições da sociedade, através de ações coletivas e projetos de desenvolvimento rural sustentável.

Portanto, observam-se claramente avanços na produção de base ecológica no Brasil, mas requer uma investigação aprofundada sobre a efetividade dos projetos, planos e discursos institucionais e, verificar em que medida poderá impactar positivamente e, contribuir para a transição da agricultura. 


\section{REFERÊNCIAS}

[1] ALMEIDA, S. G; PERTENSEN, P.; CORDEIRO, A. Crise socioambiental e conversão ecológica da agricultura brasileira: subsídios à formulação de diretrizes ambientais para o desenvolvimento agrícola. Rio de Janeiro: AS-PTA, 2001.122 p.

[2] RADCLIFFE-BROWN, A. R. Structure \& function in primitive society. Londres: Cohen \& West, 1952.

[3] ABRAMOVAY, Ricardo. A rede, os nós, as teias - Tecnologias Alternativas na Agricultura. Revista de Administração Pública - $\mathrm{n}^{\circ}$ 6, 2000:159-177, novembro/dezembro. Disponível em: http://www.econ.fea.usp.br/ abramovay/artigos_cientificos/2000/A_rede_os_nos.pdf

[4] ALTIERI, M. Agroecologia: a dinâmica produtiva da agricultura sustentável. Porto Alegre: Editora da UFRGS, 2001. 110p.

[5] CASTELLS, Manuel. A sociedade em rede. In: A era da informação: economia, sociedade e cultura. Vol. 1. S. Paulo, Paz e Terra, 2003. 7a ed. revista e atualizada.

[6] OLLIVIER, G. BELLON, S. Dynamiques des agricultures écologisées dans les communautés scientifiques internationales : une rupture paradigmatique à rebondissements, Nature, Sciences et Sociétés. 2013.

[7] LATOUR, Bruno. Le métier de chercheur. Regard d'un anthopologue. Paris, Inra, 1995.

[8] REGA Brasil. <https://regabrasil.wordpress.com/os-grupos/> acesso em 28 de agosto de 2016. 


\section{Capítulo 17}

PARTICIPACCÃO E MOBILIZACCÃO DOS ATORES SOCIAIS NO TERRITÓRIO CENTRAL DA CIDADANIA DE RONDÔNIA - TCCRO, BRASIL

\section{Tânia Olinda Lima}

\section{Clodoaldo de Oliveira Freitas}

Eliane Silva Leite

Bruna Érica de Oliveira

Resumo: 0 presente trabalho buscou analisar o funcionamento do Colegiado Territorial de Desenvolvimento Sustentável - Codeter do Território Central da Cidadania de Rondônia - TCCRO, por meio da participação e mobilização dos atores sociais. Procurouse na pesquisa utilizar as metodologias participativas com base na pesquisa-ação, observação direta, análise de dados secundários e aplicação de entrevistas semiestruturadas com $41 \%$ dos delegados do Codeter do Território Central da Cidadania de Rondônia. Os temas abordados na pesquisa foram: entidades ou instituições representadas no TCCRO; participação em outras instâncias colegiadas e nas do TCCRO; em movimentos sociais ou coletivos e seus segmentos; tempo de atuação no Codeter; metodologia de tomadas de decisões nos espaços de discussão; entre outros. Estes dados são oriundos de pesquisas realizadas pelo Projeto Núcleo de Desenvolvimento Sustentável do Território Central da Cidadania para Jovens e Mulheres da Floresta Amazônica - Rondônia (UNIR/CNPq/MDA/SPM-PR). A pesquisa mostrou que existe a participação dos membros em diversos segmentos de instâncias colegiadas, em movimentos sociais ou coletivos; apontou a inserção de novos delegados e a continuação de atores sociais antigos nas discussões territoriais, contribuindo para o fortalecimento da democracia participativa; e mostra a necessidade de inserção de outras representações no espaço de discussão. Portanto, estratégias acerca do futuro do Codeter são necessárias para atender os interesses fragmentados dos diferentes atores que deles fazem parte, em busca do fortalecimento da expressão da territorialidade, enquanto sentido de pertença, ao considerar e envolver a sociedade e seus meios de convivência no planejamento e gestão das políticas públicas.

Palavras-chave: Codeter. Política Territorial. Instâncias Colegiadas. Movimentos Sociais. 


\section{INTRODUÇÃO}

Os debates atuais sobre território e desenvolvimento territorial reúnem múltiplas visões que configuram uma realidade complexa, em permanente transformação, reflexo das dinâmicas físicas, socioeconômicas e culturais do contexto local (GEHLEN; RIELLA, 2004). Entendido tanto como resultado do processo histórico quanto a base material e social das ações humanas, o território, "visto como uma totalidade é um campo privilegiado para a análise, na medida em que, de um lado, nos revela a estrutura global da sociedade e, de outro lado, a própria complexidade do seu uso" (SANTOS, 2004).

Os estudos de Abramovay $(2000,2003,2006)$ são referências importantes no que diz respeito à complexificação da abordagem analítica do desenvolvimento territorial. Para o autor, os territórios não são apenas receptáculos neutros onde os atores estabelecem relações, sendo, portanto, sua estrutura política e organizacional um elemento de relevância na conformação das dinâmicas neles sediadas. Com base nas contribuições teóricas da nova sociologia econômica, Abramovay (2006) propõe que os territórios sejam estudados a partir da noção de campos de Bourdieu (2000), ou seja, como espaços estruturados de posições onde agentes com interesses diversos estão em concorrência.

Nessa perspectiva, o território pode ser interpretado como resultado de um processo de apropriação econômica, ideológica e política do espaço por grupos que se dão uma representação particular deles mesmos, de sua história. 0 território segundo Abramovay (2003, p. 89), "representa uma trama de relações estabelecidas, de raízes históricas, de configurações políticas e de identidades que assumem um papel ainda pouco conhecido em matéria de desenvolvimento econômico".

Sack (1980) salienta que a construção social da territorialidade só existe quando há interação entre os indivíduos, sendo ela uma tentativa de um grupo de indivíduos, por meio de suas ações, controlarem e influenciarem pessoas, fenômenos e relações. Para o autor, é o contexto social que estabelece o conteúdo humano para o território e sem esse conteúdo territorial, o conceito de território fica restrito às suas dimensões espaciais medidas pela dimensão geográfica.

A representatividade no colegiado dos territórios é um elemento preponderante para o entendimento de diversos desafios enfrentados no processo de desenvolvimento rural. Pode-se identificar à presença massiva da representação da sociedade civil, o que influência tanto na elaboração das ações territoriais quanto na execução destas ações. Esta assimetria na representação aparece como uma das causas da ausência e do desinteresse das instâncias governamentais (DIAS, 2008). Segundo Florisbelo (2005, p. 81), "falta diálogo entre os atores locais. Os movimentos sociais em geral têm resistência em se aproximar do poder público para discutir o território e a gestão compartilhada das infraestruturas".

Outra problemática é o desconhecimento por parte dos representantes do colegiado sobre os documentos oficiais da política e os documentos do próprio território. Poucos são os que possuem conhecimento, por exemplo, do PTDRS, desconhecendo seu conteúdo. A qualidade de espaço público propositivo se compromete. De certa forma, isso acentua a relação de poder dentro do colegiado. Aqueles que possuem maior conhecimento, ou "capital político" têm maior capacidade de influenciar nas decisões.

Por isso, a pesquisa buscou analisar o funcionamento do Colegiado Territorial de Desenvolvimento Sustentável - Codeter do Território Central da Cidadania de Rondônia - TCCRO, por meio da identificação, metodologia de mobilização e decisão dos atores sociais.

A pesquisa-ação participativa, observação direta, análise de dados secundários e entrevistas semiestruturadas foram às metodologias utilizadas para desenvolver o trabalho, nos anos de 2014 e 2015. Sendo entrevistados $41 \%$ dos delegados do Codeter do Território Central da Cidadania de Rondônia. Os temas abordados na pesquisa foram: entidades ou instituições representadas no TCCRO; participação outras instâncias colegiadas e nas do TCCRO; em movimentos sociais ou coletivos; segmentos de atuação; tempo de atuação no Colegiado Territorial; metodologia de tomadas de decisões nos espaços de discussão; grupos de importância para o Território; entre outros.

A coleta foi realizada durante as reuniões ordinárias do Codeter/TCCRO, consistiu em duas etapas: I breve síntese dos objetivos da pesquisa, metodologia de coleta de dados e projeção da entrevista para conhecimento dos membros; II - Entrega da entrevista juntamente com uma caneta e leitura das questões de pergunta a pergunta. Esta segunda etapa é de fundamental importância, pois entre os atores sociais existem aqueles com pouca escolaridade e com idade avançada, desta maneira evitou-se constrangimentos, além de esclarecer a questões duvidosas. 
Estes dados são oriundos de pesquisas realizadas pelo Projeto Núcleo de Desenvolvimento Sustentável do Território Central da Cidadania para Jovens e Mulheres da Floresta Amazônica - Rondônia (UNIR/CNPq/MDA/SPM-PR).

\section{POLÍTICA TERRITORIAL: ATORES SOCIAIS E OS ESPAÇOS DE DISCUSSÕES}

Essa discussão a respeito do desenvolvimento territorial já vem sendo introduzida no meio acadêmico e por formuladores de políticas públicas no Brasil a partir da década de noventa do século passado e é precedida pela discussão em torno do desenvolvimento sustentável e de outras categorias a ele correlatas, como desenvolvimento local sustentável e desenvolvimento rural sustentável, entre outras. Nesse contexto aparece um elemento considerado essencial nesse processo, o da participação social, considerado central nas propostas direcionadas à promoção do denominado desenvolvimento sustentável (JARA, 1998).

No caso específico dos desafios relacionados ao processo de descentralização das políticas públicas voltadas para a promoção do desenvolvimento rural sustentável, estes ainda são grandes e complexos, principalmente pela necessidade de se atender às especificidades e as diferenças culturais dos vários grupos e povos existentes no País.

Considerando essa problemática, no ano de 2003, o governo Lula, por meio da Secretaria de Desenvolvimento Territorial - SDT, do Ministério de Desenvolvimento Agrário - MDA, iniciou uma política de "promoção de desenvolvimento dos territórios rurais". Nesse mesmo ano iniciou-se a execução dessa política cujas ações estão ligadas ao Programa Nacional de Apoio aos Territórios Rurais - PRONAT, inserido no Plano Plurianual (2004-2008) (TEIXEIRA DA ROCHA; FILIPPI, 2008).

Como parte desta estratégia, o Ministério do Desenvolvimento Agrário - MDA passou a apoiar a criação de territórios de identidade, definido pelo do Conselho Nacional de Desenvolvimento Rural Sustentável e Solidário - Condraf (2005) entendidos como um espaço físico, geograficamente determinado, não necessariamente contínuo, compreendendo cidades e campos, caracterizados por critérios multidimensionais, tais como o ambiente, a economia, a sociedade, a cultura, a política e as instituições e uma população com grupos sociais relativamente distintos, que se relacionam interna e externamente por meio de processos específicos, onde se pode distinguir um ou mais elementos que indicam identidade e coesão social, cultural e territorial.

Ao tornar determinado espaço um território para implementação de uma política social de investimentos públicos, o MDA, por exemplo, está ativando, ao mesmo tempo, um processo de territorialização (designando regras, normas e institucionalidades desejadas) e, a possibilidade de instituição de "territorialidades", que se sobrepõem e interagem com outras já constituídas.

Trata-se de um recurso (e de um "capital") estratégico disponibilizado aos atores envolvidos pela política, que delimita fronteiras que, por sua vez, afetam o acesso da população local aos recursos e aos supostos benefícios da ação pública “territorial” (FREITAS, et al., 2010).

Em ambos os casos, estabelece-se um conjunto de regras, por meio das agências que operacionalizam a política e pela pluralidade de atores que vivem e atuam no território, aos quais o próprio Estado delega poder relativo para realizar a governança dos recursos disponíveis e alocados.

No caso do Programa Territórios da Cidadania, oficializado em 2007, a institucionalidade territorial está fundamentalmente composta, como nos territórios rurais de identidade, por representantes do Estado e da sociedade civil, com uma composição de participação que se assemelha a deste último. No entanto, há uma diferença importante. Nos territórios da cidadania, a distribuição entre os participantes do Estado e da sociedade civil deve ser, em princípio, paritária, de modo que sua orientação exige uma composição ampliada em relação ao que são os colegiados formados nos territórios rurais de identidade. Nos territórios da cidadania a recomendação é de que a presença do Estado seja maior do que nos territórios rurais de identidade, e que se expresse por meio da participação mais intensa de representantes das três esferas de governo (federal, estadual e municipal) (DELGADO e LEITE, 2011).

O processo de desenvolvimento territorial em Rondônia iniciou-se em julho de 2003. Nesta época, a proposta era somente de "Território rural" cabendo a Secretaria de Desenvolvimento Territorial SDT/MDA o desenvolvimento das ações. Neste mesmo ano foram homologados pelo Conselho Estadual de Desenvolvimento Rural Sustentável de Rondônia - CEDRS os Territórios da Cidadania Madeira-Mamoré, Vale do Jamari e Central, em 2007 foram o Território da Cidadania Rio Machado e Território Rural Vale do 
Guaporé, finalizando o processo em 2011, com a constituição dos Territórios Rurais Zona da Mata e Cone Sul (Figura 1) (PTDRS, 2013).

Figura 1 - Territórios de Rondônia.

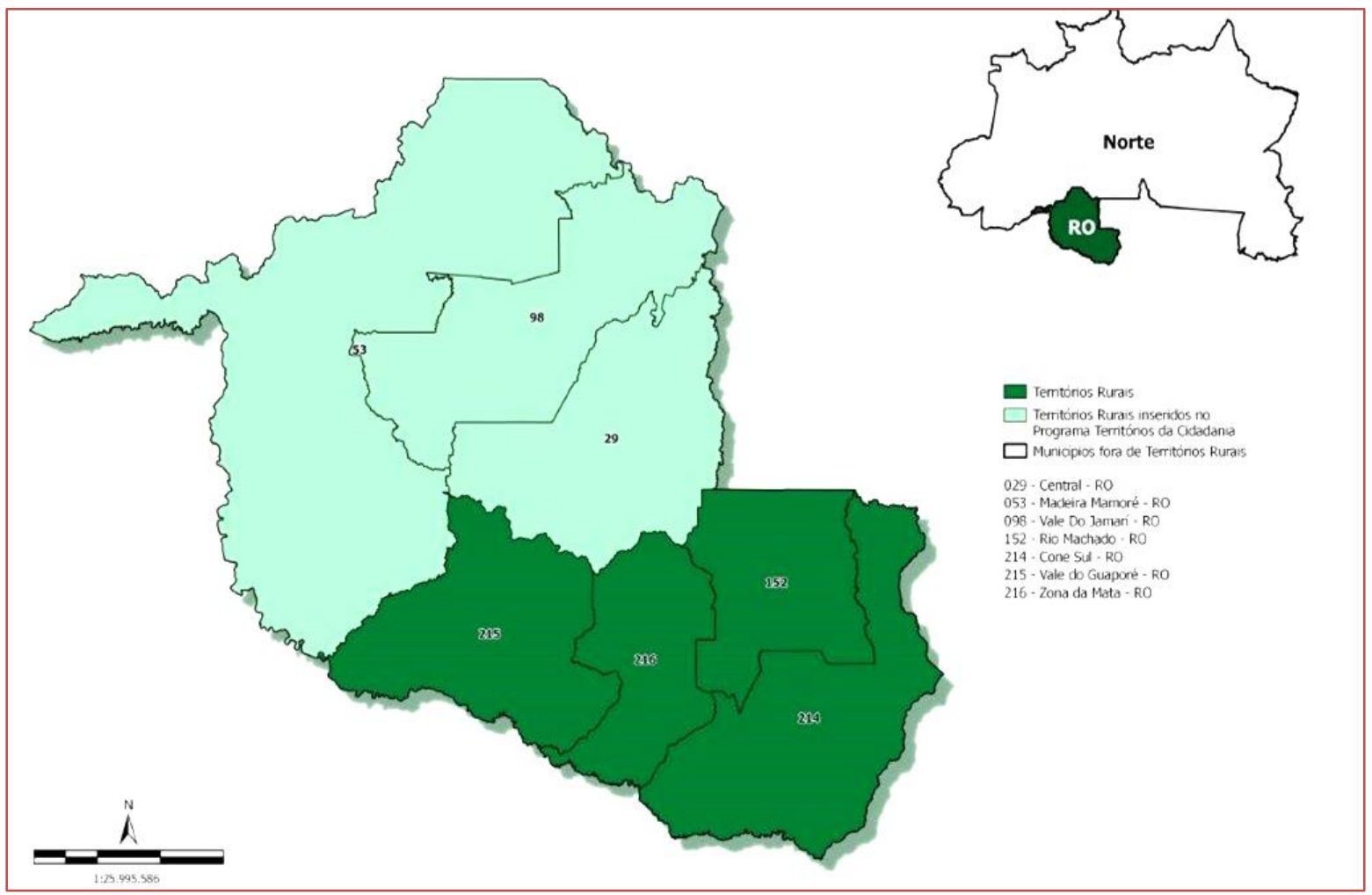

Fonte: MDA, 2016

O Território Central está localizado na região central de Rondônia, fazendo limites com os Territórios: Vale do Jamari (ao norte); Madeira Mamoré (a oeste); Rio Machado (no Sudeste) e, ao sul/sudoeste com o Território de Identidade Zona da Mata. Abrange uma área de $28.225 \mathrm{~km}^{2}$.

Os municípios do Território Central tiveram suas formações atreladas aos ciclos da borracha; à implantação de estações telegráficas através da Comissão Rondon; à abertura da rodovia BR - 364; aos projetos de colonização e núcleos urbanos implantados pelo Instituto Nacional de Colonização e Reforma Agrária - INCRA e, mais recentemente, pelos desmembramentos dando origem a vários municípios.

0 Território Central era composto, inicialmente, por 12 municípios. A inclusão do município de Alvorada do Oeste ocorreu no ano de 2008, quando o Governo Federal lançou o Programa Territórios da Cidadania, cujo objetivo do programa é "promover o desenvolvimento econômico e universalizar programas básicos de cidadania por meio de uma estratégia de desenvolvimento territorial sustentável” (PTDRS, 2013). Sendo a participação social e a integração de ações entre Governo Federal, estados e municípios são fundamentais para a construção dessa estratégia. A partir de então o território passou a fazer parte dos territórios da cidadania.

O Território Central da Cidadania de Rondônia - TCCRO foi um dos primeiros a serem homologados em Rondônia (Figura 2), para a constituição e institucionalização do território rural na política da Secretaria de Desenvolvimento Territorial - SDT foi elaborado o Plano Territorial de Desenvolvimento Rural Sustentável - PTDRS. 
Figura 2 - Território Central com destaque para os municípios constituintes.

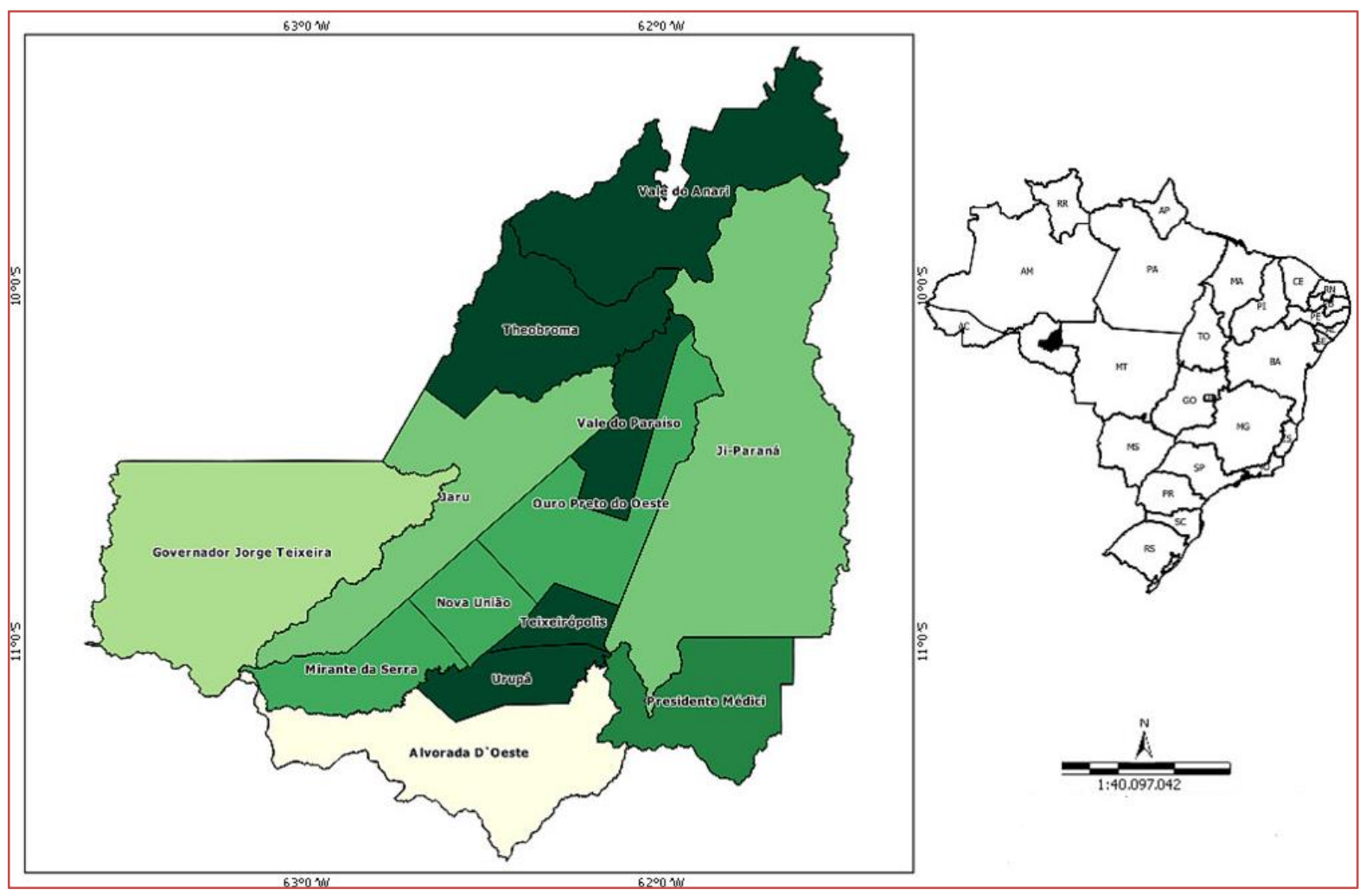

Fonte: MDA, 2016

Tanto o PTDRS quanto o Estudo Propositivo definiram como eixos temáticos: (i) produção, trabalho e renda; (ii) meio ambiente; (iii) transporte e comercialização; (iv) saúde e saneamento; (v) educação, cultura e lazer; e (vi) moradia, energia, comunicação e segurança. Estes eixos temáticos foram elaborados diante das necessidades e prioridades levantadas pelos atores do território. Uma das propostas destes eixos e dos documentos é refletir no adensamento da relação entre estes atores e provocar a reflexão de ações que sejam coniventes com a realidade e com a proposta de desenvolvimento regional e não setorial.

Atualmente o Território Central é formado por 13 municípios, figura 2, sendo eles: Alvorada D’Oeste, Governador Jorge Teixeira, Jaru, Ji-Paraná, Mirante da Serra, Nova União, Ouro Preto do Oeste, Presidente Médici, Teixeirópolis, Theobroma, Urupá, Vale do Anari, Vale do Paraíso. A população rural do Território Central em 2010 era de 106.824 habitantes e a urbana de 214.955 habitantes (PTDRS, 2013). A distribuição populacional é predominantemente urbana nos municípios de Jaru, Ji - Paraná, Ouro Preto do Oeste e Presidente Médici, excluindo estes quatro municípios, fica bem evidente a presença predominante de uma população rural no Território Central.

0 Território é caracterizado por comunidades da terra (ribeirinhos, quilombolas, indígenas, assentados, entre outros), distribuídos na área rural do Estado. Atualmente existem em Rondônia 23.242 propriedades rurais com menos de 100 hectares, mas, a população do campo está cada vez mais reduzindo e se reconfigurando, principalmente, pela quantidade de camponeses com uma faixa etária acima de 50 anos. Neste sentido, a faixa etária entre 55 e 65 anos aumentou quatro pontos percentuais, passando de $20 \%$ para 24\% do total. Em contrapartida, o agrupamento entre 35 e 45 anos de idade reduziu de 21,93\% para 18,29\% da população rural e os jovens entre 25 e 35 anos, que representavam 13,56\% do campo em 2006, hoje são apenas 9,48\% (IBGE, 2017).

0 plano territorial de desenvolvimento sustentável deste território deixa claro a necessidade de investir em ações de geração de renda e que envolvam os jovens. Com relação à dimensão social do Território Central comparando os dados populacionais dos anos de 2000 e 2010, houve, no Território Central, uma perda de aproximadamente 3,0\% em sua população, com maior destaque para os municípios de Alvorada D’Oeste e Governador Jorge Teixeira. Dos 13 municípios que compõem o Território Central, somente dois (Ji - Paraná e Vale do Anari) não apresentaram diminuição na população (PTDRS, 2013). 
Contudo, esta perda populacional já foi bem maior, quando comparado aos dados dos anos de 2000 e 2007. Neste período a perda populacional chegou a 6,0\%. De acordo com os integrantes do Codeter os motivos deste êxodo são a busca de oportunidade de ocupação, emprego e renda; e busca de melhores condições de educação (PTDRS, 2013).

No território existe demanda social, isto é, necessidade de realizar investimentos em políticas públicas para benefícios coletivos dos grupos sociais e dá indicativos de aplicação de ações de desenvolvimento sustentado centradas aos agricultores familiares, produtores rurais e políticas para mulheres.

No âmbito educacional, verifica-se uma grade curricular exclusivamente voltada ao urbano, excluindo as peculiaridades do contexto rural. De acordo com o Censo Escolar de 2010, o ensino fundamental, demonstra uma debilidade na área rural e, de um modo geral, apresenta inconstâncias ente o número de alunos nas séries iniciais e as séries finais, podendo indicar evasão escolar (PTDRS, 2013). Assim, é importante a construção de um modelo educacional destinado a atender a realidade rural.

Quanto aos pescadores artesanais, de certa maneira, estão presentes em todo o Território Central, representados pelas Colônias de Pescadores e outras entidades desse setor. Também há terras indígenas e três Reservas Extrativistas - Resex que são unidades de conservação de uso sustentado. No Território Central não foram identificadas comunidades quilombolas.

\section{PARTICIPAÇÃO E MOBILIZAÇÃO DOS ATORES SOCIAIS NO TERRITÓRIO CENTRAL DA CIDADANIA DE RONDÔNIA}

No que tange sua organização o Território Central da Cidadania de Rondônia - TCCRO é composto por duas instancias de caráter permanente: 0 colegiado territorial e o núcleo diretivo (coordenador e vice coordenador; secretariado; coordenação de comunicação). 0 colegiado territorial é composto por seis representantes de cada município, sendo três representantes do poder público municipal e três de organizações da sociedade civil, tendo ainda a representatividade nas esferas Estadual e Federal.

O Codeter é o fórum de discussão e de participação social presente em todos os Territórios. Trata-se de um espaço de planejamento, cogestão e concertação de políticas públicas, programas e projetos. Cada Território possui um colegiado, composto por representantes de organizações da sociedade, que representam toda a diversidade social do território, e de órgãos e instituições públicas municipais, estadual e federal.

O Codeter dos Territórios tem composição paritária com, pelo menos, 50\% da sociedade civil e o máximo de $50 \%$ do poder público. A consolidação dos colegiados significa a construção de políticas públicas de forma mais democrática, transparente e participativa. 0 gráfico 1 mostra que a representatividade de entidades ou instituições da Sociedade Civil e Poder Público no Codeter/TCCRO é similar, no entanto, durante as reuniões do Colegiado é visível a ausência da Sociedade Civil.

Gráfico 1 - Entidades ou Instituições representadas no Colegiado Territorial.

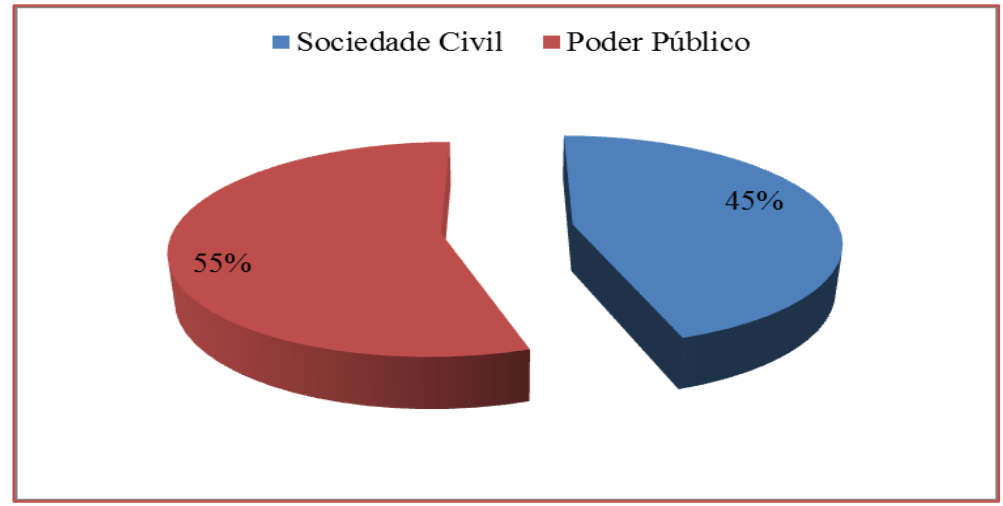

Fonte: Dados da pesquisa.

Todavia, o Codeter é constituído com o objetivo de garantir maior participação e envolvimento de atores locais na discussão sobre a política e na formulação de propostas de projetos para o desenvolvimento da 
região, elaborados a luz das prioridades e necessidades dos agricultores e demais atores (CTA/ZM, 2004). A Sociedade Civil, na prática da gestão social é fundamental para o processo de construção e tomada de decisões.

Como aponta o gráfico 2, dos membros da Sociedade Civil e Poder Público do Codeter/TCCRO, 62\% participam de outas instâncias colegiadas, garantindo a integração e envolvimento dos atores sociais e a identidade do território, surgindo diversos espaços institucionais de participação social de forma a envolver os atores sociais na dinâmica de gestão das políticas e do desenvolvimento da região.

Gráfico 2 - Participação em outras instâncias colegiadas, além do Colegiado Territorial (Conselhos, Consórcios, outros).

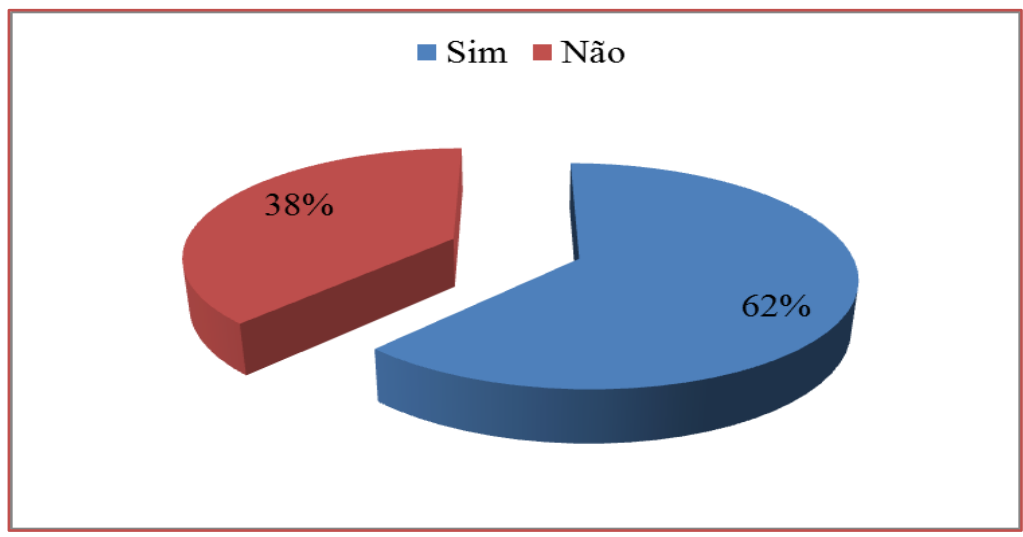

Fonte: Dados da pesquisa.

As principais instâncias colegiadas citadas foram desenvolvimento rural ou agrário e meio ambiente, respectivamente 31\% ambas (Gráfico 3). A Secretaria de Desenvolvimento Territorial - SDT (2016) afirma que é a partir dessas instâncias que se busca ampliar o acesso, a integração e articulação das políticas públicas vinculadas ao contexto e as especificidades de cada território, assegurando os canais de participação social necessários para o fortalecimento da democracia participativa.

Gráfico 3 - Instâncias colegiadas participantes.

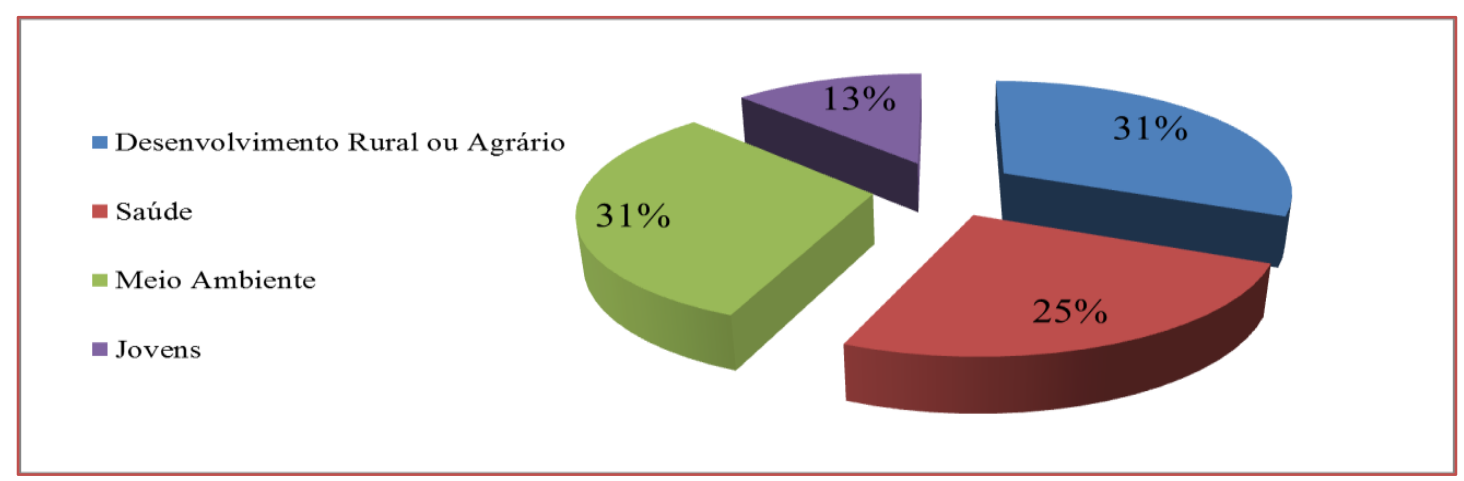

Fonte: Dados da pesquisa.

Outas instâncias mencionadas, mas em menor proporção foram: Conselho Tutelar; Direitos Humanos; Câmara Setorial da Piscicultura; Mulheres; Recursos Hídricos; Conselho das Águas.

Portanto, os espaços são abastecidos com informações técnicas que estimulem as discussões, oferecem novos elementos para as reflexões, apresentando alternativas e permitem definir as melhores estratégias de desenvolvimento. Como o planejamento é um processo, que deve se adaptar permanentemente às mudanças dos objetivos ou das condições, e cria localmente uma capacidade de planejamento e de diagnóstico técnico (GUANZIROLI, 2008). 
Quanto à participação dos membros em Movimentos Sociais ou Coletivos 66\% está vinculado, quanto aos segmentos de atuação 44\% são de Movimentos Sociais do Campo, ver gráfico 4.

Gráfico 4 - Participação em Movimentos Sociais ou Coletivos e segmentos.
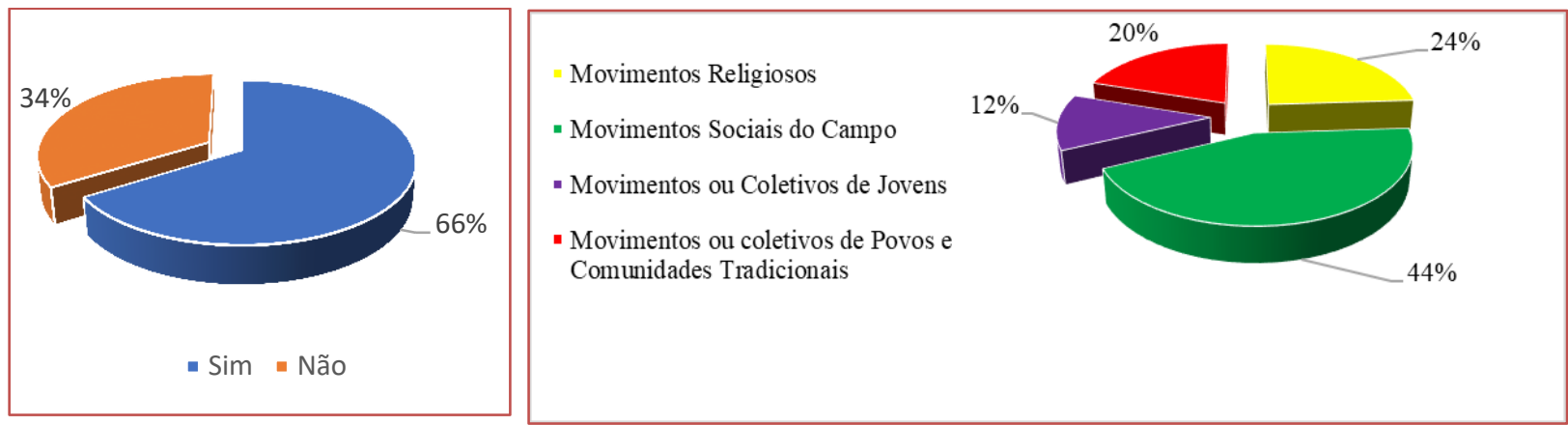

Fonte: Dados da pesquisa.

Outros segmentos citados em menores proporções foram: Assistência Técnica e Extensão Rural; Movimentos ou Coletivos de Mulheres; Rede de Agroecologia.

Medeiros e Dias (2011) mencionam que se as instituições que participam do colegiado, mas não percebem tal Política Territorial como algo estratégico, capaz de promover mudanças significativas no país, sua contribuição no debate já nasce comprometida. A presença no colegiado de entidades que não estão preparadas tecnicamente ou dispostas a contribuir com a discussão territorial faz com que o debate seja monopolizado por um grupo restrito de organizações que, no limite, pode utilizar da estrutura do colegiado para reforçar seus próprios interesses.

O Codeter/TCCRO não é apenas o espaço físico, mas um espaço dinâmico, de relações sociais, econômicas, ambientais e de construção de identidades, neste sentido o gráfico 5, mostra que $32 \%$ dos membros estão a menos de 1 ano participando das discussões territoriais, no entanto também aponta que $29 \%$ contribui para a política territorial a mais de 7 anos.

Gráfico 5 - Tempo de participação no Colegiado Territorial.

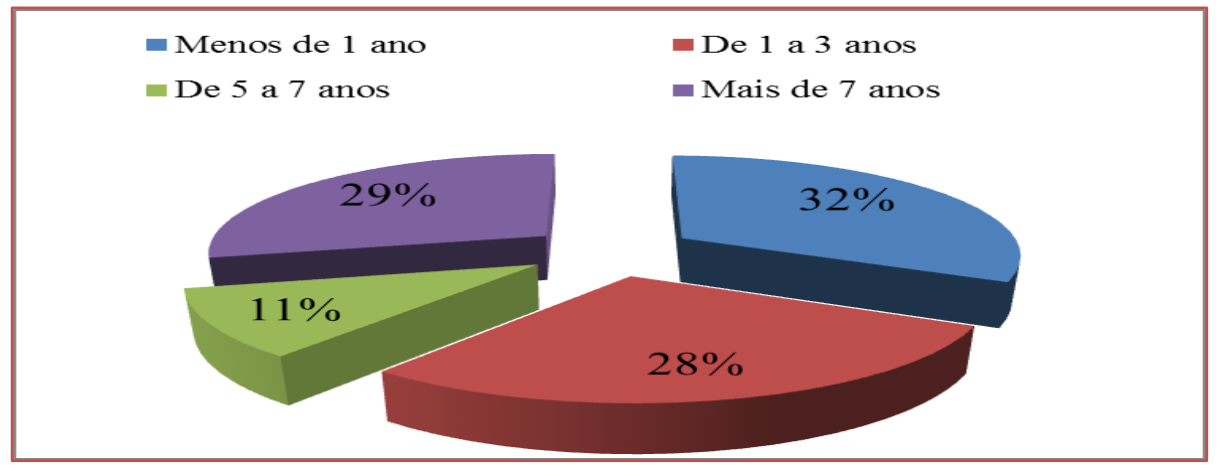

Fonte: Dados da pesquisa.

Estes atores sociais estão organizados em instâncias colegiadas territoriais, são instâncias de gestão social no território. Constituídas como espaços de pactuação e deliberação entre os diferentes segmentos organizados que o integram. Dos entrevistados $21 \%$ fazem parte das Câmaras ou Comitês Temáticos/Setoriais, 3\% Núcleo Técnico e 14\% Núcleo Diretivo/Dirigente ou Similar (Gráfico 6). 
Gráfico 6 - Instâncias do Colegiado Territorial que os membros participam.

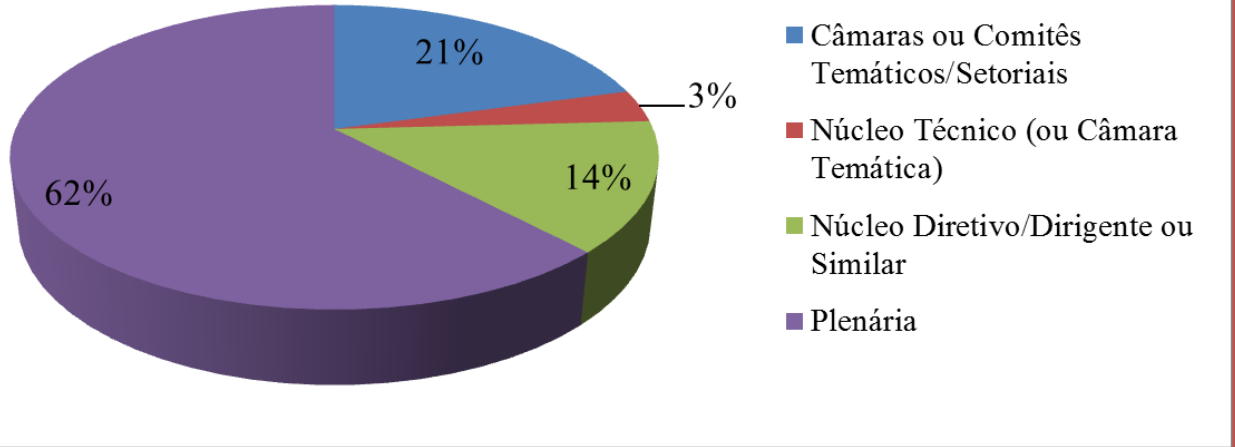

Fonte: Dados da pesquisa.

A Resolução no 52 Condraf, de 16 de fevereiro de 2005, recomenda a seguinte organização:

Plenário (instância deliberativa máxima), Núcleo Diretivo (gerencial, responsável pela implementação de ações e articulações de parcerias), Núcleo Técnico (encarregado do apoio técnico e administrativo às ações territoriais, tais como técnicos e especialistas de assistência técnica e extensão rural, universidades e instituições de ensino e pesquisa). Câmaras temáticas ou Comitês Setoriais - Câmaras Temáticas contribuem para mobilizar e articular os atores territoriais para a discussão e condução de temáticas específicas, tais como: Ater, Crédito, Inclusão Produtiva, Meio Ambiente, subsidiando as decisões do Plenário e a condução das ações pelo Núcleo Diretivo. Já os Comitês Setoriais têm por objetivo fortalecer a organização dos segmentos sociais historicamente fragilizados, consolidando um espaço de identidade e representação e para a discussão de suas pautas específicas, para além do plenário (ex: jovens, ribeirinhos, extrativistas, mulheres, povos e comunidades tradicionais, entre outros).

Estas instâncias territoriais garantem a valorização e o respeito às pessoas e o apoio à gestão democrática com participação social no Codeter/TCCRO. Por essa razão, as ações envolvendo a abordagem territorial também compreenderam a valorização e o estímulo à participação ativa das populações nos processos de planejamento e ações nos territórios.

Portanto, o modelo de democracia participativa adotada pelas instâncias, como aponta o gráfico 7, é a votação em $52 \%$ dos casos, pois valoriza a participação popular no processo de gestão social das políticas públicas.

Gráfico 7 - Metodologia de tomada de decisão nas reuniões do Colegiado Territorial.

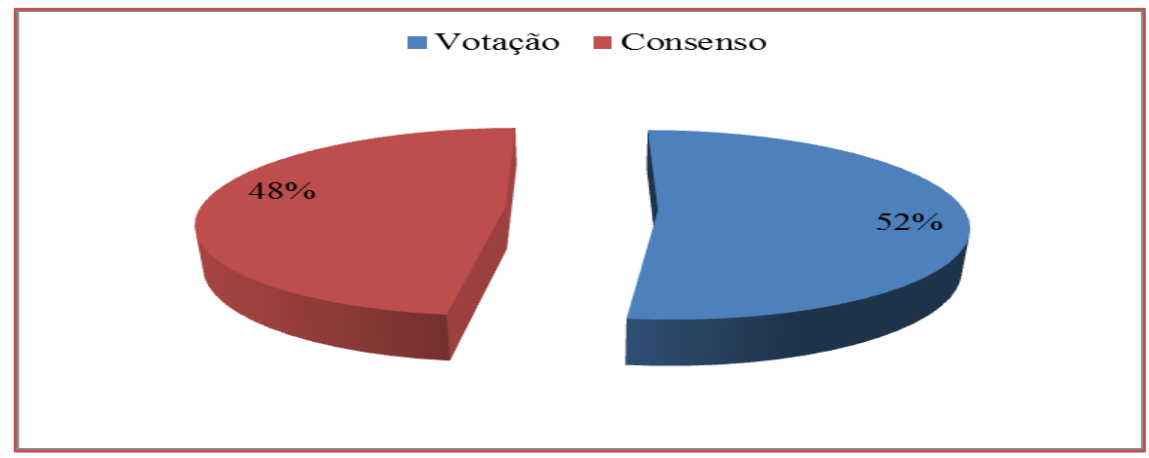


Por este motivo que o Programa Nacional de Desenvolvimento Sustentável de Territórios Rurais - Pronat para reconhecer os territórios levou em consideração à presença do poder público e da sociedade civil na composição dos órgãos colegiados, chamados de Colegiados Territoriais, gerando um ambiente inovador de diálogo e promoção do desenvolvimento (SDT, 2016).

Segundo 76\% dos membros entrevistados há necessidade no Codeter/TCCRO de representatividade de outros grupos sociais que são importantes para o desenvolvimento do território, ver gráfico 8.

Gráfico 8 - Grupos ou pessoas consideradas importantes para o desenvolvimento do território que NÃO SÃo membros do Colegiado.

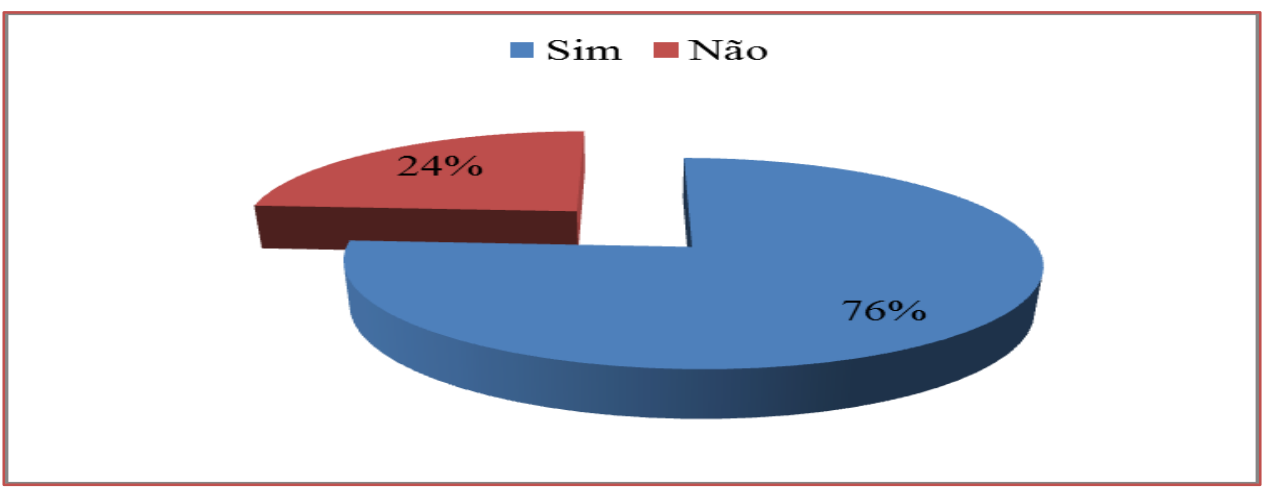

Fonte: Dados da pesquisa.

Os grupos mencionados pelos membros foram representantes de Assentados(as) e/ou acampados(as) da Reforma Agrária; Sindicatos; Colônias de Pescadores; ONGs - Organizações Não Governamentais; Associações; Cooperativas; Entidades Religiosas; Universidades e outras Instituições de Ensino; Órgãos de Pesquisa, Extensão e Assistência Técnica; Setor Empresarial/Comércio; Governo Federal, Estadual e Municipal; Conselhos Estaduais e Municipais.

Os colegiados são dotados de plena autonomia para deliberar sobre sua agenda, suas pautas prioritárias e suas estratégias de controle social das políticas públicas. Organizam-se segundo os preceitos da participação, transparência, representatividade, diversidade e pluralidade conforme estabelecido na Resolução no 52 do Condraf (2005). Portanto, a participação destes grupos é de fundamental importância para o desenvolvimento territorial, pois são capazes de desenvolver uma leitura aprofundada da realidade local e contribuir para o processo de gestão e planejamento estratégico dos programas e políticas públicas Federais, Estaduais e Municipais.

Gráfico 9 - Papel desempenhado pela Plenária do Colegiado em relação aos projetos financiados pelo PROINF.

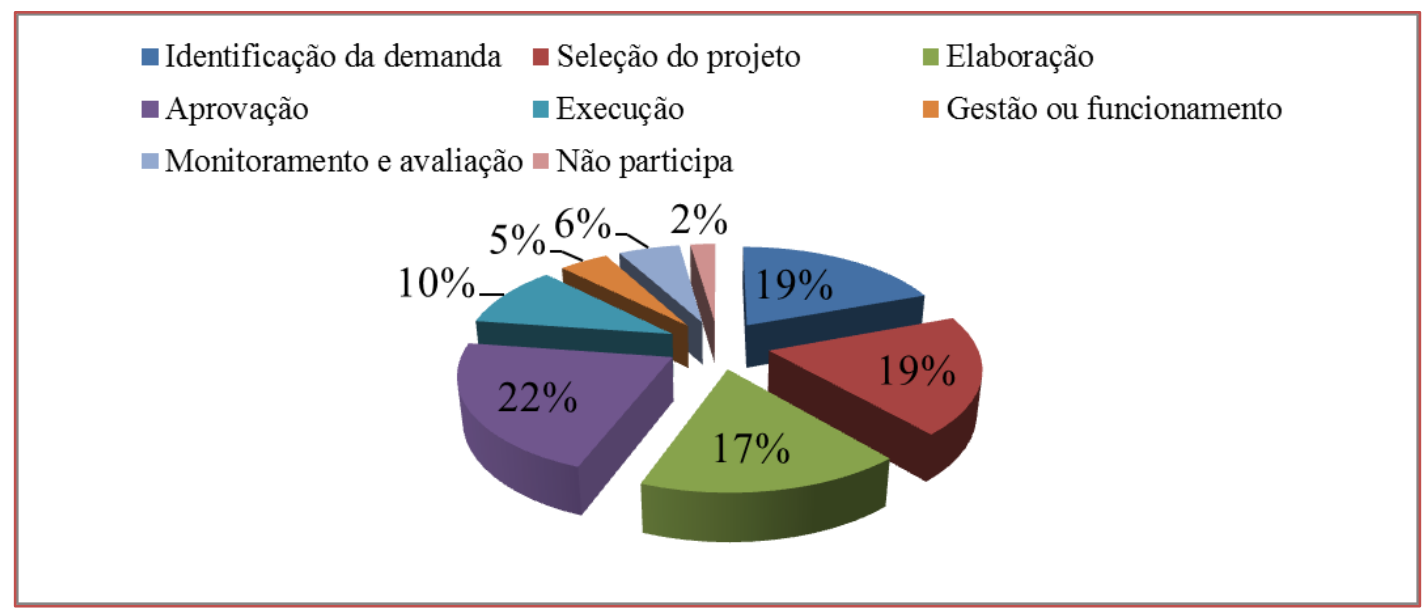

Fonte: Dados da pesquisa. 
O Codeter/TCCRO, como aponta o gráfico 9, é capaz de desempenhar em plenária o papel de identificação de demanda e seleção de projetos, ambos $19 \%$, de elaborar $17 \%$ e aprovar $22 \%$ projetos financiados pela Ação de Apoio a Projetos de Infraestrutura e Serviços em Territórios Rurais - Proinf (Gráfico 9).

o Proinf operacionalizado pela SDT/MDA tem contribuído para a qualificação de processos produtivos e econômicos da agricultura familiar nos Territórios Rurais. Parcerias com estados, municípios e participação da sociedade têm apoiado a aquisição de equipamentos e a construção de infraestrutura para a produção, beneficiamento, escoamento e comercialização de produtos da agricultura familiar nos territórios rurais. Estes resultados posicionam o Proinf como importante instrumento indutor dos processos de inclusão produtiva, de geração de trabalho e renda e de autonomia econômica de famílias e empreendimentos da agricultura familiar.

O programa de Infraestrutura e Serviços em Territórios Rurais está vinculado ao Pronat, Programa de Desenvolvimento Sustentável de Territórios Rurais. A gestão da ação e apoio aos projetos está estruturada no desenvolvimento rural sustentável e na participação dos colegiados territoriais para a definição dos projetos e demandas nos territórios rurais.

Estudos como o de Favareto e Demarco, (2004) apontam as fragilidades e limitações das experiências de espaços públicos de participação social no meio rural. Os estudos estão vínculos aos CMDRS, apontam o caráter estritamente normativo, a incapacidade de agrupar a diversidade de atores sociais, a falta de interesse dos agricultores e suas organizações, e principalmente, a restrição de sua atuação à agricultura familiar, e sua fragilidade em gerenciar os recursos públicos (oriundos de programas e políticas governamentais) e formular projetos de financiamento viáveis e adequados à realidade local.

Desde a implantação do Proinf na SDT, em 2004, o programa já disponibilizou recursos na ordem de $\mathrm{R}$ \$ 1,9 bilhões em todo o país, para Rondônia o investimento alcançou $\mathrm{R}$ \$ 72.203.814,28 com um total de 419 projetos. No Território Central entre os anos de 2003-2014 foram investidos pelo Proinf o recurso no valor de $\mathrm{R} \$ 21.944 .448,67$ com 112 projetos, todavia devido a ausência de planejamento muitos então paralisados (SDT, 2015).

Abramovay (2001, p. 124) aponta "que os projetos elaborados para acessar recursos governamentais têm um caráter de lista de compras", quando deveriam apresentar propostas estratégicas para promover a valorização dos recursos e oportunidades existentes na região. Para o autor o problema é oriundo do próprio processo de descentralização, que se reflete no funcionamento destes espaços públicos. Pois, não existe dificuldade de transferir regras formais, estruturas administrativas e procedimentos burocráticos, do governo federal para o plano local. Porém, não se transfere de forma imediata "valores, comportamentos, coesão social e, sobretudo, a confiança entre os indivíduos que os estimulem a tomar em conjunto iniciativas inovadoras". Isso já traduz o risco de que os conselhos e colegiados existam apenas como meras formalidades de obtenção dos recursos públicos.

\section{CONSIDERAÇÕES FINAIS}

0 processo de aprendizagem como resultado da participação nos espaços de discussões Territoriais possui gargalos, assim como na execução, ajuste ou orientação de algumas Políticas Públicas Federais de acordo com as realidades de cada território.

Mesmo os dados apontando a existência de similaridade na paridade de representação entre a sociedade civil e poder público nas discussões do Codeter, pode-se verificar durante as reuniões que os atores sociais da sociedade civil ainda são a minoria, o que contribui para existência de grupos marginalizados e dominantes no Colegiado, dificultando a legitimidade da política territorial.

Verifica-se a existência de participação dos membros do Colegiado em diversos segmentos de instâncias colegiadas, assim como em movimentos sociais ou coletivos de o que contribui para a gestão social do Codeter. Além disso, a pesquisa apontou a inserção de novos membros e a continuação de atores sociais antigos, assegurando os canais de participação social necessários para o fortalecimento da democracia participativa, neste sentido os dados apontaram que as tomadas de decisões são a partir de votação, portanto, cada delegado titular tem direito a voz e voto nas assembleias.

Apontou a necessidade de inserção de outras representações dentre as mais citadas estão: Assentados(as) e/ou acampados(as) da Reforma Agrária, Sindicatos, Colônias de Pescadores, ONGs - Organizações Não Governamentais, Associações, Cooperativas e Universidades e outras Instituições de Ensino. 
De modo que o Codeter/TCCRO é um importante instrumento de tomada de decisão estratégica acerca do futuro do território e não apenas para atender os interesses fragmentados dos diferentes atores que deles fazem parte, estes espaços fortalecem a expressão da territorialidade, enquanto sentido de pertença, ao considerar e envolver a sociedade e seus meios de convivência no planejamento e gestão das políticas públicas, no entanto, estas devem continuar sendo vivenciadas e investigadas para serem cada vez mais percebidas e aprimoradas.

\section{REFERÊNCIAS}

[1] ABRAMOVAY, R. Funções e medidas da ruralidade no desenvolvimento contemporâneo. Rio de Janeiro: Ipea, 2000 .

[2] _ _ Conselhos além dos limites. Estudos Avançados, São Paulo, v.15. n. 43, p.121-140, 2001.

[3] _. _ 0 futuro das regiões rurais. Porto Alegre: Editora UFRGS, 2003.

[4] ___. Para una teoria de los estudios territoriales. In: MANZANAL, M.; NEIMAN, G.; LATTUADA, M. Desarrollo rural: organizaciones, instituciones y territorios. Buenos Aires: Ciccus, 2006. p. 51-70.

[5] BOURDIEU, P. Les structures socials de l'économie. Paris: Seuil, 2000.

[6] CONSELHO NACIONAL DE DESENVOLVIMENTO RURAL SUSTENTAVEL. Resolução CONDRAF no 52 de 16 de fevereiro de 2005. Aprova Recomendações do Conselho Nacional de Desenvolvimento Rural Sustentável - CONDRAF para as Institucionalidades Territoriais de Desenvolvimento Rural Sustentável. Disponível em: <http://portal.mda.gov.br/portal/condraf/arquivos/view/resolu-es-condraf/52>.

[7] CTA-ZM, Centro de Tecnologias Alternativas da Zona da Mata. Plano Territorial de Desenvolvimento Rural sustentável (PTDRS) do Território da Serra do Brigadeiro. 2004. Disponível em: <http://sit.mda.gov.br/download/ptdrs/ptdrs_territorio078.pdf>. Acesso em: 25 fev. 2017

[8] DELGADO, N. G.; LEITE, S. P. Políticas de desenvolvimento territorial no meio rural brasileiro: novas institucionalidades e protagonismo dos atores. Revista de Ciências Sociais, Rio de Janeiro, v. 54, n. 2, p. 431-473. mar. 2010/ago. 2011.

[9] DI MEO, G. Géographie sociale et territoires. Paris, Nathan: 1998.

[10] DIAS, M. M. Relatório qualitativo do processo de desenvolvimento territorial: território médio rio doce. MDA/SDT e PLURAL, Viçosa-MG, 2008.

[11] FAVARETO, A. DEMARCO, D. Entre o capital social e o bloqueio institucional: uma análise dos CMDR em cinco estados brasileiros. In: SCHNEIDER, Sergio et al. (Orgs.) Políticas públicas e participação social no Brasil rural. Porto Alegre: UFRGS (Séries estudos rurais), 2004.

[12] FLORISBELO, Glauco R. Estudo propositivo da base econômica territorial: Território Médio Rio Doce. MDA/SDT, Viçosa-MG, 2005

[13] FREITAS, A. F. et al. O programa Nacional de Desenvolvimento Sustentável de Territórios Rurais: a indução de territorialidades à ação pública. Revista Perspectivas em Políticas Públicas, v. 3, p. 27-58, 2010.

[14] GEHLEN, I.; RIELLA, A. Dinâmicas territoriais e desenvolvimento sustentável. Revista Sociologias, Porto Alegre, v. 6, n. 11, p. 20-26, jan./jun. 2004.

[15] GUANZIROLI, C. E. Desenvolvimento territorial no Brasil: uma polemica. Niterói: UFF, 2008.

[16] IBGE. Censo demográfico 2017. Disponível em: <https://cidades.ibge.gov.br/v4/brasil/ac/panorama>. Acesso em: 10 jan. 2018.

[17] JARA, C. J. A Sustentabilidade do Desenvolvimento Local. Brasília: IICA: Recife: Secretaria de Planejamento do estado de Pernambuco. SEPLAN, 1998.

[18] MEDEIROS, L. S.; DIAS, M. M. Bases para a construção de um marco jurídico-normativo do desenvolvimento territorial no Brasil. In: MIRANDA, Carlos; TIBÚRCIO, Breno. (Org.). Políticas de Desenvolvimento Territorial: desafios para a construção de um marco jurídico-normativo. Brasília: IICA, v. 13, p. 127-242, 2011.

[19] PTDRS, Plano Territorial de Desenvolvimento Rural Sustentável. Territórios de Rondônia: Território Central. 2013. Disponível em: <http://www.rioterra.org.br/ptdrs/>. Acesso em: 11 fev. 2017.

[20] SACK, R. Human territoriality: theory and history. Cambridge: Cambridge University Press, 1980.

[21] SANTOS, M. O papel ativo da geografia: um manifesto. In: BRANDÃO, M. A. Milton Santos e o Brasil. São Paulo: Fundação Perseu Abramo, 2004. p. 253-26. 
[22] SDT, Secretaria de Desenvolvimento Territorial. Balanço de Gestão Ministério do Desenvolvimento Agrário 2015-2016 - Resultados das Ações da Secretaria de Desenvolvimento Territorial - SDT. 2016. Disponível em: <http://www.mda.gov.br/sitemda/sites/sitemda/files/user_img_21/Relat\%C3\%B3rio\%20de\%20Gest\%C3\%A3o\%2 02015.pdf>. Acesso em: 15 fev. 2017.
[23]
Caderno
Territorial.
2015.
Disponível
em:

<http://191.33.175.161/portaldosnedets/jasperphp/gerarRelatorio.php?P_USU=856\&relatorio=sdt_caderno_territor ial\&formato=pdf\&P_TER=29\&P_UF=R0\&PHPSESSID=9b811cbd23d0fa6072fa993d143ab94b>. Acesso em: $11 \mathrm{mar}$. 2017

[24] TEIXEIRA DA ROCHA, M. R.; FILIPPI, E. E. Política para o desenvolvimento dos territórios rurais no Brasil: propostas e fundamentos. In: Seminario Internacional de Desarrollo Rural - Configuraciones de los Territorios Rurales en el Siglo XXI, 4, 2007, Bogotá. Anales del VI Seminario Internacional de Desarrollo Rural. Bogotá (Colômbia), 2008. 


\section{Capítulo 18}

\section{RESPONSABILIDADE SOCIOAMBIENTAL NO TURISMO: O CASO DA EMPRESA AMBIENTAL VIAGENS E TURISMO}

\section{Denise Rugani Töpke}

\section{Mariana Pires Vidal López}

Resumo: 0 presente artigo tem como objetivo apresentar como as práticas de Responsabilidade Socioambiental podem ser úteis para a área de Turismo. Para aprofundar o tema é importante que se entenda que uma empresa turística pode ser considerada uma organização que, como tal, é influenciada e recebe influências no meio em que atua. Deste modo, para entender o papel de uma empresa turística, é fundamental que esta trabalhe o seu relacionamento com os stakeholders. Uma vez que a empresa turística faça um mapeamento de seus públicos e estabeleça estratégias adequadas de aproximação para com eles, pode, inclusive, obter vantagem competitiva em relação às outras empresas do setor. Uma área do turismo que tem ganhado destaque nas práticas de Responsabilidade Socioambiental é o Turismo Sustentável. Para exemplificar este argumento, serão apresentadas as práticas da empresa turística Ambiental Viagens e Turismo, ganhadora do Prêmio Braztoa de Sustentabilidade, que é uma referência nesta área.

Palavras-chave: Responsabilidade Socioambiental, Turismo Sustentável, stakeholders. 


\section{INTRODUÇÃO}

A Responsabilidade Socioambiental tornou-se uma preocupação fundamental no meio empresarial. 0 tema da "responsabilidade" trouxe a "moda" das propagandas institucionais. As organizações, mais do que nunca, vendem seus produtos e serviços; mas, acima de tudo, suas imagens corporativas.

Para trabalhar sua imagem empresarial de forma positiva, muitas empresas têm associado suas práticas, produtos e serviços aos conceitos de "verdes", "sociais", "sustentáveis" e uma série de outras terminologias similares. Isso tem acontecido porque os empresários perceberam que os consumidores estão cada vez mais informados e exigentes e que agregar valor à imagem institucional, por sua vez, agrega valor à imagem dos produtos e serviços vendidos pela empresa.

Em um mercado globalizado onde produtos e serviços tem se tornado cada dia mais similares devido à concorrência em nível global e às mudanças tecnológicas constantes, criar diferenciais de marca transformou-se num desafio para os profissionais de marketing. Esses diferenciais estão migrando para os "valores intrínsecos" das marcas, ou seja, questões como "onde o produto é fabricado?", "como é fabricado?", "a empresa utiliza mão de obra escrava?", "polui o meio ambiente para fabricar seus produtos?" e etc. tem se tornado uma preocupação de uma parcela dos consumidores e da opinião pública em geral.

Deste modo, as empresas perceberam que trabalhar com a Responsabilidade Social Empresarial (RSE) é de fundamental importância no contexto atual. Vincular a imagem corporativa às práticas que minimizem o impacto da empresa no meio ambiente e que possibilitem melhorias sociais pode representar uma vantagem competitiva20 para a empresa. Ou seja, se as empresas atuarem de forma responsável, todos ganham: a empresa, a sociedade e o meio ambiente.

Neste contexto, a área de Turismo também não poderia ficar de fora. Alguns meios de hospedagem, por exemplo, já iniciaram ações sustentáveis, como a coleta seletiva, horta orgânica, redução e reuso da energia e da água e etc.21 No segmento de

agências de viagens e turismo destaca-se a empresa Ambiental Viagens e Turismo que em 2012 ganhou o prêmio Braztoa no quesito de Responsabilidade Socioambiental. Este artigo tem como um de seus objetivos apresentar as ações socioambientais praticadas por esta empresa.

\section{RESPONSABILIDADE SOCIOAMBIENTAL}

Em uma sociedade globalizada onde a informação circula de maneira contínua e pulverizada, os consumidores tem muito mais facilidade de acesso a informações sobre as empresas fabricantes dos produtos e serviços que consomem. Neste cenário, os indivíduos possuem maior capacidade de interação, e, portanto, esperam respostas das empresas em tempo real.

Para Dias (2012), em relação às ligações entre empresa e sociedade, existem duas abordagens: uma considera que a empresa tem papel unicamente econômico, com produção eficiente de bens e serviços; a outra apresenta uma perspectiva mais social, que considera que a empresa, além dos benefícios econômicos, integra a estrutura social em que atua.

Por esta perspectiva mais social, as empresas de um modo geral podem ser entendidas como organizações e, portanto, como "organismos vivos" que interagem com o ambiente, recebendo e exercendo influência sobre ele.

20 Carneiro, Cavalcanti e Silva (1997) revisitam a obra de Michael Porter e concluíram que na obra de 1980 Porter fundamenta a vantagem competitiva na criação de barreiras de entrada ou de mobilidade. Já em 1996, Porter apresenta uma visão sistêmica da vantagem competitiva. A vantagem competitiva não está nas partes de uma empresa e, sim, nas relações e ajustes das atividades de seu sistema complexo. De acordo com Ghemawat (1998, p.31), as vantagens competitivas sustentáveis devem estar incluídas em três categorias: "porte no mercado-alvo, acesso superior a recursos ou clientes e restrições a opções dos concorrentes".

21 Ver artigos anteriores das autoras: Hotelaria sustentável: preocupação com a comunidade local ou diferencial competitivo? Publicado na Revista Acadêmica do OIT (Observatório de Inovação do Turismo), Vol. VI, n.3, 2011. E $O$ paradigma ambiental sob a ótica da Hotelaria Sustentável: o caso do Hotel Bühler. Publicado no livro eletrônico "Comunidades, natureza e cultura no turismo" do I Congresso Nacional de Turismo Comunitário e VI Simpósio de Turismo Sertanejo, realizado em 2012. 
De acordo com Sousa (1978, p.22), os primeiros teóricos a tratar o tema da "organização" desconsideravam o meio externo e tratavam a organização como um sistema fechado, analisando apenas a sua estrutura formal (divisão do trabalho, processos funcionais e etc.).

Na década de 1920, Karl Ludwig Von Bertalanffy (1901-1972), um biólogo austríaco que desenvolveu a maior parte dos seus trabalhos nos Estados Unidos, sentiu-se incomodado com as evidentes lacunas que existiam na teoria e na pesquisa no campo da Biologia. 0 enfoque mecanicista, que predominava na época, não considerava uma visão organísmica; ou seja, não entendia um organismo vivo como uma totalidade ou sistema. E, assim, Ludwig tornou-se um dos precursores da Teoria Geral dos Sistemas. O biológico enfatizava que os organismos vivos são essencialmente sistemas abertos e que, portanto, trocam matéria com o ambiente. Este estudo questionava a abordagem tradicional da física e da físico-química que considerava os organismos como sistemas fechados.

Crucial na Teoria Geral de Sistemas é a concepção de abertura para tratar dos sistemas. A partir dessa premissa, as organizações são tidas como sistemas abertos. Abertos porque uma organização é composta por pessoas e, portanto, ao contrário do que ocorre nos sistemas fechados, que basicamente se caracterizam pela previsibilidade e a conformidade; as pessoas são imprevisíveis.

Nas últimas décadas do século XX, algumas tendências sociais como a aceleração do processo de inovação tecnológica, a intensificação da globalização e os processos de reformulação do papel do Estado contribuíram para alterar a dinâmica de funcionamento da sociedade. Essas mudanças sociais ocasionaram a necessidade de uma transformação no papel das empresas que passaram a ser entendidas como agentes sociais.

Sardinha (2009) destaca esse papel social das organizações

Para construir de forma bem-sucedida um posicionamento estratégico pautado pela responsabilidade socioambiental, é necessário, antes de tudo, compreender a essência da responsabilidade empresarial. Toda empresa ou, no sentido mais amplo, toda organização humana, atua como um organismo em permanente interação com seu ambiente. Essas interações provocam externalidades que afetam seus stakeholders não só do ponto de vista econômico e legal, mas também social e ambiental. (SARDINHA, 2009, p.43)

Todas as organizações, de qualquer natureza, interagem com a comunidade e o ambiente. Neste contexto, é compreensível que as organizações reconheçam a Responsabilidade Social como um tema relevante. 0 Instituto Ethos22 define Responsabilidade Social Corporativa como

Responsabilidade social empresarial é a forma de gestão que se define pela relação ética e transparente da empresa com todos os públicos com os quais ela se relaciona e pelo estabelecimento de metas empresariais que impulsionem o desenvolvimento sustentável da sociedade, preservando recursos ambientais e culturais para as gerações futuras, respeitando a diversidade e promovendo a redução das desigualdades sociais. (Disponível em http://www1.ethos.org.br)

Conforme ressalta esta definição, a prática da Responsabilidade Social Empresarial (RSE) pressupõe uma relação ética e transparente com os públicos com os quais a empresa se relaciona. Mas quem são os "públicos" de uma empresa?

Atualmente fala-se como nunca do conceito de RSE, entretanto, a área de Relações Públicas há muito tempo considera o conceito, visto que entende que a atuação de uma empresa em um determinado mercado nunca poderá se dar de maneira isolada, pois ela precisa se relacionar continuamente com os públicos envolvidos. Conforme ressalta Fortes (2003, p.18), "Estão na abrangência da esfera das Relações Públicas os grupos que possivelmente tenham ou venham a ter curiosidade ou inquietação com uma empresa específica". Ou seja, o relações-públicas é um conciliador entre os diversos interesses da empresa e dos públicos com os quais ela se relaciona.

220 Instituto Ethos de Empresas e Responsabilidade Social é uma associação de empresas, sem fins lucrativos, criada com a missão de mobilizar, sensibilizar e ajudar as empresas a gerir seus negócios de forma socialmente responsável, tornando-as parceiras na construção de uma sociedade sustentável e justa. Interesse Público (Oscip). 
Deste modo, podemos recorrer ao conceito de "públicos" a partir da abordagem das Relações Públicas. França (2009) revisita este conceito e, dentre todas as revisões bibliográficas que o autor faz, podemos resumir três aspectos fundamentais sobre o conceito de "públicos" em RP. Primeiro, é importante destacar que os públicos representam a matéria prima da área de RP, visto que é primordial para o profissional desta área identificá-los e conhecê-los para aprender a lidar com eles e consequentemente possibilitar que as empresas sejam bem sucedidas nesses relacionamentos. Além disso, não se pode falar em "público geral", pois os públicos são sempre específicos, uma vez que diferentes públicos apresentam problemas comuns. E, por último, cabe destacar que o trabalho de RP possibilita o estabelecimento de listas de públicos para os quais se planejam ações específicas de "aproximação".

Uma abordagem muito similar e que se tornou bastante difundida recentemente propõe o conceito de stakeholders. Para Rocha e Goldschmidt (2010, p.13) "Na visão baseada na gestão dos stakeholders, a empresa é vista como o centro de uma rede de públicos interessados e a obtenção da vantagem competitiva baseia-se na gestão superior do relacionamento e comunicação com esses públicos". Ou seja, a empresa entende que um bom relacionamento com os stakeholders permite um ganho de vantagem competitiva e, portanto, é vantajoso que a empresa administre esses relacionamentos.

Tanto o conceito de "públicos" quanto o de "stakeholders" pressupõe que a empresa precisa estar "aberta" e "antenada" para se relacionar com o meio em que está inserida e que, portanto, precisa saber administrar os diversos relacionamentos que possui. A adoção das práticas de RSE é uma atitude voluntária das empresas que também pode representar uma vantagem competitiva dentro do mercado em que ela atua.

A RSE ultrapassa as determinações legais. É uma mudança de orientação empresarial que exige novas lideranças, conectadas às constantes modificações de um ambiente dinâmico e de públicos cada vez mais informados e exigentes em relação à atividade empresarial. Esta necessidade de mudança de orientação empresarial é um reflexo da evolução das questões sociais. Conforme aponta Sardinha (2009),

No início do último século, a responsabilidade empresarial correspondia às questões de natureza econômica e legal, compreendendo o papel das empresas de gerar empregos, pagar os impostos devidos, cumprir as leis e contribuir para o desenvolvimento econômico. Ações na esfera social se davam apenas em termos de práticas individuais. (SARDINHA, 2009, p.44)

Cabe também ressaltar a diferença conceitual entre filantropia e RSE. Conforme define o site do Instituto Ethos

A filantropia é basicamente uma ação social externa da empresa, que tem como beneficiária principal a comunidade em suas diversas formas (conselhos comunitários, organizações não-governamentais, associações comunitárias etc) e organizações. A responsabilidade social é focada na cadeia de negócios da empresa e engloba preocupações com um público maior (acionistas, funcionários, prestadores de serviço, fornecedores, consumidores, comunidade, governo e meio ambiente), cuja demanda e necessidade a empresa deve buscar entender e incorporar aos negócios. Assim, a responsabilidade social trata diretamente dos negócios da empresa e de como ela os conduz. (Disponível em http://www.ethos.org.br).

O conceito de cidadania corporativa é muito similar ao da Responsabilidade Social e considera que as empresas não devem ser entendidas apenas como agentes econômicos, mas também como agentes sociais. Por este conceito, a cidadania corporativa é a concretização na prática do conceito de Responsabilidade Social. Ou seja, as empresas passam a ser como as pessoas, "integrando a sociedade como unidades autônomas e como tal possuindo responsabilidades que lhes são inerentes e que lhes concedem o status de cidadania" (DIAS, 2012, p.56).

As empresas que praticam a cidadania corporativa assumem voluntariamente o seu papel social e agem além de obrigações econômicas e legais. A prática da Responsabilidade Social Empresarial beneficia a todos: empresa, sociedade, meio ambiente, uma vez que permite identificar, corrigir e prevenir os impactos negativos da atuação empresarial. 


\section{TURISMO E RESPONSABILIDADE SOCIOAMBIENTAL}

O turismo nos dias atuais é uma das ferramentas essenciais para o crescimento econômico de um país. De fato, sabe-se que o turismo traz melhorias para as populações locais através da economia, permitindo sua alavancagem e movimentação. Sendo uma alternativa de apoio às demais economias locais e, ao mesmo tempo, gerador de divisas e de inúmeros outros benefícios. Mas é necessário compreender, que toda atividade turística também ocasiona vários impactos negativos ao meio ambiente e à população autóctone, conforme destacaremos abaixo.

Grande parte do dinheiro investido e gasto nos destinos não fica no destino turístico, uma vez que a maioria das empresas turísticas não são locais, com sede, muitas vezes, até mesmo em outros países. Além disso, a oferta de empregos gerada pelo turismo corresponde, muitas vezes, a cargos operacionais, que não necessitam de maior qualificação e que, portanto, não contribuem para elevar a capacitação da mão de obra local. Outra questão se refere ao fato das comunidades criarem certa dependência econômica em relação ao turismo. Também há a possibilidade de perda da identidade da população autóctone, que pode ser ocasionada pela falta de sensibilização e pelo choque cultural proporcionado pela atividade. Ainda podemos destacar a degradação ao patrimônio histórico, artístico e paisagístico das comunidades, principalmente, em decorrência de seu mau uso.

Dentro desta perspectiva, torna-se relevante a participação de diversos segmentos da sociedade e a interação entre si, em especial do trade turístico a fim de colaborar com a promoção de um turismo melhor e mais inclusivo. Os impactos causados pela atividade turística representam um entrave ao seu completo desenvolvimento como indutor de uma sociedade solidária e sustentável do ponto de vista socioambiental.

Acredita-se que a Responsabilidade Socioambiental é um fator capaz de agregar valor à cadeia do turismo, em conjunto com entidades do governo, iniciativa privada e sociedade civil organizada a fim de estabelecer ações de cidadania. (Virginio e Fernandes, 2011).

A atividade turística, seguindo os passos de outros setores, vem utilizando novos procedimentos mercadológicos, sendo um deles direcionado para a qualidade do atendimento ao cliente e o outro destinado aos seus aspectos de cidadania junto à comunidade; buscando agir de forma ética e preservar valores morais e sociais.

Quando se pensa em responsabilidade social atrelada ao turismo logo se faz uma associação restrita à preservação ambiental, mas sendo o turismo multidisciplinar, este pode englobar várias formas possíveis de Responsabilidade Socioambiental que uma empresa nesta área seja capaz de realizar.

0 turismo tem tentado trabalhar suas interrelações em uma visão holística de desenvolvimento sustentável ao qual se pode inserir a Responsabilidade Social, para restituir a sociedade no uso de recursos naturais e culturais, através de ações sociais. (Bahl, 2004).

Segundo Kotler (1996):

(...) responsabilidades sociais são atribuições que a sociedade estipula para as instituições, tendo por objetivos definir algumas obrigações relacionadas à preservação do meio ambiente, dos direitos das minorias e dos direitos das populações estabelecidas (nativas ou não). Muitos empresários do setor turístico, infelizmente, ainda entendem que sua responsabilidade social é exclusivamente para com o turista, restrita unicamente ao cumprimento da obrigação legal de oferecer-lhe o que é prometido nas divulgações para venda de pacotes e ofertas turísticas.

Segundo Beni (2001)

(...) no cenário nacional, surgiu recentemente um avanço no sistema de parceria em virtude da falência do Estado na solução dos problemas sociais com responsabilidade e justiça. 0 próprio governo federal vem conferindo ênfase à formação de organizações sociais.

Neste contexto o setor turístico pode contribuir com a comunidade e fazer com que o turismo se desenvolva para benefício de todos.

O turismo é uma atividade privilegiada para a reflexão do tema, na medida em que a atividade afeta a sociedade sobre diferentes e abrangentes aspectos. Além do aspecto econômico, nos mais variados níveis e, neste âmbito, com uma ampla gama de setores envolvidos, em razão de sua extensa cadeia produtiva, o 
turismo produz mudanças socioespaciais e põe em contato grupos sociais diferenciados. A forma como é organizado, planejado e operado, portanto, com maior ou menor comprometimento com as sociedades e com o meio ambiente das localidades envolvidas, produzirá impactos positivos ou negativos em diferentes gradações (Ferreira, 2008).

Para que um destino seja receptor de turistas, este deve realçar aspectos da sua riqueza natural, cultural e exótica, pois estes fatores, atrelados às boas condições estruturais de acesso e serviços, tendem a impulsionar o interesse por parte das pessoas quando decidem visitar um destino. Dentro desta perspectiva, uma empresa que se configure como responsável socioambiental deve ter características, como por exemplo: manter um sistema de gerenciamento ambiental evitando desgastes ao meio; aplicar medidas de proteção ambiental no seu entorno e minimizar os riscos; adotar medidas de racionalização dos principais insumos industriais, como energia elétrica, combustível e água, entre outros. (Virginio e Fernandes, 2011).

Com isso, a Responsabilidade Social no turismo nasce com o intuito de amenizar impactos causados por empresas de modo a garantir respeito e admiração por parte das pessoas, sejam elas consumidores ou não. Nestes aspectos podem ser consolidadas ações que interferem nas atividades desenvolvidas pelas empresas, a fim de minimizar possíveis danos ao meio ambiente e, mais especificamente, à sociedade localizada em seu entorno.

\subsection{AÇÕES DE RSE NA ÁREA DE TURISMO}

Na área do Turismo as ações de Responsabilidade Social Empresarial que tem ganhado destaque se referem às práticas ligadas ao conceito de desenvolvimento sustentável nas localidades.

Conforme aponta Irving (2002), a concepção de desenvolvimento sustentável implica em um novo paradigma do pensar nas sociedades humanas segundo uma nova ética de democratização de oportunidades e justiça social. Assim,

Um projeto de desenvolvimento sustentável verdadeiro deve ser centrado nos valores tradicionais dos povos e suas conexões holísticas. Desse modo as desigualdades serão reduzidas e a qualidade de vida e ambiental universalizadas (SEABRA, 2011, p. 26).

A aplicação dos princípios da sustentabilidade ao turismo integra-se à dicotomia existente entre a difusão e a limitação do progresso alcançado. Desses princípios que norteiam o paradigma da sustentabilidade, há o debate das implicações do turismo para o desenvolvimento e seus efeitos ambientais, socioculturais e econômicos (DIAS, 2008). Segundo a Carta de Turismo Sustentável de Lanzarote (1995),

0 desenvolvimento sustentável é um processo orientado que contempla uma gestão global dos recursos com o objetivo de assegurar sua durabilidade, permitindo conservar nosso capital natural e cultural, incluindo as áreas protegidas. Sendo o turismo um poderoso instrumento de desenvolvimento, pode e deve participar ativamente na estratégia de desenvolvimento sustentável. Uma boa gestão do turismo exige garantir a sustentabilidade dos recursos dos quais depende (CARTA DE TURISMO SUSTENTÁVEL DE LANZAROTE, 1995 apud DIAS, 2008, p.74)

A sustentabilidade constitui uma estratégia para o desenvolvimento equilibrado em médio e longo prazo dos destinos e regiões turísticas. Por isso, os conceitos de desenvolvimento e turismo sustentável estão intimamente ligados à sustentabilidade do meio ambiente. Isto porque o desenvolvimento sustentável e o desenvolvimento do turismo dependem da preservação e da viabilidade de seus recursos de base (MATHEUS, MORAES E CAFFAGNI, 2005).

Um dos objetivos que almeja a sustentabilidade consiste em tornar a comunidade local mais participativa dos benefícios da atividade turística, não apenas por meio de geração de empregos terceirizada, mas também dando a oportunidade dos próprios locais criarem micro e pequenas empresas, sendo eles os próprios gestores locais. Deste modo, o turismo traz um grande benefício para a comunidade, visto que toda a renda gerada pelo turismo fica na própria comunidade.

Segundo Leff (2010, p.157), "O turismo deve incorporar-se a processos integrais de desenvolvimento sustentável dos povos baseados na preservação de suas riquezas naturais e de suas tradições culturais". Um caminho para atingir tal objetivo pode ser trilhado através do turismo sustentável; donde destacamos a atividade do ecoturismo. 
Para Dias (2012), “0 ecoturismo pode ser entendido como o turismo sustentável praticado em áreas naturais”. Um ecoturismo genuíno, que não objetiva mercantilizar a natureza e nem torná-la objeto de contemplação pelo turista, deve também refletir sobre os objetivos do desenvolvimento sustentável.

A participação da população local na atividade ecoturística é de fundamental importância na busca do desenvolvimento sustentável. De acordo com Cavalcanti (2011),

As atividades ecoturísticas devem promover as práticas de lazer, esportivas ou educacionais, em áreas naturais, utilizando de forma sustentável o patrimônio natural e cultural, incentivando sua proteção, promovendo a formação de uma consciência ambiental e garantindo o bem-estar das comunidades envolvidas. Na implantação dessas atividades deve-se contar com o envolvimento efetivo da comunidade local, garantindo que uma parcela significativa da renda fique para as localidades e que sejam respeitadas as características culturais da sociedade, bem como o crescimento do individuo, com noções de tempo, espaço e limites de paisagem (CAVALCANTI, 2011, p.238)

Para Dias (2012, p.104), o ecoturismo “é algo mais que a publicidade de um cenário e a proteção de alguma espécie", pois pretende "oferecer opção real de desenvolvimento sustentável para as populações locais". Ainda de acordo com o autor, o ecoturismo deve "gerar recursos para proteger efetivamente os ecossistemas".

Pode-se dizer que gradualmente algumas empresas turísticas tem despertado para a prática de Responsabilidade Socioambiental através do turismo sustentável e do ecoturismo. Uma empresa que se destaca neste cenário é a Ambiental Viagens e Turismo.

\section{ESTUDO DE CASO: A EMPRESA AMBIENTAL VIAGENS E TURISMO E SEU TRABALHO DE RSE.}

A empresa Ambiental Viagens e Turismo é uma Operadora de Turismo de Natureza que existe há 25 anos no mercado e atua em três segmentos: viagens de lazer e turismo, viagens pedagógicas e de estudo do meio e viagens de incentivo. A empresa visa desenvolver práticas sustentáveis que sejam referência e que contribuam para a mudança no mercado turístico.

Dentre os prêmios recebidos pela empresa, podemos destacar o Prêmio BRAZTOA de Sustentabilidade, recebido em 2012, este prêmio visa à premiação das empresas turísticas que realizaram as melhores práticas do mercado, contribuindo para a promoção do desenvolvimento sustentável do turismo brasileiro. A Associação Brasileira de Operadoras de Turismo (BRAZTOA) congrega as mais conceituadas empresas do setor, entre operadoras de turismo e empresas de representação de produtos nacionais e internacionais e destinos turísticos23.

A Ambiental Viagens e Turismo tem diversas ações de incentivo ao desenvolvimento sustentável no turismo24, dentre elas podemos destacar algumas, conforme veremos a seguir.

A ação Viagem Limpa e Consciente que tem como objetivo, em parceria com a ONG S.O.S Mata Atlântica, fazer o plantio de uma muda nativa, por viajante, para a neutralização do carbono emitido em decorrência da viagem para todos os passageiros em viagem de lazer. Por esta ação, foram plantadas mais de 5000 mudas no período entre 2007 e 2009.

Na mesma ação Viagem Limpa e Consciente foi implementada a adoção de sacolinhas de lixo que foram colocadas no kit de viagem para promover a conscientização do viajante, permitindo que carregasse consigo o lixo gerado, produzido durante sua viagem, evitando o descarte e poluição de trilhas, praias, áreas naturais e etc. Os guias locais também estavam orientados a dar o exemplo e, inclusive, incentivar a limpeza das áreas naturais.

Há também o Projeto de Criação de Abelhas Nativas da Amazônia que se desenvolveu junto com o Projeto Iraquara, especializado em meliponicultura25 e que funciona como o canal de comunicação entre a Ambiental e a comunidade local, sendo responsável por preparar e capacitar a comunidade para

${ }^{23}$ Disponível em http://www.braztoa.com.br. Acesso em 24 de junho de 2013.

24 Todas as ações divulgadas neste trabalho foram fornecidas pela própria empresa através de seu formulário de iniciativas sustentáveis submetido ao Prêmio Braztoa de Sustentabilidade 2012.

${ }^{25}$ É a criação de abelhas sem ferrão. . Sua criação está associada com as espécies que fabricam e armazenam maior quantidade de mel. As abelhas Melipona são as prediletas. Disponível em http://www.webbee.org.br acessado em 01 de julho de 2013. 
potencializar essa atividade econômica. Este projeto reconheceu atividades econômicas sustentáveis para comunidades locais amazônicas, não dependentes do fluxo turístico e ação de conscientização sobre essa atividade considerada ecologicamente correta. A produção do mel, além de se tornar um atrativo ao turista, passa a ser oferecido como produto artesanal local para a comercialização, impulsionando a economia local. Este projeto se reverteu em renda para aproximadamente 120 famílias locais do município de Boa Vista dos Ramos (AM).

A Ambiental desenvolve em parceria com escolas, colégios, faculdades e universidades da cidade de São Paulo e seu entorno, roteiros turísticos adaptados ao formato educacional com foco no meio ambiente, geografia, geologia, além de história e cultura local, desenvolvimento interpessoal e comportamental; ação conhecida como Viagens de Estudo do Meio. No roteiro da Amazônia, por exemplo, se aborda o conteúdo socioambiental de forma interativa, onde a visitação dos alunos nas comunidades locais contribui para a construção da cidadania e quebram-se os preconceitos em torno das diferenças culturais. Esta parceria entre colégio e a operadora visa conquistar a confiança dos pais de alunos e garantir a sustentabilidade das viagens em diferentes gerações. Outro aspecto da Responsabilidade Socioambiental praticada pela empresa ocorre no processo de escolha dos fornecedores, guias e comunidade local que passa a ser transparente e ter o envolvimento dos colégios, universidades etc. Assim, se assimila o sentimento de responsabilidade com a comunidade pela realidade local no destino e se faz de grande relevância vivencial para os alunos.

\section{CONSIDERAÇõES FINAIS}

Conforme foi exposto neste trabalho, uma empresa do trade turístico pode ser entendida como uma organização. Portanto, sua atuação em um destino turístico deve sempre ser pensada em termos dos impactos positivos e negativos que podem ser gerados nesse meio.

A fim de minimizar os impactos negativos, as empresas turísticas podem trabalhar o relacionamento com seus mais diversos públicos, sobretudo comunidade autóctone e turista. Um papel importante de uma empresa turística em relação a esses dois públicos seria o de sua conscientização em relação à preservação ambiental, uma vez que suas atuações são interdependentes. 0 Projeto de Criação de Abelhas Nativas da Amazônia organizado pela Ambiental Viagens e Turismo representa um bom exemplo deste trabalho de conscientização; uma vez que há uma integração entre meio ambiente, comunidade local e turista.

As empresas do trade turístico estão começando a perceber a necessidade de modificação de sua atuação e algumas, sobretudo na área de Turismo Sustentável (ecoturismo), começam a desenvolver trabalhos de Responsabilidade Socioambiental. Entretanto, o trabalho desenvolvido pela empresa citada ganhou destaque neste mercado. Esta empresa, com certeza, deve estar sendo bastante beneficiada por seus ganhos de imagem empresarial, alcançados pelo diferencial de "ser sustentável" e "responsável socialmente".

Uma vez que as empresas turísticas percebam a importância da Responsabilidade Socioambiental, não só para melhorar seu relacionamento com os stakeholders, mas também como uma importante ferramenta para adquirir vantagem competitiva e solidificar sua imagem empresarial, mais práticas serão utilizadas pelas empresas deste ramo de atividade.

Quanto mais empresas praticarem ações de RSE, mais teremos um turismo, de fato, responsável, uma vez que todos os membros da cadeia turística estarão conscientes de seu papel e de sua responsabilidade em relação à preservação do patrimônio histórico, artístico e paisagístico das comunidades locais. 


\section{REFERÊNCIAS}

[1] BAHL, Miguel. Turismo com Responsabilidade Social. São Paulo: Roca, 2004.

[2] BENI, Mario C. Análise Estrutural do Turismo. São Paulo: Senac, 2001.

[3] BERTALANFFY, Ludwig Von. Teoria Geral dos Sistemas. Petrópolis, Vozes, 1977.

[4] CARNEIRO, Jorge M. T. CAVALCANTI, Maria Alice F. D. SILVA, Jorge F. da. Porter revisitado: análise crítica da tipologia estratégica do mestre. Revista de Administração Contemporânea. V.1, n.3, Curitiba, Set/Dez, 1997. Disponível em: http://www.scielo.br. Acesso em 30 de junho de 2013.

[5] CAVALCANTI, Agostinho. Ecoturismo, meio ambiente e sustentabilidade: análises e propostas. In: SEABRA, Giovanni. Educação Ambiental no Mundo Globalizado. João Pessoa: Editora Universitária/UFPB, 2011.

[6] DIAS, Reinaldo. Sociologia do Turismo. São Paulo: Atlas, 2008.

[7] _ _ Responsabilidade social: fundamentos e gestão. São Paulo: Atlas, 2012.

[8] _ _ _ Turismo sustentável e meio ambiente. São Paulo: Atlas, 2012.

[9] FERNANDES, Lissa V. VIRGINIO, Darlyne F. Responsabilidade socioambiental na hotelaria: um estudo na via costeira de Natal - RN. Caderno Virtual de Turismo.V.11, n.2, 2011.

[10] FERREIRA, Helena C. H. Turismo e responsabilidade social: um debate no campo da sustentabilidade. UFRRJ, CPDA, 2008. Disponível em http://www.proppi.uff.br. Acesso em 01 de julho de 2013.

[11] FRANÇA, Fábio. A releitura dos conceitos de público pela conceituação lógica. In: Relações Públicas: história, teorias e estratégias nas organizações contemporâneas. São Paulo: Saraiva, 2009.

[12] GHEMAWAT, Pankaj. Vantagem sustentável. In: MONTGOMERY, Cynthia A. Estratégia: a busca da vantagem competitiva. Rio de Janeiro: Elsevier, 1998.

[13] GUTIERREZ FORTES, Waldyr. Relações Públicas: processo, funções, tecnologia e estratégias. São Paulo: Summus, 2003.

[14] IRVING, Marta. AZEVEDO, Júlia. Turismo: o desafio da sustentabilidade. São Paulo: Futura, 2002.

[15] KOTLER, Philip. Administração de Marketing: Análise, Planejamento, Implementação e Controle. São Paulo: Atlas, 1996.

[16] LEFF, Enrique. Discursos sustentáveis. São Paulo: Cortez, 2010.

[17] MATHEUS, Carlos E. MORAIS, América. CAFFAGNI, Carla. Educação ambiental para o turismo sustentável. São Carlos: RIMA, 2005.

[18] ROCHA, Thelma. GOLDSCHMIDT, Andrea. São Paulo: Saraiva, 2010.

[19] SARDINHA, Geraldo. Sustentabilidade nas organizações. In: FÉLIX, Joana d'Arc B. BORDA, Gilson Z. (org.). Gestão da comunicação e responsabilidade socioambiental: uma nova visão de marketing e comunicação para o desenvolvimento sustentável. São Paulo: Atlas, 2009.

[20] SEABRA, Giovanni. Educação ambiental: caminhos para conservação da sociobiodiversidade. In: SEABRA, Giovanni. Educação Ambiental no Mundo Globalizado. João Pessoa: Editora Universitária/UFPB, 2011.

[21] SOUSA, Edela L. P. de. Clima e cultura organizacionais: como se manifestam e como se manejam. São Paulo: Edgar Blucher; (Porto Alegre): Programa de pós-graduação em Administração, PPGA-URGS, 1978. 


\section{Capítulo 19}

\section{A PERCEPÇÃO AMBIENTAL DOS TURISTAS QUE VISITAM A APA DOS RECIFES DE CORAIS NO RIO GRANDE DO NORTE}

\section{Maria Célia Fernandes \\ Ana Neri da Paz, Justino \\ Jurema Márcia Dantas da Silva}

Resumo: A Área de Proteção Ambiental Recife dos Corais (APARC) é uma Unidade de Conservação marinha, que tem atraído turistas para a prática de lazer através do passeio de barco, onde os visitantes poderão vislumbrar a fauna aquática durante o mergulho recreacional em plataforma formada por banco de corais e contemplar a natureza. Este texto apresenta os resultados de uma investigação realizada com o objetivo de avaliar o nível de consciência ambiental dos turistas que visitam a APARC, por meio de um estudo de percepção ambiental. Para tanto, utilizou-se de um aporte teórico-metodológico que considera as concepções e representações do ambiente como uma construção social baseada nas formulações Tuan (1980), Moscovici (1978), entre outros, bem como, de uma intervenção empírica por meio da aplicação de questionários, a fim de apreender a representação ambiental desse público visitante antes do passeio (expectativa) e após a realização do passeio (percepção), quando teve a oportunidade de vivenciar momentos de interação com a natureza. Pode-se considerar que os turistas que visitam a APARC apresentam um nível satisfatório de consciência ambiental, creditado ao fato de apresentarem um elevado nível de escolaridade. Acrescente-se, ainda, o fato de os mesmos praticarem atividades de lazer em uma UC, ter contribuído para elevar o seu nível de consciência, uma vez que nas discrepâncias entre expectativa (antes do passeio) e percepção (após o passeio) há uma significativa parcela de visitantes que apresenta concordância com os aspectos comportamentais de adoção de condutas positivas e proativas no tocante à conservação ambiental. 


\section{INTRODUÇÃO}

A criação de territórios demarcados legalmente pelo poder público em áreas que apresentam vulnerabilidade ecológica, como as áreas naturais protegidas, e, em especial as Unidades de Conservação (UCs), tem se revertido em estratégias de gestão, voltadas para a preservação e promoção do desenvolvimento sustentável, a partir do uso racional dos seus recursos naturais pelo turismo ecológico ou ecoturismo.

O turismo em UCs, nessa perspectiva, tem sido estimulado pelos instrumentos de regulação e controle da política ambiental no Brasil, o que têm atraído de forma crescente visitantes e/ou turistas que estão à procura de um contato direto com a natureza, por meio da prática de lazer ou da simples contemplação dos seus recursos ambientais. É preciso entender que essa relação turista e natureza, é amalgamada de concepções, representações e percepções que refletem às construções formuladas pelo homem sobre o meio ambiente no espaço da vida cotidiana e que se apresenta de forma "múltipla e diferenciada". São formulações concebidas na relação sociedade e meio ambiente que são construídas "a partir de várias determinações, sejam em nível cultural, social, psicológico, físico, espacial ou histórico" (ZYSMAN, 2007, p. 3).

Essa multiplicidade de determinações aponta para o entendimento de que o ambiente é um campo fértil de significações que expressa percepções, atitudes, valores e visões de mundo (TUAN, 1980). Nesse sentido, poder-se-ia afirmar que se trata, portanto, de uma construção social, o que leva a ratificação de que o conceito de natureza não é natural, mas sim criado pelos homens (GONÇALVES, 1980). E por ser uma construção coletiva, é travestido de valores simbólicos, sensações e afetividades que expressam processos mentais cognitivos e perceptivos. (DEL RIO \& OLIVEIRA, 1997, apud ZYSMAN, 2007, p. 4).

Há de se destacar que esses processos cognitivos e perceptivos estão enraizados em uma base concreta - a realidade social, que constitui o espaço ou a morada de todos os seres humanos (SANTOS, 2006). Um espaço social ou a própria sociedade, cuja realidade é impressa pelas marcas da cultura, onde a ideia de natureza se torna uma construção histórica, elaboração humana e representação social.

É nesse viés teórico-metodológico, onde convergem formulações das áreas da psicologia ambiental, da sociologia e da geografia entre outras disciplinas das ciências sociais, que gravita a discussão do presente texto, no sentido de contribuir para análise dos resultados preliminares, ora apresentados, de uma investigação empírica, em andamento, que busca apreender a percepção ambiental dos turistas que visitam a Área de Proteção Ambiental Recife dos Corais (APARC), no Rio Grande do Norte. Uma pesquisa que tem por objetivo avaliar o nível de consciência desses visitantes com relação aos comportamentos e condutas proativas, inerentes às necessidades de conservação dos seus recursos ecológicos.

Trata-se de uma UC marinha, onde é oferecido o passeio de barco a uma formação coralina, denominada de parrachos, por abrigar uma rica biodiversidade. Nesse ambiente, os turistas e/ou visitantes poderão entrar em contato com a fauna aquática através do mergulho recreacional na parte rasa dos corais. Uma atividade que, devido a fragilidade dos ecossistemas onde é praticada, exige um monitoramento ambiental, socioeconômico e turístico sistemático, como componente indispensável à gestão ambiental e à integridade ecológica da unidade.

Os estudos científicos sistemáticos acerca da percepção do visitante da APA tornam-se relevantes para orientar o monitoramento socioeconômico e turístico, uma vez que tem a função de contribuir para a conscientização ambiental dos turistas e/ou visitantes que fazem o passeio de barco para os parrachos, a partir da compreensão de que a "percepção ambiental é pré-requisito para se atingir diferentes níveis de conscientização ambiental. 0 somatório de percepção e conscientização ambiental com conhecimento científico, são os vetores que apresentam potencial para se promover a efetiva conservação ambiental" (FREITAS, 2009, p. 16).

Desse modo, esse trabalho tem como ponto de partida realizar uma reflexão acerca da percepção ambiental, em face às formulações teóricas que percebem o ambiente como uma construção social. Para tanto, sinaliza para as representações sociais como um campo de domínio epistemológico, desenvolvido por Moscovici (1991), que poderá auxiliar no entendimento da apreensão da realidade empírica, descrita na segunda parte desse artigo, seguida de uma discussão e análise dos resultados preliminares da pesquisa de campo e algumas considerações sem finalizações. 


\section{A PERCEPÇÃO AMBIENTAL E A TEORIA DAS REPRESENTAÇõES SOCIAIS: UMA APROXIMAÇÃO POSSÍVEL}

Os estudos sobre a percepção ambiental têm seu campo de origem na Psicologia, a partir do final do século XIX. A psicologia experimental de Wilhelm Wundt (1832-1920), cuja maior contribuição foi elevar essa disciplina ao estatuto de ciência, se voltou para o estudo da percepção humana, a partir do desenvolvimento do método da introspecção, cuja compreensão é a de que se trata de um ato em que a pessoa entra em contato com seus estados mentais, como as crenças, imagens, emoções, memórias visuais, auditivas, tácteis, olfativas -, e pensamentos. A esse estado introspectivo o autor denomina de percepção interior, que se encontra associado aos estímulos e reações provenientes das sensações e dos sentimentos (Schultz \& Schultz, 1992).

Além dos estímulos internos como resultante de um estado introspectivo, a psicologia experimental de Wundt também identificou os estímulos externos, que somados aos primeiros, influenciavam o comportamento dos indivíduos (op. cit, 1992).

Marin (2008), ao fazer uma revisão sobre as abordagens teórico-metodológicas que contribuíram para o estabelecimento dos estudos em psicologia ambiental, apresenta as principais contribuições da psicologia e de outros campos de conhecimento como a filosofia, a geografia, a arquitetura, a sociologia e a literatura. Para essa autora, além do introspeccionismo já citado, o estruturalismo juntamente com o behaviorismo, na psicologia, priorizava indicar os comportamentos diretamente observáveis como respostas a estímulos ambientais ou do ambiente físico. Destaque se faz para Gestalt que com sua teoria da forma, em determinado momento exerceu influência para o surgimento da Psicologia Ambiental.

Mas, é com a obra Psicologia Ambiental de Heimstra e MacFarling (1978), que essa disciplina ganha campo teórico próprio, uma vez que na obra "destacam [os autores] a variação de comportamento em ambiente construídos (salas, moradias, edifícios, cidades), inclusive já discutindo mapa psicológicos, condições de estresse e de satisfação residencial, e naturais (recreação, parques e percepção de perigos naturais) (MARIN, 2008, p. 208).

Vale destacar que essa publicação seminal influenciou as pesquisas de percepção nas disciplinas que tem como foco principal o estudo do espaço. É o caso da Geografia e da Arquitetura. No caso da Geografia, o livro Topofilia de Tuan (1980) apresenta uma grande contribuição para os estudos de percepção ambiental, como o próprio autor credita: "Este trabalho contribui para a psicologia ambiental e possui implicações importantes para o planejamento", em que manifesta sua preocupação "com a formação e a natureza das atitudes e valores positivos" (p. 4).

Nessa obra é dada prioridade aos conceitos de percepção, atitude, valor e visão de mundo, cujos sentidos atribuídos depende do contexto em que cada termo se coloca, embora os seus significados se superponham. Mas o tema presente em todo o texto, que está vinculado aos conceitos citados, é o de topofilia, concebido como "o elo afetivo entre a pessoa e o lugar ou ambiente físico. Difuso como conceito, vívido e concreto como experiência pessoal..." (p.5).

Ao enfocar a importância da percepção ambiental para o planejamento, Tuan (1980), se aproxima, de certo modo, das formulações e percursos trilhados pela UNESCO, que no início da década de 1970, passa a desenvolver e veicular resultados das pesquisas desenvolvidas pelo Grupo de Trabalho Man and Biosphere - 13 (MAB), conforme explicita Melo (2005) apud Marin (2008, p. 209):

[...] o projeto da UNESCO enfatiza o estudo de percepção do meio ambiente, como fundamental para a gestão de lugares e paisagens que tinham importância para a humanidade, e o objetivo do MAB era estudar as relações entre as populações e o meio ambiente em diversas cidades em torno do mundo, distribuídas em um conjunto de 40 países, entre elas a cidade de Porto Alegre.

O estudo de percepção do meio ambiente como instrumento para a gestão dos lugares e paisagens, proposto pelo MAB, inaugura uma nova estratégia de intervenção no espaço social, que no Brasil toma forma com o trabalho dos autores Del Rio \& Oliveira (1999), intitulado Percepção ambiental: a experiência brasileira. Marin (2008), identifica três vertentes teóricas no trabalho desses autores: estudos de caráter intervencionista; estudos de caráter interpretativos; e, estudos de caráter educacional.

Os estudos de caráter intervencionista, estão voltados para projetos de gestão ambiental, vinculados a área da arquitetura e urbanismo. Os de caráter interpretativos abarcam áreas como a semiótica, sociologia, geografia humanística, e, ainda, a fenomenologia da arquitetura. Nesses campos estão 
presentes estudos de percepção como fenômeno de comunicação, construção social da imagem, comportamento social, uso de espaços simbólicos e mitos da vida, e, ainda, compreensão fenomenológica do meio ambiente em suas várias dimensões. E, por fim, os estudos de caráter educacional voltados para o campo da educação ambiental e áreas correlatas, com foco para a formação do conhecimento, sistemas de valores, ensino de classes populares e percepção de riscos ambientais (MARIN, 2008).

0 que se destaca na produção científica relacionada a percepção, apresentada por essa autora, é o aporte teórico-metodológico no campo da abordagem fenomenológica com influências filosóficas recebidas de Merleau-Ponty (1999), em sua obra Fenomenologia da percepção, de Gaston Bachelard em A poética do espaço (1993), de Ernest Cassirer em sua publicação A filosofia das formas simbólicas (2001), e Mircea Eliade em Imagens e símbolos (1991) entre outros.

Mas, é na teoria das representações sociais26 desenvolvida por Serge Moscovici em 1961, por meio da sua obra A representação da psicanálise: sua imagem e seu público, e do seu diálogo com os autores que concebem a percepção ambiental como uma construção social, que a percepção encontra um terreno fértil para ampliação do conhecimento e da aplicação no campo da pesquisa empírica, uma vez que segundo Del Rio e Oliveira, 1999, apud Zysman (2007, p. 4):

A representação, neste contexto, atua como um prolongamento da percepção porque a introduz num sistema de significação representativo, envolvendo a diferenciação entre os significantes que podem ser as formas de linguagem ou imagens, gestos, desenhos e os significados que compreendem os espaços.

Os significados que compreendem os espaços se remetem ao espaço vivido, cuja representação é o espaço objeto. E esse espaço objeto é percebido de forma múltipla e diferenciada, uma vez que reflete as condições subjetivas dos sujeitos, embora apoiada em uma realidade concreta.

Reigota (1997), no seu trabalho Meio ambiente e representação social, conceitua o espaço percebido como um ambiente, que reflete uma construção social. Para ele meio ambiente é definido como "o lugar determinado ou percebido, onde os elementos naturais e sociais estão em relações dinâmicas e em interação. Essas relações implicam processos históricos e sociais de transformação do meio natural e construído" (p. 14).

Fica claro na citação do autor de que o ambiente é uma construção social e como tal é objeto de transformações, onde o natural passa a ser, também, construído a partir de relações dinâmicas e processos interativos, gestado no espaço da vida em comum. E o que dizer da gestão de espaços amalgamados pela simbologia de um mundo natural selvagem e inexistente, para se reportar ao mito da natureza intocada como afirma Diegues (1996)? Uma construção, que no Brasil, veio importada de uma visão biocêntrica americana que emergiu no contexto da expansão urbano-industrial naquele país no final do século XIX. A visão veiculada era a de que o homem era destruidor da natureza o que justificava a instituição de "widerness" (lugar selvagem), dotado de grande beleza cênica e paisagística, para que os habitantes das cidades pudessem usufruir desses espaços para fins de lazer.

Para Zysman (2007) a natureza percebida dessa forma mitificada, serve como escape para a fuga do estresse dos grandes centros urbanos. Uma natureza admirada, símbolo da liberdade para os que desfrutam de sua beleza com forte apelo romântico, espiritual e religioso e de alienação para outros que atribui um sentido anti-social. "E a natureza é, assim, elemento constitutivo das representações sobre o Brasil dos próprios brasileiros, fato que tem motivado, em nosso país, mais recentemente, o fenômeno das viagens aos "paraísos ecológicos" (p. 1).

Portanto, buscar apreender a percepção ambiental dos atores sociais que visitam áreas naturais protegidas significa estabelecer conexões entre suas condições sócio-históricas, culturais, políticas e psicológicas, identificando, também, suas imagens, símbolos, signos e valores cognitivos e perceptivos carregados de subjetividades, mas em processos interativos com o espaço vívido e concreto.

A pesquisa de percepção como instrumento para identificar comportamentos, valores e condutas positivas e/ou negativas diante da natureza é utilizada como estratégia para se pensar a gestão desses espaços controlados, regulados e protegidos, cujo uso pelo turismo está associado a compreensão de que esta atividade poderá contribuir para a manutenção e conservação dos recursos ambientais. Mas, é preciso que

26 Moscovici (1978, p. 26), afirma que as representações sociais se constituem "uma modalidade do conhecimento particular que tem por função a elaboração de comportamentos e a comunicação entre indivíduos". 
se tenha em mente que para além da identificação de valores e condutas, os estudos de percepção ambiental poderão favorecer a formação de práticas de novas condutas sociais.

Nessa ótica, Moscovici (1978) que pensa no fortalecimento de uma ciência engajada, por meio da aplicação teórico-metodológica das representações sociais, como um recurso de se produzir conhecimento a partir do senso comum, cuja produção científica deverá ser socializada e replicada na vida em comum ou cotidiana, apresenta em sua obra Natureza: para pensar a ecologia inquietações e inspirações para reinventar a natureza e voltar a encantar o mundo: "A sociedade pela e com a natureza não esquece jamais o homem, não esquece jamais sua natureza que é ser livre” (MOSCOVICI, 2007, p. 64).

Portanto, incentivar a pesquisa de percepção ambiental por meio de uma postura crítica e ecologicamente política, do ponto de vista de se buscar influenciar a formação de novas atitudes, valores e visões de mundo diante da natureza, poderá efetivamente contribuir para a gestão de espaços ambientalmente vulneráveis.

É nessa perspectiva que apresenta-se a seguir uma caracterização da realidade empírica investigada - APA Recife dos Corais -, e seu percurso metodológico, bem como os primeiros resultados sobre a expectativa e a percepção do turista que busca praticar o lazer por meio da realização do passeio de barco ao ambiente coralino da unidade, e que oportuniza um contato direto com os seus recursos ambientais, no sentido de medir o seu comportamento e conduta com relação à conservação ambiental desses atributos físicos e socioespaciais.

\section{A REALIDADE EMPÍRICA: APROXIMAÇÕES COM OS SUJEITOS DA PESQUISA}

O litoral do Rio Grande do Norte exibe um rico e extenso ecossistema recifal ao longo da região costeira dos municípios de Maxaranguape, Rio do Fogo e Touros, com três principais bancos coralíneos, conhecidos localmente por "parrachos" (IDEMA, 2012). Tal região, face às suas belezas naturais e diversidade biológica, encontrou amparo legal através do Sistema Nacional de Unidades de Conservação da Natureza (SNUC), e transformou-se na "Área de Proteção Ambiental dos Recifes de Corais" (APARC), instituída através do Decreto $n^{\circ} 15.746 / 2001$, com o objetivo de proteger a região marinha e sua diversidade, contando com uma área de 136 mil hectares (FUNDEP, 2017).

A região apresentada na Figura 1 destaca a APARC, bem como indica as plataformas rasas de Maracajaú e Rio do Fogo, que são basicamente compostas por corpos de arenitos que abrigam os corais, e consequentemente uma série de outros organismos como esponjas, moluscos e peixes, formando os recifes, que concentram uma grande quantidade e variedade de vida marinha (Adaptado de AMARAL, et al., 2005 apud IDEMA, 2012).

Por ser a única unidade de conservação que possui em sua área marinha ecossistemas recifais, a APARC apresenta uma singularidade diante das demais unidades de conservação existentes no Rio Grande do Norte. Esse patrimônio ambiental constitui atualmente um produto turístico que atrai um fluxo considerável de visitantes e/ou turistas, para fazer o passeio de barco aos parrachos e praticar o mergulho raso na formação coralina, onde poderá ter o contato visual com corais, peixes, águas vivas, ouriços entre outras espécies. 
Figura 1 - Mapa de localização da APARC

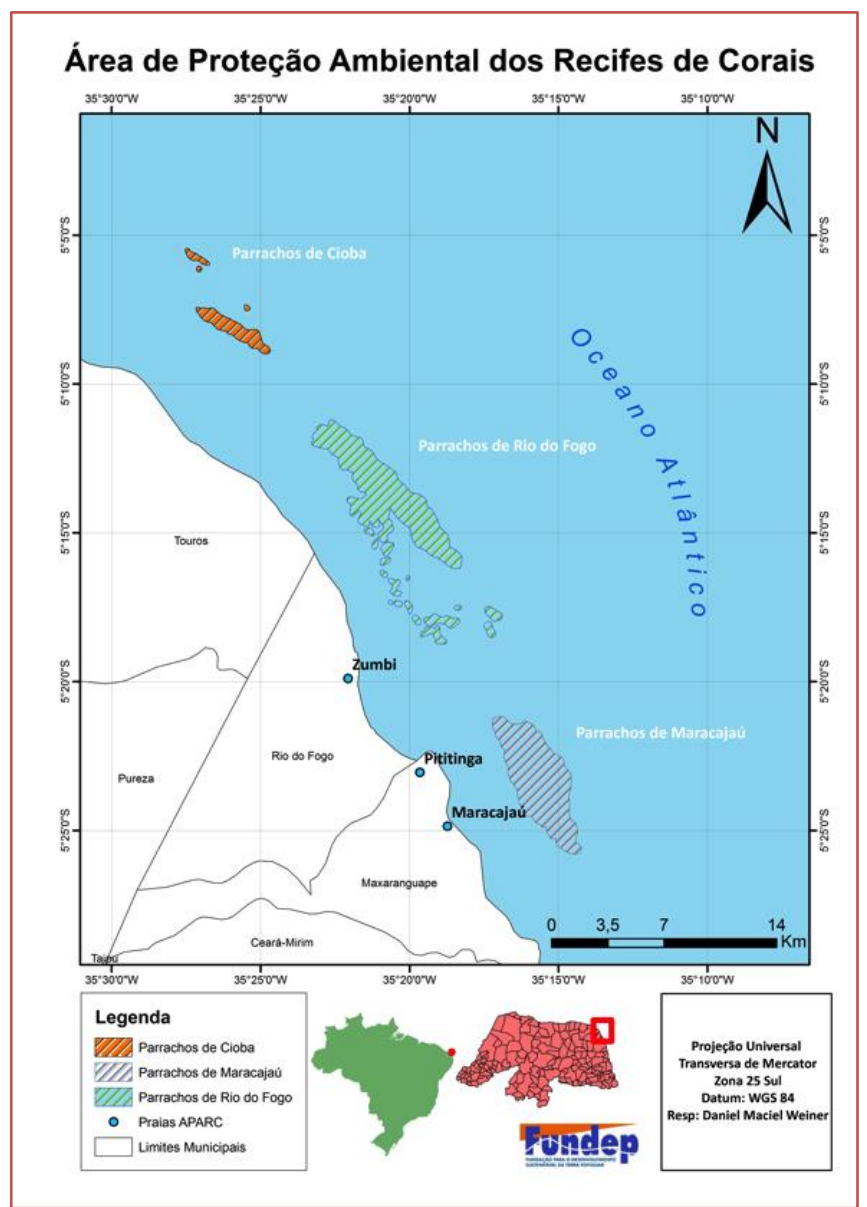

Fonte: FUNDEP, 2017.

O uso turístico de uma área com atributos ambientais de grande vulnerabilidade ecológica, exige, de um lado, o manejo adequado e sistemático, visando a conservação e preservação de seus recursos bióticos e abióticos. Por outro lado, o desenvolvimento de um turismo sustentável, poderá contribuir significativamente para a conservação e ampliação do tempo de vida desses atrativos, por meio de ações de planejamento e manejo como o monitoramento ambiental e turístico das áreas naturais. A visitação turística na localidade caracteriza-se, prioritariamente, como sendo o passeio de catamarã seguido de mergulho livre com profundidade variando entre $1.0 \mathrm{~m}$ e $3.0 \mathrm{~m}$, durante o ano, como pode ser visto na figura 2.

Figura 2 - Passeio de catamarã seguido de mergulho livre na APARC

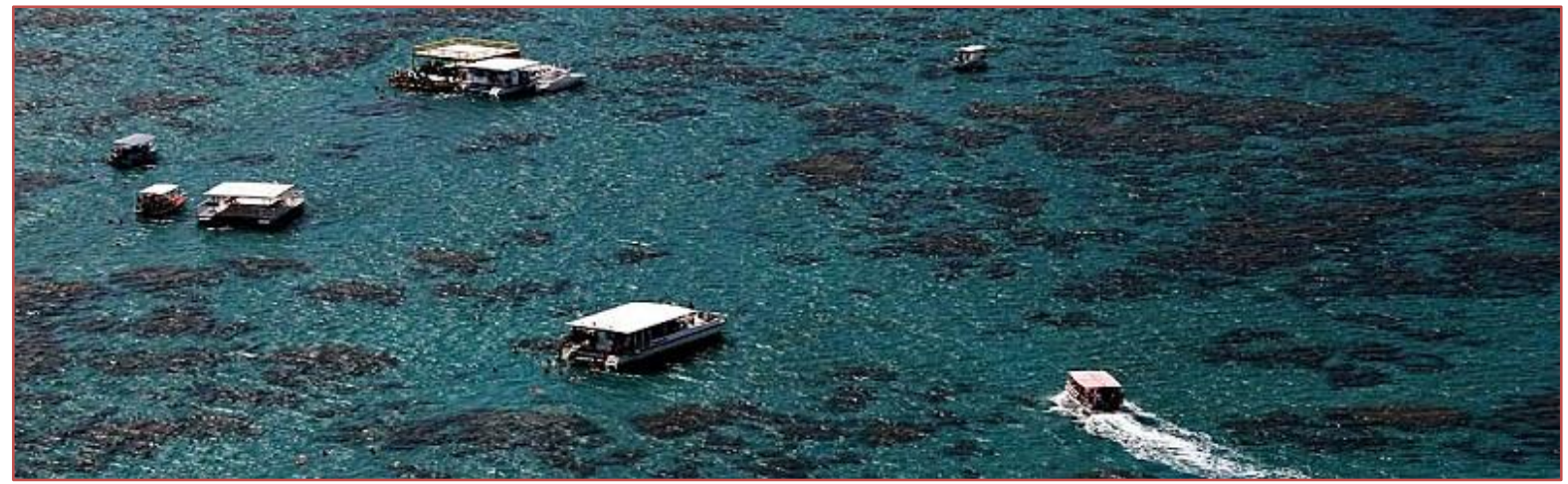


Desde 2005, o Instituto de Desenvolvimento Sustentável e Meio Ambiente do Rio Grande do Norte (IDEMA), órgão ambiental do estado, vem desenvolvendo, através da contratação de equipe especializada, Programas de Monitoramento de Visitação Turística e Ambiental. Diante das informações geradas durante esse período, a gestão da APARC tem considerado a importância de utilizar os dados ambientais, turísticos e socioeconômicos de forma integrada, relacionando o número e a conduta dos visitantes, registrados diariamente, com o comportamento do ecossistema recifal, a fim de responder uma série de questões que norteará a gestão da APARC e contribuirá para a implementação do seu Plano de Manejo (IDEMA, 2016).

Com o intuito de monitorar os recifes de corais da APARC, avaliando periodicamente os parâmetros ambientais deste ecossistema, bem como de monitorar o fluxo turístico nos Parrachos da APARC, através do registro e controle diário do número de visitantes, e das condutas praticadas pelos mesmos, o órgão ambiental estadual realizou a contratação de serviços especializados para o desenvolvimento bienal (2017/2018) da Pesquisa de Monitoramento Ambiental e Turístico da Área de Proteção Ambiental dos Recifes de Corais (EcoRecifes) (IDEMA, 2016). A intervenção ocorre através da formalização do contrato no 002/2017 entre o IDEMA e a Fundação Para o Desenvolvimento Sustentável da Terra Potiguar (FUNDEP). Dentre as atividades estabelecidas em contrato está a aplicação de questionários sistemáticos com turistas, antes e depois da visita aos parrachos para avaliação do seu nível de consciência ambiental (IDEMA, 2016).

A partir da celebração desse contrato, iniciaram-se as intervenções no sentido da execução do mesmo, ou seja, recrutar, selecionar e treinar os indivíduos vinculados à operacionalização das atividades propostas. Uma vez constituída a equipe para o desenvolvimento houve a necessidade de se estabelecer o percurso metodológico para alcançar as prerrogativas contratuais. Assim, durante os meses de fevereiro e março se elaborou e se discutiu o projeto da intervenção científica e no mês de abril de 2017 realizou-se um estudo preliminar acerca da temática em questão, como forma de validar o instrumento estabelecido para tal, bem como, qualificar os colaboradores inseridos no processo. Finalizado o período de testagem e validação das ferramentas de pesquisa, deu-se início a partir do mês de maio daquele ano a investigação definitiva, com encerramento previsto para o mês de janeiro de 2019, cujos resultados são expostos a seguir.

De forma breve pode-se destacar que os sujeitos da pesquisa são majoritariamente do sexo feminino, casados, com idade entre 21 e 40 anos, renda mensal individual de 2 a 4 salários mínimos e formação superior completa, inclusive com um percentual significativo de pós-graduados. No que diz respeito à visitação turística considera-se relevante destacar que este público pratica turismo em família e utilizouse das novas Tecnologias da Informação e Comunicação (TIC's) para fins de conhecimento prévio da destinação turística em questão, e revelou que estava na UC pela primeira vez, com o objetivo de realizar atividades de lazer e recreação.

A respeito da atratividade principal da localidade turística, o mergulho a partir do passeio realizado em embarcações, o público registra, em sua maioria, que nunca havia praticado tal atividade. Além disso, um fator a ser considerado com relação aos sujeitos da pesquisa refere-se ao fato dos mesmos terem revelado ciência de estar em uma unidade de conservação. Campos; Vasconcelos \& Félix (2011) acreditam que a elaboração de estratégias de manejo de visitantes de modo a corroborar para uma experiência de visitação satisfatória se faz a partir do conhecimento do seu perfil. Entretanto as autoras indicam que tal intervenção não é suficiente para fins de planejamento, uma vez que é necessário reconhecer as percepções, motivações, expectativas, atitudes, valores e condutas dos indivíduos que visitam uma UC.

\subsection{CARACTERIZAÇÃO DA PERCEPÇÃO AMBIENTAL NA APARC}

0 estudo de percepção ambiental tem se configurado em um poderoso instrumento para identificar as representações sociais - abordagem metodológica que ancora esse tipo de investigação - que os indivíduos constroem sobre o meio ambiente, bem como, seu nível de consciência ecológica e o seu processo educativo. Através da aplicação de um questionário é possível verificar o comportamento ambiental responsável de uma população. Segundo Fernandes et al. (2004), o questionário é um significativo instrumento pedagógico complementar à gestão de instituições que atuam no campo ambiental.

Nas pesquisas empíricas relacionadas aos estudos de percepção são estabelecidas variáveis27 que expressam a variabilidade de comportamentos e dos estados subjetivos, pensamentos, sentimentos e

27 As variáveis foram construídas tendo como referências o Manual de conduta consciente em ambientes recifais, produzido pelo Ministério do Meio Ambiente, 2009. 
necessidades articuladas em forma de pergunta e, estipula-se escalas de medidas como ferramenta de mensuração através de números ou outros símbolos atribuídos às características pré-definidas (GÜNTHER, 2006). Trata-se de atribuir uma escala a fim de obter as informações requeridas nos objetivos formulados nos estudos. De modo geral faz-se uso da escala Likert, que consiste em quatro ou cinco categorias ordinais (1 - "Discordo totalmente", 2 - "Discordo em parte", 3 - Não discordo, nem concordo", 4 - "Concordo em parte", 5 - Concordo totalmente"), e atribuições de escore para cada alternativa elencada na escala, constante do questionário (ALEXANDRE et al, 2003). Para fins de atendimento dos pressupostos metodológicos foram estabelecidas, neste estudo, catorze variáveis, à luz de Brasil (2009), conforme demonstrado na Figura 3.

Figura 3 - Variáveis para análise

\begin{tabular}{|c|c|}
\hline No & VARIÁVEIS PARA ANÁLISE \\
\hline 1 & $\begin{array}{l}\text { Os recifes dos corais que você irá visitar estão situados em uma Área de Proteção Ambiental } \\
\text { (APA). }\end{array}$ \\
\hline 2 & Os corais são organismos vivos encontrados em ambientes marinhos. \\
\hline 3 & $\begin{array}{l}\text { As unidades de conservação são Áreas protegidas por lei, criadas com o objetivo de conservar a } \\
\text { natureza. }\end{array}$ \\
\hline 4 & Os recifes dos corais abrigam uma diversidade de fauna e flora marinha. \\
\hline 5 & A conduta consciente e ambientalista não é necessária à prática de mergulho nos corais. \\
\hline 6 & O toque nos corais não prejudica e nem provoca a sua morte. \\
\hline 7 & $\begin{array}{l}\text { Nos recifes existem organismos que possuem substâncias urticantes e tóxicas que poderão } \\
\text { machucá-lo se pisados ou tocados. }\end{array}$ \\
\hline 8 & $\begin{array}{l}\text { A coleta de restos de conchas, corais, estrelas do mar não compromete à integridade ecológica } \\
\text { dos corais. }\end{array}$ \\
\hline 9 & $\begin{array}{l}\text { Oferecer qualquer tipo de alimento, inclusive pequenos peixes em iscas, prejudica a saúde dos } \\
\text { peixes e corais. }\end{array}$ \\
\hline 10 & $\begin{array}{l}\text { O uso de protetor solar à prova de água durante o mergulho no ambiente coralino compromete } \\
\text { a saúde dos animais e outros organismos aquáticos. }\end{array}$ \\
\hline 11 & $\begin{array}{l}\text { O uso de óleos ou cremes durante o mergulho no parrachos não é nocivo à saúde dos corais e } \\
\text { outros organismos. }\end{array}$ \\
\hline 12 & O uso de nadadeiras em águas rasas pode quebrar os corais e outros organismos. \\
\hline 13 & O uso de arpão e espeto durante o mergulho espantam os animais e trazem riscos de acidentes. \\
\hline 14 & O lixo produzido deve ser depositado em local apropriado e não jogado no mar. \\
\hline
\end{tabular}

Fonte: Dados da pesquisa, 2017.

As assertivas das variáveis foram analisadas obedecendo uma relação Expectativa x Percepção por parte dos sujeitos da pesquisa. Vale salientar que as mesmas trazem elementos tanto da caracterização física do ambiente coralino, quanto das possiblidades de conduta no mesmo. Considerando o perfil do turista no período da investigação, percebeu-se que esse visitante tem uma relação de conhecimento mais próxima com o ambiente visitado, provavelmente em razão do seu nível de escolaridade, considerado satisfatório para fins do objeto deste estudo.

O estudo revelou discrepâncias entre a expectativa e a percepção, ou seja, os gaps que são os hiatos, espaços, ou lacunas entre os elementos expectativa e percepção. Tal cenário foi utilizado para apresentar a percepção ambiental dos turistas que visitaram a APA Recife dos Corais no Rio Grande do Norte no período de abril/2017 a janeiro/2019, de acordo com a pactuação contratual entre IDEMA e FUNDEP, onde os questionários deveriam ser aplicados com os mesmos sujeitos antes e depois da visita aos parrachos para avaliação do seu nível de consciência ambiental, de modo que seja possível verificar o impacto da realização das atividades turísticas na consciência ambiental dos praticantes. Para fins de melhor entendimento das respostas obtidas, decidiu-se distribuir sua análise por três grupos de interpretação: 1) relação equitativa entre expectativa e percepção; 2) discrepância entre expectativa menor que a percepção; e, 3) lacuna entre expectativa maior que a percepção. 
Assim, entre as variáveis de análise que apresentaram relação equitativa entre expectativa e percepção, destaca-se a variável 14 - o lixo produzido deve ser depositado em local apropriado e não jogado no mar. Neste aspecto todos os entrevistados concordaram totalmente com as assertivas apresentadas. Isso significa afirmar que o conhecimento prévio do local visitado foi suficiente para o visitante construir a imagem do mesmo, bem como, expressar comportamentos necessários à sua conservação. Acrescente-se a isso o fato de estar na UC não trouxe elementos de incremento e/ou mitigação de tal percepção.

A discrepância entre expectativa menor que a percepção é verificada nas demais variáveis, conforme constam da Figura 3 já exposta. Neste grupo de afirmações há sentenças positivas e negativas. A proposição de situações dessa natureza se encontra disposto nos estudos de percepção ambiental, de modo a colocar o respondente em situação de reflexão e comparação acerca das asseverações que lhe são apresentadas, inclusive sendo propostas em condições de alternância. No que se refere as assertivas positivas as respostas da percepção apresentaram maior aproximação do "concordo totalmente", do que as da expectativa. 0 inverso ocorreu nas assertivas negativas, onde maior parte das respostas se aproximou da extremidade "discordo totalmente".

A partir dessa constatação é possível considerar que estar na APARC foi significativo para ampliar o entendimento acerca do ambiente recifal, bem como, da sua necessidade de proteção, por meio da criação da UC, juntamente com a adoção de condutas conscientes no contato com tal ambiente. Um resultado que indica, ainda, a ausência de gaps negativos, cuja ocorrência se dá quando a Expectativa é superior a Percepção.

Não obstante, deve-se considerar que o fato de a percepção do local visitado em relação a expectativa ter se mostrado superior naquelas categorias que apresentam pontos extremos de avaliação "Discordo Totalmente" ou "Concordo Totalmente" indicar um resultado satisfatório, não assegura uma total mudança de comportamento que possa qualificar os turistas e visitantes de apresentarem um nível de consciência ambiental em sinergia com as necessidades de conservação e preservação dos recursos ambientais. Em uma análise mais atenta desse cenário investigativo e de avaliação observou-se a existência de variáveis em que há uma certa resistência dos informantes em exibir um nível de consciência ambiental mais consistente, conforme pode-se observar na incidência de percentuais nas demais categorias da escala likert como: "discordo em partes"; "não discordo, nem concordo"; e, "concordo em partes", em algumas delas com percentuais elevados para o propósito da pesquisa.

Diante do cômputo geral das respostas apresentadas é válido registrar que das catorze variáveis de análise elencadas para medir o nível de percepção ambiental dos visitantes e/ou turistas da APARC, em treze delas pode-se observar a ampliação do nível de percepção ambiental após a realização do passeios aos parrachos da unidade, onde o sujeito da pesquisa pôde a contemplar o ambiente visitado e praticar o mergulho na plataforma coralina. A esse respeito vale trazer a reflexão do quão estar em uma unidade de conservação pode contribuir para maximizar a percepção positiva do ambiente, estimulando a adoção de condutas conscientes com vistas a prática de ações responsáveis.

\section{4 À GUISA DE CONSIDERAÇÕES}

Os resultados apresentados ao longo do trabalho, correspondem às observações e análises formuladas a partir da aplicação de questionários de uma pesquisa de percepção realizada durante o período de abril/2017 a janeiro/2019, o que não garante qualquer posicionamento final, muito pelo contrário, apenas aponta para pequenos sinais ou lampejos de uma dada realidade contextual, que poderá ser modificada ao longo do tempo, daí a necessidade de que o monitoramento socioeconômico e turístico em uma UC seja sistemático.

As discrepâncias ou gaps existentes entre a expectativa e a percepção dos visitantes com relação as variáveis pré-estabelecidas, que teve como referência os instrumentos institucionais de planejamento e gestão do Ministério do Meio Ambiente como Manual de Conduta Consciente em Ambientes Recifais (2009), demostram às múltiplas e diferenciadas compreensões do meio ambiente mediadas por representações sociais.

A escala lickert utilizada enquanto um recurso metodológico para se fazer as devidas aproximações conceituais e perceptivas, se revelou eficiente na abstração da percepção ambiental dos sujeitos da investigação. A título de exemplo, cabe informar que entre os fatores positivos da percepção, com relação a expectativa, que indicava o conhecimento prévio do visitante sobre o fato de que se encontrava em uma área protegida, este resultado foi de $97 \%$, contra a expectativa de $83 \%$ que manifesta um conhecimento 
prévio anterior ao passeio. Embora, o comportamento associado a um nível de consciência ambiental satisfatório não se faz presentes em todas as variáveis analisadas na mesma pesquisa.

Assim, desses fatos inerentes a perspectiva de mudanças comportamentais, pode-se indicar, a título de contribuição que:

a visita guiada aos parrachos contribuiu para mudança positiva de atitudes, valores e visões sobre a conservação ambiental, o que confirma a importância dos estudos de percepção para a gestão de Unidades de Conservação do ponto de vista da instituição executora do planejamento e da gestão de UCs, como assinala Tuan (1980);

as representações formuladas pelos visitantes sobre o objeto analisado, são dinâmicas e impõem novas elaborações, a partir das interações socialmente estabelecidas, como defendem os estudiosos das representações, em que se destaca as observações defendidas por Reigota (1997);

as características estéticas da paisagem visitada corroboram para a mudança de atitudes e comportamentos, por estimular um pensamento simbólico e imagético permeado de sistemas sensoriais, afetivos e espirituais, que desafia outros campos de conhecimento como defendem os filósofos de abordagem fenomenológica; e,

a aquisição de uma consciência ambiental baseada na compreensão de que o espaço, o território e a paisagem enquanto categorias geográficas possuem movimento e expressam transformações históricas, culturais, políticas e socioambientais que podem influenciar na ideia de que a natureza como construção social precisa ser protegida.

Enfim, essas arguições se colocam como ideias anunciadas por meio do tratamento e análises dos resultados à luz de contribuições teórico-metodológicas, que permitem fazer os dados de uma pesquisa "falarem" e apontarem novos focos de luz para se pensar uma determinada realidade que se propõe a investigar.

\section{REFERÊNCIAS}

[1] ALEXANDRE, J. W. C. et al. Análise do número de categorias da escala de Likert aplicada à gestão pela qualidade total através da teoria da resposta ao item. In: ENEGEP, 2003 Disponível em: <http://www.abepro.org.br/biblioteca/ENEGEP2003_TR0201_0741.pdf>. Acesso: 10 mar. 2017.

[2] BRASIL. Ministério do Meio Ambiente. Manual de conduta consciente em ambientes recifais. Brasília, MMA, 2009. Disponível em: < http://www.mma.gov.br/estruturas/205/_arquivos/livromultiplicador_2011_205.pdf>. Acesso: 10 mar. 2017.

[3] CAMPOS, Renata Ferreira; VASCONCELOS, Fernanda Carla Wasner; FÉLIX, Lilian Araújo Grossi. A importância da caracterização dos visitantes nas ações de ecoturismo e educação ambiental do Parque Nacional da Serra do Cipó/MG. Revista Turismo em Análise, Brasil, v. 22, n. 2, p. 397-427, aug. 2011. ISSN 1984-4867. Disponível em: <http://www.revistas.usp.br/rta/article/view/14255/16073>. Acesso em: 15 jul. 2017.

[4] DIEGUES, Antônio Carlos. 0 mito moderno da natureza intocada. São Paulo: Hucitec, 1996.

[5] FERNANDES, R. S. et al. Uso da percepção ambiental como instrumento de gestão em aplicações ligadas às áreas educacional, social e ambiental. Rede Ceas, USP, 2004. Disponível em: <http://www.redeceas.esalq.usp.br/noticias/Percepcao_Ambiental.pdf > Acesso em: 10 mar., 2017.

[6] FREITAS, M. R. de. Conservação e percepção ambiental por meio da triangulação de métodos de pesquisa. Dissertação (Mestrado em Ciências Florestais) - Universidade Federal de Lavras, 2009.

[7] FUNDAÇÃO PARA O DESENVOLVIMENTO SUSTENTÁTEL DA TERRA POTIGUAR - FUNDEP. Relatório mensal da contabilização e controle do fluxo diário de visitantes nos parrachos rasos da APARC-05/2017. Natal: Fundep, 2017.

[8] GONÇALVES, Walter Carlos P. Os (des)caminhos do meio ambiente. São Paulo: Contexto, 1989.

[9] GÜNTHER, H. Pesquisa qualitativa versus pesquisa quantitativa: esta é a questão? Psicologia: Teoria e

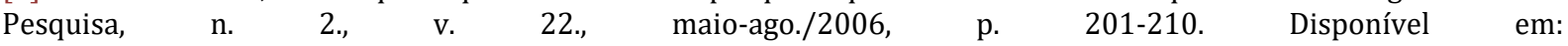
<http://www.scielo.br/pdf/ptp/v22n2/a10v22n2.pdf > Acesso: 10 mar., 2017.

[10] INSTITUTO DE DESENVOLVIMENTO SUSTENTÁVEL E MEIO AMBIENTE DO RIO GRANDE DO NORTE IDEMA. IDEMA fiscaliza Parrachos da Área de Proteção Ambiental Recifes de Corais. Natal: IDEMA, 2017. Disponível em: <http://www.rn.gov.br/Conteudo.asp?TRAN=ITEM\&TARG=137127\&ACT=\&PAGE=\&PARM=\&LBL=Materia> Acesso: 30 mar., 2017. 
[11] _. Termo de Referência para execução do Projeto de Pesquisa "Monitoramento Ambiental e Turístico da APA dos Recifes de Corais- APARC". Natal: IDEMA, 2016.

[12] MARIN, Andreia Aparecida. Pesquisa em educação ambiental e percepção ambiental. Pesquisa em Educação Ambiental, v. 3, n. 1, p. 203-222, 2008. Disponível em: < http://journals.usp.br/pea/article/viewFile/30047/31934 >. Acesso em: 20 jun., 2017.

[13] MOSCOVICI, Serge. Natureza: para pensar a ecologia. Tradução Maria Louise Trindade Conilh de Beyssac e Regina Mathieu. Rio de Janeiro: Mauad, 2007. Coleção Elcos.

[14] _ _ _ A representação social da psicanálise. Rio de Janeiro: Zahar Editores, 1978.

[15] REIGOTA, Marcos. Meio ambiente e representação social. 2 ed. São Paulo: Cortez, 1997 (Questões de nossa época, v. 41).

[16] SANTOS, Milton. A natureza do espaço: técnica e tempo, razão e emoção. 4. ed. São Paulo: Edusp, 2006.

[17] SCHULTZ, Duane P.; SCHULTZ, Sydney Elien. História da psicologia moderna. 5 ed. rev. e ampl. São Paulo: Cultrix, 1992.

[18] TUAN, Yi-fu. Topofilia: um estudo de percepção, atitudes e valores do meio ambiente. São Paulo: Difel, 1980.

[19] ZYSMAN, Neiman. Percepção e representações: aspectos da psicologia ambiental. In: ENCONTRO DE PESQUISA EM EDUCAÇÃO AMBIENTAL, 4. ...Anais. UNESP, 2007. Disponível em: < http://www.epea.tmp.br/epea2007_anais/pdfs/plenary/TR60.pdf >. Acesso em: 20 jun., 2017. 


\section{Capítulo 20}

\section{TRANSPORTE PÚBLICO: EFICIENTE PROMOTOR DA QUALIDADE DE VIDA}

\section{Jurandir Moura Dutra \\ Marcelo José de Lima Dutra \\ Samara Barbosa de Menezes \\ Josildo Severino de Oliveira}

Resumo: 0 planejamento do transporte público é fundamental por ser o elemento balizador da economia. Políticas públicas de mobilidade urbana influenciam diretamente na qualidade de vida da população. Entretanto, nos últimos anos, devido a incentivos fiscais, o modal rodoviário individual cresceu vertiginosamente. Esse crescimento se deu sem que a infraestrutura viária acompanhasse essa evolução. Como consequência restou lentidão no trânsito, acidentes e priorização do modal individual em detrimento do coletivo. 0 objetivo deste trabalho é compreender que a qualidade de vida da população tem relação direta com a sustentabilidade no transporte de acordo com que prenuncia a literatura clássica relativa ao setor. Para essa análise foram avaliados dados brutos publicados pelo Sistema de Informação na Mobilidade Urbana - Relatório Comparativo 2003 a 2011 emitido pela Associação Nacional de Transportes Públicos - ANTP, assim como foram consultadas fontes bibliográficas. Os resultados apontam que uma melhor qualidade de vida da população está associada a políticas de incentivos aos modais coletivos de transportes nos grandes centros associados ao fomento de modais não motorizados, cuja tendência pode ser observada nas dimensões que induzem ao desenvolvimento sustentável.

Grupo Temático: Problemas e políticas socioambientais no meio urbano 


\section{INTRODUÇÃO}

O homem por meio de suas atividades tem lançado na atmosfera do planeta, no processo histórico, altas concentrações de gases poluentes. As consequências são danos à saúde humana e à produtividade agrícola. Ocorre também o incremento na espessura de certos gases de efeito estufa e local - precursores de ozônio - que contribuem para as mudanças climáticas. Os grandes centros urbanos, por causa de suas atividades produtivas e sociais, estimulam e concentram a queima de combustíveis fósseis, sendo, portanto, forte contribuinte para esse processo. As necessidades de geração de energia para o desenvolvimento econômico, no espaço urbano, assim como as atividades de apoio de transporte de cargas e pessoas, fomentam esse fenômeno.

O setor de transportes, sobretudo o rodoviário, é um grande emissor de gases de efeito estufa para a atmosfera, pois tem nos combustíveis fósseis sua principal matriz geradora (BRASIL, 2009). No entanto, quando compreendido e avaliado o sistema de transporte público de passageiros, percebe-se que as relevâncias social e ambiental devem estar em sintonia com as políticas públicas, pois ele é elemento balizador do desenvolvimento econômico.

O objetivo deste trabalho é compreender e associar a qualidade de vida da população a políticas de transporte público sustentável, pois a literatura há muito as associam (BALASSIANO et a.l, 1993; OLIVEIRA et al., 2010a). A metodologia adotada é condizente com a dedução, pois partiu do geral para o particular. Os dados usados foram extraídos do Sistema de Informação da Mobilidade Urbana - Relatório Comparativo 2003/2011 emitido pela Associação Nacional de Transportes Públicos - ANTP (ANTP, 2012), além de consultas a fontes bibliográficas.

Espera-se contribuir para a literatura, no sentido de apresentar considerações que tratem a sustentabilidade do transporte público enquanto aliada da qualidade de vida e desta forma promover desenvolvimento, social, econômico e ambiental que são o alicerce das sociedades sustentáveis.

\section{METODOLOGIA}

A metodologia do presente artigo foi baseada em pesquisa bibliográfica com análise de dados secundários. Os dados brutos foram coletados do Sistema de Informações da Mobilidade Urbana - Relatório Comparativo 2003/2011 da Associação Nacional de Transportes Públicos - ANTP que é uma entidade civil sem fins lucrativos voltada para o setor de transporte público e trânsito no Brasil, cujo objetivo é disseminar conhecimento. Foram analisadas a evolução socioeconômica dos municípios que integram o sistema, a evolução do consumo de energia em tep (toneladas equivalentes de petróleo), as emissões de gases poluentes de efeito estufa e local e a evolução dos custos de externalidades, sempre comparando os modais coletivo e individual.

No que tange à natureza, a pesquisa foi aplicada, porque tem como objetivo gerar conhecimentos para aplicação prática dirigida à solução de problemas específicos, visto que envolve verdades e interesses locais ou paroquiais do setor de transportes. A maneira de abordagem do problema aponta para uma pesquisa quantitativa.

Por ser uma pesquisa baseada em dados publicados pelo governo brasileiro, a análise tendeu à pesquisa descritiva uma vez que visa descrever as características de determinada população ou fenômeno, ou o estabelecimento de relações entre variáveis.

A fim de fundamentar a base de avaliação dos dados, foi realizada uma pesquisa bibliográfica. Foram consultados impressos, livros e artigos científicos, assim como material disponível na rede virtual de computadores - internet.

\subsection{TRANSPORTE PÚBLICO URBANO}

A missão do transporte público urbano está associada a uma imagem de coletividade que remete a questões de cunho social, cujo valor mais significativo direciona-se para a relevância da prestação de serviços de utilidade pública.

0 transporte urbano é empregado para efetivar o deslocamento de pessoas, dentro dos limites geográficos da cidade, por modais motorizados ou não, mas que viabilizem a locomoção. 0 metrô e o ônibus são conceituados como mais importantes. Proporciona integração e desenvolvimento, em moldes democráticos. "A mobilidade é, sem dúvida, o elemento balizador do desenvolvimento urbano". 
Conquanto, Não só é eixo condutor da economia como determina para o transporte uma ação social, pois "proporcionar uma adequada mobilidade para todas as classes sociais constitui uma ação essencial no processo de desenvolvimento econômico das cidades" (FERRAZ \& TORRES, 2001a, p. 01).

O Poder Público enquanto gestor do sistema de transporte público regula o serviço ou o executa. 0 planejamento e a gestão, em geral, são realizados pelo governo municipal, já que este serviço influi na qualidade de vida da população, na justiça social, no uso e ocupação racional do solo, nas atividades econômicas e no desenvolvimento das cidades. Um transporte público eficiente pressupõe o atendimento de requisitos, considerados básicos, condicionados à educação, ao planejamento, à gestão, à legislação e à conscientização do usuário enquanto consumidor final. Gerir o transporte público requer, ainda, o estabelecimento de normas e regulamentos de operação, fiscalização, programação operacional, sistema de comunicação com o usuário, educação e capacitação de todos os atores entre outras atribuições (FERRAZ \& TORRES, 2001b; VASCONCELLOS, 2013a).

No processo de gestão alguns fatores têm de ser considerados relevantes e complementam a literatura necessária para o efetivo desempenho da qualidade do serviço. Esses fatores são a acessibilidade, a frequência de atendimento, o tempo de viagem, a lotação, a confiabilidade, a segurança, as características dos veículos e dos pontos de parada, os sistemas de informações, a transbordabilidade, o comportamento dos operadores e o estado das vias (DUARTE et al., 2007a; VASCONCELLOS, 2013b).

Cada ator do sistema - usuário, governo, empresário - busca satisfazer os seus objetivos. 0 poder público deve ponderar os anseios das partes, de forma que, fundamentado em sua função social de existência, execute os serviços, ou permita a terceiros, a sua execução, consoante o exercício da qualidade atrelado a uma tarifa de baixo custo econômico-social. No transporte público:

\begin{abstract}
"A eficiência social é avaliada com base no custo social, o qual reflete não apenas o custo monetário da produção do bem ou serviço, mas também os custos dos impactos (positivos e negativos) sobre a qualidade de vida da comunidade, o meio ambiente, a infraestrutura, os serviços públicos etc". (FERRAZ \& TORRES, 2001c, p. 116).
\end{abstract}

No custo social do transporte público devem estar embutidos os impactos ambientais, a fluidez do trânsito, a segurança das viagens, toda e qualquer forma de poluição atmosférica, a sustentabilidade econômica, o uso do solo, a geração de empregos, a taxa de ocupação urbana e assim por diante. No sistema de transporte público, cada ator - governo, usuário, empresário, trabalhador e comunidade possui objetivos distintos. Cabe, portanto, à esfera competente, regular o sistema de maneira a equilibrar as relações entre os atores (FERRAZ E TORRES, 2001d; DUARTE et al., 2007b; VASCONCELLOS, 2013c).

\title{
2.2 0 CONSUMO DE ENERGIA NO TRANSPORTE PÚBLICO
}

0 setor de transportes por ser uma das mais importantes forças que impulsionam a economia, acrescenta algo em torno de 3 a 5\% do Produto Interno Bruto - PIB de um país. Quando os investimentos em modernização da malha e infraestrutura em transportes são priorizados e ultrapassam a casa dos $3 \%$ do PIB, o setor representa de 5 a $8 \%$ da fatia paga aos trabalhadores (WORLD BANK, 2000).

Os diversos modais de transporte apresentam grandes variações no consumo e uso de energia e, por conseguinte, têm diferentes graus e intensidades de emissões de gases de efeito estufa e local. Alguns modais são menos intensivos em energia, o que faz oscilar os gastos para a realização do mesmo trabalho. Entretanto, outros fatores além da distribuição dos modais influenciam no consumo, relacionados à frequência das viagens, à distância viajada e à tecnologia empregada. Essa energia consumida no setor de transportes é rateada entre o transporte de passageiros e de cargas.

Os combustíveis derivados de petróleo no Brasil representam, em média, 97\% do total de energia consumida no setor de transportes. Contudo iniciativas que contemplam biocombustíveis ou tecnologias menos poluentes têm sido implantadas nas mais diversas cidades americanas e européias. A partir de 1975 iniciou-se a mistura de álcool etílico anidro na gasolina, a fim de reduzir o consumo de combustíveis fósseis, como saída alternativa à crise do petróleo instalada no mundo em anos anteriores. 0 modal rodoviário, o mais utilizado no Brasil, é o mais intensivo em consumo de energia, tendo representado 90,1\% da energia total consumida no setor de transportes no ano de 1999 no Brasil (BRASIL, 2000).

No Brasil, os combustíveis fósseis são os principais responsáveis imediatos pela geração de energia no setor de transportes de passageiros no cenário atual e 26\% das emissões de CO2 advém dos ônibus 
urbanos. Se nada for feito nos próximos anos o transporte coletivo urbano e rodoviário representará 33\% das emissões desse gás (BRASIL, 2012a).

Contudo, no cenário de biocombustíveis, o Brasil deve aumentar sensivelmente a produção de etanol dos atuais 12 para 92 bilhões de litros em 2035, se mantidas as premissas dos cenários estabelecidos pelo IPCC. Já a partir de 2015, o país deve liderar as exportações desse produto (SBD, 2010).

É possível que uma revolução econômica nos países em desenvolvimento e emergentes ocorra no campo, diferentemente da evolução histórica no setor industrial dos países europeus. Entretanto, para evitar a concorrência por terras cultiváveis entre a agropecuária e a indústria de biocombustíveis é necessário catalogar as áreas já desmatadas e partilhá-las a fim de torná-las mais eficientes (SACHS, 2010).

Entretanto, um paradoxo se instala em economias, como a brasileira. 0 estímulo para o desenvolvimento de carros híbridos - movidos a gasolina e biocombustível - pode gerar um contrassenso. Corre-se o risco de incentivar a migração para o uso de biocombustíveis na frota, sem incentivar seu uso no transporte público. Ocorre que, em certo tempo, se as políticas públicas suscitarem tecnologias menos poluentes para os modais coletivos a fim de reduzir as emissões, caminhar-se-á para o retrocesso do transporte das massas, vez que o uso do particular estará mais eficiente do ponto de vista ambiental (BRASIL, 2012b).

\subsection{A SUSTENTABILIDADE E 0 TRANSPORTE PÚBLICO}

O antagonismo percebido entre crescimento econômico, desenvolvimento e conservação do meio ambiente veio a fazer parte das discussões mundiais a partir da Primeira Conferência das Nações Unidas Para o Meio Ambiente, realizada em Estocolmo, 1972. Posteriormente, essas discussões tomaram corpo com a Assembleia Geral da ONU em 1983, onde foi constituída a Comissão Mundial do Meio Ambiente e Desenvolvimento cujo propósito era avaliar o comprometimento real dos recursos naturais e indicar estratégias para compatibilizar crescimento com preservação ambiental, de forma a corrigir os padrões vigentes (SEIFFERT, 2011).

Embora o conceito de sustentabilidade seja recente, a ideia de limites geológicos, físicos e biológicos ao crescimento está presente há mais tempo. Os Ensaios de Malthus remontam aos anos de 1796 e 1803. Neles relacionou a tendência de crescimento exponencial da população à tendência de crescimento linear da produção de alimentos, em um mundo finito conduziria à redução da disponibilidade per capita de alimentos e outros bens. Na conjectura de Malthus, a natureza impõe limites à produção de alimentos e, em consequência ao crescimento da população. A sua profecia alardeava assombrosos cenários de fome e destruição, em vista da incapacidade produtiva do planeta. Um ponto deixou de ser considerado por ele: o avanço tecnológico como fator otimizante do processo produtivo.

Mais adiante, num outro cenário, derrubado o assombro inicial das previsões de Malthus, as relações entre sistema econômico e ecossistemas foram ficando mais evidentes à medida que os impactos foram crescendo em escala e amplitude. Enfim, o Relatório Brundtland, intitulado Our Common Future aponta limitações de vários tipos e caracterizações ao desenvolvimento: tecnológicas, de organização social, recursos ambientais e capacidade de absorção pela biosfera. Contudo conclui que são passíveis de solução.

Do ponto de vista econômico, uma implicação é decisiva. A proposta do desenvolvimento sustentável requer a manutenção no tempo, do estoque de capital, agregando a este os recursos naturais. De certa forma, significativa parcela conceitual foi acrescentada à sua gênese, sendo hoje concebido como aquele que obtém o crescimento econômico através da racionalidade e do manejo dos recursos naturais, implementando tecnologias mais eficientes e menos intensivas em carbono, de forma a elevar a qualidade de vida e erradicar a miséria para que se supram as necessidades desta geração e da posteridade (BRUNDTLAND, 1988).

Têm proliferado, ultimamente, instrumentos econômicos baseados nos conceitos neoclássicos de equilíbrio respaldados na microeconomia e metodologias de gestão ambiental que privilegiam a conservação e o controle de impacto. Percebe-se, então, que ambos tratam as relações econômicas e os ecossistemas como dimensões separadas.

Hoje, os ensaios que se articulam em torno da sustentabilidade apontam para a existência de um campo, baseado na ideia que afirma sê-lo "um jogo que se joga segundo as regularidades que estão nas regras, mas onde se pode também jogar para transformar as regras ou as regularidades" (BOURDIEU, 2012, p. 156).

Nesse sentido, a sustentabilidade não mais exprime um conceito ou uma noção de valor, mas um campo de lutas, no qual se manifestam embates entre agentes. Esses agentes estão contidos numa teia relacional ou 
social, cuja divergência científica ou ideológica pode, paradoxalmente, convergir para o estreitamento de pensamentos em situações de interesses congruentes.

Evidentemente que no campo da sustentabilidade a concepção do desenvolvimento sustentável é a ideia corrente mais bem aceita e amplamente pregada pela comunidade internacional, talvez por se tratar de uma solução capitalista para a manutenção dos hábitos de consumo, ainda que racionalizado o comportamento requerido pelo modelo. Ele é interdisciplinar vez que agrega economistas, ecólogos, geógrafos, biólogos, engenheiros, geólogos, climatólogos, físico-matemáticos, mas também psicólogos, cientistas políticos e sociais entre outros. Esta interdisciplinaridade está pautada em dimensões econômicas, sociais e ambientais. Mas podem ser agregadas as dimensões ética, religiosa, cultural, tecnológica, espacial, demográfica, política e a institucional.

Esta interdisciplinaridade se aplica ao transporte público que para alcançar a sustentabilidade na mobilidade urbana, em face, sobretudo, do seu pressuposto social e econômico, são necessárias estratégias de gerenciamento. 0 gerenciamento caminha no sentido de encontrar formas mais eficientes de uso dos recursos, sem considerar o aumento da oferta de infraestrutura. Mas, também o incentivo à reformulação da configuração das cidades ao passo de intervir no planejamento urbano, levando-se em consideração o desenho do sistema viário, a incorporação de novas modalidades de transporte e o incentivo aos modais não motorizados, pois são capazes de reduzir o sedentarismo e, portanto, apresentar reflexos na saúde pública e na qualidade de vida da população (OLIVEIRA et al., 2010b).

A sustentabilidade no transporte tem características multidimensionais. "A sustentabilidade deveria ser entendida como uma nova ciência capaz de fazer a integração entre processos industriais, sociais e ambientais em um contexto global". (MIHELNIC et al., 2003). 0 plano de transportes deve estar focado num modelo de gestão sustentável que busque, sobretudo, a qualidade de vida e que seja capaz de estabelecer vínculos entre a operação do setor com o sistema viário, dada a sua complexidade e relevância.

\section{ANÁLISES E DISCUSSÕES}

Consultando os dados reunidos na Tabela 1 observa-se que o ritmo de crescimento de veículos foi maior que o ritmo de crescimento de todas as outras variáveis socioeconômicas, entre elas a população.

Nos grandes centros esse fenômeno vem sendo observado, sobretudo, no aumento considerável dos congestionamentos de tráfego, pois tem evoluído em ritmo maior o crescimento do transporte individual e o aumento da frota em detrimento do coletivo graças, em parte, à política de incentivos fiscais fornecidos ao setor com o intuito de aquecer a economia nacional (DENATRAN, 2014a).

Por tudo isso o aumento no número de acidentes de trânsito é uma consequência desastrosa ocasionada pelo estresse do tempo gasto no percurso. Isso se traduz em piora da qualidade de vida, sobretudo dos grandes centros urbanos o que afeta o desempenho econômico, vez que o transporte público é elemento balizador da economia (FERRAZ \& COCA, 2001e; BRASIL, 2009). Nesse sentido, o transporte público compete em desvantagem com o individual, tendo em vista inclusive o excesso de rolamento provocado pelo volume de automóveis nas vias, o que gera disputa pelo espaço e diminui a demanda pelo modal.

Tabela 1: Dados socioeconômicos dos municípios (438 municípios) que integram o sistema de informações da ANTP.

\begin{tabular}{|c|c|c|c|c|c|c|c|c|c|}
\hline Informação & 2003 & 2004 & 2005 & 2006 & 2007 & 2008 & 2009 & 2010 & 2011 \\
\hline População28 (milhões) & 108 & 111 & 1113 & 115 & 117 & 120 & 121 & 122 & 124 \\
\hline Empregos29 (milhões) & 13 & 13 & 14 & 14 & 14 & 15 & 15 & 15 & 16 \\
\hline $\begin{array}{c}\text { Renda média chefe } \\
\text { Família (R\$)30 }\end{array}$ & 1034 & 1025 & 1044 & 1091 & 1128 & 1270 & 1310 & 1359 & 1395 \\
\hline Matrículas 31(milhões) & 28 & 28 & 28 & 29 & 29 & 29 & 30 & 30 & 30 \\
\hline Veículos32 (milhões) & 18 & 19 & 20 & 21 & 24 & 26 & 28 & 30 & 33 \\
\hline
\end{tabular}

Fonte: Sistema de Informação de Mobilidade Urbana - Relatório Comparativo 2003/2011.

\section{Fonte: FIBGE}

${ }^{29}$ Considerados apenas empregos na indústria. Fonte: RAIS

30 Dados Censo de 200 FIBGE atualizado com taxas obtidas na PME - Pesquisa mensal de emprego - FIBGE.

31 Consideradas as matrículas nos ensinos fundamental, médio e superior. Fonte: INEP

${ }^{32}$ Considerando automóvel, utilitário, camioneta, ônibus, microônibus, motocicleta e motoneta, classificação e dados do DENATRAN. 
Outro ponto importante de comparação nesta análise refere-se ao consumo de energia entre os modais coletivo e individual (Tabela 2). Mais uma vez se observa que o ritmo de evolução deste último supera o primeiro, principalmente devido ao crescimento da frota particular e ao cenário de uso do espaço viário em massa (DENATRAN, 2014b). Entretanto, o Relatório Comparativo 2003-2011 não separou a adoção de matrizes de fontes renováveis das não-renováveis.

Sabe-se, contudo, que já há no mercado oferta de tecnologia de motores híbridos e/ou menos intensivos em carbono a base de hidrogênio líquido, por exemplo. Essas alternativas são importantes porque o petróleo e os seus derivados, em conjunto com o gás natural e o carvão respondem por cerca de $81 \%$ da demanda de energia primária brasileira (GOLDEMBERG, 2010a).

A energia é um fator fundamental para a obtenção do desenvolvimento econômico de qualquer nação, uma vez que fomenta o trabalho e a produção de bens e serviços. O seu consumo per capita é habitualmente associado ao grau de desenvolvimento que um país atingiu (OMENA NETO, 2006; BRASIL, 2010). Contudo, as informações prestadas no referido documento emitido pela ANTP não vislumbram esse indicador.

No processo de produção e consumo de energia elétrica, a eficiência é medida para que se verifique a sustentabilidade energética. Esse processo é uma preocupação do setor e dos governos. Quanto mais eficientes os resultados dessa razão entre produção e consumo, menores serão os custos totais de produção e os impactos ambientais, o que afeta diretamente a qualidade de vida da população. Por tudo isso, deve-se planejar o setor e estimular a adoção de matrizes menos poluentes para alcançar um cenário de sustentabilidade.

Tabela 2: Brasil: evolução do consumo de energia por modo (milhões de tep/ano).

\begin{tabular}{|l|c|c|c|c|c|c|c|c|c|c|}
\hline Modo & 2003 & 2004 & 2005 & 2006 & 2007 & 2008 & 2009 & 2010 & 2011 \\
\hline Municipal & 1,6 & 1,7 & 1,8 & 1,7 & 1,8 & 1,8 & 1,8 & 1,8 & 1,8 \\
Metropolitano & 0,5 & 0,6 & 0,6 & 0,6 & 0,6 & 0,6 & 0,6 & 0,6 & 0,6 \\
\hline Trilhos & 0,4 & 0,4 & 0,4 & 0,5 & 0,5 & 0,5 & 0,5 & 0,6 & 0,6 \\
\hline TC - total & 2,6 & 2,7 & 2,8 & 2,8 & 2,9 & 2,9 & 3 & 2,9 & 3 \\
\hline Auto & 7,6 & 7,8 & 8,1 & 8,3 & 8,6 & 8,8 & 8,9 & 9,2 & 9,5 \\
Moto & 0,2 & 0,2 & 0,3 & 0,3 & 0,3 & 0,4 & 0,4 & 0,5 & 0,5 \\
\hline TI - total & 7,8 & 8 & 8,4 & 8,6 & 8,9 & 9,1 & 9,3 & 9,7 & 10 \\
\hline Total & 10,4 & 10,8 & 11,2 & 11,4 & 11,8 & 12,1 & 12,3 & 12,6 & 13,1 \\
\hline
\end{tabular}

Fonte: Sistema de Informação de Mobilidade Urbana - Relatório Comparativo 2003/2011.

As Tabelas 3 e 4 apresentam dados sobre o cenário das emissões dos gases de efeito local - GEL e de estufa - GEE. Percebe-se que houve redução nas emissões de gases de efeito local no modal coletivo enquanto o individual apresentou crescimento significativo de emissões. Isso ocorreu provavelmente por causa do desenvolvimento de tecnologias - filtros- que minimizaram as emissões de monóxido de carbono - CO no escapamento dos veículos, um dos principais precursores do ozônio troposférico. Evidentemente que a evolução desta tecnologia atingiu o modal individual, mas o crescimento vertiginoso da frota foi diretamente responsável pelo incremento das emissões. 
Tabela 3: Brasil: emissões de poluentes locais (mil ton/ano).

\begin{tabular}{|l|c|c|c|c|c|c|c|c|c|c|}
\hline \multicolumn{2}{|c|}{2003} & 2004 & 2005 & 2006 & 2007 & 2008 & 2009 & 2010 & 2011 \\
Municipal & 185 & 170 & 168 & 164 & 162 & 158 & 154 & 154 & 158 \\
Intermunicipal & 69 & 60 & 58 & 54 & 52 & 54 & 54 & 59 & 59 \\
\hline TC & 255 & 230 & 226 & 218 & 214 & 212 & 208 & 213 & 217 \\
\hline Auto & 1160 & 1172 & 1100 & 1146 & 1200 & 1237 & 1275 & 1320 & 1367 \\
Moto & 176 & 175 & 176 & 175 & 175 & 176 & 179 & 197 & 217 \\
\hline TI & 1336 & 1348 & 1276 & 1321 & 1375 & 1413 & 1451 & 1517 & 1584 \\
\hline Total & 1590 & 1578 & 1502 & 1539 & 1590 & 1625 & 1659 & 1730 & 1801 \\
\hline
\end{tabular}

Fonte: Sistema de Informação de Mobilidade Urbana - Relatório Comparativo 2003/2011.

Tabela 4: Brasil: emissões de poluentes de estufa (mil ton/ano).

\begin{tabular}{|l|c|c|c|c|c|c|c|c|c|c|}
\hline \multicolumn{2}{|c|}{2003} & 2004 & 2005 & 2006 & 2007 & 2008 & 2009 & 2010 & 2011 \\
\hline Municipal & 6341 & 6724 & 6979 & 6978 & 7110 & 7161 & 7130 & 7058 & 7301 \\
Intermunicipal & 2380 & 2369 & 2397 & 2302 & 2276 & 2443 & 2488 & 2727 & 2736 \\
\hline TC & 8720 & 9093 & 9376 & 9281 & 9386 & 9604 & 9617 & 9785 & 10037 \\
\hline Auto & 13813 & 14167 & 14716 & 15129 & 15559 & 15909 & 16118 & 16729 & 17319 \\
Moto & 602 & 653 & 712 & 788 & 890 & 1005 & 1107 & 1220 & 1344 \\
\hline TI & 14415 & 14820 & 15428 & 15917 & 16449 & 16914 & 17225 & 17949 & 18663 \\
\hline Total & 23135 & 23913 & 24804 & 25198 & 25835 & 26518 & 26842 & 27734 & 28700 \\
\hline
\end{tabular}

Fonte: Sistema de Informação de Mobilidade Urbana - Relatório Comparativo 2003/2011.

Quanto às emissões de GEE, elas cresceram tanto no modal coletivo quanto no individual, mas em proporções desiguais. Essa desproporção está associada ao crescimento da frota do modal individual, mas também ao uso massificado de derivados de petróleo (GOLDEMBERG, 2010b).

Contudo, se não houver modificações na matriz e na infraestrutura do modal coletivo, o cenário de emissões tenderá à elevação nos próximos 20 anos, de acordo com o Plano Setorial de Transporte e de Mobilidade Urbana para Mitigação da Mudança do Clima - PSTM que é parte integrante da Política Nacional de Mobilidade Urbana - PNMU (BRASIL, 2012).

Os GEL são gases lançados na atmosfera e que em contato com a radiação solar e o vapor d'água produzem ozônio troposférico - 03. 0 ozônio troposférico produz, no campo, fitoxicidade a certas culturas, como soja e milho, o que reduz a produtividade agrícola. Em áreas urbanas ele afeta as vias respiratórias podendo ser um sério problema de saúde pública. Esse gás quando na estratosfera - em torno de 20 a $50 \mathrm{~km}$ de altitude - é altamente benéfico à vida humana, pois filtra a radiação ultravioleta do sol em processo fotoquímico de geração e extinção de ozônio. Contudo, na troposfera - camada da atmosfera mais próxima à superfície - a sua ação não é saudável (LOGAN et al, 1981).

Há ainda dúvidas acerca de todos os impactos causados por esse gás, visto também ser considerado de estufa, embora seus precursores sejam reconhecidos de efeito local (IPCC, 2001). Os seus principais precursores são o monóxido de carbono - CO, os Compostos Orgânicos Voláteis - COV's e os Hidrocarbonetos - HC.

Os GEE são gases eficientes em absorção de radiação termal emitida pela superfície ou captada pela atmosfera e são responsáveis por manter a temperatura média do planeta em torno de 15ํㅡ. Todavia, as atividades antrópicas têm elevado consideravelmente a espessura ótica (grossura da camada) desses gases na atmosfera. Este incremento acarreta, provavelmente, o aquecimento global, cujo fenômeno é parte manifesta das mudanças climáticas. A principal espécie química deste grupo é o dióxido de carbono - CO2, mas há outros contribuintes, como o metano - CH4 e o vapor d'água - H2O.

0 aumento das emissões no conjunto, de GEL e GEE, reduz a qualidade de vida da população, tendo em vista as consequências descritas nesta seção. 
A avaliação dos custos das externalidades (poluição e acidentes) pode ser observada com a ajuda dos dados reunidos na Tabela 5. Novamente o modal individual apresentou comportamento singular e recorrente. 0 volume dos custos mais que dobrou entre o fim e o início da série, enquanto o modal coletivo não atingiu essa marca. Evidente que a elevação dos custos nesta análise tem a mesma explicação já apresentada acima. Trata-se do aumento significativo na frota individual nos últimos anos e as suas consequências negativas na qualidade de vida. Mais acidentes de trânsitos, mais estresses, mais gastos com saúde pública e assim por diante.

Tabela 5: Brasil: evolução dos custos das externalidades (bilhões de reais/ano).

\begin{tabular}{|l|c|c|c|c|c|c|c|c|c|}
\hline \multicolumn{1}{|c|}{ Tipo } & 2003 & 2004 & 2005 & 2006 & 2007 & 2008 & 2009 & 2010 & 2011 \\
\hline $\begin{array}{l}\text { TC - } \\
\text { Poluição33 }\end{array}$ & 1,5 & 1,6 & 1,7 & 1,7 & 1,8 & 1,9 & 2,0 & 2,1 & 2,2 \\
\hline $\begin{array}{l}\text { TC - } \\
\text { Acidentes34 }\end{array}$ & 0,7 & 0,8 & 0,9 & 0,9 & 1,1 & 1,3 & 1,4 & 1,6 & 1,9 \\
\hline TC - Total & 2,2 & 2,4 & 2,5 & 2,6 & 2,9 & 3,2 & 3,4 & 3,5 & 4,0 \\
\hline $\begin{array}{l}\text { TI - } \\
\text { Poluição35 }\end{array}$ & 3,4 & 3,6 & 3,8 & 4,1 & 4,4 & 4,8 & 5,1 & 5,6 & 5,8 \\
\hline $\begin{array}{l}\text { TI- } \\
\text { Acidentes36 }\end{array}$ & 4,2 & 4,7 & 5,3 & 5,6 & 6,7 & 7,7 & 8,6 & 10,0 & 11,4 \\
\hline TI - Total & 7,6 & 8,3 & 9,1 & 9,7 & 11,1 & 12,5 & 13,8 & 15,6 & 17,2 \\
\hline
\end{tabular}

Fonte: Sistema de Informação de Mobilidade Urbana - Relatório Comparativo 2003/2011.

Com base na análise socioconômica e ambiental, pilares da sustentabilidade histórica, é possível afirmar que o desenvolvimento condiz com a melhoria da qualidade de vida da população. Entretanto, é preciso adotar posturas e instrumentos legais para a manutenção de um planejamento e gestão do sistema a fim de atingir níveis ótimos e indicadores que reflitam avanços. A maior dúvida é se a sustentabilidade será capaz de garantir qualidade de vida às gerações futuras e às atuais, do mesmo jeito das sociedades que já alcançaram altos níveis de qualidade de vida, ou se teremos que repensar a visão desenvolvimentista baseada no crescimento econômico infindo (NASCIMENTO, 2012).

\section{CONSIDERAÇÕES FINAIS}

A mobilidade urbana quando não tratada como política pública de interesse da coletividade contribui fortemente para a redução da qualidade de vida da população, além de interferir negativamente no desempenho econômico. A perda de competitividade do modal coletivo para o individual deu-se num cenário de estímulo ao aquecimento econômico do setor de transportes. Os incentivos fiscais dados a ele perduraram por certo tempo em detrimento dos investimentos em infraestrutura de transportes públicos. As consequências foram desastrosas para a fluidez do tráfego, devido ao incremento da frota nos últimos anos.

0 volume de veículos particulares que ingressa mensalmente nas vias dos grandes centros adensa cada vez mais o rolamento, o que conduz à concorrência desleal com o transporte de massas, dada a sua ineficiência, altos custos, inadequação do planejamento e gestão inapropriada.

Não se trata de regulação, mas é importante a elaboração de instrumentos legais, como o plano diretor de transportes e o plano de mobilidade urbana, a fim de determinar as diretrizes de longo prazo a serem cumpridas no sistema de transportes. Assim se definirá os investimentos necessários na infraestrutura e na frota com o intuito de atingir o tão almejado padrão de qualidade.

Como sugestão para a gestão do sistema sugere-se aplicar técnicas de benchmarking. É salutar a implantação de planejamento estratégico para períodos, nunca inferior, a uma década.

\footnotetext{
33 Baseado em custos por tonelada de cada poluente ( $\mathrm{CO}, \mathrm{HC}, \mathrm{NO}_{\mathrm{x}}, \mathrm{MP}, \mathrm{SO}_{\mathrm{x}}, \mathrm{CO}_{2}$ ), média de valores internacionais, adaptados à economia brasileira por meio da PPC - Paridade do poder de Compra (Banco Mundial) - Refere-se ao Transporte Coletivo

${ }^{34}$ Custo de horas perdidas de trabalho, custos médios hospitalares, reparação de veículos e outros. Referência: IPEA/ANTP (2002) - Refere-se ao Transporte Coletivo

35 Idem nota 6 - Refere-se ao Transporte Individual

${ }^{36}$ Idem nota 7 - Refere-se ao Transporte Individual
} 
Deve-se propor prioridade de circulação do transporte público, investimentos em redes e modais urbanos modernos e integrados, a construção de uma política de mobilidade que aprecie inclusive os deslocamentos a pé e por bicicleta, a desoneração da planilha de custos da tarifa, racionalização das gratuidades e institutos democráticos de participação popular. Certamente, em longo prazo, essas mudanças afetarão consideravelmente a qualidade de vida da população.

\section{REFERÊNCIAS}

[1] ANTP (Associação Nacional de Transportes Públicos). (2012). Sistema de Informação de Mobilidade Urbana - Relatório Comparativo 2003/2011. <Disponível em http://www.antp.org.br>. Acessado em 11/06/2014.

[2] BALASSIANO, Ronaldo; CHIQUETTO, Sérgio Luiz; ESTEVES, Ricardo. Transporte e Qualidade de Vida. Revista de Transportes: Associação Nacional de Pesquisa e Ensino em Transportes - ANPET, v. 1, n. 1, 1993.

[3] BOURDIEU, Pierre. Sur l'État. Cours au Collège de France, 1989-1992. Paris: Seuil, 2012.

[4] BRASIL. Balanço Energético Nacional 2000: ano base 1999. Ministério das Minas e Energia, Brasília, DF, 2000.

[5] BRASIL. Ministério das Minas e Energia-MME. Balanço Energético Nacional 2009: Ano base 2008. Empresa de Pesquisa Energética-EPE, Rio de Janeiro. 274 p., 180, 23 cm, 2009.

[6] BRASIL. Ministério do Planejamento, Orçamento e Gestão - MPOG. Índice de Desenvolvimento SustentávelIDS. Estudos e Pesquisas, no 7, Rio de Janeiro, 2010.

[7] BRASIL. Plano Setorial de Transporte e Mobilidade Urbana para Mitigação da Mudança do Clima - PSTM. MinC(Ministério das Cidades) www.minc.gov.br. Acessado em 10/03/2013, 2012.

[8] BRUNDTLAND, Gro Harlem. Nosso Futuro Comum. Rio de Janeiro: Fundação Getúlio Vargas, 1988.

[9] DUARTE, Fábio; LIBARDI. Rafaela; SÁNCHEZ, Karina. Introdução à mobilidade urbana. Curitiba: Juruá Editora, 2007.

[10] FERRAZ, A. C. P.; TORRES, I. G. E. Transporte Público Urbano. São Carlos: Rima, 2001.

[11] GIL, Antônio Carlos. Como Elaborar Projetos de Pesquisa. 4. Ed. São Paulo: Atlas, 2008.

[12] GOLDEMBERG, José. Energia e Desenvolvimento Sustentável. Gestão e Regionalidade, Vol. 27, no 79, jan-abril, 2010.

[13] IPCC (Intergovernmental Panel on Climate Change), Climate Change, 2001.

[14] LOGAN, Jennifer; Prather, Michael; Wofsy, Steven; McElroy, Michael. Tropospheric Chemistry: A Global Perspective. Journal Geophysical Research. 86: 7.210-7.254, 1981.

[15] MIHELNIK, James et al. Sustainability Science and Engineering: The Emergence of a New, 2003.

[16] NASCIMENTO, Elimar Pinheiro. Sustentabilidade: o campo de disputa do nosso futuro civilizacional. Rio de Janeiro, Garamond, 2012.

[17] OLIVEIRA, Marília Flores Seixas; Oliveira, Orlando J. R.; Oliveira, Joaquim F. Seixas Mobilidade e Sustentabilidade Urbana. V Encontro Nacional da Anppas 2010, <Disponível em http://www.anppas.org.br/encontro5>. Acessado em 05/06/2014.

[18] OMENA NETO, Alcides José. Energia Alternativa: processo de Desenvolvimento Tecnológico, Econômico e Ambiental. PRODEMA, UFAL, 2006.

[19] SBD/FEA/USP. Economia da Mudança do Clima no Brasil: custos e oportunidades / editado por Sérgio Margilus e Carolina Burle Schimidt Dubeux. São Paulo: IBEP Gráfica, 2010.

[20] SACHS, Ignacys. Barricadas de ontem, campos de futuro. São Paulo, v. 24, n. 68, 2010.

[21] SEIFFERT, Mari Elizabeth Bernardini. Gestão Ambiental: instrumentos, esfera de ação e educação ambiental. São Paulo: Atlas, 2011.

[22] VASCONCELLOS, Eduardo Alcântara. Mobilidade urbana: o que você precisa saber. São Paulo: Companhia das Letras, 2013.

[23] ANUÁRIO WORLD BANK. <Disponível em http://www.worldbank.org> Acessado em 23/10/2013.

[24] ANUÁRIO DENATRAN 2014. <Disponível em http://www.denatran.gov.br/frota> Acessado em 05/06/2014. 


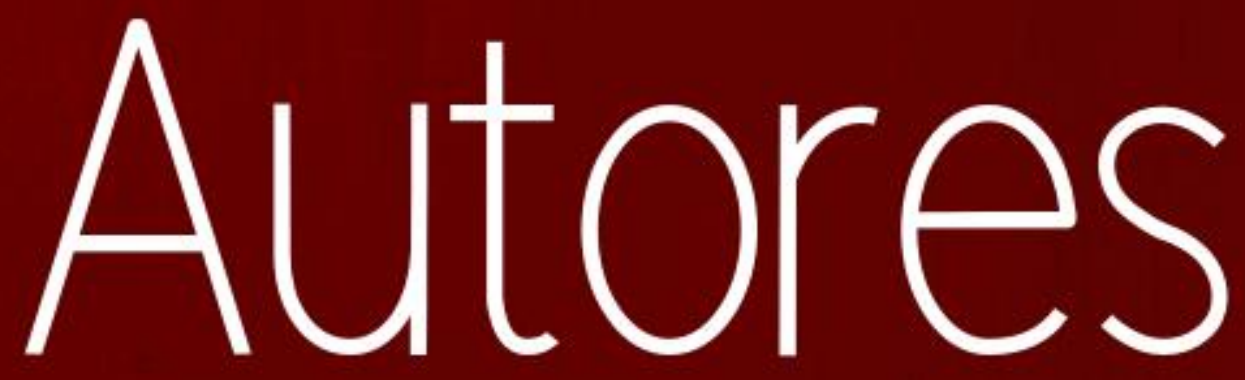




\section{ADNA AMORIM DOS SANTOS}

Graduada em Engenharia de Produção na Universidade do Estado de Minas Gerais - UEMG, natural de Itaú de Minas/MG.

\section{ADRIANA SALETE DANTAS DE FARIAS}

Possui doutorado em Recursos Naturais pela Universidade Federal de Campina Grande (2014); e, mestrado em Engenharia de Produção pela Universidade Federal da Paraíba (2002). É especialista em Logística e Mobilização Nacional, pela Escola Superior de Guerra (ESG, 2017). Professora do Curso de Administração da Universidade Federal de Campina Grande - UFCG. Tem experiência na área de Administração, com ênfase em Administração de Logística e de Cadeias de Suprimentos, atuando principalmente nos seguintes temas: Logística e SCM; Logística Reversa e P+L; Logística Reversa em atividades militares; Eco-inovações e sustentabilidade de atividades produtivas; agronegócio.

\section{ANA NERI DA PAZ JUSTINO}

Possui graduação em Turismo, especialização em Educação Ambiental e em Práticas Pedagógicas no Ensino Superior e Mestrado pelo Programa de Pós-Graduação em Administração da UnP. Atualmente é acadêmica do Programa de Pós-Graduação em Turismo da UFRN e Professora EBTT do Instituto Federal de Educação, Ciência e Tecnologia do Rio Grande do Norte (IFRN). Atuou com Professora DNS III da Universidade Potiguar (UnP) e Professora Auxiliar na Universidade do Estado do Estado do Rio Grande do Norte. Tem experiência na área de turismo, docência, administração pública, lazer, recreação, meio ambiente, eventos e planejamento público e privado. É gestora ambiental habilitada pelo Programa Nacional de Gestores Ambientais e consultora nas áreas de domínio de formação em projetos desenvolvidos pela Fundação Para o Desenvolvimento Sustentável da Terra Potiguar (FUNDEP/RN). Atua como tutora e autora de material didático para EaD. Atuou como educadora ambiental no Projeto Barco-Escola Chama-Maré (IDEMA/RN FUNDEP/RN).

\section{ANDRÉ SPANHOL}

Possui graduação em Engenharia química pela Universidade Estadual de Maringá (2017). Realizou graduação sanduíche com a Universidade de Debrecen, na Hungria (2015). Atualmente é aluno do Programa de Mestrado em Engenharia mecânica pela Universidade Tecnológica Federal do Paraná e atua como Engenheiro Pleno na empresa Cargill Agrícola em Ponta Grossa - PR.

\section{ANTONIA ARISDELIA FONSECA MATIAS AGUIAR FEITOSA}

Professora Associada do Departamento de Sistemática e Ecologia do CCEN/UFPB. Doutora em Educação (PPGE/UFPB). Mestre em Desenvolvimento e Meio Ambiente (PRODEMA/UFPB). Especialista em Educação Ambiental (UFPB). Graduada em Ciências Biológicas (UFPB). Docente Permanente do PROFBIO/UFPB, Orientadora no Programa Residência Pedagógica - Biologia, Campus I da UFPB. Experiência em pesquisa e extensão nas áreas de Ensino de Ciências Biológicas, Educação, Processos de Aprendizagens, Ecologia, Ciências Ambientais e Educação Ambiental. Atuação em disciplinas relacionadas às Ciências Ambientais, Ecologia, Estágios Supervisionados e Metodologias do Ensino em Ciências Biológicas. arisdelfeitosa@gmail.com

\section{ANTÔNIO RODRIGUES ALBUQUERQUE FILHO}

Mestrando em Administração e Controladoria pela Universidade Federal do Ceará - UFC (Fortaleza/CE) 


\section{BRUNA ÉRICA DE OLIVEIRA}

Engenheira Agrônoma pela Universidade Federal de Rondônia. Mestranda no Programa de Desenvolvimento Sustentável e Extensão da Universidade Federal de Lavras. Experiência em projetos de extensão rural para agricultores (as) familiares do estado de Rondônia. E também em projetos e consultorias em associativismos e cooperativismo rural. Atualmente no projeto Plantar Rondônia.

\section{CAMILA SOTERO}

Engenheira Civil formada pela Faculdade de Tecnologia e Ciências - FTC. Especialista em Geoprocessamento e Georreferenciamento pela Universidade Candido Mendes Especialista em Engenharia das Estruturas pela Faculdades Santo Agostinho Docente do curso de Engenharia Civil da Faculdades Santo Agostinho

\section{CARLOS HENRIQUE FERNANDES}

Graduado em Engenharia de Produção na Universidade do Estado de Minas Gerais - UEMG, natural de Passos/MG, Estagiário na área de processos e controle de produção.

\section{CAROLINE ALVES RESENDE}

Graduada em Administração de Agronegócios pela Pontifícia Universidade Católica de Goiás (PUC), pós-graduada em Formação de Consultores de Negócios (PUC) e mestre em Aquicultura Continental. Coach Executive pela Academia Brasileira de Coaching (ABC). Empresária, professora universitária de graduação e pós-graduação, desenvolvedora de projetos e consultora de negócios. Possui artigos publicados na área de gestão, logística e agronegócios

\section{CIBELE ROBERTA SUGAHARA}

Doutora em Ciência da Informação pela Universidade de São Paulo - USP. Professora e Pesquisadora da Faculdade de Administração e do Programa de Mestrado em Sustentabilidade da Pontifícia Universidade Católica de Campinas - PUC Campinas / SP -Brasil.

\section{CLODOALDO DE OLIVEIRA FREITAS}

Doutor em Administração pela Universidade Nacional de Misiones - UNAM - Argentina (2015), validado pela UFRJ (2016). Mestre em Administração e Doutor em Administração pela Universidade Nacional de Misiones - UNAM - Argentina (2015), validado pela UFRJ (2016). Mestre em Administração pela Faculdade de Estudos Administrativos - FEAD/MG (2012). Graduação em Ciências Contábeis pela Universidade Federal de Rondônia - UNIR (Cacoal, 2006) e Licenciatura Plena em Matemática pela UNIR (Ji-Paraná, 1997) Especialista em Matemática. Atualmente é Professor Adjunto II da UNIR, dos Departamentos: de Engenharia de Pesca e Zootecnia do Campus de Presidente Médici - RO. Membro do Conselho Superior Acadêmico - CONSEA, na Câmara de Pesquisa e Extensão - CPE. Trabalha com Administração Rural, Economia Rural, Cálculo, Gestão de Custos e Gestão Participativas. Desenvolvendo projetos de pesquisa e extensão com Agroecologia, agricultura familiar, territorialidades e gestão de propriedades. Membro do Grupo de Estudo e Pesquisa em Biociências - GPBio e Grupo de Estudo e Pesquisa em Contabilidade e Sustentabilidade de Cacoal - GEPSCAL.

\section{DAYANA PRISCYLA DA SILVA FRANÇA}

Graduanda do Curso de Engenharia Ambiental-UFPB e Tecnóloga em Geoprocessamento -IFPB, Atuações na áreas de educação ambiental na Comunidade Porto do Capim, João Pessoa/PB, no Parque Zoobotânico Arruda Câmara, João Pessoa/PB realizando oficinas, aulas de campo, trabalhos práticos e monitora na disciplina de bases da educação ambiental, assim como estudos na área de desertificação no interior da Paraíba e trabalhos com sensoriamento remoto e banco de dados espaciais. 


\section{DENISE RUGANI TOPKE}

Doutora em Psicossociologia de Comunidades e Ecologia Social (EICOS) na UFRJ, Mestre em Comunicação Social (UERJ), Pós-graduada em Marketing (PUC-Rio) e Gestão de Pessoas (Unigranrio) e Graduada em Comunicação Social (RP) pela UERJ. Atualmente é coordenadora do Curso de Marketing da Faculdade Gama e Souza e do MBA em Gestão e Marketing de Academias e professora dos cursos de Marketing e Gestão Comercial na mesma Instituição. Também leciona as disciplinas de Fundamentos de Marketing, Liderança e Gestão de Pessoas e Projeto 2: planejamento de um evento no curso técnico de Gastronomia do SENAC. Foi membro do Conselho Regional dos Profissionais de Relações Públicas (CONRERP) do Rio de Janeiro. Profissional com mais de 10 anos de experiência como professora e coordenadora de Curso.

\section{EDUARDO VASCONCELOS FERREIRA CANTARELLI}

Engenheiro Civil, formado pela UVA

\section{ELIANE SILVA LEITE}

Graduada em Licenciatura em Física pela Universidade Federal de Rondônia (2006). Mestrado (2009) e Doutorado (2013) em Física pela Universidade de Brasília (UnB). Professora adjunta do Departamento de Engenharia de Pesca da Universidade Federal de Rondônia (UNIR) e professora do Mestrado Nacional Profissional em Ensino de Física - MNPEF, UNIR, polo de Ji-Paraná. Pesquisadora dos Grupos de Pesquisa: Grupo de Pesquisa em Biociências, Grupo de Estudo em Agroecologia, GEPSCAL, GPAEFI.

\section{ELIVALDO RIBEIRO DE SANTANA}

É graduado em Gestão Ambiental pela Universidade de Brasília (UnB - 2014) e possui especialização em Geografia e Análise Ambiental pela Universidade Estadual de Goiás (UEG 2018). Atualmente é técnico de laboratório, área - Biologia na UnB; graduando em Biologia no Instituto Federal de Educação, Ciência e Tecnologia de Brasília - IFB; participa do grupo de pesquisa Estudos Ambientais e Sustentabilidade do IFB; tem experiência e interesses em: Análises quali-quantitativas de dados, Análises estatísticas uni e multivariadas, Marketing ambiental, Gestão de resíduos sólidos e Avaliação de impactos ambientais.

\section{FABIANA RODRIGUES BARBOZA DE ANDRADE}

Graduação em Ciências Biológicas (Licenciatura), Universidade Salgado de Oliveira, Graduação em Gestão Ambiental, Instituto Federal de Educação, Ciência e Tecnologia do Rio de Janeiro, PósGraduação em Ensino de Ciências e Biologia, Universidade Federal do Rio de Janeiro, PósGraduação em Engenharia Ambiental, Universidade Cândido Mendes (em andamento). Áreas de atuação: gestão ambiental pública e empresarial e gestão de processos relativos a atendimento aos clientes.

\section{FABIO MEDEIROS DOS SANTOS}

Engenheiro Civil formado pela UVA em 2016, pós-graduado em Gerenciamento de Projetos pela FGV em 2018.

\section{FRANCISCA FRANCIVANIA RODRIGUES RIBEIRO MACEDO}

Doutora em Ciências Contábeis e Administração pela Universidade Regional de Blumenau - FURB (Blumenau/SC)

Professora Adjunta da Universidade Estadual Vale do Acaraú - UVA (Sobral/CE) 


\section{GABRIELE CRISTINE BERNARDO DE CARVALHO}

Zootecnista, formada pela UFRRJ em 2009 e Engenheira Civil formada pela UVA em 2018, pós graduanda em Gestão e Gerenciamento de Projetos.

\section{IONARA DOS SANTOS BISCOLA}

Educanda no curso de Licenciatura em Educação do Campo com Habilitação em ciências da Natureza (UFGD)-(2015-2018).

\section{JANEIDE FERREIRA ALENCAR DE OLIVEIRA}

Tecnóloga da Construção Civil - URCA; Mestre em Gestão Ambiental pelo ITEP; Especialista em Gerenciamento da Construção Civil - URCA; Especialista em Geoprocessamento e Georreferenciamento de Imóveis rurais - IBENC; Professora Substituta da Universidade Regional do Cariri - URCA; Assessora Técnica do Instituto Tecnológico do Cariri - ITEC.

\section{JEFFERSON LUIZ ALVES MARINHO}

Engenheiro Civil com mestrado em Engenharia e Tecnologia Ambiental pela Universidad de León Espanha. Advogado com mestrado em Direito. Diretor do Instituto Tecnológico do Cariri - ITEC. Professor Adjunto da Universidade Regional do Cariri - URCA. Coordenador da pós-graduação lato sensu em Gerenciamento da Construção Civil - ITEC/URCA.

\section{JEFFERSON PEREIRA DA SILVA CASTRO}

Mestre em Sustentabilidade pela Pontifícia Universidade Católica de Campinas (PUC-Campinas). Graduado em Ciências Econômicas pela Universidade Metodista de Piracicaba (2008).

\section{JOSÉ RIBAMAR TOMAZ DA SILVA FILHO}

Prof. Mestre em Administração com MBA em Gestão de Pessoas e Graduação em Administração. Docente dos cursos de Administração e Ciências Contábeis da Universidade Estadual de Goiás UEG.

\section{JOSILDO SEVERINO DE OLIVEIRA}

Possui Licenciatura em Estudos Sociais, pela Universidade do Amazonas - UA (1991); Licenciatura em Geografia, pela Universidade Federal do Amazonas - UFAM (2000); Especialização em Metodologia do Ensino Superior, pelas Faculdades Objetivo/AM e Mestrado em Geografia (Geografia Física) pela Universidade de São Paulo - USP (2011). Exerceu a função de técnicopedagógico na Gerência de Ensino Fundamental/SEDUC-sede (Secretaria de Estado da Educação e Qualidade do Ensino do Amazonas) e atualmente é membro do Núcleo de Gestão de Currículos da SEDUC/AM; foi professor do Centro Universitário do Norte (UNINORTE/Laureate)ministrando disciplinas nos Cursos de Licenciatura em Pedagogia e Geografia; Relações Internacionais; Jornalismo; Tec. em Petróleo e Gás; Engenharia Ambiental. É avaliador de Cursos Superiores pelo Conselho Estadual de Educação do Amazonas (CEE-AM) e Redator do Referencial Curricular Amazonense de Geografia/BNCC. Possui experiência na área de Geografia, com ênfase em Geografia Física e Urbana, atuando principalmente na Geografia da saúde, análise espacial e variáveis meteorológicas; Ensino e Pesquisa em Geografia; e Formação inicial, em cursos de Licenciatura.

\section{JURANDIR MOURA DUTRA}

Possui graduação em Administração, Mestrado em Clima e Ambiente pelo Instituto Nacional de Pesquisas da Amazônia - INPA (2012) e Doutorado em Ciências Ambientais e Sustentabilidade na Amazônia - UFAM (2018). É professor de carreira da Universidade Federal do Amazonas - UFAM 
ministrando disciplinas do curso de administração na modalidade presencial e a distância. Já atuou como gestor da qualidade na Superintendência Municipal de Transportes Coletivos. Foi Diretor do Departamento de Desenvolvimento de Pessoas da estrutura da Pro-Reitoria de Gestão de Pessoas da UFAM. Tem experiência na área de gestão, com ênfase em Administração de Recursos Humanos, Pública e do Meio Ambiente

\section{JUREMA MÁRCIA DANTAS DA SILVA}

Mestre em Gestão de Negócios Turísticos pela Universidade Estadual do Ceará (UECE). Graduação em Arquitetura e Urbanismo pela Universidade Federal do Rio Grande do Norte (1980). Diretora Presidente e Pesquisadora da Fundação de Desenvolvimento Sustentável para a Terra Potiguar (FUNDEP).

\section{LARIANA NEGRÃO BERALDO DE ALMEIDA}

Possui graduação em Engenharia Química pela Universidade Tecnológica Federal do Paraná (2015). Concluiu Mestrado pelo Programa de Pós-graduação em Engenharia Química na Universidade Estadual de Maringá (2017). Atualmente é aluna de Doutorado Programa de Pósgraduação em Engenharia Química na Universidade Estadual de Maringá tendo como linha de pesquisa Fotocatálise Heterogênea.

\section{LAURA VISINTAINER LERMAN}

Possui graduação em Engenharia de Produção pela Universidade Federal do Rio Grande do Sul (2017) e graduação em Administração pela Pontifícia Universidade Católica do Rio Grande do Sul (2013). Tem experiência na área de Engenharia de Produção, com ênfase em Sistemas de Energias Renováveis, atuando principalmente nos seguintes temas: renewable energy systems, semistructure interviews, germany, intraempreendedorismo e sistemas de energias renováveis. Atualmente, é Bolsista de Mestrado Acadêmico.

\section{LILIAN BECHARA ELABRAS VEIGA}

Graduação em Arquitetura, Universidade Federal do Rio de Janeiro, mestrado em Engenharia de Produção, Universidade Federal do Rio de Janeiro, Mestrado em Gestão de Negócios pela School of Professional Studies in Business and Education, Johns Hopkins University, Doutorado em Planejamento Ambiental, Universidade Federal do Rio de Janeiro, Pós-doutorado em Gestão de Recursos Hídricos e Mudanças Climáticas, Universidade Federal do Rio de Janeiro. Pesquisadora do Programa de Planejamento Energético, COPPE/UFRJ de 2002 a 2014. Atualmente é professora do Instituto Federal de Educação, Ciência e Tecnologia do Rio de Janeiro. Áreas de atuação: Planejamento e Gestão Ambiental, nos temas: gestão ambiental pública, gestão ambiental empresarial, ecologia industrial, produção sustentável, gestão de recursos hídricos, gestão de resíduos sólidos e mudanças climáticas.

\section{LO-RUANA KAREN AMORIM FREIRE SANJULIÃO}

Mestre em Desenvolvimento Regional e Meio Ambiente pelas Faculdades Integradas do Sudoeste Mineiro - Universidade do Estado de Minas Gerais UEMG, Especialista em Gestão Estratégica de Negócios pela Universidade de Franca e Graduado em Engenharia de Produção pela Universidade de Franca, natural de Itaú de Minas/MG. Docente designado nível IV da Universidade do Estado de Minas Gerais - Unidade Passos. Atua nas áreas de Gestão de processos produtivos, Gestão Estatística da Qualidade do produto e do processo, Gestão da Cadeia de Suprimentos.

\section{LUAN DE CARVALHO DANTHES}

Engenheiro Civil, formado pela UVA, Pós Graduando em Gestão e Gerenciamento de Projetos pela UFRJ. 


\section{LUCAS MARCOS SILVA QUEIROZ}

Graduado em Engenharia de Produção na Universidade do Estado de Minas Gerais - UEMG, natural de Itaú de Minas/MG, atua na área de controladoria e finanças.

\section{LUCAS WAGNER RIBEIRO ARAGÃO}

Licenciado em Ciências Biológicas na Universidade Estadual de Mato Grosso do Sul (2013). Mestre em Recursos Naturais pelo Programa de Pós-Graduação em Recursos Naturais pela universidade Estadual do Mato Grosso do Sul (CAPES 2017 Atualmente é aluno do Programa de Pós-Graduação em Recursos Naturais, Nível de Doutorado pela Universidade Estadual de Mato Grosso do Sul (UEMS). Atuando na área de produtos naturais, desenvolvendo pesquisa frente análise de classes de metabólitos secundários, avaliação de atividade antioxidante e ensaios biológicos bem como estudo químico e biológico de óleos essenciais.

\section{LUCIMAR SANTIAGO DE ABREU}

Engenheira Agrônoma, possuí Mestrado em Sociologia pela Universidade Estadual de Campinas (1994) e Doutorado em Ciências Sociais pela Universidade Estadual de Campinas (2002). Estágio Pós Doutoral pela Universidade de Paris X, realizado em 2011. Missão de Estudo Internacional realizada entre novembro de 2014 e fevereiro de 2015, vinculada ao conjunto de atividades do Projeto Capes Cofecub, de Cooperação entre instituições brasileiras e francesas. Desde 1984 é pesquisadora da Empresa Brasileira de Pesquisa Agropecuária (www.cnpma.embrapa.br). Desenvolve pesquisas principalmente em agricultura familiar, agricultura de base ecológica, agroecologia e desenvolvimento rural sustentável. Atualmente, é membro de redes de pesquisas no âmbito da Agricultura Familiar, Transição Agroecológica, Agricultura Orgânica e da Rede de Estudos Rurais. Soma se as atividades de pesquisa propriamente dita, a contribuição junto à UFSCar, onde é responsável pela orientação de jovens estudantes do Programa de Pós Graduação em Agroecologia e Desenvolvimento Rural. Autora de diversos livros sobre a temática sociológica e desenvolvimento sustentável e agroecologia, contribui também, com a publicação de um conjunto de artigos, capítulos, etc. Também é representante da Embrapa Meio Ambiente, na Comissão da Produção Orgânica de São Paulo (CPORG/MAPA).

\section{MARCELO JOSÉ DE LIMA DUTRA}

Doutor em Ciências do Ambiente e Sustentabilidade na Amazônia pelo PPGCASA, Universidade Federal do Amazonas. Possui graduação em Administração com ênfase em Meio Ambiente. Especialista em Gestão Ambiental, com ênfase em Perícia e Auditoria Ambiental, formado pelo Centro de Ciências do Ambiente da UFAM. Especialista em Aperfeiçoamento em Políticas Púbicas Ambientais para a Amazônia pela Escola Nacional de Administração Pública - ENAP. É Analista Ambiental do Instituto Brasileiro de Meio Ambiente e Recursos Naturais Renováveis - IBAMA

\section{MARIA ANTONIA VEIGA ADRIÃO}

Doutora em História Social (Universidade Federal do Ceará-UFC/Intercâmbio com Universidade Estadual de Campinas-UNICAMP-Bolsa CAPES/PROCAD). Mestre em História (Universidade Federal de Pernambuco-UFPE). Licenciatura Plena em História (Universidade Estadual Vale do Acaraú-UVA). Prof. adjunta UVA-Curso de História atuando como coordenadora e orientadora dos Estágios Curriculares Obrigatórios realizados em escolas públicas situadas nas regiões noroeste e norte cearense, tendo como linha de pesquisa: Continuidades e Descontinuidades das Políticas Educacionais da Cultura Escolar e do Ensino de História. Orientadora do Subprojeto de História do Programa de Residência Pedagógica CAPES/UVA que tem o objetivo de pesquisar/contribuir com a "Leitura Histórica e Crítica da Palavra" . Coordenadora do Laboratório de Ensino e Aprendizagem de História (LEAH). 


\section{MARIA CÉLIA FERNANDES}

Doutora em Ciências Sociais pela Universidade Federal do Rio Grande do Norte (UFRN, 2011), Mestre (1996) e graduada em Ciências Sociais (1984) também pela UFRN. Professora Adjunto da Universidade Potiguar (UnP), durante o período de 1997 a 2010. Professora Adjunto Faculdade Estácio de Sá, Unidade Natal-RN, de 2013 a 2014. Professora Colaboradora da UFRN, durante o período de 2014 a 2017. Atualmente exercendo as funções de pesquisadora e instrutora de cursos de capacitação de projetos nas áreas de meio ambiente e turismo, como bolsista da Fundação para o Desenvolvimento Sustentável da Terra Potiguar (FUNDEP).

\section{MARIA JOSÉ REIS}

Mestre em Desenvolvimento Regional e Meio Ambiente (FESP/UEMG) (2016), possui graduação em Engenharia Florestal (1994) e Arquitetura e Urbanismo (2013). Pós-Graduação em Cultura de Tecidos Vegetais (2005). Professora na Universidade do Estado de Minas Gerais UEMG - Unidade Passos, no Engenharia Ambiental, atua nas áreas de Meio Ambiente e Estudo de aproveitamento de rejeitos para Construção Civil.

\section{MARIA MACILÉYA AZEVEDO FREIRE}

Mestranda em Administração e Controladoria pela Universidade Federal do Ceará - UFC (Fortaleza/CE)

\section{MARIA NEIDE MOURA MARTINS DE ANDRADE}

Coordenadora do setor de Educação Ambiental da SEMAM- Secretária do Meio Ambiente da prefeitura Municipal de João Pessoa-PB; Elaboração de Programa de Educação Ambiental (PEA), através palestras ilustrativas e interativas, oficinas ecológicas, jogos, dinâmicas e outros eventos tendo como público alvo as principais comunidades do entorno do Parque Arruda Câmara, escolas públicas e privadas, Ongs e Universidades; Representante da SEMAM na CIEA- Comissão Interestitucional de Educação Ambiental da Paraiba; Experiência na área de paisagismo e jardinagem, com atuação em projetos de médio e grande porte, , atuando no mercado de João Pessoa/Paraíba desde 2002, coordenando equipe multidisciplinar, grande experiência no paisagismo de Hotéis( Mussulo Beach Resort, Hotel Atlântico), e empresas.

\section{MARIANA DOS SANTOS DO NASCIMENTO}

Possui graduação em Engenharia Química pela Universidade Tecnológica Federal do Paraná (2017). Realizou graduação sanduíche com a Universidade de Debrecen, na Hungria (2015). Atualmente é mestranda em Engenharia Química pela Universidade Tecnológica Federal do Paraná e atua como Diretora Executiva na Mink Cosméticos.

\section{MARIANA PIRES VIDAL LÓPEZ}

Doutora em Administração e Turismo da Universidade do Vale do Itajaí (UNIVALI). Mestre em Administração e Desenvolvimento Empresarial pela Universidade Estácio de Sá (MADE). Possui MBA em Gestão Empresarial pela Fundação Getúlio Vargas (FGV) e graduação em Turismo pela Universidade Estácio de Sá. Integrante do grupo de pesquisa Grupo de Estudos em Sustentabilidade e Gestão (GESeG) da UNIVALI, onde desenvolve pesquisas na área de hotelaria e sustentabilidad

\section{MÔNICA DE OLIVEIRA ROCHA}

Mestranda em Psicologia pela Pontifícia Universidade Católica de Campinas - PUC-Campinas. MBA em Gestão de Negócios em Energia Elétrica e Especialização Administração de Empresas pela Fundação Getúlio Vargas - FGV. PCC - Professional Coach Certification. 


\section{NATÁLIA ELOÍSA SANDER}

Possui graduação em Engenharia de Produção pela Universidade Federal do Rio Grande do Sul (2018). Tem experiência na área de Engenharia de Produção, com ênfase em Engenharia Econômica e Gestão de Riscos. Atualmente, é Bolsista de Mestrado Acadêmico.

\section{ODAIR LACERDA LEMOS}

Professor Doutor em Sistemas de Produção Agricola e Florestal lotado no Departamento de Engenharia Agrícola e Solos da Universidade Estadual do Sudoeste da Bahia. Atua na área de Geotecnologia Aplicadas aos estudos nas áreas agrícola, ambiental e florestal.

\section{PAULO SÉRGIO MONTEIRO MASCARENHAS}

Engenheiro Agrônomo formado pela Universidade Federal da Bahia Mestre em Manejo e Conservação de Solos pela Universidade Federal da Paraíba Docente dos cursos de engenharia civil e arquitetura da Faculdade Independente do Nordeste FAINOR

\section{RAQUEL DE ABREU PEREIRA UHR}

Possui graduação em Engenharia Civil pela Universidade Federal do Rio Grande do Sul (2018). . Tem experiência na área de Engenharia Civil e Engenharia de Produção, com ênfase em Lean construction e Modelos de Negócios. Atualmente, é Analista de Projetos e Processos.

\section{RENATA CRISTINA ALMEIDA DE MENDONÇA VELOSO}

Graduada em Administração de empresas com ampla experiência na área administrativa

\section{ROSANGELA SARMENTO SILVA}

Doutora em Administração pela Universidade Municipal de São Caetano do Sul -USCS e Mestre em Administração -USCS, linha de pesquisa Redes Organizacionais e Inovação, graduada em Administração de Empresas pela Faculdade Atual da Amazônia, especialista em Recursos Humanos pela FACINTER - Faculdade Internacional de Curitiba. Experiência na área de marketing Professora Dra do Departamento de Administração da Universidade Federal de Sergipe-UFS . Foi professora da Faculdade Metropolitas Unidas - FMU, Anhaguera Educacional, Senac Vila Prudente-SP e Universidade Estadual de Roraima - UERR. Avaliadora de cursos e instituições do MEC

\section{SAMARA BARBOSA DE MENEZES}

Professora concursada da Secretaria de Estado de Educação do Amazonas - SEDUC, possui Graduação em Letras pela Universidade Federal do Amazonas - UFAM (1991) e Mestrado em Educação pela Universidade Federal do Amazonas - UFAM (2009). Atualmente é Pró - Reitora de Interiorização na Universidade do Estado do Amazonas - UEA

\section{SAMUEL CARVALHO DE BENEDICTO}

Doutor em Administração pela Universidade Federal de Lavras (UFLA). Professor, Pesquisador e Coordenador do Mestrado em Sustentabilidade da Pontifícia Universidade Católica de Campinas (PUC-Campinas). Membro do Grupo de Pesquisa "Gestão Estratégica e Sustentabilidade".

\section{SHALINE SÉFARA LOPES FERNANDES}

Possui graduação em Agronomia pela Faculdade Anhanguera de Dourados (2010), mestrado em Biologia Geral pela Universidade Federal da Grande Dourados (2013) e doutorado em Recursos Naturais da Universidade Estadual do Mato Grosso do Sul (2017), atuando principalmente nos 
seguintes temas: florística, fitossociologia, sistemas agroflorestais, serviços ambientais e restauração de áreas degradadas. É membro do Grupo de Estudos em Recursos Vegetais (GERV).

\section{STÉPHANE BELLON}

Possuí formação em Engenharia Agronômica. É pesquisador Senior do INRA (Instituto Nacional da Pesquisa Agronômica) vinculado à Unidade de Ecodesenvolvimento (localizada em Avignon, França) desde 1991. Anteriormente, nos anos 80 anos, atuava em cooperação no Caribe (Dominicana) e, em seguida, em um serviço de Extensão Rural Francês. A sua linha principal de pesquisa diz respeito ao tema das transições para agricultura de base ecológica, tomando como referência especialmente sistemas diversificados e multiestratificados nas agriculturas orgânicas e integradas. Ele é coautor de mais de 100 artigos e, recentemente coordenou a edição de dois livros sobre o Desenvolvimento da Agricultura Orgânica. 0 último foi lançado em 2014, (S. Bellon \& S. Penvern (Editores), "Agricultura Orgânica, Protótipo de Agriculturas Sustentáveis", Ed. Springer"). Stéphane Bellon foi responsável pelo Programa Nacional de Pesquisa do INRA na área de Agricultura e Alimentos Orgânicos (2006-2013). Também é representante do INRA, no novo EraNet Core Organic + (Coordenação da Pesquisa Transnacional Europeia, que estabelece parcerias com 21 países de UE). Participa da organização e contribui em eventos nacionais e internacionais relacionados à agricultura orgânica e agroecologia. Ele é membro de vários Comitês Científicos Nacionais e Sociedades internacionais, entre os quais: Comitê da Associação Internacional dos Sistemas de Produção (IFSA, grupo da UE), Sociedade Ecológica da América (ESA), Sociedade Internacional de Ciência de Horticultura (ISHS). Ele é membro do conselho editorial do jornal "Agroecology and Sustainable Food Systems". Também está envolvido em atividades do Comitê Científico da Escola Internacional de Verão em Agroecologia (ISSAE: http:// issae.enfa.fr/). Foi um dos fundadores e, Presidente da Associação Européia de Agroecologia. Tem contribuído também na orientação de estudantes franceses e estrangeiros sobre o temática da agroecologia.

\section{TÂNIA OLINDA LIMA}

Graduação em Engenharia de Pesca pela Universidade Federal de Rondônia (UNIR), Pós-graduação lato sensu em Gestão Ambiental e Desenvolvimento Sustentável e Mestrado pelo Programa de PósGraduação em Geografia (PPGG/UNIR). Pesquisadora do Grupo de Pesquisa em Gestão do Território e Geografia Agrária da Amazônia (GTGA/UNIR) e do Núcleo de Estudos em Agroecologia (NEA/UNIR).

\section{TATIANA GULMINIE JOSUÉ}

Possui graduação em Engenharia Química pela Universidade Tecnológica Federal do Paraná (2016). Atualmente é aluna de Mestrado do Programa de Pós-graduação em Engenharia Química na Universidade Tecnológica Federal do Paraná tendo como linha de pesquisa Processos de Separação e Tecnologia Ambiental.

\section{TAUANE CATILZA LOPES FERNANDES}

Graduada em Química pela Universidade Estadual de Mato Grosso do Sul (UEMS), (2013). Mestre em Recursos Naturais pela Universidade Estadual de Mato Grosso do Sul (UEMS) (2015). Atualmente é aluna do Programa de Pós-Graduação em Recursos Naturais, Nível de Doutorado pela Universidade Estadual de Mato Grosso do Sul (UEMS), com experiencia na área de Química orgânica, com ênfase em estudo químico, biológico e etno-farmacológico de óleos essenciais.

\section{TERCIA ZAVAGLIA TORRES}

Doutora e Mestre em Educação, pela Universidade Federal de São Carlos (UFSCar). Graduada em Administração pela Pontifícia Universidade Católica de Brasília. Analista A da Empresa Brasileira de Pesquisa Agropecuária - Embrapa, em Campinas, SP, com atuação em projetos de pesquisa relacionados às seguintes temáticas: organização e tratamento da informação digital, gestão do conhecimento, organização de conteúdos digitais em ambientes virtuais de colaboração e aprendizagem, organização de ambientes colaborativos para redes de pesquisa, organização de 
conteúdos para dispositivos móveis, inovação em instituições de pesquisa, desenvolvimento e inovação (PD\&I), gestão de redes de pesquisa, redes de pesquisa, prospecção de demandas, gestão de projetos, gestão de processos técnicos e gerenciais, comunicação digital em redes de pesquisa, gestão da informação, narrativas digitais, transmídias, educação, educação corporativa, aprendizagem organizacional, aprendizagem com mobilidade, microaprendizagem, aprendizagem colaborativa, ensino a distância, educação não-formal para transferência de tecnologia no meio rural, design instrucional e design multimídia. Professora do Centro Universitário de Paulínia, SP (UNIFACP) nos cursos de graduação em Direito e Tecnologia em Gestão de Recursos Humanos, Gestão Financeira, Gestão da Qualidade e Processos Gerenciais. Coordenadora dos cursos superior de Tecnologia de Gestão de Recursos Humanos, Secretariado e Processos Gerenciais da UNIFACP. Coordenadora do curso de pós-graduação lato sensu em Estratégias Empresariais da UNIFACP.

\section{THALES VOLPE RODRIGUES}

Graduado em Engenharia de Produção na Universidade do Estado de Minas Gerais - UEMG, natural de São Sebastião do Paraíso/MG, atua nas áreas de planejamento e controle de produção - PCP, logística, compras e custos.

\section{THAYS LORRANNY DA SILVA JANUÁRIO}

Possui graduação em Tecnologia em Alimentos pela Faculdade de Tecnologia CENTEC, FATEC (2012). Atualmente é acadêmica de Engenharia de Produção Mecânica na Universidade Regional do Cariri, URCA.

\section{TONY STEVÃO ALVES DA SILVA}

Pós-graduado em Relações Internacionais pela PUC-Goiás. Docência em politica internacional, comércio exterior, sociologia, administração mercadológica e logística internacional. Empresário da área de cursos, treinamentos e visitas técnicas.

\section{VIVIANE MALLMANN}

Graduada em Química pela Universidade Estadual de Mato Grosso do Sul (UEMS), (2013). Mestre em Recursos Naturais pela Universidade Estadual de Mato Grosso do Sul (UEMS) (2015). Atualmente é aluna do Programa de Pós-Graduação em Recursos Naturais, Nível de Doutorado pela Universidade Estadual de Mato Grosso do Sul (UEMS), com experiencia na área de Química orgânica, com ênfase em estudo químico, biológico e etno-farmacológico de óleos essenciais. 


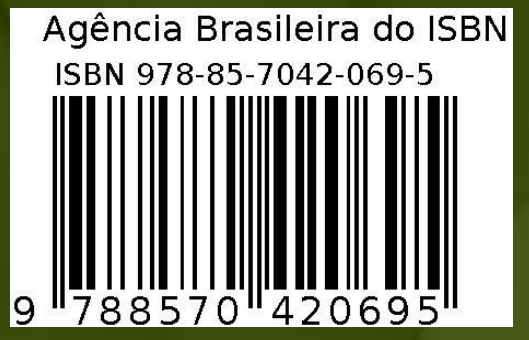

